\title{
La contribution du droit penal de l'environnement a la repression des atteintes a l'environnement au Benin
}

Citation for published version (APA):

Tchoca Fanikoua, F. (2012). La contribution du droit penal de l'environnement a la repression des atteintes a l'environnement au Benin. [Doctoral Thesis, Maastricht University]. BOXPress. https://doi.org/10.26481/dis.20121115ft

Document status and date:

Published: 01/01/2012

DOI:

10.26481/dis.20121115ft

Document Version:

Publisher's PDF, also known as Version of record

\section{Please check the document version of this publication:}

- A submitted manuscript is the version of the article upon submission and before peer-review. There can be important differences between the submitted version and the official published version of record.

People interested in the research are advised to contact the author for the final version of the publication, or visit the DOI to the publisher's website.

- The final author version and the galley proof are versions of the publication after peer review.

- The final published version features the final layout of the paper including the volume, issue and page numbers.

Link to publication

\footnotetext{
General rights rights.

- You may freely distribute the URL identifying the publication in the public portal. please follow below link for the End User Agreement:

www.umlib.nl/taverne-license

Take down policy

If you believe that this document breaches copyright please contact us at:

repository@maastrichtuniversity.nl

providing details and we will investigate your claim.
}

Copyright and moral rights for the publications made accessible in the public portal are retained by the authors and/or other copyright owners and it is a condition of accessing publications that users recognise and abide by the legal requirements associated with these

- Users may download and print one copy of any publication from the public portal for the purpose of private study or research.

- You may not further distribute the material or use it for any profit-making activity or commercial gain

If the publication is distributed under the terms of Article $25 \mathrm{fa}$ of the Dutch Copyright Act, indicated by the "Taverne" license above, 


\section{LA CONTRIBUTION DU DROIT PENAL DE L'ENVIRONNEMENT A LA REPRESSION DES ATTEINTES A L'ENVIRONNEMENT AU BENIN}

François TCHOCA FANIKOUA 
(C) François TCHOCA FANIKOUA, Maastricht 2012

ISBN 978-90-8891-505-5

Printed \& lay-out by: Proefschriftmaken.nl || Printyourthesis.com Published by: Uitgeverij BOXPress, Oisterwijk 


\title{
LA CONTRIBUTION DU DROIT PENAL DE L'ENVIRONNEMENT A LA REPRESSION DES ATTEINTES A L'ENVIRONNEMENT AU BENIN
}

\author{
DISSERTATION
}

To obtain the degree of Doctor at Maastricht University,

on the authority of the Rector Magnificus, Prof. dr. L.L.G. L. Soete

in accordance with the decision of the Board of Deans, to be defended in public on Thursday 15 November 2012, at 14.00 hours

by

François TCHOCA FANIKOUA 


\section{Supervisors}

Prof. Dr. Michael G. FAURE, Université de Maastricht (Pays-Bas)

Prof. Dorothé C. SOSSA, Prof. Agrégé des facultés de Droit, Université d'AbomeyCalavi, (Bénin)

\section{Assessment Committee}

Prof. Dr. C.A. SCHWARZ (chairman), Université de Maastricht, (Pays-Bas)

Dr. L. CHOUKROUNE, Université de Maastricht, (Pays-Bas)

Prof. A. DE NAUW, Vrije Universiteit Brussel, (Belgium) 
L'UNIVERSITE D'ABOMEY-CALAVI, LA FACULTE DE DROIT ET DES SCIENCES POLITIQUES ET LA CHAIRE UNESCO DES DROITS DE LA PERSONNE HUMAINE ET DE LA DEMOCRATIE (BENIN) ET LA FACULTE DE DROIT ET DES SCIENCES POLITIQUES DE L'UNIVERSITE DE MAASTRICHT (PAYS BAS) N'ENTENDENT DONNER NI APPROBATION NI IMPROBATION AUX OPINIONS EMISES DANS CETTE THESE. ELLES DOIVENT ETRE CONSIDEREES COMME PROPRES A LEURS AUTEURS 



\section{DEDICACE}

A TOI MA CHERE MERE ET A TOI MA CHERE EPOUSE CHARLOTTE, A VOUS, BENEDICTA ET CEDRIC, MES CHERS ENFANTS, JE DEDIE CETTE THESE. 



\section{REMERCIEMENTS}

Sans le concours et le soutien de certaines personnes, les travaux de recherches qui ont abouti à l'élaboration et à la finalisation de cette Thèse de Doctorat en Droit n'auraient pas pu voir le jour.

Je voudrais donc remercier et témoigner ma gratitude en cet instant solennel de mon existence, à mon Directeur de recherche, le Professeur FAURE G. Michael de l'Université de Maastricht aux Pays Bas, une référence intarissable qui m'a inspiré sur la richesse du droit de l'environnement et m'a été tout au long de la rédaction de cette Thèse, d'un soutien inestimable ; qu'il trouve à travers cette œuvre, le couronnement de ses efforts.

Je dis, également, merci à tout son entourage, notamment l'équipe de I'Institut Metro (Institute for Transnational Legal Research) dont il a la charge et qui n'a ménagé aucun effort pour se mettre à mon service et à mon écoute tout au long de mes travaux de recherches; je pense particulièrement à madame Yleen SIMONIS.

Le Professeur Dorothé C. SOSSA, Agrégé des Facultés de Droit, Professeur titulaire de droit privé, ancien Doyen de la Faculté de Droit et des Sciences Politiques de l'Université d'Abomey-Calavi, ancien Titulaire de Chaire UNESCO des Droits de la personne humaine et de la démocratie à la Faculté de Droit et des Sciences Politiques de l'Université d'Abomey-Calavi et actuellement Secrétaire Permanent de l'Organisation pour l'Harmonisation en Afrique du Droit des Affaires (OHADA), en poste à Yaoundé au Cameroun, mon codirecteur de recherches, qui très tôt, m’a encouragé à persévérer dans mes recherches ; qu'il en soit remercié pour ses multiples conseils.

Monsieur Koffi AHADZI-NONOU, Professeur Titulaire de Droit public, Président de I'Université de Lomé (Togo), mon précepteur depuis mon DEA, dont il a été le Directeur de recherches. A l'issue de cette soutenance, il m'a encouragé à poursuivre mes recherches doctorales en droit de l'environnement ; qu'il trouve dans cette thèse le réconfort nécessaire.

Au Doyen de la Faculté de Droit et de Sciences Politiques, le Professeur Georges Barnabé GBAGO et au Professeur Athanase LAWOGNI, Coordonnateur 
de la coopération scientifique interuniversitaire entre la Faculté de Droit et des Sciences Politiques de l'UAC (République du Bénin) et la Faculté de Droit et des Sciences Politiques de I'Université de Maastricht (Royaume des Pays-Bas), je dis merci et que vive cette coopération interuniversitaire !

Au Président et aux Honorables membres du Jury, pour leur contribution enrichissante en vue de l'amélioration de cette Thèse.

A vous, Honorables Députés BANGANA et KASSA pour votre soutien.

A toi cher ami, Adjima KALIFA, Juge d'Instruction près le Tribunal de Première Instance d'Abomey, pour le soutien technique et moral que tu m'as spontanément apporté et à toi Oba KOTCHIKPA pour ton appui technique dans la finalisation de cette thèse.

Enfin, à mes collègues du Ministère de l'Environnement, de l'Habitat et de I'Urbanisme (MEHU), du Ministère Chargé des Relations avec les Institutions (MCRI) et mes collègues du Conseil Communal de Tanguiéta avec à sa tête le Maire SIMBA B. K. Kouagou (Serge) et à tous mes frères et amis Bruno AGOSSA, Président de l'ONG ANAP et ceux dont j'ignore volontiers le nom, je vous prie de trouver ici, ma modeste manière de vous dire merci. 


\section{SOMMAIRE}

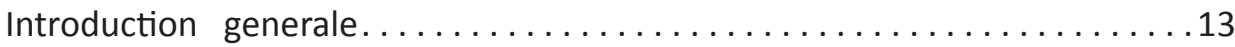

Premiere partie : un cadre juridique et institutionnel pertinent mais ineffectif et insuffisant . . . . . . . . . . . . . . . . . . . 21

Titre premier : un cadre juridique et institutionnel pertinent $\ldots \ldots \ldots \ldots 23$

Chapitre premier : les elements d'une politique criminelle environnementale 23

Section I : une legislation environnementale pertinente $\ldots \ldots \ldots \ldots \ldots .24$

Section II : les aspects institutionnels de la politique criminelle $\ldots \ldots \ldots .60$

Chapitre II : l'existence d'un systeme repressif environnemental en developpement................................78

Section I : la mise en mouvement de l'action publique..............78

Section II : le regime repressif tel que prevu par les textes. . . . . . . . . . . . 107

Titre II : un dispositif environnemental repressif ineffectif, insuffisant et peu performant................................144

Chapitre III : la performance de l'arsenal repressif beninois............144

Section I : le cadre normatif pénal . . . . . . . . . . . . . . . . . . . . . . . . 145

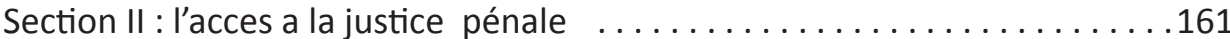

Chapitre IV: l'effectivite des sanctions pénales environnementales. . . . . . . 191

Section I : la mise en œuvre des sanctions pénales environnementales ....192

Section II : la tendance a l'indulgence en matiere de sanctions pénales environnementales...............................219

Deuxieme partie : la necessaire protection de l'environnement par le droit pénal et perspectives.......................235

Titre I : vers la mise en œuvre effective du droit pénal de l'environnement 236 
Chapitre V : le renforcement des moyens d'action et de mise en œuvre du droit pénal de l'environnement . . . . . . . . . . . . . . 238

Section I : la restructuration du cadre juridique................238

Section II : I'analyse economique du droit pénal de l'environnement . . . . . 267

Chapitre VI : la definition des elements constitutifs de l'infraction environnementale.................................292

Section I : l'element legal ou l'exigence de textes clairs et precis.........293

Section II : les autres elements constitutifs de l'infraction environnementale 309

Titre II : les perspectives pour un droit pénal plus efficace .............326

Chapitre VII : l'effectivite de la responsabilite pénale de la personne

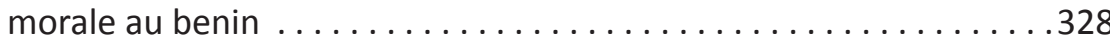

Section I : un bref apercu de la portee de la responsabilite pénale applicable a la personne morale ...................330

Section II : l'effectivite de la responsabilite pénale de la personne morale au benin ............................... 346

Chapitre VIII : la repression de la pollution transfrontiere $\ldots \ldots \ldots \ldots \ldots 35$

Section I : la competence en matiere de pollution transfrontiere .........356

Section II : la competence non juridictionnelle de reglement de conflit en droit de l'environnement. . . . . . . . . . . . . . . . . . 378

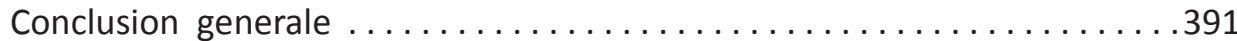


INTRODUCTION GENERALE 
L'évènement le plus considérable et le plus marquant dans l'histoire du droit international de l'environnement a été nul doute, la Conférence de Stockholm sur l'environnement en 1972. Depuis cette conférence, les problèmes environnementaux sont devenus une préoccupation majeure pour l'humanité et suscitent un intérêt croissant. Dès lors, la communauté internationale a amorcé une prise de conscience vis-à-vis des préoccupations environnementales, avec la création d'institutions internationales de préservation et de protection de l'environnement ${ }^{1}$, la conclusion des traités internationaux et l'adoption de normes et règlements en la matière. Cette prise de conscience de la communauté internationale aura pour conséquence, le développement d'instruments juridiques aussi bien en droit international qu'en droit interne. Le droit apparaît dès lors, indissociable de la protection de l'environnement dans la mesure où il est lié à toute forme de protection. C'est la naissance du droit de l'environnement.

Si dans les pays du Nord, ${ }^{2}$ la riposte aux problèmes brûlants de l'environnement consiste à apporter à leurs populations une réponse plus ou moins satisfaisante, les tendances au sein des Etats africains, dans le sens du développement du droit de l'environnement, sont, sommes toutes, encore embryonnaires, voire naissantes. Deux événements ont marqué l'éveil de conscience des peuples africains : le premier qui est la découverte en 1988 d'un trafic de déchets dangereux entre pays industrialisés et certains pays africains, comme le Bénin, en quête de ressources financières, a véritablement déclenché l'alerte écologique en Afrique en donnant naissance au droit pénal de l'environnement; le second est la Conférence des Nations Unies pour l'Environnement et le Développement, qui a eu lieu a Rio de Janeiro au Brésil en Juin 1992 et qui a connu une très forte participation des Etats africains (sur 178 délégations, les 52 Etats africains étaient présents) contrairement à celle de

1 C'est au lendemain de cette Conférence que par exemple le PNUE a été créé en 1972. Et cette même année a été proclamée par la communauté internationale, année internationale de l'environnement.

2 A noter que nous utilisons " pays du Nord " ou " pays développés " dans le sens usuel, c'est-à-dire en contraste aux pays sous développés ou en voie de développement africain. 
Stockholm ${ }^{3}$. Le Bénin ${ }^{4}$ y a particulièrement joué un rôle important. Très actif, il occupera l'un des postes de la Vice-présidence du Sommet au nom du Groupe africain $^{5}$.

Dès lors, le Bénin est entré de plein pied dans la dynamique environnementaliste par la création $d^{\prime}$ institutions de définition et de mise en œuvre de la politique ${ }^{6}$ et d'instruments juridiques internes et plusieurs traités ou conventions internationales régulièrement ratifiés pour sauvegarder et protéger l'environnement. C'est donc un arsenal juridique en nette progression, qui est ainsi créé pour mettre en œuvre la politique environnementale du pays, confronté aux défis majeurs de la protection de l'environnement. La dégradation du couvert végétal, le pillage de la faune, la gestion des déchets, la détérioration des conditions d'hygiène et du cadre de vie, dus à l'insouciance et l'incivisme des citoyens ont pris des proportions inquiétantes et expliquent l'avancée sensible du désert ainsi que la précarité de la santé de la population. Le recours au droit pénal de l'environnement est une solution alternative, capable d'apporter une riposte adéquate auxdites préoccupations. Cette riposte s'entend de l'ensemble des normes qui sanctionnent les manquements au droit de l'environnement.

En effet, l'une des fonctions essentielles du droit pénal, et particulièrement du droit pénal de l'environnement, est de protéger les valeurs reconnues essentielles pour l'environnement en créant et en appliquant les sanctions. Dès lors, comment déterminer les incriminations et les sanctions y afférentes en cas d'atteintes à la santé humaine et à l'environnement? II s'agira de mettre en relief

3 M. KAMTO, Droit de l'environnement en Afrique, EDICEF, 1996, p.44-45.

4 Le Bénin est un pays de l'Afrique de l'Ouest. Il est limité au Nord par le fleuve Niger qui le sépare de la République du Niger, au Nord Ouest par le Burkina Faso, à l'Ouest par le Togo, à l'Est par le Nigeria et au Sud par l'océan atlantique. II couvre une superficie de 114.763 km2 (données intervenues à la suite de la cession de quelques iles, (affaire ile de Leté) avec une densité moyenne de $57 \mathrm{hts} / \mathrm{km} 2$. Sa population est estimée à $6.752 .596 \mathrm{hts}$ avec un accroissement annuel de $2.8 \%$ (données 2002, RGPH 3). Cette population est jeune (plus de la moitié de la population totale à moins de 20 ans). Le taux d'analphabétisme des adultes de 15 ans et plus est de $60 \%$ environ. L'agriculture est la principale activité économique et représente $36 \%$ du PIB. L'industrie y occupe $14,3 \%$ du PIB tandis que le tertiaire représente $49,7 \%$. Cf. Cyrille GOUGBEDJI, Thèse citée infra.

5 Idem.

6 Le Ministère chargé de l'environnement créé en 1992, l'Agence Béninoise pour l'Environnement créée en 1995, la Commission Nationale pour le Développement Durable, 
l'efficacité de la sanction pénale. Au regard des autres disciplines concurrentes (droit civil de l'environnement, droit administratif de l'environnement, les mesures économiques), quelle peut être la contribution du droit pénal de l'environnement dans la préservation et la conservation de l'environnement? Comment concilier les impératifs du développement socioéconomique et parfois même de subsistance avec les exigences du droit pénal de l'environnement? Comment déterminer l'auteur du dommage environnemental? Comment mettre en œuvre la répression pénale quant on sait surtout qu'en matière environnementale, le plus souvent, " les victimes sont l'environnement, l'air, l'eau, la faune, la flore ...toutes victimes incapables de porter plainte et d'agir. Comment, dans ces conditions, rendre effective la répression ? ${ }^{7}$. Ces difficultés s'ajoutant au contenu souvent incertain des incriminations expliquent sans doute le nombre restreint de condamnations.

Cet ensemble de questionnements, pose avec acuité la problématique du sujet de thèse qui va alimenter notre réflexion tout au long de nos travaux de recherches. II est intitulé :

\section{La contribution du droit pénal de l'environnement à la répression des atteintes à l'environnement au Bénin.}

Les raisons qui motivent un tel choix découlent essentiellement de l'originalité du thème puisque aucun travail scientifique n'est encore consacré à ce secteur du droit positif béninois, encore largement ignoré des chercheurs. II n'existe pratiquement pas d'analyse doctrinale, ce qui peut s'expliquer par la complexité et la technicité du sujet et, par la quasi inexistence de la jurisprudence. Néanmoins, notre volonté d'apporter notre modeste contribution au développement du droit de l'environnement, et en particulier du droit de l'environnement au Bénin, discipline scientifique encore naissante, est à l'origine de notre motivation à explorer ce thème qui nous apparaît d'un grand intérêt.

Notre approche consistera à mener une réflexion allant dans le sens de l'analyse des textes pénaux et la littérature juridique existant en rapport avec l'ordonnancement juridique béninois en matière d'atteinte à 
l'environnement et de démontrer en quoi il peut contribuer au succès ou non des politiques ou stratégies de protection de l'environnement dans le pays. En un mot, il s'agira de faire l'inventaire de l'application du droit positif béninois de l'environnement en ce qu'il a de substantielle, (lois, conventions internationales, ordonnances, décrets, arrêtés, jurisprudence, doctrine) en matière de répression de l'environnement. Il conviendra de spécifier le droit pénal de l'environnement du droit pénal commun classique, d'une part et d'autre part de mettre en exergue les limites et les avantages de la notion de " dépendance administrative du droit pénal de l'environnement», laquelle apparaît à nos yeux comme le point commun des deux disciplines. Cette notion signifie que l'infraction, en droit pénal est toujours fonction d'une violation d'un texte législatif ou réglementaire. L'existence ou non d'une autorisation administrative, fonde le point de départ de l'infraction environnementale. II s'ensuit que c'est généralement l'acte administratif qui détermine le comportement illicite ou non du délinquant. La thèse mettra ainsi en exergue l'interdépendance qui existe entre le droit pénal et le droit administratif.

Dans cet ordre d'idée, la gamme de sanctions corrigeant l'acte illicite prévu par ces textes, (amende, emprisonnement, mesures prononcées par le juge ou peines complémentaires) fera également l'objet d'une réflexion approfondie afin de jauger de leur efficacité. II faut arriver à trouver non seulement la sanction qui convient à la personne physique ou morale coupable d'infraction, mais aussi dans la détermination de l'infraction et la fixation de la peine, le juste milieu entre le «minima » et le « maxima ».

En effet, le Bénin, à l'instar des autres Etats africains, présente dans le domaine de la protection de l'environnement, un droit positif se caractérisant par la croissance des textes mais aussi par leur insuffisance. Le législateur, soucieux de faire respecter les réglementations protectrices de l'environnement a, de plus en plus, fait appel au droit répressif, créant ainsi un droit pénal de l'environnement. Ce droit pénal béninois est caractérisé en outre par sa dispersion, sa relative multiplicité des incriminations, la faiblesse du taux d'accès aux juridictions, l'inadéquation de certaines sanctions, et surtout des contraintes réelles quant à l'applicabilité desdites sanctions aussi bien par l'administration que par le juge pénal. Face à un tableau quelque peu déprécié du droit pénal 
de l'environnement béninois, comment arriver à renverser la tendance et faire en sorte que le droit pénal ait une place de choix dans le dispositif répressif environnemental? Tout ceci ne dépend-il pas de la particularité même de l'infraction environnementale?

La démarche méthodologique, à l'origine de ce travail, nous permettra de circonscrire notre champ d'application. Dès lors, les aspects relatifs aux sanctions pénales en relation avec le droit pénal et la procédure pénale et aux sanctions administratives, en cas d'infraction frappant la santé humaine ou l'une des composantes de l'environnement, seront abordés. C'est donc sur quelques domaines précis à savoir: la pollution des eaux, la pollution de l'air, la pollution sonore, la protection de la faune et de la flore, que portera essentiellement l'objet d'un diagnostic. Mais l'environnement étant une science interdépendante, les autres disciplines et mécanismes de protection de l'environnement pourront être, au besoin, abordés de façon incidente.

L'objectif général, de cette étude est de jeter un regard analytique et critique sur le droit pénal de l'environnement béninois, sa mise en œuvre effective au Bénin, sa conformité au droit international, afin d'en dégager les perspectives.

Cet objectif général, est décliné en plusieurs objectifs spécifiques relatifs entre autres à :

- I'identification des textes pénaux environnementaux, tant législatifs que réglementaires en matière de droit répressif de même que l'état de la jurisprudence existant au Bénin, en conformité au droit international de l'environnement ;

- la détermination des obstacles ou contraintes rencontrées lors de la mise en œuvre;

- l'analyse de l'effectivité de leur mise en pratique en relation avec la doctrine et la jurisprudence existantes en la matière;

- les perspectives qui s'offrent au droit de l'environnement béninois dans le contexte de la mondialisation pénale. 
Pour atteindre les objectifs que nous nous sommes ainsi fixés, il convient de préciser que la démarche méthodologique reposera évidemment sur une méthode scientifique. Cette dernière se définit comme un ensemble ordonné de manière logique de principes, de règles, d'étapes permettant de parvenir à un résultat. Des méthodes ou Ecoles juridiques existantes, la méthode exégétique, la méthode de la libre recherche scientifique et la méthode stratégique seront mis à contribution.

La première, l'Ecole exégétique, fondée sur le rationalisme et la volonté générale, est née dans le courant du XVIIİ̀me siècle. Elle est une méthode des sciences sociales qui consiste en une explication philosophique et doctrinale d'un texte, à faire une interprétation des textes juridiques dont le sens et la portée sont obscurs ou équivoques ou sujets à interprétation. Elle se fonde sur l'étude exclusive du texte de loi. Elle recherche dans la lettre de la loi et les travaux préparatoires, l'intention du législateur, donc l'esprit de la loi.

La seconde, la méthode juridique de la "libre recherche scientifique", issue des Ecoles scientifiques ${ }^{8}$, est celle qui retiendra plus notre attention. Elle nous permettra de faire l'analyse de la jurisprudence et de la doctrine et nous conduira à la comparaison des textes légaux et réglementaires internes ou externes, aux réalités sur le terrain afin de constater leur démarcation et tirer les conséquences qui en découlent. Ainsi, le droit comparé, sera fortement sollicité afin de mettre en relief les réponses pénales de certains pays développés, plus expérimentés en matière d'usage de droit pénal de l'environnement. Le droit béninois étant un droit d'origine francophone, s'inspirant donc du droit français, la jurisprudence francophone et européenne, en particulier belge et française, très abondantes en matière de contentieux de l'environnement seront d'un grand atout pour enrichir le travail.

La troisième méthode est celle dite stratégique. Elle prend en compte les déterminants d'un problème particulier qu'elle apprécie et analyse en fonction des situations qui peuvent changer rapidement. Elle nous permettra de voir si

8 L'un des tenants de cette Ecole est François GENY, dont le maitre-livre est, Méthode d'interprétation et sources en droit en droit privé positif (1899). On peut citer aussi, R. SALEILLES, A. ESMEIN. Ce dernier, fonda la Revue trimestrielle de droit civil (1902) 
les moyens et stratégies utilisés par les différents acteurs lors de l'application des textes s'avèrent efficaces et appropriés. ${ }^{9}$

Notre hypothèse de travail consistera, tout au long de cette étude, à démontrer que le droit pénal, en dépit des critiques ou faiblesses dont-il fait l'objet, peut aussi, au même titre que les autres disciplines juridiques, préserver et protéger l'environnement. Notre hypothèse place donc l'approche pénale, au cœur des préoccupations environnementales. Dans ce cadre, il conviendrait dans une vision prospective de lutte contre la délinquance environnementale, d'orienter l'arsenal répressif béninois encore très timide, à se conformer aux normes, aux pratiques et aux exigences internationales du droit pénal de l'environnement notamment, dans le cadre des pollutions transfrontières.

Enfin au regard de tout ce qui précède, et dans une dynamique de recherche scientifique, nous ferons faire le diagnostic du cadre juridique et institutionnel sur lequel repose la politique pénale béninoise en matière de sauvegarde de l'environnement (Première partie) et au regard de ce diagnostic, caractérisé par la timidité du contentieux pénal, nous identifierons l'intérêt de la protection de l'environnement par le droit pénal et les perspectives qui s'offrent à cette discipline juridique assez complexe (Deuxième partie).

9 Sur ces différentes méthodes juridiques, V. X. DIJON, Méthodologie juridique, L'application de la norme, KLUWER Editions Juridiques Belgique, 1996, p.120 et ss. 


\section{PREMIERE PARTIE}

UN CADRE JURIDIQUE ET INSTITUTIONNEL PERTINENT MAIS INEFFECTIF ET

INSUFFISANT 
Cette première partie, essentiellement diagnostique, fera l'inventaire du cadre juridique et institutionnel de mise en œuvre de la politique et des stratégies de l'environnement qui fondent sa pertinence (Titre I er) avant d'apprécier dans une dimension analytique, au delà de la performance de ce cadre, les insuffisances et les contraintes de cette politique répressive (Titre II). 


\section{TITRE PREMIER : UN CADRE JURIDIQUE ET INSTITUTIONNEL PERTINENT}

Pour mieux appréhender le cadre juridique et institutionnel, notre analyse abordera les éléments caractéristiques qui fondent la politique criminelle

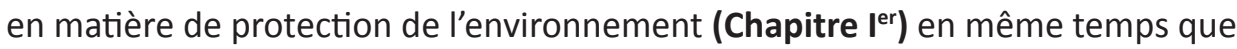
le niveau de développement du système répressif béninois en matière d'atteinte à l'environnement (Chapitre II).

\section{CHAPITRE Ier : LES ELEMENTS D'UNE POLITIQUE CRIMINELLE ENVIRONNEMENTALE}

Le Bénin est un pays dont l'économie reste largement tributaire de l'exploitation directe des ressources naturelles. A titre illustratif, le troisième recensement générale de la population et de l'habitat réalisé en 2002 rend compte à ce propos que près de la moitié des actifs occupés (49\%) travaillent dans les secteurs de la production agricole, la chasse, la pêche et la coupe de diverses essences forestières utilisées dans les travaux de construction et dans la production des énergies pour la cuisine traditionnelle. Il s'ensuit que les principaux défis auxquels sont confrontés les pays africains en général, sont, nul doute, d'une part la désertification, la déforestation, l'érosion et l'appauvrissement des sols et d'autre part, la conservation des espèces animales et végétales, le traitement des eaux usées et les déchets ainsi que l'approvisionnement en eau potable, l'assainissement dans un contexte de croissance démographique et d'urbanisation rapide. C'est devant ce schéma qui influence négativement la durabilité des ressources environnementales, qu'intervient le droit de l'environnement. C'est une discipline, nous l'avons précisé plus haut, assez jeune. Mais, de nos jours en Afrique et particulièrement au Bénin, l'environnement est devenu une préoccupation majeure pour les dirigeants ; avec l'émergence des stratégies, des plans ou programmes, des lois et règlements afin d'asseoir une politique offensive de préservation de l'environnement.

Le recours au droit de l'environnement et précisément au droit répressif (droit pénal et droit administratif) de l'environnement qui se définit comme «la 
mise en action du dispositif judiciaire destiné à atteindre les fins que se propose le droit $\rangle^{10}$, constitue entre autres, une réponse singulière aux manquements et aux atteintes graves à l'environnement et à la nature. Il apparaît évident que ces atteintes soient d'origine anthropiques; d'autant plus que l'homme, au lieu d'œuvrer dans le sens d'annihiler les principaux défis précités, les galvanisent et les favorisent au quotidien de façon consciente ou inconsciente. Dans le cadre de la définition d'une politique criminelle, ces activités humaines seront réglementées aussi bien par le droit pénal que par le droit administratif. Cette prise de conscience qu'accompagne une volonté politique particulièrement manifeste, notamment à partir des années 1990, est amorcée depuis la conférence des forces vives de la nation ${ }^{11}$.

Ainsi, le droit de l'environnement, en l'occurrence le droit pénal de l'environnement béninois, dans son développement et dans l'ordonnancement juridique béninois, repose sur des sources et normes législatives et constitutionnelles, assez pertinentes (Section $\mathbf{1}^{\text {ère}}$ ), soutenues par un soubassement institutionnel et conventionnel, caractérisé par l'influence décisionnelle des institutions politiques (Section 2).

\section{SECTION I ère : UNE LEGISLATION ENVIRONNEMENTALE PERTINENTE}

Le droit est, sans doute, le moteur des politiques environnementales. II en facilite l'adoption et leur mise en œuvre. II ne saurait avoir protection ou prévention sans interdiction ou plus largement, sans incriminations. Or, «le droit n'est rien d'autre qu'un ensemble de prescriptions prohibitives ou permissives ${ }^{12}$. C'est dans cette logique de préservation de l'environnement, notamment par le droit pénal, que s'inscrit l'intervention du législateur béninois qui a produit

10 BERKAERT $(\mathrm{H})$, L'évolution de la répression pénale.

11 La conférence nationale organisée au Bénin, à Cotonou, à l'hôtel PLM Alédjo, du 18 au 28 février 1990, a décrété la fin du monolithisme politique et l'avènement du renouveau démocratique. C'est au cours de cette conférence, qui a jeté les bases de la protection de l'environnement qu'est apparu nécessaire la création d'un Ministère chargé de l'environnement. M. KAMTO, Droit de l'environnement en Afrique, EDICEF/AUPELF, Paris, 1996) 
une série de textes répressif couvrant divers domaines: la faune, la flore, l'eau, l'air, les déchets, etc. Ce regain d'intérêt du législateur est appuyé par la détermination du constitutionnaliste béninois qui a pu élaborer une constitution dont la vision, emprunte d'une dynamique évolutive, est entre autres, de lutter contre la criminalité environnementale en prévoyant des incriminations et des sanctions en cas d'atteinte grave à l'environnement, à la hauteur de la forfaiture (§ $1^{\mathrm{er}}$ ). De même, plusieurs textes de lois ainsi que leurs textes d'application dont l'objectif est de dissuader et de réprimer les atteintes à l'environnement existent mais éparpillés (§ 2). Dans cette lutte contre les prédateurs de l’environnement, le droit international de l'environnement, qui joue un rôle considérable dans la législation nationale, vient à la rescousse du droit interne, en édictant des normes, dans le cadre des traités ou accords internationaux, bilatéraux et multilatéraux, lesquels, une fois ratifiés, par l'organe compétent, comme le parlement dans le cas du Bénin, s'imposent à l'Etat et influencent de ce fait le droit positif (§3).

\section{$\S$ : L’apport du droit constitutionnel béninois}

L'érection de l'environnement au rang de règles à valeur constitutionnelle, est l'expression de la volonté manifeste des pouvoirs publics, de garantir plus efficacement le respect des normes assurant la protection de l'environnement. Cette volonté a été clairement affirmée dans la constitution béninoise ${ }^{13}$.

Dès lors, afin de mieux appréhender l'apport du droit constitutionnel à la répression des atteintes à l'environnement, notre analyse consistera à prouver, tour à tour, la consécration constitutionnelle du droit à un environnement sain (A) et la criminalisation des infractions environnementales (B).

\section{A) La consécration constitutionnelle du droit à l'environnement}

Des indépendances jusqu'aux années 70 voire 80 , avec le recul, l'on peut faire le constat selon lequel, les Etats africains, dans leur majorité avaient des 
constitutions essentiellement considérées comme un «document déterminant le régime politique et décrivant le fonctionnement des institutions» ${ }^{14}$ bien que l'année 1970 ait été proclamée par la communauté internationale "année internationale de l'environnement ${ }^{15}$. Ces pays ne laissèrent passer aucune occasion d'exprimer leur crainte de voir l'idée de protection de l'environnement se transformer en un obstacle pour leur développement ${ }^{16}$. En revanche, ce n'est qu'à partir des années 90 que les constitutions africaines en général et la constitution béninoise en particulier, accordera une attention particulière à la protection de l'environnement.

En effet, accédée à l'indépendance le $1^{\text {er }}$ août 1960, la République du Dahomey, aujourd'hui République du Bénin, au regard de son histoire constitutionnelle assez mouvementée, a connu sept Constitutions ${ }^{17}$. De toutes ces constitutions, seule la dernière, celle dont les bases ont été fixées par la Conférence Nationale, met un accent particulier sur la préservation de l'environnement; les autresn'en n'ont pas faitétat puisquel'environnement n'était pas une préoccupation majeure pour les autorités politiques d'alors, lesquelles nourrissaient à l'égard de la protection de l'environnement, une "méfiance»" ${ }^{18}$. Dès lors, il y a là une évolution assez remarquable du droit constitutionnelle béninois. Cette évolution est corollaire du faible niveau de développement du droit de l'environnement dans la sous région ou prédominait le Parti- Etat. L'on peut affirmer aujourd'hui, eu égard à l'émergence des préoccupations environnementales dans la loi fondamentale, sans risque de se tromper que la

12 FALLOUX (François) et TABOT (Lee), Crise et opportunité. Environnement et développement en Afrique, édit. G.P. Maisonneuve \& La Rose. ACCT, Paris, 1992, p : 290291.

$15{ }^{13}$ ROBERT (Jacques-Henri), in, Le problème de la responsabilité et des sanctions en France, RIDP, op. cit. $p$ : 949 M. KAMTO, op. Cit. $p: 32$

17 De GAUDUSSON (Jean du Bois), CONAC (Gérard) et DESOUCHES (Christine), in, Les constitutions africaines, Tome 1, édit. Bruylant, Bruxelles, 1997 II s'agit de : la constitution du 15 février 1959, la constitution du 25 novembre 1960; la constitution du 05 janvier 1964 ; la constitution du 31 mars 1968 ; la constitution du 07 mai 1970 ; la loi fondamentale du 26 août 1977 promulguée le 09 septembre 1977 et la constitution du 11 décembre 1990.

18 Cf. KAMTO (M), op. cit. p:32, 33 ; FALLOUX (François) et TABOT (Lee), Crise et opportunité. Environnement et développement en Afrique, édit. G.P. Maisonneuve \& La Rose. ACCT, Paris, 1992, p : 290-291. 
constitution béninoise du 11 décembre 1990, est une " constitution verte ", une constitution qui place l'environnement au centre des préoccupations des droits de l'homme.

\section{Le droit à un environnement sain}

$\mathrm{Au}$ plan planétaire, deux instruments des Nations Unies ont été précurseurs dans la proclamation du droit de jouir d'un environnement sain. C'est d'abord la Déclaration Universelle des Droits de l'Homme et des Peuples qui, dès 1948, énonçait dans son article 25 que " toute personne à droit à un niveau de vie suffisant pour assurer sa santé et son bien être ». Ensuite, ce droit a été, cette fois-ci, réaffirmé d'une manière directe à la Conférence de Stockholm sur l'environnement en 1972 dans le Principe1 de la Déclaration de Stockholm comme suit : "I'homme a un droit fondamental à la liberté, à l'égalité et à des conditions de vie satisfaisantes, dans un environnement dont la qualité lui permette de vivre dans la dignité et le bien être. Il a le devoir solennel de protéger et d'améliorer l'environnement pour les générations présentes et futures. ${ }^{19}$

A l'instar de ces instruments internationaux, la constitution béninoise clarifie davantage en disposant que: «Toute personne a droit à un environnement sain, satisfaisant et durable et a le devoir de le défendre. L'Etat veille à la protection de l'environnement $»^{20}$. Il en est de même de la Charte africaine des droits de I'homme et des peuples adoptée lors de la XVIIIème Conférence des Chefs d'Etat et de Gouvernement de l'Organisation de l'Unité Africaine, le 18 juin 1981 à Nairobi au Kenya, et ratifiée par le Bénin le 20 janvier 1986 et qui fait partie intégrante de la présente constitution. Cette Charte qui est intervenue 10 ans avant le Sommet de Rio, se réfère aux valeurs de la civilisation africaine pour proclamer

19 - PRABHU (Mohan), Rapport Général du congrès international sur les crimes contre l'environnement, organisé par la section canadienne de l'Association Internationale de Droit Pénal Ottawa, Canada. RIDP, AIDP, Les atteintes à l'environnement. 3ème et 4ème trimestre 1994.

- SHELTON (D), Techniques et procédures en droit international de l'environnement, cours $3, p: 83$ 
pour la première fois, en tant qu'instrument international en matière de droit de I'homme, une consécration juridique formelle au droit à l'environnement, ${ }^{21}$ que " tous les peuples ont droit à un environnement satisfaisant et global, propice à leur développement $\aleph^{22}$. Les conséquences de ses dispositions sont énormes pour l'Etat. Un environnement " sain » suppose un environnement ou un cadre de vie non dégradé, non pollué, hygiénique et salubre. L'environnement est l'affaire de tous. Cette évidence qui implique des droits et des devoirs, signifie que chacun est à la fois acteur et victime de l'environnement, pollueur et pollué. Cette implication à la fois individuelle et collective correspond bien à la nature spécifique du droit à l'environnement en tant que droit pouvant s'exercer aussi bien individuellement que collectivement. La Constitution donne "à chacun» le droit de vivre dans un environnement sain lorsqu'il dispose que "toute personne a ...». Une analyse exégétique de ce texte nous permet de conclure qu'il est inclus dans ce membre de phrase, aussi bien les personnes physiques que les personnes morales; quant on sait surtout que se sont ces dernières qui dégradent plus l'environnement à travers leurs entreprises. Par la valeur constitutionnelle ainsi conférée, la protection de l'environnement devient un intérêt supérieur, qui doit être assorti de toutes les garanties juridiques relevant de son rang. L'Etat ou les collectivités publiques ont la lourde responsabilité de créer, ce " droit ", qualifié de droit de la troisième génération ${ }^{23}$. Ce cadre de vie, a pour finalité de «réaliser une politique de préservation et de gestion collective des milieux, des êtres vivants et des ressources ${ }^{24}$. C'est en raison de ce critère finaliste qu'on estime indispensable la consécration constitutionnelle d'un droit à l'environnement ${ }^{25}$. II y a de la part des populations un besoin de vivre dans un milieu sain et protecteur des équilibres naturel $s^{26}$. Pour ce faire, l'Etat est obligé

21 KAMTO (M), op. cit., p: 51, 52. L'Afrique est la première à consacrer formellement le droit à l'environnement dans un instrument juridique régional ayant force contraignante.

22 Article 24 de la Charte africaine des droits de l'homme.

23 Cf. BELET(J.M) et COLARD(D), Les droits de l'homme, Tome I, Paris, Economica, 1982, p : 15 et ss. Historiquement, les droits de l'homme sont classés en trois catégories. La première concerne les droits civils et politiques, la seconde, les droits économiques, sociaux et culturels. La troisième catégorie est constituée des droits de la troisième génération dits " droit de solidarité » au nombre desquels figure le droit à un environnement sain. M. PRIEUR, Droit de l'environnement, 3ème édit. Dalloz, Paris, 1996.p :09 Idem 
de légiférer et de réglementer le comportement des citoyens. Ces derniers ont des droits mais aussi des devoirs ; notamment le devoir de défendre et de maintenir durablement l'environnement. Afin de mieux accomplir ce devoir, le constituant béninois, contrairement aux autres constitutions, notamment la constitution française de la $5^{\text {ème }}$ République ${ }^{27}$, a pourvu le citoyen béninois d'un droit de saisine direct de la cour constitutionnelle pour soit soulever l'inconstitutionnalité d'une loi ou d'un règlement soit pour soulever une exception d'inconstitutionnalité devant une juridiction. C'est l'article 122 qui consacre cette progression du droit constitutionnel béninois en disposant que " tout citoyen peut saisir la cour constitutionnelle sur la constitutionnalité des lois, soit directement, soit par la procédure de l'exception d'inconstitutionnalité invoquée dans une affaire qui le concerne devant une juridiction. Celle-ci doit surseoir jusqu'à la décision de la cour constitutionnelle qui doit intervenir dans un délai de trente jours.». Ainsi, on peut soutenir que la consécration constitutionnelle d'un environnement sain, qui apparaît ici comme un principe constitutionnel, est un acquis environnemental considérable, de sorte qu'une loi qui violerait de façon manifeste et massive cet acquis environnemental sera très probablement déclarée anticonstitutionnelle. II s'ensuit que, tout acte de délinquance écologique apparaîtra dès lors comme une manifestation d'indifférence ou d'hostilité à l'égard de cette valeur qu'est la constitution et doit, de ce fait, être pénalement sanctionné. En disposant ainsi qu'il l'a fait, le législateur constitutionnel béninois « a nécessairement entendu ériger le droit à l'environnement en liberté fondamentale de valeur constitutionnelle $"{ }^{28}$ Par ailleurs, au lendemain de l'entrée en vigueur de la Charte africaine des droits de

27 cf. VINCENT (J), GUINCHARD(S), MONTAGNIER (G), VARINARD (A), La justice et ses institutions, édit. Dalloz, précis, 4ème édit., Paris, 1996, p: 230 «originairement, l'article 61 de la Constitution française, n'ouvrait la saisine du conseil constitutionnel, qu'au président de la République, au 1er Ministre et aux Présidents de chaque Assemblée parlementaire. Pratiquement ceci revenait à en écarter les députés et les sénateurs de l'opposition; cet inconvénient a été supprimé par la réforme de l'article 61 introduite en 1974 à l'initiative de M. Giscard D'ESTAING après son élection, qui permet également la saisine du conseil par soixante députés, soit par soixante sénateurs» 
I'homme et des peuples ${ }^{29}$, presque tous les pays africains $\mathrm{s}^{30}$ ont évolué dans cette dynamique constitutionnelle de protection de l'environnement. Ces Etats dont globalement les constitutions des trois premières décennies post-indépendances étaient oublieuses de l'environnement, ${ }^{31}$ ont " proclamé dès le départ un droit à l'environnement non pas dans quelques textes obscurs de leur législation mais au fronton de leur droit interne, c'est-à-dire dans leur constitution ${ }^{32}$ se faisant, ils participent au développement des sources constitutionnelles du droit de l'environnement. Ces dispositions constitutionnelles africaines consacrent toutes, de manière directe, le droit à un environnement sain. La protection de l'environnement est donc élevée au rang d'une obligation constitutionnelle. Ainsi, fort de cette reconnaissance constitutionnelle, le Bénin est sur une bonne voie. Dès lors, on note une avancée, même si elle est virtuelle, de la constitution béninoise par rapport à la constitution française par exemple, qui est caractérisée par l'entrée tardive de l'environnement dans la constitution. Ce qui a permis à M. PRIEUR, d'écrire qu' " alors qu'au plan international et dans de nombreux pays étrangers, le droit à l'environnement est reconnu, en France la protection de l'environnement n'est toujours pas une liberté publique constitutionnellement garantie, même si la loi du 02 février 1995 admet le droit de chacun à un environnement sain. " Elle n'est intervenue qu'à l'issue d'un long processus, fait de débat juridique de fond, qui a conduit au vote par le Parlement et la promulgation le $1^{\text {er }}$ mars 2005, par le Président de la République, Monsieur Jacques CHIRAC de la loi constitutionnelle relative à la Charte de l'environnement. ${ }^{33}$ Ainsi, à l'instar de l'article 27 de la constitution béninoise, les

29 Elle est adoptée par la XVIIème Conférence des chefs d'Etat et de Gouvernement de l'OUA le 18 juin 1981 à Nairobi, au Kenya. Elle est ratifiée par le Bénin le 20 janvier 1986 et entrée en vigueur le 21 Octobre 1986

30 -Cf., Mohamed Ali MEKOUAR, Etude juridique de la FAO, en ligne avril 2001 ; cité par RJE, $n$ • spécial 2005, Dispositions constitutionnelles dans certains pays africains, in, «le droit de l'environnement dans la charte africaine des droits de l'homme".

31 M. KAMTO, Droit de l'environnement en Afrique, EDICEF/AUPELF, Paris, 1996), p : 67

32 DESIDERI (Jean-Pierre), in Le droit de l'environnement dans les pays francophones de l'Ouest africain, article, dans l'Académie des juristes Tarnais, www.agoramed.org., Paris mars 2008.

33 Actes du colloque organisé avec le concours du conseil constitutionnel, Paris, les 20 et 21 juin 2005 par la SFDE. Elle n'est intervenue qu'après un long débat dont le processus a commencé en 2002. 
articles $1^{\text {er }}$ et $2^{\text {ème }}$, de la Charte française disposent respectivement : "Chacun a le droit de vivre dans un environnement équilibré et respectueux de la santé »; "Toute personne a le devoir de prendre part à la préservation et à l'amélioration de l'environnement». ${ }^{34}$ Le Professeur Stéphane DOUMBE-BILLE a pu même s'exclamer à propos "Enfin! Enfin, la Charte constitutionnelle française ! " comme pour dire à la face du monde, ouf ! Enfin la France a franchi le cap d'une véritable garantie de la préservation de l'environnement en élevant en valeur constitutionnelle, la sauvegarde de l'environnement. À Véronique JAWORSKI, de renchérir : " s'inscrivant dans un mouvement général de constitutionnalisation des diverses branches de droit, l'environnement faisait une entrée, historique et symbolique, dans le bloc de constitutionnalité» ${ }^{36}$.

Par contre, si en France la constitution française, comme on le constate, a accusé un retard dans la reconnaissance de ce droit constitutionnel, les constitutions de certains Etats comme le Canada, les USA, la Belgique, ne reconnaissent pas ce droit. ${ }^{37}$ Ainsi, en Belgique «la constitution belge ne reconnaît pas expressément un droit à un environnement convenable, ni directement ni indirectement par le biais du droit à la vie, à la santé et à la sécurité. De telles dispositions n'ont pas paru nécessaires aux constituants en 1831 et les révisions subséquentes de la constitution ont répondu à d'autres attentes ${ }^{38}$. Ce n'est qu'en janvier 1994 que la loi fondamentale Belge consacre le principe en son article 23, alinéa $3,4^{\circ 39}$.

En Allemagne, l'idée d'insérer un droit à l'environnement dans la loi fondamentale, fut exprimée pour la première fois dans le programme de la protection de l'environnement publié par le gouvernement fédéral en 1971, le

34 Loi constitutionnelle $n^{\circ}$ 2005-205 du 1er mars 2005 relative à la Charte de l'environnement, JORF $n^{\circ} 51$ du 02 mars 2005, p : 3697.

35 La Charte constitutionnelle et le droit international, in RJE nº spécial 2005.

36 La Charte constitutionnelle de l'environnement face au droit pénal, in RJE nspécial 2005.

3735 Les crimes contre l'environnement en droit belge, article publié par C. HENNAU-HUBLET et J.P. PIRET, lors du congrès international sur les crimes contre l'environnement, organisé par la section canadienne de l'Association Internationale de Droit Pénal Ottawa, Canada. RIDP, AIDP, les atteintes à l'environnement. 3ème et 4ème trimestre 1994, pp : 782-783.

3836 C. HENNAU-HUBLET et J.P. PIRET, idem. pp : 782-783.

39 NEURAY (J.F.), Principes de droit de l'environnement, Kluwer édit. Juridiques, Belgique \& Story Scientia, 1995, p : 53. 
premier grand document pragmatique visant la protection de l'environnement en Allemagne. Depuis ce temps, il existe en Allemagne une unanimité politique de ce qu'il faudrait insérer dans la constitution une disposition obligeant l'Etat à protéger l'environnement. Mais c'est beaucoup plus l'événement relatif à la réunification allemande qui a ouvert la voie à la protection de l'environnement par la constitution car " le traité de l'unification prévoit un mandat de réforme constitutionnelle $»^{40}$. C'est donc cette réforme que traduit l'article 20 a lorsqu'il dispose " Assumant ainsi également sa responsabilité pour des générations futures, l'Etat protège les fondements naturels de la vie et des animaux par l'exercice du pouvoir législatif, dans le cadre de l'ordre constitutionnel, et des pouvoirs exécutif et judiciaire dans les conditions fixées par la loi et le droit». ${ }^{41} \|$ s'ensuit que même si c'est sur un plan purement formel, certains pays africains paraissent ainsi, bien en avance sur de nombreux pays développés où la constitutionnalisation du droit à l'environnement, voire sa simple consécration juridique aux moyens même des catégories normatives inférieures à la constitution, demeure une revendication; en dépit de la multitude des règles et procédures existantes en matière de droit de l'environnement, celui-ci est encore dans ces pays, au stade du «non droit» $»^{42}$

Nous venons ainsi de développer les grands axes liés à la consécration constitutionnelle d'un droit à un environnement sain qu'une certaine doctrine qualifie de "droit programmatoire»" ${ }^{43}$. A première vue le droit de l'homme à l'environnement pourrait paraître superflu puisque, tendre vers un droit à l'environnement sain, c'est aussi assurer à l'être humain ses droits fondamentaux. C'est assurément un droit qui protège l'homme et le milieu dans lequel il vie. Mais, pour des raisons méthodologiques et de clarification nous optons sans

40 BOTHE (Michael), in, Le droit à l'environnement dans la Constitution Allemande, RJE, $\mathrm{n}^{\circ}$ spécial 2005, p : 35.

41 Idem

42 KAMTO(M), op. cit. , $p: 51$

43 AHADZI NONOU (K), Droits de l'homme et environnement : théories et réalités. Contribution aux « Mélanges » en I'honneur du Doyen Yves MADIOT, Bruxelles, Bruyant, 2000, p : 7. Cité par GOUGBEDJI (C) Le droit à un environnement sain. Mémoire, DEA Droits de l'Homme et Démocratie. $P$ : 37. C'est un droit dont on ne peut exiger la mise en œuvre immédiate. II se limite à une norme de programme ; c'est-à-dire une mission de l'autorité consistant à poursuivre un résultat déterminé. 
toutefois verser dans la polémique doctrinale, de faire un développement séparé des deux notions complémentaires à savoir le droit à un environnement sain et le droit de l'homme à l'environnement. Puisque si dans le premier cas, le concept embrasse l'environnement au sens large (êtres vivants ou éléments biotiques : hommes et plantes ; et éléments abiotiques : eau, sol, air,...) ; dans le deuxième cas, c'est-à-dire dans le cas des droits de l'homme, il s'agit uniquement que de la dimension humaine, la dimension "anthropocentrique» ${ }^{44}$, qu'il conviendrait de privilégier même s'il faut comprendre le droit à l'environnement comme un droit bidimensionnel ${ }^{45}$, c'est-à-dire, à la fois comme un droit humain et un droit de la nature.

\section{L'environnement, objet d'un droit de l'homme}

Environnement et droit de l'homme constitue effectivement une préoccupation dans la constitution béninoise. Le Titre II intitulé « Des droits et devoirs de la personne humaine» est déjà évocateur et illustratif de la volonté du constituant d'accorder le même rang aussi bien à l'environnement qu'aux autres droits fondamentaux de la personne humaine comme le droit de tout individu à la vie, à la liberté, à la sécurité et à l'intégrité de sa personne, le droit à la propriété, le droit d'assurer sa défense, etc. ...En revanche, «la conciliation des droits devra se faire sous le contrôle des juges et l'on peut se demander si le droit à l'environnement, par son caractère à la fois universel et transversal, individuel et collectif, affectant l'homme, sa survie, sa santé, l'humanité et la diversité biologique, ne va pas se révéler comme devant bénéficier d'une certaine prééminence sur certains autres droits fondamentaux» ${ }^{46}$.

Plusieurs dispositions de la constitution béninoise, notamment les articles $27,28,29,74,98,147$ sont consacrés à la sauvegarde de l'environnement. Le non respect desdites dispositions doit être considéré comme une violation des droits de l'homme ou comme «crime contre la nation». Autrement dit, tout

44 M. PRIEUR, Droit de l'environnement, 3ème édit. Dalloz, Paris, 1996.p :65

45 KAMTO (M), op. cit., Paris, 1996), p : 52

46 Michel PRIEUR, in Vers un droit de l'environnement renouvelé. Etudes et doctrine.; Cahiers du Conseil constitutionnel $n^{\circ} 15,14 \mathrm{p}$. 
doit être mis en œuvre par les pouvoirs publics de sorte que «la préservation de l'environnement doit être recherchée au même titre que les autres intérêts fondamentaux de la nation " ci-dessus énumérés au paragraphe précédent; puisque «les enjeux environnementaux font désormais partie des droits de I'Homme $»^{47}$.

Cependant, I'on pourrait s'attarder sur ces notions de droit à l'environnement et droit de l'homme, pour faire remarquer la controverse doctrinale qu'alimentent ces deux concepts. La question se pose de savoir si l'environnement peut faire l'objet d'un droit de l'homme. N'est-ce pas un euphémisme que de parler de protection de l'environnement comme un droit de l'homme ? II est scientifiquement admis par tous que la vie des hommes sur terre est étroitement liée à celle des autres espèces vivantes. Protéger la nature à travers la faune, la flore et la biodiversité, est en même temps protéger l'homme. Détruire la nature ou épuiser ses ressources, prive l'homme d'un développement durable. La déclaration de Rio de Janeiro de 1992 sur l'environnement et le développement énonce que " la terre constitue un tout marqué par l'interdépendance ". Si les êtres humains sont bien évidemment au centre des préoccupations relatives au développement durable, ils ont droit à une vie " en harmonie avec la nature ${ }^{4}{ }^{48}$ II apparaît donc évident qu'on ne peut pas, à propos de l'environnement, dissocier l'homme de son milieu de vie et des éléments physiques et biologiques qui composent ce milieu.

Au delà des controverses doctrinales, la problématique du rattachement du droit de l'environnement au droit de l'homme et à la démocratie a pris une ampleur exceptionnelle avec l'attribution du prix Nobel de la paix 2004, pour son action contre la déforestation, à madame Wangari MAATHAI, Secrétaire d'Etat à l'environnement du gouvernement Kényan ${ }^{49}$.

L'effectivité des valeurs constitutionnelles environnementales réside aussi bien dans la détermination des incriminations que dans l'application des sanctions pénales. Dès lors, le droit pénal béninois de l'environnement,

47 V. JAWORSKI, La Charte constitutionnelle de l'environnement face au droit pénal, in RJE $\mathrm{n}^{\circ}$ spécial 2005.

$48 \quad$ Principe 1 de la déclaration de Rio, 1992.

49 Prix Nobel de la paix décédé en octobre 2011 
actuellement inadapté et insuffisamment appliqué, ne peut que tirer avantage de cette promotion constitutionnelle.

\section{B) La criminalisation constitutionnelle des infractions environnementales}

Les articles 29, 73, 74, 136, 137 et 138 de la constitution béninoise apportent une contribution inestimable au développement du droit pénal de l'environnement. Ces articles incarnent, à n'en point douter, le caractère novateur de la constitution béninoise en matière de préservation de l'environnement. Pour en arriver à ces articles, le constituant béninois a été inspiré par un événement majeur, " la découverte d'un trafic de déchets dangereux entre pays industrialisés et certains pays africains dont le Bénin vers la fin des années 1980, précisément en 1988. Cette découverte macabre a déclenché l'alerte écologique en Afrique ${ }^{50}$. Aujourd'hui encore, les faits donnent raison aux pays africains afin qu'ils cultivent une vigilance écologique permanente contre les multinationales en quête de dépotoir en Afrique. L'exemple de la Côte-d'Ivoire dans l'affaire de "déversement des déchets toxiques du cargo Probo Koala», affrété par la firme Trafigura en Août 2006 est illustratif à plus d'un titre de par ses conséquences. Nous y reviendrons ultérieurement.

L'article 29 de la constitution béninoise ${ }^{51}$ dispose que "le transit, l'importation, le stockage, l'enfouissement, le déversement sur le territoire national des déchets toxiques ou polluants étrangers et tout accord y relatif constitue un crime contre la nation. Les sanctions applicables sont définies par la loi.». Une analyse de ces dispositions fait ressortir les éléments matériels constitutifs de l'infraction de "crime contre la nation» qui apparaît ici en droit béninois, comme la plus grande infraction pénale sanctionnée en matière environnementale. Ainsi, l'infraction est consommée et qualifiée de crime contre la nation béninoise, lorsque l'un quelconque des faits ou activités

50 F. TCHOCA FANIKOUA, Analyse critique du cadre institutionnel de mise en ceuvre des politiques environnementales en Afrique, le cas du Bénin, Mémoire de DEA., UB, Lomé, Togo, 1998,77p.

51 Constitution béninoise du 11 décembre 1990 
suivants relatifs à la manipulation ou à l'exploitation sur le territoire national des déchets toxiques ou polluants provenant de l'étranger, à savoir « le transit, l'importation, le stockage, l'enfouissement et le déversement » est constitué. En d'autres termes, ces activités, constitutifs de l'infraction de crime contre la nation, lorsqu'elles se déroulent telles que décrites, sont qualifiées d'atteintes graves à l'environnement donc, d'activités criminelles passibles de la peine capitale.

Autre infraction pénale qualifiée de crime contre la nation béninoise, est celle prévue par les dispositions de l'article 74 de la constitution. En effet, c'est d'abord l'article 73 qui pose le principe de la responsabilité pénale personnelle du Président de la République en cas de haute trahison. En revanche, est qualifié de haute trahison ou est constitué, comme élément matériel de cette infraction hautement politique, le fait pour le Président de la République, non seulement, de violer son serment, d'être reconnu comme auteur, co-auteur ou complice de violations graves et caractérisées des droits de l'homme, de session d'une partie du territoire, mais aussi et surtout «d'acte attentatoire au maintien d'un environnement sain, satisfaisant, durable et favorable au développement». Ainsi, des quatre chefs d'accusations qui pèsent sur le Président de la République, figure en bonne place l'atteinte à l'environnement. Le cas échéant, il perd son immunité et engage sa responsabilité pénale et est poursuivi devant la Haute Cour de Justice ${ }^{52}$. L'infraction de Haute trahison concerne aussi bien le Président de la République que les membres de son gouvernement. Cependant, avant d'être poursuivi, le Président de la République ou l'un quelconque des membres de son gouvernement doit franchir une barrière hautement politique, à savoir, la décision de poursuite puis la mise en accusation du Président de la République et des membres du gouvernement votée à la majorité des deux tiers des députés composant l'Assemblée Nationale ${ }^{53}$. C'est déjà, reconnaissons-le, important que la constitution ait prévue ce processus de mise en accusation, du Chef de l'Etat, premier magistrat, et des membres de son gouvernement en cas d'atteintes graves à l'environnement. Cette criminalisation des infractions est un acquis fondamental pour l'avancée du droit de l'environnement au Bénin. Ce courage

52 Cf. art.136 et suivants de la constitution du Bénin du 11-12-90. ; loi-organique n93-013 du août 1999 portant loi organique de la Haute Cour de Justice. 
juridico-politique n'existe pas dans d'autres constitutions. Il en est ainsi de la constitution française, laquelle a inspiré fortement le constituant béninois. La Charte constitutionnelle française, " est muette sur le droit pénal " ${ }^{54}$. Le simple fait que ces infractions existent et sont qualifiées d'environnementales est déjà une victoire contre la délinquance environnementale.

Le législateur béninois a eu pourtant la lucidité de comprendre que la consécration solennelle du droit à l'environnement fut-ce dans une constitution ne suffit pas, mais qu'elle doit être relayée dans un souci d'efficacité par des dispositions législatives et réglementaires adéquates.

\section{§II : L’existence de dispositions législatives et réglementaires répressives.}

La protection légale de l'environnement signifie l'établissement d'un cadre légal qui assure les normes de protection de l'environnement et qui élabore d'avance les peines répressives. Rappelons que « pour exister, une loi pénale doit avoir été mise en vigueur et n'être pas encore caduque au moment ou le juge statue $»^{55}$. Le droit positif interne de l'environnement au Bénin, qui s'insère dans cette optique, est plus ou moins riche en textes législatifs et réglementaires. La production législative, commencée à l'époque coloniale, s'est accrue à partir des années 1990, période du renouveau démocratique. Entre autres innovations du secteur de l'environnement, le législateur a fondé sa politique environnementale sur l'amélioration du cadre législatif et réglementaire. Il conviendra pour nous de revisiter ce cadre qui offre une possibilité théorique en faisant une analyse descriptive de l'existant, en mettant en exergue les dispositions pénales de portée générale (A) ainsi que celles relatives à la législation sectorielle (B).

54 (V). JAWORSKI, La charte constitutionnelle de l'environnement face au droit pénal, RJE, N Spécial 2005. 


\section{A) Les textes de portée générale}

II s'agit d'une part des anciens textes ou codes remontant à la période coloniale et d'autre part de la récente loi-cadre sur l'environnement.

\section{Les anciens textes répressifs}

Se sont des textes juridiques quasi inadaptés pour la protection de l'environnement mais universellement reconnus. Il s'agit par exemple, du code de procédure pénale et du code pénal.

\section{a) Le Code de Procédure Pénale ${ }^{56}$}

Au lendemain des indépendances, le législateur a très tôt fait de doter le pays d'un code de procédure pénale dont la première édition est apparue en août 1967. La deuxième édition est apparue le 08 novembre 1982 et aujourd'hui, la troisième édition en 2000. Ainsi, en matière pénale classique ou en matière environnementale, ce code est actuellement applicable notamment en matière de droit processuel environnemental. II devrait l'être en tenant compte des spécificités du droit pénal de l'environnement ; mais il a été voté et révisé sans la dimension environnementale..$^{57}$.

56 Ordonnance n²5/PR/MJL du 07 août 1967, ONEPI, Bénin

57 Cf. Décret $n^{\circ} 99-211 d u 30$ avril 1999 portant transmission à l'Assemblée Nationale du projet de loi portant code de procédure pénale. Au moment où nous mettons sous presse, ce code vient d'être voté par les députés le 30 mars 2012 avec des améliorations quant aux droits de la personne mais sans changement dans le domaine de l'environnement. 


\section{b) Le recueil de Code pénal « BOUVENET » ${ }^{58}$}

Depuis son accession à la souveraineté nationale, le Bénin n'a pu se doter d'un code pénal. Le code pénal colonial, ou code napoléonien ou code pénal de $1810^{59}$ ou encore "Code BOUVENET» qui n'est en réalité qu'un recueil de textes, est le code en vigueur au Bénin. Il est désuet et son application remonte au XIXème siècle. Ce code n'est pas du tout adapté à la protection de l'environnement ; c'est un droit colonial qui assure une protection indirecte et essentiellement utilitariste de l'environnement. II organise l'appropriation publique ou privée et une exploitation absolument libérale des ressources naturelles ${ }^{60}$. C'est dans ce cadre que s'inscrit, la section III intitulé " destructions, dégradations, dommages » des articles 434 et suivants qui déterminent les incriminations à caractère environnemental qu'elle réprime.

Contrairement à la loi-cadre, aux législations sectorielles, les articles du code pénal qui ont un rapport avec ce que l'on nomme aujourd'hui «environnement», visaient principalement la protection des droits d'un propriétaire à l'égard d'éléments naturels. La protection de l'environnement y trouvait son compte mais d'une manière tout a fait incidente à travers la satisfaction de l'intérêt du propriétaire. Ainsi, le code pénal ne protège certains éléments naturels que parce qu'ils sont considérés comme éléments de la propriété publique ${ }^{61}$ ou privé : « quiconque aura abattu un ou plusieurs arbres

58 Cf. le décret du 6 mai 1877 qui avait rendu applicable «Le Code BOUVENET»; en Afrique Occidentale Française (AOF). C'est ainsi qu'il s'applique au Bénin jusqu'à ce jour. Le pays n’ayant pas encore un code pénal propre à lui. V. aussi Lucien ACCAD, EJA, T.10 : Droit pénal et procédure pénale. Définition des comportements délictueux. p.21; on peut voir que contrairement à certains pays africains qui se sont dotés au lendemain des indépendances d'un code pénal comme le Niger par loi 61-27 du 15 juillet1961; Gabon par loi 2163 du 31 mai 1963 ; Cameroun par loi n65-24 du 21 novembre 1965; Guinée décret de promulgation du 30 octobre 1965 ; Tchad par ord. 1267 PR-MJ de 1967 ; Côte-D'ivoire, 1960 mis à jour le 1er avril 1968 ; Mali loi du 29 août 1961 ; Rouanda décret-loi n 21-77 du 18 Août 1977.

59 PRADEL(J), op.cit.,p:90

60 Cf. KAMTO (M), op. cit. $p: 66$

61 Cf. Gaston Jean BOUVENET et Paul HUTIN, Recueil annoté des textes de Droit pénal applicable en AOF ; Dégradation de monuments article 257 CP. 
qu'il s'avait appartenir à autrui... $»^{62}$; "Quiconque aura sans nécessité tué un animal domestique ${ }^{63}$. Cette forme implicite de protection des biens naturels ne rompt pas avec une visée anthropocentrique. Comme l'a bien montré $M$. Agulhon,ce type originel de protection de l'animal n'a rien à voir avec l'écologie. L'intérêt protégé n'est pas un bien naturel menacé mais la morale civique « on espérait qu'en refreinant cette violence mineure, on aiderait à refréner la violence majeur des humains entre eux... c'était un problème de relation à I'humanité et non de relation à la nature ${ }^{64}$. On pourrait à titre d'exemple, faire remarquer que l'article 479.8 du CP et l'article 86 de la loi-cadre prohibent tous deux l'émission du bruit, mais le premier l'interdit « afin d'éviter qu'on ne trouble la tranquillité des habitants ", le second en revanche, en plus de la première, l'interdit afin de causer " une gêne excessive à la nature ". Par contre, le code pénal burkinabé rompt avec le classicisme colonial et incrimine directement l'environnement en temps qu'un "bien n'appartenant à personne ", lorsqu'il dispose que " quiconque aura, par inattention, imprudence ou négligence directe ou indirecte porté atteinte à la santé de l'homme, des animaux, des plantes en altérant l'équilibre du milieu naturel soit les qualités essentielles du sol, de l'eau, ou de l'air sera déclaré coupable de délit contre l'environnement et puni conformément aux dispositions du code de l'environnement " ${ }^{65}$. Au Bénin, le projet de nouveau code pénal introduit par le gouvernement, depuis quelques années et toujours en souffrance au Parlement, n'aborde pas les délits liés à l'environnement.

62 Idem Article 445

63 Idem Article 454

64 Le sang des bêtes, in romantisme $n^{\circ} 31,1981, p: 81$ cité par Lascoumes $P$, La « nature comme intérêt protégé par le droit pénal : les trois étapes d'un parcours incertain in Images et usages de la nature en droit, 1993. p : 223-224 ; cf. SOGLO AGUEDE (Giséle), Le droit pénal de l'environnement en droit positif béninois : possibilités et limites de la répression, Mémoire de DEA, $p: 9,1998$, Lomé, Togo

Art. 194 de la Loi n43-96ADPdu 13 novembre 1996 portant code pénal du Burkina Faso cf. www.ahjucaf.org/Burkina- Faso 


\section{Les possibilités offertes par la loi-cadre sur l'environnement au Bénin}

Certaines dispositions constitutionnelles autorisent le législateur, de façon expresse, à adopter des lois qui permettent de mettre en œuvre la protection juridique de l'environnement. La gestion des ressources naturelles et de l'environnement étant du domaine de la loi, elle est régit par une loi-cadre. C'est l'exemple de la plupart des constitutions d'expression française, comme celle du Bénin. Dans le contexte général du bloc de légalité tel que dégagé dans la doctrine juridique française, une loi-cadre environnementale peut être définit comme " une loi ordinaire dont l'objet et la portée s'adressent aux problèmes de gestion et protection de l'environnement; avec toutes les perspectives d'application des approches de gestion intégrée du secteur des ressources environnementales $"{ }^{66}$ La loi-cadre sur l'environnement du Bénin, apparait donc comme un instrument qui encourage une gestion visant à centraliser et à coordonner les différentes interventions ou approches, ainsi que les régimes qui sont centrés autours des ressources fonctionnelles des différents secteurs d'intervention pour protéger l'environnement. Le Bénin dispose ainsi d'un moyen formel d'obtenir un système intégré de gestion environnementale, en rassemblant les régimes juridiques souvent autonomes à chaque secteur, tout en établissant un système généralisé d'interface entre les secteurs.

En effet, la loi $n^{\circ}$ 98-030 du 12 février 1999 portant loi-cadre sur l'environnement en République du Bénin, sans être une loi organique, fixe les principes, définit les bases de la politique environnementale et organise sa mise en œuvre et ce, en application des dispositions des articles 27, 28, 29, 74 et 98 de la constitution. C'est elle qui rend effective et applicable les dispositions constitutionnelles. Très exhaustive dans la définition des infractions et des peines, elle énonce les principes généraux à respecter pour une meilleure protection de l'environnement. Elle est la principale loi sur l'environnement au

66 E. G. MOUTONDO, Les lois-cadre environnementales dans les pays francophones d'Afrique, article, in, Aspects contemporains du droit de l'environnement en Afrique de l'Ouest et centrale, sous la coordination de L. GRANIER, UICN, 2008. 
Bénin. A l'instar du Bénin, une loi ou un code de l'environnement est en vigueur également dans plusieurs pays africains ${ }^{67}$.

La loi-cadre sur l'environnement du Bénin, comprend 123 articles, 07 titres et 22 chapitres. Dans cette loi-cadre, la répression de l'environnement est organisée autour des sources de dégradations potentielles.

\section{a) L'énoncée des principes généraux de l'environnement}

Selon la doctrine, "les principes généraux servent de critères d'interprétation pour résoudre des questions que pourraient susciter l'application des règles de compétences ». Les principes généraux ou « principes fondamentaux ${ }^{168}$, constituent en réalité des lignes directrices, autour desquelles va s'inspirer la politique environnementale du pays. Ces principes cardinaux, au nombre de six, sont :

- " l'environnement béninois est patrimoine national et fait partie intégrante du patrimoine commun de l'humanité ;

- chaque citoyen à droit à un environnement sain, satisfaisant et durable et à le devoir de le défendre ;

- la protection et la mise en valeur de l'environnement doivent faire partie intégrante du plan de développement économique et social et de la stratégie de sa mise en œuvre ;

- les différents groupes sociaux doivent intervenir à tous les niveaux dans la formulation et l'exécution de la politique nationale en matière d'environnement ; ce principe est capital dans la lutte contre la pauvreté et favorise le développement du pays ;

67 C'est le cas au Sénégal, un code de l'environnement a été adopté en 1983 ; au Togo, un code de l'environnement a été adopté en 1988 ; au Tchad, une loi définit depuis 1998 certains principes de protection et de gestion durable, ainsi que le régime des études d'impact ; au Maroc, une loi du 12 mai 2003 régit la protection et la mise en valeur de l'environnement ;Gabon, 1996 ;Cameroun, 1996 ; Côte-d'Ivoire, loi n96-766du 03 octobre 1996 portant code de l'environnement de Côte-d'Ivoire.

68 Cf. Art. 3 de la loi n²001-01 du 15 janvier 2001 portant code de l'environnement au Sénégal. 
- les autorités doivent tout mettre en œuvre pour optimiser l'investissement dans le développement des capacités nationales en vue de la réalisation progressive et effective de la politique en matière d'environnement ;

- tout acte préjudiciable à la protection de l'environnement engage la responsabilité directe ou indirecte de son auteur qui doit en assurer la réparation. ${ }^{69}$

Cependant, la formulation de ces principes par la loi-cadre sur l'environnement, laisse à désirer d'autant puisqu'elle manque, à notre sens, de rigueur juridique. Le premier principe qui commence par " l'environnement béninois...l'humanité ", n'en est pas un et le troisième aurait pu s'intituler " principe de participation ». Car ces principes devraient être identiques et en conformité avec ceux affirmés par la communauté internationale et exprimés par les instruments internationaux. Il s'agit par exemple du principe de prévention, du principe de précaution, du principe de participation, du principe du développement durable, du principe pollueur payeur, du principe de l'intégration de l'environnement dans les plans de développement.

L'on peut se poser la question de savoir quel rôle joue véritablement ces principes ? En droit, ces principes, qui sont des principes juridiques, d'émanation législative et doctrinale, sont d'une importance capitale aussi bien pour le législateur que pour le juge. En effet, le juge dans ses diverses applications peut s'en inspirer. Car c'est à la lumière de ces principes qu'il interprétera une loi obscure ou une loi dont le sens est douteux ${ }^{70}$. respectivement les objectifs desdits principes et les dispositions pour atteindre ces objectifs. 


\section{b) Les incriminations ou infractions prévues par la loi-cadre}

Conformément au principe de la légalité des délits et des peines, les crimes et délits ne peuvent être prévus que par une loi au sens formel, c'est-à-dire un texte voté par le parlement ou par un acte assimilé tel que les ordonnances prise par le gouvernement en vertu d'une habilitation légale. Ainsi, lorsqu'on viole les règles établies, il y a infraction qui est définit comme "toute action ou omission que la société interdit sous la menace d'une sanction pénale $»^{71}$ ou comme "une conduite frappée d'une sanction pénale $»^{72}$; on commettrait alors un délit ou un crime.

L'histoire du droit français de l'environnement dont est issu le droit positif béninois, nous renseigne que l'ancêtre des lois sur l'environnement est le célèbre décret de Louis XIV, qui avait été conçu pour protéger le patrimoine de la Couronne, le décret royal d'août 1669 , qui énonçait des règlements d'ordre général visant les eaux et forêts et qui fut suivi du décret d'Août 1681 sur les eaux territoriales, lequel visait entre autres à protéger les ports et les côtes ${ }^{73}$.

L'on a pu définir le droit de l'environnement comme un ensemble de règles tendant à organiser la pression des activités humaines sur la nature de telle sorte que celle-ci puisse demeurer apte à remplir ses fonctions ${ }^{74}$.

La loi-cadre sur l'environnement du Bénin, dont l'élaboration réside dans un souci global de préserver l'environnement, aborde presque tous les compartiments ou du moins les principaux domaines du droit de l'environnement secteur par secteur.

71 PRADEL (J), op. Cit. p: 241.

72 GIROUX (M) et OSULLIVAN(E), Droit pénal Général, vol. 7 ; édit. Yvon Blais Inc, Québec, 1997, p :7

73 PRABHU (Mohan) Op. Cit. RIDP, AIDP, p: 671-672. Lire aussi, ROBERT (Jacques-Henri), in, Le problème de la responsabilité et des sanctions en France, RIDP, op. cit. p : 951 ou il est question au lieu de décret royal, d'ordonnances de Louis XIV. HENNAU-HUBLET(C) et PIRET (J.P.), Les crimes contre l'environnement en droit belge, article, in, RIDP. Op. Cit., AIDP, p: 777 
Les infractions relatives à la dégradation du sol et du sous sol

Toutes les activités humaines découlent de l'occupation du sol qui est définie comme " tout terrain ou espace souterrain, même submergée d'eau ou couvert par une construction ${ }^{75}$; le sous-sol étant le prolongement en profondeur du sol. Ainsi, sur le sol comme dans le sous-sol existent des richesses; d'où une gestion rationnelle desdites richesses s'impose pour limiter leurs exploitations incontrôlées et dégradantes. C'est pourquoi, leur affectation et leur aménagement à des fins agricoles, industrielles, urbaines ou autres, ainsi que les travaux de recherches ou d'exploitation de leurs ressources, lorsqu'ils portent atteinte à l'environnement béninois donnent lieu à une étude d'impact préalable ${ }^{76}$. Il s'ensuit alors que l'inobservation de cette norme, donne lieu à I'infraction environnementale qualifiée de « délit de non respect de la procédure d'étude d'impact environnemental $\aleph^{77}$.

\section{Les infractions relatives aux eaux continentales et aux eaux maritimes.}

Les eaux continentales concernent les eaux de surfaces et les eaux souterraines qu'il conviendrait de bien gérer et de gérer durablement. II s'agit en réalité des eaux résiduaires, des eaux de ruissellement, de l'eau potable, des eaux des différents plans d'eau (lagunes, cours d'eau, fleuves, lacs, étangs, marres, rivières, etc....). L'exploitation ou la manipulation de ces eaux est généralement source potentielle de diverses infractions. Ainsi, sont considérés, entre autres, comme actes délictuels : les déversements, écoulements, rejets, dépôts directs ou indirects de toute nature pouvant provoquer ou accroître la pollution des eaux (art. 28) ; non respect des normes de rejets dans les eaux continentales (art. 36). 
En ce qui concerne les eaux maritimes et leurs ressources, le législateur béninois incrimine les faits délictuels comme suit : " sont interdits le déversement, I'immersion, l'introduction directe ou indirecte, l'incinération en mer de matières de nature à porter atteinte à la santé publique et aux ressources biologiques ; entraver les activités maritimes, y compris la navigation maritime et la pêche ; altérer la qualité de l'eau de mer ; dégager les valeurs d'agrément et le potentiel touristique de la mer ${ }^{78}$.

$>\quad$ Les infractions relatives à la pollution de l'air.

Au Bénin, en particulier dans la capitale économique Cotonou, la qualité de l'air est détériorée par deux catégories de polluants issus de la combustion industrielle ou domestique, des combustibles fossiles ou de la consommation des produits pétroliers comme les carburants. Ces polluants sont généralement émis directement comme les oxydes de soufre, les oxydes d'azote, les poussières ou particules en suspension, l'acide chlorhydrique, les composés organiques volatiles et l'oxyde de carbone. Les polluants ainsi identifiés agissent sur la santé, soit directement lors de la respiration soit indirectement par la modification de l'environnement (retombées acides, déplétion de la couche d'ozone, effet de serre). Ils agissent en outre à court ou à long terme, soit en provoquant de l'inconfort (irritation des yeux et de la gorge, maux de tête, toux, nausée), soit en provocant des troubles graves pouvant conduire à la mort, notamment des personnes les plus fragiles (personnes âgées, enfants en bas âges, personnes atteintes de troubles respiratoires...). Ces agents polluants étant essentiellement d'origine anthropique, afin de limiter les dégâts, le législateur a convenu de réprimer les personnes physiques et morales à l'origine de ces dégradations.

Ainsi, au sens de la présente loi, constitue une infraction atmosphérique, " toute pollution au delà des normes fixées par les lois et règlements » (art.46). Il y a donc délit de pollution de l'air, lorsque les immeubles, établissements agricoles, industriels, commerciaux ou artisanaux, véhicules, ou autres objets sont construits, exploités, ou utilisés en violation des normes en vigueur en 
matière d'émission dans l'air (art.47). Ces infractions interviennent en cas de dépassement d'un seuil toléré.

\section{Les infractions relatives à la faune et à la flore}

Les infractions liées à la flore et à la faune sont généralement les plus nombreuses. Dans ce secteur, l'atteinte aux ressources naturelles est régulière et fréquente. Dans la loi-cadre sur l'environnement, ce secteur est régi par les dispositions des articles 49 et suivants. Fort de leur caractère de loi-cadre, ces dispositions se contentent de déterminer les domaines dans lesquels il conviendrait de légiférer ou de réglementer et renvoient ainsi donc, la définition des infractions et des sanctions aux différentes conventions intervenues dans ce secteur et aux législations sectorielles que compléteront des règlements. Conséquences, la rubrique sanctions, portant titre $\mathrm{VI}$, ne comporte nulle part des sanctions aux manquements relatifs à la flore ou à la faune. Cette technique, si elle est propre aux lois cadre, elle a pourtant ses limites, notamment l'éparpillement des textes.

\section{Les infractions relatives aux pollutions et aux nuisances.}

La gestion des déchets constitue de nos jours, l'un des principaux problèmes environnementaux auxquels sont confrontées les villes africaines. La ville de Cotonou produit à elle seule environ 708 tonnes par jour de déchets solides ménagers ${ }^{79}$. La salubrité et l'assainissement de cette ville dépendent de la rigueur et la détermination des pouvoirs publics à juguler ce fléau en réprimant à travers les moyens juridiques, les mauvais comportements des populations.

Aussi, les installations classées, qu'on défini comme étant tous établissements industriels ou commerciaux qui présentent des causes de dangers ou des inconvénients, soit pour la sécurité, la salubrité, la commodité ou la santé du voisinage (article 74), sont elles réglementées en fonction de leur classe ou de leur importance. II en est de même des nuisances acoustiques, 
sources de troubles incommodant le voisinage. En vue de réprimer les atteintes à ces diverses pollutions, le législateur sanctionne quiconque sera coupable de :

- rejet, dépôt ou émission d'un contaminant dans l'environnement audelà de la quantité prescrite (art.15) ;

- non dénonciation de la présence accidentelle dans l'environnement d'un contaminant (art.67) ;

- divagation d'animaux dans les agglomérations urbaines (art.17);

- dépôt des déchets dans un endroit autre qu'un lieu d'entreposage ou une usine de traitement des déchets appropriés (art.68) ;

- non communication aux autorités compétentes des informations relatives à l'analyse des déchets gérés par une installation classée (art.71, 83 et suivants) ;

- défaut de prise de mesures nécessaires préventives de lutte contre la pollution de l'environnement (art.75, 76) ;

- émission de bruit susceptible de causer des troubles de voisinage (art.86) ;

Les infractions relatives aux respects des conditions préalables (déclaration, autorisation ou permis) à l'exercice d'activité comportant un risque pour l'environnement.

La loi-cadre prévoit à cet effet une série d'infractions administratives :

- défaut d'installation de dispositifs pour le traitement des eaux usées (art.29);

- défaut d'autorisation ou de permis spécial (art.70, et suivants);

- défaut ou absence ou altération du certificat de conformité environnementale pour toute activité éligible à l'étude d'impact environnemental (art.87 et suivants). 
- défaut d'autorisation pour travaux de reconstruction, d'extension, d'installation ou de raccordement entre les conduites d'un système public et celles d'un système privé (art. 30);

- $\quad$ non respect de la réglementation en vigueur ;

- défaut d'autorisation de faire des sondages ou des forages dans le but de chercher ou de capter en profondeur des eaux souterraines (art. 33) ;

- non conformation à la présente loi des installations établies antérieurement à la promulgation de la loi et rejetant des eaux résiduaires dans les eaux continentales béninoises (art. 35);

- défaut d'autorisation des autorités béninoises compétentes d'une occupation, exploitation, construction ou établissement susceptible de constituer une source de nuisance de quelque nature que ce soit, effectuée ou réalisée sur le rivage de la mer et sur toute l'étendue du domaine public maritime (art. 43) ;

Des textes de lois votés avant ou après cette loi-cadre, la complètent afin d'en faciliter l'application.

B) Une législation sectorielle en évolution

La législation béninoise sur la protection de l'environnement présente de grandes disparités. C'est une législation dont les débuts remontent à l'époque coloniale, ce qui explique de nos jours, la survivance de législations vieillissantes et quasi désuètes. Nous avons dès lors, axé notre réflexion sur l'inventaire ou l'état des lieux des principaux textes de lois sectorielles entrant dans le domaine de la répression de l'environnement. Ce travail d'inventaire et d'analyse des textes existants, permettra de nous rendre compte de la nature et de la diversité de l'arsenal législatif dont dispose le droit positif béninois. 


\section{Dans le domaine de la flore, de la faune et de la chasse}

Le premier texte spécifique réglementant le domaine est l'Ordonnance $n^{\circ}$ 80-8 du 12 février 1980 portant réglementation de la protection de la faune et de l'exercice de la chasse en République Populaire du Bénin. Elle est intervenue dans la logique de la conférence des nations unies sur l'environnement tenue à Stockholm en Suède du 05 au 06 juin 1972.

En 1987, la Commission Nationale de Législation et de Codification, a initié plusieurs textes législatifs qui ont été tous votés par l'Assemblée Nationale Révolutionnaire (ANR), le parlement béninois à l'époque. La loi n87-012 du 21 septembre1987 portant code forestier ainsi votée à l'époque, a abrogé l'ordonnance. Mais, avec l'adoption de la loi-cadre sur l'environnement, et les exigences de protection de l'environnement au plan international, le législateur béninois a senti la nécessité d’abroger ladite loi par la Loi n93-009 du 02 juillet 1993 portant régime des forêts en République du Bénin, dont les dispositions répressives sont plus ou moins pertinentes. Cette loi met principalement l'accent sur les délits forestiers. Seule est considéré comme crime " l'incendie volontaire de plantation avec intention criminelle ». Sont donc, considérées comme infractions à la réglementation forestière et interdits, les délits ciaprès : la transhumance (art.59); la divagation d'animaux( art.58) l'usage de la tronçonneuse (art.53, et 99); les feux de brousse tardif ou incendie de plantation (à l'exception des feux précoces) ; l'occupation du domaine forestier (art.56); l'outrage au forestier en exercice ; les coupes ou prélèvements abusives ; la dégradation ou la destruction d'espèce protégée " abatage, émondage, ébranchage, mutilation, arrachage, incinération, annihilation et saignée ${ }^{80}$; l'exercice illégal de la profession d'exploitant forestier.

La seconde loi qui a abrogé l'Ordonnance $n^{\circ}$ 80-8 du 12 février 1980 est la loi $n^{\circ}$ 87-014 du 21 septembre 1987 portant réglementation de l'exercice de la chasse en République du Bénin. Elle protège mieux la faune contre ses prédateurs que sont les hommes en mettant un accent particulier sur les sanctions pénales en cas de « dégradation ou de destructions d'espèces intégralement ou partiellement protégées ». Le législateur a même prévu des 
circonstances aggravantes. C'est le cas « lorsque le délit a été commis dans une réserve naturelle intégrale, dans un parc national, dans une réserve de faune, dans une zone cynégétique $~^{81}$ ou a lieu dans la " nuit avec un engin éclairant $»^{82}$. Dans le souci de ce coller à la loi-cadre et de protéger davantage la faune, en s'inspirant des techniques les mieux élaborées, des réalités socio-économiques, ce texte a été à nouveau révisé par la loi n²002-016 du 18 octobre 2004 portant régime de la faune en République du Bénin. Cette dernière réprime sévèrement " quiconque chasse ou capture des animaux sauvages sans permis ou dans les lieux interdits (...), chasse des femelles en gestation, des animaux suités ou jeunes "; ou simplement " ramasse des œufs ou détruit des nids d'animaux dans les zones protégées ${ }^{83}$.

Dans le même ordre d'idée au cours de l'année 1987, le législateur béninois, dans le souci de légiférer dans le secteur, a voté des règles relatives à la vaine pâture et la transhumance. La vaine pâture est le droit pour un éleveur de faire paître son bétail sur les espaces naturels et non clos d'autrui après la récolte alors que la transhumance est un déplacement organisé, de nature saisonnière et cyclique, des troupeaux à la recherche d'eau et de pâturage ${ }^{84}$. Ces deux activités d'éleveurs très récurrentes, sont à l'origine de conflits meurtrières et de délits environnementaux dans nos régions. La loi n87-013 du 21 septembre 1987 portant réglementation de la vaine pâture, de la garde des animaux domestiques et de la transhumance en République du Bénin, vient réglementer le secteur. Ainsi, elle incrimine également la divagation d'animaux, la dégradation de récolte, l'entrée illégale de bétail sur le territoire national, et le défrichement de zone de pâturage.

Par ailleurs, des normes protègent bien évidemment les végétaux à travers la loi n 91-004 du 11 février 1991 portant réglementation phytosanitaire en République du Bénin. Elle punit « quiconque aura introduit, détenu, multiplié, transporté sur le territoire de la République du Bénin des organismes nuisibles

83 Article 154 loi n²002-016 du 18 octobre 2004 portant régime de la faune en République du Bénin. 
aux végétaux et produits végétaux préjudiciables à l'environnement, à la santé publique ou à l'économie nationale ${ }^{85}$.

Enfin, dans le domaine de la faune aquatique, la gestion des ressources halieutiques a retenu depuis la période coloniale l'attention du législateur. En effet, si la réglementation s'est montrée moins abondante dans les domaines précédents, il n'en a pas été ainsi en ce qui concerne la pêche. Ainsi, on note des textes, très anciens pour la plupart, mais qui demeurent toujours applicables. Le texte chapeau en la matière, demeure l'Ordonnance $n^{\circ} 20 / P R / M D R C / S P$ du 25 avril 1966 portant réglementation générale de la pêche dans les eaux continentales du Dahomey. Elle réglemente les pêcheries dans les divers plans d'eau, réprime les infractions telles que l'usage comme moyen de pêche de toute drogue, herbe, feuille, racine,...toute substance destinée à tuer, à endormir ou à enivrer le poisson; des armes à feu ou explosifs; la pêche d'alevins etc. Par la suite est intervenue l'ordonnance73-41 du 5 mai 1973 portant réglementation de la profession de mareyeur au Bénin ainsi que plusieurs textes réglementaires ${ }^{86}$ qui font référence à l'ordonnance principale en termes de dispositions répressives.

Néanmoins, remarquons que cette réglementation ancienne sur les pêcheries, a pour objectif premier non pas la protection de l'environnement mais la préservation de la santé humaine donc de l'homme tout court.

\section{$85 \quad$ Art.37 idem}

86 -Arrêté du 15 mai 1914 promulguant en AOF le décret du 12 avril 1914 portant réglementation de la pêche et l'exploitation industrielle de la baleine dans les colonies françaises ;

- Décret du 29 juillet 1924 interdisant en AOF, la pêche pratiquée à l'aide des explosifs, de poisons ou autres drogues ;

Décret n²07 du 30 janvier 1950 interdisant l'utilisation des armes à feu ou des explosifs comme moyens de pêche.

Décret $n^{\circ} 204$ PC/MDRC du 1er octobre 1964 instituant un contrôle des produits de la pêche et des conditions de commercialisation de ces produits ;

Arrêté n²3 MDRC/SP du 08 février 1968 déterminant la taille minimum des crevettes de lagunes, destinés à un traitement industriel ;

Arrêté interministériel $n^{\circ} 100$ MTPTPT/MDRC du 31 juillet 68 fixant les conditions d'exercice de la pêche dans les eaux territoriales du Dahomey;

Arrêté $n^{\circ} 152 / \mathrm{MDRC} / \mathrm{SP}$ du 16 septembre 1970 portant enlèvement des acadjas du lac Ahéme et des Lagunes de Ouidah et de Grand-Popo ;

Arrêté interministériel $n^{\circ} 5 \mathrm{MDRC} / \mathrm{MEF}$ du 16 janvier 1974 portant réglementation de la pêche et de la commercialisation des crevettes des lacs et lagunes du Dahomey 
Consommer du poisson capturé à l'aide de ces engins de mort, serait aussi s'exposer à l'intoxication alimentaire, voire à la mort, d'où l'interdiction desdits engins. L'environnement dans son sens strict n'était donc pas à l'époque une préoccupation des pouvoirs publics.

\section{Dans le domaine de l'eau et des pollutions et nuisances.}

Les règles de ce secteur relèvent plus du domaine réglementaire ${ }^{87}$ que législative. Deux lois spécifiques seulement réglementent le domaine. II s'agit : de la loi n $87-015$ du 21 septembre 1987 portant Code de l'hygiène publique en République du Bénin et de la loi n87-016 du 21 septembre 1987 portant Code de l'eau en République du Bénin ;

La première, bien avant l'avènement de la loi-cadre sur l'environnement, apparaissait, au regard de tout observateur averti des règles protégeant l'environnement, comme la loi qui préservait mieux l'environnement, notamment en milieu urbain et périurbain puisqu'elle touche tous les compartiments de I'hygiène publique. En effet, elle se préoccupe de l'amélioration du cadre de vie des populations. Elle réprime les atteintes à la salubrité publique, à l'hygiène et à l'assainissement des lieux publics. On peut énumérer entre autres : le rejet dans la nature d'eaux résiduaires industrielles (art.3), l'émission de fumé par les engins, ou par des entreprises industrielles, etc., pour ne citer que ces cas. Les autres infractions, telles l'hygiène sur la voie publique (dépôt d'ordure ou

87 Décret : n²001-109 du 04 avril 2001 fixant les normes de qualité des eaux résiduaires en République du Bénin ;

Décret $n^{\circ} 2001-093$ du 20 février 2001 fixant les normes de qualité de l'eau potable en République du Bénin ;

Décret $n^{\circ} 2001-110$ du 04 avril 2001 fixant les normes de qualité de l'air en République du Bénin

Décret n²003-332 du 27 août 2003, portant gestion des déchets solides en République du Bénin ;

Arrêté interministériel $n^{\circ} 136$ MISAT/MEHU/MS/DC/DATC/DE/DHAB du 26 juillet 1995, portant réglementation des activités de collecte, d'évacuation, de traitement et d'élimination des déchets solides en République du Bénin 
d'urine ou d'excrément sur la voie publique (art.4, 59,61) etc....) sont également sanctionnées. Un décret ${ }^{88}$ d'application fixe davantage le contenu.

La deuxième, contrairement à la première, est pratiquement en désuétude et dépourvu de texte d'application. Cette loi, malgré l'absence d'un décret d'application compte dans l'arsenal répressif ${ }^{89}$. Les diverses pollutions des eaux y sont réprimées. Mais le déversement des eaux usées ou eaux résiduaires dans la nature fait par exemple l'objet d'un décret ${ }^{90}$ pris sur le fondement des articles $28,35,37$ et 38 de la loi-cadre sur l'environnement et de l'article 3 du code de l'hygiène publique.

\section{Dans le domaine foncier}

Il s'agit de la loi n²007-03 du 16 octobre 2007 portant Régime Foncier en République du Bénin dont les dispositions pénales renvoient à l'application de la loi portant réglementation de la vaine pâture, de la garde des animaux domestiques et de la transhumance en ce qui concerne les infractions relatives à la dégradation de la faune et de la flore, telle, la divagation des animaux domestiques dans les forêts. Les dispositions de la loi-cadre sur l'environnement et celles relatives au régime de la faune s'appliquent également. Le contentieux foncier rural pure est réglé si possible d’abord à l'amiable avant toute saisine du juge.

\section{Dans le domaine de la gouvernance locale}

L'avènement de la décentralisation au Bénin, devenue effective avec l'élection, l'installation et l'entrée en fonction en février 2003 des Maires de la première mandature, a inauguré l'ère de la décentralisation des préoccupations environnementales, au nom du principe de subsidiarité avec la prise d'une kyrielle

88 Décret $n^{\circ} 97-616$ du 18 décembre 1997 portant application de la loi $n^{\circ} 87-015$ du 21 septembre 1987 portant code de l'hygiène publique en République du Bénin

89 Vient d'être abrogée par la loi-n ${ }^{\circ} 2010-44$ du 24 novembre 2012 portant gestion de l'eau en République du Bénin.

90 Idem 
de textes de lois, dont entre autres, la loi n97-029 du 15 janvier 1999 portant organisation des communes en République du Bénin. Avec cette loi, l'autorité communale, en sa qualité d'officier de police judiciaire, exerce des pouvoirs de police en matière d'atteinte à l'environnement ${ }^{91}$. Quelle jouissance le Maire en fait? Et comment juguler les potentiels conflits d'attributions avec le pouvoir central ? Cet ensemble de questionnements, constitue des préoccupations essentielles pour la mise en œuvre de la qualité d'OPJ du Maire.

En conclusion, disons que ce répertoire des textes législatifs et réglementaires est caractéristique de ce que l'élément légal des infractions ne figure presque jamais dans le code pénal mais dans les lois de polices spéciales ou dans la loi-cadre comme le précise si bien le professeur PRIEUR. L'élément matériel est rarement présenté de façon spécifique et l'élément moral est rarement exigé du fait de la clause générale d'incrimination qui s'appuie sur une simple faute matérielle d'inobservation des règlements. Mais, de plus en plus, la doctrine reste attachée aux principes traditionnels du droit pénal qui exige un élément intentionnel ${ }^{92}$.

91 Cf. Recueil des lois sur la décentralisation 2002, Mission de décentralisation Cotonou; article 93 : la commune à la charge de : de la fourniture et de la distribution de l'eau potable ; de la collecte et du traitement des déchets liquides; du réseau public d'évacuation des eaux usées ; du réseau d'évacuation des eaux pluviales ; etc....

Article 94 : la commune à la charge de la création et de l'entretien des plantations, des espaces verts et de tout aménagement public visant l'amélioration du cadre de vie. Elle veille à la protection des ressources naturelles, notamment des sols, de la faune, des ressources hydrauliques, des nappes phréatiques et contribue à leur utilisation.

Elle est consultée sur tout aménagement relatif aux sites miniers se trouvant sur son territoire.

Article 95 : la commune veille à la préservation des conditions d'hygiène et de salubrité publique notamment en matière de :

- $\quad$ De prospection et de distribution d'eau potable ;

- $\quad$ De périmètre de sécurité sanitaire autour des captages, forages et puits ;

- D’assainissement privé des eaux usées ;

- $\quad$ De lutte contre les vecteurs de maladies transmissibles ;

- D'hygiène des aliments et des lieux et établissements accueillant du public ;

- $\quad$ De déchets industriels ;

92 Droit de l'environnement, op.,cit.,p.820. V. aussi pour plus de précision, le chapitre : VI. 
Ce tableau synoptique des textes législatifs et réglementaires béninois fait apparaitre les caractéristiques des incriminations pénales en matière d'environnement.

Ce dispositif législatif et réglementaire, est renforcé par les conventions internationales en matière d'environnement.

\section{§III : L'apport des conventions internationales dans le développement du droit pénal interne de l'environnement}

Le droit international de l'environnement est un droit essentiellement constitué de traités auxquels les Etats africains sont parties que ce soit à un niveau régional, multinational ou universel. En effet, un traité ou une convention internationale est « un accord international conclu par écrit entre Etats et régi par le droit international, qu'il soit consigné dans un instrument unique ou dans deux ou plusieurs instruments connexes, et quelle que soit sa dénomination particulière ${ }^{93}$. En général ces traités sont conclus soit entre les Etats, soit entre les Etats et les organisations internationales, comme l'ONU. Ce dernier cas de figure est plus remarquable en matière environnementale. Les " traités qu'ils soient de type traité-cadre, traité-loi ou traité-contrat sont juridiquement contraignants dès lors que l'Etat partie a exprimé sa volonté d'être lié selon les formes requises par la convention de Vienne sur le droit des traités ou suivant le droit coutumier. Etant des sources juridiques incontestables de droit positif même dans l'ordonnancement juridique des Etats, ils constituent le socle juridique sur lequel repose un système de normes. ${ }^{194} C^{\prime}$ 'est ce que confirme le Professeur Dinah SHELTON lorsqu'elle écrit " le droit international de l'environnement engage les Etats à adapter les moyens d'action appropriés dans leur système

93 Cf. Article 2 de la convention de Vienne sur le droit des traités. Adopté par la communauté internationale le 23 mai 1969 et entrée en vigueur le 27 janvier 1980.

94 Cf. Valentin Y AMEGANKPOE et Kodjo AVODE, in, La force contraignante et le degré d'efficacité variable du droit international matériel et de ces principes naissants. Intensité de la règle selon les secteurs. Les sanctions non juridictionnelles : cas de l'Afrique. Article de doctrine publié dans La protection de l'environnement au cœur du système juridique international et du droit interne ; sous la direction des Professeurs M. PAQUES et M. FAURE, 2001, Université de Maastricht et de Liège. 
juridique interne afin d'appliquer les lois qu'ils ont édicté, conformément à leurs obligations internationales $1{ }^{95}$.On peut dès lors en déduire que les obligations conventionnelles, une fois nées, ne pourraient perdre leurs effets de contrainte que lorsqu'elles sont exécutées et ceci avec une bonne foi parfaite ${ }^{96}$. Quelles pourraient être leur influence dans le droit interne?

En droit béninois, dès lors qu'une convention est régulièrement ratifiée et publiée, elle a une autorité supérieure à celle de la loi ${ }^{97}$. Elle entre ainsi en vigueur et s'applique. Ce qui suppose que dans la hiérarchie des normes, après la constitution, suit la convention qui est supérieure à la loi ordinaire. II en est ainsi d'autant plus que le droit béninois, héritage du droit français est un droit d'essence « moniste $»^{98}$.

En Afrique, les conventions internationales ont énormément contribué au développement du droit de l'environnement au niveau national ; d'autant plus que, non seulement ces conventions intègrent le droit national mais aussi et surtout elles servent de base à l'élaboration des textes législatifs et réglementaires. Elles déterminent en général les mesures visant leur mise en œuvre sur le territoire d'un Etat signataire afin que ce dernier s'approprie des techniques juridiques et des terminologies appropriées pour asseoir une politique criminelle en fonction des réalités locales. C'est ce que confirme PRABHU Mohan lorsqu'il écrit dans le rapport général que « dans la communauté internationale, plusieurs organismes gouvernementaux et internationaux ont joué un rôle dynamique dans la promotion ou l'adoption d'ententes, de recommandations ou de résolutions qui prévoient l'ajout de sanctions criminelles dans les lois

95 Techniques et procédures en droit international de l'environnement, Cours 3, UNITAR, 1999

96 Cf. C.I.J, arrêt du 25 septembre 1997.Rec. 1997, p.114

97 Cf. article 147 de la Constitution béninoise du 11 décembre 1990

98 PRADEL (Jean), Droit pénal général, 16ème édit. Editions Cujas, Paris, 2006, p : 147. C'est une théorie selon laquelle le droit est un tout constitué par une combinaison du droit interne et du droit international de sorte qu'en cas de conflit c'est le droit international qui l'emporte car il est considéré comme hiérarchiquement supérieur au droit interne. Cette théorie s'oppose à la théorie dualiste. 
nationales d'environnement ou qui demandent aux signataires des conventions internationales de le faire ${ }^{99}$.

A titre illustratif, le Bénin a pris une part active à la Conférence des Nations Unies sur l'Environnement et le Développement à Rio de Janeiro au Brésil en 1992 et a ratifié les trois conventions qui en sont issues ${ }^{100}$. Dans la même période, il a créé le Ministère chargé de l'administration de l'environnement, le Ministère de l'Environnement, de l'Habitat et de l'Urbanisme (MEHU), devenu MEPN, il est aujourd'hui redevenu MEHU ${ }^{101}$. Véritables sources de droit, l'on a pu dénombrer au cours des années 80 , dans la sphère des relations internationales " plus de 300 conventions multilatérales consacrées entièrement ou partiellement à la protection de l'environnement et environ 900 traités bilatéraux ayant un objet similaire et de nombreux textes de caractère déclaratoire ou programmatoire $»^{102}$. Le Bénin, dans sa vision de protection de l'environnement, en a signé ou ratifié les principales ${ }^{103}$.

Parmi ces instruments de politique criminelle ayant inspiré des incriminations pénales on peut citer :

- la convention internationale de Londres du 02 novembre 1973 sur la prévention de la pollution par les navires, modifiée par le protocole du 17 février 1973 en ses règles 9 et 11 de l'annexe 1 concernant la prévention de la pollution par les hydrocarbures (convention Marpol 73/78) ;

99 Cf. Rapport Général du congrès international sur «les crimes contre l'environnement ", organisé par la section canadienne de l'Association International de Droit Pénal qui a eu lieu à Ottawa du 02 au 05 novembre 1992.

100 Il s'agit de : convention cadre des nations unies sur les changements climatiques ; convention des nations unies sur la diversité biologique et convention des nations unies sur la lutte contre la désertification dans les pays gravement touchés par la sécheresse et/ ou la désertification en particulier en Afrique.

101 Le MEHU est crée par le décret n92-17 du 28 janvier 1992. Cf. note 120

102 A. MAIDOKA, lors de son intervention à l'ERSUMA sur le droit de l'environnement dans l'espace AA-HJF, décembre 2006. www.ahjucaf.org Cf. aussi Maurice KAMTO citant M. PRIEUR dans, Droit de l'environnement en Afrique, EDICEF, 1996, p : 68.

103 Cf. Annexe N II. Principaux Accords bilatéraux et multilatéraux auxquels le Bénin est partie. Source, MEPN, 2009. 
- la convention sur le commerce international des espèces de faune et flore sauvages menacées d'extinction (CITES), signée le 13 mars 1973 à Washington ;

- la convention de Bâle sur le contrôle des mouvements transfrontières des déchets dangereux et leur élimination, signée le 22 mars 1989 ;

- la convention de Bamako sur l'interdiction d'importer en Afrique des déchets dangereux et sur le contrôle des mouvements transfrontières et la gestion des déchets dangereux produit en Afrique, signée le 30 janvier 1991 ;

- la convention de Stockholm sur les polluants organiques persistants, adoptée le 21 mai 2001.

Certes, ces instruments supra nationaux n'ont ni édicté des normes ni mis en place des juridictions susceptibles d'assurer la répression des manquements au droit de l'environnement. Mais leur mérite est d'agir sur la conscience des Etats parties en leur indiquant ce qui devrait être fait. Ainsi, dans le souci de rendre effective les prescriptions découlant des obligations conventionnelles, l'Etat élabore sa politique criminelle en conformité avec la réglementation internationale, régionale bilatérale ou interétatique par la prise de textes d'application appropriés.

Par exemple, pour atteindre, son objectif visant à garantir que le commerce international des espèces concernées ne nuise pas à la conservation de la biodiversité et repose sur une utilisation durable des espèces sauvages, la CITES a fixé un cadre juridique et édicté une série de procédures afin que les espèces sauvages faisant l'objet d'un commerce international ne soient pas surexploitées. Ainsi, la convention dispose en son article VIII que : « les parties prennent les mesures appropriées en vue de la mise en application de la présente convention ainsi que pour interdire le commerce de spécimen en violation de ces dispositions. Ces mesures comprennent : a) les sanctions pénales frappant soit le commerce, soit la détention de tels spécimens ou les deux ; b) la confiscation ou le renvoi à l'Etat d'exportation de tels spécimens ».

De même, la convention internationale sur la prévention de la pollution par les navires, prescrit aux Etats parties des mesures qui, pour la plupart, 
appellent l'édiction de législations nationales à orientation pénale. C'est ce que prévoit l'article 4 " conformément aux dispositions de la présente convention, chaque partie contractante interdira l'immersion de tous déchets ou autres matières sous quelque forme ou quelconque conditions que se soit ... " l'article 5 quant à lui précise : " $1^{\circ}$ les dispositions de l'article 4 ne s'appliquent pas lorsqu'il est nécessaire d'assurer la sauvegarde de la vie humaine ou la sécurité des navires...2 $2^{\circ}$. Chaque partie prend sur son territoire les mesures appropriées pour prévenir et réprimer les actes contraires aux dispositions de la présente convention ».

Il en est ainsi également du point 5 de l'article 9 de la convention de Bâle qui prescrit que : " chaque Partie adopte les lois voulues pour interdire et réprimer sévèrement le trafic illicite de déchets dangereux... ".

Quant à la convention de Bamako, en son article 4-1, elle dispose que tout Etat partie a l'obligation de prendre des mesures nécessaires de manière à interdire l'importation en Afrique de déchets dangereux en provenance de Parties non contractantes.

Mais, entre la rédaction d'un texte et son application effective, il y a un fossé qu'il conviendrait aux institutions des pouvoirs publics de franchir ; puisque toute politique criminelle repose sur des institutions républicaines fortes.

\section{SECTION II : LES ASPECTS INSTITUTIONNELS DE LA POLITIQUE CRIMINELLE}

Dans la mise en place de la politique répressive environnementale de tout pays, le cadre institutionnel, qui est le socle ou le soubassement de cette politique, joue un rôle primordial. Selon F. FALLOUX et L.TABOT, le cadre institutionnel, peut se comprendre comme " la façon dont un gouvernement s'organise pour assumer ses responsabilités et fonctions $»^{104}$. Les différents efforts effectués par le Bénin pour asseoir un cadre institutionnel, témoigne d'une volonté politique

104 Cité par GOUGBEDII C., La protection de l'environnement dans les pays de l'Afrique de l'ouest : aspects juridiques et politiques (Bénin, Burkina Faso, Niger, Sénégal et Togo., Thèse de Doctorat unique en droit, Chaire UNESCO, UAC, FADESP, 2011. 
de s'adapter aux exigences de l'environnement international. Ainsi, après cet inventaire de la législation béninoise, peu abondante et disparate, il serait intéressant d'apprécier le concours des différentes institutions de la République à savoir les institutions décisionnelles nationales ( $\S 1$ ) ensuite la police environnementale (\$2) et enfin les associations de défense de l'environnement (§3), dans la mise en œuvre de la répression.

\section{§ : La contribution des institutions nationales.}

L'efficacité de la politique répressive environnementale repose sur un fondement institutionnel national fiable et en adéquation avec l'évolution du droit de l'environnement. Le droit interne béninois est doté de ces genres d'institutions qui apparaissent comme de véritables catalyseurs du droit répressif de l'environnement. Leur influence s'analysera du point de vue des institutions constitutionnelles d'une part et des institutions gouvernementales d'autre part.

\section{A) L'influence des institutions constitutionnelles dans la répression des atteintes à l'environnement}

Dans nos développements antérieurs, nous avons précisé la contribution de la norme constitutionnelle dans la protection de l'environnement. Ici, nous revenons pour mettre un accent particulier sur l'influence de chaque organe constitutionnel sur la politique répressive puisqu'il s'agit là des instances de prise de décisions.

\section{Le Président de la République}

Au Bénin, le Président de la République est l'institution suprême. II conduit la politique du Gouvernement en tant que Chef du Gouvernement. II détient le pouvoir exécutif, qui lui permet d'exercer le pouvoir réglementaire. Or, l'appareil administratif qui produit les textes réglementaires repose 
pratiquement sur l'exercice de ce pouvoir qui se traduit par l'élaboration des décrets, les arrêtés, les circulaires, les décisions. Quant on sait que s'agissant de la répression en matière environnementale, " la dépendance administrative du droit pénal ${ }^{105}$ » est une règle essentielle, on mesure alors toute l'importance et le rôle que pourrait jouer le Chef de l'Etat, Président de la République dans la protection de l'environnement, notamment dans l'édition des règles et leur application. Le droit, ou plus précisément les normes juridiques et les décisions de justice n'ont aucun effet s'il n'existe une force pouvant imposer leur respect. Cette force, c'est la puissance publique qu'incarne le Président de la République.

Par ailleurs, il partage concurremment avec les Députés ${ }^{106}$, I'initiative des lois. L'exécutif initie tous les projets de lois qu'il transmet au parlement qui les vote et les renvoie au Président de la République pour être promulguées ; acte sans lequel, aucune loi ne peut entrer en vigueur, donc ne peut être appliquée. En outre, la procédure d'habilitation législative permet au Président de la République de prendre " les mesures exceptionnelles ${ }^{107}$ de l'article 68 de la constitution qui pose le principe constitutionnel des pouvoirs de crise ou encore de pouvoirs exceptionnels, pour se substituer aux Députés et prendre, en cas de désaccord sérieux entre les deux institutions, une ordonnance, laquelle a valeur de loi. Remarquons pour le moment, qu'aucune de ces ordonnances n'est relative à une loi d'environnement.

105 Cf. chapitre II pour plus d'information sur ce concept.

106 Il s'agit des membres de l'Assemblée Nationale, le Parlement Béninois.

107 Elles ont été utilisées par les Présidents N. SOGLO et M. KEREKOU pour légiférer et notamment pour faire voter les lois de finances. Ce fut le cas avec les ordonnances $n^{\circ} 2002-$ 001, 2002-002 et 2002-003 du 31 janvier 2002 portant respectivement loi de finances pour la gestion 2002, principes fondamentaux du régime des télécommunication en République du Bénin, création et attribution de l'autorité de régulation des télécommunications en République du Bénin sous le Président KEREKOU. Le Président SOGLO en a fait usage en 1996. Et tout récemment de 2006- 2010, le Président YAYI Boni en a fait abondamment usage, trois budget sur cinq sont pris par ordonnance ainsi que plusieurs lois non ratifiées par le parlement. 


\section{L’Assemblée Nationale}

Presque tous les pays sont dotés de cette institution essentielle pour l'émergence du droit de l'environnement. Le Bénin, dès son ascension à I'indépendance, s'est doté d'un parlement. Ce parlement, appelé «Assemblée Nationale Révolutionnaire " est aujourd'hui dénommé «Assemblée Nationale ». Organe délibérant, l'Assemblée Nationale joue un rôle très important dans le dispositif répressif. Elle vote la loi, qu'elle soit initiée par elle (proposition de loi) ou par l'exécutif (projet de loi). C'est elle qui donne aussi au gouvernement I'autorisation de ratification des différents accords multilatéraux ou bilatéraux. II convient dès lors, de travailler pour que les parlementaires puissent s'approprier les grands défis environnementaux afin de légiférer dans le sens de doter le pays de textes pénaux ou répressifs appropriés et réellement applicables. Le vote de toutes les lois dépend du bon fonctionnement du Parlement. Pour se faire, cinq commissions permanentes ont été créées. Au nombre de ces commissions, on peut citer : la Commission des lois, de l'administration et des droits de l'homme, qui est chargée de finaliser tout ce qui est projet ou proposition de loi et la commission des relations extérieurs, de la coopération, du développement, de la défense et de la sécurité qui se préoccupe d'étudier tous les traités signés par le Bénin dans le domaine de l'environnement. La célérité dans le traitement des dossiers et le vote des lois sont très souvent subordonnés aux choix politiques et stratégiques qu'adoptent les Députés. II arrive, que des dossiers relatifs aux textes de lois soient en souffrance dans les tiroirs des parlementaires. II en est ainsi, du projet de loi portant code pénale.

\section{La Cour Constitutionnelle}

Pour que l'affirmation de la suprématie de la constitution ne soit pas un vain mot, il est important de prévoir des mécanismes qui permettent de sanctionner la violation de ces dispositions. C'est ce que le constituant béninois a compris en dotant le pays en 1990, d'une cour constitutionnelle. Jeune, elle est plus ambitieuse que plusieurs autres cours constitutionnelles plus anciennes et plus expérimentées, comme le Conseil Constitutionnel 
français. Nous l'avons précisé plus haut, cette cour qui a innové en matière de protection de l'environnement, a une particularité qu'elle permet à tout citoyen intéressé ou toute association régulièrement déclarée de la saisir. "La saisine est ouverte à tout citoyen pour les lois, les textes réglementaires, les actes administratifs et la violation des actes fondamentaux de la personne humaine et des libertés publiques ${ }^{108}$. Cette particularité de la constitution béninoise participe du dynamisme de l'institution chargée de faire respecter les droits de l'homme et conditionne la soumission de tous ; c'est à dire des pouvoirs publics et des individus, au respect de la légalité ${ }^{109}$. Elle inspire confiance quant à la qualification de certaines infractions environnementales érigées en crimes. Néanmoins, malgré la saisine directe du citoyen, en la matière, il n'existe pas encore de jurisprudence criminelle ${ }^{110}$ mais plutôt une jurisprudence de contrôle de conformité constitutionnelle très peu abondante ${ }^{111}$. Mieux, on pourrait penser qu'il s'agit d'une juridiction politique étant donné que trois des membres sont nommés par le Président et quatre par l'Assemblée Nationale. Mais on peut objecter contre cette opinion qu'aux USA trois des membres de cette institution homologue sont nommés aussi par le Président, trois par le Sénat et trois par la Chambre des Représentants, tous organes politiques. En effet, installée le 07 juin 1993, la Haute Juridiction se révèle comme une véritable gardienne de la constitution et du respect des lois de la République. Juge de la constitutionnalité des lois, garante des droits fondamentaux et des libertés publiques, et organe régulateur du fonctionnement des institutions et de l'activité des pouvoirs publics, elle œuvre aussi au développement du droit pénal de l'environnement à travers ses décisions et avis qui sont sans recours.

108 Article 24 de la loi organique et article 29 du règlement intérieur de la cour constitutionnelle du Bénin.

109 ADELOUI (Arsène-Joël), Transition démocratiques et coopération au développement. Approches comparative Bénin, Mali, Niger et Togo. Thèse de Doctorat, UAC, FADESP, Chaire, UNESCO, droit de l'homme et démocratie, Cotonou, 2006.p : 169

110 Puisque la cour constitutionnelle est appelée à connaître du contentieux criminel lié aux atteintes à l'environnement. Et elle n'a rendue ce jour aucun arrêt en relation avec I'infraction de crime contre la nation, art. 29. Constitution.

111 Cf. décision DDC 08-091 du 20 août 2008 ; décision DDC 08-029 du 03 mars 2008; décision DDC 04-038 du 20 avril 2004 ; décision DDC 04-037 du 20 avril 2004 ; décision DDC 02-055 du 04 juin 2002 ; décision DDC 02-065 du 05 juin 2002 ; 


\section{La Cour Suprême}

La Cour Suprême du Bénin et spécialement la chambre administrative, est la juridiction habilitée à connaître du contentieux environnemental. C'est la plus haute juridiction en matière administrative ${ }^{112}$, judiciaire et des comptes. A I'instar de la cour constitutionnelle, ses décisions ne sont susceptibles d'aucun recours. Elles s'imposent au pouvoir exécutif, au pouvoir législatif ainsi qu'à toutes les juridictions. Elle est compétente pour connaître du contentieux relatif à tous les actes administratifs comme les autorisations administratives ou permis délivrées par l'administration environnementale. La cour suprême est consultée par le gouvernement plus généralement sur toutes les questions administratives et juridictionnelles, notamment sur tous les projets de lois, ordonnances et actes réglementaires. Elle peut à la demande du Chef de l'Etat, être chargée de la rédaction et de la modification de tous les textes législatifs et réglementaires, préalablement à leur examen par l'Assemblée Nationale. Ainsi, cette cour, haut lieu du savoir juridique, apporte en dernier ressort sa touche à l'élaboration de tous les projets de lois y compris ceux relatifs à l'environnement en donnant son avis. Elle est en outre chargée d'une mission permanente d'inspection à l'égard de toutes les autres juridictions ${ }^{113}$.

\section{La Haute Cour de Justice}

Installée en 2002, la Haute Cour de Justice du Bénin, juridiction répressive, tire sa légitimité de la constitution ${ }^{114}$. En effet, la compétence de la Haute juridiction est limitée au Président de la République et aux membres du gouvernement ainsi qu'à leurs complices. En vertu de l'article 136, « la Haute Cour de Justice est compétente pour juger le Président de la République et

112 La loi n²001-37 du 27 avril 2002 portant organisation judiciaire en République du Bénin, publiée au J.O. 116 année $n^{\circ} 16$ du 15 août 2005, p.783 et ss, dispose en son article 53 que les TPI peuvent maintenant, connaitre du contentieux administratif en premier ressort.

113 Cf. loi $n^{\circ}$ 2004-07 du 23 octobre 2007 portant composition, organisation, fonctionnement et attributions de la cour suprême

114 Articles 135, 136,137 et 138 de la loi n90-32 du 11 décembre 1990 portant constitution de la République du Bénin. 
les membres du gouvernement à raison de faits qualifiés de haute trahison (...) d'infractions commises dans l'exercice ou à l'occasion de l'exercice de leurs fonctions ainsi que pour juger leurs complices en cas de complot contre la sûreté de l'Etat». Est considéré comme haute trahison, dans la plupart des constitutions du monde : la violation du serment du Président de la République, les cas de violations graves et caractérisées des droits de l'homme, la cession frauduleuse d'une partie du territoire national. Mais, au Bénin, en plus de ces cas, « tout acte attentatoire au maintien d'un environnement sain, satisfaisant, durable et favorable au développement $»^{115}$ est aussi considéré comme élément constitutif de l'infraction de haute trahison, donc comme un crime contre la nation, sévèrement réprimé. En effet, en cas de mise en accusation, le Président de la République et les membres du gouvernement sont suspendus de leurs fonctions. En cas de condamnation, ils sont déchus de leurs charges.

Par ailleurs, même si cette cour n'a connu encore aucune affaire, la hantise de tomber sous le coup de la loi cohabite les dirigeants et les rendent plus avisés et plus sage.

Longtemps décriée comme une institution budgétivore sans réelle emprise juridictionnelle, la Haute Cour de Justice est saisie depuis 2006 d'un dossier d'instruction dans lequel un ancien Ministre ${ }^{116}$ est poursuivi pour détournement de denier public. En revanche, elle n'a connu encore aucun dossier relatif au crime contre l'environnement

Force est de constater que dans la pratique, la sanction criminelle ainsi que la procédure de mise en accusation sont difficilement réalisable. Le juge, dans l'application de la loi, va certainement heurter des écueils juridicopolitiques, quasi impossibles à surmonter. Dans ce cadre, une réflexion est en cours pour réviser la loi organique sur la haute cour de justice et clarifier la procédure à suivre en cas de mise en accusation.

\footnotetext{
115 Idem Articles 74

116 Il s'agit du Ministre Alain ADIHOU, alors Ministre chargé des relations avec les Institutions au sujet de la gestion de la LEPI. Depuis, octobre 2009, il est mis en liberté provisoire sous caution.
} 


\section{B) Les institutions gouvernementales}

Le Président de la République en tant que chef du gouvernement délègue à chacun des membres du gouvernement une parcelle de pouvoir pour gérer un Ministère. L'environnement étant une science à caractère transversale, presque tous les Ministères en font une préoccupation. Les problèmes environnementaux sontmultiples, variés, complexes et multisectoriels. C'est ce qui explique le partage de compétence au sein de cette administration, créant ainsi une dispersion institutionnelle. Cette " dispersion de responsabilité " ou l'émiettement de structures semblait bien inévitable, dans la mesure ou l'environnement n'était pas encore devenu un objet spécifique d'administration ${ }^{117}$. Mais, notre analyse qui se veut purement juridictionnelle, portera sur le rôle de certains Ministères clés en matière de législation environnementale.

\section{Le Ministère chargé de l'Environnement}

Créé par décret en $1992^{118}$, conformément aux recommandations de la Conférence Nationale ${ }^{119}$, le Ministère de l'Environnement, de l'Habitat et de

117 PRIEUR (M), Droit de l'environnement, Dalloz, Paris, 1996, p : 148

118 Cf. décret n`92-17 du 28 janvier 1992 portant attributions, organisation et fonctionnement du MEHU.

119 Cf. La nation $\mathrm{n}^{\circ}$ Spécial an 2 de la conférence Nationale. Les dossiers de la conférence, 1992.

La Conférence Nationale tenue du 19 au 28 février 1990 à Cotonou au Bénin, a été déterminante. Cette période qualifiée de Renouveau Démocratique, a jeté les bases d'une politique environnementale. En effet, au plan environnemental, les recommandations ciaprès ont été adoptées à savoir :

- $\quad$ Fixer les bases juridiques nécessaire à l'aménagement de l'espace, à la conservation de l'environnement et à la mise en œuvre des plans et programmes ;

Créer un département ministériel chargé de l'environnement, de l'urbanisme, de l'habitat et de l'aménagement du territoire ;

Elaborer une législation en vue de la gestion et de la protection de l'environnement ;

Définir une politique nationale en matière d'environnement et une stratégie de sa mise en œuvre ;

Diffuser et populariser les textes législatifs et réglementaires relatifs à la gestion et à la conservation de l'environnement

Adopter une loi portant interdiction d'importation de déchets toxiques ;

Initier des études sur l'assainissement et l'élimination des déchets de toutes sortes. 
I'Urbanisme, a connu une évolution qualitative fortement appréciable pour devenir aujourd'hui, Ministère de l'Environnement et de la Protection de la Nature ${ }^{120}$, avec entre autres missions la protection de la nature, attribution initialement dévolue au Ministère chargé de l'agriculture. Ce Ministère est la cheville ouvrière en matière d'initiation et d'élaboration de projets de textes réglementaires et législatifs en matière environnementale et de la protection de la nature. Deux structures représentant les deux grands pôles du Ministère à savoir la Direction Générale de l'Environnement et la Direction Générale des Forêts et des Ressources Naturelles, chacun dans son domaine de compétence et en collaboration avec les autres structures nationales concernées, jouent un rôle déterminant dans l'exécution de cette mission qui se décline essentiellement en des tâches de conception, d'application et de suivi de la réglementation environnementale. Ces mêmes structures gèrent dans leur domaine respectif, les conventions internationales ratifiées par le Bénin. Le Ministère abrite également des structures sous tutelles ${ }^{121}$ qui jouent un rôle essentiel dans la mise en œuvre de la répression notamment dans le domaine de la préservation de la faune et de la flore avec la police forestière animée par les agents des Eaux et Forêts et dans le domaine des pollutions et nuisances par la police environnementale.

La création d'un ministère spécialisé en environnement traduit à l'évidence, sur le plan structurel, l'importance nouvelle accordée aux problèmes de la défense de l'environnement. Mais, des ministères sectoriels se préoccupent également de la politique répressive.

120 Cf. décret $n^{\circ} 2007-493$ du 02 novembre 2007 portant attributions, organisation et fonctionnement du Ministère de l'Environnement et de la Protection de la Nature source : MEPN. Aujourd'hui, à la faveur d'un remaniement ministériel, il est redevenu MEHU avec le rattachement des volets de l'habitat et de l'urbanisme par décret n²012-004 du 24 janvier 2012 portant composition du gouvernement.

121 II s'agit de l'ABE, qui a été le chef de file dans l'élaboration des textes d'application de la loi-cadre sur l'environnement. Il est le bras opérationnel du ministère. II s'agit aussi de la CNDD, du FNE et du CENAGREF. 


\section{Le Ministère chargé de la justice et de la législation}

Comme l'indique son intitulé et conformément au décret créant le Ministère de la Justice, de la Législation et des Droits de l'Homme (MJLDH), ce dernier est considéré dans ses prérogatives comme le Ministère le plus compétent en matière d'élaboration des textes de loi. C'est à ce Ministère, en l'occurrence à sa Direction de la Législation, de la Codification et des Sceaux, Secrétariat Permanent de la Commission Nationale de Législation et de Codification que revient en principe l'initiative de la collecte des besoins des Ministères sectoriels en terme d'élaboration d'avant-projets de lois de la République afin de permettre à ladite Commission d'être opérationnelle. Mais, dans la pratique, cette commission interministérielle qui se réunit une fois par semestre n'est pas opérationnelle. Elle fonctionne de manière irrégulière de sorte que ce sont les Ministères sectoriels concernés qui initient et élaborent les avants projets de lois avant de les acheminer parfois vers la commission. En ce qui concerne la réglementation, son élaboration incombe entièrement aux Ministères sectoriels concernés avant son adoption par le gouvernement. Seules les structures sectorielles impliquées dans sa mise en œuvre sont invitées aux différentes réunions de validation de textes comme le précise si bien, le membre de phrase «...en collaboration avec les structures concernées» du $1^{\text {er }}$ alinéa de l'article 28 du décret organisant le MEPN. L'avis du Ministère chargé de la justice n'est pas sollicité.

\section{Le Ministère chargé de l'agriculture, de la pêche et de l'élevage}

Ce ministère couvre un domaine de compétence à impact environnemental très négatif. II ne fait aucun doute que c'est le département qui concurrence durement celui chargé de l'environnement. En effet, le département du développement rural s'est toujours occupé fondamentalement des questions du monde rural : forêt, élevage, chasse, faune, flore, transhumance, foncier rural, braconnage, etc. Dès lors, ce département a acquis administrativement et juridiquement des compétences non seulement de protection (prise 
de divers arrêtés et initiateurs de plusieurs décrets) mais aussi de gestion de l'environnement. Ce n'est que tout récemment en 2006 que suite à de hautes luttes entre les cadres de ce ministère et ceux du ministère chargé de l'environnement que le secteur des ressources naturelles (eaux, forêts, chasse et parcs nationaux) a été enfin détaché pour être rattaché au ministère chargé de la protection de l'environnement comme c'est le cas dans la plupart des pays de la sous région ${ }^{122}$.

Somme toute, de toutes les structures intervenant dans le secteur de la répression des atteintes à l'environnement, la police environnementale, structure interne au MEHU, mérite une attention particulière.

\section{§ II : L’expérience béninoise de la Police Environnementale}

L'administration environnementale béninoise s'inspirant de l'expérience canadienne des Inspecteurs de l'Environnement, a innové en créant une police environnementale. Elle est une structure répressive, chargée de traquer les délinquants environnementaux. Animée par des Inspecteurs de l'Environnement sous serment, recrutés niveau licence et formés en gestion de l'environnement " sur le tas ${ }^{123}$, ils ont une compétence nationale. Créée par décret ${ }^{124}$, elle est placée sous la tutelle de la Direction Générale de l'Environnement du Ministère de l'Environnement et de la Protection de la nature à qui elle rend compte périodiquement. Lorsqu'on parle de police, on pense à la sanction. La police environnementale a pour mission :

- de veiller à l'application de la législation environnementale ;

- d'informer et de sensibiliser les populations sur les questions environnementales ainsi que sur la stratégie nationale de protection de l'environnement ;

122 Togo, Niger, Burkina Faso, Sénégal, etc....

123 Une formation non diplomate.

$124 \mathrm{~N}^{\circ}$ 2001-096 du 20 février 2001portant création, attributions, organisation et fonctionnement de la police environnementale, 
- de rechercher, constater et de réprimer les infractions à la législation environnementale et ce, concurremment avec les Officiers de Police Judiciaires et les agents habilités par les lois spéciales ${ }^{125}$.

Les mêmes missions sont assignées à leurs homologues togolais avec cette nuance que ces derniers, ne sont pas directement recrutés mais relèvent du personnel du Ministère chargé de l'environnement ${ }^{126}$.

Il conviendrait dès lors, de mettre en relief les moyens d'action $(A)$ dont dispose cette institution pour mener à bien ses activités répressives (B).

\section{A) Les moyens d'action}

En terme de moyens humains, la Police Environnementale n'est dotée que de 24 agents assermentés dénommés "Inspecteurs de l'Environnement " répartis sur tout le territoire national à raison d'une moyenne de deux inspecteurs par département. Il est attribué à chaque policier de l'environnement une motocross, un badge ou une carte professionnelle, pour assurer leur déplacement et faciliter leurs activités. Il est mis également à leur disposition dans leur structure ou lieu de travail, des équipements de travail dont entre autres, les analyseurs de gaz pour le contrôle des gaz d'échappement des véhicules à deux ou à quatre roues, un véhicule laboratoire spécialement conçu pour l'analyse de gaz à effet de serre (GES), en vue des activités de lutte contre la pollution atmosphérique. Par contre, ils n'ont pas encore d'uniforme pouvant les différencier à l'image de leurs homologues agents d'hygiène et, dissuader les contrevenants. Ce qui permet à quelques vils individus, de se passer pour des policiers de l'environnement ${ }^{127}$.

\footnotetext{
125 Cf. infra chapitre II

126 Cf. Arrêté $n^{\circ} 009 / \mathrm{MERF} / \mathrm{CAB} / \mathrm{SG} / \mathrm{DE}$ portant création de la police environnementale au Togo.

127 Cf. note de service $n^{\circ} 352 /$ DDEPEN-AL/MEPN/SRCC/DPE/SA du 6 novembre 2007 dénonçant les usurpateurs de titres
} 


\section{B) Les activités répressives ${ }^{128}$}

En collaboration avec les forces de sécurité publique et de l'autorité communale ou municipale, les Inspecteurs de l'Environnement mènent des activités répressives. Ces activités interviennent pour la plupart du temps, après une période préventive relativement longue faite de campagne de sensibilisation des populations ou des groupes cibles en vue d'un changement de comportement. Ainsi, à la suite de ces mesures préventives, la prévention, étant une action anticipatrice, consistant à empêcher la survenance d'atteintes à l'environnement ${ }^{129}$, suivent des mesures coercitives, lesquelles interviennent après une atteinte avérée à l'environnement. Dans leur mission de police répressive, les agents de la police environnementale, sans être officiers de police judiciaire, se confondent quasiment à cette dernière puisqu'elle vise la recherche des infractions et leurs auteurs. Ils disposent aussi de pouvoirs au même titre que ceux reconnus aux agents de police judiciaire. Ils peuvent ainsi recevoir des plaintes relatives aux pollutions et nuisances, pénétrer librement sans avertissement préalable dans les installations ou établissements, interroger des personnes, se faire produire des documents, dresser des procès verbaux, apposer des scellés, et opérer des saisies; ils peuvent, en outre ordonner l'arrêt des travaux, opérations ou activités effectués en infraction aux règles de l'environnement ${ }^{130}$. Dans ce cadre, les Inspecteurs de l'Environnement consacrent principalement leurs activités à mener une lutte contre la pollution de l'air dans les grandes villes du pays et principalement dans la métropole Cotonou. Outre la lutte antipollution, le respect des textes réglementaires et législatifs amène les inspecteurs à poursuivre et à verbaliser les tenanciers de bar ou buvette, les responsables des lieux de culte, et autres indélicats, menant des activités bruyantes et qui, suite à des inspections de routines, n'ont pas cru devoir obtempérer aux injonctions ou aux mesures correctives recommandées et ce, après une mise en demeure infructueuse. Dans ce cas, un avis d'infraction pour pollution sonore est adressé au mis en cause. Dans leur activité de

128 Il s'agit des mesures coercitives de verbalisations qui interviennent lors des contrôles de routines des inspecteurs et après sensibilisation.

129 M.PRIEUR, Droit de l'Environnement, 3ème édit., Dalloz, 1996, p : 70

130 Cf. article 5 du décret précité, note 124, p.61 
verbalisation, les Inspecteurs de l'environnement sont accompagnés des forces de sécurité publique (gendarmes ou policiers) en tenue et en arme, afin de faciliter les opérations de conduite à la fourrière ou de saisie du corps du délit. Le retrait ou le paiement des amendes infligées, intervient ultérieurement.

Deux autres structures apparentées mènent des activités similaires. Il s'agit de la Police Sanitaire ${ }^{131}$ et de la Brigade de protection du littoral ${ }^{132}$. La première est composée des agents d'hygiène et la seconde est constituée d'un détachement d'agents de la Police nationale. La Police Sanitaire a essentiellement pour mission de faire respecter le code de l'hygiène publique en recherchant et en constatant les infractions y relatives par les agents d'hygiène qui existent dans toutes les communes. Elle relève du Ministère de la Santé alors que la brigade de protection du littoral relève du Ministère chargé de l'intérieur et de la sécurité publique. Ces structures complémentaires travaillent en harmonie pour faire régner la sécurité environnementale.

Dans ses attributions de défense de l'environnement, la police environnementale est assistée souvent par des associations ou ONG de défense de l'environnement.

\section{$\S$ III : La contribution des associations de défense de l'environnement}

En application du principe de participation ${ }^{133}$, les associations de défense de l'environnement jouent un rôle essentiel en tant qu'acteurs aux côtés des pouvoirs publics. Avouons pourtant que l'intérêt pour l'action associative née avec la loi de $1901^{134}$ qui consacre le principe de s'associer pour la défense d'un objectif précis, est une préoccupation assez récente en

131 Cf. décret n 97-624 du 31 décembre 1997 portant structure, composition et fonctionnement de la police sanitaire.

132 Cf. arrêté $\mathrm{n}^{\circ}$ 862/MISD/DC/DGPN/DAP/SA du 12 septembre 2002 portant création d'une brigade de protection du littoral et de la lute anti-pollution au sein de la police nationale.

133 Cf. PRIEUR (M), op. Cit. p : 108 ; Agenda 21 National, MEPN, 1996, p : 141

134 Il s'agit de la loi du 1er juillet 1901 relative au contrat d'association, dite loi « Waldeck Rousseau » dont nous venons en 2001 de fêter le centenaire. Elle a fait du droit d'association une liberté publique fondamentale 
matière environnementale. Elle n'est apparue en France qu'au cours des années 1970 suite aux grandes catastrophes écologiques, avec la reconnaissance par le législateur français d'un droit associatif, en l'occurrence la loi $n^{\circ} 76-629$ du 10 juillet 1976 relative à la protection de la nature. Cette loi reconnaît la possibilité d'octroi d'agrément aux associations. Elle permet aux associations, ayant pour objet la protection de la nature, d'engager des procédures devant les juridictions pour toutes décisions leur faisant grief. Se faisant, elle reconnait aux associations agréées, le droit de se constituer partie civile pour les faits constituant une infraction aux dispositions législatives instaurées par cette loi et portant préjudice direct ou indirect aux intérêts collectifs qu'elles défendent statutairement ${ }^{135}$.La législation environnementale béninoise accorde une place considérable aux associations de défense de l'environnement. II en est ainsi puisque l'un des objectifs de la loi-cadre sur l'environnement est de " faciliter la création d'associations de protection, de défense et de mise en œuvre de l'environnement, tant au niveau national que local. Ces organismes peuvent être associés aux actions entreprises par le gouvernement, notamment en matière d'information, d'éducation et de communication des citoyens et peuvent être reconnus d'utilité publique $\aleph^{136}$. Au regard de la diversité de ces associations ${ }^{137}$ et de leurs actions, la dimension qui semble nous intéresser ici est relative à leur comportement vis à vis des infractions environnementales. Ce comportement s'analysera autour de deux axes essentiels, d'abord les conditions d'accès des

135 Charles LAGIER et Gilles POLLET (sous la direction de), Les associations de protections de l'environnement et le droit : quelles actions juridiques pour garantie un plus grand respect de l'environnement dans la décision ? Mémoire de DEA, 2005

Cf. la loi 95-101 du 2 février 1995 relative au renforcement de la protection de l'environnement, JORF, 03 février 1995.

136 L'article 5, 5 ème tiret de la loi-cadre sur l'environnement du Bénin.

137 II serait fastidieux de tenter une énumération même indicative de ces ONG d'environnement qui sont de plus en plus nombreux. En 1997, une étude de l'ABE intitulée " répertoire national des structures non gouvernementales intervenant dans le domaine de l'environnement " avait dénombrée 152 associations à caractère environnemental mais aujourd'hui on peut estimer le nombre à environ 1000, vu l'inflation galopante en matière de création d'association puisque l'autorisation qui relevait entre temps du pouvoir central, est déconcentré et relève depuis 2000 du domaine de compétence du Préfet. Un travail de recensement national des organisations de la société civile est actuellement en cours au MCRI 
associations à la justice (A) ensuite en cas d'atteinte manifeste à l'environnement les contours de l'action contentieuse (B).

\section{A) Les conditions d'accès des associations à la justice}

II n'est pas aisé d'apporter une définition claire et nette à la notion d'association de défense de l'environnement néanmoins, on peut convenir avec les dispositions de l'article L141-1du code de l'environnement français de les définir comme " associations régulièrement déclarées et exerçant leurs activités statutaires dans le domaine de la protection de la nature, de l'amélioration du cadre de vie, de la protection de l'eau, de l'air, des sols, des sites et paysages, de l'urbanisme ou ayant pour objet, la lutte contre les pollutions et les nuisances et, d'une manière générale, œuvrant principalement pour la protection de l'environnement ». Et à l'article L142-2C dudit code d'accorder une habilitation générale " aux associations de protection de l'environnement " afin qu'elles puissent exercer « les droits reconnus à la partie civile en ce qui concerne les faits portant un préjudice direct ou indirect ou intérêts collectifs qu'elles ont pour objet de défendre (...) ». A travers cette définition, il ressort qu'un certain nombre de conditions à savoir la reconnaissance de l'association par l'autorité compétente (Préfet) qui conduit à l'octroi de l'agrément et l'exercice d'activité relatif à son objet, doivent être remplies avant toute action contentieuse. Au Bénin, le législateur béninois s'inscrit dans cette dynamique lorsqu'il reconnaît que " les associations compétentes en matière d'environnement, légalement reconnues et représentatives, peuvent mettre en mouvement l'action publique et se constituer partie civile $»^{138}$. Au Togo, elles doivent en outre, exercer « depuis au moins trois ans, leurs activités dans le domaine de la protection de la nature et de l'environnement $~^{139}$ et l'intérêt défendu par eux doit rentrer " dans le champ de leur objet statutaire ${ }^{140}$. Autrement dit, une association ne peut intenter une action en justice contre un industriel pour pollution de la lagune ou

138 Article 109 de la loi-cadre sur l'environnement du Bénin.

139 KOKOUME (Koffi), La protection de l'environnement dans la législation sur la ZFI au Togo. Cité par GBENOU (Kokouvi), La sanction des atteintes à l'environnement en droit togolais. Mémoire DEA, droit et politique de l'environnement, 2005, Lomé, Togo. Idem. 
de la mer à la suite de rejet d'effluents que si la protection de la lagune ou de la mer fait partie des intérêts qu'elle a pour mission de défendre.

Ainsi donc, les associations de défense de l'environnement remplissant les conditions de la loi, peuvent ester en justice.

\section{B) Les modalités de leur action au pénale}

L'action devant le juge judiciaire en réparation du dommage causé par un crime, un délit ou une contravention appartient à tous ceux qui ont personnellement souffert du dommage directement causé par l'infraction. Ainsi les juges se sont basés sur l'article 2 du code de procédure pénale pour écarter de la constitution de partie civile, toutes les personnes physiques ou morales qui ne sont pas directement et personnellement touchées par un préjudice. Une association pour être recevable, devra satisfaire à ces conditions devant le juge. En fait, il n'est pas besoin d'un texte spécifique en la matière. Car, dès lors qu'elles sont régulièrement déclarées, "légalement reconnues et représentatives " $^{141}$, les associations acquièrent la personnalité morale et peuvent à ce titre, être recevables en justice.

A titre illustratif, une association de défense de milieu aquatique a été déclarée recevable à agir dans un cas de pollution marine par hydrocarbures. Les juges de la cour d'appel de Rennes ont considéré que cette pollution lésait « les intérêts défendus par l'association qui a pour obligation statutaire de protéger la qualité de l'eau et notamment les estuaires et rivages marins et les eaux de mer, lieux de séjours et de passage des espèces migratrices $»^{142}$. Par contre, dans une autre affaire, le juge a dénié le droit d'exercice de l'action publique à une population riveraine d'une forêt sur exploité ${ }^{143}$. Il est remarquable de constater ici que les juges se réfèrent à l'objet statutaire de l'association ce qui montre à quel point la précision des statuts est importante. A l'inverse, dans une affaire de

141 Cf. article 109 de la loi-cadre sur l'environnement au Bénin

142 CA Rennes, 23 mars 2006, n05/01913 cité par Laurent NEYRET, in, la réparation des atteintes à l'environnement par le juge judiciaire, communication, colloque, Paris, 2006.

143 Cf. GRANIER (L) (sous la dir), Aspects du droit de l'environnement en Afrique de l'ouest et centrale, op. cit.p.98, note 223. 
braconnage, les constitutions de parties civiles de plusieurs sociétés de chasse ont été déclarées irrecevables dans la mesure où elles n'avaient pas prouvé que le prévenu avait chassé sur leurs territoires ${ }^{144}$.

Par ailleurs, le mode de saisine de la cour constitutionnelle béninoise accorde également une place considérable aux associations de défense de l'environnement. Dans sa procédure de saisine, elle est saisie par requête comportant obligatoirement : les noms, prénoms, adresse précise et signature ou empreinte digitale du requérant qui peut être une personne physique ou une personne morale, justifiant de sa capacité à ester en justice ${ }^{145}$.

En Conclusion, retenons que, ce diagnostic de la législation environnementale béninoise, révèle que les sources potentielles du droit pénal national de l'environnement repose essentiellement sur quatre ensembles législatifs à savoir le code pénal, le code de procédure pénale, la loi cadre sur l'environnement et les lois spécifiques à certains domaines récurrentes. II convient d'élargir ces sources aux différents textes d'application, notamment les règlements administratifs (décrets, arrêtés), qui sont constamment utilisés dans le domaine du droit répressif. Ces différents textes définissent les incriminations et les peines applicables au nom du principe de la légalité des cimes et délits et des peines ${ }^{146}$ ou principe de " textualité pénale ${ }^{147}$. Il apparaît évident à travers ce survol de la législation que l'une des particularités des incriminations pénales est que l'élément légal est contenu dans la loi ou dans les règlements et non dans le code pénal, d'où la notion de dépendance administrative du droit pénal en matière environnementale. La volonté de réprimer les comportements illicites de l'environnement au Bénin, peut se comprendre déjà par cet effort de production de textes et de signature ou de ratification de conventions internationales mais il ne faut pas s'arrêter en si bon chemin.

144 CA Aix en Province, 13 mars 2006, $n^{\circ}$ 408/M2006 à propos de la destruction par un braconnier de 304 chamois dans le parc national de Mercantour et dans le parc national des Ecrins, cité par Laurent NEYRET, in, la réparation des atteintes à l'environnement par le juge judiciaire, communication, colloque, Paris, 2006.

145 Cf. articles 24 de la loi n91-009 du 4 mars 1991 portant loi organique de la cour constitutionnelle du Bénin et 29 du Règlement intérieur

146 Cf. article 98 de la constitution béninoise du 11 décembre 1990

147 GUIHAL (D) Droit répressif de l'environnement, 3ème éd. Economica, Paris, 2008, p : 104 


\section{CHAPITRE II : L'EXISTENCE D'UN SYSTEME REPRESSIF ENVIRONNEMENTAL EN DEVELOPPEMENT}

L'examen du chapitre précédent a mis l'accent sur les traits caractéristiques de la politique criminelle environnementale au Bénin en mettant en relief les textes législatifs et réglementaires et les institutions républicaines chargées de les appliquer. A l'analyse, l'application desdits textes conduit effectivement à l'existence d'un système répressif environnemental. Un système inféodé à un appareil répressif encore certes, en balbutiement, notamment en ce qui concerne les atteintes à caractère strictement environnemental, encore au stade embryonnaire mais, riche de quelques actions répressives dans le domaine des délits forestiers. L'analyse de la mise en mouvement de l'action publique (Section I) et du régime répressif des atteintes à l'environnement (Section II), nous permettent de mieux cerner les contours et l'évolution du droit pénal béninois de l'environnement.

\section{SECTION I : LA MISE EN MOUVEMENT DE L'ACTION PUBLIQUE}

L'action publique s'entend de " l'action exercée devant une juridiction répressive pour l'application des peines ou mesures de sûretés à l'auteur d'un crime, d'un délit ou d'une contravention ${ }^{148}$. Dès lors, le déclenchement de l'action publique tend à l'application des peines. Il convient alors dans le domaine du droit pénal de l'environnement, d'examiner les personnes habilitées à exercer l'action publique (§I) d'une part, afin de s'appesantir spécifiquement sur la surveillance ou le contrôle qui est à l'avant-garde des recherches et des poursuites (§II), d’autre part.

148 (J) VINCENT, (R) GUILIEN (S) GUINCHARD, (G) MONTAGNIER, Lexique de termes juridiques, Précis DALLOZ, 7ème éd. Paris 1988. 


\section{§I : La constatation des infractions : l'exercice de l'action publique}

La constatation des infractions interpelle aussi bien les officiers de police judiciaires qui animent l'enquête préliminaire que le ministère public qui est au centre de l'exercice de l'action publique.

\section{A) L'enquête préliminaire par les OPJ}

Le bon déroulement du procès pénal est subordonné à une bonne enquête préliminaire. Elle est définie comme " l'enquête diligentée d'office ou à la demande du parquet par la police ou par la gendarmerie avant l'ouverture de toute information et permettant au ministère public d'être éclairé sur le bien fondé d'une poursuite ${ }^{149}$ ». Quant à l'action publique, " elle est l'action exercée devant une juridiction répressive pour l'application des peines ou mesures de sûreté à l'auteur d'un crime, d'un délit ou d'une contravention. Même si elle peut être mise en mouvement par la partie civile, c'est toujours au ministère public ou aux administrations habilitées (agents assermentés des eaux et forêts et chasse par exemple) qu'il convient de conduire l'action publique jusqu'à son terme. ${ }^{150}$ »)

Selon la jurisprudence, l'action publique se définie comme « un mal infligé par la justice répressive en vertu de la loi, à titre de punition ${ }^{151}$ ou de sanction ${ }^{152} d^{\prime}$ 'un acte que la loi défend. Elle est exercée par les magistrats ou par les fonctionnaires auxquels elle est confiée par la loi ${ }^{153}$. Ainsi que l'observent les Professeurs J. LARGUIER et P. CONTE, « l'infraction en tant que violation de la loi

149 GUILLIEN (R), VINCENT (J), et GUINCHARD (S) MONTAGNIER (G) (sous la dir), Lexique de termes juridiques, Dalloz, 7ème éd. Paris, 1988

150 Idem.

151 Cass. (Belg.), 14 juillet 1914, Pas. 1924, I, p. 473 cité par (F) ROGGEN, Le juge pénal et la protection de l'environnement, in, Les juges et la protection de l'environnement, édit. Bruylant, Bruxelles

152 Cass. . (Belg.), 4 Décembre 1994, Pas. 1945, I, p. 159 ; Liège 12 mars 1973, J.T., 1973, p. 424, in op. Cit.

153 cf. Art. 1er du C. pr. pén béninois, édit. 1982. 
pénale, fait naitre l'action publique, exercée au nom de la société et tendant en principe au prononcé d'une peine ou mesure pénale $»^{154}$.

De la lecture croisée de la position doctrinale et jurisprudentielle, il s'ensuit que la commission de l'acte infractionnel peut déclencher l'enquête préliminaire, notamment, la réunion des éléments caractérisant l'acte, donc la constatation de l'infraction. Cette constatation relève de la compétence des officiers de police judiciaire qui en sont les acteurs traditionnels auxquels s'ajoutent, avec le développement du droit de l'environnement, une autre catégorie spécifique d'acteurs, les agents assermentés.

\section{1) La constatation des infractions}

La constatation étant l'état d'une chose ou d'une situation que l'on consigne dans un écrit, en vue d'éclairer le juge, sa pratique ne peut qu'être confiée aux professionnels. C'est ainsi que cette compétence est exercée par les officiers de police judiciaire de la police et de la gendarmerie en tant qu'acteurs classiques et par les fonctionnaires de l'administration publique, en tant qu'agents « nouveaux » habilités à exercer lesdites fonctions.

\section{a) Les acteurs classiques de constatation des infractions : les OPJ}

Il s'agit des fonctionnaires de la police judiciaire dont les fonctions traditionnelles reposent sur la recherche et la constatation des infractions en matière de droit commun.

Au regard du code de procédure pénale béninois, presque identique au code de procédure pénale français, ont qualité d'Officiers de Police Judiciaire : les officiers, adjudants et adjudants- chefs, les maréchaux des logis-chefs de la gendarmerie ; les commissaires de police et officiers de police ; les inspecteurs 
de police ${ }^{155}$. Le rôle de ces autorités consiste à recevoir des plaintes et des dénonciations; procéder à des auditions et surtout établir des procès-verbaux à transmettre au parquet ou au procureur de la République. En cas de crime ou délit fragrant, c'est-à-dire « qui se commet actuellement, ou qui vient de se commettre (...) ou lorsque la personne soupçonnée est poursuivie par la clameur publique ou est trouvée en possession d'objets (...) $\|^{156}$ du délit ou du crime; se saisir de tout ce qui paraîtra avoir servi ou avoir été destiné à commettre le crime ou délit, ainsi que tout ce qui paraîtra en avoir été le produit, enfin de tout ce qui pourra aider à la manifestation de la vérité. Ils ont le droit de procéder aussi à des perquisitions. Ils sont au service du Parquet et du juge d'instruction et peuvent requérir la force publique pour l'exécution de leur mission. Ces officiers qui ont en outre l'obligation de compte rendu « sont tenus d'informer sans délai le procureur de la République des crimes, délits et contraventions dont ils ont connaissance. A la clôture de leurs enquêtes, ils doivent lui faire parvenir directement l'original ainsi qu'une copie certifiée conforme des procèsverbaux qu'ils ont dressé ; tout acte ou documents y relatifs lui sont en même temps adressés ; les objets saisis sont mis à sa disposition $»^{157}$. Cette obligation est même élargie au « (...) fonctionnaire ${ }^{158} »$. Ainsi, de l'article $33 \mathrm{du}$ code de procédure pénale, il ressort que les fonctionnaires qui constatent une infraction n'ont pas théoriquement la faculté de ne pas la relever et que le procureur de la République a seul le pouvoir de classer sans suite une procédure pénale. Notons tout de même que ce texte est dépourvu de sanction. De sorte que le défaut de non dénonciation du fonctionnaire ou de l'agent ayant connaissance de l'infraction n'est pas qualifié de délit répréhensible mais ce dernier peut échopper d'une "répression disciplinaire, d'autant plus improbable que la jurisprudence du Conseil d'Etat ne considère pas comme fautif le refus de l'administration de provoquer les poursuites pénales à défaut de textes spécial I'y contraignant formellement ${ }^{159}$. II serait à notre avis difficile de réunir les éléments de preuves pouvant soutenir la thèse de complicité du fonctionnaire,

155 Art. 16 du CPP béninois.

156 Idem, art 40

157 Idem, art. 17 et 19

158 Idem art 33 al.2 du C.PP béninois et art 40 aliéna 2 C.PP français

159 D. GUIHAL, Droit répressif de l'environnement, Economica 3ème édit., Paris 2008, p : 28 
en cas de non dénonciation. Même si, D. GUIHAL, développe que « son inaction peut aussi le rendre complice de l'infraction principale du fait que détenant le pouvoir juridique de s'opposer à l'infraction, l'agent s'est abstenu volontairement de le faire ${ }^{160}$

Quant aux Agents de Police Judiciaire, ils sont des agents de forces de sécurité publique (gendarmes ou policiers) n’ayant pas la qualité d'OPJ. II s'agit des militaires de la gendarmerie affectés dans les brigades; les officiers, les brigadiers et sous brigadiers de paix de la police nationale. Leur mission est de seconder ou d'assister les OPJ. Ainsi, sous l'autorité hiérarchique de ses derniers, ils reçoivent les plaintes, constatent les crimes, délits et contraventions et rédigent les procès-verbaux, mais ils n'ont pas qualité pour décider de la garde à vue ${ }^{161}$. Contrairement aux APJ, les OPJ sont des agents professionnellement assermentés. II s'agit des agents dont l'activité principale oblige à prêter serment devant le tribunal dont ils ressortent juridiquement avant leur entrée en fonction.

Enfin, les agents et officiers de police judiciaire ont une compétence générale pour constater et rechercher toutes les infractions, même dans le silence des textes spéciaux d'incrimination ${ }^{162}$. Tel est le cas par exemple en matière $d^{\prime}$ infraction à la réglementation des parcs nationaux ${ }^{163}$.

Au Bénin, dans la pratique, en matière de délit forestier ou de délit d'environnement tout court, cette catégorie d'OPJ classique demeure très inactive. Dans la plupart des cas, on ne constate pas d'auto saisine relativement aux infractions d'environnement et les rares cas de dénonciations qui leur parviennent sont classés très souvent sans suite. Mais de temps à autre, ces

160 D. GUIHAL, Op.cit. p: 29. Cas d'un douanier qui ferme volontairement les yeux sur les agissements de fraudeurs connus de lui sans que sa négligence procède d'un pacte de corruption. Ch. Cour cass. Crim. 27 oct.1971 Bull.384 (France), Rev.sc.crim.1972 p : 375 obs. A. Légal et p. 385 obs. A. Vitu ; à propos d'un Expert comptable, qui en négligeant de vérifier les documents fournit par son client se rend coupable de complicité de présentation de faux bilan ainsi que de fraude fiscale. Sur l'ensemble de la question, cf. A. Decoq, inaction, abstention et complicité par aide ou assistance, JCP 1983. I. 3124.

161 Art. 20 et 21 du CPP béninois précité.

162 Cass. (Fce) Crim. 22juin 1977 : Bull. crim. $n^{\circ} 232$, en matière de publicité mensongère.

163 Art. L331-18 C.envir France. V. aussi art.3 et 4, non codifiés de la loi du 2 août 1961 relative à la lutte contre les pollutions atmosphériques et les odeurs 
OPJ prêtent mains fortes aux OPJ fonctionnaires assermentés de l'administration publique en vue de réprimer certains comportements délictueux des populations.

\section{b) Les nouveaux acteurs de constatation des infractions}

La fonction de constatation des infractions environnementales ne peut être confiée aux non initiés. Elle incombe naturellement aux spécialistes de la protection de la nature ou aux environnementalistes, a priori, outillés techniquement pour traquer les délinquants environnementaux. Les différents textes spécifiques législatifs en la matière, précisent bien la qualité des agents chargés du contrôle ou des poursuites. Puisque la fonction de police judiciaire suppose une reconnaissance officielle de l'aptitude à constater les infractions, ces agents à qui sont confiés des missions de police judiciaire, sont soit désignés par un texte légal soit par l'administration, sur habilitation du législateur. Ainsi, en matière de constatation des infractions, le droit positif béninois confère des pouvoirs de police judiciaire à des agents commissionnés et à des agents assermentés des administrations publiques autres que les OPJ classiques « purs et durs ». Ils exercent ces missions « dans les conditions et dans les limites fixées par les lois» ${ }^{164}$ et les règlements.

En effet, la recherche des infractions en matière d'environnement n'est possible que si des fonctionnaires en sont chargés et s'ils disposent à cette fin des pouvoirs nécessaires. ${ }^{165}$ Ainsi, le contrôle et la surveillance des infractions posent la question de savoir quel est le personnel compétent à cet effet et quel est son pouvoir. La liste de ce personnel est conçue généralement de la façon la plus large possible. Sa limite tient à la nécessité où l'on se trouve d'avoir des agents spécialement habilités pour constater avec toute l'autorité voulu les infractions. Dans les pays de tradition juridique latine ces agents doivent être assermentés de manière à pouvoir dresser des procès-verbaux qui feront foi devant les

164 Art. 23 du CPP béninois; art 28 CPP français

165 Henri. D. BOSLY, Mise en œuvre des poursuites et pouvoirs d'investigation dans l'entreprise, in, Le risque pénal dans la gestion des entreprises, Commission droit et Vie des affaires, Story Scientia, Université de Liège, 1991, p.181. 
tribunaux " jusqu'à preuve du contraire "ou " jusqu'à inscription de faux ». Aux côtés de ces agents assermentés, on retrouve des agents commissionnés.

L'assermentation est le fait pour les agents publics, dans le cadre de leur fonction de prêter serment devant le tribunal relevant de leur juridiction. La cérémonie de prestation de serment consiste donc pour l'agent à " jurer solennellement de remplir loyalement sa fonction ${ }^{166}$ devant le juge, qui en prend acte. En France, elle a lieu généralement devant le tribunal de grande instance et parfois devant le tribunal d'instance. S'agissant particulièrement des agents forestiers béninois, c'est la loi qui met en œuvre le renvoi opéré par le code pénal. Ce texte détermine deux catégories d'agents forestiers : ceux qui ont prêté serment devant le tribunal et ceux qui n'ont pas été soumis à cette formalité. Les agents non assermentés, ont seulement le droit de procéder aux arrestations. Ils ont le droit d'arrêter toute personne en infraction à la législation forestière et de les conduire devant l'agent assermenté le plus proche ou a défaut devant l'officier de police compétent. II résulte de la loi qu'ils n'ont pas le droit de placer en garde à vue le prévenu alors que les agents assermentés peuvent ordonner les mesures de garde à vue. Le code pénal n'a pas expressément envisagé cette mesure mais cela s'induit des dispositions combinées des articles 68 et 69 de la loi portant régime forestier. ${ }^{167}$

Quant au commissionnement, il est considéré comme un acte administratif délivré à l'agent ${ }^{168}$. II consacre l'aptitude de cet agent à constater certaines infractions en considération de sa compétence professionnelle et de son affectation dans un service chargé de mission de police judiciaire ${ }^{169}$. Ainsi, ces agents conduisent pour l'essentiel des enquêtes ou des investigations consistant à relever des infractions et à dresser des procès-verbaux. Ils sont diversifiés. Le droit béninois de l'environnement, en a prévu dans chaque secteur d'activité. II

166 Cf. Notre cadre de vie, Bulletin d'information du MEHU, $\mathrm{n}^{\circ} 008$ de janvier 1999, prestation de serment de 12 Inspecteurs de la Police Environnementale le 06 janvier 1999 au tribunal de 1ère instance de Cotonou; $p: 04$.

167 DJOGBENOU (Joseph) Les privations de liberté individuelles de mouvements non consécutives à une décision pénale de condamnation, Thèse de doctorant unique, Droit privé, UAC, 2007,p.104.

168 D. GUIHAL, Op.cit. p : 24

169 D. GUIHAL, Op.cit. $p: 24$ 
est à observer tout de même que leurs prérogatives sont pratiquement virtuelles puisque dans la réalité aucune " commission » ne se délivre.

Le secteur des eaux et forêts et chasse qui relève désormais du Ministère de l'Environnement et de la Protection de la Nature ${ }^{170}$, est le secteur dans lequel s'observe couramment les agents assermentés des eaux, forêts et chasse. Ils sont disséminés à travers tout le territoire national sous forme de brigades forestières et de cantonnements forestiers que commande nécessairement un agent forestier, officier de police judiciaire. Par ailleurs, nous constatons qu'en matière de contrôle et de surveillance, que ça soit en théorie ou en pratique, la législation forestière et faunique met plus en relief les agents assermentés que les agents commissionnés ${ }^{171}$. Plus opérationnels, ils sont mobilisés sur toute l'étendue du territoire national pour la protection des forêts classées et des réserves de faunes ${ }^{172}$. Dans l'exercice de leurs fonctions, ils sont chargés du contrôle et de la surveillance des atteintes aux ressources naturelles. Ils sont compétents pour interpeler les personnes, à s'assurer de leur identité, à contrôler les documents administratifs (tels que les permis et licences d'exploitation), à opérer des perquisitions et saisies.

Par ailleurs, dans les parcs, il faut noter qu'il existe une catégorie d'agents à statut hybride. II s'agit des éco gardes. Ils sont créés en 2000 par un arrêté ministériel et dotés de statuts régit par la loi de 1901. Ils ne sont ni forestiers, ni agents assermentés ou commissionnés mais dans la pratique, leurs attributs et leurs attributions font d'eux apparemment des agents forestiers. Se substituant ainsi aux agents forestiers, ils délivrent les rapports de constat sur lesquels se fondent les PV de constat des agents assermentés. Il en est ainsi, puisque se sont eux qui appréhendent très souvent les délinquants lors des patrouilles nocturnes ou diurnes qui sont périodiquement organisées dans la réserve conformément à

170 Aujourd'hui renommé Ministère de l'Environnement, de l'habitat et de l'Urbanisme (MEHU) par décret $n^{\circ}$ 2011-500 du 11juillet 2011 portant composition du gouvernement

171 Art. 106 de la loi-cadre sur l'environnement du Bénin ; Art. 65 de la loi n93-009 du 02 juillet 1993 portant régime des forets en République du Bénin.

172 Le Bénin dispose de deux parcs nationaux : le parc de la Pendjari et le parc W. La réserve de la Pendjari est classée réserve totale de faune de la Pendjari par décret $n^{\circ} 2579 \mathrm{ST} / \mathrm{F}$ du 06 avril 1955. En 1961 par décret n61-132/FR/MAC/CF du 06 mai 1961, la réserve est transformée en parc national de la Pendjari avant d'être classée par décret n 94-64 du 21 mars 1994« réserve de la Biosphère » par l'UNESCO. 
leur mission de surveillance du parc. C'est aussi le cas, à quelques nuances près, des auxiliaires villageois qui assistent les forestiers à savoir les pisteurs, les gardes barrières, les porteurs, les chasseurs traditionnels et les guides touristiques. Ils sont tous des agents non assermentés ${ }^{173}$ assistent les forestiers.

Outre les agents des eaux, forêts et chasse, une autre catégorie d'agents assermentés qu'on pourrait qualifier $d^{\prime}$ "acteurs actuels» ${ }^{174}$ ou nouveaux parce que intervenant spécifiquement dans la protection de l'environnement, est constituée des " policiers de l'environnement " encore appelés " inspecteurs de l'environnement ". En effet, la police environnementale mène d'une part, des opérations de police administrative en vue de préserver ou de rétablir l'ordre public qui en l'espèce n'est pas général mais spécial ${ }^{175}$. Un ordre public que le Professeur PRIEUR qualifie " d'écologique ". Dans ce cadre, elle joue un rôle préventif de contrôle et de surveillance pour empêcher la commission d'infraction. D'autre part, la police environnementale, compte tenu de sa mission, ne s'approprie-t-elle pas les compétences de la police judiciaire ? Car, intervenant après l'infraction, elle viserait la recherche et la constatation des infractions et la sanction ${ }^{176}$ de leurs auteurs. L'administration à travers ces agents joue, dès lors un rôle essentiel en matière de répression. C'est ce que confirme d'ailleurs madame Maryse GRANDBOIS lorsqu'elle écrit que " c'est l'administration qui fait, applique et interprète le droit de l'environnement. C'est également l'administration qui commande la procédure, mène la recherche, la constatation et la poursuite des infractions $"{ }^{177}$. C'est pourquoi, ses agents, semblent-ils, disposent de pouvoirs au même titre que ceux reconnus aux Officiers de Police Judiciaire ${ }^{178}$. Ainsi, ils n'ont pas besoin de commission rogatoire pour les perquisitions et saisies par exemple. Ils peuvent pénétrer librement et

173 Art.131 de la loi-n016-2002 du 18 oct.2004 portant régime de faune au Bénin.

174 SOGLO (G) Le droit pénal de l'environnement en droit positif béninois : possibilités et limites de la répression, Mémoire de DEA, UB/ FDD, Lomé, 1998, p : 11.

175 Pour en savoir plus sur la notion de police administrative voir : M. Waline, Précis de droit administratif éd. Montchrestien, Paris 1969 p : 100 et 438-440 ; Les ABC du droit, Tome II éd. Philippe Auzou, Paris 1973, p : 466-474 ; et surtout E. Picard, Notion de police administrative Tome I, P.U.R et L.G.D.J paris 1984.

176 Il s'agit des sanctions administratives.

177 Cf. article " Le droit pénal de l'environnement : une garantie d'impunité ? Extrait de Criminologie, vol. 21, n¹, p : 77. Environnement Canada, Ottawa, 1986.

178 Art.64 et s. du CPP béninois 
à toute heure de jour et de nuit (conformément au code de procédure pénale) sans avertissement préalable dans une installation ou établissement, interroger des personnes, se faire produire des documents, apposer des scellés et opérer des saisies; ils peuvent au besoin faire appliquer des mesures conservatoires à l'encontre du mis en cause, suite à un avis technique adressé au Ministre chargé de l'environnement ${ }^{179}$. Ils peuvent même ordonner l'arrêt de travaux effectués en violation des dispositions législatives et réglementaires ${ }^{180}$. A l'évidence, ces agents disposent de larges pouvoirs que renforcent les dispositions pénales qui punissent l'obstacle à leur fonction ${ }^{181}$. Ainsi, afin de pallier l'absence de pouvoirs coercitifs des verbalisateurs spécialisés, de nombreuses législations répriment le délit d'obstacle aux opérations de contrôle et de surveillance ${ }^{182}$.

Ces pouvoirs dont jouissent ces agents se justifient d'une part parce qu'une attitude passive comme le remarque le professeur A. De Nauw, qui se limiterait à la seule réception de plaintes, présente l'inconvénient d'être tardive, la plainte intervenant presque toujours après la commission de délit, d'autre part ces interventions ont l'avantage de prévenir les atteintes qui pourraient être portées à l'environnement par la menace implicite d'être découvert ${ }^{183}$.

Notons que les agents habilités pour constater les infractions d'environnement relèvent de diverses administrations ministérielles ainsi que le précise l'Annexe II. ${ }^{184}$. Mais, ces fonctionnaires, comparativement à leur

179 Cf. décret n $2005-437$ du 22 juillet 2005 portant organisation de la procédure d'inspection environnementale en République du Bénin. V. aussi arrêté n0045/MEHU/DC/SG/DE/ SQEPE/DPE/SA du 23 oct.2002 fixant les conditions et modalités d'exercice de la fonction d'agent de police environnementale.

180 Pour plus d'information se référer à l'ouvrage, Les métamorphoses administratives du droit pénal de l'entreprise, A. De NAUW, Gand, Mys et Breessch 1974,

181 Art.41 de la loi n ${ }^{\circ} 87-014$ du 21 septembre 1987 portant régime des forêts au Bénin ; art.73 de la loi n93-009du 02 juillet 1993

182 D. GUIHAL, op , cit. $p: 41$

183 A. de NAUW, op. Cit.

184 Cf. Annexe II : les agents habilités outre les OPJ à surveiller et contrôler les infractions au droit de l'environnement dans le dispositif pénal béninois. 
homologue français ${ }^{185} n^{\prime}$ ont qu'une existence purement virtuelle dans la mesure où dans la pratique, ils n'exercent pratiquement pas. Ils sont inactifs alors qu'ils cohabitent tous les jours les infractions environnementales. Et la question se pose même de savoir s'ils sont réellement outillés pour exercer dans le domaine environnemental.

En effet, remarquons que les pouvoirs de police conférés à chacun des agents ont un caractère spécial. Ainsi, un agent muni de pouvoir de verbaliser ne saurait se substituer à un agent muni de pouvoir de perquisitionner. C'est à ce niveau que la jurisprudence française évoque, le principe de spécialité qui fait obligation auxdits agents à exercer " leurs pouvoirs dans les conditions et les limites fixées par les lois spéciales ${ }^{186}$. Dès lors, le pouvoir de verbaliser n'emporte pas celui de pénétrer dans les lieux privés ${ }^{187}$; le droit de visite domiciliaire n'implique pas celui d'obtenir communication des pièces ${ }^{188}$; le pouvoir de procéder à des saisies et prélèvement ne permet pas d'exiger la communication d'une " formule de fabrication ${ }^{189}$. La conséquence logique qui découle de ce principe est que les pouvoirs conférés par une loi ne peuvent être mis en œuvre pour la recherche d'infraction à une autre loi.

Néanmoins, il ne faudrait pas s'arrêter seulement à la prise d'une loi spéciale d'habilitation ; il faut prendre un texte réglementaire qui énumère clairement les agents potentiels assermentés et les agents commissionnés de façon à ce qu'ils soient préalablement connus et leur fonction clairement définit afin que le procès-verbal qu'ils ont l'obligation de rédiger, ne souffre d'aucune insuffisance quant à sa valeur probante.

185 Cf. Rapport interministériel français sur le Renforcement et la structuration des polices de l'environnement, février 2005. Ce rapport dénombre 55 agents habilités à exercer les fonctions d'OPJ. "Ils appliquent de façon quasi quotidienne les polices relevant de leurs compétences. Mais il est loisible de reconnaître que cette application n'est que relative puisque " d'autres apportent leurs concours plus épisodiquement et certains méconnaissent même leur capacité à intervenir ».

186 Art.23 CPP béninois et art.28 CPP français.

187 Ch. Réunies 29 juin 1911 ; S.1911.1.593 note Roux.

188 Cass.crim. 6 mai 1964 Bull. n¹53 p.341, Rev. Sc. Crim.1982 p.522 obs. Bouloc.

189 Cass.crim. 22 mai 1989, Bull. n²11 p.535. 


\section{2) La force probante du procès-verbal de constatation}

La constatation des infractions à la loi pénale et la recherche des auteurs par l'officier ou l'agent de police judiciaire, ou par tout autre agent habilité, conduit à l'établissement du procès-verbal, lequel apparaît comme l'une des phases décisives de l'enquête préliminaire. En effet, nous convenons avec $D$. GUIHAL, que « les procès-verbaux sont les actes par lesquels les agents habilités à exercer des fonctions de police judiciaire relatent les diligences accomplies dans l'exercice de cette mission, et décrivent les faits qu'ils ont constaté qui caractérisent les éléments constitutifs d'une infraction à la loi pénale ${ }^{190}$. En pratique, les procès-verbaux établis par des agents spécialement habilités, notamment les agents assermentés, se révèlent être les principales sources des poursuites. Ils bénéficient même « d'une présomption de vérité $»^{191}$. Cette force probante, dérogatoire au droit commun, est attachée exclusivement « aux faits constatés par les rédacteurs eux-mêmes ${ }^{192}$.

\section{a) Les conditions de validité des procès-verbaux}

La partie poursuivante joue un rôle essentiel dans la manifestation de la vérité. Elle doit supporter la charge de la preuve. Le procès-verbal, dit de "présomption légale " est " une conséquence logique de la présomption d'innocence » reconnue par presque tous les textes pénaux nationaux, d'origine conventionnelle ou internationale. C'est vrai aussi bien pour la doctrine que pour la jurisprudence. Comme l'a décidé la Cour de cassation, " le juge doit admettre comme vraies les constatations matérielles régulièrement faites personnellement par le verbalisant dans les limites de sa mission légale aussi longtemps que la partie intéressée n'en a pas démontrées l'inexactitude ; le juge apprécie souverainement la valeur probante des éléments de cette preuve

190 D. GUIHAL, Op. Cit. $p: 42$

191 Idem. $p: 53$

192 R.MERLE et A. VITU, Traité de droit criminel, T2, Procédure pénale, Cujas, 4ème éd. 1989, $p: 293, n^{\circ} 236$ 
contraire $\aleph^{193}$. La preuve contraire peut être apportées par la défense au moyen de témoignages ou par la production de documents écrits ${ }^{194}$ ou testimoniaux ${ }^{195}$. Pour le Professeur SOYER, « on ne peut la combattre que par la procédure longue et compliquée de l'inscription en faux $\aleph^{196}$. La seule dénégation du prévenu n'autorise pas la relaxe ${ }^{197}$. En droit béninois, le prévenu qui veut s'inscrire en faux contre un procès-verbal est tenu de le faire par écrit huit (8) jours avant l'audience indiquée par la citation, en déposant les moyens de faux et en indiquant ses témoins ${ }^{198}$. Les témoignages et non des « indices " peuvent tenir lieux de moyens de preuves ${ }^{199}$.

Mais pour être valide et assorti de nullité, un certains nombres de critères entourent le procès-verbal. II s'agit par exemple de :

- La compétence des agents verbalisateurs : ces derniers doivent être les autorités légalement compétentes pour exercer cette fonction et ce dans la zone relevant de leur compétence ${ }^{200}$. Puisque " l'incompétence territoriale des verbalisateurs est une cause de nullité substantielle qui est présumée porter atteinte aux droits de la défense $\aleph^{201}$. II en est ainsi des constatations opérées par un garde-chasse dans le ressort d'un tribunal de grande instance auprès duquel son assermentation avait été enregistrée, mais qui n'était pas compris dans l'étendue de son commissionnement ${ }^{202}$. Lorsque par exemple, l'agent forestier béninois assermenté ou non appréhende un délinquant dans une zone qui ne relève pas de sa compétence, le droit béninois exige qu'il le conduise devant l'agent territorialement compétent qui dresse le procès-verbal

193 H. D. BOSLY, in La preuve en droit pénal de l'environnement. Kluwer Editions Juridiques Belgique Aménagement- Environnement, 1995, nº spécial, p: 35

194 D. GUIHAL, op.cit. $p: 53$

195 (J) VINCENT, (S) GUINCHARD, (G) MONTAGNIER, (A) VARINARD, La justice et ses institutions. Précis DALLOZ, 4éd. Paris 1996 p : 559.

196 J.C SOYER, Droit pénal et Procédure Pénale, 17ème éd. L.G.D.J, Paris, 2003, p : 294

197 D. GUIHAL, op.cit. $p: 53$

198 Art. 72 loi portant régime des forêts en République du Bénin ; art.137 de la loi portant régime de la faune.

199 Cf. art.431 et 537 du CPP français

200 Art.126 et 127 de la loi-n²002-016 du 18 octobre 2004 portant régime de la faune en RB.

201 D. GUIHAL, Op. Cit. $p: 44$

202 D. GUIHAL Op. Cit. p: 42 . Cass.Crim. 4 janvier 1985 : Bull., crim. n8. 
au regard du constat d'infraction ${ }^{203}$. Cette disposition, si elle est assez pertinente, elle recèle pourtant des limites en ce sens qu'elle imprime une procédure assez lourde voire déconcertante pour l'agent verbalisateur ; de sorte que le délinquant à tout le loisir de s'évader en cours de route ou à la possibilité de détruire le corps du délit. Ce cas de figure pose le problème de la compétence nationale des agents assermentés. Ne seraient-ils pas plus opérationnels s'ils avaient une compétence nationale?

- Les procès-verbaux doivent, sous peine de nullités, être assortis de délai dès leur clôture et adressés au procureur de la République. En droit français, ce délai n'excède pas cinq jours francs ${ }^{204}$. Il est de dix (10) jours par contre en droit pénal belge ${ }^{205}$. Le législateur béninois ne prévoit pas de délai mais le procès-verbal, doit être rédigé dans un " bref délai », donc dans un délai raisonnable d'autant plus que la plupart des infractions d'environnement sont des cas de flagrant délit.

Notons que la question de délai soulève des préoccupations juridiques relatives à la computation des délais en ce qui concerne la transmission du procès-verbal au procureur de la République. Ainsi, par arrêt rendu le 28 avril 1998, la cour d'Appel de Besançon à rejeté l'exception de nullité du PV de constatation de l'infraction, soulevée par le prévenu condamné pour chasse à l'aide d'un moyen non autorisé. Ce dernier invoquait l'application des articles L 215-5 et L 215-6 du code rural, aux termes desquelles, les PV dressés par les fonctionnaires et agents désignés à l'article $L$ 215-5 dudit code doivent être transmis au procureur à peine de nullité, cinq jours francs après celui où l'infraction a été constatée. Confirmant la décision de la cour d'appel, la chambre criminelle de la cour de cassation française, rappelle l'exacte portée desdits articles, dont de transmission des Procès-verbaux en matière de police de pêche. Cité par D. GUIHAL, op. cit. p : 331. V. aussi art. L163-2; Art. 226-5 du Code. de l'env.

205 M. FAURE, Ordonnance belge du 25 mars 1999 relative à la recherché, la constatation, la poursuite et la répression des infractions en matière d'environnement. Edition Kluwer Aménagement-Environnement, 2000/3, p.184
} 
les dispositions, notamment celles concernant le délai de transmission des procès-verbaux au procureur de la République, ne s'appliquent pas aux infractions de la police de chasse ${ }^{206}$. En effet, les délais prévus par certains textes spéciaux sont variables, sans harmonie et tiennent compte de la catégorie d'agents verbalisateurs ou de la nature de I'infraction. Il est par exemple de trois jours ${ }^{207}$ en matière de chasse et de cinq jours francs ${ }^{208}$ en matière de pêche.

- Les mentions de forme du procès-verbal dont l'absence peut entraîner la nullité: les procès-verbaux sont datés avec précision de l'heure et signés ; la signature au moins d'un agent assermenté est obligatoire sur chaque feuille du procès-verbal, les signatures des personnes présumées coupables ayant fait l'objet d'interrogatoire (signatures ou empreintes digitales), le nom et la qualité du rédacteur sont également obligatoires.

- Les agents non assermentés ne dressent pas de procès-verbal mais des rapports de constat qui une fois validés par l'agent assermenté deviennent des procès-verbaux de constat ${ }^{209}$. II en sera ainsi des constatations opérées par un agent ou un fonctionnaire relativement à une infraction qu'il n'est pas habilité à relever. Ces infractions ne sont pas nulles. C'est le cas par exemple des constatations opérées par un agent non assermenté. Dans ce cas d'espèce, ces constatations doivent plutôt être considérées « comme un simple rapport qui ne fait pas foi jusqu'à preuve contraire $»^{210}$ mais exploitable par le juge.

Par ailleurs, il faut distinguer entre le procès-verbal qui « fait foi jusqu'à preuve contraire » (rapporter par écrit ou par témoins) et le procès-verbal

206 A cet effet, le dispositif est sans équivoque " attendu que, contrairement à ce qu'énonce le moyen, la loi n'impose pas aux gardes nationaux de la chasse et de la faune sauvage, commissionnés par le ministre de la chasse et employés par l'ONC, de transmettre au procureur de la république, dans le délai de cinq jours francs ou dans tout autre délai limitativement fixé, les PV par lesquels ils constatent les infractions à la police de la chasse ; que dès lors, le moyen ne peut être admis. Et attendu que l'arrêt est régulier en la forme, rejette le pourvoi. » cf. C. cass. (Crim). 29 juin 1999, req. $n^{\circ}$ C.98-84 735 D., in, RJE 4/2000.

207 Art. L428-25 du C. env. V. art. L 215-6 du C. rural.

208 Art. 437-5 du C. Env.

209 Art.70 de la loi n93-009 du 2 juillet 1993 portant régime des forêts en RB

210 D. GUIHAL, op. cit., $p: 40$ 
qui « fait foi jusqu'à inscription de faux » des faits matériels délictueux qu'ils constatent ${ }^{211}$ lorsqu'il est dressé par les agents assermentés. Par le qualificatif "fait foi jusqu'à inscription de faux ", la loi accorde au procès-verbal plus de considération. Tel est le cas lorsque les constatations ont été opérées par deux agents. Ces cas de figures sont prévus par la " police " des forêts ${ }^{212}$, la police de la faune et la pêche ${ }^{213}$ en matière de perquisition en droit béninois. En droit français on note un cas similaire en matière de police de la pêche ${ }^{214}$ où lorsque le PV a été dressé et signé par deux fonctionnaires ou agents, il fait foi jusqu'à inscription de faux. Une disposition similaire est prévue aussi à l'article L102 du code de l'environnement sénégalais ${ }^{215}$. Pour ce dernier cas, le code sénégalais distingue et précise bien que les procès-verbaux dressés par " un seul agent » font « foi jusqu'à preuve contraire ».

En tout état de cause, une telle règle suppose évidemment un allègement du fardeau de la preuve du ministère public qui est lié par le procès-verbal, qu'il soit rédigé par deux ou par un seul agent. II ne peut donc accepter les constatations aussi longtemps que le prévenu n'aura pas démontré l'inexactitude de ces constatations ${ }^{216}$.

En revanche, la force probante de la preuve contraire, confronté aux libertés publiques, suscite en nous quelques analyses. En l'espèce, la question se pose par exemple de savoir si une telle force probante n'est pas contraire à la présomption d'innocence ${ }^{217}$ ancrée dans les textes répressifs nationaux qu'internationaux. Rappelons que la force probante d'un procès-verbal ne

211 Art.144 de la loi $n^{\circ} 87-014$ du 21 septembre 1987potant réglementation de la protection de la nature et de l'exercice de la chasse en République Populaire du Bénin et art.71 de la loi n93-009 du 2 juillet 1993 portant régime des forêts en RB.

212 Art. 67 de la loi n93-009 du 2 juillet 1993 portant régime des forêts en RB

213 Art.132 de la loi $n^{\circ} 2002-016$ du 18 octobre 2004 portant régime de la faune en RB.

214 Cf. art. L437-4 du code envir.

215 Loi $n^{\circ}$ 2001-01 du 15 janvier 2001

216 M. FAURE, ordonnance du 25 mars 1999 relative à la recherche, la constations, la poursuite et la répression des infractions en matières d'environnement, Editions Kluwer. Aménagement -Environnement, 2000, p. 184

217 Cass., belge, 10 mars 1987, arr. Cass., 86-87.p.907 ; cass.14 déc.1988, pas. 1990, I. p.418. et V.Ph. TRAEST, « Enkele bernerkingen bij de processen-verbaal met. Bewijswaarde tot, bewijs van het tegendeel, note sous cass., 4 oct.1988, R.W., 1988-1989, p.885. Cité par M. FAURE, Edition Kluwer, Aménagement-Environnement, 200/3 p.184. 
s'attache qu'aux constatations matérielles faites personnellement par un agent compétent. Elle s'applique à la conformité entre les faits constatés par l'agent et leur consignation dans le procès-verbal mais ne s'étend pas au « caractère correct, complet, objectif des perceptions du verbalisant dans ce qu'il a pu bien constater ${ }^{218}$. Le cas échéant, le prévenu peut se défendre en alléguant, par exemple sur la base d'éléments de preuves, que « le verbalisant a été trompé par ses propres sens $»^{219}$. Et, pour combattre ce type d'allégation, il est utile de pouvoir exposer les faits, non seulement tels que le verbalisant a pu les percevoir, mais aussi tels qu'ils se sont présentés réellement et qu'un œil neutre, objectif, aurait pu les observer en " bon père de famille ».

L'arme clé du procès-verbal de constatation, qui est " souvent l'arme fatale " au prévenu est l'étape interrogatoire, où pour un " oui » ou un «non », le prévenu appelé à répondre " obligatoirement aux questions ", peut plaider coupable malgré lui et amené devant le procureur de la République qui peut à son tour lui décerner un mandat de dépôt (étape très redouter en Afrique : on donnerait tout pour que cette phase n'arrive pas). Dès lors, l'on peut se demander l'étendue des limites du droit d'interroger le prévenu reconnu aux agents de contrôle. Un tel droit est -il compatible avec le droit au silence reconnu au prévenu ? Le prévenu peut-il exercer ce droit pendant la phase de contrôle ${ }^{220}$ ? La réponse, nous la devons à un arrêt de la cour de cassation belge du 13 mai 1986 qui fait apparaître que les droits de la défense, auxquels appartient le droit au silence, peuvent ressortir leurs effets jusque dans l'enquête administrative lorsque l'action pénale est intentée par la suite sur la base de cette enquête administrative. Même si l'arrêt évoque le droit au silence qui appartient au prévenu, la lecture de l'arrêt fait apparaître clairement que les moyens de preuve qui ont été obtenus en méconnaissance du droit au silence pendant une enquête préliminaire effectuée par l'administration, sont illégaux, lorsque cette enquête est à la base de la déclaration et constitue le fondement de l'enquête

218 CH. LAMBRECHTS, la valeur, en matière pénale, des preuves des violations de la convention Marpol, 73/78, in, revue de droit pénal, p.738.

219 Idem

220 L'art.14,§3 de la Convention relative aux droits civils et politiques prévoit que pour déterminer le fondement d'une poursuite pénale, aucun prévenu ne peut être contraint de témoigner contre lui-même ou de faire des aveux. 
d'instruction et de l'action intentée par le ministère public ${ }^{221}$. En d'autres termes, de tels moyens de preuves doivent être rejetés.

Ainsi la jurisprudence fait apparaître que nul n'est tenu de répondre aux questions qui lui sont posées pendant la phase de contrôle ou « ne peut

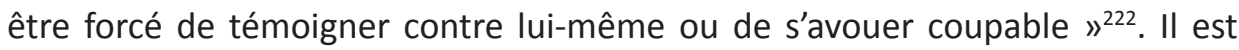
à noter à cet égard que l'exercice du droit de garder le silence au cours de la phase de contrôle ne peut être considéré comme un délit d'outrage à agent en exercice ; il "signifie tout d'abord que le manque ou le refus d'explication ne peut entrainer à lui tout seul une conviction de culpabilité $»^{223}$. Ensuite, il signifie que l'inculpé peut s'abstenir de toute collaboration s'il estime qu'il n'est pas de son intérêt ou tout simplement s'il n'a pas envie de participer aux investigations entreprises $»^{224}$.

Comme on le voit, ces jurisprudences, constantes en la matière, relèvent assez de garanties à l'endroit de la personne humaine. Le droit pénal africain devrait pouvoir s'en inspirer même si la culture du recours à un avocat n'est pas encore totalement ancrée dans les mentalités de sorte qu'en refusant par exemple de parler, le prévenu permet à son avocat de se substituer à lui.

\section{b) Les pouvoirs d'investigation}

Les pouvoirs des agents verbalisateurs peuvent être distingués selon qu'ils visent la constatation de l'infraction ou la recherche des auteurs. Pour rechercher les infractions, les agents ont le droit d'interpeler les personnes suspectes et de procéder à des fouilles. Sur ce point, les législations consultées énumèrent avec plus ou moins de précision les possibilités de fouilles. Celles-ci vont des bagages personnels des personnes interpelées jusqu'aux constructions en passant par les véhicules. Toutefois, il n'est pas admis qu'un agent puisse pénétrer sans le

221 A. DE NAUW et B. BRONDERS, Contrôle, Rapport p.11. v. Cass. Belge 13 mai 1986 Arr. Cass. 1985-1986, 1230, conclusion J. DUJARDIN.

222 Cass., belge 11 mars 1992, Pas., 1992, I, 619 ; V, aussi Cass., 6 mai 1993, Bull., 1993, p.452.

223 Fabienne KEFER, Question a propos du droit d'obstacle à la surveillance en droit belge, Rev. Trim. dr. H. (56/2003), p.1308.

224 Fabienne KEFER, op. cit. , p.1309. 
consentement de ses occupants dans une maison d'habitation lorsqu'il n'est pas porteur d'un mandat de perquisition délivré conformément aux dispositions du code de procédure pénale. A défaut de mandat de perquisition, le simple port de «l'uniforme ou de la détention de la carte professionnelle» ${ }^{225}$ suffit.

En matière de délit forestier par exemple, lorsque l'agent a constaté une infraction, la loi lui donne la possibilité d'exercer des pouvoirs conservatoires destinés à garantir aussi bien la répression qu'à éviter les pertes d'animaux. C'est ainsi que l'agent peut mettre le contrevenant présumé en état d'arrestation dès lors qu'il y a lieu de craindre qu'il se soustrait à l'instance pénale ${ }^{226}$ et qu'il peut pratiquer diverses saisies. Celles-ci concernent d'une part les objets ayant servi à commettre l'infraction tels que les armes, les vélos, les motos et les véhicules et d'autre part, le corps du délit. Les textes prévoient le plus souvent les mesures que devra prendre l'agent à l'égard des animaux saisis et qui comportent la remise en liberté des spécimens vivants susceptibles de survivre, l'abattage de ceux qui se trouvent dans le cas contraire, la distribution de viande que l'on ne peut conserver, le prélèvement des trophées de valeur au profit de l'Etat. Aussi, « la législation faunique établit des systèmes de présomptions facilitant la constatations des infractions. On présumera par exemple que les objets trouvés à proximité immédiate d'un campement appartiennent aux utilisateurs de campement, ou encore celui qui transporte des animaux tués dans son véhicule à connaissance de ce fait. L'avantage de la présomption est de renverser la charge de la preuve. Il appartiendra à l'auteur ou au complice présumé de l'infraction de prouver qu'il ignorait la nature de ce qu'il transportait, ou que le piège trouvé dans le voisinage de son campement ne lui appartenait pas ${ }^{227}$.

Les investigations des agents verbalisateurs peuvent s'étendre aussi à l'audition des témoins, à des prélèvements d'échantillons et à des analyses. Puisque généralement, la démonstration des infractions environnementales est

225 Art.66 de loi n93-009 du 2 juillet 1993 portant régime des forêts en RB ; art. 130 de la loi n²002-016 du 18 octobre 2004 portant régime de la faune en RB.

226 Au Bénin, en cas de délit forestier, lorsqu'un prévenu est interpelé, il est gardé à vue à la gendarmerie de la localité conformément à un accord qui lie la gendarmerie nationale à la direction du Parc, notamment du Parc de la Pendjari.

227 C. SAUSSAY, La législation sur la faune et les aires protégées en Afrique. Etude législative $n^{\circ} 25$ FAO, Rome, 1981, p : 47. 
souvent tributaire de mesures physico-chimiques, les verbalisateurs peuvent prendre l'initiative des contrôles techniques, réaliser des prélèvements et confier l'analyse à des laboratoires dépendant de leur administration ou agréés par elle.

D'une manière générale, cette fonction de constatation des infractions lorsqu'elle est bien exercée, facilite la tâche au juge mais d'abord au procureur de la République qui, quant à lui est principalement chargé des poursuites.

\section{B) Le ministère public au centre de l'exercice de l'action publique}

L'action publique dont la finalité est l'application de la sanction au délinquant, appartient principalement au ministère public appelé « magistrature débout ${ }^{228}$ ou " parquet " ou encore procureur de la République. Le droit du ministère public de mettre en mouvement l'action publique est, en principe, général et inconditionnel. Ces magistrats, procureurs ou substituts, participent au procès en ce sens qu'ils représentent les intérêts de la société. Le procureur de la République est chargé directement ou indirectement (par commission rogatoire signifiée à l'OPJ) de la recherche des infractions et de la poursuite de leurs auteurs. Le procureur de la République reçoit les plaintes et les dénonciations et apprécie la suite à leur donner. Ainsi, en dehors de l'auto saisine du procureur de la République, que cela soit en droit commun ou en droit de l'environnement, la saisine directe de ce dernier est aussi requis par tout citoyen. Car le procureur devrait être informé par toute personne ayant connaissance d'un délit ou d'un crime ${ }^{229}$. Il revient alors à ce magistrat qui a l'opportunité des poursuites (on oppose à ce système celui de la légalité des poursuites), de poursuivre ou de ne pas poursuivre l'affaire.

L'opportunité des poursuites peut amener le procureur de la République à ne pas momentanément, mettre en mouvement l'action publique. Pour ce faire, il utilise la technique de classement sans suite. C'est une décision à caractère

228 Comparativement à leur collègue les magistrats de siège qui sont toujours assis alors qu'eux restent debout pour prononcer leurs réquisitions.

229 Cf. art. 33 al. 2 du C. pr. pén. du Bénin ; V. art. 29 al. 1er du code d'instruction criminelle belge, article 16 de la loi cadre béninois sur l'environnement 
provisoire car lorsque certains éléments sont réunis, il peut reprendre le dossier classé. En droit pénal, il y a de très nombreux classements sans suite dus à ce que les auteurs de l'infraction n'ont pas été identifiés (65\%) ou à ce que les faits ne constituent pas en réalité une infraction. ${ }^{230}$ Dès lors, d'une constatation correcte et complète de la situation infractionnelle, va dépendre, la suite de l'affaire ${ }^{231}$. Un rapport étroit relie le procureur de la République et le Ministre de la Justice ; de sorte que tous les membres du ministère public relèvent hiérarchiquement « du Ministre de la justice représentant le pouvoir exécutif mais ne faisant pas partie du ministère public, et qui, par instruction générale, veille à la cohérence de la politique d'action publique sur le territoire et qui exerce sur les membres du ministère public entre autre un droit d'impulsion, en ordonnant des poursuites par instructions écrites et versées au dossier..1232

A ce propos, une certaine doctrine, mettant en avant les inconvénients de cette relation hiérarchique, tendait à souhaiter une réforme séparant le ministère public et le Ministre de la justice, pour une meilleure indépendance des magistrats. Mais une totale "coupure» aurait eu pour inconvénient de faire obstacle aux directives générales mettant en œuvre une politique criminelle nationale.

Comme on le constate alors, sans être Officier de Police Judiciaire, le procureur de la République a tous les pouvoirs et prérogatives attachés à la qualité d'officier de police judiciaire. A ce titre, il est le supérieur hiérarchique des officiers de police judiciaire. Mais, il ne peut pas en principe transiger mais à compétence pour homologuer parfois une transaction sur l'action publique ${ }^{233}$ en France.

Le rôle prépondérant du procureur de la République ou procureur du Roi est bien mis en relief dans la législation belge par le professeur M. FAURE,

230 (J.) LARGUIER et (P) CONTE, Procédure pénale, 21ème édit. Mémentos, Dalloz, p : 94

231 (A) LEBRUN, La sanction pénale en matière d'environnement, en région wallonne. In, La répression des infractions en matière d'environnement en Région Wallonne, $B$. JADOT, édit. Story Scientia $p$ : 53. Cité par M. FAURE, dans le syllabus de cours de Master de droit pénal de l'environnement, Lomé, FDD, 1999.

232 (J.) LARGUIER et (P) CONTE, Procédure pénale, 21ème édit. Mémentos, Dalloz, p : 87, Paris 2006. V. art. 29 du CPP béninois

233 (J.) LARGUIER et (P), op. cit., p : 88. ; V. art. 29 du CPP béninois 
lorsqu'il écrit que « seul le procureur du Roi peut (...) donner suffisamment de garanties d'impartialité et d'indépendance nécessaire à une répression optimale du droit de l'environnement $»^{234}$. Or, on ne peut que déplorer l'effacement des parquets dans ce domaine, qui a pour conséquence un manque de lisibilité de l'action judiciaire et laisse le champ libre à des actions associatives ${ }^{235}$. Encore, faudrait -il que ces procureurs bénéficient d'une connaissance spécialisée en droit de l'environnement. Ce qui n'est pas toujours évident surtout en ce qui concerne les procureurs africains.

Le régime de contrôle prévu par la législation béninoise et décrit ci-dessus comprend outre les OPJ, les agents habilités (Inspecteurs de l'Environnement, forestiers, agents d'hygiène, agents commissionnés ou assermentés des ministères sectoriels). Ce régime établit une relation hiérarchique fonctionnelle entre les OPJ, les agents habilités et le procureur de la République. Ils ont tous l'obligation de compte rendu envers le procureur (la transmission des procèsverbaux et informations diverses). Il est intéressant de faire remarquer que selon le droit forestier béninois, il est prévue que les actions et les poursuites soient exercées directement, par l'administration forestière, qui a le droit d'exposer l'affaire devant le tribunal compétent où il siège au côté du procureur de la République ${ }^{236}$ qui a seul le monopole de la mise en œuvre du régime répressif.

Au regard de tout ce qui précède, il nous paraît opportun de clarifier les concepts de contrôle et de recherche très souvent utilisés en droit pénal de l'environnement.

234 M. FAURE, Un défi : les contours de plus en plus flous du droit pénal de l'environnement, art., in, Aménagement-Environnement, 2000, nº spécial. P. 94 Editions Kluwer.

235 D. GUIHAL, in, Mieux maitriser le risque pénal en matière d'environnement, CCIP, paris 2002.

236 Art.79 de la loi n93-009 du 2 juillet 1993 portant régime des forêts en République du Bénin. et art.143 et suivants de la loi $n^{\circ} 2002-16$ du 18 octobre 2004 portant régime de la faune en République du Bénin. 


\section{$\S$ II : Le régime juridique de la surveillance et du contrôle ${ }^{237}$}

Comme nous l'avons examiné plus haut, la procédure pénale en matière d'environnement, met constamment en relief, les notions de surveillance, de contrôle, de recherche, de poursuite, d'investigation et de sanction. En d'autres termes, elle met en exergue d'une part les fonctions de surveillance et de contrôle dans une perspective préventive apparemment en concurrence avec les fonctions proprement répressives de recherches et de poursuites d'autre part. Bien qu'au plan dogmatique une clarification desdits concepts s'impose, au plan théorique et pratique, il est difficile de cerner les contours et les limites de ces fonctions. C'est pourquoi le présent paragraphe, à la suite du précédent, se propose de démêler l'écheveau, de lever l'équivoque en examinant d'abord le caractère hybride de la surveillance et du contrôle pour ensuite d'apprécier son caractère nécessaire et particulier.

\section{A) Le caractère hybride de la surveillance ou du contrôle}

Aux termes des dispositions législatives environnementales, contenues en l'occurrence dans les lois particulières, les fonctions de contrôle ou de surveillance occupent une place considérable dans le dispositif répressif. En effet, la fonction de contrôle, dévolue aux agents et aux OPJ qualifiés, précède celle de la poursuite reconnue au procureur de la République. Selon A. DE NAUW et B. BRONDERS, le contrôle s'entend de la « surveillance exercée par les agents habilités à cet effet et disposant à cette fin de compétences particulières permettant une poursuite pénale d'un délit constaté au moyen de cette surveillance ${ }^{238}$ ». Ainsi, le contrôle est une forme administrative de surveillance avec un intérêt marqué en procédure pénale. II concerne les activités qui interviennent avant le moment où il est présumé qu'un fait punissable a été commis. Une compétence de contrôle ne présuppose aucune présomption,

237 Dans ce contexte de préservation de l'environnement, les notions de contrôle et de surveillance sont considérées ici comme relevant de la même famille car jouant les mêmes fonctions de veille permanente de l'environnement. 
contrairement à la notion de compétence de recherche qui s'entend de la phase préparatoire au procès pénal ${ }^{239}$. Dès lors, on constate qu'il existe une relation identitaire entre la notion de recherche et la notion de police judiciaire, parce que la police judiciaire ne peut exercer aucune compétence s'il n'y a pas la présomption qu'un fait punissable a été commis. Autrement dit, l'identification d'un « prévenu » ou d'un« coupable », interpelle la police judiciaire. Par contre, le contrôle n'aboutit pas forcement à des recherches d'infractions. Toutefois, il « peut aboutir à la constatation d'infraction et à l'application de peines ${ }^{240}$.

La notion de contrôle, qui se rapproche de celle de la surveillance, est donc une activité préventive d'exercice de la police administrative, dont le but est de faire respecter les normes prescrites en empêchant que la loi soit transgressée. A l'inverse, si l'action consiste à enquêter et à constater des violations de la loi déjà commises, aspect répressif, nous parleront d'exercice de la police judiciaire. Il s'agit du pouvoir d'investigation ou de rassemblement de preuves consacré par l'enquête préliminaire et l'enquête de fragrance conformément au code de procédure pénale. En revanche, le critère déterminant de la distinction entre les deux notions repose sur la finalité de l'intervention de l'autorité. II s'ensuit que le contrôle présente un caractère mixte ou « hybride ${ }^{241}$.

En matière de délit classique, généralement l'infraction est constatée par I'OPJ après la commission du délit. C'est le cas par exemple en matière de vol, de viol ou de meurtre. L'OPJ compétent en la matière, suite à la commission d'une telle infraction, déclenche en même temps les recherches et les investigations en vue de retrouver les présumés coupables, auteurs ou co-auteurs.

En droit de l'environnement, vu la nature spécifique des infractions où il est difficile, a priori, de déterminer les éléments constitutifs de l'infraction et son auteur, le droit pénal spécial de l'environnement s'efforce d'avoir une procédure autre que la procédure classique. Cette procédure se fonde essentiellement sur l'élément matériel qu'est la violation d'une prescription

239 A. De NAUW, Les métamorphoses administratives du droit pénal de l'entreprise, MYS \& Breesch, Uitgevers, $p: 75$, cité par FAURE, Cour de droit pénal de l'environnement, troisième cycle de DEA, 1999. 
administrative (dépendance administrative du droit pénal) et accessoirement sur une pénalisation autonome. ${ }^{242}$ Les atteintes à l'environnement étant la plupart du temps des infractions à caractère diffus et aux conséquences imprévisibles, appellent de la part des autorités administratives, le développement d'une politique préventive basée sur des compétences de surveillance et de contrôle de l'environnement afin de limiter sérieusement ces infractions qui sont inhérentes à la vie quotidienne. Ces compétences peuvent-elles s'exercer par la police judicaire classique au même titre que le fonctionnaire habilité à le faire ? Tous les textes pénaux relatifs à l'environnement répondent par l'affirmative. La formule consacrée en la matière est "sans préjudice des compétences des officiers de police judiciaire ${ }^{243}$ ou " outre les agents de police judiciaire .... ${ }^{244}$, utilisée régulièrement dans les lois cadres et dans les lois spéciales d'environnement, implique une référence à cette compétence générale de constatations des délits reconnus aux OPJ par le droit pénal général. Selon la doctrine et la jurisprudence, l'absence d'une telle formule ne porterait pas préjudice aux compétences des officiers de police judiciaire. Toutefois, le souci de clarté recommande une référence explicite à cette compétence. Mais cette compétence générale de constatation ne s'inscrit-elle pas davantage dans le cadre de la recherche que du contrôle effectué par des agents relevant des agences ou des inspections environnementales, tels que visés à l'Annexe II ? Les agents de contrôle concernés devront avoir une expertise en matière de surveillance et de contrôle contrairement aux OPJ qui ne sont pas astreints à une telle expertise. Dans la pratique, c'est donc à tord qu'ils exercent parfois les activités de contrôle ou de surveillance de sorte que la présence sur les lieux de constat des agents fonctionnaires habilités en la matière, dessaisirait l'OPJ. Ainsi, l'adage " qui peut le plus peut le moins » ne trouve pas ici une application effective. Aussi les agents de contrôle, au cours de leurs activités, exercent très souvent, des compétences de poursuite, de recherche ou d'investigation.

En droit belge, il y a " une disposition générale relative aux recherches qui permet non seulement les actes de contrôle qu'il énumère, mais toutes

242 V. infra chapitre III pour plus d'information

243 Art.262 de la loi N0016101 du 31 déc. 2001 portant code forestier en république gabonaise

244 Art.106 de la loi n98-030 du 12 février 1999 portant loi-cadre sur l'environnement du Bénin. 
mesures de recherches pour autant qu'elles aient pour objectif d'exercer un contrôle ${ }^{245}$.

De même en droit béninois, la loi sur la forêt dispose en son article 79 que « les actions et poursuites sont exercées directement par le directeur des forêts et des ressources naturelles ou son représentant " ; l'article 65 précise que " les agents forestiers assermentés recherches et constatent par procès-verbal des infractions... " ${ }^{246}$ C'est ce même directeur ou son représentant qui exerce les fonctions de contrôle et de surveillance, en tant que premier responsable technique de ce secteur ; d'où un cumul de fonction qui n'est pas clairement défini. Comme on le constate donc, la législation béninoise accorde aux agents de contrôle d'énormes pouvoirs de police dans l'exercice de leur fonction. Ils peuvent recourir à des saisies ou ordonner selon le cas, la fermeture temporaire de l'objet du délit, perquisitionner, avoir accès a tout endroit où s'exerce une activité dégradante de l'environnement, recourir à la force publique et aux mesures pouvant faire cesser les troubles, prélever des échantillons, faire effectuer des analyses, etc. ${ }^{247}$

Ainsi, quelque soit le camp où se trouve l'agent de contrôle, l'option répressive est toujours implicitement ou explicitement présente dans les cas de constatation d'une infraction. Mieux, lorsqu'il constate un délit ou un crime, il doit en vertu de l'article 33 CPP béninois (art.29 code de procédure criminelle belge), le signaler immédiatement au procureur de la République ou au procureur du Roi de la juridiction où le délit a été commis ou de la juridiction où le suspect pourra être trouvé, et fournir à ce magistrat toute information, tous procès-verbaux et actes y afférents. C'est pourquoi, à notre avis, il serait utile que les agents chargés du contrôle disposent non seulement de compétences leur permettant d'exercer leur mission de contrôle, mais aussi de compétences spécifiques leur permettant d'assurer le suivi pénal des délits constatés, tels

245 A. DE NAUW et B. BRONDERS, op. cit.

246 V. aussi art.9 arrêté n0045/MEPN/DC/SG/DE/SQEPE/DPE/SA du 23 oct.2002 fixant les conditions et modalités d'exercice de la fonction de la police environnementale

247 Voir à cet effet, la législation béninoise, notamment la loi-cadre sur l'environnement, les lois relatives à la faune et à la flore précitées. V. aussi Les textes précités relatifs à la police environnementale. Cf. loi nº7-008 du 21 sept.1987 portant régime des taxes de contrôle de conditionnement et de normalisation de produits agricoles. 
la rédaction et la transmission de procès-verbal au procureur, le prélèvement d'échantillon et l'imposition de mesures de contraintes afin de permettre une saisie judiciaire régulière et légale ${ }^{248}$.

Il s'ensuit, comme on peut le remarquer, un caractère hybride de la surveillance ou du contrôle qui se manifeste par le fait que l'agent de contrôle dans ses compétences, endosse aussi bien les pouvoirs dévolus au " modèle administratif " de la répression qu'au " modèle répressif ». Ainsi, l'examen des règles de contrôle en droit de l'environnement permet de distinguer deux modèles d'application de la loi : le modèle de surveillance de l'environnement qui comporte un régime de contrôle sommaire qui vise, en fin de compte, un maintien administratif tandis que le modèle de surveillance pénale confère des pouvoirs de contrôle en vue d'une ultime protection de droit pénal. La différence entre ces deux modèles souligne la relation existante entre les options de maintien de la loi : un modèle administratif et un modèle de droit pénal. ${ }^{249}$

C'est donc ce caractère hybride ou mixte de la mission des agents de contrôle qui conduit au caractère particulier et nécessaire du contrôle.

\section{B) Le caractère particulier et nécessaire du contrôle et de la surveillance.}

Comme nous l'avons examiné plus haut, le rôle et les missions de chaque catégorie d'agents intervenant en matière d'environnement sont pourtant bien précis. Qu'il s'agisse de l'aspect préventif du contrôle ou de l'aspect répressif, le contrôle a un caractère primordial pour la préservation de l'environnement. Les compétences liées à ce contrôle ne sauraient s'exercer par un quelconque agent

248 A l'instar de leurs homologues OPJ classiques. Les inspecteurs de l'environnement sont recrutés par exemple avec le niveau licence, (agents d'hygiène sont recrutés niveau BEPC ou Bac) toutes séries confondues. Une fois formés en quelques semaines, ils ne bénéficient plus de formation de renforcement de capacités, pourtant indispensable à leur mission. Or il aurait fallu privilégier les titulaires d'une licence professionnelle ou d'une maitrise en droit. Les forestiers quant à eux, après leur diplôme, sont soumis au régime d'obtention du grade d'OPJ avant de prêter serment.

249 A. DE NAUW et B. BRONDERS, op, cit. V. aussi M. FAURE, in, Aménagement-Environnement, 2000/3, p.181 
des forces de sécurité publique qui n'est pas habilité. Ainsi, sans disposition légale plus détaillée, ou spéciale, les OPJ peuvent faire tout ce que le simple citoyen peut faire également : regarder, observer, parler aux agents, etc. Toutefois, ils ne peuvent pas, du moins s'ils ne sont pas cités expressément en qualité d'agent de contrôle, exercer les compétences spéciales qu'une loi spéciale peut reconnaître aux agents de contrôle en vue de l'exercice du contrôle. Dans la pratique, ils interviennent principalement à la suite d'une déclaration ou d'une plainte ou dans les cas de pollution grave ou manifeste. Une telle action présente l'avantage qu'elle intervient trop tard dans de nombreux cas. Souvent, le délit a déjà été commis ou le dommage a été déjà causé. En outre, les délits qui ne causent pas directement une nuisance ou un dommage ou qui ne sont pas visibles ne seront jamais découverts. De plus ces délits causent dans la plupart des cas un dommage à l'intérêt général plutôt qu'à des intérêts particuliers et la volonté de déclaration de ces derniers sera réduite lorsqu'ils ne subissent aucun un préjudice direct du délit qu'ils ont constaté. Le principe de spécialité qui soustend cette démarche des agents fonctionnaires est affirmé par l'article $23 \mathrm{du}$ code béninois de procédure pénale qui correspond à l'article 28 CPP français. Ainsi, la chambre criminelle française fait respecter, à la lettre, cet article en refusant toute interférence entre, d'une part, les dispositions générales qui régissent l'enquête préliminaire effectuée par les officiers et agents de police judiciaire et, d'autre part, les règles procédurales particulières mises en place par des lois spéciales. ${ }^{250} \mathrm{C}^{\prime} \mathrm{est}$ certainement pour ces motifs que les lois en matière d'environnement chargent des agents du contrôle et de la surveillance, du respect de la législation.

Ainsi, dans la pratique, on peut convenir avec Dominique GUIHAL que la technicité des incriminations, si elle n'évince pas totalement cette catégorie classique d'OPJ, donne, tout de même, un rôle prépondérant à la deuxième catégorie d'agents à savoir les fonctionnaires et agents auxquels sont attribuées par la loi, certaines fonctions de police judiciaire ${ }^{251}$. C'est également dans cette logique que s'inscrit Michel PRIEUR qui les absout, lorsqu'il écrit « on peut noter toutefois que les officiers de police judiciaire, sauf pollution spectaculaire, sont 
mal armés juridiquement, techniquement et matériellement en matière de protection de la nature et de pollutions et qu'ils s'en remettent aux administrations spécialisées ${ }^{252}$ lesquelles sont pourvuees d'agents fonctionnaires spécialisés dans la constatation des infractions environnementales.

A ce propos, le droit pénal belge est illustratif à plus d'un titre. Ainsi en Région flamande, la commission interuniversitaire de révision du droit de l'environnement a lancé un avertissement de principe en déclarant qu'il serait absurde de conférer des pouvoirs à des OPJ dans le cadre du contrôle. En effet, les OPJ exercent en principe des pouvoirs dans le cadre de la recherche et ne peuvent donc pas exercer de pouvoirs lorsqu'il n'est pas question de suspicion d'une infraction. C'est la raison pour laquelle la commission s'est opposée à un modèle dans lequel l'OPJ aurait également des pouvoirs de contrôle ${ }^{253}$. Selon la commission, ceci serait contraire à la spécificité des pouvoirs de contrôle qui ne peuvent s'exercer que dans le cadre du contrôle du respect de la législation en matière d'environnement. Certains agents chargés de la surveillance, qui ont des pouvoirs de contrôle, peuvent également se voir accorder par le gouvernement le pouvoir d'agir en tant qu'OPJ. Bien qu'à ce niveau, il y ait également un risque de confusion de pouvoirs en matière de recherche avec les pouvoirs de contrôle propre au droit de l'environnement, ce risque est moindre dans ce cas. Cela signifie que lorsque certains agents chargés de la surveillance ont après contrôle, constaté des infractions, ils peuvent ensuite également exercer dans le cadre de la recherche, des pouvoirs qui reviennent à l'OPJ.

Par ailleurs, la jurisprudence fait une distinction entre le " contrôle " et la « recherche ». Elle interdit que des compétences de recherche soient utilisées à des fins de contrôle et que des compétences de contrôle soient exercées après l'apparition d'une suspicion. ${ }^{254}$

Ainsi, pour permettre un contrôle plus efficace, les agents de contrôle doivent être habilités comme démontré plus haut, de compétences particulières

252 Michel PRIEUR Op. Cit. p : 824

253 Cf. A. DE NAUW et B. BRONDERS, op, cit. pp.691-693 ; V. aussi M. FAURE, in, Editions Kluwer, Aménagement-Environnement, 2000/3, p.181

254 Voir notamment Ch. Acc. Liège, 23 juin 1983. JDF, 1984, 42.cité par A. DE NAUW et B. BRONDERS, op, cit. p.5 
tels que la compétence d'accès, la consultation de documents, le prélèvement d'échantillon et autres. Autrement, le plus parfait des systèmes de responsabilité et de sanction resterait lettres mortes.

\section{SECTION II : LE REGIME REPRESSIF TEL QUE PREVU PAR LES TEXTES}

La gestion de l'environnement exige non seulement des mesures préventives de police qui, par des autorisations ou des interdictions, permettent d'empêcher ou de contrôler des activités susceptibles de nuire au milieu naturel et à la santé humaine mais aussi des mesures coercitives même si « la répression n'est pas la méthode généralement utilisée en la matière ${ }^{255}$. Pour se faire, et dans le souci de garantir l'impunité des actes anti écologiques, le législateur béninois a prévu toute une gamme de sanctions. Notre étude analysera aussi bien le régime juridique des peines applicables devant les juridictions (§l) que le traitement extra juridique dont font l'objet, très souvent, les délinquants environnementaux (§II).

\section{$\S$ : Le régime juridique des peines}

La peine, se définie selon J. PRADEL, comme " un mal infligé à un délinquant à cause de sa faute, une souffrance imposée par l'autorité à titre de sanction de la violation de règles fondamentales de la vie d'un groupe ${ }^{256}$. II ressort de cette définition que la peine à pour but ultime de faire souffrir l'individu, de lui faire " payer sa dette ${ }^{257}$ » vis-à-vis de la société. La peine a pour finalité de « remplir une triple fonction : (...) empêcher par l'effet d'intimidation, la réalisation ou le renouvellement d'une infraction ; (...) réprimer les comportements fautifs (...) ; inciter l'auteur à (...) réparer le dommage causé $^{258}$.

255 M. PRIEUR, op. cit.,p : 801

256 J. PRADEL, Manuel de droit pénal général. 16ème éd. CUJAS. Paris, 2006, p : 524

257 Idem

258 NERAC-CROISIER Roselyne, Sauvegarde de l'environnement par le droit pénal, L'Harmattan, Sciences Criminelles, 2005, Paris, p.52 
Remarquons que pour punir l'individu, comme le souligne le Professeur FAURE, "plusieurs variables déterminantes comme la gravité du crime, et la capacité intentionnelle du criminel, sont pertinentes pour choisir la sanction optimale dans un cas particulier ${ }^{259}$. Dès lors, le droit répressif comprend essentiellement les sanctions pénales (A) d'une part et d'autre part les sanctions administratives (B).

\section{A) Les sanctions pénales}

La détermination des peines applicables est une prérogative qui incombe exclusivement aux juridictions pénales en ce qui concerne les sanctions pénales. Ainsi, les sanctions pénales, à savoir les peines et les mesures de suretés, sont prononcées uniquement par le juge pénal sur la base d'une infraction à la loi pénale. ${ }^{260}$ Elles doivent suivre le principe classique de la légalité des peines, selon lequel le juge ne peut prononcer une peine que si le législateur l'a prévu. Mais, elles n'ôtent pas au juge la possibilité d'accorder au coupable des circonstances atténuantes ${ }^{261}$; de sorte que le juge jouit donc d'une liberté d'appréciation très étendue qui lui permet de réduire considérablement la peine privative de liberté indiquée par le législateur. Cette détermination des peines, notamment du minima et du maxima est liée non seulement à la gravité de l'infraction mais aussi à la définition claire et nette de l'élément infractionnel. Ainsi, comme le précise le Professeur M. FAURE, un délit définit vaguement comme la " pollution de l'environnement » est inutile puisque dans la pratique, aucune législation sur l'environnement $n$ 'interdit toutes les formes de pollution ${ }^{262}$; car le droit de l'environnement tolère la pollution en la contrôlant par un système d'autorisation, comme nous l'avons développé plus haut.

Ainsi, les textes pénaux en général, définissent les peines principales et les peines complémentaires ou accessoires.

259 M. FAURE, L'analyse économique du droit de l'environnement, Bruylant, Bruxelles, 2007,p : 255

260 J. PRADEL, Manuel de droit pénal général. 16ème éd. CUJAS. Paris, 2006, p : 524

261 J. PRADEL, op. Cit. 539

262 M.FAURE, L'analyse économique du droit de l'environnement, éd. Bruylant, Bruxelles, 2007, p : 289 


\section{Les peines principales : l'amende et l'emprisonnement}

La peine principale est définie comme « une peine qui, prévue par la loi à titre principal pour sanctionner un comportement déterminé, caractérise à la fois l'existence d'une infraction pénale et la nature criminelle, correctionnelle et contraventionnelle de celle-ci ${ }^{263}$.Dans le même ouvrage, la cour de cassation française la définit comme « mal infligé par la justice répressive en vertu de la loi, à titre de punition ou de sanction d'un acte que la loi défend ".

Au regard de la doctrine, l'amende et l'emprisonnement, sont les deux peines principales les plus importantes. Ils ont un caractère à la fois "personnel » et " punitif ${ }^{264}$. La privation de liberté s'entend de la réclusion criminelle ou la détention criminelle à temps ou à perpétuité (peine criminelle) et l'emprisonnement (peine correctionnelle) ${ }^{265}$.Elles sont assorties en général dans leur fixation, de peine minima et de peine maxima.

« La condamnation à la peine des travaux forcés à temps sera prononcée pour cinq (5) ans au moins et vingt (20) ans au plus ${ }^{266}$. Le juge peut aussi prononcer la « perpétuité » ou la " peine de mort " $^{267}$. En matière correctionnelle, la durée de cette peine sera au moins de " onze (11) jours et de cinq (5) ans au plus, sauf les cas de récidive ou autres pour lesquels la loi détermine d’autres limites $»^{268}$.

263 NERAC-CROISIER Roselyne, op.,cit. p.51

264 D. GUIHAL, op, cit, $p: 229$.

265 J. PRADEL, Manuel de droit pénal général. 16ème éd. CUJAS. Paris, 2006, p : 539 et 540

266 Art. 19 du recueil annoté des textes de droit pénal applicables en AOF. G.J. BOUVENET et Paul HUTIN.

267 Art. 7 du recueil annoté des textes de droit pénal applicables en AOF. G.J. BOUVENET et Paul HUTIN. La peine de mort ne fait plus partie de l'arsenal répressif béninois. Elle vient d'être abrogée par la loi du 18 août 2011 portant autorisation de ratification du protocole des nations unies visant l'abolition de la peine de mort. Dès lors, le Bénin se prépare à être le 75ème pays partie au second protocole facultatif de la convention internationale sur l'abolition de la peine de mort, le 5 octobre 2012. 
En la matière, le droit pénal français a beaucoup évoluée ${ }^{269}$. Par exemple, depuis 1981, la peine de mort ne " figure plus dans l'arsenal répressif français "270. La conséquence qui en découle est que le maximum de la peine encourue est désormais la perpétuité ${ }^{271}$. Les autres peines criminelles sont suivant les cas de « 30 ans au plus, ou de 20 ans au plus ou de 15 ans au plus $»^{272}$.

Plus que le code pénal ${ }^{273}$, en droit interne, se sont surtout des textes de lois spécifiques au secteur de l'environnement qui définissent les peines applicables.

Remarquons tout de même que des deux peines, la peine d'amende apparaît comme la plus utilisée. En effet, le recours à l'amende ou plus récemment le recours au jours-amende ${ }^{274}$, s'est considérablement développé au cours du XIXème et du XXème siècle. Cela peut certainement s'expliquer par son efficacité relative en ce sens qu'il frappe le délinquant directement dans son « patrimoine ». D'autre part, le recours à l'amende peut s'entendre comme moyen de " supprimer les courtes peines d'emprisonnement ou tout au moins d'en réduire le nombre $»^{275}$.

Alors que l'emprisonnement est une peine privative de liberté, du point de vue de la doctrine, l'amende ou " peine pécuniaire ${ }^{276}$ » se définit comme étant " l'obligation pour le condamné de payer à l'Etat, à titre de sanction pénale, une somme d'argent ${ }^{277}$ ». De ce fait, elle se distingue des dommages et intérêts

269 Cf. J. PRADEL, op, cit, p : 540 voir notamment la loi du 29 décembre 1972 et loi du 11 juillet 1975. Des réformes bouleversant le concept de peine principale sont intervenues.

270 Cf. loi n 81-908 du 9 octobre 1981 portant abolition de la peine de mort

271 (J.C)SOYER, Droit pénal et Procédure Pénal, 17ème éd. L.G.D.J, Paris, 2003, p : 161

272 J(J.C) SOYER, Droit pénal et Procédure Pénal, 17ème éd. L.G.D.J, Paris, 2003, p : 161

273 M. PRIEUR, op, cit, $p:$ 820. Il développe à cet effet, que "L'élément légal ne figure jamais dans le code pénal mais soit dans les lois particulières soit dans les codes spécialisés ».

274 C'est une innovation du droit français qui s'inspire des expériences allemandes et autrichienne, selon laquelle le juge détermine le montant de chaque jour- amende en fonction des ressources et des charges du prévenu. Le maximum du montant est 300 euros et le maximum du nombre de jours est $360 »$. Cette pratique, bien que voisine de la contrainte par corps n'existe pas encore en droit béninois.

275 G. KELLENS, Précis de pénologie et de droit des sanctions pénales : la mesure de la peine. Collection Scientifique de la Faculté de Droit de Liège, 1991, p : 222

276 J.C SAUYER, op.cit. , $p: 158$

277 J. PRADEL, op., cit, p : 566 
qui sont des numéraires alloués à la victime en réparation de son préjudice. L'amende pénale s'oppose aussi à l'amende fiscale et à l'amende civile et même à l'amende prononcée dans le cadre de la procédure de la composition pénale. Elle intervient fréquemment en matière correctionnelle et peut accompagner " exceptionnellement ${ }^{278}$ certaines condamnations en matière criminelle.

En matière d'amende et de peine d'emprisonnement, on observe une sévérité du droit béninois, avec la possibilité de criminalisation de certaines infractions. Par exemple, il est clairement définit qu'en cas de pollution relative au déversement, rejet, écoulement, dépôt direct ou indirect dans les eaux continentales, le prévenu est passible d'une amende deux cent mille (200.000) à deux (2) millions FCFA et/ou d'une peine d'emprisonnement de un (1) à cinq (5) $a^{279}$. Lorsque les infractions sont relatives au milieu marin, l'amende devient plus importante et varie entre 100 millions et un (1) milliard de francs CFA et/ ou douze (12) à vingt quatre (24) mois de prison ${ }^{280}$. Mais la sanction devient criminelle si le déversement est relatif aux déchets toxiques ou dangereux, à leur transit, stockage ou enfouissement sur le territoire national. L'infraction dans ce cas, qualifiée de crime contre la nation est punie de la réclusion criminelle à temps à savoir cinq (5) à vingt (20) ans de prison et d'une amende de vingt cinq (25)millions à cinq cent (500) millions FCFA d'amende ${ }^{281}$. L'amende dans ce cas n'est pas facultative mais elle est prononcée par le juge cumulativement avec la peine d'emprisonnement. Cette sévérité du législateur permet certainement de dissuader les délinquants potentiels.

Dans le domaine de la pollution de l'air dû aux rejets dans l'atmosphère de gaz, l'amende est de cent (100) mille à deux (2) millions de francs CFA et/ ou douze (12) à trente (36) mois d'emprisonnement. Mais lorsque l'infraction résulte de l'utilisation de véhicules de deux à quatre roues, l'amende qui est la peine unique varie entre un minima de 10.000 à un maxima de cinquante mille (50.000) FCFA ${ }^{282}$ et c'est seulement en cas de récidive que la peine

\footnotetext{
278 J. PRADEL, op., cit, $p: 541$

279 Loi cadre sur l'environnement du Bénin Art.39

280 Idem art. 117

281 Idem art.118

282 Idem art.116
} 
d'emprisonnement de simple police de $\operatorname{dix}(10)$ à trente (30) jours pourra être prononcée ${ }^{283}$.

Par ailleurs, par la technique de renvoi ${ }^{284}$, les peines relatives à la faune et à la flore qui sont tous des délits forestiers, sont fixées par des lois spécifiques. Ainsi, le simple fait de " couper ", " mutiler "ou " écorcer " un arbre est puni d'une amende de cinq (5000) mille à cinquante (50.000) mille francs CFA et/ou d'un emprisonnement de 15 jours à 6 mois $^{285}$. Lorsque l'objet de l'infraction est plutôt relatif à une espèce protégée partiellement ou intégralement, l'amende est multipliée par dix et l'emprisonnement peut atteindre deux ans. Ainsi en cas de délit de feu de brousse ou d'incendie de plantation, de transhumance ou d'usage de la tronçonneuse, le prévenu est passible d'une peine d'amende de 50.000 à 500.000FCFA et/ou 3 mois à 3 ans de prison. Elle peut atteindre 5 ans assortie de dommages et intérêts si l'incendie est volontaire ${ }^{286}$. On peut citer par exemple, l'affaire Ministère Public $c /$ les sieurs W. E et S.J reconnus coupables d'incendie involontaire de plantation d'anacarde de monsieur B. E. Ils ont été condamnés chacun à 6 mois d'emprisonnement assorti de sursis et à 200.000 FCFA d'amende chacun par le TPI de Natitingou. En outre le tribunal les condamne solidairement à verser à titre de dommages et intérêts à la victime la somme de 2.500 .000 F CFA. A ce sujet, le dispositif de la cour est sans équivoque dans l'application de l'article 94 de la loi sur la faune béninoise " attendu qu'il résulte du dossier et des débats, preuves et charges suffisantes contre les nommés.... d'avoir courant année 2008.... par imprudence, négligence, inattention ou inobservation des règlements, involontairement causé un feu de brousse ou un incendie de la plantation de M.... ${ }^{287}$.

En ce qui concerne le régime de la faune, il convient de retenir que « la chasse illégale » ou "le défaut de permis de chasse ", " le commerce d'animaux sauvages sans autorisation, ... ", sont punis d'une amende variant entre 300.000 et 800.000 FCFA et/ou 6 mois à 5 ans de prison ${ }^{288}$, alors que " le pâturage

\footnotetext{
283 Idem art. 119

284 Par la loi-cadre

285 Loi n93-009 du 2 juillet 1993 portant régime des forêts en République du Bénin. , Art. 88.

286 Idem, art.94

287 TPI, Jugement $n^{\circ} 181 / 08$ du 28/10/08, 1ère Ch. Répertoire des décisions de justice.

288 Art. 154, 155 de la loi sur la faune béninoise.
} 
illégal " et " le défrichement illégal " sont sanctionnés par une même peine d'emprisonnement mais avec une amende qui oscille entre 50.000 et 1.000.000F CFA. ${ }^{289}$ Lorsque l'infraction est relative à " une espèce protégée partiellement ou intégralement " ou a lieu dans " un parc national, » ou encore a lieu dans " la nuit ", il y a circonstances aggravantes d'où les sanctions deviennent plus sévères. Il en est ainsi, des espèces que les droits nationaux soustraient plus ou moins aux prélèvements et auxquelles ils devront, ou devraient, reconnaître une vocation prioritaire à bénéficier de toutes les mesures de protection ${ }^{290}$. La faune est le domaine par excellence de la répression par les tribunaux correctionnels. Cela est dû essentiellement par la recrudescence du braconnage dans les réserves de faune.

Le Tableau $N^{\circ} 1$ ci-dessous, fait le récapitulatif des sanctions pénales applicables par le juge béninois. Ce dernier applique effectivement ces sanctions mais dans des ratios non encore satisfaisantes puisqu'on constate aisément sur le Tableau $N^{\circ} 2$ la faiblesse du ratio des jugements relatifs aux délits environnementaux dans le grand ensemble des décisions de justice rendues chaque année par le Tribunal de Première Instance de Natitingou. Et, dans ces jugements, il est noté la prédominance les délits forestiers soit environ $90 \%$ chaque année. Cette situation est identique dans les autres juridictions du pays.

289 Idem.

290 C. du SAUSSAY, op,cit, $p: 11$ 
Tableau №1: Récapitulatif de quelques sanctions pénales applicables par le juge béninois

\begin{tabular}{|c|c|c|c|c|c|}
\hline \multirow{4}{*}{01} & \multirow{4}{*}{$\begin{array}{l}\text { INFRACTIONS DÉLICTUELLES } \\
\text { OU CRIMINELLES } \\
\text { Pollution de l'eau relative } \\
\text { au rejet, écoulement, dépôt } \\
\text { direct ou indirect dans les eaux } \\
\text { continentales }\end{array}$} & \multicolumn{4}{|c|}{ SANCTIONS APPLICABLES } \\
\hline & & \multicolumn{2}{|c|}{ Amende (CFA) } & \multicolumn{2}{|c|}{ emprisonnement } \\
\hline & & minimum & maximum & minimum & maximum \\
\hline & & $200.000 \mathrm{f}$ & $2000.000 f$ & $1 \mathrm{an}$ & 5 ans \\
\hline 02 & $\begin{array}{l}\text { Pollution de l'eau relative au } \\
\text { milieu marin }\end{array}$ & $100.000 .000 \mathrm{f}$ & $1.000 .000 .000 \mathrm{f}$ & 12 mois & 24 mois \\
\hline 03 & $\begin{array}{l}\text { Pollution relative au déversement } \\
\text { des déchets toxiques, à leur } \\
\text { transit, stockage } \\
\text { ou enfouissement sur le territoire } \\
\text { national (crime) }\end{array}$ & $25.000 .000 \mathrm{f}$ & $500.000 .000 \mathrm{f}$ & 5 ans & 20 ans \\
\hline 04 & $\begin{array}{l}\text { Pollution de l'air : rejet dans l'air } \\
\text { de } \\
\text { gaz à effets de serre }\end{array}$ & $100.000 \mathrm{f}$ & $2.000 .000 \mathrm{f}$ & 12 mois & 36 mois \\
\hline 05 & $\begin{array}{l}\text { Rejet dans l'air dû aux véhicules } \\
\text { à deux } \\
\text { ou quatre roues }\end{array}$ & $10.000 \mathrm{f}$ & $50.000 \mathrm{f}$ & $\begin{array}{l}10 \text { jours } \\
\text { (récidive) }\end{array}$ & $\begin{array}{l}30 \text { jours } \\
\text { (récidive) }\end{array}$ \\
\hline 06 & $\begin{array}{l}\text { Couper, mutiler ou écorcer un } \\
\text { arbre }\end{array}$ & $5000 \mathrm{f}$ & $50.000 \mathrm{f}$ & 15 jours & 6 mois \\
\hline 07 & $\begin{array}{l}\text { Feu de brousse ou incendie de } \\
\text { plantation, } \\
\text { transhumance, usage de la } \\
\text { tronçonneuse }\end{array}$ & $50.000 \mathrm{f}$ & $500.000 \mathrm{f}$ & 3 mois & $\begin{array}{l}\text { 3ans et } \\
5 \text { ans en } \\
\text { cas } \\
\text { d'incendie } \\
\text { volontaire }\end{array}$ \\
\hline 08 & $\begin{array}{l}\text { Chasse illégale, défaut de permis } \\
\text { de chasse, } \\
\text { commerce d'animaux sauvages } \\
\text { sans autorisation }\end{array}$ & $300.000 \mathrm{f}$ & $800.000 \mathrm{f}$ & 6 mois & 5 ans \\
\hline 09 & $\begin{array}{l}\text { Pâturage illégal, défrichement } \\
\text { illégal }\end{array}$ & $50.000 \mathrm{f}$ & $1.000 .000 \mathrm{f}$ & 6 mois & 5 ans \\
\hline
\end{tabular}

Source : loi-cadre sur l'environnement et les lois sur la faune et sur la flore au Bénin 
Tableau $\mathrm{N}^{\circ} 2$ : Nombre de décisions de justice rendues en matière environnementale au cours des cinq dernières années par le Tribunal de Première Instance de Natitingou.

\begin{tabular}{|l|l|}
\hline Année & Nombre de jugements rendus \\
\hline $\mathbf{2 0 0 5}$ & $\begin{array}{l}14 \text { décisions de justice à caractère environnemental sur un total de } 885 \\
\text { dossiers vidés par le tribunal }\end{array}$ \\
\hline $\mathbf{2 0 0 6}$ & $\begin{array}{l}\text { 20 décisions de justice à caractère environnemental sur un total de } \\
401 \text { dossiers vidés par le tribunal }\end{array}$ \\
\hline $\mathbf{2 0 0 7}$ & $\begin{array}{l}16 \text { décisions de justice à caractère environnemental sur un total de } \\
380 \text { dossiers vidés par le tribunal }\end{array}$ \\
\hline $\mathbf{2 0 0 8}$ & $\begin{array}{l}12 \text { décisions de justice à caractère environnemental sur un total de } \\
365 \text { dossiers vidés par le tribunal }\end{array}$ \\
\hline $\mathbf{2 0 0 9}$ & $\begin{array}{l}26 \text { décisions de justice à caractère environnemental sur un total de } \\
\text { 423 dossiers vidés par le tribunal }\end{array}$ \\
\hline
\end{tabular}

Source : répertoire des décisions de justice au Tribunal de Première Instance de Natitingou, 2010.

L'application du droit cynégétique béninois fait ressortir la fréquence de trois délits forestiers à savoir la chasse illégale et la pèche illégale, communément appelées délit de braconnage et la transhumance ou le pâturage illégal. La jurisprudence est assez fournie en la matière mais elle reste inédite. On peut citer par exemple les cas du sieur K. T. condamné à 12 mois d'emprisonnement ferme et 100.000FCFA d'amende ${ }^{291}$; du sieur B. P. condamné à trois mois de prison, pour abattage illégal d'un boa ou python d'Afrique ${ }^{292}$; du sieur O. B. qui échoppe de 6 mois de prison ferme et de 50.000 F CFA d'amende pour tentative de capture illégale d'animaux ${ }^{293}$; de N. K., puni de 5 mois d'emprisonnement ferme pour chasse illégale ${ }^{294}$, de $S$. D. poursuivit pour autorisation illégale de pêche clandestine et condamné à 6 mois de prison assortis de sursis ${ }^{295}$, de $\mathrm{B}$. M. T condamné à 12 mois de prison assortis de sursis et 200.000 francs CFA

291 TPI Natitingou, jugement $n^{\circ} 42 / 06$ du 22/02/06, répertoire des décisions de justice de Natitingou.

292 TPI Natitingou, jugement $n^{\circ} 32 / 06$ du 22/02/06, répertoire des décisions de justice de Natitingou

293 TPI Natitingou, jugement $n^{\circ} 48 / 08$ du 04/03/08, répertoire des décisions de justice de Natitingou

294 TPI Natitingou, jugement $n^{\circ} 111 / 09$ du 25/08/09, répertoire des décisions de justice de Natitingou

295 TPI Natitingou, jugement $n^{\circ} 174 / 08$ du 21/10/08, répertoire des décisions de justice de Natitingou 
d'amende pour pâturage illéga ${ }^{296}$, de Monsieur W. K. poursuivi pour chasse illégale avec abattage d'un buffle dans la réserve de faune de la Pendjari et qui a été condamné à trois mois avec sursis et 100.000 FCFA d'amende ferme ${ }^{297}$ seulement pour un buffle tué, animal pourtant partiellement protégé.

Néanmoins on note quelques cas de décisions sévères. Cas du sieur $\mathrm{G}$. K. qui a abattu un ourébi et deux varans, espèces non protégées, et a été puni de six mois d'emprisonnement ferme et à 300.000F CFA d'amende ${ }^{298}$.

Il en est ainsi de l'abattage d'un lion, animal partiellement protégé ; l'auteur a été sanctionné d'une peine de 24 mois d'emprisonnement ferme et 50.000 francs CFA d'amende avec constitution de partie civile pour un montant de 1.245.000 francs CFA ${ }^{299}$. Cette sévérité se lit également dans la décision $n^{\circ} 8 / 90$, rendu par le tribunal de Natitingou. Le juge pénal a condamné à 13 mois de prison ferme et à 20.000F CFA d'amende le sieur D.K. pour avoir, dans le Parc national de la Pendjari le 03 avril 1990 illégalement chassé et avoir dans les mêmes circonstances de temps et de lieu exercé des violences et voies de fait sur les agents de la brigade forestière. On pourrait à raison relever la sévérité d'une telle peine par rapport à celle que prononce habituellement le juge. En effet, pour presque toutes les décisions rendues, par ce tribunal, la peine d'emprisonnement dépasse rarement 12 mois ferme même avec obstacle au contrôle ${ }^{300}$. Dans tous les cas, il est nécessaire que ces agents bénéficient d'une protection sûre car ils opèrent la plupart du temps dans des conditions très difficiles. Mais ils ont aussi le devoir d'être courtois envers les usagers. Ce qui dans la pratique, ne s'observe que très peu ${ }^{301}$.

296 TPI Natitingou, jugement $n^{\circ} 70 / 09$ du 12/05/09, répertoire des décisions de justice de Natitingou

297 TPI Natitingou, jugement $n^{\circ} 28 / 05$ du 20/07/05, répertoire des décisions de justice de Natitingou

298 TPI Natitingou, jugement $n^{\circ} 29 / 07$ du 20/07/05, répertoire des décisions de justice de Natitingou

299 TPI Natitingou, jugement $n^{\circ} 369 / 09$ du 2/6/09, répertoire des décisions de justice de Natitingou

300 Dans la période allant de 2005 à 2009, au TPI de Natitingou, à peine 7décisions de justice ont atteint 12 mois ferme d'emprisonnement et aucune n'est allée au delà.

301 G. SOGLO, op, cit, p. 44. 
Le constat qui se dégage de cette jurisprudence, est que les juges accordent de larges circonstances atténuantes de sorte que les peines sont très souvent en deçà du minima légal avec un usage régulier de la peine sursitaire, fondée sur "l'indulgence du juge ${ }^{302}$. Le caractère " d'espèce intégralement ou partiellement protégée " qui devrait apparaître en termes de circonstance aggravante, $n^{\prime}$ influence guère la sanction pénale. Notons que la qualification de I'infraction d'abord par l'agent des eaux et forêts lors de l'élaboration du procèsverbal et ensuite par le juge, en des termes imprécis tels que « abattage illégal d'animaux » ou de " chasse illégale " ou encore de "pêche illégale " sans définir la nature de l'espèce, de sorte qu'on ne puisse savoir de quel genre d'animal il s'agit : est-ce un animal partiellement ou intégralement protégé ? Femelle ou suitée ? La non détermination par exemple du statut d'un tel animal abattu illégalement, participe de cette confusion et n'est pas de nature à déterminer avec précision la sanction qui convient. De plus, il est de notoriété publique que ces infractions de braconnage ont souvent lieu dans la nuit et dans la réserve de faune. Or les circonstances de temps et de lieu comme la "nuit » et la " réserve » sont des circonstances aggravantes de l'infraction, donc logiquement les peines devraient être plus sévères mais ce n'est pas souvent le cas, mieux les prévenus peuvent bénéficier des circonstances plutôt atténuantes conformément aux dispositions de l'article 463 du code pénal.

Dans le souci de renforcer l'efficacité de la sanction pénale, et compte tenu de la gravité de l'infraction commise, le juge applique en sus des peines principales, des peines complémentaires.

\section{Les peines pénales complémentaires}

La doctrine observe une nuance entre peine complémentaire et peine accessoire. Que ce soit l'une ou l'autre, il s'agit des peines qui s'ajoutent à la peine principale. Tandis que l'accessoire est celle qui s'ajoute automatiquement, le complémentaire s'ajoute mais pas de plein droit. II faut que le juge la prononce expressément. Elle est alors tantôt obligatoire tantôt facultative ${ }^{303}$. Mais, selon J.

302 J. PRADEL, op, cit., $p: 615$

303 Cf. J.C SOYER, op.cit., p : 160 ; art.131-21 du code pénal français. 
PRADEL, qui semble mettre un terme à la controverse doctrinale, en dehors de la peine de confiscation, «le code pénal français ne connaît en principe que des peines complémentaires facultatives ${ }^{304}$. Quant aux peines dites accessoires, naguères appliquées systématiquement à toute condamnation criminelle, emportait une interdiction légale. Mais avec l'évolution du droit pénal français, cette peine n'existe plus dans le nouveau code pénal, puisque ses rédacteurs «ont posé le principe de sa disparition $»^{305}$ et la doctrine semble bien « unanime $»^{306}$ là-dessus.

Ainsi, on qualifie de peine complémentaire criminelle, " l'interdiction légale d'exercer une fonction publique ", de l'interdiction de séjour, la déchéance, la double incapacité de recevoir à titre gratuit $»^{307}$. Est qualifié aussi de peine complémentaire, la perte des droits civiques (droit d'être expert devant une juridiction, droit de détenir une arme, droit de voter et d'être élu.... ${ }^{308}$ et la publicité du jugement qui apparaît comme une mesure qui porte atteinte à la réputation du condamné.

Par exemple, dans l'affaire de déchets toxiques d'Abidjan, la cour d'assises a prononcé une peine complémentaire d'interdiction de séjour sur le territoire national pour une durée de dix (10) ans à l'encontre de S. U. et la même peine de privation de droits civiques à l'encontre de l'ivoirien E.K ${ }^{309}$.

Le Président de la République s'expose aussi à de telles sanctions lorsqu'il est par exemple reconnu coupable de " crime de haute trahison, comme le déversement sur le territoire national des déchets toxiques » ou « en cas d'acte attentatoire au maintien d'un environnement sain $»^{310}$.

\footnotetext{
304 Op, cit, $\mathrm{p}: 542$

305 Idem, $p: 542$

306 Idem, $\mathrm{p}: 542$

307 J. PRADEL, op., cit, p. 581. Notons que ces sanctions criminelles qui appartenaient au code pénal de 1810 sont pratiquement supprimées dans le nouveau code pénal français puisqu'il n'en fait pas cas. Mais elles demeurent applicables en droit positif béninois.

308 Art 34 du code pénal Bouvenet applicable en AOF ; voir aussi J.C SOYER, op.cit., p : 161

309 Cf. infra §II. B) p : 221.

310 Cf. art. 29 ; 74 de la constitution béninoise ; art.414-5 CP français.
} 
La peine de confiscation ${ }^{311}$ est aussi une peine complémentaire. Cette peine, très utilisée en droit de l'environnement est définie comme une " peine par laquelle est transféré autoritairement à l'Etat tout ou partie des biens d'une personne à titre de peine principale accessoire ou complémentaire $»^{312}$. A titre d'exemple, on peut citer les dispositions de l'article 118 de la loi-cadre sur l'environnement au Bénin qui prévoit en cas de déversement des déchets toxiques ou polluants, en plus des peines criminelles, la peine de confiscation à savoir " la saisie du navire ou du véhicule ou des engins ayant servi à la commission de l'infraction ".

Mentionnons que le droit commun de la procédure pénale française comme béninoise, offre peu de dispositifs conservatoires pertinents en matière environnementale. La principale qui existe est « la saisie " ou " la confiscation » qui peut être ordonnée par un OPJ, au cours de l'enquête préliminaire ou en cas de flagrance, et sur décision du juge d'instruction lorsqu'une information est ouverte. Si la saisie a un objectif principalement probatoire (placer sous mains de justice les objets et documents utiles à la manifestation de la vérité), elle remplit également une fonction conservatoire, d'une part en garantissant l'effectivité d'une condamnation ultérieure à la confiscation, d'autre part en permettant le retrait d'objets dangereux. En tant que peine, la confiscation ne porte que sur les choses, qui ont servi à commettre l'infraction ou sur les choses qui en sont le produit ${ }^{313}$. Le juge pénal ordonne couramment la confiscation au profit de l'Etat de l'objet du délit ${ }^{314}$. Par exemple, une telle peine aurait pu intervenir dans l'affaire des déchets toxiques d'Abidjan et aurait vu la confiscation du navire PROBO KOALA, ayant servi à la commission du crime. Elle est obligatoire pour les objets qualifiés par la loi de dangereux ou nuisibles. Même en absence de condamnation expresse à la confiscation, la dangerosité pour les personnes ou les biens des choses placées sous mains de justice, fait obstacle à leur restitution ${ }^{315}$.

311 Elle est prévue par l'article 38 du Code Pénal Bouvenet .et par art.132-121 CP français « la peine de confiscation est obligatoire pour les objets qualifiés par la loi ou le règlement de dangereux et nuisibles ».

312 De R. GUILLIEN et J. VINCENT, Lexique de termes juridiques, Dalloz, Paris, 1988.

313 cf. art.131-21 du code pénal français.

314 TPI Natitingou, jugement n²13/06/FD/du 29/12/06, répertoire des décisions de justice de Natitingou. Au sujet de la confiscation du fusil objet du scellé n¹85/06 GT-N du 29/12/06. Art. 177 et 212 du CPP français. 
Si l'affaire a été classée sans suite ou lorsque la juridiction saisie a épuisé sa compétence sans avoir statué sur les restitutions, il appartient au parquet, sous réserve de recours devant le tribunal correctionnel ou devant la chambre d'instruction de la cour d'appel, de répondre à la demande de restitution.

Par ailleurs, la remise en état ou la mise en conformité des lieux, sanction à prédominance réparatrice ${ }^{316}$, est aussi une mesure pénale prévue également par les textes et largement utilisée en droit de l'environnement ${ }^{317}$. Ainsi, " tout site ayant fait l'objet d'une exploitation doit être remis en état ...selon les conditions fixées par le ministre chargé de l'environnement $»^{318}$ mais " (...) des décisions de justice peuvent aussi ordonner les mêmes sanctions $\|^{319}$. Il ressort de ces dispositions que la remise en état apparaît comme une sanction hybride pouvant être prononcée tantôt par l'administration tantôt par le juge pénal ou par le juge administratif ou encore par le juge civil. Cette indétermination de la nature juridique de cette mesure est confortée par l'inconsistance de la doctrine et la jurisprudence. En effet, on peut convenir avec C. OUEDRAOGO ${ }^{320}$ que « la Chambre criminelle de la cour de cassation française a, dans un premier temps, affirmé sans ambigüité le caractère indemnitaire de la remise en état : " la mise en conformité ou la démolition ne sont pas des peines, mais des réparations civiles ${ }^{321}$. Mais elle va par la suite adopter une position beaucoup plus prudente qui laisse entrevoir une possible double nature de la mesure, en soutenant que, « si la démolition présente le caractère d'une réparation civile, il n'en demeure pas moins vrai que ces mesures sont demandées par le ministère public en réparation d'un trouble causé à l'ordre public ${ }^{322}$ ». Après, elle reconnu expressément la double nature de la remise en état en affirmant clairement que la mise en conformité, la démolition, si elles présentent le caractère d'une

316 C. OUEDRAOGO, op, cit.

317 M. PRIEUR, op, cit. p. 864

318 Art. 22 de la loi-cadre béninoise

319 Idem Art. 111

320 Op. cit.

321 Cass.crim.(fr),27mai1967,Bull. crim.1967, n¹62; v dans le même sens. Cass. Crim. (fr) 3 février 1965, Bull. crim.1965, n³2; 29 avril 1970 Bull. crim. 1970, n 149

322 Cass. Crim. (fr), 20 janvier1981.Bull.crim. 1981, nº 26. 
réparation civile, n'en constituent pas moins également des peines ${ }^{323}$. Mais cette situation de reconnaissance de la double nature ne fut que de courte durée ; car en effet, en 1989, la Chambre criminelle préférera à nouveau la solution de la prudence, cette fois-ci en parlant de catégorie autonome, c'est-à-dire une mesure qui n'est ni une peine, ni une simple mesure civile de réparation, mais une mesure à caractère réel destinée à faire cesser une situation illicite ${ }^{324}$.

II nous semble en définitive comme le souligne C. OUEDRAOGO, que malgré une prédominance réparatrice, la remise en état emprunte néanmoins certaines caractéristiques de la peine, autrement on ne saurait imaginer le prononcé d'une remise en état de la nature par le juge dans une hypothèse que la loi ne prévoit pas. La cour de cassation la rappelée dans une espèce ${ }^{325}$.

Au-delà de la polémique sur la nature juridique de la mesure, une réalité incontestable et mise en exergue par la plupart des auteurs est centrée sur I'utilité de la mesure. Quelle autre peine, mieux que la remise en état détériorée ou la restitution d'une espèce animale ou végétale illégalement enlevée est susceptible de rétablir l'ordre troublé par l'infraction ? Puisque " ordonner la restitution des milieux dégradés, la décontamination d'un sol pollué par des rejets ou le stockage de déchets, la destruction d'ouvrages irréguliers, est évidemment la solution la plus adéquate tant pour remédier aux conséquences d'un comportement délictueux que pour y mettre fin ${ }^{326}$ ". Même si cette remise en état, ne saurait retrouver totalement sa situation antérieure ${ }^{327}$, I'objectif comme le souligne le professeur PRIEUR, « devrait être d'aboutir au rétablissement du milieu dans un état le plus proche possible de sa situation antérieure, compte tenu des possibilités technologiques et de la capacité de régénération du milieu détérioré ${ }^{328}$ ».

323 Cass. Crim. (fr), 12 juin 1982 .Bull.crim. 1982, n 13 ; v. dans le même sens Cass. Crim. (fr), 13mai 1988.RSC. 1989, p. 134, obs. F. Boulan ; et P. 313, obs. A. Vitu.

324 Cass. Crim. (fr), 8 juin 1989 .Bull.crim. 1989, RSC 1990, p 130 obs. F. Boulan ; v. dans le même sens Cass. Crim. (fr), 23 novembre 1994. Dr pénal 1995, comm. 72, J. H. Robert. .

325 Cass. Crim. (fr), 5 juin1996. Dr. pénal 1996, comm. №224, J. H. Robert. .

326 M.J. LITMMANN-MARTIN, Les infractions relatives à l'environnement et la remise en état des lieux ordonnée par le juge pénal, p. 431

327 M. PRIEUR, op, cit, p.863

328 Op, cit, p.868 
En dépit de ces obstacles, on pourrait affirmer que la remise en état demeure pour le droit de l'environnement, une sanction assez intéressante puisqu'elle s'emploie à restaurer l'environnement. Elle est abondamment utilisée comme sanction administrative.

\section{B) Les sanctions administratives}

Deux types de sanctions caractérisent les sanctions administratives, d'une part les sanctions administratives relevant du juge administratif et d'autre part les sanctions relevant des autorités administratives.

\section{Les sanctions administratives relevant du juge administratif}

Comme nous l'avons dit précédemment, le droit pénal de l'environnement étant essentiellement un droit fondé sur "la dépendance administrative ", le juge administratif est appelé à connaître du contentieux environnemental, notamment tout acte à caractère réglementaire (décisions, circulaires, arrêtés ou décrets d'autorisations, ou permis) pris par les autorités gouvernementales et administratives chargées d'administrer l'environnement et portant grief aux intérêts des tiers. C'est un " contentieux de l'autorisation ${ }^{329}$. Ainsi, tous les actes soumis à autorisation, sont susceptibles de recours devant le tribunal administratif. Dans la mesure où il s'agit des actes administratifs dont le régime général est celui du recours pour excès de pouvoir. C'est une action intentée contre un acte administratif visant à obtenir du juge son annulation. C'est le cas lorsqu'un tiers s'estime lésé par une décision administrative relative par exemple aux conditions d' exercice de certaines activités liées à la production agricole, à la chasse, à la pêche, à la flore, à la faune, à la gestion des déchets, etc. ....Au Bénin, c'est la chambre administrative de la Cour Suprême qui fait office de tribunal administratif qui est compétente pour connaître ces genres de litiges en attendant la mise en œuvre effective des chambres administratives dans les 
différents TPI. Le juge administratif peut ${ }^{330}$ ainsi ordonner la remise en état d'un site pollué ou dégradé331 bien que cette notion soit beaucoup plus à connotation réparatrice. Elle est même très souvent ordonnée par le juge sous astreinte ${ }^{332}$ et son exécution d'office au frais du prévenu dans un délai déterminé ${ }^{333}$.

En matière environnementale, que ce soit la chambre administrative ou la chambre judiciaire, il n'existe pratiquement pas de jurisprudence ${ }^{334}$. Cette situation se trouve conforter avec l'irresponsabilité pénale des personnes morales. Comme en témoigne cet arrêt de la Cour d'Appel de Cotonou où le juge pénal affirme clairement que « dans le droit positif béninois, il n'existe pas de responsabilité pénale des personnes morales; et que les personnes morales sont des êtres juridiques fictifs dont tous les actes sont posés par les personnes physiques qui les dirigent ${ }^{335}$ »; alors que se sont les sociétés ou entreprises qui, dans le cadre de leurs activités dégradent ou polluent quotidiennement l'environnement, plus que les particuliers.

Remarquons qu'au Bénin, en matière de saisine de juridiction, les citoyens préfèrent saisir directement la cour constitutionnelle que la juridiction administrative ou judiciaire. Cela peut s'expliquer par la rapidité avec laquelle la Haute juridiction rend les décisions qui sont sans recours d'une part et d'autre part cette saisine est sans frais pour les justiciables alors qu'elle est assortie de frais devant les autres juridictions. De plus, une fois la décision de la cour constitutionnelle rendue, il y a possibilité de se constituer partie civile et

330 C'est une faculté qui lui est réservé il n'est pas contrait de le faire. L'application effective de la sanction dépend donc de son intime conviction ou de sa sensibilité aux problèmes environnementaux.

331 M. PRIEUR, op.cit., p.865

332 Idem

333 Art.19 arrêté n ${ }^{\circ} 0045 / \mathrm{MEHU} / \mathrm{DC} / \mathrm{SG} / \mathrm{DE} / \mathrm{SQEPE} / \mathrm{DPE} / \mathrm{SA}$ fixant les conditions et modalités d'exercice de la fonction d'agent de la police environnementale

334 Nous y reviendrons ultérieurement dans nos développements au titre II

335 Cf. arrêt n²1/2000 du 27 janvier 2000 de la Cour d'Appel RGN006/2000 dans l'affaire Société des Ciments d’Onigbolo Agent judiciaire du Trésor c/Société Groupe MYC International SARL. 
demander réparation des préjudices subis ${ }^{336}$, devant la chambre administrative de la cour suprême lorsque le contentieux est dirigé contre l'Etat.

\section{Les sanctions complémentaires relevant des autorités administratives}

«Spécialement prévues pour chaque infraction et destinées comme son nom l'indique, à compléter la peine principale ${ }^{337}$, les sanctions complémentaires administratives ont un rôle très pertinent en droit de l'environnement. L'exécutif produit en effet un nombre impressionnant de décrets et d'arrêtés relatifs à la gestion et à la protection de l'environnement. L'incrimination à essence écologique en général, consiste comme nous l'avons précisé déjà, en une violation d'une prescription administrative protégeant l'environnement. Dès lors, le droit pénal de l'environnement prend la forme d'une collection de polices administratives pénalement sanctionnées. Cela s'explique par le fait que la législation pénale, constituée de quelques lois, fixe les peines correctionnelles, les peines et les mesures complémentaires, et évoque en termes souvent vagues, les comportements infractionnels, laissant au pouvoir réglementaire le soin de les préciser. C'est ce que dispose précisément le dernier tiret de l'article 82 de la loi-cadre sur l'environnement au Bénin : « sont déterminés par décret pris en conseil des ministres : (...) les sanctions administratives telles que les procédures de suspension et d'arrêt de fonctionnement et les pénalités» ${ }^{338}$. Plus loin, l'article 111 renforce la compétence desdites autorités et pose le principe de cumul de sanctions pénales et de sanctions administratives ${ }^{339}$, en disposant que « les peines prévues par la présente loi ne font pas obstacle au

336 Cette possibilité existe depuis la Décision DCC 02-052 du 31 mai 2002 par laquelle la haute juridiction à jugé que "...les préjudices subis par toute personne, du fait de la violation de ses droits fondamentaux, ouvrent droit à réparation ». V. à ce sujet l'affaire BOYA, Décision DCC 02-065 du 5 juin 2002 dont l'article 2 précise " les préjudices subis par monsieur Eugène Comlan BOYA ouvrent droit à réparation"

337 (F) DESPORTES et le GUNEHEC (F), cité par C. OUDRAOGO, RJE, avril 2000, p : 535.

338 Cf. loi précitée. Voir aussi à cet effet, les dispositions des articles 154 et suivants du code de l'hygiène publique béninois.

339 D. GUIHAL, op, cit, p, 275 
retrait ou à la révocation, par les autorités compétentes, des certificats, permis ou autorisations qu'elles ont eu à délivrer ».

Ainsi, la gamme de sanctions administratives couramment utilisée aussi bien contre les personnes physiques que les personnes morales, et destinée à compléter les sanctions classiques, est constituée: d’amende transactionnelle forfaitaire ${ }^{340}$, d'amendes administratives issues des verbalisations administratives, de la remise en état du site dégradé ou pollué, qui s'articule avec le principe pollueur payeur, de la suspension du permis ou de l'autorisation ou d'un titre quelconque délivré par l'autorité compétente ${ }^{341}$. Ce retrait peut être temporaire ou définitive en fonction de la gravité du dommage causé, ce qui suppose immédiatement la fermeture temporaire ou définitive de l'entreprise. L'administration peut également à travers ses agents assermentés ou commissionnés procéder à des saisies ou confiscation d'objets du délit lorsque cela s'avère nécessaire ${ }^{342}$. Les lois béninoises relatives à la protection de la faune et de la flore ne font pas de distinction entre la saisie et la confiscation de l'objet du délit. Elles précisent que tous les produits appréhendés en situation irrégulière sont confisqués d'office par l'administration forestière et le matériel qui a servi à les récolter, à les transporter est saisie jusqu'au règlement définitif du litige ${ }^{343}$. Le plus souvent, la saisie sera opérée par les verbalisateurs ou les enquêteurs, mais elle pourra aussi l'être par le juge d'instruction ou la juridiction de jugement si elle ne l'a pas été auparavant. A cet égard, il nous est revenu de constater au cours de nos investigations que très souvent, l'administration forestière procède à des ventes aux enchères publiques des biens saisis.

340 Des agents des eaux et forêts comme des inspecteurs de l'environnement du MEHU.

341 Rapport d'activité 2009 de la Police Environnementale, DDEPN/MEPN, Cotonou, Bénin. Ce rapport nous renseigne qu'au titre de l'année, les Inspecteurs ont procédé dans le cadre des mesures conservatoires de lutte contre le bruit, à la fermeture provisoire de deux scieries à Cotonou, à l'arrêt des activités d'un groupe de prière dans la même ville et le retrait de plusieurs objets, sources de pollution sonore (enceintes acoustiques, amplificateurs, égaliseurs et autres).

342 Décret $n^{\circ}$ 2005-437 du 22 juillet 2005 portant organisation de la procédure d'inspection environnementale en République du Bénin. 
L'amende apparaît ainsi à nos yeux comme la forme de sanction la plus usitée par l'administration environnementale béninoise ${ }^{344}$. Il en est ainsi des amendes issues des verbalisations des agents forestiers et des Inspecteurs de l'environnement. Par exemple, au titre de l'année 2009, les Inspecteurs de l'environnement ont dressé 26 verbalisations dans les Départements de Littoral et de l'Atlantique pour un montant total de 1.880.000F CFA ${ }^{345}$.

Dans ce domaine, il est a noté que le Ministère de l'Environnement et de la Protection de la Nature, a été particulièrement opérationnel dans la lutte contre la pollution de l'air. En effet, suite à l'élaboration de la stratégie nationale de lutte contre la pollution atmosphérique ${ }^{346}$ au cours des années 2000, le gouvernement, à travers l'administration environnementale, a initié une action répressive, dénommée " mesure coercitive " contre les émissions de gaz provenant des véhicules à deux ou à quatre roues, particulièrement dans la ville de Cotonou où sévit une pollution de l'air sans précédent. Cette opération qui a duré cinq ans, a consisté à appliquer le principe pollueur payeur en verbalisant systématiquement tous les contrevenants dont les engins ont été déclarés pollueurs ${ }^{347}$. La base légale de cette opération est l'article 116 de la loi-cadre sur l'environnement qui fixe l'amende à payer entre dix (10) mille et cinquante (50) mille francs CFA et la loi de finance gestion 2002 qui en donne une clé de répartition comme suit : 10.000 francs CFA pour les véhicules à deux roues ( en particulier les taxis moto communément appelés "Zémidjan» sont les vrais auteurs de la pollution), 20.000 francs CFA pour les véhicules de tourisme, 25.000 francs FCFA pour les véhicules utilitaires et 35.000 francs CFA pour les gros porteurs. Dénommées écotaxes, ces amendes administratives sont perçues directement par les fonctionnaires du ministère chargé de l'environnement sur les voies publiques à l'aide de la force publique au près des pollueurs en cas de pollution dépassant la norme autorisée.

344 Elle est appliquée couramment par la police environnementale et les agents des eaux et forêts

345 Rapport d'activité 2009 de la Police Environnementale, DDEPN/MEPN, Cotonou, Bénin.

$346 \mathrm{MEHU}$, Stratégie nationale de lutte contre la pollution atmosphérique en République du Bénin, Cotonou, 2000.

347 L'Annexe III récapitule le niveau de pollution des véhicules à deux ou à quatre roues sur la période allant de 2002 à 2005. Source MEPN. 
Le commentaire qu'on pourrait faire de l'Annexe III est que sur la période allant de 2002 à 2005, la pollution de l'air au Bénin est préoccupante dans les grandes villes et dominée par les véhicules à deux roues (taxi moto ou «Zémidjan») dont le taux de pollution est nettement croissant dans la ville de Cotonou. Remarquons que l'opération se fait de façon inopinée, donc ce ne sont pas les mêmes véhicules qui sont inspectés. Les usagés des véhicules déclarés pollueurs sont orientés à leur frais vers les garagistes formés à cet effet au réglage des moteurs. Mais, dans la pratique, ces usagés ne le font pas et la pollution peut reprendre de plus belle malgré les mesures coercitives prises. En définitive, ces mesures n'ont pas eu un effet positif sur la pollution de l'air puisque tout au moins pendant cette période on aurait pu constater une amélioration de la qualité de l'air. Par la suite, des difficultés d'ordre civique (manifestation d'hostilité des usagers, l'incivisme, etc.) ont précipité le déclin de cette activité dite " phare » du ministère. Seulement, le succès d'une telle opération réside en ce qu'elle a permis au trésor public de gagner près de 100 millions de francs CFA de 2001 à 2005.

Quant aux agents forestiers et douaniers, à leurs différents postes de contrôle frontalier, ils verbalisent aussi chaque jours des " trafiquants environnementaux ${ }^{348}$.

De même au niveau communal, la police municipale s'inscrit aussi dans cette logique de verbalisation. Ainsi, au sujet de l'occupation anarchique du domaine public, tout occupant illégal du domaine public est « verbalisé avec payement d'une amende de 15.000Fà 25.000F CFA ou confiscation de ses biens installés sur le domaine ${ }^{349}$. Signalons que ces règlements administratifs, dans le respect de la hiérarchie des normes, doivent être conformes à la loi d'où ils tirent leur base légale au risque d'être déclaré illégal.

348 Commerçants ou individus qui font des trafics ou des ventes de produits illicites relevant du domaine forestier ou environnemental tels que les produits forestiers, les trophées d'animaux, certaines espèces rares d'animaux ou de végétaux ou de bois qui transitent par la frontière.

349 Voir arrêté municipal n026/MCOT/SG/DSEF/DST/RP du 31 mars 2004 portant réglementation de l'utilisation temporaire du domaine public local aux fins d'activités privées lucratives. 
En tout état de cause, l'amende, la confiscation des armes, engins ou véhicules objet du délit et les retraits ou suspensions de licences ou permis prononcés par les autorités administratives, sont en réalité des sanctions complémentaires administratives qui ne font pas obstacles aux sanctions juridictionnelles. II s'ensuit dès lors, le développement de sanctions alternatives tantôt administratives tantôt juridictionnelles.

\section{§II : Les sanctions alternatives}

Entendue au sens étroit, la peine alternative se définit comme " une peine qui est prévue dans une disposition de portée générale, en remplacement d'une peine principale ${ }^{3350}$. C'est dans cet ordre d'idée que la plupart des législations admettent que la constatation d'une infraction par procès-verbal n'implique pas que son auteur sera nécessairement déféré devant un tribunal ${ }^{351}$. En effet, à l'instar du droit pénal général, le droit pénal de l'environnement a développé des techniques qui empêchent, à l'égard du prévenu l'application des sanctions pénales classiques, notamment l'emprisonnement afin d'assurer une répression plus rapide " compte tenu de l'encombrement des tribunaux ${ }^{352}$ » et de la lourdeur de la procédure pénale. Ainsi, plutôt que de condamner les délinquants à des peines d'emprisonnement, le droit pénal de l'environnement recherche la cessation du trouble causé par l'infraction et la restauration du milieu naturel dégradé. La plus importante de ces techniques est la transaction à laquelle s'ajoute d'autres procédures alternatives telles que la prescription, la composition pénale, l'ajournement de peine et l'amende forfaitaire.

350 (F) DESPORTES et le GUNEHEC (F), cité par C. OUDRAOGO, RJE, avril 2000, p : 535.V. aussi Roselyne NERAC-CROISIER, Sauvegarde de l'environnement et droit pénal, op.,cit.,p.55.

351 D. GUIHAL, op. cit. p. 78 ; voir aussi les articles 76,77et 78 de la loi $n^{\circ} 005 / 97 / A D P$ portant code de l'environnement au Burkina Faso ; l'article 7 du CPP béninois. M. PRIEUR, op. cit. p.829. 


\section{A) Le recours de plus en plus fréquent à la transaction}

Retenons avec D. GUIHAL, que l'économie générale de la transaction pénale, peut être synthétisée dans les termes suivants de l'arrêt du Conseil d'Etat : " la transaction pénale, entre une autorité administrative habilitée à la conclure et une personne susceptible d'être poursuivie pour la commission d'une infraction pénale, résulte d'un accord qui détermine les suites à donner à la commission de cette infraction et, en particulier, les réparations en nature et en espèces que devra assurer l'intéressé ; cet accord doit être donné librement et de manière non équivoque par l'auteur des faits litigieux, éventuellement assisté de son avocat ; I'homologation de cet accord éteint l'action publique dès lors que les engagements ont été tenus $\|^{353}$. II s'ensuit que la transaction consiste donc, à rechercher un accord amiable avec l'auteur de l'infraction sur deux points, soit une amende transactionnelle, soit l'accomplissement d'une prestation en nature.

Ainsi, la transaction sur l'action publique, telle que prévue par le code de procédure pénale, longtemps demeurée cantonné dans le domaine des infractions impliquant les intérêts patrimoniaux de l'Etat (douane, fisc), apparaît aujourd'hui abondamment dans le domaine de l'environnement par le truchement de l'administration des eaux et forêts et chasse avant de s'étendre à d'autres secteurs.

L'administration forestière et faunique béninoise dispose d'un pouvoir de transaction dont la base légale est au cœur des articles 85 et 86 de la loi portant régime des forêts et des dispositions des articles 149 et 150 de la loi portant régime de la faune. D’une manière générale, les dispositions de l'article 108 de la loi-cadre viennent habiliter l'administration environnementale en précisant : « lorsque le cas est prévu par la loi et les règlements, les délits et les infractions en matière d'environnement peuvent faire l'objet de transaction avant ou pendant le jugement ". Au Sénégal, elle se conclue plutôt avant le jugement ${ }^{354}$,

353 D. GUIHAL Op.cit. P: 81.

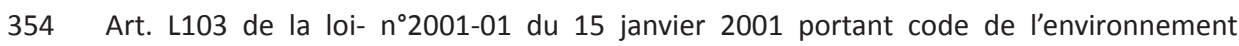
sénégalais. 
au Togo, elle intervient " avant ou après le jugement même devenu définitif ॥ $^{355}$. Il s'ensuit que la transaction peut se conclure en dehors de toute juridiction. Dans la pratique, c'est cette forme de transaction qui est plus fréquente.

Dans tous les cas, le procureur de la République au Bénin n'a pas d'influence sur l'acte transactionnel contrairement à ce qui se passe en France. II n'exerce aucun contrôle sur les transactions. II n'intervient qu'en cas de contentieux en relation avec le non respect des engagements pris par le prévenu. Mais en cas de respect desdits engagements dans les délais indiqués, " les poursuites judicaires sont abandonnées à l'encontre du prévenu. »356

Aux termes de ces dispositions prévues par le législateur béninois, le champ d'application de la transaction est bien vaste, puisqu'elle concerne " tous les délits et infractions en matière d'environnement ". On peut également en déduire qu'en droit béninois, la transaction a une base légale ou réglementaire alors qu'elle est strictement légale dans d'autres législations ${ }^{357}$ et que son champ d'application n'est pas limité comme dans la législation française (police de la pêche et police de l'eau) ${ }^{358}$ ou togolaise (flore, faune, pêche) ${ }^{359}$ ou encore hollandaise ${ }^{360}$ mais large comme au Burkina Faso puisque couvrant tout le domaine environnemental, aussi bien les crimes que les délits, pourvu qu'il soit

355 Art.52 du décret du 5/2 /1938 portant organisation du régime forestier du territoire du Togo et art.10 de l'ordonnance n)4 du 16/1/1968 réglementant la protection de la faune et l'exercice de la chasse au Togo. Cité par K. GBENOU, La sanction des atteintes à l'environnement en droit togolais. Mémoire, DEA, UL/Lomé, Togo 2005. Remarquons qu'elle est pourtant ignorée par le code togolais de l'environnement institué par la loi n88-054 du 3 novembre 1988.

356 Art.150 al.2 de la loi béninoise sur la faune précitée

357 Voir à cet effet, la législation française : article 6 CPP « ...lorsque la loi en dispose expressément ", Code de l'environnement. Voir les infractions relatives à la police de la pèche et à la police de l'eau et aux parcs nationaux) ; voir article L103 du code sénégalais de l'environnement.

358 Voir à ce sujet le rapport précité de la mission interministérielle sur le renforcement et la structuration des polices environnementales qui suggère l'abandon des projets d'extension du domaine de la transaction; cf. aussi D. GUIHAL, Op.cit. p. 86.

359 K. GBENOU, La sanction des atteintes à l'environnement en droit togolais, Mémoire de troisième cycle, DEA, UL,FDD, Lomé, 2005, p.49.

360 Au Pays Bas, elle est prévue par l'article 74 du code pénal. Elle intervient en cas de crime puni de 6 ans d'emprisonnement au plus et en cas de contravention. L'amende transactionnelle est évaluée en tenant compte des ressources du délinquant. 
prévu par un texte ${ }^{361}$. Par contre, la législation gabonaise se particularise, en considérant la transaction comme une peine complémentaire au même titre que la confiscation ou la suspension que pourrait prononcer l'administration ${ }^{362}$ en complément à une sanction classique ultérieurement prononcée par le juge. Se faisant, le législateur gabonais se montre très sévère et cette rigueur permet de mieux protéger l'environnement.

Dans la pratique au Bénin, en matière environnementale, seule l'administration des Eaux, Forêts et Chasse, utilise abondamment cette technique. Ainsi, les termes de la transaction sont généralement proposés par l'agent verbalisateur assermenté et soumis au Directeur des Eaux Forêts, et Chasse ou son représentant qui après étude et certification, renvoie l'offre de transaction à l'agent pour exécution et ce, sans consultation préalable du procureur de la République. Si l'offre est acceptée et effectivement accomplie par l'infracteur, la voie pénale sera alors définitivement abandonnée ${ }^{363}$ et toute poursuite pour les mêmes faits est désormais impossible même sous une qualification différente. Cette extinction de l'action publique, ouvre la voie à l'application de la règle " non bis in idem ». Dans ce cas, un récépissé correspondant au montant versé lui est délivré pour servir et valoir ce que de droit. Ce montant qui est discrétionnairement déterminé par l'administration, est généralement compris entre le minima et le maxima de la peine pécuniaire légale. Comme en Belgique, elle n'est pas prononcée par le juge mais sanctionnée par un acte administratif.

Dans plusieurs systèmes juridiques, on note que le recours à la transaction est systématique et s'impose au délinquant qui n'a pas d'autre choix que d'aller au procès. C'est cette puissance de l'administration qui est exposée en ces termes « dans la procédure transactionnelle, le choix du recours

361 C. OUEDRAOGO, Les sanctions alternatives et complémentaires aux peines classiques en droit de l'environnement : étude comparative (France et Burkina Faso), article, RJE, 4/2000 : Art.76 du code l'environnement ; art.253 du code forestier.

362 Loi n00016101 portant code forestier en République gabonaise, art 281 dispose assez clairement que "Sans préjudice des dispositions des articles $273 a ̀ 280$....toute infraction commise en matière de chasse ou de foret peut donner lieu, selon le cas et, dans les conditions fixées par voie réglementaire à (...)- la confiscation de produits fauniques au forestiers ou au paiement par transaction d'une pénalité égale à leur valeur s'ils n'ont pas être saisis (...) ".

C. OUEDRAOGO, op, cit. 
à la transaction, la détermination du montant de l'amende transactionnelle, la définition des travaux imposés au contrevenant pour faire cesser l'infraction ou éviter son renouvellement et la fixation du délai ${ }^{364}$ d'accomplissement des obligations transactionnelles appartiennent à l'administration ${ }^{365}$. En revanche, les décisions prises en la matière " sont regardées par la jurisprudence comme détachables de la procédure judiciaire et susceptibles d'un recours pour excès de pouvoir» ${ }^{366}$.

Par ailleurs, si le prévenu refuse la solution transactionnelle, son procèsverbal est transmis au procureur de la République qui pourra alors mettre en mouvement l'action publique. Mais, à ce stade, il n'est pas exclu que le prévenu et l'administration transigent ${ }^{367}$. En cas de succès des négociations, le tribunal informé par l'administration, arrête les poursuites. S'il était déjà saisi, et le dossier en instruction, il ne peut le faire que par une décision de justice. Tel fût le cas, de l'un des rares exemples dans le jugement n 46/77 du 19 janvier1977 de la chambre correctionnelle du tribunal de première instance d'Abomey :

« Attendu que le prévenu A. L. s'est rendu coupable d'avoir à Sinhoué Légo (Abomey) le 29 mai 1975...abattu sans autorisation administrative 34 palmiers à huile.

Attendu que ces faits constituent le délit prévu et puni par les articles 21 et 57 du décret du 4 juillet 1935 .

Attendu que le délinquant a transigé en nature dans le périmètre de reboisement des Eaux , Forêts et Chasse d'Abomey pendant le mois de mars à avril 1976 ainsi qu'en fait foi la lettre n 4318/IFMS du 9 novembre 1976 ; qu'il échet de déclarer l'action publique éteinte par transaction ${ }^{368}$.

La transaction par nature consiste, pour le prévenu, à s'acquitter de la peine en exécutant sous le contrôle de l'administration forestière, des

\footnotetext{
364 F. ROGGENS, La répression des infractions contre l'environnement. Dans cet article, par exemple, II est de huit jours au Pays Bas, de 8 jours au moins et de 3 mois au plus en Belgique et selon C. OUEDRAOGO II est « d'un mois au Burkina Faso ».

365 D. GUIHAL, Op.cit. p. 81

366 Idem

367 Cf. art. 108 de la loi cadre précité.

368 Cité par G.SOGLO, op, cit, p. 40
} 
" travaux d'intérêt forestier " consistant à l'enrichissement, au reboisement, à la réalisation de pépinières, d'ouverture de pistes ou de conservation de sols. Dans ce cas la valeur compensatoire est calculée sur la base du taux salarial quotidien ou mensuel en vigueur ${ }^{369}$. La transaction par nature s'assimile ainsi au " travail d'intérêt général » ou " d'intérêt commun » prévue respectivement par les législations française ${ }^{370}$ et burkinabé ${ }^{371}$.

Enfin, des arguments militent en faveur de la procédure transactionnelle. Il en est ainsi de Françoise ROGGENS, Avocate à l'Université Libre de Bruxelles, qui soutient qu'en matière environnementale, la procédure transactionnelle s'y prête ${ }^{372}$. De plus, cette procédure laisse présumer que chacun y trouve son compte. Pour les agents forestiers, l'intérêt est évident puisque la loi leur accorde $20 \%$ du produit des transactions et les $80 \%$ vont au trésor public ${ }^{373}$. Pour le délinquant présumé, c'est l'assurance que l'acte ne sera pas porté à la connaissance du public dans la mesure où la publicité de l'audience pénale n'est pas toujours vécue comme une garantie mais comme une sanction et la peine complémentaire de publicité ne pourra pas être appliquée ${ }^{374}$. Mais, l'on pourrait argumenter aussi en soutenant la disponibilité de l'argent frais permettant de faire face aux préjudices, la rapidité dans la répression de l'infraction, dans la mesure où la procédure pénale étant couteuse, longue et désastreuse pour la victime enfin la volonté d'une politique pénale de désengorger les prisons

369 Art.89 du décret $n^{\circ} 96-271$ du 2 juillet 1996 portant modalité d’application de la loi-n93-009 du 2 juillet 1993

370 Art.131-8 et 131-22 à 131-24 du Code Pén.

371 Art.262 du code forestier où il est stipuler que « dans un but éducatif et en tenant compte des circonstances de l'espèce, le tribunal peut remplacer les sanctions prévues à l'article précédent par un travail d'intérêt commun.

372 La répression des infractions contre l'environnement, article, In, L'actualité du droit de l'environnement, Actes du colloque des 17 et 18 novembre 1994, Bruylant Bruxelles.

373 Art.108 de la loi portant régime des forêts en République du Bénin. V. aussi l'article 90 du décret d'application de ladite loi qui répartit comme suit les $20 \%$ : indicateur agent forestier ou non $35 \%$, constatateur $25 \%$, verbalisateur $15 \%$, poursuiveur $15 \%$ et contentieux $10 \%$. Dans la pratique par exemple à la Direction du Parc National de la Pendjari, après chaque versement d'une amende transactionnelle, le chargé des finances de la Direction établit un état de paiement au profit des bénéficiaires qui perçoivent conformément à la clé de répartition leurs primes.

374 Brigitte le PAGE, Transaction pénale pour pollution de cours d'eau, in, Revue de Droit Rural, n²15 août-septembre 1993, cite par A. SOGLO, op, cit, p. 40. 
déjà surpeuplées constitue un élément non négligeable. Néanmoins, cet intéressement, s'il a pour but de mettre " théoriquement » les agents poursuivants à l'abri de la corruption, a surtout comme inconvénient l'accroissement de cette procédure exceptionnelle au détriment de la voie judicaire.

Ainsi, en dehors des atouts certains de cette procédure, quelques inconvénients de cette pratique méritent d'être relevés. D’abord par ce mécanisme, " ce qui était une affaire pénale susceptible d'être réglée sur la place publique, devient une affaire purement interne à l'administration ${ }^{375}$, puisque sa conclusion échappe au juge, ce qui parfois ouvre la voie au laxisme et à l'injustice à l'égard du justiciable. Même en cours d'instruction ou de jugement du dossier, il y a possibilité de transiger. Ce qui porte énormément préjudice au prérogative du juge pénal qui peut se trouver ainsi dessaisi par l'administration. Cet empiétement de l'administratif sur le judiciaire, pose non seulement le problème de l'indépendance du juge, mais aussi du rôle réel du droit pénal de l'environnement dans le règlement des contentieux. Ensuite rares sont les textes qui imposent comme conditions préalables à la transaction, la cessation de l'infraction et la remise en état. Cette condition est d'ailleurs inexistante dans les textes prévoyant la transaction. Enfin, les droits des victimes ne sont pas toujours bien protégés, les textes étant muets sur leur sort.

Mais, malgré ces inconvénients, le recours à ce mécanisme de règlement des litiges est de plus en plus abondant. En France par exemple, selon les statistiques, du ministère de l'environnement, $74,63 \%$ des décisions rendues en 1991 pour la pollution des cours d'eau étaient des transactions ${ }^{376}$. De même au Bénin, la procédure transactionnelle est de loin préférée au procès pénal, dans les mêmes proportions presque, seulement sans l'intervention du juge. Même si les délinquants sont parfois insolvables, ils pourront opter pour les prestations en nature (les agents forestiers ne préfèrent pas les transactions sous cette forme puisqu'elles ne sont pas rentables pour eux).

Le défaut de statistiques de l'administration environnementale ne nous permet pas d'avoir des informations précises, mais quelques données croisées des rapports saisonniers de la Direction du Parc National de la Pendjari

375 De ROETS, cité par C. OUEDRAOGO, op. cit. p : 548

376 C. OUEDRAOGO, op, cit. p: 548 
à Tanguiéta, nous donnent des résultats édifiants quant à l'utilisation de cette technique répressive ${ }^{377}$. A l'examen desdits tableaux, notamment du Tableau $\mathrm{n}^{\circ} 4$, sur une période de trois saisons touristiques, un faible taux des PV de constatations des infractions qui parviennent au procureur de la République. A l'examen du Tableau $n^{\circ} 4$, la question que l'on pourrait se poser est de savoir : où sont passés les 104 procès-verbaux de constatations des infractions après déduction avec le nombre totale des infractions? Nul doute que ces infractions régulièrement constatées ont fait l'objet de transaction avec les prévenus. C'est donc cela qui explique le taux très faible des décisions de justice rendues par les tribunaux de fragrance délit. La conséquence d'une telle situation est que prés de $70 \%$ des infractions constatées sont concernées par des transactions. Notons pourtant qu'il y a quelques rares cas de prévenus étrangers qui font objet de transfèrement dans leur pays ${ }^{378}$. Par ailleurs, on note à la lecture du Tableau $n^{\circ} 5$, un accroissement progressif du montant des amendes transactionnelles. Ce qui dénote de la fréquence de cet outil de sanction. Les réelles motivations de l'administration forestière à recourir à cette procédure, s'expliquent plus par des raisons financières qu'écologiques ; les administrations concernées ayant besoin des ressources financières pour leur unité de production et pour améliorer leurs conditions de travail. Mieux, on ne voit pas directement ce à quoi servent concrètement les produits issus des transactions en terme de préservation des ressources naturelles. L'on sait simplement que les $80 \%$ des produits des amendes vont au trésor public.

377 Cf. Tableaux : $n^{\circ} 3, n^{\circ} 4$ et $n^{\circ} 5, p p .132,133,134$ et 135

378 Ce fût notamment les cas des prévenus Lompo ANHADI, YONLI Souguilidioa et OUOBA Yemboani, poursuivi pour circulation et introduction illégale d'espèces animales domestiques (pintades et canards) dans le parc national de la Pendjari, objet du PV $\mathrm{N}^{\circ}$ 002/2008/SSA/DPNP du 30/01/08, transférés au Burkina Faso le 30/1/08; du sieur YOUMANI Salifou, poursuivi pour délit illégal de pêche dans le parc national de la Pendjari , objet du PV N³0/2008/SSA/DPNP du 18/02/08. 
Tableau $\mathbf{N}^{\circ} \mathbf{3}$ : Point des infractions et condamnations liées aux délits constatés dans la réserve de la biosphère de la Pendjari au titre des années touristique 2006 à 2009

- Période du $1^{\mathrm{er}}$ juin 2006 au 30 juin 2007

- $\quad$ Point des infractions

\begin{tabular}{lccccc}
\hline Type d'infraction & Batia & Porga & Arly & Konkombri & TOTAL \\
\hline Braconnage & 4 & 28 & - & - & 32 \\
Transhumance & 1 & 5 & - & 8 & 14 \\
Pêche frauduleuse & 4 & 13 & - & 1 & 18 \\
Autres & - & - & - & - & - \\
TOTAL & $\mathbf{9}$ & $\mathbf{4 6}$ & - & $\mathbf{9}$ & $\mathbf{6 4}$ \\
\hline
\end{tabular}

- Point financier des infractions

\begin{tabular}{lccccc}
\hline $\begin{array}{l}\text { Type } \\
\text { d'infraction }\end{array}$ & Nombre & $\begin{array}{c}\text { Montant } \\
\text { brut }\end{array}$ & $\begin{array}{c}\text { Retenue de 20\% } \\
\text { payé }\end{array}$ & $\begin{array}{c}\text { Montant } \\
\text { net } \\
\text { encaissé }\end{array}$ & $\begin{array}{c}\text { Observa } \\
\text { tions }\end{array}$ \\
\hline Braconnage & - & - & - & - & \\
Transhumance & 04 & 205000 & 41000 & 164000 & \\
$\begin{array}{l}\text { Pêche } \\
\text { frauduleuse }\end{array}$ & 05 & 330000 & 66000 & 264000 & \\
Autres & - & - & & - & - \\
TOTAL & $\mathbf{0 9}$ & $\mathbf{5 3 5 . 0 0 0}$ & $\mathbf{1 0 7 . 0 0 0}$ & $\mathbf{4 2 8 . 0 0 0}$ & \\
\hline
\end{tabular}

- Décisions de justice rendues

\begin{tabular}{lcc}
\hline Type de sanction & Nombre & Observations \\
\hline Contrainte par corps & - & \\
Emprisonnement ferme & 29 \\
Emprisonnement assorti de sursis et amende & 05 \\
Amende & - \\
Réparation dommages et intérêts & - \\
Relaxé pour insuffisance de charges & 01 \\
Total : & $\mathbf{3 5}$ \\
\hline
\end{tabular}


- Période de $1^{\text {er }}$ juillet 2007 au 30 juin 2008

- Point des infractions

\begin{tabular}{lccccc}
\hline Type d'infraction & Batia & Porga & Arly & Konkombri & TOTAL \\
\hline Braconnage & & 6 & 4 & & 11 \\
Transhumance & & 4 & 1 & 6 & 11 \\
Pêche frauduleuse & & 17 & 4 & & 21 \\
Autres & & & & & \\
TOTAL & $\mathbf{1}$ & $\mathbf{2 7}$ & $\mathbf{9}$ & $\mathbf{6}$ & $\mathbf{4 3}$ \\
\hline
\end{tabular}

- Décisions de justice rendues

\begin{tabular}{lcc}
\hline Type de sanction & Nombre & Observations \\
\hline Contrainte par corps & - & \\
Emprisonnement ferme & - \\
Emprisonnement assorti de sursis et amende & - \\
Amende & - \\
Réparation dommages et intérêts & - \\
Relaxé pour preuve insuffisante & $\mathbf{0 7}$ \\
TOTAL & \\
\hline
\end{tabular}

- Période de $1^{\text {er }}$ juillet 2008 au 30 juin 2009

- Point des Infractions

\begin{tabular}{lccccc}
\hline Type d'infraction & Batia & Porga & Arly & Konkombri & TOTAL \\
\hline Braconnage & 7 & 7 & - & 2 & 16 \\
Transhumance & 2 & 7 & - & 1 & 10 \\
Pêche frauduleuse & - & 19 & - & 1 & 20 \\
Autres & - & 1 & - & - & 1 \\
TOTAL & $\mathbf{9}$ & $\mathbf{3 4}$ & - & $\mathbf{4}$ & $\mathbf{4 7}$ \\
\hline
\end{tabular}

- Point financier des infractions

\begin{tabular}{|c|c|c|c|c|c|}
\hline $\begin{array}{l}\text { Type } \\
\text { d'infraction }\end{array}$ & Nombre & $\begin{array}{c}\text { Montant } \\
\text { brut }\end{array}$ & $\begin{array}{l}\text { Retenue de } \\
20 \% \text { payé }\end{array}$ & $\begin{array}{c}\text { Montant } \\
\text { net encaissé }\end{array}$ & Observations \\
\hline Braconnage & 04 & 400000 & 80000 & 320000 & \\
\hline Transhumance & 07 & 550000 & 110000 & 440000 & \\
\hline Pêche frauduleuse & 12 & 885000 & 177000 & 708000 & \\
\hline \multicolumn{6}{|l|}{ Autres } \\
\hline TOTAL & 23 & 1835000 & 367000 & 1468000 & \\
\hline
\end{tabular}


- Décisions de justice rendues

\begin{tabular}{lcc}
\hline \multicolumn{1}{c}{ Type de sanction } & Nombre & Observations \\
\hline Contrainte par corps & - \\
Emprisonnement ferme & 2 \\
Emprisonnement assorti de sursis et amende & 6 \\
Amende & - \\
Réparation dommages et intérêts & - \\
Relaxé pour preuve insuffisante & - \\
Total : & $\mathbf{8}$ \\
\hline
\end{tabular}

Tableau $N^{\circ} 4$ : point récapitulatif des décisions rendues par rapport aux infractions constatées au cours de la saison touristique et cynégétique 2006 à 2009

\begin{tabular}{lllll}
\hline Année & $\begin{array}{c}\text { Nombre } \\
\text { d'infractions } \\
\text { constatées }\end{array}$ & $\begin{array}{c}\text { Nombre de décisions } \\
\text { de justice }\end{array}$ & Taux & Observations \\
\hline $\mathbf{0 6 - 0 7}$ & 64 & 35 & 22,4 & \\
$\mathbf{0 7 - 0 8}$ & 43 & 07 & 2,91 & \\
$\mathbf{0 8 - 0 9}$ & 47 & 08 & 3,76 & \\
Total & 154 & 50 & 29,07 & $\begin{array}{l}\text { La différence soit 104 } \\
\text { infractions ou PV de } \\
\text { constatations } \\
\text { d'infraction échappent } \\
\text { à la justice sur un } \\
\text { total de 204 }\end{array}$ \\
\hline
\end{tabular}

Tableau $\mathbf{N}^{\circ} 5$ : Récapitulatif des recettes issues des transactions au cours de la saison touristique et cynégétique 2006 à 2009.

\begin{tabular}{ccl}
\hline Années & $\begin{array}{c}\text { Montant net des transactions } \\
\text { (en francs CFA) }\end{array}$ & \multicolumn{1}{c}{ Observation } \\
\hline $2006-2007$ & 428.000 & Le montant total représente le \\
$2007-2008$ & 912.000 & net, après déduction des 20\% qui \\
$2008-2009$ & 1.468 .000 & reviennent aux agents forestiers sinon \\
Total & 2.808 .000 & le brut est de 3.369.600. \\
\hline
\end{tabular}

Source : Rapports annuels des saisons touristiques de la DPNP (Natitingou Bénin, 2010). 


\section{B) Les autres mesures alternatives aux sanctions classiques}

En dehors de la transaction, plusieurs législations admettent la possibilité d'éviter une condamnation à une peine classique par le tribunal qui peut opter pour un classement sous condition, la composante pénale, l'ajournement de la peine, la médiation pénale, le travail d'intérêt général ${ }^{379}$. La différence que l'on pourrait observer entre l'amende transactionnelle et ces mesures voisines, réside dans le fait que ces dernières sont accordées au prévenu sous l'autorité judiciaire.

\section{1) Le classement sous condition}

Le classement sous condition, une technique purement prétorienne prévue par l'article 41-1 du CPP ${ }^{380}$ qui permet au procureur de la République " préalablement à sa décision sur l'action publique (...) et avec l'accord des parties, de recourir à une médiation s'il lui apparait qu'une telle mesure est susceptible d'assurer la réparation du dommage causé à la victime, de mettre fin au trouble résultant de l'infraction et de contribuer au reclassement de l'auteur de l'infraction ». Elle suspend la prescription de l'action publique. Ainsi, en contrepartie des obligations accepter par le délinquant, le procureur de la République classe l'affaire sans suite. Mais, ceci n'engage que lui-même et les victimes qui ont conclu avec l'auteur de l'infraction une transaction civile. L'action publique n'étant pas éteinte, elle peut être mise en mouvement par une victime malencontreusement oubliée. Or en matière environnementale, il est malaisé de déterminer les victimes potentielles, notamment associatives ${ }^{381}$.

379 Cette technique s'assimile à la transaction par nature.

380 CPP français ; Lire également la loi du 9 mars 2004.

381 D. GUIHAL, op. cit, p: 78. 


\section{2) L'ajournement de la peine,}

En matière correctionnelle, après avoir déclaré le prévenu coupable, la juridiction peut prononcer soit la dispense soit l'ajournement de la peine ${ }^{382}$. Cette mesure est assortie d'une triple condition à savoir que tout d'abord: le reclassement du coupable est en voie d'être acquis; ensuite le dommage causé par l'infraction est en voie d'être réparée et enfin, le trouble causé par $I^{\prime}$ infraction est en voie de cessation ${ }^{383}$. Cependant, même lorsque ces conditions sont réunies, l'ajournement n'est que facultatif. Cette peine rejoint celle de mise en état dans la mesure où « la juridiction qui reconnaît la culpabilité d'un prévenu est autorisé à ajourner le prononcé de la peine en lui prescrivant de remettre en état les lieux dégradés, le cas échéant sous astreinte ${ }^{384}$. La peine ne sera effectivement infligée au délinquant que s'il n'exécute pas l'injonction dans le délai fixé. Pour certains auteurs cette mesure présente davantage une garantie d'efficacité, car en effet, " la crainte d'une sanction encore indéterminée et l'espoir d'une dispense de peine sont de puissants moyens de pression sur le prévenu auxquels peut s'ajouter la menace d'une astreinte ${ }^{385}$.

Prévue par le code pénal, ${ }^{386}$ cette mesure en vigueur en France, n'est pas encore applicable au Bénin ni au Burkina Faso ${ }^{387}$.

\section{3) La médiation pénale et la composition pénale}

La médiation pénale, ou placement conditionnel, consiste pour le parquet à suggérer à l'auteur de l'infraction diverses mesures destinées à éviter qu'elle se renouvelle et à indemniser les victimes, après quoi, l'affaire est classée

385 D. GUIHAL, Répression et réparation des atteintes à l'environnement, Gaz, Palais. Doct., p.123 et s. spéc. p.124. Cité par C. OUEDRAOGO.

386 Art. 132-58 CP français et suivants

387 Aucun texte ne le prévoit. Par contre en France il est prévu par les articles L571-25 du code de l'environnement relative à la lutte contre le bruit ; L216-9 relative à la protection de l'eau ; L514-9 relative aux installations classées 
sans suite. Mais cela n'éteint pas l'action publique : une association qui n'aurait pas été associée à ce processus pourrait encore saisir ultérieurement le tribunal correctionnel. C'est une procédure qui se confond au classement sous condition. Elle ne s'applique pas en droit de l'environnement en l'état actuel du droit positif français. ${ }^{388}$ C'est également le cas au Bénin.

Quant à la composition pénale, elle est applicable à tous les délits punis d'une peine classique n'excédant pas 5 ans et aux contraventions. Le procureur de la République peut proposer à une personne physique qui reconnaît les faits : une amende de composition dans la limite du maximum encourue, le dessaisissement au profit de l'Etat de la chose qui a servi ou était destiné à commettre l'infraction, ou qui en est le produit, le retrait du permis, l'accomplissement d'un travail d'intérêt public. Au cas où le prévenu ne remplit pas ses obligations, le procureur met en mouvement l'action publique, sauf fait nouveau ${ }^{389}$.

Remarquons que bien que certains auteurs voient dans ces procédures des solutions particulièrement adaptées au droit de l'environnement où les infractions ont un caractère technique et une faible charge morale, aucune de ces mesures précitées n'est applicable encore au Bénin. Elles ne sont pas prévues expressément par le législateur béninois. Cependant, pour certains auteurs comme D. GUIHAL, ces méthodes suscitent des réserves dans le domaine de I'environnement ${ }^{390}$.

Par ailleurs, la prescription de l'action publique par l'écoulement d'un certain délaij ${ }^{391}$, la mort du prévenu, l'abrogation de la loi, la chose jugée, l'amnistie, le retrait de la plainte ${ }^{392}$ sont également les moyens d'extinction de l'action publique que prévoit le législateur. La prescription de l'action publique suppose par exemple que l'auteur de l'infraction ne peut être poursuivi si

388 Cf. Mieux maitriser le risque pénal en matière d'environnement, Rapport, Chambre de Commerce et d'Industrie de Paris, mars 2002.

389 D. GUIHAL, Op.cit. p. 79

390 Op. cit. p: 79

391 En droit béninois, elle est de 3ans pour les délits, 1 an pour les contraventions et 10 ans. Cf. art. 8 CPP béninois. V. aussi art.83 de la loi portant régime de faune précitée.

392 Art.7 du code de procédure pénale béninois et art.6 CPP français. 
l'inaction de la société se prolonge au-delà d'un certain temps ${ }^{393}$. Elle est d'ordre public. Le prévenu peut l'invoquer à tous les niveaux de jugement ${ }^{394}$.

L'hypothèse du décès du prévenu n'appelle normalement aucun commentaire. C'est une cause d'extinction à caractère personnel dont ne peuvent bénéficier ni coauteurs ni complices ${ }^{395}$.

En ce qui concerne l'abrogation de loi pénale, retenons que c'est " l'anéantissement pour l'avenir d'une mesure législative ou réglementaire par un acte explicitement ou implicitement contraire ${ }^{396}$ ». Ainsi, une loi abrogée sort de l'arsenal juridique, donc du droit positif de sorte qu'une incrimination qui découle d'une telle loi ne saurait s'appliquer à un prévenu. Cependant, il conviendrait de nuancer cette analyse d'autant plus qu'il peut arriver que le prévenu soit sous l'emprise de deux lois en conflit dans le temps. C'est le cas par exemple lorsque le prévenu commet une infraction sous l'empire d'une première loi ; ce peut être l'interdiction d'introduction de déchets dans un pays puis quelques mois ou quelques années plus tard, cette interdiction est levée par une nouvelle loi pour des raisons particulières. Dans un tel cas d'espèce, le prévenu est poursuivi toujours et peut être condamné du chef de l'ancienne loi abrogée, qui demeure applicable en l'espèce au moment des faits.

Enfin, ces dernières mesures alternatives aux sanctions pénales précitées, sont d'application en droit commun. Elles s'accommodent aussi bien au droit pénal de l'environnement. Elles sont au regard de celles précitées plus haut, qui relèvent de l'appréciation du juge, généralement d'application d'ordre public puisqu'elles s'imposent au juge.

L'analyse du cadre juridique et institutionnel de mise en œuvre des stratégies et politiques environnementales, que nous venons de faire, nous renseigne que le tissu répressif béninois, quoique quelque peu pertinent, avec des dispositions législatives et réglementaires assez contraignantes, est encore au stade embryonnaire. La construction d'un droit pénal de l'environnement est une œuvre de longue haleine. Puisque le simple fait de l'existence de

393 J.C. SOYER, op.cit., p.280

394 Idem, p. 282

395 D. GUIHAL, Op.cit. p. 88

396 Lexique de termes juridiques, op. cit. $p: 1$ 
telles dispositions pénales écologiques, ne suffit pas pour se convaincre de l'existence d'un droit pénal de l'environnement réellement fonctionnel. Le droit pénal béninois s'inscrit certes, dans la perspective d'actions soutenues et cohérentes en vue d'endiguer les atteintes à l'environnement mais, le dispositif environnemental qui sous-tend sa mise en œuvre, nous apparait insuffisant, ineffectif voire même difficile d'application. 


\section{TITRE II : UN DISPOSITIF ENVIRONNEMENTAL REPRESSIF INEFFECTIF, INSUFFISANT ET PEU PERFORMANT}

Le droit pénal de l'environnement béninois, à l'étape actuelle de son évolution, comme nous l'avons dit est en plein développement. Au regard des principes qui gouvernent l'application du droit pénal spécial de l'environnement, nous examinerons dans quelle mesure le régime répressif en vigueur au Bénin peut contribuer à la sauvegarde de l'environnement. Il conviendrait dès lors de l'apprécier, d'une part, du point de vue de son cadre législatif et réglementaire (Chapitre III) et d'autre part du point de vue de l'effectivité des sanctions pénales (Chapitre IV).

\section{CHAPITRE III : UN ARSENAL REPRESSIF PEU PERFORMANT}

À l'analyse, le système répressif béninois de la responsabilité pénale en matière environnementale, est encore jeune mais assez significative. Afin de mieux apprécier sa performance, nous analyserons successivement le cadre normatif et institutionnel (Section I) et l'accès du justiciable à la justice (Section II). 


\section{SECTION I : LE CADRE NORMATIF PENAL}

L'état des lieux de la législation environnementale tel que décrit plus haut dans les chapitres précédents, révèle à n'en point douter une multitude de textes législatifs et réglementaires. Déjà en 1992, une étude ${ }^{397}$ relative à I'inventaire de la législation béninoise environnementale, avait répertoriée près de 500 textes $^{398}$ organisés autour de 17 centres d'intérêts dont la majorité est obsolète et désuète ${ }^{399}$. Au regard de cette production législative éparpillée dans presque tous les secteurs et la multitude d'infractions qui en découlent, peut-on réellement parler " d'inflation législative» ou " d'inflaction pénale ${ }^{400}$ " comme l'avocate Françoise ROGGEN qualifie les textes pénaux belge? Dans le cas du Bénin, cette conclusion serait hâtive car elle doit être nuancée.

Si la simple existence des normes réglementaires et législatives, comme nous l'avions précisé, constitue déjà en soi un atout important du fait de leur caractère dissuasif, car « la vocation du droit n'est pas d'être totalement appliqué mais de tenir à sa fonction symbolique et d'apaisement de l'opinion publique par

397 S. ADOKPO \& T. FANOU, Consultation sur l'inventaire et analyse de la législation environnementale au Bénin. Juin -aout 1992, ABE, Cotonou.

398 C'est encore rien à coté de la production législative et réglementaire française. Puisque dans la même période, précisément en 1992, la section du rapport et des études du Conseil d'Etat français, en France a recensé 7500 lois, 82.000 décrets et 20.000 règlements communautaires applicables. Cité par J.F. NEURAY, Principes de droit de l'environnement, KLUWER, EDITION Juridiques, Belgique et Story-Scientia, 1995, p.3.

399 II s'agit des secteurs ci-après : énergie et industrie, explosif, faune, flore, gestion du littoral et exploitation portuaire, gestion des ressources en eau, gestion du sol, hygiène alimentaire, hygiène santé et salubrité publique et assainissement, mer, mines et carrières, pèche, police sanitaire, pollution du milieu marin, secours en cas de sinistre, substances vénéneuses et produits dangereux, transhumance et vaine pâture.

400 F. ROGGEN, La répression des infractions contre l'environnement, article, in l'Actualité du droit de l'environnement. Actes du Colloque, Bruylant Bruxelles, novembre 1994. V. D. ROETS, Les sanctions pénales du droit de l'environnement sont-telles utiles ? , in, Revue de Droit Rural n² 205 aout-septembre 1992 p : 324. V. aussi (J) PRADEL, Droit pénal général, 16ème édition CUJAS, 2006, Paris, p.107, 108. 
sa seule existence ${ }^{401} »$; force est de constater que le système répressif béninois quoique apparemment abondant est non seulement insuffisant, incomplet et vétuste (§ I) mais aussi éparpillé et sans cohésion (§ II)

\section{$\S$ I : Le caractère insuffisant et vétuste des textes pénaux}

L'inexistence ou l'insuffisance de réglementation dans certains domaines sensibles et la vétusté des textes qui ne sont pas en harmonie ni avec les réalités du pays, ni avec l'évolution du droit pénal général, constituent l'un des points faibles de la législation environnementale béninoise.

\section{A) Le caractère insuffisant ou incomplet des textes répressifs}

Le droit de l'environnement est un droit qui embrasse tous les domaines de la vie active. Ce qui nécessite la réglementation de plusieurs secteurs d'activités, lesquels se multiplient davantage au regard du développement technologique et scientifique. Une telle réglementation favorise une application aisée du principe de la légalité criminelle. Rappelons que du point de vue psychologique, l'argument qui sous-tend ce principe est que la loi avertisse avant de frapper afin que le citoyen sache, avant d'agir, ce qui est interdit et puni. En conséquence, en cas de carence de texte législatif ou réglementaire, il ne saurait $y$ avoir d'infraction ni de peine.

En effet, nonobstant les textes juridiques précités dans le domaine environnemental, on observe une carence législative et réglementaire voire un vide juridique dans certains secteurs très sensibles. Et pour cause, plusieurs secteurs échappent encore au législateur béninois. Ainsi, l'analyse de la loi-cadre sur l'environnement au Bénin, principal texte répressif utilise abondamment la «technique de renvoi» pour son application effective. II s'agit de la prise

401 V. Y. AMEGANKPOE \& K. AVODE (sous la direction de M. PACQUES et de M. FAURE), La force contraignante et le degré d'efficacité variable du droit international matériel et de ses principes naissants. Intensité de la règle selon les acteurs. Les sanctions non juridictionnelles cas de l'Afrique, article, in, La protection de l'environnement au cœur du système juridique international et du droit interne, acteurs, valeurs et efficacité, 2001. 
de textes complémentaires par l'exécutif. Précieux outil répressif, cette loi, entrée en vigueur en 1999, présente par endroits des dispositions directement applicables mais elle appelle aussi, la prise de près de 25 textes d'application ${ }^{402}$ nécessaires pour son application efficiente. Un effort plus ou moins important a été fait pour produire près de 16 décrets $\mathrm{i}^{403}$. II reste donc près d'une dizaine de décrets à prendre ainsi que plusieurs arrêtés. Afin d'apprécier l'efficacité et la performance de la loi-cadre, une réglementation de tous les secteurs visés nous parait nécessaire. Or, plus de dix ans après, pas de projet de décret en instance. Aussi, pour une bonne application desdits décrets, renvoient- ils à la prise d'arrêtés dont l'objectif est de clarifier, d'expliciter et de rendre opérationnel ou fonctionnel les décrets en donnant plus de détails. Mais, force est de constater que pour la plupart de ces textes, les arrêtés d'application ne sont pas pris. ${ }^{404}$

Le tableau ci-dessous renseigne davantage sur les réalisations du législateur et sur ce qui lui reste à faire en matière de législation environnementale au regard de la loi-cadre sur l'environnement au Bénin.

402 La loi camerounaise du 19 janvier 1994 et les décrets de 1994 et de 1995 relatifs, respectivement, aux régimes des forêts et de la faune, prévoit quant à eux 137 renvois à des textes d'application, dont plus des trois quarts restent attendus à ce jour. A ce sujet, les Députés camerounais se sont émus, " déplorant les nombreux renvois aux décrets d'application ", et ont émis le vœu " qu'il y est à l'avenir moins de références aux textes réglementaires». V. Samuel NGUIFFO, Les difficultés de l'encadrement juridique de la durabilité : le nouveau régime des forets en Afrique centrale, in, Aspect contemporains du droit de l'environnement en Afrique de l'Ouest et centrale, (coord), Laurent GRANIER, UICN, Gland, 2008, Suisse, p.96.

403 Cf bibliographie pour la liste des principaux textes réglementaires.

Contre cinq décrets et plusieurs arrêtés d'application pris en application du code Burkinabé de l'environnement.

404 C'est le cas par exemple du décret $n^{\circ} 2003-332$ du 27 aout 2003 portant gestion des déchets solides en République du Bénin ; du décret n²003-330 du 27 aout 2003 portant gestion des huiles usagées en République du Bénin ; du décret n²002-484 du 15 novembre 2002 portant gestion rationnelle des déchets biomédicaux en République du Bénin, pour ne citer que ces textes pris en application de la loi-cadre sur l'environnement du Bénin. 


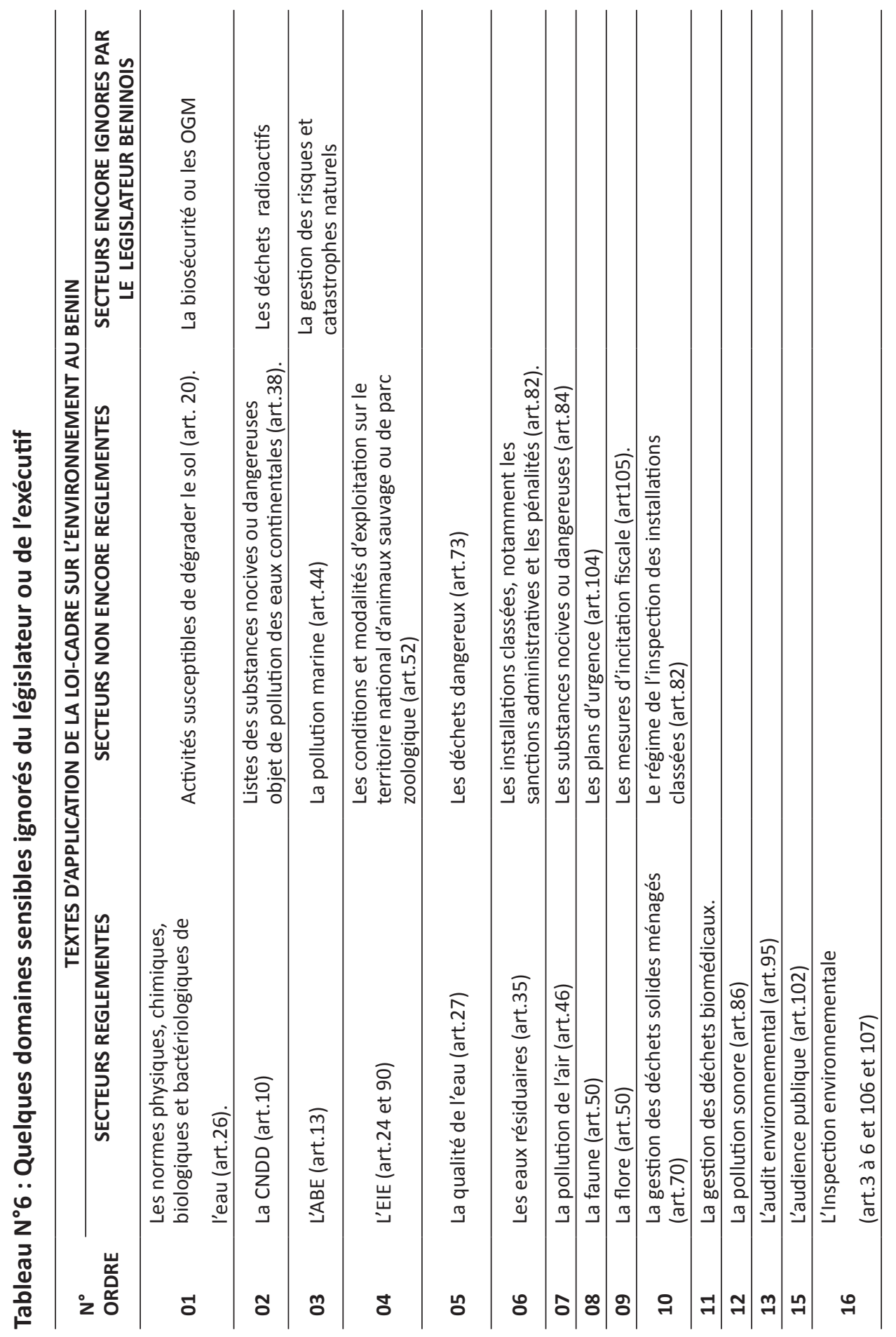


La dizaine de décrets ou de lois non encore pris concerne les secteurs sources potentielles de dégradations humaines et environnementales telles que : les activités susceptibles de dégrader le sol, les substances nocives ou dangereuses objet de diverses pollutions des eaux, la gestion des déchets dangereux, la réglementation des installations classées, l'exploitation des espèces sauvages animales ou la réglementation des parcs zoologiques ${ }^{405}$, les substances chimiques nocives ou dangereuses ${ }^{406}$. Ainsi, l'usage des substances susceptibles d'altérer la qualité de l'eau, comme le déversement ou l'épandage d' effluents des exploitations agricoles, l'usage des pesticides ou engrais chimiques agricoles, abondamment utilisés par les paysans, notamment producteurs de coton, est certes réglementé ${ }^{407}$ en ce qui concerne la procédure d'agrément et leur manipulation surtout quant à la santé humaine mais pas en ce qui concerne les conséquences désastreuses sur l'environnement ${ }^{408}$. En l'absence de statistiques béninoises sur le droit des pesticides, sur l'impact négatif de ceux-ci sur l'environnement, et, afin de se faire une opinion sur l'ampleur des dégâts, nous empruntons les statistiques canadiennes. Ainsi, Maryse GRANDBOIS nous renseigne " qu'au Québec, $40 \%$ des ventes des produits antiparasitaires sont constitués d'insecticides dangereux, lesquels sont responsables de 422 intoxications pour la seule année $1979 \aleph^{409}$. II en est de même du secteur des inondations qui reste marqué par un vide juridique alors que le phénomène

405 Par exemple en France, le principe est celui de l'autorisation préalable pour l'ouverture d'établissement détenant les animaux sauvages. L'article 6 de la loi du 10 juillet 1976, complété par le décret $n^{\circ} 77-1297$ du 25 novembre 1977 organise un contrôle sévère de l'ouverture et du fonctionnement des établissements de vente, d'élevage, de location, de transit d'animaux non domestiques ainsi que des établissements fixes ou mobiles destinés à la présentation au public de spécimens vivants de la faune locale ou étrangère. V. M. PRIEUR, Droit de l'environnement, 3ème édition, Dalloz, Paris, 1996 p.284.

406 Cf. Tableau ${ }^{\circ} 6$

407 Cf. loi $n^{\circ}$ 91-004 du 11 février 1991 portant réglementation phytosanitaire en République du bénin et le décret $n^{\circ} 92-258$ du 18 septembre 1992 qui fixe les modalités de son application

408 Les conséquences sont énormes et sont relatifs à la baisse de fertilité des sols, pollution des eaux, de l'air. La rémanence de la DDT dans le sol atteindrait près de 40 ans.

409 Op cit. cf. http: //id.erudit.org/017258ar, www.erudit.org. Au Mali, l'activité est régit par le décret n02-014du 03 juin 2002 instituant l'homologation et le contrôle des pesticides en République du Mali et son décret d'application n02-306P/RM du 023 juin 2002 fixant les modalités d'application de ladite loi. 
est cyclique et occasionne d'importants dégâts humains et environnementaux chaque année. A défaut d'une réglementation en bonne et due forme (décret ou loi) du secteur, définissant entre autres, les modalités de lutte contre ces risques naturels et les mesures répressives préconisées pour remédier aux défaillances du système, le législateur béninois se contente simplement d'un arrêté ministériel laconique, définissant les zones impropres à l'habitation ${ }^{410}$. Cette situation n'augure pas d'une bonne gestion des inondations dues en grande partie àl'occupation anarchique des populations de l'espace urbain impropre aux habitations et ce, sans impunité.

En outre, une lecture approfondie de la loi-cadre sur l'environnement montre que certains domaines demeurent encore sans textes d'application. Il s'agit des domaines très sensibles non réglementés ou ignorés encore du législateur ${ }^{411}$; et dont l'importance se fait de plus en plus remarquer du fait du développement scientifique et technologique très avancé. On peut citer en l'occurrence le secteur de la biosécurité ou biotechnologie ${ }^{412}$, notamment en ce qui concerne la gestion des $\mathrm{OGM}^{413}$ et la gestion du secteur de la radioactivité en ce qui concerne les déchets radioactifs et la gestion des catastrophes naturels, notamment les inondations. N'est -ce pas la loi qui devrait être au service de la

410 Art. $N^{\circ}$ 0002/MEHU/DC/DUA du 7 février 1992, définissant les zones impropres à I'habitation. En France par contre, la gestion des inondations est régit par la loi $n^{\circ} 2003-$ 699 du 30 juillet 2003 relative à la prévention des risques technologiques et naturels et à la réparation de leurs dommages (C. env. art.211-12 et L 211-13). Cette loi a instituée des servitudes d'utilité publique.

411 Cf. Tableau $n^{\circ} 6$

412 Le Burkina Faso, connaît à ce sujet un progrès remarquable avec la loi n005-2006/AN du 17 mars 2006 portant régime de sécurité en matière de biotechnologie. Elle détermine entre autres, les conditions d'utilisation des OGM et leurs produits dérivés, les mesures préventives et les mesures répressives. Il en est ainsi puisque depuis juillet 2003, le Burkina Faso pratique des essais sur le coton Bt. V. à cet effet, la revue, semences de la biodiversité, n³9 mai 2005, ONG Grain, Cotonou, Bénin.

413 Rappelons à cet effet que le Bénin, conformément au principe de précaution et se fondant sur le protocole de Cartagena sur la prévention des risques technologiques a interdit temporairement l'utilisation des OGM sur son territoire à travers un moratoire de cinq (05) ans (2002-2007). Suite a une évaluation, le moratoire a été reconduit pour une nouvelle période de cinq ans qui court de 2008 à 2013. Le moratoire interdit l'importation, la circulation et la commercialisation des OGM et dérivés dans le pays. Malheureusement jusqu'à ce jour aucun décret d'application du moratoire n'est pris du fait, entre autres, de la pression des multinationales sur les autorités politiques du pays a en croire l'ONG Grain. 
technologie et non la technologie au service de la loi ? La loi devrait s'inscrire dans une vision anticipatrice de l'approche pénale pour assurer une meilleure protection de la société.

Il s'ensuit qu'il y a possibilité pour le juge, quand le cas se présentera à lui, d'avoir des difficultés pour rendre sa décision au quel cas, il rendra un mauvais jugement pour éviter de se rendre coupable d'un déni de justice. Dans le souci d'échapper à des situations désagréables de ce genre, il faut éviter les vides juridiques en légiférant afin de faciliter la tâche au juge. Car le principe de la légalité pénale est claire : «nul ne peut être frappé de sanctions pénales qui n'étaient pas prévues par la loi avant la commission de l'infraction » d'une part, et « le juge ne peut prononcer la sanction pénale qu'autant que le fait poursuivi était prévu et qualifié par la loi ». Autrement dit, une action ou une abstention, aussi préjudiciable soit-elle à l'ordre social, ne peut être sanctionnée par le juge que lorsque le législateur l'a visé dans un texte et interdite sous la menace d'une peine.

Par ailleurs, en droit africain, la procédure d'internalisation de normes internationales au plan interne dans le domaine environnemental n'est pas toujours respectée. S'il est aisé de constater que certaines conventions internationales relatives à la protection de l'environnement ont fait, à ce jour, l'objet de mesures législatives, réglementaires ou autres de mise en œuvre ${ }^{414}$, la plupart d'entre elles ne connaissent pas de mesures internes de mise en œuvre ${ }^{415}$; de sorte qu'à l'instar de certaines lois demeurant toujours sans texte d'application ${ }^{416}$, il y a des conventions sans lois d'habilitations et sans décret ou arrêté d'application. Car pour être mis en œuvre et intégrer l'ordonnancement juridique interne, les conventions ou traités doivent se traduire sous la forme

414 Comme la convention relative au Statut de Rome de la Cour Pénale Internationale autorisée par la loi n²001-26 du 9 août 2001portant autorisation de ratification du statut de Rome du 17 juillet 1998 portant création de la cour pénale internationale et son décret de ratification signé le 28 août 2001.

415 Vincent ZAKANE, Problématique de l'effectivité du droit de l'environnement en Afrique : l'exemple du Burkina Faso. P.22. ces conventions n'ont point été publiées et n'ont fait l'objet d'aucune mesure législative d'incorporation ou de mesures administrative d'application. Par exemple au Bénin, de 1986 à 1990 la parution du JORB a été interrompue.

416 C'est le cas de la loi-n²002-16 du 18 octobre 2004 portant régime de la faune en République du Bénin, le code de l'eau. 
de lois, décrets ou arrêtés. Le Bénin ne fait pas exception. L'acte de ratification de ces conventions leur confère certes, habilitation permettant leur intégration dans l'ordonnancement juridique interne, mais l'acte qui est en réalité une loi, ne vaut pas texte d'application pourtant nécessaire à sa mise en œuvre. Ce sont donc ces textes d'application qui font souvent défaut, d'où le faible degré d'opérationnalisation desdites conventions. ${ }^{417}$

Au regard de tout ce qui précède, on peut affirmer avec M. FAURE que l'hostilité des pouvoirs publics à légiférer ou à réglementer certaines activités portant atteintes à l'environnement, peut tenir essentiellement à des raisons économiques qui malheureusement emboitent le pas aux considérations écologiques. ${ }^{418}$ Ainsi, la différence entre les délits écologiques et les délits classiques tient au fait que la pollution est d'habitude le résultat d'activités ayant une «valeur sociale» ${ }^{419}$. En conséquence, la plupart des lois et décrets environnementaux donnent a priori aux autorités administratives plus qu'aux juges répressifs, le pouvoir de décider dans quelle mesure il est possible de mettre en danger les intérêts écologiques ou d'y porter atteinte. Le droit pénal de l'environnement, nous le verrons plus loin, punit surtout le non respect des normes administratives. Se sont les autorités administratives qui définissent le contenu, mais aussi l'étendue de la protection qu'offre le droit pénal. C'est à notre avis, l'exercice de ce " pouvoir très compliqué et difficile ${ }^{420}$ de «balance des intérêts ${ }^{421}$ » en cause, qui oriente l'administration ou les pouvoirs publics à réglementer tel ou tel domaine. Cette situation lorsqu'elle se développe, conduit inexorablement soit à une carence législative ou réglementaire soit à la confection

417 Vincent ZAKANE, Problématique de l'effectivité du droit de l'environnement en Afrique : l'exemple du Burkina Faso. P.22.

418 M. FAURE, La protection de l'environnement par le droit pénal ? Une perspective économique, p.145.

419 Voir à cet effet, l'article de M FAURE, La protection de l'environnement par le droit pénal ? Une perspective économique.

$420 \quad$ Idem p.146

421 Idem p. 146 
de normes " inefficaces $"^{422}$ ou " obsolètes $"^{423}$ ou encore " incomplètes $\|^{424}$ dans la mesure où il s'agit d'une législation vétuste et caduque.

\section{B) Le caractère vétuste et caduc des textes pénaux existants}

Le droit applicable au Bénin, est un droit incomplet et parfois obsolète. Il est inadapté dans une certaine mesure aux réalités sociales. L'apparent foisonnement de textes législatif et réglementaire, tel que décrit au premier chapitre, n'est en réalité que constituée de textes très anciens datant, pour la plupart, de l'époque coloniale ou néo-coloniale et qui sont encore en vigueur. II s'agit des textes pénaux à caractère général ${ }^{425}$ et des textes pénaux à caractère sectoriel.

En ce qui concerne les textes à caractère général, il s'agit essentiellement du code pénal et du code de procédure pénale. Le premier, comme nous l'avons signifié date de l'époque de Napoléon; d'où son appellation de " code napoléonien ". Il a subi certes, des modifications jusqu'à la veille des indépendances africaines pour être applicable en AOF et AEF en 1958 sous le nom de " code Bouvenet ". Dès lors, 50 ans après les indépendances africaines, ce texte continue encore de guider le juge dans plusieurs pays. Au Bénin, il s'applique comme telle, sans amendement aucune et ne reflète ni les réalités socioculturelles, ni le niveau de développement du pays. Par exemple, le montant des amendes est demeuré invariable, même après la dévaluation du franc CFA intervenu en janvier 1994 et le renchérissement du coût de la vie avec la crise économique et financière qui secoue particulièrement les Etats africains. La conséquence qui s'ensuit est que les amendes deviennent dérisoires. En France, le code est révisé chaque année. Bien qu'étant muet sur

\section{Idem p.146}

423 Idem p. 146

424 V. Samuel NGUIFFO, Les difficultés de l'encadrement juridique de la durabilité : le nouveau régime des forets en Afrique centrale, in, Aspect contemporains du droit de l'environnement en Afrique de l'Ouest et centrale, Laurent GRANIER(coord),, UICN, Gland, 2008, Suisse, p.96.

425 A l'exception de la loi-cadre sur l'environnement du Bénin qui compte parmi les textes généraux. 
la répression de l'environnement ${ }^{426}$, il continue d'inspirer non seulement le juge mais aussi le législateur dans la détermination et l'application des peines ${ }^{427}$. Aussi, comme le prévoit la loi béninoise portant régime des forêts en matière de préjudices corporels ou d'obstacle à agent dans l'exercice de ses fonctions, "seule la procédure criminelle, s'appliquent ${ }^{428}$ ", c'est-à-dire le code pénal. De plus, aujourd'hui, le juge répressif utilise très souvent les théories générales de

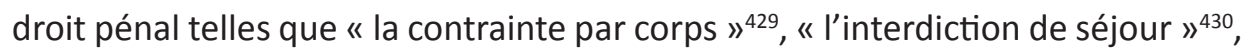
" la récidive $»^{431}$ envers les délinquants endurcis, "le sursis ${ }^{432}$ accordé aux délinquants primaires, etc. Toutes ces théories sont organisées nulle part ailleurs que par le droit pénal général contenu dans le code pénal en vigueur. Or avec l'avènement du droit de l'environnement et le développement du droit moderne, la législation ${ }^{433}$ et la jurisprudence pénale ont beaucoup évolué et ce, avec l'influence de plusieurs tendances doctrinales : l'Ecole néo-classique, l'Ecole positiviste, l'Ecole de la défense sociale ${ }^{434}$. Elles conduisirent à l'adoption de l'actuel code pénal français ${ }^{435}$, lequel ayant subi de profondes mutations, continu d'être objet de réformes législatives et réglementaires approfondies chaque année.

426 En dehors de la section III art.434 et ss. Intitulée destructions, dégradations, dommages qui de manière incidente quelque préoccupations environnementales.

427 Il en est ainsi de l'article 15 al.2 de la loi-cadre sur l'environnement du Bénin qui dispose " quiconque se rend coupable d'une pollution de l'environnement est tenu d'en réparer les conséquences conformément aux dispositions de la présente loi et des règlements y afférents et sans préjudice de l'application a son encontre des dispositions du code pénal ».

428 Cf.art. 102 de la loi-93-009 du 2 juillet 1993 portant régime des forets en République du Bénin.

429 Cf. Loi du 22 juillet 1867, relative à la contrainte par corps, in, code pénal applicable en AOF

430 Cf. loi du 27 mai 1885 (art.19) remplaçant la surveillance de la haute police par l'interdiction de séjour, in, code pénal applicable en AOF

431 Loi du 14 aout 1885 sur les moyens de prévenir la récidive, in, code pénal applicable en AOF

432 Loi du 26 mars 1891 et la loi n 51-144 du 11 février 1951 abrogeant toutes restrictions légales à l'application de la loi de sursis (JO. AOF 1952, p.577), in, code pénal applicable en AOF

433 L'actuel code pénal français est à sa 107ème édition en 2010

434 (J-C) SOYER, Droit pénal et procédure pénale, 17ème édition, LGDJ, 2003, Paris, p.27-30.

435 La commission de révision du code pénal commencée en novembre 1974, a déposé son projet de code qui est entrée en vigueur le 1er mars 1994. Cf. (J-C) SOYER, op. Cit. p.36. 
Techniquement, J. PRADEL soutient que ce code pénal ancien est une "œuvre imparfaite» ${ }^{436}$ non seulement à cause de la rareté des constructions juridiques ${ }^{437}$ mais aussi de l'absence des théories à portée générale lesquelles ont un rôle prépondérant actuellement en droit répressif. II s'agit de la théorie de la faute, du non cumul des peines, de l'erreur ou de l'état de nécessitét38. D'autres, comme celle de la force majeure n'ont été écrites que pour les crimes et délits de sorte que la jurisprudence a dû l'étendre aux contraventions ${ }^{439}$. Il en est ainsi de la légitime défense dont le champ d'action apparaît très limité dans ce code ${ }^{440}$. Aussi, note-t- on que l'ossature même de ce code est « illogique $»^{441}$ puisque la sanction est envisagée avant l'infraction. Par exemple on a, " Livre I: Des peines en matière criminelle et correctionnelle (art. 6 à 58) ; Livre II : Des personnes punissables, excusables ou responsables pour crimes ou délits (art.59 à 69) ; Livre III : Des crimes, des délits et de leur punition (art.70 à 463) ; Livre IV : Contravention de police et peines (art.464 à 477) ». Et, on aurait pu s'attendre à voir figurer en tête du code une théorie générale de l'infraction telle qu'on la trouve dans de nombreux codes modernes alors que la partie préliminaire ne comporte que cinq articles d'un laconisme surprenant.

Cependant, cette position du Professeur PRADEL mérite d'être nuancée dans la mesure où ses critiques aussi bien de forme que de fond ne concernent pas que le code pénal applicable en AOF ou au Bénin. Les codes pénaux européens à l'instar de celui applicable en Belgique ${ }^{442}$ sont similaires et même plus anciens. L'on ne trouvera pas, par exemple, la théorie de l'état de nécessité qui est purement de création prétorien. Donc, il ya possibilité pour la jurisprudence de créer le droit pour améliorer le code pénal.

En effet, on pourrait tirer, avec la professeur Maryse GRANDBOIS, la conclusion que le développement récent du droit pénal de l'environnement

436 (J) PRADEL, Droit pénal général, 16ème édition CUJAS, 2006, Paris, p.92

437 Idem

438 Idem

439 Idem

440 Elle concerne les dispositions des art.327 et 328 les quelles sont relatives uniquement aux homicides et aux coups et blessures alors qu'elle s'applique à bien d'autres infractions.

441 (J) PRADEL, Droit pénal général, 16ème édition CUJAS, 2006, Paris, p.92

442 La Belgique à appliqué pendant longtemps le code pénal français avant d'adopter son propre code en 1867 très proche de ce dernier. 
montre qu'il se constitue parallèlement au code criminel. Certaines infractions du code criminel peuvent d'ailleurs être utilisées dans la lutte contre les pollutions : la négligence criminelle, la nuisance publique, le méfait, etc. mais l'Etat porte rarement de telles accusations et le code criminel demeure d'une utilité limité pour dissuader les pollueurs ${ }^{443}$.

Afin d'éviter les anachronismes, certains Etats africains comme le Burkina Faso, ont adopté un code pénal post colonial ; alors que, le droit pénal béninois végète toujours dans cet archaïsme du droit pénal ancien.

Quant au code de procédure pénale, retenons que le code d'instruction criminelle de 1808 aussi dénommé " code napoléonien, " est l'ancêtre du code de procédure pénale français de 1959 dont s'est largement inspiré le code de procédure pénale béninois. Au Bénin, ce code à certainement connu un sort nettement meilleur que le précédent. Sa rédaction remonte aux années des indépendances avec la première édition qui est apparue le 7aoùt 1967, avec l'ordonnance $n^{\circ} 25 \mathrm{PR} / \mathrm{MJL}$ portant code de procédure pénale. La deuxième édition est intervenue le 8 novembre 1982 et la troisième le 2 avril 1998. Malgré toutes ces éditions, rien n'a changé fondamentalement au code initial qui n'a pas connu de révision. Aucun article n'a été modifié et aucun commentaire ni réforme n'a suivi. Ce n'est que tout récemment le 30 mars 2012 qu'est intervenu le vote de la loi portant code de procédure pénale du Bénin. On note dans l'ensemble quelques améliorations dans le domaine des droits de l'homme mais rien dans le domaine de la protection de l'environnement. Dans le même domaine, il est à remarquer que le code de procédure pénale français connaît une évolution constante.

Quant au code pénal, il est en cours de révision au parlement depuis plus de 10 ans $^{444}$.Tout porte à croire qu'en cas de vote de cette loi, les infractions environnementales n'auront pas, malgré leur spécificité, un traitement particulier dans la gamme des infractions en général. Puisque qu'à l'examen 
le contenu du projet de loi n'apporte aucune innovation quant aux infractions environnementales. II n'existe pas dans le projet de code d'infractions qu'on pourrait qualifier, comme l'a fait le nouveau code criminel québécois, de « crime contre l'environnement ${ }^{445}$ ).

Dans le domaine de la réglementation sectorielle, on note également la survivance de plusieurs textes coloniaux cohabitant avec des textes plus ou moins récents. C'est une réglementation éclatée et fragmentée, parfois inadaptée et même frappée de caducité. Il en est ainsi par exemple du secteur de l'eau avec le code de l'eau ${ }^{46}$ qui n'a connu jusqu'à son abrogation aucun texte d'application. C'est également le cas de la loi relative à la transhumance et à la vaine pâture ${ }^{447}$ ainsi que celle relative à l'usage, le commerce, la détention et l'emploi des substances vénéneuses ${ }^{48}$ dont les dispositions ne cadrent plus avec l'évolution actuelle du secteur, pour ne citer que celles -là.

\section{§II : L'éparpillement des textes répressifs}

La dispersion des textes ${ }^{449}$ est corollaire de la dispersion des services administratifs del'environnement. La responsabilitéen matièreenvironnementale demeure à ce jour, partagée entre plusieurs secteurs ministériels. Il en est ainsi puisque le législateur et l'exécutif entendent assurer le respect d'une multitude de normes techniques, touchant tous les domaines d'activité, par la voie répressive. Celle-ci devient alors une " panacée » pour faire appliquer correctement la règle de droit. D’où l'émergence d'un corpus de législations

\footnotetext{
445 M. GANDBOIS, op, cit. p.61

446 Loi-n87-06 du 21/9/1987, portant code de l'eau en RPB, abrogée par la loi portant gestion de l'eau précité.

447 Loi n87-013 du 21septembre 1987 réglementation de la vaine pâture, de la garde des animaux domestiques et de la transhumance en RPB.

448 Loi $n^{\circ} 87-009$ du 21septembre 1987 relative à la répression des infractions en matière d'usage, de commerce, de détention et d'emploi des substances vénéneuses en RPB.

449 Voir, M. PRIEUR, Droit de l'environnement, 3ème édition, Dalloz, Paris 1996, p. 148 et 814. V. aussi, Vincent ZAKANE, Problématique de l'effectivité du droit de l'environnement en Afrique : l'exemple du Burkina Faso. P.22 ; (Jacqueline) MORAND-DEVILLIER, Droit de l'environnement, AUPELF-UREF, Paris 1996, p.50.
} 
satellites, toutes pénalement sanctionnées. ${ }^{450}$ II s'agit en réalité des textes isolés et disparates, consacrés à tel ou tel secteur, et adoptés au gré de l'apparition des problèmes spécifiques liés à l'environnement ${ }^{451}$. Ainsi, outre la loi cadre sur l'environnement, qui trouve son fondement essentiel dans la constitution du 11 décembre 1990, le dispositif juridique environnemental béninois est constitué de législations spécifiques et sectorielles concernant différents secteurs environnementaux, tels que l'eau, les mines, les pesticides, l'hygiène publique, les pêcheries, la faune, la flore, etc.... outre ces textes d'origine nationale, il convient de mentionner un grand nombre de textes datant de l'époque coloniale ${ }^{452}$. Plusieurs conventions internationales et régionales consacrées à la protection de l'environnement et qui ont acquis une force juridique au plan national, du fait de leur ratification par les autorités compétentes nationales, viennent également renforcer la panoplie de textes applicables.

Par ailleurs, on remarque une tendance du législateur à s'en remettre au pouvoir réglementaire voire à l'autorisation individuelle, pour déterminer les éléments constitutifs des délits. Il s'agit de l'utilisation fréquente par le législateur de la technique dite "du renvoi ". Bien qu'elle soit admise par le Conseil

450 V. à cet effet, le Rapport, intitulé, Mieux maitriser le risque pénal en matière d'environnement, présenté par M. Guy PALLARUELO au nom de la commission juridique, de la commission du commerce intérieur et de la commission de l'aménagement régional, de l'environnement, du tourisme et des transports et adopté par l'Assemblée générale du 7 mars 2002. Chambre de Commerce et d'industrie de Paris.

451 Avant la Conférence de Rio de Janeiro, le Bénin disposait de textes législatifs et réglementaires disparates concernant les secteurs déterminés comme la forêt, la pèche, la faune et la chasse. Le droit de l'environnement qui était pas une préoccupation essentielle, se limitait à quelques réglementations adoptées au coup par coup en fonction des besoins du moment.

452 Les premières réglementations remontent à l'époque coloniale et concernent notamment la protection des animaux, les forêts, les pêcheries.... Et demeurent toujours applicables. C'est le cas par exemple de l'ordonnance n²0/PR/MDRC/SP du 25 avril 1966 portant réglementation générale de la pêche dans les eaux continentales du Bénin et son décret d'application n¹83 PR/MDRC du 25 avril 1966 et plusieurs autres arrêtés coloniaux précédemment cités; l'ordonnance n³8/PR/MTPTPT du 18 juin 1968 portant code de la marine marchande de la République du Bénin ; aussi dans le domaine du foncier, de I'habitat, de l'urbanisme il n'existe plusieurs textes coloniaux applicables. 
constitutionnel ${ }^{453}$ et le Conseil d'Etat ${ }^{454}$ français, à cause certainement de ses atouts indéniables, elle ne manque pas de susciter des interrogations au regard du principe de légalité des délits et des peines et, surtout créer des « situations juridiques confuses ${ }^{455}$ " ou " une insécurité juridique " par l'enchevêtrement de textes de portée juridique différente mais toujours assortis de dispositions répressives ${ }^{456}$. Le droit pénal étant d'interprétation stricte, on risque de verser dans le laxisme du pouvoir réglementaire qui détermine et précise les contours de l'infraction qui normalement relève du législatif. Plus concrètement, la loi édicte, de plus en plus souvent des incriminations correctionnelles dont la constitution dépens de données techniques (par exemple, dépassement de seuils de pollution) fixées par des décrets, renvoyant à des arrêtés. Plus préoccupant encore, certaines administrations, dans la logique de la hiérarchie des normes, vont jusqu'à pousser à l'extrémité en opérant des renvois d'arrêté aux circulaires administratives ${ }^{457}$. Cela pose dès lors, le problème de la portée juridique de la validité d'un tel acte réglementaire. On peut dire d'emblée qu'en droit africain francophone de l'environnement, le renvoi des textes s'arrête généralement à la prise d'arrêté ministériel. La circulaire ministérielle n'est pas concernée. Selon une certaine doctrine, elle est sans portée juridique contraignante. Elle n'est qu'indicative, sauf à être requalifiée en règlement ${ }^{458}$.

453 Conseil Constitutionnel, décision du 10 novembre 1982, JO du 11 novembre 1982, p. 3393.

454 Conseil d'Etat, 114 novembre 1984, syndicat des naturalistes de France, RJE 1984, p. 338, conclusions R. DENOIX de Saint-Marc.

455 G. PALLARUELO, Cf. Rapport précité op. Cit., note 449

456 Idem.

457 G. PALLARUELO, cf. rapport précité.

458 Ces situations donnent lieu à des jurisprudences incertaines : une circulaire fixant les méthodes de prélèvement d'eau pollué nécessaire à l'établissement du délit de pollution des eaux visé à l'article L 232-2 du code rural, a été écarté » en qu'étant que fondement pénal par la cour de cassation, compte tenu de son caractère indicatif ; le prévenu ne pouvait donc l'invoquer comme moyen de défense. Or, la nature réglementaire de cette circulaire apparaissait clairement, puisqu'elle édictait des modes de preuves. Ce texte était au demeurant illégal, car le Ministre ne disposait pas de la compétence réglementaire en ce domaine (crim.18 juin1969, JCP 1970, II, 16531, note M. DESPAX). 
Il a été même jugé que « les circulaires ministérielles ne peuvent exercer aucune influence sur l'incrimination ou la pénalité. Elles ne lient point le juge pour l'interprétation de la loi et n'ont qu'une autorité purement doctrinale ${ }^{459} \%$.

Au total, cet éparpillement ne facilite pas une bonne coordination de l'activité réglementaire, dans la mesure où chaque ministère sectoriel, chaque direction du ministère, puis chaque bureau de la direction à tendance à rédiger ses propres textes, sans toujours tenir compte des textes rédigés par ailleurs. On trouve ainsi des textes chargés de protéger la faune et d'autres qui visent pour leur part à protéger le gibier. Mais, beaucoup d'animaux font à la fois partie de la faune et du gibier...Une question fondamentale se pose : quel texte doit alors s'appliquer ? On le voit, les textes ne sont pas toujours cohérents entre eux.

Mieux, outre ces problèmes d'éparpillement et d'incohérence des textes environnementaux qui " perturbent " le juge dans l'application de la loi, ce dernier ainsi que le justiciable, doivent affronter la « face cachée » de la justice pénale en Afrique.

459 Cass. 1er juillet 1948 (B.180), in, Code pénal annoté, Emile GARCON, Nouvelle édition refondue et mise à jour par Marcel ROUSSELET, Maurice PATIN, Marc ANVEL, T1 art.1 à 294. Recueil Sirey, Paris 1952, p.39. 


\section{SECTION II : L’ACCES A LA JUSTICE PENALE}

Des textes internationaux ${ }^{460}$ et nationaux ${ }^{461}$ consacrent l'accès à la justice dans les Etats africains et en particulier au Bénin. Comment s'exerce ce droit d'accès à la justice aussi bien dans le domaine du droit pénal en général que dans celui relevant spécifiquement du droit répressif de l'environnement au Bénin? Pour mieux cerner les contours d'une telle problématique, nos travaux de recherches se sont appesanti sur le mode de fonctionnement intrinsèque de la justice pénale (§I) et sur les obstacles ou pesanteurs socio-économiques et politiques d'une telle justice (§II).

\section{§I : Les obstacles liés au mode de fonctionnement de la justice}

Ces obstacles s'analyseront quant aux constatations des infractions et à leurs poursuites d'une part et quant au mode d'organisation et de fonctionnement des juridictions, d'autre part.

460 V. art. 8 de La Déclaration Universelle des droits de l'homme du 10 décembre 1948 ; art.2 $\S 3$ du Pacte international relatif aux droits civils et politiques de 1966 ; le Principe 10 de la Déclaration de Rio de 1992 sur l'environnement et le développement, qui concerne spécifiquement l'environnement dispose " qu'un accès effectif à des actions judiciaires et administratives, y compris des sanctions et réparation doit être assuré ". Le principe 23 de la charte mondiale de la nature. V. aussi l'art.7, §1 de la Charte africaine des droits de l'homme et des peuples de juin 1981. On peut voir également les art.2, §5 et 9 §2 al.2, de la convention sur l'accès à l'information, la participation du public au processus décisionnel et l'accès à la justice en matière d'environnement, adoptée à Aarhus au Danemark le 25 juin 1998 et entrée en vigueur le 30 octobre 2001 ; l'art.235 (2) de la convention des ONU sur le droit de la mer et l'art. 230 al.4, du Traité de Rome.

461 La Constitution du Bénin du 11 décembre 1990 auquel est incorporée la Charte africaine des droits de l'homme et des peuples de juin 1981; la loi-cadre sur l'environnement du Bénin en son art. 109 al.2 qui déterminent les conditions de mise en œuvre de l'action publique en reconnaissant " aux associations environnementales légalement reconnues et représentatives le droit d'ester en justice et de se constituer partie civile... » 


\section{A) Quant aux constatations des infractions et à leurs poursuites}

La constatation des infractions, nous l'avons déjà précisé, c'est l'une des phases préliminaires mais essentielle de la procédure contentieuse pénale. Elle est diligentée par les Officiers de la Police Judiciaire. En effet, les services chargés de rechercher les infractions et leurs auteurs, de rassembler les preuves, sont essentiellement constituées de la police et de la gendarmerie. Or, les agents issus de ces différents services ne connaissent pratiquement pas le droit de l'environnement et ne disposent généralement ni de compétences techniques en la matière ni les moyens matériels nécessaires pour constater les délits dans ce domaine. Leur répartition spatiale $e^{462}$ devrait pourtant constituer un atout formidable de mise en œuvre du principe de subsidiarité avec le rapprochement des autorités de la police judiciaire des justiciables afin de mieux poursuivre les délinquants ou les présumés coupables.

Quant à certains agents qui assurent le contrôle et la surveillance des diverses pollutions et dégradations environnementales et habilités par les lois spéciales au sein des administrations d'environnement, la situation n'est pas n'ont plus reluisante. En effet, ces agents fonctionnaires assermentés ou commissionnés sont dispersés au sein des administrations publiques. Ils ne coopèrent pas volontiers entre eux et encore moins avec les forces de sécurité publique ou avec les autorités judiciaires. Il y a donc comme une absence de coordination des actions, notamment l'action du ministère public et les autres actions émanant des agents fonctionnaires assermentés. Lorsque ces derniers appréhendent des infractions, ils sont tenus par les textes d'adresser systématiquement les procès-verbaux au procureur de la République. Mais pour des raisons qui leurs sont propres et tenant compte du souhait du contrevenant, ils préfèrent généralement rechercher des solutions à l'amiable comme le recours à la transaction ou appliquer des mesures de contraintes administratives comme des verbalisations couramment employées par les forestiers et les inspecteurs de l'environnement, au lieu de travailler en étroite collaboration avec le procureur de la République. Cette situation n'est-elle pas due à la complexité de leurs

462 Au Bénin et partout ailleurs, les forces de sécurité publique (gendarmes et policiers) sont disséminées dans tout le pays à travers les postes de polices et de gendarmeries. 
fonctions ? Puisqu'ils doivent procéder à tous les examens, contrôles, enquêtes, perquisitions, prélèvements, analyses, saisies nécessaires pour s'assurer du respect des mesures relatives à l'environnement ${ }^{463}$.

Au demeurant, la méconnaissance du droit pénal de l'environnement risque d'amener ces agents à dresser des procès-verbaux entachés de nullités ou difficilement exploitables ${ }^{464}$ par le procureur de la République qui est l'autorité judiciaire qui réceptionne le procès-verbal ou la plainte du plaignant. A ce niveau, le magistrat a l'opportunité des poursuites. Autrement dit, se fondant sur son intime conviction, il apprécie la suite à donner en procédant au règlement du PV ou de la plainte ; ce qui lui permet de poursuivre ou de procéder à un classement sans suite. Ce principe dit "d'opportunité des poursuites » ne constitue t-il pas un autre handicap à l'épanouissement du droit pénal de l'environnement ? M. PRIEUR, tente de répondre par l'affirmative en estimant que ce principe devrait être écarté en ce qui concerne les infractions à la réglementation écologique ${ }^{465}$ certainement à cause du caractère d'ordre public attaché aux infractions environnementales. II s'ensuit que, dans l'exercice des poursuites, seule une autorité judiciaire jouissant d'une certaine indépendance, de pouvoir de décision et d'une bonne connaissance du droit applicable, au service exclusif de la loi peut exercer une action efficace et légitime. Néanmoins, au Bénin, en ce qui concerne la procédure d'inspection environnementale, on assiste à une incohérence des textes puisque l'article 107 de la loi-cadre sur l'environnement précise que "les procès-verbaux de constatations des infractions rédigés par les policiers de l'environnement dans le cadre de leurs activités répressives, sont adressés au Ministre (entendre Ministre chargé de la protection de l'environnement) alors que l'un des décrets portant application ${ }^{466}$ de cette loi dispose en son article 21 que " deux copies du procès-verbal de constatation

463 Présentation de l'état du droit pénal gabonais par la délégation gabonaise au Colloque de AHJUCAF, www.ahjucaf.org

464 (G) CANIVET, Protection de l'environnement par le droit pénal : l'exigence de formation et de spécialisation des magistrats, in, allocution prononcée à Luxembourg (CJCE) le 26 avril 2004.

465 Droit de l'environnement, 3ème édition, Précis Dalloz, 1996, Paris, p.824.

466 Décret $n^{\circ} 2005-437$ du 22 juillet 2005 portant organisation de la procédure d'inspection environnementale en République du Bénin. V. aussi l’art.69 de la loi n²010-44 du 24 nov.2010 portant gestion de l'eau en République du Bénin. 
des infractions sont transmis au procureur de la République qui se trouve ainsi saisi de l'infraction». L'analyse qui s'ensuit est qu'une lecture combinée des deux textes ne rassure pas quant à la pertinence de la répression. II y a conflit de normes; en ce sens que le texte d'application à savoir le décret visé qui est plus cohérent et en phase avec la pratique de la procédure répressive normale du fait qu'il implique le procureur de la République dans la poursuite est contraire à l'article 107 de la norme supérieur qu'est la loi précitée.

\section{B) Quant au mode d'organisation de la justice pénale}

À l'examen des registres disponibles au sein des tribunaux que nous avons consultés au Bénin, à défaut des statistiques, l'on se rend compte aisément que le déclenchement de l'action publique en matière environnementale et particulièrement en matière de protection des ressources naturelles est l'œuvre, presque uniquement, de l'administration des Eaux et Forêts et Chasse et dans une certaine mesure des inspecteurs de l'environnement qui font acheminer quelques plaintes ou procès-verbaux au procureur de la République. Rarement le procureur de la République ou un tiers supposé victime, prend l'initiative de déclencher l'action publique. Cette situation qui dénote de la faiblesse du recours juridictionnelle peut s'expliquer d'une part par le phénomène de la dépénalisation des infractions et d'autre part par la lourdeur du processus pénale.

\section{La dépénalisation des infractions}

En parcourant la législation béninoise en matière d'environnement, on observe de façon pertinente qu'elle est pourtant plus répressive que réparatrice. L'intervention du juge pénal est constamment et clairement affirmée dans toutes les lois protectrices de l'environnement. Mais force est de constater que dans la pratique, nonobstant ces dispositions, les recours non juridictionnels comme la transaction pénale sont plus utilisés que la voie juridictionnelle pénale. Cette 
position est aussi confortée par les textes pénaux ${ }^{467}$ qui prévoient l'arrêt des poursuites contre le délinquant qui accepte de transiger.

Si la transaction n'est pas mauvaise en soi, puisqu'elle a l'avantage de frapper le délinquant dans son patrimoine pécuniaire, qu'elle rend disponible dans l'immédiat pour des actions envers la restauration de l'environnement, il faut reconnaître qu'en cas d'usage abusif, elle affaiblit la force du système répressif reléguant ainsi au second plan le recours pénal. Une situation que favorise d'ailleurs dans les textes de loi, le silence du législateur quant au moment de la transaction qui n'apparaît pas clairement. Si l'article 108 de la loicadre béninoise précise que ce peut être "avant ou pendant le jugement», les autres textes spécifiques sont muets sur la question. Ce silence du législateur est relatif aussi au domaine d'application. Cette législation doit-elle intervenir dans tous les cas ? Dans d'autres pays elle est restrictive et concerne les infractions relatives à l'eau, à la pêche, à la faune ou à la flore.

L'administration forestière a cru devoir répondre devant le silence du législateur et elle y recourt systématiquement et dans tous les cas bien que les lois précitées précisent bien " que les délinquants récidivistes ne peuvent bénéficier de cette transaction ${ }^{468}$. Ainsi, nous référant à nos investigations dans les juridictions béninoises, on peut noter qu' au cours de l'année 1996 au niveau de la Direction des Forêts et de la Protection des Ressources Naturelles (DFPRN) de Lokossa, sur 48 cas d'atteintes portées à la flore, 10 cas seulement ont été portées à la connaissance des juridictions répressives. Il convient de noter que sur les 38 cas restants, aucun n'a fait l'objet d'une transaction en nature. Au niveau de la DFPRN de Natitingou, il faut noter que sur 20 infractions portées à leur connaissance, seuls 2 cas ont été déféré au Tribunal de Première Instance de Natitingou au cours de l'année 1997. En 1998, sur 34 cas enregistrés, 33 ont été l'objet de transaction, le tribunal n'a été d'ailleurs que saisi d'un seul cas ${ }^{469}$.

467 C'est le cas des articles 85 et 86 de la loi du 02 juillet 1993 portant régime des forets ; l'article 108 de la loi-cadre sur l'environnement et l'article 21 du décret d'application de la loi du 15 mars 1984 sur le contrôle des denrées alimentaires ; les articles 149 et 150 de la loi-2002-16 du 18 octobre 2004 portant régime de la faune en République du Bénin.

468 Art.85 al.2 de la loi relative à la flore et 149 al.2 de la loi relative à la faune au Bénin.

469 (G) SOGLO, Le droit pénal de l'environnement en droit positif béninois : possibilités et limites de la répression, Mémoire, DEA, 1998, UB, Lomé, Togo, p.52. 
Dès lors, nous constatons que le juge pénal ne peut intervenir que lorsque toutes les solutions alternatives sont épuisées. Le droit pénal devient ainsi l'accessoire, ultima ratio. Ce qui fait dire à Eric Staudt, procureur du Roi, que « le droit pénal de l'environnement aurait un caractère subsidiaire au regard du droit administratif, la sanction intervenant seulement comme agent de dissuasion à l'égard des sujets de droit ${ }^{470}$.

Outre la procédure de l'administration forestière béninoise, la procédure d'inspection environnementale des inspecteurs de l'environnement s'inscrit aussi dans cette dynamique de reléguer à l'arrière plan la saisine du juge pénal ou de le dessaisir tout simplement. ${ }^{471}$

Par ailleurs, il ne serait pas superflu de préciser que, le déroulement de la procédure contentieuse de la transaction hors de la présence du juge, peut sembler dangereux pour le respect du droit ; même si l'implication du pouvoir judiciaire ne constitue pas toujours une garantie d'efficacité.

En dépit de ce que l'acceptation de la transaction par l'auteur constitue une présomption irréfragable de faute ${ }^{472}$, qui permet à ce dernier d'échapper à la justice, il semble que la matière de l'environnement se prête positivement à cette procédure transactionnelle. En effet, d'une part le prévenu en cette matière est souvent solvable et d'autre part la réparation du dommage causé

470 La répression des infractions en matière d'environnement, in, syllabus du cours de DEA droit et politique de l'environnement, 1998, UB Lomé Togo.

471 Lire à cet effet, l'article 18 du décret $n^{\circ} 2005-437$ du 22 juillet 2005 portant organisation de la procédure environnementale en République du Bénin, qui dispose : " A l'expiration du délai prévu pour la mise en œuvre des mesures correctives, une seconde inspection est effectuée. Après cette inspection, le Ministre ou l'autorité administrative compétente peut décider :

De classer le dossier lorsque le contrevenant s'est conformé aux lois et règlements en matière d'environnement ;

D’accorder un délai supplémentaire aux contrevenant qui ne s'est pas conformé aux lois et règlements en matière d'environnement ;

De faire procéder d'office auprès du contrevenant, à l'exécution des mesures prescrites ;

D'initier un audit externe ;

De poursuivre le contrevenant devant les juridictions compétentes en cas de récidive ou de non respect des mesures correctives. "

472 (F) ROGGEN, La répression des infractions contre l'environnement, in L'actualité du droit de l'environnement, Actes du colloque, novembre 1994, édition Bruylant, Bruxelles. 
ainsi que la prise de mesures destinées à supprimer le risque ou le danger, ne relève pas souvent du droit pénal.

En dehors de cet obstacle légal à la justice que constitue la procédure non juridictionnelle, des faits inhérents à la procédure pénale émoussent I'intime conviction du juge et freinent la volonté des justiciables à porter leur litige devant les juridictions.

\section{Les carences organisationnelles et la complexité de la procédure pénale}

En Afrique, des carences organisationnelles sont multiples et multiformes. Le premier obstacle que l'on peut signaler en la matière est bien l'éloignement géographique des juridictions par rapport aux justiciables.

Un regard critique sur la justice au Bénin permet de mettre en évidence que l'appareil judiciaire est resté figé dans le passé et n'a pas suivi le rythme de l'évolution de la société au point de paraître complètement en déphasage avec l'attente des justiciables. Cet anachronisme à la limite du déni de justice réside dans la carte judiciaire du pays qui date des années 60 et qui était peut être suffisante pour couvrir une population de deux millions d'habitants, mais qui aujourd'hui ne répond plus aux exigences d'un Etat de droit qui suppose que le citoyen puisse accéder facilement à la justice pour se faire reconnaitre son droit. L'implantation et le nombre réduit des juridictions font aujourd'hui que certains citoyens sont contraints de parcourir plus de $200 \mathrm{~km}$ pour saisir le juge en première instance. D’autres sont amenés à franchir jusqu'à $700 \mathrm{~km}$ pour atteindre la seule juridiction d'appel qui existait dans le pays. II suffit dans ces conditions que le juge, face à la masse de dossiers qu'il a à traiter ${ }^{473}$, procède a un ou deux renvois pour que le justiciable, découragé et désormais septique se désintéresse de son affaire et n'ait plus envie de recourir à la justice dans tous les cas de figure. N'est-ce pas là en réalité une forme de déni de justice qui ne dit pas son nom?

473500 à 700 dossiers par an. 
Mais depuis 2009, on note une nette amélioration de la carte judiciaire du Bénin. Ainsi, l'organisation judiciaire comprend actuellement neuf Tribunaux de Première Instance ${ }^{474}$ et trois cours d'appel seulement auxquels s'ajoutent la Cour Suprême et les 84 tribunaux de conciliation ${ }^{475}$. Pendant longtemps le pays ne comptait qu'une cours d'appel basée à Cotonou, la capitale économique. Le justiciable qui vit dans le nord et qui interjette appel, devait effectuer environ $700 \mathrm{~km}$ chaque fois qu'il répond à une convocation du juge. Ce n'est que tout récemment en Août 2010, qu'une seconde cour d'appel a été créée à Parakou dans le Nord pour desservir cette localité du pays. La ville d'Abomey au centre, abrite la troisième cour d'appel du pays depuis décembre 2011. Le justiciable le plus éloigné peut alors parcourir environ $300 \mathrm{~km}$ pour atteindre la Cour d'Appel. Mais la distance est beaucoup moins maintenant en ce qui concerne les TPI qui sont au nombre de neuf ${ }^{476}$.

La situation est plus dramatique au Tchad du fait de l'étendue du territoire. Avec une superficie de $1.284 .200 \mathrm{~km}^{2}$ ce pays est 11 fois plus vaste que le Bénin qui ne compte que $112.600 \mathrm{~km}^{2}$ et 22 fois le Togo avec $56000 \mathrm{~km}^{2}$. Or, il ne dispose à l'instar du Togo que d'une seule Cour d'Appel située dans la capitale N'Djaména. Cette cour est distant de $500 \mathrm{~km}$ pour le justiciable domicilié à Abéché ; de plus de $700 \mathrm{~km}$ pour celui habitant à Faya-Largeau ; de plus de $1000 \mathrm{~km}$ pour celui d'Oum-Chalouba. ${ }^{477}$

Un tel éloignement est de nature à décourager même les plus entreprenant des justiciables. Ce phénomène s'explique surtout, au-delà des arguments financiers et de la faiblesse des ressources humaines, par le manque

474 Alors que la loi n²001-37 du 27 aout 2002 portant organisation judiciaire au Bénin, n’en a prévue 28.

475 II s'agit des TPI de Cotonou (1ère classe), les autres sont de deuxième classe et basés à Porto-Novo, Parakou, Natitingou, Kandi, Ouidah, Lokossa et Abomey; Abomey-Calavi et Savalou les Cour d'Appel de Cotonou, de Parakou et d'Abomey; la Cour Suprême de Cotonou ; une Cour d'Assise qui devrait se tenir une fois par semestre et 84 tribunaux de conciliation, pour la plupart sans locaux propres.

476 Cf. Tableau $n^{\circ} 11$

477 (K) AHADZI L'accès à la justice : brèves réflexions sur le cas des Etats d'Afrique noire francophone, article publié dans, La protection de l'environnement au cœur du système juridique international et du droit interne. Acteurs, valeurs et efficacité, (sous la direction de M. FAURE et de M. PAQUES). Faculté de droit de Liège, octobre 2001. 
de volonté des dirigeants politiques africains de faire de la justice un secteur prioritaire de développement.

Outre ce problème d'éloignement très préoccupant, l'accès à la justice est aussi limité par des difficultés liées à la procédure. En effet, il est de notoriété publique en Afrique noire francophone, lorsqu'un justiciable a une affaire pendante devant le tribunal son "chemin de croix " commence ou comme le stigmatise J.F. NEUREY, « la répression tient lieu du parcours du combattant ${ }^{478}$ ". Il doit affronter la lenteur de la procédure judiciaire. La cour constitutionnelle du Bénin n'a t-elle pas dans une jurisprudence constante ${ }^{479}$ et conformément aux dispositions de l'article 7 de la Charte Africaine des Droits de l'Homme et des Peuples, condamné le délai anormalement long qui s'observe dans le règlement des affaires au niveau des tribunaux béninois? Un procès trop long ruine chez les parties toute espérance, car il vide l'objet du litige de son sens. " La justice face au défi du délai raisonnable ${ }^{480} "$, voilà le thème de la rentrée solennelle du 13 novembre 2009 du barreau béninois. Le non respect du délai d'un procès est-il un déni de justice? Le délai s'apprécie au cas par cas. II n'est pas étonnant donc de voir la cour constitutionnelle béninoise qualifiée de délai anormalement long une procédure qui dure 4 ans $^{481}$ alors qu'elle a, elle-même mis plus de 4 ans et demi pour répondre à un recours en inconstitutionnalitée ${ }^{482}$.

L'analyse révèle que le juge béninois n'arrive pas à respecter les délais puisqu'il est surchargé voire inondé de dossiers de droit commun ${ }^{483}$. Quelques statistiques permettent de cerner le volume des affaires tranchées par le tribunal de première instance de Cotonou. En décembre 1994, la première chambre commerciale (affaires au fond) a inscrit 270 dossiers sur lesquels 44 décisions ont été définitivement rendues et 29 ont été radiés. En 1995, 70 nouvelles affaires sont venues s'ajouter au solde de l'année précédente, de sorte qu'à la fin

\footnotetext{
478 Principes de droit de l'environnement, Kluwer, éditions juridiques, Belgique, 1995. p.236

479 Nous pouvons citer 6 décisions ayant constatés cette violation pour l'année 2006. II s'agit des décisions : DCC06-046 ; DCC 06-078, DCC 06-103 ; DCC 06-151 ; DCC 06-161 ; DCC 06176.

480 Droit et Lois, Périodique béninois, Revue Trimestrielle d'informations juridiques et judiciaires, $\mathrm{n}^{\circ} 017,2008$

481 DCC 00-41 du 29 juin 2000

482 DCC 00-18 du 25 juillet 1996, 1er avril 1998 et 3 mars 2000

483 Cf. Tableau $n^{\circ} 7$.
} 
de l'année 1995, ce sont donc 267 dossiers qui étaient toujours en instance. Les chambres de fragrants délits ont inscrits 1112 dossiers à leur rôle durant toute l'année judiciaire 1992-1993. Par ailleurs, dans le même rapport diagnostic, on peut lire qu'en 1995, 8968 plaintes générales ont été reçues au parquet de Cotonou, dont 2113 ont donné lieu à des procès-verbaux d'arrestation et 3047 à l'engagement de procédure et près de 1800 dossiers sont toujours en attentes d'être enrôlés. Le juge a en moyenne 500 à 700 dossiers par an ${ }^{484}$ soit un peu plus de 50.000 dossiers toutes juridictions confondues ${ }^{485}$. C'est à cet ensemble de dossiers de droit commun ${ }^{486}$ que viennent s'ajouter les plaintes à caractères environnementaux. Or les infractions environnementales sont pour l'essentielle des infractions nécessitant un règlement rapide (procédure de fragrant délit) ou à défaut la prise de mesures conservatoires.

Par ailleurs, on assiste à la complexité des procédures. Par exemple, le demandeur qui veut faire une assignation rencontre de nombreux écueils liés notamment à l'identité et au domicile du défendeur. En effet, l'identification est rendue difficile par le fait que bon nombre d'africains ne sont pas enregistrés à l'état civil soit parce que ce service fait défaut, soit parce qu'il est ignoré. Alors comment assigner en justice un individu juridiquement inexistant ? Que faire lorsque le défendeur n'a jamais eu d'identité officielle ? Il va s'en dire que l'on est là devant un obstacle difficile à surmonter, car, dans ces conditions, l'assignation ne peut être faite valablement ${ }^{487}$. Si devant les Tribunaux de Première Instance, la procédure est pratiquement orale, elle est par contre en français ${ }^{488}$ et en général, écrite devant la cour Suprême. Pour ce qui est de la chambre administrative, compétente pour connaître les litiges engageant un tiers et l'administration

484 Rapport, étude diagnostique du système judiciaire béninois, MJL, Cotonou, 1996, p.12.

485 Cf. Tableau n ${ }^{\circ} 6$. Pour apprécier la masse de dossiers annuels, en 2008.

486 Les statistiques avancées sont encore valable de nos jours à cause surtout de la maigreur du personnel magistrat. Cf. Tableau $n^{\circ} 7$

487 (K) AHADZI L'accès à la justice : brèves réflexion sur le cas des Etats d'Afrique noire francophone, article publié dans, La protection de l'environnement au cœur au cœur du système juridique international et du droit interne. Acteurs, valeurs et efficacité, (sous la direction la direction de M. FAURE et de M. PAQUES). Faculté de droit de Liège, octobre 2001, p.404.

488 Nous notons également, que la langue de communication qu'est le français n'est pas maitrisée par les justiciables. Les interprètes ont souvent du mal à traduire les concepts juridiques modernes en langues nationales. 
publique, elle est saisie par requête introductive d'instance signée du demandeur ou de son avocat. Cette requête doit mentionner les noms, prénoms, profession et domicile du demandeur et du défendeur.

En ce qui concerne le pourvoi en cassation, en matière judiciaire, il est formé par déclaration au greffe de la juridiction qui a rendue la décision attaquée et signé du déclarant et du greffier. Dans un délai d'un mois ${ }^{489}$, la déclaration est notifiée au défendeur par les soins du greffier en chef qui l’a reçu. Dans le même délai le dossier est transmis au procureur général de la cour suprême par les soins du ministère public ; alors que le délai pour se pourvoir en cassation en matière pénale est de trois(3) jours francs ${ }^{490}$. Une fois la juridiction compétente saisie, le dossier doit franchir d'autres étapes marquées par la production de mémoires, par les parties, la rédaction du rapport par le conseiller rapporteur, les conclusions du ministère public avant le déroulement du procès.

L'accomplissement de toutes ces formalités nécessite des connaissances et une vigilance qui fait défaut à plusieurs plaideurs. Les juges font preuve d'une stricte fermeté dans leur appréciation, on assiste souvent à des situations plus ou moins fâcheuses donnant naissance à plusieurs cas d'irrecevabilité et de lenteur de procédure.

La conséquence logique qui découle de ces obstacles à la justice est que le juge africain et le béninois en l'occurrence est particulièrement limité dans son intervention dans la protection de l'environnement. Le résultat en est que la jurisprudence africaine est quasiment inexistante en matière de contentieux environnemental491 à l'exception bien sûr de quelques jugements rendus au niveau des juridictions pénales de premières instances du pays en fragrant délit, dans le domaine des infractions forestières surtout492. Mais, très rarement ces

489 Article 49 et 50 de la loi $n^{\circ} 2004-20$ du 17 aout 2007 portant règles de procédures applicables devant les formations juridictionnelles de la cour suprême du Bénin, qui a abrogé la loi n90-012 du 1er juin 1990 remettant, l’ord. N²1/PR du 26 avril 1966 portant composition, organisation, fonctionnement et attribution de la cour suprême.

490 Article 56 de la loin $^{\circ} 2004-20$ du 17 aout 2007 portant règles de procédures applicables devant les formations juridictionnelles de la cour suprême.

491 (K) AHADZI, op. cit. p.405

492 .En dehors des cas de fragrant délit, les juridictions béninoises ne connaissent pratiquement pas de contentieux pénal. 
jugements sont frappés d'appel et le recours en cassation est quasi nul. Pourtant, sur cet aspect, l'on aurait pu disposer d'une jurisprudence fournie en fonction de l'importance des règles de polices en matière de protection de l'environnement. C'est l'intérêt affiché des pouvoirs publics avec le concours des partenaires au développement comme l'UE et la GTZ493 de préserver des parcs nationaux qui permettent aux tribunaux de régler quelques contentieux à eux transmis par les forestiers.

Tableau N N7 : Taux de dossiers sortis par les TPI de 2005 à 2008

\begin{tabular}{lllll}
\hline Rubriques & $\mathbf{2 0 0 5}$ & $\mathbf{2 0 0 6}$ & $\mathbf{2 0 0 7}$ & $\mathbf{2 0 0 8}$ \\
\hline Volume des affaires & 50.276 & 53.554 & 50.567 & 55.854 \\
Dossiers sortis au cours de la période & 19.668 & 18.385 & 15.229 & 17.363 \\
Dossiers restants en fin de période & 30.608 & 35.159 & 35.275 & 38.491 \\
Taux de dossiers sortis en fin de période & 39 & 34 & 30 & 31 \\
\hline
\end{tabular}

Source : Tableau de bord social 2008, INSAE, Cotonou 2009.

\section{Le caractère spécifique de l'infraction pénale environnementale}

Le traitement par le juge des infractions à caractère environnemental déroge des infractions de droit commun. En droit commun procédural, il est un principe cher aux juges et aux pénalistes à savoir " pas d'intérêt, pas d'action» et l'intérêt, lorsqu'il existe doit être non seulement personnel mais aussi « né et actuel ». Cet adage ou principe ne trouve pas entièrement application en droit pénal de l'environnement. En effet, l'environnement est constitué d'éléments «biotiques » et d'éléments « abiotiques », d'éléments susceptibles d'appropriation et d'éléments insusceptibles d'appropriation privée comme les res communes ou res nullius c'est-à-dire des choses sans maître qui " n'appartiennent à personne mais dont l'usage est commun à tous ${ }^{494}$, d'autant plus qu'elles sont à

493 Respectivement pour le Parc National de la Pendjari et le parc " w »

494 Cf. art.714 du code civ. ; F. OST et S. GUTWIRTH (sous la direction), Quel avenir pour le droit de l'environnement ? (sous la direction). Actes du colloque organisé par le CEDRE, Bruxelles, 1996, p.105. 
la disposition des intérêts du genre humain, présent et futur. II s'agit par exemple de l'eau, de l'air, de la terre, des biens déclarés par les organismes internationaux $\left(\right.$ UNESCO) ${ }^{495}$, " patrimoines communs de l'humanité " (cas de la réserve de biosphère de la Pendjari au Bénin, de la forêt de l'Amazonie, etc....). Il en est ainsi des espèces animales ou végétales partiellement ou intégralement protégées. Pour tous ces différents cas précités, la qualification de l'infraction, l'intérêt à agir qui aurait pu être direct et personnel ne l'est pas. II s'efface au détriment de l'intérêt collectif, de l'intérêt de l'humanité à sauvegarder telle que la destruction des « processus écologiques, des diversités génétiques, des écosystèmes ou des paysages ${ }^{496}$, des fonds marins, de la biosphère etc.

L'humanité n'appartient à personne. La prise en compte de ces destructions se heurte alors à l'absence de "victime titulaire » d'un droit à réparation, d'où la notion de " dommage écologique " défendue par les Associations d'obédience écologiques régulièrement habilitées. II en est ainsi puisque l'environnement n'est pas un sujet de droit, bien que des propositions intéressantes en ce sens aient été faites ${ }^{497}$.

Mais cette conception nouvelle de voir les choses en privilégiant l'action collective de défense des milieux naturels, se heurte à l'article 2 du CPP ${ }^{498}$ et rencontre des résistances parfois de la part de certains juges, attachés notamment

495 Sous l'égide de l'UNESCO, il a été adopté en 1972, la convention relative à la protection du patrimoine mondial, culturel et naturel. Le parc de la Pendjari au Bénin est classé aire protégée par décret $\mathrm{N}^{\circ} 8839 \mathrm{ST} / \mathrm{F}$ du 13 décembre 1954. Son objectif principal au départ était la protection des grands mammifères pour la chasse sportive coloniale. En 1961, la réserve est devenue parc national de la Pendjari avec les mêmes objectifs. Ce n'est que par décret N94-64 du 21 mars 1994 qu’elle est classée par le gouvernement réserve de la biosphère du programme sur l'homme et la biosphère. (cf. rapport de mission pour l'élaboration du plan de l'aménagement et de la gestion de la gestion de la réserve de biosphère de la Pendjari, février-mars 2002, CENAGREF, Tanguiéta).

496 (M-J) LITTMANN-MARTIN et C. LAMBRECHTS, Rapport général, Le dommage écologique, en droit interne communautaire et comparé, collection droit et économie de l'environnement, Economica, colloque, Paris 1991, p.64.

497 Idem

498 CPP français et béninois qui dispose que « l'action civile en réparation des dommages causés par un crime, un délit ou une contravention appartient à tous ceux qui ont personnellement souffert du dommage causé par l'infraction. " Or les Associations de défense ne sont pas personnellement victimes. 
au principe " nul ne plaide par procureur ${ }^{499}$ ». En effet, l'hostilité de la chambre criminelle de la cour de cassation française à l'action civile des associations a été maintes fois soulignée. Elles s'expliquent par le particularisme de l'action civile devant les juridictions répressives puisque celles-ci en mettant en mouvement l'action publique, pallie l'inertie du parquet, mais, de ce fait, porte atteinte au principe de l'opportunité des poursuites, au monopole du ministère public dans le déclenchement des poursuites ${ }^{500}$. Pour J.F. Neurey, « nul besoin de préciser que si les animaux et les plantes ne sont pas sujet de droits, ils n'ont pas, $a$ fortiori, accès au prétoire. Les mentalités et la jurisprudence majoritaire exigent toujours que l'on soit atteint dans sa chaire ou dans ses biens, ou que l'on risque de l'être, avant d'introduire une action ${ }^{501}$ ». II poursuit en précisant que « pourtant, si l'on veut bien se placer dans l'optique d'une protection efficace de l'environnement, n'importe quel citoyen ou groupe de citoyens devrait pouvoir se plaindre d'une nuisance, sans être tenu d'administrer la preuve qu'il n'est directement la victime ${ }^{502}$ ).

En effet, cette position d'hostilité de la cour de cassation française, à l'égard des associations de défense d'environnement est donc à relativiser. Puisque, depuis la loi dite " Barnier » de $1995^{503}$, en passant par le code rural et l'ordonnance du 18 février 2000 et actuellement par le code de l'environnement ${ }^{504}$, le droit pénal relatif aux associations de défense de l'environnement a évolué. Aujourd'hui, ces associations ont le pouvoir d'ester en justice et de se constituer parties civiles « en ce qui concerne les faits portant un préjudice direct ou indirect aux intérêts collectifs qu'elles ont pour but de défendre... ${ }^{505}$. C'est ainsi, que la cour d'appel de Caen a condamné la COGEMA à verser dix (10.000) mille euro de dommages intérêts à GREENPEACE le 12 avril 2005 pour importation et stockage

499 On consultera avec profit l'article de M. Caballero qui, en terme acides, présente et condamne le conservatisme de la doctrine et de la jurisprudence française relative à l'accueil réservé à l'action de groupe comparé aux solutions hardies de certains droits étrangers, in " plaidons par procureur ! De l'archaïsme procédural à l'action de groupe ", Rev. Trim. dr.civ.1985, p. 247 et s.

500 (M-J) LITTMANN-MARTIN et C. LAMBRECHTS, op. cit., p.69

501 Principes de droit de l'environnement, Kluwer, éditions juridiques, Belgique, 1995. p.212

502 Idem.

503 Loi n95-101 du 2 févier 1995

504 Art. L141-1 du C. de l'Env.

505 Art. L 142-2 du C.env. 
illégal de déchets nucléaire portant nuisance à l'environnement. GREENPEACE a qualifié cette décision d'historique. ${ }^{506}$

En effet, si nous sortons du cadre habituellement connu par les juges béninois en matière de contentieux environnemental, notamment les dommages à caractère forestier, l'on s'en convainc facilement de la complexité du droit pénal de l'environnement et de la difficulté qu'ont les juges de dire le droit en matière de préjudices strictement environnementaux. Et pour cause, les juges n'arrivent pas à déterminer avec suffisamment de précision la consistance et l'étendue du dommage. La qualification précise de l'infraction et la détermination de son auteur, constituent à n'en point douter des sources de controverses doctrinales et jurisprudentielles qui illustrent parfaitement la difficulté du juge pénal dans le processus de règlement des litiges.

Ainsi, la destruction d'un spécimen de faune, d'une espèce rare, tel un balbuzard ${ }^{507}$, le retournement ou le bétonnage d'une station unique d'espèce de flore menacée de disparition, l'extraction de graviers dans une frayère d'esturgeons détruisant tout espoir de reproduction ${ }^{508}$, la pollution massive, chronique ou accidentelle de la mer, d'un lac, d'un cour d'eau entrainant la mort constatée de poissons, d'oiseaux, sont autant d'exemples de préjudices incontestables car d'ores et déjà réalisés ${ }^{509}$.

Cependant, la simplicité de ces exemples n'est qu'une apparence. La réalité du dommage écologique subira l'épreuve du doute scientifique, tout particulièrement dans les faits de pollution. La prudence des experts, formés aux méthodes de preuves rigoureuses propres aux sciences exactes, les conduira souvent à des preuves dubitatives quant aux effets véritablement destructeurs de certains rejets dans le milieu naturel. La controverse sur les conséquences dans le milieu naturel des lessives avec ou sans phosphates, l'incinération en mer du nord des déchets hautement toxiques sont des exemples parmi tant

506 Greenpeace-newsletter avril 2005, www.greenpeace.fr/newsletter

507 Tri .inst. Tournon, 28 avril 1981, gaz.pal.1981, 2.J.560, note Ed .Alauze ; rev. Trim.. dr.civ.1981, p.853, obs. Durry ; Cass.civ., 16 nov.1982, Bull.civ.l, n³31, p.282

508 Tri. Corr. Marmende, 25 janv.1990, confirmé par Agen, 15 octobre 1990, inédits.

509 (M-J) LITTMANN-MARTIN et C. LAMBRECHTS, Rapport général, Le dommage écologique, en droit interne communautaire et comparé, collection droit et économie de l'environnement, Economica, colloque, Paris 1991, p.51. 
d'autres, de ces incertitudes scientifiques, sources de difficultés juridiques. Le tribunal de Bastia, dans sa décision du 4 juillet 1985 relative à la responsabilité de la Montedison pour les rejets effectués au nord du cape Corse, a relevé quant aux conséquences dues aux rejets acides, "que les Experts ont précisé qu'il s'agit là d'un des problèmes les plus complexes de l'écotoxicologie marine, d'une part parce que la capacité de résistance des organismes marins à l'acidité n'est pas connue, et d'autre part, parce que l'eau de mer n'est pas neutre mais alcaline, que l'extrême diversité des organismes marins n'a pas permis de dire ce qui était tolérable de ce qui ne l'était pas en fonction de chacun d'eux... ". Ces inconnues rendaient impossible la constatation d'un dommage certain. Mais semble t-il, pour les victimes, l'affirmation par ces mêmes experts, d'une perte incontestable de la biomasse causant aux lieux de pêche un dommage, permit de conclure à la réalité du préjudice subi par la prud'homme des pêcheurs de Bastia $^{510}$.

Outre ces " doutes scientifiques " qui s'imposent aux juges, son intime conviction fondée parfois sur " une rigueur scientifique fragile " l'influence très souvent. C'est le cas par exemple d'une décision du tribunal d'instance de Nice. Saisi d'une demande en réparation de l'Association pour la protection des animaux sauvages et du patrimoine naturel (ASPAS), à la suite de la destruction d'un loup, sans nier le rôle que cet animal est susceptible de jouer dans la chaîne écologique notamment en détruisant les animaux nuisibles ou malades, conclut à l'absence de dommage, l'animal étant lui-même devenu nuisible. Le défendeur faisait valoir que I'ASPAS « ne peut arguer d'un préjudice quelconque dans ces efforts pour sauvegarder les espèces en voie de disparition, du fait notamment que l'animal abattu, solitaire et handicapé, ne représentait aucune valeur pour la faune sauvage ${ }^{511}$.

Enfin, l'accès à la justice pénale est aussi confrontée aux exigences socioéconomiques qui limitent le juge dans son élan de dire le droit.

510 Inédit. Pour les décisions antérieures ayant retenues la compétence du tribunal de grande instance de Bastia et ordonner une expertise pour déterminer et évaluer le dommage, voir TGI, Bastia, 8 décembre 1976, D. 1977

427, note de Raymond-Gouilloud. Citer par (M-J) LITTMANN-MARTIN et C. LAMBRECHTS, op. cit. p.51

511 Gaz. Pal.1990, I, Jur. p. 213. op. cit. 52. 


\section{§II : Les obstacles socio-économiques et politiques à l’accès à la justice}

Le Bénin, à l'instar de plusieurs pays africains, a commémoré en 2010 le cinquantenaire, donc les " noces d'or » de son indépendance, de son accession à la souveraineté nationale. L'heure est au bilan dans tous les secteurs afin de jauger de la capacité intrinsèque de cette souveraineté recouvrée. Plusieurs défis restent encore à relever aux nombres desquels l'on peut s'interroger sur le bilan à retenir dans le cadre de l'accès à la justice pénale. Afin de mieux apprécier le fonctionnement de la justice pénale, il nous apparaît nécessaire d'analyser d'abord les pesanteurs sociologiques qui caractérisent le contexte africain de la justice pénale avant d'évaluer les moyens matériels, financiers et humains au service de cette justice pénale.

\section{A) Un contexte sociologique africain peu favorable}

Le droit en général et le droit pénal en particulier est une discipline hautement technique mais au service des populations. Les populations face à un tel droit ont déjà assez de mal à cerner les contours d'une science qui réprime. C'est bien dans ce contexte, qu'au nom de la préservation de la nature et de l'environnement qu'elles doivent se familiariser avec de nouveaux concepts et les exigences du droit pénal et de la procédure pénale de l'environnement. II nous semble alors nécessaire de faire d'abord une clarification en examinant ce contexte sociologique qui s'apparente à notre sens à « une sociologie pénale ${ }^{512}$ ». C'est dans cette logique que, nous focaliserons notre réflexion sur deux centres d'intérêt qui fondent notre appréhension quant à la fiabilité des procédures judiciaires : I'analphabétisme et l'ignorance d'un côté et la crainte excessive mais justifiée à l'égard de la justice pénale de l'autre. 


\section{L’analphabétisme et l'ignorance}

L'effectivité du droit suppose qu'une règle de droit qui existe est connue des citoyens qui en sont les principaux destinataires. Il est, en effet, évident que I'on peut difficilement respecter une norme si on en ignore l'existence ou si on ne peut en saisir la signification. Si le destinataire de la règle de droit se voit imposer un modèle de comportement auquel il doit se soumettre, encore faut-il qu'il en est connaissance. C'est cette exigence élémentaire du droit que traduit l'adage hérité du droit romain selon lequel « nul n'est censé ignoré la loi » ${ }^{513}$.

Or, en Afrique subsaharienne, il n'échappe à personne que la plupart des règles de droit édictées par les pouvoirs publics sont ignorées par la grande partie de la population qui reste analphabète et n'a pas accès au droit. Ainsi, au Bénin, la première cause qui entrave l'accès des populations à la justice est le taux d'analphabétisme très élevé ${ }^{514}$, même si des efforts ont été consentis durant le demi-siècle dans le domaine de la scolarisation, il n'en demeure pas moins vrai que dans leur grand ensemble, les populations africaines sont analphabètes. Ce phénomène d'analphabétisme qui perdure, induit au plan juridique des conséquences quant à l'accès à la justice pénale. Ainsi, dans une très large mesure, les populations béninoises ignorent l'existence des textes pénaux législatifs et réglementaires qui organisent leur vie quotidienne.

Remarquons que si l'analphabétisme touche la couche illettrée constituée de la majeur partie de la population, ne sachant ni lire ni écrire le français, l'ignorance, mal endémique, gagne non seulement cette couche mais aussi la petite minorité dite lettrée ou instruite. Car, ils sont très nombreux, la proportion des fonctionnaires ou cadres des administrations publiques ou privées qui ignorent aussi les procédures judiciaires et ne font aucun effort pour en savoir plus.

513 V. ZAKANE, (Coord. de L. GRANIER), Problématique de l'effectivité du droit de l'environnement en Afrique: I'exemple du Burkina Faso, in, Aspects contemporains du droit de l'environnement en Afrique de l'Ouest et centrale. UICN, Gland, Suisse, 2008, p.26.

514 Selon la BAD, il est 63\% en 1995, rapport sur le développement en Afrique, Paris, Economica, p.219. V. aussi le RGPH3 du Bénin de 2002 qui affiche un taux d'analphabétisme des femmes de $72 \%$ sur une population de 6.769 .914 hts. 
Selon les conclusions des travaux des états généraux de la fonction publique béninoise (1996), le système juridique béninois fonctionne mal dans son ensemble. Cette situation s'explique par : la faible couverture juridictionnelle du pays, l'insuffisance des infrastructures et des moyens, le dualisme juridique qui rend difficile l'administration de la justice et la lenteur des procès. II en résulte une méfiance des populations vis-à-vis de la justice à savoir que $64,5 \%$ des justiciables pensent que les jugements ne sont pas bien rendus et $48 \%$ approuvent les actes de vindicte populaire selon les résultats d'un sondage réalisé dans le cadre des préparatifs des Etats généraux de la justice ${ }^{515}$. C'est dans cet ordre d'idée que s'inscrivait l'allocution de l'ancien président de la cour suprême béninois, Maitre A. ZINZINDOHOUE lorsqu'il déclarait « la loi qui autorise tout citoyen ayant intérêt à agir, à savoir la justice administrative, n'est pas connue de tout le monde et la cour suprême a organisé des journées portes ouvertes au moins trois fois depuis son existence pour se faire mieux connaître afin de mieux expliquer à la population la procédure de saisine des différentes juridictions ${ }^{516}$ ».

Reconnaissant la réalité d'un tel problème, le professeur DEGNI-SEGUI a pu écrire : en ces termes « l'un des obstacles majeurs à l'accès du prétoire en Afrique, c'est l'ignorance du droit en général et de leurs droits en particulier par des citoyens qui sont pourtant censés ne pas les ignorer en vertu de l'adage nemo legem ignorare censitur ${ }^{517}$. La question est d'autant plus cruciale que le droit applicable est pour l'essentiel un droit hérité de la colonisation et, donc, étranger aux mœurs de ceux qu'il est censé régir. Les gouvernants une fois les textes adoptés et publiés ne se préoccupent plus de leur vulgarisation à grande échelle, ce qui aggrave l'absence d'information des citoyens.

Il importe de mentionner toujours dans l'optique de stigmatiser la non internalisation des préoccupations environnementales l'indifférence parfois manifeste des populations à l'égard de ce qui est considéré dans le droit moderne comme des inconvénients anormaux de voisinage : il s'agit des bruits excessifs

515 , Rapport intégré sur l'état de l'environnement au Bénin, ABE, MEHU, Cotonou, 2002.

516 A. ZINZINDOHOUE, Brèves aperçu de la justice administrative béninoise, in, La Nation, $n^{\circ}$ 2775 du vendredi 6 juillet 2001, p.2

517 In, L'accès à la justice et ses obstacles, p.252. Cité par (K) AHADZI, op. cit. p.401. 
et des odeurs incommodantes. Ailleurs, dans les pays du nord par exemple, ces manifestations constituent un champ très fertile pour la multiplication des actions judiciaires pour trouble de voisinage. Mais en Afrique, par tolérance ou par résignation on les supporte avec philosophie ${ }^{518}$.

De cette analyse, on pourrait déduire ce qui suit : si le droit moderne en général qui existe depuis des lustres et enseigné dans les écoles ou dans les universités est voué au sort précédemment décrit, à savoir sa méconnaissance fragrante, qu'en sera -t-il alors du droit de l'environnement et en particulier du droit pénal de l'environnement, discipline encore naissante ? Dès lors seule une volonté politique émergente soutenue des pouvoirs publics, peut imprimer une vision salutaire en commençant par éradiquer la crainte excessive des justiciables à l'égard des juridictions.

\section{Une crainte excessive mais justifiée à l'égard de la justice}

Le libre accès à la justice est constamment entravé par la révérence excessive que le justiciable manifeste à l'égard de l'administration et des juges. La simple évocation d'une juridiction ou du nom de juge suscite peur et inquiétude permanente au sein des populations. Il est extrêmement rare que les justiciables saisissent les tribunaux pour les atteintes à l'environnement. ${ }^{519}$

Dans l'opinion, l'administration est même considérée comme " dangereuse et intouchable ». Poussant à fond son analyse, le professeur A. HADZI estime que " cette attitude est fondée sur deux phénomènes caractéristiques du pouvoir politique moderne africain : une personnalisation souvent excessive des fonctions politiques et une tendance accentuée à l'autoritarisme dans les rapports avec les administrés $5^{520} »$. Ces deux phénomènes découragent les quelques rares citoyens qui voudraient bien faire valoir leur droits en justice de peur que leur attitude ne soit perçue comme une attaque personnelle contre

518 K. AHADZI, op. cit. p.402

519 V. ZAKANE, (Coord. de L. GRANIER), Problématique de l'effectivité du droit de l'environnement en Afrique: I'exemple du Burkina Faso, in, Aspects contemporains du droit de l'environnement en Afrique de l'Ouest et centrale. UICN, Gland, Suisse, 2008, p.23. 
telle ou telle autorité avec les risques supposés ou réels de représailles que celle-ci pourrait être amené à exercer contre le " rebelle ${ }^{521}$. Dès lors s'installe le clientélisme, le népotisme, le trafic d'influence, le favoritisme, la concussion et la corruption qui sont d'une manière générale inhérentes aux procédures judicaires notamment en Afrique.

Ainsi, la lenteur judiciaire, l'obsolescence des textes juridiques, l'incertitude de la jurisprudence ainsi que la corruption réelle ou supposée qui sévit dans le secteur ont fini par éroder la confiance que le citoyen devrait avoir dans le système judiciaire béninois ${ }^{522}$. Selon une enquête sur la corruption et la gouvernance au Bénin, en 2006, les sondés trouvent que la longueur des procédures (81\%), leur complexité (76\%), les frais des avocats très élevés (73\%), I'influence de la corruption sur les décisions du tribunal (71\%) et le coût non officiel trop élevé (66\%) sont des obstacles majeurs au recours aux tribunaux.

Ces fléaux constituent en réalité des faits de société envers lesquels il faut engager une lutte implacable. Lorsque vous connaissez un juge ou une autorité politique "bien placée ", votre dossier aura plus de chance d'être étudié favorablement. Au cas où vous ne connaissez personne et que vous n'avez pas d'argent non plus, encore moins d'avocat, votre dossier peut être classé sans suite ou subir le drame de la lenteur judiciaire. Même les juridictions de conciliation $s^{523}$ créées au niveau de chaque commune du pays, n'échappent pas à ces fléaux malgré leur très faible taux de fréquentation.

Ce désintérêt de la justice, et particulièrement de la justice pénale des populations, facilite le développement des procédures alternatives comme le recours au règlement des conflits à l'amiable selon les procédures coutumières. Ainsi, que le souligne le professeur SAWADOGO, « l'engagement d'une action en justice est considéré comme un acte d'inimitié à l'endroit du défendeur qui

521 K. AHADZI, op. cit. p.402.

522 V. «Le livre blanc sur l'etat de la corruption au Bénin., Réalisé par l'observatoire de lutte contre la corruption, éd.2009. Site www.olcbénin.com

523 Cf. art.21 de la loi $n^{\circ}$ 2001-37 portant organisation judicaire en République du Bénin. il s'agit des juridictions au bas de l'échelle de l'organisation judicaire. Il n'en existe au moins une par commune. 
ne manquera pas d'occasion de se venger. II n'est donc pas étonnant que de nombreux débiteurs ne soient pas attraits en justice ${ }^{524}$ ».

Dans le domaine répressif environnemental, le règlement amiable se traduit même parfois par l'immixtion de l'administratif dans le juridictionnel. Comme en témoigne le ministère camerounais chargé de la protection de la nature dont " l'omniprésence vient éclipser le rôle juridictionnel décisif que seraient amenés à jouer les juridictions nationales compétentes ${ }^{525}$ ».Les litiges sont donc résolus par voie de négociation, ce qui n'est pas mauvais en soi. Mais il faut bien voir que cette attitude prive le juge pénal africain d'une grande partie du contentieux, notamment celui relatif à l'environnement.

Le coût élevé de la justice et le déficit de moyens matériels et humains, viennent aussi entraver la procédure pénale.

\section{B) La carence des moyens matériels, financiers et humains}

Il conviendrait ici d'examiner les moyens mis au service de la justice au Bénin afin d'observer son fonctionnement marqué par son coût élevé et par son déficit chronique en moyens matériels et humains.

\section{Le coût élevé de la justice pour les justiciables}

Conformément à l'article 7 de la charte africaine des droits de l'homme et des peuples, on peut lire à l'article 5 de la loi n90-003 du 15 mai 1990 portant remise en vigueur de la loi n64-28 du 9 décembre 1964 portant organisation judicaire en République du Bénin et abrogée par la loi n²001-37 du 27 avril 2002, dont l'article 6 qui demeure inchangé, dispose, que « la justice est gratuite sous les seules réserves des dispositions des lois fiscales concernant le droit de timbre

\footnotetext{
524 M. SAWADOGO, L'accès à la justice en Afrique francophone. Problèmes et perspectives : le cas du Burkina Faso, in, actes du colloque du Maurice. P.308. cité par (K) AHADZI, op. cit. p.402.

525 J.C. TCHEUWA, Les préoccupations environnementales en droit positif camerounais, article, RJE 1/2006.
} 
et d'enregistrement ". Ces dispositions posent ainsi le principe de la gratuité de la justice. Cependant, à l'épreuve des faits, ce principe souffre de fréquents démentis en ce sens que le procès, notamment le procès pénal entraine un coût auquel ne peuvent faire face que peu de citoyens. Par exemple, devant la cour suprême, tout justiciable doit s'acquitter d'une caution non remboursable ayant évolué de 5.000f CFA sous l'empire de l'ancienne loi à $15.000 f$ CFA ${ }^{526}$ sous la nouvelle loi. ${ }^{527}$ II faut également tenir compte du ministère d'un avocat qui est pratiquement obligatoire devant cette cour et aux frais du requérant ${ }^{528}$. Pour la plupart du temps, ces honoraires ne sont pas accessibles aux démunis ou aux pauvres. De plus, en général, à l'issue du procès, les dépens sont mis à la charge du plaideur perdant alors que le gagnant doit engager des frais de justice pour faire exécuter la décision. II n'est pas exclu qu'il se heurte à l'insolvabilité du débiteur ou à des résistances de l'administration au cas où cette dernière est elle-même la cause.

En définitive, comme le précise le professeur K. AHADZI, « l'accès à la justice, on, le sait est subordonné à l'acquittement de certains droits. Ainsi, le justiciable doit -il payer le droit de timbre ; parfois il est obligé de prendre en charge les frais de transport du juge ou des forces de l'ordre en cas de descente sur les lieux ; il doit aussi faire face aux honoraires d'avocat, d'huissier, etc. Tout ceci est de nature à décourager les citoyens dont les moyens économiques et financiers sont dérisoires ». Et, à NKOU MVONDO, de renchérir « beaucoup de justiciables sont découragés lorsqu'ils pensent aux taxes à verser, aux timbres à apposer, aux cautions exigées. En Afrique, tout cela ne suffit pas pour que la justice soit en fait saisie. II faut encore compter avec les pourboires et autres

526 Alors que le SMIG qui était de $25.000 \mathrm{f}$ au Bénin, conformément au décret $\mathrm{n}^{\circ} 2000-162 \mathrm{du}$ 29 mars 2000, n'est actuellement d'environ 30.000 f CFA.

527 Art.6 de la loi n²004-20 du 7 aout 2007 portant règles de procédures applicables devant les formations juridictionnelles de la cour suprême. JORB n06 du 15 mars 2008.

528 Avec l'entrée en vigueur de la loi n²008-07 du 28 février 2011 portant code de procédure civile, commerciale, administrative, sociale et des comptes, en son article $23-2^{\circ}$, le ministère d'avocat devient aussi obligatoire devant les cours d'appel. 
" dessous de tables » dont il faut s'acquitter pour que le dossier déposé suive son cours normal ${ }^{529}$ \%.

En outre, l'assistance judiciaire qui vise à " aider financièrement le plaideur démuni de ressources, à mener ou à subir un procès devant une juridiction civile, pénale ou administrative ${ }^{530}$ 》 bien que prévue par les textes béninois ${ }^{531}$ afin d'alléger les peines des citoyens aux maigres ressources, elle est difficile à obtenir. Elle peut être " accordée pour tous les litiges devant la cour suprême(...). Elle doit être étudiée par une commission. Elle doit être accompagnée de toutes les pièces susceptibles de justifier de l'indigence du demandeur ${ }^{532}$. D'abord rares sont les justiciables qui sont informés d'une telle procédure ensuite pour ceux qui sont informés et acceptent d'engager la procédure, le défaut de production d'une quelconque pièce du dossier entraine I'irrecevabilité de la demande. Si la commission accepte, elle peut octroyer une assistance partielle ou totale.

En France, par exemple, cette forme d'assistance judiciaire est dépassée. Elle a été successivement remplacée par l'aide judicaire ${ }^{533}$ et l'aide juridique ${ }^{534}$. Elle s'étend non seulement à la prise en charge des frais du procès au cours d'une instance juridictionnelle mais aussi à tous les frais inhérents à la défense d'un droit. L'aide juridique comprend donc l'aide juridictionnelle, l'aide à l'accès au droit et l'aide à l'intervention de l'avocat au cours de la garde à vue et en matière de médiation pénale et de la composition pénale ${ }^{535}$ de sorte à obtenir un procès équitable, idéalement à un niveau similaire à ce qu'un client payant recevrait comme c'est le cas au Canada ${ }^{536}$.

529 N.P. NKOU MVONDO, La crise de la justice de l'Etat en Afrique noire francophone, PENANT, n824,1997, p.218.

530 R. GUILLIEN et J. VINCENT, op. cit., p.30

531 Elle est organisée par les art.7, 8,9 et 10 de loi n²004-20 du 7 aout 2007 précité.

532 Idem.

533 Elle est instituée par la loi $n^{\circ} 72-11$ du 3 janvier 1972qui fixe un certain seuil de revenu mensuel : cf. R. PERROT, op. cit., p.71

534 Loi- n91-647 du 10 juillet 1991 relative à l'aide juridique. V. aussi la Loi n 2007-210 du 19 février 2007 portant réforme de l’assurance de protection juridique.

535 Idem. Cf. art.1

536 Patricia HUGHES et Mary Jane MOSSMAN, Repenser l'accès à la justice pénale au Canada : un examen critique des besoins, des réponses et des initiatives de justice réparatrice, Canada, mars 2001. 
Comme on le constate au Bénin, l'accès à l'assistance judiciaire nécessite des frais supplémentaires au requérant pour constituer le dossier. C'est, avouons-le assez pénible pour ces mêmes démunis de jouir de ce droit. Cette forme d'assistance judiciaire dont le mobile repose sur la détermination de I'indice de pauvreté ou d'indigence est -t-il encore fiable ? Et comment se calcul cet indice de pauvreté ?

Au regard de tous ce qui précède, nous estimons que les craintes des populations au regard du fonctionnement de la justice pénale, nous paraissent justifiées.

Tous ces paramètres, les uns plus imprévisibles que les autres, peuvent dissuader d'innombrables citoyens à engager ou à poursuivre une action en justice. Or la défense de leur droit en dépend.

\section{Un déficit chronique de magistrats spécialisés.}

Le Bénin, dans sa politique répressive est très limité aussi bien par les infrastructures judiciaires que par les ressources humaines qualifiées, en l'occurrence les magistrats.

Ainsi, comme en témoigne le rapport sur les Etats généraux de la Justice ${ }^{537}$, l'insuffisance quantitative et qualitative du personnel au sein de l'administration judiciaire est aisément perceptible. En 1996, le Bénin comptait 180 magistrats environ dont une vingtaine dans diverses administrations non judicaires. Pour les aider dans leur tâche on dénombrait 170 fonctionnaires des greffes et parquets, soit un ratio magistrats sur fonctionnaires des greffes de un environ (cf. Tableau $n^{\circ} 8$ ci-dessous). 


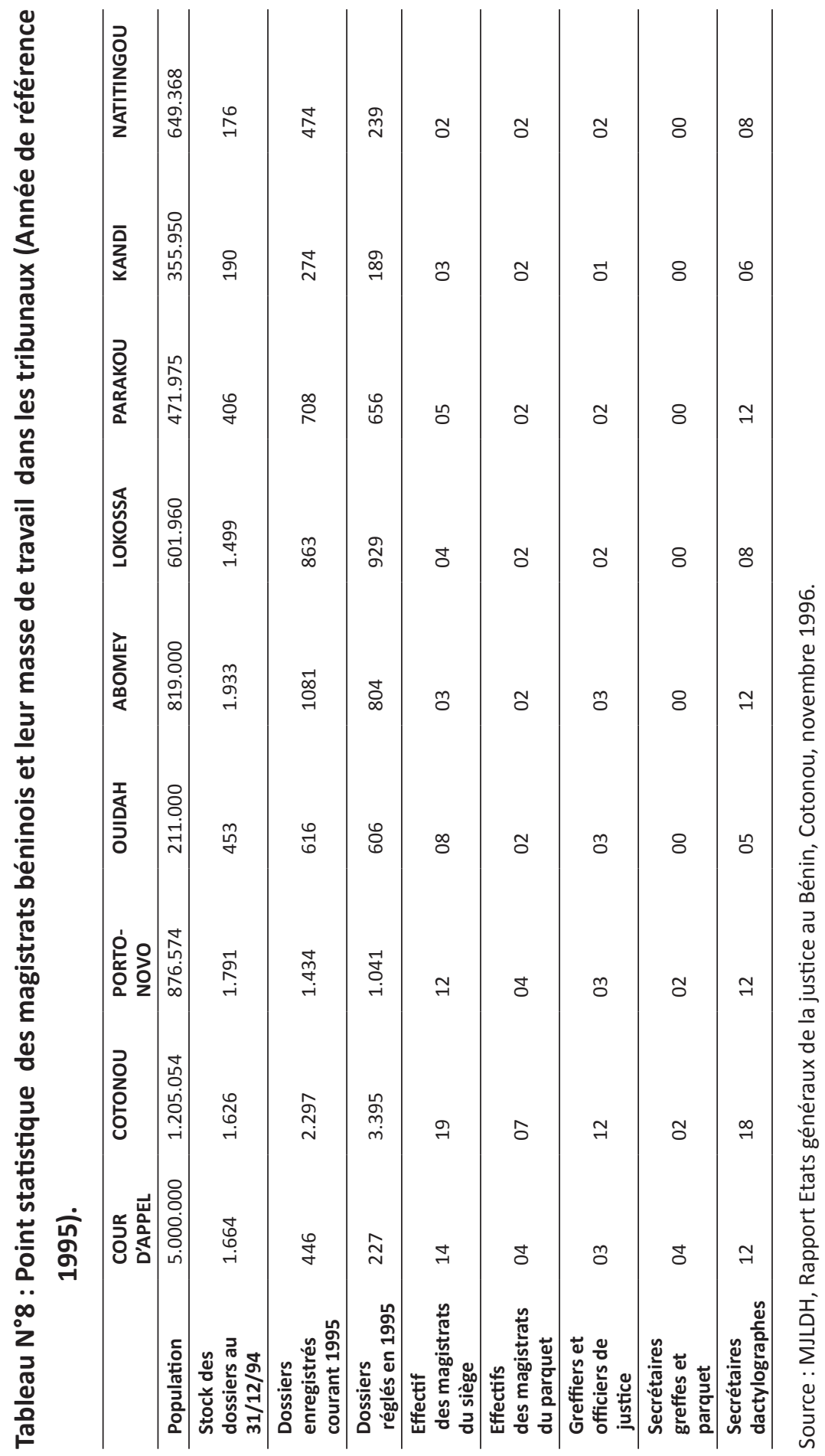


Tableau $N^{\circ} 9$ : Effectif du personnel greffier en exercice dans les TPI et les CA de 2005 à 2008

\begin{tabular}{lllll}
\hline INDICATEURS & 2005 & 2006 & 2007 & 2008 \\
\hline $\begin{array}{l}\text { Effectifs des greffiers en exercice } \\
\text { dans les TPI et CA }\end{array}$ & & & & \\
Cour d'appel Abomey & & 7 & 7 & 7 \\
Cour d'appel Cotonou & 7 & 7 & 11 & 12 \\
Cour d'appel Parakou & 2 & 5 & 4 & 4 \\
TPI Abomey & 12 & 11 & 15 & 13 \\
TPI Cotonou & 16 & 32 & 31 & 28 \\
TPI Kandi & 7 & 7 & 8 & 7 \\
TPI Lokossa & 7 & 11 & 12 & 12 \\
TPI Natitingou & 8 & 10 & 8 & 8 \\
TPI Ouidah & 9 & 11 & 11 & 10 \\
TPI Parakou & 11 & 14 & 14 & 12 \\
TPI Porto-Novo & 13 & 18 & 18 & 15 \\
Ensemble & 92 & 133 & 139 & 128 \\
\hline
\end{tabular}

Source : Tableau de bord social 2008, INSAE, Cotonou 2009.

Tableau N 10 : Effectif magistrats en exercice dans les TPI et les CA de 2002 à 2008

\begin{tabular}{|c|c|c|c|c|c|c|c|}
\hline INDICATEURS & 2002 & 2003 & $* 2004$ & 2005 & 2006 & 2007 & 2008 \\
\hline \multicolumn{8}{|c|}{$\begin{array}{l}\text { Effectifs des magistrats en } \\
\text { exercice dans les TPI et CA }\end{array}$} \\
\hline Cour d'appel Abomey & & & & & 8 & 8 & 8 \\
\hline Cour d'appel Cotonou & & & & 15 & 13 & 12 & 12 \\
\hline Cour d'appel Parakou & & & & 12 & 9 & 9 & 9 \\
\hline TPI Abomey & 5 & 5 & & 6 & 7 & 7 & 7 \\
\hline TPI Cotonou & 18 & 19 & & 19 & 24 & 25 & 25 \\
\hline TPI Kandi & 2 & 3 & & 5 & 5 & 5 & 5 \\
\hline TPI Lokossa & 4 & 4 & & 4 & 7 & 7 & 7 \\
\hline TPI Natitingou & 3 & 3 & & 7 & 6 & 6 & 6 \\
\hline TPI Ouidah & 3 & 3 & & 6 & 6 & 6 & 6 \\
\hline TPI Parakou & 5 & 5 & & 10 & 6 & 9 & 9 \\
\hline TPI Porto-Novo & 9 & 8 & & 9 & 12 & 11 & 11 \\
\hline Ensemble & 49 & 50 & & 93 & 103 & 105 & 105 \\
\hline
\end{tabular}

Source : tableau de bord social 2008, INSAE, Cotonou 2009.

$(*)$ Données non fiables, donc non disponible 
Au regard du Tableau $n^{\circ} 8$ dont l'année de référence est 1995, il ressort que la cour d'appel et les huit tribunaux de première instance du pays à l'époque comptaient 178 magistrats, 97 étaient effectivement employés dans les juridictions d'instance et d'appel (70 au siège et 27 au parquet). Le reste était soit en service à la chancellerie ou soit mis à disponibilité ou en détachement dans d'autres secteurs de l'administration ou les conditions de travail et de vie sont plus attrayantes. Sur les 171 fonctionnaires des greffes, 132 servaient dans les juridictions.

A titre comparatif, toute proportion gardée, la France comptait dans la même période environ 6800 magistrats pour plus de 18.000 fonctionnaires des greffes et parquets, soit un ratio de un tiers. Autrement dit, au Bénin, un magistrat a approximativement un fonctionnaire pour l'assister dans son travail alors qu'en France son collègue en a trois. Un autre ratio que l'on peut tirer de ces données chiffrées concerne celui de la démographie sur le nombre de magistrats; pour la population béninoise de cinq millions d'habitants à l'époque, nous avons un magistrat pour 28.000 habitants environ tandis que pour la France qui comptait à la même année 55 millions habitants, nous avons un ratio de un magistrat pour 8500 habitants environ.

L'effectif du personnel judiciaire n'a pas tellement varié. Mieux, les difficultés sont plus accentuées avec les mêmes infrastructures, l'accroissement des besoins et le gel des recrutements des magistrats pendant plus d'une décennie ${ }^{538}$ avec une timide reprise en 2000, et bien entendu, la radiation de magistrats par le conseil supérieur de magistrature. Ces causes ont contribué à réduire considérablement le nombre des magistrats qui s'est stabilisé au cours de la période 2005 à 2008 à environ 100 magistrats $^{539}$ pour 128 greffiers en $2008^{540}$. Aujourd'hui en 2012, on dénombre 151 magistrats en fonction dans

538 De 1986 à 2000, le Bénin a connu un gel du recrutement des agents permanents de l'Etat, tout corps et toutes catégories confondues imposé par les institutions de breton Wood afin de mieux contrôler la masse salariale.

539 Cf. Tableau n¹0: Effectif magistrats en exercice dans les TPI et les CA de 2002 à 2008.

540 Cf. Tableau n ${ }^{\circ}$ 9: Effectif du personnel greffier en exercice dans les TPI et les CA de 2005 à 2008 
les cours et tribunaux du pays selon le décret $n^{\circ}$ 2011-800 du 29 décembre 2011 portant nomination des magistrats dans les TPI ${ }^{541}$.

Tableau $N^{\circ} 11$ : Nombre de magistrats actuellement en fonction dans les 17 cours et tribunaux du Bénin

\begin{tabular}{|c|c|c|c|}
\hline & PARQUET & SIEGE & TOTAL \\
\hline \multicolumn{4}{|c|}{ TPI DE LA COUR D’APPEL DE COTONOU } \\
\hline TPI/Cotonou & 06 & 26 & \multirow{6}{*}{76} \\
\hline TPI/Porto-Novo & 04 & 11 & \\
\hline TPI/Ouidah & 03 & 07 & \\
\hline TPI/Pobè & 01 & 02 & \\
\hline TPI/Abomey-Calavi & 03 & 10 & \\
\hline TPI/Allada & 01 & 02 & \\
\hline \multicolumn{4}{|c|}{ TPI DE LA COUR D’APPEL D’ABOMEY } \\
\hline TPI/Abomey & 03 & 08 & \multirow{4}{*}{24} \\
\hline TPI/Lokossa & 02 & 05 & \\
\hline TPI/Savalou & 01 & 02 & \\
\hline TPI/ Aplahoué & 01 & 02 & \\
\hline \multicolumn{4}{|c|}{ TPI DE LA COUR D'APPEL DE PARAKOU } \\
\hline TPI/Parakou & 02 & 06 & \multirow{4}{*}{22} \\
\hline TPI/kandi & 02 & 04 & \\
\hline TPI/ TPI/Natitingou & 02 & 03 & \\
\hline TPI/ TPI/Djougou & 01 & 02 & \\
\hline Cour d'appel de Parakou & 02 & 04 & 06 \\
\hline Cour d'appel d'Abomey & 03 & 04 & 07 \\
\hline Cour d'appel de Cotonou & 03 & 04 & 07 \\
\hline TOTAL & & & 151 \\
\hline
\end{tabular}

Source : Décret n²011-800 du 29 décembre 2011 portant nomination des magistrats dans les TPI

A ce déficit chronique en ressource humaine qu'accompagne une très faible répartition géographique des tribunaux sur le territoire national (17 cours ou tribunaux), doublé de mauvaises conditions de travail des juges, l'appareil judiciaire ne peut être performant. L’on déplore également la maigreur des ressources financières allouées aux parquets et au ministère en charge de la protection de la nature qui en réalité ne contribue pas à asseoir une confiance et à rassurer véritablement les usagers. Toute chose qui éloigne

541 Cf. Tableau $\mathrm{n}^{\circ} 11$ qui décline l'effectif actuel des magistrats dans les juridictions du pays. 
ces derniers des tribunaux. C'est dans cette logique que s'inscrit l'inquiétude de E. STAUDT lorsqu'il écrit que : " La précarité endémique des moyens mis à la disposition des parquets d'instance ont jusqu'à présent constitué autant d'obstacles indéniables au développement raisonné d'une politique criminelle de protection de l'environnement ${ }^{542} »$. Comme pour expliquer que le mal n'est pas seulement qu'africain, encore moins béninois, un éminent avocat parisien Daniel Soulez LARIVIERE renchérit en décrivant un tableau bien sombre pour la justice de son pays : " la médiocrité de la justice française est à cet égard effrayante. Par son budget, ses instruments de travail, son personnel et son domaine d'intervention...Le budget de la Justice, c'est 1,35\% du budget de l'Etat, c'est-à-dire deux à trois fois moins que dans les démocraties comparables... La vérité est celle-ci : les politiques se fichent complètement de la justice... Les moyens matériels : il s'agit des méthodes de travail des juges, mais aussi des moyens de fonctionnement. Songeons que les juges n'ont, pour la plupart aucune bibliothèque sérieuse digne d'un avocat normalement équipé. Ils ont peu de données informatiques. Ils ne disposent d'aucun collaborateur pour effectuer leurs recherches ou préparer sur leurs instructions la décision qu'ils vont prendre. Aucun, chef de service, aucun haut fonctionnaire, aucun avocat ne pourrait, à partir d'un certain niveau, travailler de cette manière. Au tribunal de grande instance de Béthune (mars 1988) retard de 2 à 7 mois à la dactylographie des minutes, des pièces d'exécution et des extraits financiers ; 800 décisions signifiées en attente d'exécution ${ }^{543} \ldots$ ».

En conclusion, on peut affirmer que le système répressif béninois de l'environnement est fonctionnel mais il est confronté à des disfonctionnements liés à la faiblesse du cadre normatif de sorte que les sanctions applicables par le juge pénal s'en ressentent.

542 E. STAUDT, La répression des infractions en matière d'environnement, article, in, Le droit des affaires en évolution, l'entreprise face au droit pénal, Bruylant, Bruxelles, 1995, p.157 


\section{CHAPITRE IV : L'EFFECTIVITE DES SANCTIONS PENALES ENVIRONNEMENTALES}

Si " qui condamner ?" s'avère difficile, " comment condamner? " est quasiment insoluble. Lorsque les éléments constitutifs de l'infraction sont réunis, pourquoi ne pas condamner ? Comment, par exemple intervenir pénalement pour les actes ou les omissions qui peuvent avoir pour conséquence de déséquilibrer pour des années le biotope dont dépendent des populations entières, une faune et une flore ${ }^{544}$ ? Cette série de questionnement prouve bien les difficultés du juge pénale de rendre effective l'application des sanctions pénales, particulièrement en matière d'atteinte à l'environnement. Le droit pénal n'a pas pour vocation de réparer mais de punir. Or, les poursuites contre les pollueurs, notamment les plus importants sont très rares et plus rares encore les condamnations prononcées à ce titre ${ }^{545}$. Certains systèmes juridiques, n'ont pas du tout recours au droit pénal mais uniquement à des sanctions administratives ou de réparation civiles, d'autres ne proposent de sanctions pénales que très peu dissuasives et donc sans effet probant sur le comportement des délinquants écologiques, dans la mesure où ces sanctions pénales environnementales devraient être " effectives, proportionnées et dissuasives ${ }^{546}$. Quelle est la réponse du droit pénal béninois en terme d'application des sanctions pénales environnementales ? La problématique de l'effectivité des sanctions pénales environnementales, pose le problème de l'applicabilité des sanctions pénales ou de leur mise en œuvre effective (section I) d'une part et la tendance à l'indulgence à l'égard des sanctions pénales environnementales d'autre part (section II).

544 Christian-Nils ROBERT, in, article, Limites du droit pénal : quelques interrogations. Travaux CETEL, p. 20, n³5 Oct., 1989.

545 Christian-Nils ROBERT, in, article, Limites du droit pénal : quelques interrogations. Travaux CETEL, p. 20, n³5 Oct., 1989.

546 V. JAWORSKI, L'union européenne et la protection pénale de l'environnement, www. cdpt.u-strasbg.fr. 


\section{SECTION I : LA MISE EN CEUVRE DES SANCTIONS PENALES ENVIRONNEMENTALES}

Le droit de l'environnement, nous l'avons déjà précisé, est un droit essentiellement basé sur le droit administratif en ce sens qu'il participe de la détermination des éléments constitutifs de l'infraction environnementale lesquels se résume en la violation de prescriptions administratives. On parle dès lors, comme nous l'avions déjà dit de " dépendance administrative " du droit pénal de l'environnement. Traditionnellement, l'ordre public correspond à la tranquillité, à la sécurité et à la salubrité. II s'agit pour les autorités publiques d'éviter des dommages individuels ou collectifs, provoqués par des désordres, des accidents, des atteintes à la santé, à l'hygiène publique et à l'environnement. Ainsi, l'autorisation est instituée quand une activité donnée présente certains dangers mais ne mérite pas pour autant d'être interdite : toute personne qui désir entreprendre n'a pas le droit d'apprécier elle-même le risque que son projet comporte et doit confier le choix de ce pronostic à l'administration, laquelle refuse ou délivre l'autorisation en l'assortissant ou non de conditions à respecter par le pétitionnaire ${ }^{547}$. C'est pourquoi, des mesures de polices préventives ou réglementaires telles que les autorisations, les déclarations, les permis, les interdictions, les injonctions, les obligations, ou toute autre mesure coercitive, permettent d' appréhender le risque ou l'action nuisible avant qu'il ne se réalise. Ces mesures pour la plupart administratives, viennent réglementer les diverses activités anthropiques quotidiennes dégradantes de l'environnement. Ces mesures qui se confondent aux prérogatives de puissance publique, s'exercent en l'occurrence à travers les trois fonctions juridiques de l'Etat que sont : la fonction administrative, la fonction normative et la fonction juridictionnelle $e^{548}$.

En effet, la fonction normative (pour ne parler que de celle là), consiste à créer des règles de droit ou des mesures de police générales ou spécifiques. Elle est fondamentale en droit de l'environnement. Elle permet non seulement d'avoir

547 J.H. ROBERT, chronique de jurisprudence ; infractions contre la qualité de la vie : environnement, RSC octobre -décembre 1990, p : 801.

548 Cf. M. PAQUES, Eléments de droit public, université de Liège, 2ème éd. 1995 pour de plus amples informations. 
des incriminations claires, mais aussi de préciser le mode d'incrimination des atteintes à l'environnement. C'est donc cette clarification que fait le Professeur A. DE NAUW, dans son ouvrage Les Métamorphoses Administratives du droit pénal de l'entreprise ${ }^{549}$ lorsqu'il déclare qu'il « existe en droit pénal de l'environnement deux manières d'élaboration des incriminations. Une première manière consiste à rédiger des incriminations accessoirement par rapport au droit administratif. Cette manière s'exprime le plus souvent en termes de pénalisation de la non détention de l'autorisation ou de l'agréation requise par la loi et aussi par le non respect des conditions qui l'assortissent. (...) une seconde manière d'élaboration des incriminations détache en revanche les délits de la matière administrative et consiste à définir au regard du droit pénal, le caractère illicite d'un acte ou d'une abstention. Dans cette hypothèse la manière d'élaborer l'incrimination est autonome par rapport au droit administratif.». La première hypothèse, qualifiée de dépendance administrative des incriminations, s'analyse en une pénalisation indirecte des infractions environnementales que consacrent la plupart des systèmes répressifs $(\S ા)$. La deuxième apparaît comme une pénalisation directe qu'incarne le droit pénal autonome (§ II).

\section{§ I : La pénalisation indirecte ou dépendance administrative du droit pénal de l'environnement}

Les pouvoirs publics déterminent, par voie d'un système d'autorisation, ou de permis, dans quelles mesures la pollution est tolérée ou interdite. C'est aussi de la compétence des autorités administratives de déterminer dans quelles mesures les intérêts écologiques sont oui ou non à protéger. En effet, dans la plupart des législations et règlements, les dispositions pénales, sont en appendices à ces textes et sanctionnent essentiellement le non respect d'obligations ou de prescriptions administratives. C'est essentiellement « la pollution non autorisée » ou « la violation des obligations administratives » qui

549 A. De NAUW, Les métamorphoses administratives du droit pénal de l'entreprise, MYS \& Breesch, Uitgevers,. p : 83, cité par FAURE, Cour de droit pénal de l'environnement, troisième cycle de DEA, 1999 
est punie. Dans ce modèle, dite de " mise en danger abstraite ${ }^{550}$ ", le contenu des normes n'est pas défini par le législateur au moment de l'incrimination, mais par l'administration qui délivre une autorisation, détermine les prescriptions générales, octroie ou non un permis assorti de conditions ou non. La législation environnementale regorge d'exemples qui illustrent l'application de cette technique répressive de même que la doctrine et la jurisprudence.

\section{A) Au niveau des violations de normes administratives}

En droit positif béninois de l'environnement, le mode d'incrimination correspond bien à ce descriptif qui fait du droit pénal, un droit entièrement dépendant du droit administratif, voire "subordonné ${ }^{551}$ » " ou accessoire ${ }^{552}$ » à ce dernier. L'on procède par la technique de renvoi en citant les dispositions pénales de la loi objet du texte d'application ${ }^{553}$. Il en est ainsi de la loi-cadre sur l'environnement qui octroie de larges pouvoirs à l'exécutif (recours fréquent au règlement) et à l'administratif (fixations des conditions particulières des autorisations). Elle comprend 123 articles dont les 17 derniers abordent les dispositions pénales. Ces incriminations pénales, dans leur quasi entièreté, dans leur conception et formulation n'appréhendent pas directement l'infraction environnementale. Des exemples de textes sont abondants. L'on pourrait par exemple citer des dispositions pénales dont l'incrimination est libellée sous une formule fréquente dans le texte de loi : "l'exploitation sans autorisation ... ${ }^{554}$ ou « est puni d'une amende de ...toute personne ayant contrevenu à la

550 M. FAURE, Vers un nouveau modèle de protection de l'environnement par le droit pénal, REDE, 1/2005, $p: 9$

551 F. ROGGEN, in, article, La répression des infractions contre l'environnement, L'actualité du droit de l'environnement, actes du colloque des 17 et 18 novembre 1994, éd. Bruylant Bruxelles.

552 J.H. ROBERT, Le contentieux pénal. Contribution lors du colloque international d'AHJUCAF, 2005.

553 En droit béninois la détermination des crimes et délits sont du domaine du législateur et les règlements du domaine de l'exécutif.

554 Art. 120 de la loi cadre 
réglementation $»^{55}$ ou encore " nul ne peut sans autorisation... $\|^{556}$. Il en est de même des dispositions de l'article 89 de loi de police spéciale sur la forêt « quiconque aura coupé, exploité, ...sans autorisation de l'administration forestière ... »; de l'article 155 de la loi de police spéciale en matière de chasse " est puni de... quiconque fait acte de guide de chasse sans licence professionnelle ... » etc.

La jurisprudence béninoise peu abondante en général, nous offre aussi quelques exemples. C'est le cas dans l'affaire objet de la procédure $n^{\circ} 36 / 89$ où il a été reproché aux sieurs B.T. et consorts d'avoir dans le parc national de la Pendjari les 17 et 18 avril 1989, ensemble et de concert « illégalement pêché des poissons sans être muni d'une autorisation administrative, de s'être rendu coupables de délit d'exploitation forestière sans autorisation administrative ${ }^{557}$. Aussi a-t-il été déclaré " coupable de chasse illégale, le sieur K.O pour avoir à Porga dans le parc national de la faune le 3 avril 1990...illégalement chassé... $»^{558}$

Un autre cas similaire a été jugé dans l'affaire Ministère publique c/T.B. : " attendu qu'il résulte du dossier et des débats, preuves et charges suffisantes contre les nommés D.J. et D.S d'avoir a Kpodaha (Dogbo) courant septembre 1996... abattu 30 pieds d'orangers sans autorisation administrative... ${ }^{559}$.

Notons pour conclure la jurisprudence béninoise en cette matière qu'au tribunal de Lokossa de 1994 à 1998, sur environ 16 décisions retenues et étudiées, 11 sont relatives à l'abatage de palmiers à huile sans autorisations administratives, deux à la destruction d'essences forestières protégées (iroko, samba...), 3 concernent la destruction de plantes, la coupe illicite de bois dans un périmètre reboisé ${ }^{560}$. Comme on le constate, la plupart des décisions rendues par les tribunaux béninois en matière de protection de ressources naturelles, sont relatives à des violations de prescriptions administratives.

555 Art. $114 ; 120 ; 121 ; 122$ de la loi cadre

556 Art. $29 ; 33 ; 62 ; 68$

557 Jugement $n^{\circ} 36 / 89$ tribunal de première instance de Natitingou. cf. G. SOGLO, op.cit. p : 37

558 Jugement $n^{\circ} 8 / 90$ du TPI de Natitingou (inédit).

559 Tribunal de première instance de Lokossa, 1996, idem. Voir aussi le jugement n) 46/77 du 19/1/77 de la chambre correctionnelle du TPI d'Abomey : " attendu que le prévenu A.L. s'est rendu coupable d'avoir Sinhouè Lègo (Abomey) le 29 mai 1975... abattu sans autorisation administrative 34 palmiers à huile ».

560 Cf. jugements $n^{\circ} 690 / 94$ du 13/12/94; $n^{\circ} 004 / 95$ du 10/1/95; $n^{\circ} 415 / 87$ du 16/7/96; $n^{\circ} 73 / 97$ du 21/2/97; n $109 / 97$ du 18/3/98. 
En France, on retrouve également le même scénario. C'est le cas de la loi $n^{\circ} 76-663$ du 19 juillet 1976 relative aux installations classées pour la protection de l'environnement, quoique les dispositions pénales aient été amendées, entre autres par la loi n85-661 du 3 juillet 1985 et par la loi n921336 du 16 décembre 1992 ; l'article 18 dispose : " quiconque exploite une installation sans autorisation requise sera puni d'une peine de prison d'un an et d'une amende de ...F ou de l'une de ces deux peines ... ${ }^{561}$. Cette loi a été codifiée aux articles L511-1 à L517-2 du code de l'environnement. L'article L5149, relative aux dispositions pénales, précise par exemple que : « le fait d'exploiter une installation sans autorisation ou l'enregistrement est requis est puni d'un an d'emprisonnement et de 75.000 euros d'amende $»^{562}$.

En droit belge, une jurisprudence récente, dite " affaire BAYER ", illustre fort bien le désastre écologique que crée ce mode d'incrimination indirecte. Courant 1987, certains travailleurs de l'entreprise BAYER établis en région anversoise, ont été poursuivis par le ministère public au titre de pollution de l'eau. Est punissable sur la base de l'article 41, §1, 20 de la loi belge du 26 mars 1971 sur les eaux de surface celui qui, en violation de l'article 5, sans autorisation préalable, ou sans respecter les conditions d'autorisation accordée, déverse des eaux usées dans les eaux visées à l'article premier ou dans les égouts publics. Selon le tribunal correctionnel d'Anvers, qui connaissait cette affaire en première instance, il était établi que l'entreprise ne disposait pas d'une autorisation, mais le tribunal a été sensible au fait que l'entreprise avait déjà sollicité une nouvelle autorisation depuis 1974. Cette autorisation n'avait pu être délivrée parce que les autorités avaient omis de fixer des normes sectorielles pour le développement d'eau usée provenant de la production de dioxyde de titane. Selon le tribunal, cette absence de réglementation créait un " vide juridique " par lequel le demandeur de l'autorisation ne pouvait pas agir autrement que de supposer qu'une autorisation lui serait accordée. En outre, le tribunal souligne que l'administration, qui avait reçu la demande d'autorisation, n'avait jamais

561 M. FAURE, Vers un nouveau modèle de protection de l'environnement par le droit pénal, REDE, 1/2005, $p: 5$

562 V. aussi l'art. L428-2 qui punit pour non détention de permis de chasse et l'art. L415-3 al.5 qui punit de 6 mois et 9.000 euros d'amende d'ouvrir ou d'exploiter sans autorisation un établissement d'élevage d'animaux d'espèces non domestiques. 
formulé aucune observation concernant ces déversements, bien qu'elle en fut effectivement bien informée, étant donné les échantillons d'eaux usées qui avaient été prélevés. Le tribunal conclu dans ces circonstances que « les inculpés invoquent en raison, une situation d'erreur invincible pour justifier les faits portés à leur charge ${ }^{563}$ et les relaxe.

Ainsi, dans ce jugement, le tribunal estime que la loi du 26 mars 1971 sur les eaux de surface pénalise uniquement le fait de ne pas détenir une autorisation de déversement ou d'agir en violation des conditions de cette autorisation à déverser. Bien qu'il y ait pollution matérielle, donc une situation infractionnelle, qui se traduit par le déversement de dioxyde de titane dans les égouts publics, le tribunal, a relaxé les inculpés en arguant du fait qu'aucune norme administrative n'a été violée. II n’a pas cru devoir vérifier si les déversements ont provoqué une pollution des eaux de surface. On en déduit de cette jurisprudence que la loi belge sur les eaux de surface limite la pénalisation de la violation des prescriptions administratives. Puisque le tribunal ne dispose d'aucune autre possibilité de vérifier si les eaux de surface ont été polluées ou non. II s'agit là de la mise en évidence de la faiblesse de cette dépendance absolue.

Cette situation « battade " ${ }^{564}$ apparaît à nos yeux comme si la détention de l'autorisation ou le retard dans l'octroi d'autorisation régulièrement demandée était un blanc seing pour pollution. Si ce danger ou délit abstrait suffit comme le précise le Professeur ROBERT, pour justifier l'intervention du droit pénal|565, le seul fait d'être titulaire d'une autorisation, pour l'exercice d'une action ne justifie pas la production d'un dommage incriminé par la loi pénale. Par exemple,

563 Tribunal correctionnel d'Anvers, 28ème Ch. Bis, jugement du 8 mai 1987, non publié. Ce jugement a été confirmé (pour d'autres motifs) par un arrêt de la cour d'appel d'Avers, 7ème Ch., 6 avril 1989, non publié. Cet arrêt est depuis passé en force de chose jugée. Cité par M. FAURE, dans son article « Vers un nouveau modèle de protection de l'environnement par le droit pénal, REDE, 1/2005, p : 6

564 Souligné par nous.

565 ROBERT, RIDP, vol. 65, 1994, p.955. II l'explique comme suit: "quoique ces comportements surnommés "délits-papiers", ne constituent pas un péril physique pour l'environnement, ils sont considérés comme le signe d'une dangerosité potentielle chez l'assujetti ». Se référer aussi à l'art. 122-4 du CP français qui dispose que " n'est pas pénalement responsable la personne qui accomplit un acte prescrit ou autorisé par des dispositions législatives ou réglementaires » 
l'autorisation d'exploiter une installation dangereuse et polluante ne met pas à l'abri de poursuite de chef de délit de rejet dans un cours d'eau de substances qui ont détruit la faune piscicole. Le respect par l'exploitant des conditions de fonctionnement imposées par l'administration n'est non plus pas considéré par la jurisprudence française comme exonératoire de responsabilité pénale sauf disposition expresse de la loi qui incrimine la production du dommage. Il a été ainsi jugé que lorsqu'en raison de l'étiage du cours d'eau récepteur des concentrations de substances chimiques admises par l'autorisation de rejet, devenaient elles-mêmes toxiques, l'obligation générale de prudence et de diligence imposait à l'exploitant d'adapter le mode de fonctionnement de son entreprise aux conditions atmosphériques ${ }^{566}$. Mieux, la cour de cassation française préfère généralement rattacher au principe de séparation des pouvoirs qui « s'oppose à ce qu'une autorisation administrative relève le juge répressif du devoir qui n'incombe qu'à lui d'appliquer la loi pénale..1567

Du point de vue théorique, la conséquence logique qui se dégage en droit pénal de l'environnement à l'application de cette technique, est la suprématie du règne de l'administratif sur le pénal. Pour paraphraser la figure de style en droit pénal général chère aux pénalistes, à savoir " le criminel tient le civil en l'état ", on pourrait dire sur la même lancée, en droit pénal de l'environnement, "l'administratif tient le pénal en l'état ${ }^{568}$. En effet, pour le professeur M. FAURE, cette " dépendance administrative » induit un certain comportement au juge pénal : d'abord le droit pénal intervient parfois en matière d'infractions purement administratives sans qu'il soit établi globalement qu'un dommage écologique ait été occasionné ; ensuite si aucune obligation juridique administrative n'a été violée, une intervention du droit pénal serait impossible de sorte que les nuisances écologiques qui ne violent aucune obligation juridique administrative ne sont pas, la plupart du temps, répréhensibles ${ }^{569}$; puisque dans la pratique, le ministère public poursuit généralement les personnes

566 Millieras c. Association nationale pour la protection des eaux et rivières, Cour de Cass. France, ch. Crim., 10 nov.1997, n96-86. 694.

567 Cass.crim. 26 juin 1974 : bull.crim.n²41 ; D. 1975 Jurisprudence. P.81, note Puech, JCP éd. G.1975. II. 18011, note Lindon, en matière de publicité contraire à la décence.

568 Cité par nous même

569 M. FAURE, Un défi : Les contours de plus en plus flous du droit pénal de l'environnement, Editions Kluwer. Aménagement- Environnement, 2000, nspécial, p : 93. 
qui ont agi sans autorisation ou ont enfreint les conditions d'autorisation ${ }^{570}$. D'une manière générale, on peut retenir que la dépendance administrative implique que le bien juridique directement protégé n'est pas l'environnement. L'environnement est uniquement protégé de manière indirecte pour autant qu'il soit sauvegardé par les dispositions administratives. Chaque cas de pollution ne sera pas automatiquement constitutif d'infraction. Ce ne sera le cas que si l'acte ou l'omission constitue également une atteinte à une obligation en matière d'autorisation ${ }^{571}$. Cela veut dire que ce n'est pas par exemple la pollution ellemême qui est directement punie mais plutôt le non respect d'une disposition administrative comme signalé plus haut dans les exemples cités. D’où les nuisances écologiques qui ne violent aucune obligation juridique administrative ne sont donc pas répréhensibles pour la plupart du temps. Le professeur PRIEUR dénonce si bien cette technique répressive lorsqu'il écrit «ll est anormal que le respect des règles administratives conduise à empêcher toutes sanctions pénales alors qu'il y a cependant un dommage à l'environnement ${ }^{572}$.

Au total, II s'agit d'une dépendance administrative classique, absolue où uniquement le non respect des décisions et actes administratifs est puni, sans la moindre prise en compte de l'impact écologique d'un comportement. ${ }^{573}$ Il va s'en dire que dans le droit interne de plusieurs pays, à l'instar des pays comme la France, la Belgique, les Etats africains francophones, la violation des valeurs juridiques écologiques n'est pas encore ancrée dans le Code pénal, contrairement à l'Allemagne et aux Pays-Bas. ${ }^{574}$

Dès lors, l'analyse de cette technique répressive soulève aussi des conséquences juridiques dans le domaine du contrôle de la légalité.

\footnotetext{
570 M. FAURE, idem. $p: 17$.

571 A. De NAUW, op. cit. p : 34.

572 Droit de l'environnement, éd. Dalloz, 4ème éd, p : 859

573 M. FAURE, Vers un nouveau modèle de protection de l'environnement par le droit pénal, REDE, 1/2005, $p: 4$

574 M. FAURE, Un défi : les contours de plus en plus flous du droit pénal de l'environnement, Editions Kluwer. Aménagement- Environnement, 2000, nºspécial, p : 93.
} 


\section{B) Au niveau du contrôle de légalité}

Dans la pratique judiciaire, l'une des conséquences les plus importantes est que le juge pénal pourrait être amené, au cours d'un contentieux pénal, à apprécier les actes juridiques administratifs (autorisations ou permis). C'est bien ce qu'explique J. MORAND-DEVILLIER lorsqu'elle écrit que "les délits consistent en l'absence d'autorisation, le non respect des réglementations et prescriptions techniques, la poursuite de l'exploitation malgré une mise en demeure, l'obstacle aux droits de contrôle ${ }^{575}$. II s'ensuit que le procureur de la République ne peut poursuivre que ceux qui polluent sans autorisation. Admettons comme le suggère le Professeur FAURE, que le ministère public poursuive un prévenu qui a agi sans autorisation ; celui-ci prétend bien disposer d'une autorisation valable alors que le parquet estime qu'il ne peut être tenu compte de cette autorisation dite libératoire simplement parce que le procureur affirme que cette autorisation a été accordée de façon illicite ou parce que celle-ci enfreint des normes supérieures ${ }^{576}$.Dans ce cas de figure, la question se pose de savoir quelle serait l'attitude du juge pénal. Va-t-il suspendre le procès et attendre que l'administration ou le juge administratif règle cette question préjudicielle ? Ou poursuivra t-il le jugement ? Se fondant sur « le principe de l'autonomie du droit pénal ", la jurisprudence et la doctrine ${ }^{577}$ estiment que le juge ne devrait pas suspendre le procès. II peut et doit même d'office exercer son contrôle. Autrement dit, le principe est l'appréciation de l'acte administratif par le juge pénal. Cependant, au plan pénal, lorsqu'un prévenu est condamné pour violation d'une condition d'autorisation qui est annulée ultérieurement avec effet rétroactif par le Conseil d'Etat, il y a rupture du principe de l'unité de l'ordre juridique. Selon ce principe, dans le cas d'espèce, le juge pénal ne peut déclarer un acte administratif illégal, que lorsqu'il est déclaré illégal par le juge administratif. Le Professeur A. De NAUW, en donne une définition sans

575 J. MORAND-DEVILLIER In, Droit de l'environnement, Ed. ESTEM, p : 141, Paris, 1996

576 Voir à cet effet les articles de M. FAURE, Vers un nouveau modèle de protection de l'environnement par le droit pénal, REDE, 1/2005; Un défi : les contours de plus en plus flous du droit pénal de l'environnement, Editions Kluwer. Aménagement- Environnement, 2000, nspécial ; Les causes exonératoires en droit pénal de l'environnement. Editions Kluwer. Aménagement- Environnement, 1995, nspécial. Idem. 
équivoque : "l'unité du système juridique requiert un même jugement sur la légitimité d'un acte si bien que le comportement que l'administration autorise ne peut pas être considéré comme illicite en droit pénal ${ }^{578}$ \%. Par ailleurs, ce dilemme dans lequel se trouve le juge pénal pourrait se corser davantage si le juge pénal, en plus des peines principales alourdissait la sanction par des peines complémentaires, telle une réparation en nature sur la base d'une demande en réparation. La jurisprudence belge de cassation récente admet que dans ce cas, l'affaire principale et la décision sur la demande de réparation doivent pouvoir être scindées. Le juge pénal pourrait par exemple déjà statuer sur l'infraction mais suspendre son jugement sur une demande en réparation jusqu'à ce que le conseil d'Etat se soit prononcé sur le recours en annulation. La cour d'appel d'Anvers a en tout cas déjà prononcé dans plusieurs arrêts inédits, la suspension des poursuites afin d'attendre la décision sur le plan du droit administratif ${ }^{579}$

En définitive, le juge pénal est bien tenue, lorsque le cas se présente, et en vu d'éviter des conflits d'ordre judiciaire, de suspendre le jugement, même si cela lui coûte la perte de son autonomie. Dès lors, la suspension des poursuites pénales pendant la procédure administrative apparaît comme la conséquence procédurale la plus importante de la dépendance administrative puisque le juge se trouve ainsi lié par la réponse ou la décision « erga omnès » donnée à cette question préjudicielle.

Une autre conséquence pas des moindre de la dépendance administrative du droit pénal est que le prévenu peut alléguer comme moyen de défense, les faits justificatifs.

\section{Idem.}

579 Voir par exemple, Anvers, 7ème Ch. 15 janvier 1992, en cause MP. Cuppens Jacobs et crts. C. Steensels. Inédit : les débats ont été recouverts afin de prendre connaissance des décisions définitives se rapportant à deux procédures pendantes devant le Conseil d'Etat; la cause a été remise à date indéterminée et la prescription de l'action pénale a été suspendue jusqu'à la date desdites décisions définitives. Entre temps, un arrêt définitif vient d'être rendu dans cette affaire (Anvers, 7ème Ch. 19 avril 1995, même parties inédit) :v. aussi Anvers 10ème Ch.10 janvier 1995, en cause MP. Peeters et crts. C. Vervloet. Inédit. Qui a débouché sur un même jugement : remise à date indéterminé jusqu'à la décision définitive sur le plan administratif. Cité par M FAURE, op.cit. 


\section{C) Au niveau des faits justificatifs}

Circonstances exceptionnelles dérogeant à la loi pénale, les faits justificatifs sont applicables en droit pénal de l'environnement. Ainsi, le prévenu se fondant sur son autorisation administrative ${ }^{580}$, peut se prévaloir de l'état de nécessité, de l'erreur de droit ou l'erreur invincible. II peut aussi invoquer la légitime défense ${ }^{581}$.

\section{1) L'état de nécessité}

Selon PRADEL, qui cite P. FORIERS, « l'état de nécessité est la situation dans laquelle se trouve une personne qui ne peut raisonnablement sauver un bien, un intérêt ou un droit que par la commission d'un acte qui, s'il état détaché des circonstances qui l'entourent, serait délictueux». ${ }^{582}$ Dans la plupart des systèmes juridiques, la loi ou la jurisprudence admet que l'état de nécessité joue un rôle d'atténuation ou d'exonération de responsabilité pénale et laisse subsister la responsabilité civile ${ }^{583}$.

Ainsi, au regard du nouveau code pénal français, « n'est pas pénalement responsable, la personne qui, face à un danger actuel ou imminent qui menace, elle-même, autrui ou un bien, accompli un acte nécessaire à la sauvegarde de

580 Cf. le paragraphe précédent qui a abordé les contours.

581 La légitime défense, est une notion difficile d'application en droit pénal de l'environnement. Longtemps écartée par la jurisprudence (voir Cass. France, Crim.14 oct.1997, Bull. $\mathrm{n}^{\circ}$ 334), elle est aussi devenue de nos jours un fait justificatif sans pour autant être une conséquence directe de la dépendance administrative du droit pénal. Mais, elle est souvent alléguée par les exploitants agricoles dont les cultures ou les élevages subissent les incursions d'animaux appartenant à des espèces protégées (D. GUIHAL, op.cit., p: 224). Dans les régions limitrophes aux parcs nationaux, il n'est pas rare d'assister aux agressions dévastatrices des éléphants comme c'est le cas dans les villages riverains du parc de la Pendjari et du W au Bénin. Dans ce cas, les victimes demeurent indifférents, impuissants, sans poursuite et sans indemnisation. Car il n'existe aucun texte qui réprime ce fait contrairement au droit pénal français où la légitime défense est étendue aux biens (art.122-5 al.2 NCP français). II revient aux paysans de prendre des mesures appropriées pour éviter d'être à proximité du périmètre de la réserve.

582 J. PRADEL, Droit pénal général, 16ème édit. CUJAS, Paris, 2006, p.321.

583 Idem p.329 
la personne ou du bien, sauf s'il y a disproportion entre les moyens employés et la gravité de la menace ${ }^{584}$. Avant d'être consacré par la loi, l'état de nécessité était à l'origine, prétorien. C'est une cause de justification qui existe lorsqu'une personne en présence d'un mal grave et imminent n'a raisonnablement d'autres ressources que de commettre une infraction pour sauvegarder un intérêt égal ou supérieur à celui que cette infraction sacrifie ${ }^{585}$. Il se dégage alors deux conditions fondant la relaxe du prévenu et relative à la nature du danger et à l'actualité du danger. L'intérêt sacrifié qui doit être inférieur à celui que l'infraction permettait de sauvegarder et l'état de nécessité n'est pas exonératoire si le danger avait été créé par l'agent lui-même. Ces conditions n'apparaissent pas explicitement dans l'article précité qui retrace le cadre théorique, il n'est pas douteux qu'elles continueront d'inspirer la pratique judiciaire.

Le droit béninois étant défaillant en la matière aussi bien dans la législation qu'en jurisprudence, nous allons une fois de plus illustrer notre propos à travers la jurisprudence belge et française qui regorgent d'exemples où le prévenu met régulièrement en conflit l'application du droit pénal de l'environnement et les exigences socio-économiques de développement.

En Flandre (Belgique), des poursuites avaient été introduites relatives au déversement des eaux usées ne respectant pas les conditions d'une autorisation de déversement. Cette autorisation avait été délivrée le10 mars1977 avec un délai transitoire de 40 mois, prorogeant ainsi le délai au plus tard au 10 juillet 1980. Devant le juge, le prévenu soutient qu'il ne pouvait pas respecter les conditions imposées par l'autorisation au motif que cela impliquerait pour lui un investissement financier énorme à l'époque en 1980 ; période au cours de laquelle son secteur d'activité a justement traversé une crise. Les dépenses financières nécessaires auraient impliqué la disparition de l'entreprise et le licenciement de 600 personnes. La cour d'Appel de Gand a admis cet argument de l'emploi et a déclaré fondée la défense invoquant « la force majeure», «l'état de nécessité " et "l'absence de toute culpabilité », ce qui a entrainé l'abandon

584 Art.122-7 du CP. Cf. D. GUIHAL, op.cit., p: 226

585 A. Dr NAUW, op.cit., p : 88 
des poursuites judiciaires ${ }^{586}$. Dans cet exemple, pour donner gain de cause au prévenu, le juge a considéré « la perte de l’emploi » comme une valeur supérieure consacrant ainsi la suprématie des «raisons socio-économiques» ${ }^{57}$ par le jeu "d'équilibrage des intérêts" ${ }^{588}$ sur le respect des conditions de l'autorisation, donc des conséquences qu'engendrerait cette activité sur l'environnement comme valeur inférieure.

En matière d'état de nécessité, la jurisprudence est fluctuante, les juges de Neufchâteau sont par exemple sans équivoque quant à la sauvegarde des intérêts socio-économiques pour reconnaître qu'il y a état de nécessité lorsqu'il a été jugé " que la ruine et la faillite de l'entreprise d'un prévenu et ses conséquences graves au point de vue sociale et économique ou le mal irréparable qu'aurait constitué la suspension de son activité, représentaient une valeur supérieure à la sauvegarde de l'environnement ${ }^{589}$ ».

L'exemple qui suit traduit la démarche inverse. Un chef d'entreprise qui invoquait l'état de nécessité a été débouté parce qu'il avait déversé dans une rivière du lactosérum entrainant la mort de nombreux poissons. Le prévenu a affirmé que s'il n'avait pas pu effectuer un déversement, il aurait dû fermer son entreprise, ce qui aurait entrainé le licenciement de 40 travailleurs. Dans son jugement, le juge pénal a rejeté cet argumentaire fondé sur l'état de nécessité en expliquant que "Attendu que le prévenu ne réunissait pas de son chef les conditions de l'état de nécessité : qu'en bref, il ne peut être dit qu'en commettant les faits qui lui sont reprochés, il a sauvegardé des intérêts supérieurs à ceux de son industrie et de ceux qui en vivent, alors que justement l'autorité publique, chargée du bien, admettait la nécessité d'une certaine pollution, au delà de laquelle il n'est plus possible d'admettre cette cause justificative $»^{590}$.

586 Cour d'appel de Gand, 27 juin 1985. R.W.1986-1987,1691, avec la note de A. VANDELAS. V. aussi, Gand 3 octobre 1985, R.W. 1986-1987, 1694 et la note de M. Boes. Cité par M. FAURE; Les causes exonératoires en droit pénal de l'environnement. Editions Kluwer. Aménagement- Environnement, 1995, nºspécial.

587 M. FAURE; Les causes exonératoires en droit pénal de l'environnement. Editions Kluwer. Aménagement- Environnement, 1995, nºspécial. p.22

588 M. FAURE; idem.

589 Correct. Neufchâteau, 13 octobre 1977, Jurisp., Liège, 1977/1978, p : 155. Cité par F. ROGGEN, op.cit., p : 214

590 Jugement rendu le 24 déc. 1968 par le tribunal correctionnel de Verviers (Belgique). 
Dans l'un ou dans l'autre cas, le prévenu est poursuivi non pas pour une atteinte à l'environnement, bien qu'elle soit manifeste, par la pollution de la rivière ou du plan d'eau, du fait des déversements opérés, mais simplement parce qu'il y a non respect des conditions d'autorisation.

A notre avis, nous estimons, avec un regard critique, que l'existence d'une autorisation administrative ne suffit pas pour retirer à l'acte accompli son caractère délictueux. II revient au juge pénal, en application de la théorie de la " balance des intérêts » de respecter les éléments constitutifs qui se dégagent de la loi et de la jurisprudence relative à l'état de nécessité. A ce niveau, la question se pose de savoir s'il faut s'en tenir seulement à ces conditions légales et jurisprudentielles. Le législateur, dans la détermination des conditions exigibles, n'avait pas prévu par exemple l'éventualité qu'un prévenu pourrait alléguer des difficultés financières. Quant on sait surtout que dans la mesure du possible, le législateur et l'autorité administrative, dans leur rôle " d'arbitrage des intérêts " n'ont pas prévu tous les paramètres de sorte qu'il revient au juge d'apprécier la situation au cas par cas en tenant compte de l'esprit du texte.

Néanmoins, la solution dégagée par le juge dans le premier exemple, a suscité beaucoup de critiques. Le professeur FAURE, par exemple, n'approuve pas cet arrêt de la cour. Il a estimé que « le juge n'a pas opéré de distinction dogmatique entre les causes d'exemption de culpabilité et celles de justification. II n’a pas non plus vérifié si les difficultés financières alléguées par le prévenu auraient pu être prévues par le législateur ou par l'autorité administrative. Il s'avéra in casu que l'intéressé avait la possibilité d'obtenir une subvention couvrant jusqu'à $45 \%$ du prix de revient de l'installation d'épuration des eaux ; de plus, le législateur avait prévu une période de transition de 40 mois. Qu'est ce que le prévenu avait pu faire pendant cette période pour démontrer au juge sa bonne foi ? ". Il poursuit en précisant " qu'on peut douter que le juge ait pu tenir compte des conditions classiques de l'état de nécessité " dans la mesure où les juges n'ont pas examiné s'il était réellement impossible pour le prévenu d'agir légalement. Il est soutenu par BOSLY qui dans la même lancée estime qu'il 
" faut une situation exceptionnelle où le respect de la loi pénale entrainerait des conséquences graves que le législateur n'a certainement pas voulues ${ }^{591}$.

La jurisprudence française est aussi abondante en la matière mais souvent sans succès pour les prévenus qui invoquent l'état de nécessité. II en est ainsi par exemple de la destruction des rapaces, espèces protégées, qui viennent chercher leur pitance dans des élevages de volailles ou de lapins. Les tribunaux sont, par rapport à ces violations, sévères au motif que les incursions des prédateurs ne sont possibles que parce que leurs proies sont retenues dans de simples enclos dépourvus de protection aérienne. Le choix de ne pas s'équiper de dispositifs préventifs rend illégitime le recours à des destructions pénalement sanctionnées ${ }^{592}$. Ainsi, le caractère d'espèces protégées des rapaces a une valeur supérieure que toutes autres considérations économiques.

Tel était aussi le cas de 49 faucheurs de maïs transgénique poursuivis devant la juridiction pénale d'Orléans pour dégradation de bien d'autrui (destruction d'un champ de maïs). II s'agit en l'espèce des essais opérés dans ledit champ, conformément à une autorisation ministérielle. Poursuivis devant le tribunal, les prévenus ont été relaxés par le tribunal correctionnel d'Orléans en première instance au motif qu'il y a état de nécessité en leur faveur ${ }^{593}$; état de nécessité qu'a refusé de reconnaître la cour d'appel d'Orléans dans son arrêt infirmatif en date du 27 juin 2006. ${ }^{594}$

591 V.H. BOSLY, o.c. 57 ; v. dans le même sens : Liège, 23 oct.1985.J.T.T. 1986. 425. Jur. Liège, 1986. 227 : " que les inconvénients anormaux à la loi ne constituent pas l'état de nécessité » et Bruxelles. 19 nov. 1986. Jur. Liège. 1987, 47 : Bruxelles, 17 déc.1986.J.T. 1987. 127 et Corr. Charleroi, 1er juin 1988. J.T., 625.

592 Cf. D. GUIHAL, op.cit., p: 226 Voir T.pol. Ploermel 9 mai 1974 : D.75 p : 36 note Bouche, condamnation d'un éleveur qui utilisait des pièges à poteaux contre des buses ; CA. Paris 10 mai 1989, Bourdon : Dr. Env. n¹ p. 12. J.H. Robert : condamnation d'un éleveur de lapin pour avoir abattu un rapace qui emportait l'un de ses animaux.

593 Trib. Corr. d’Orléans, jugement du 9 déc. 2005.

594 CA. D’Orléans, ch. Corr. 27 juin 2006, voir Juris Data n² 2006 -309801. Les prévenus ont été condamnés à deux mois d'emprisonnement avec sursis pour 48 d'entre eux et à une amende de 1000 euros chacun 


\section{2) L'erreur de droit ou erreur invincible}

L'erreur de droit ou erreur invincible ${ }^{595}$ qui est une notion voisine de l'état de nécessité, est définie par l'article L122-3 NCP français. Les termes de cette disposition correspondent à la définition doctrinale de l'erreur invincible, c'est-à-dire, celle que le délinquant n'aurait pas été « en mesure d'éviter soit en se renseignant par lui-même, soit en s'informant auprès de tiers ${ }^{596}$ ». La complexité croissante des réglementations a conduit la jurisprudence belge, allemande, hollandaise, italienne, française, ou les codes pénaux récents (Allemagne, Portugal, Espagne, France) à prendre en considération l'erreur de droit. L'une des conditions générales qui gouvernent l'application effective de l'erreur de droit est, d'après la cour de cassation belge, de s'assurer que l'auteur a agi comme l'aurait fait toute personne raisonnable et prudente dans les mêmes conditions ${ }^{597}$; de sorte que si le prévenu a agi comme toute personne raisonnable et prudente qui se serait trouvé dans la même situation, l'erreur peut être considérée comme invincible ${ }^{598}$. La bonne foi du prévenu constitue certes, une condition nécessaire mais elle n'est pas suffisante pour que l'erreur de droit soit déclarée invincible ${ }^{599}$.

Plusieurs formes d'application jurisprudentielle de l'erreur de droit existent. Mais comment cette erreur de droit se manifeste comme une conséquence de la dépendance administrative?

595 "L'erreur de fait qui est la méprise de l'agent sur la matérialité de l'acte », n'est pas pris en compte dans plusieurs systèmes juridiques comme le système français. L'erreur de droit qui consiste soit dans l'ignorance de la loi, soit dans sa mauvaise interprétation, n'est pas une cause d'irresponsabilité. Puisque le droit est gouverné par un grand principe général (non écrit) selon lequel « nul n'est sensé ignoré la loi ». Il y a donc comme une présomption irréfragable de connaissance des textes qui pèsent sur chaque citoyen. V. J. PRADEL, Droit pénal général, 16ème édit. CUJAS, Paris, 2006, p.454.

596 D. GUIHAL, Droit répressif de l'environnement, 3ème édit. Economica. , Paris 2008 p: 222

597 Cass. Belge 6 oct.1952.Pas. 1953. I. 37: Cass. 10 déc. 1986. Arr. Cass. 1986-1987, 482. A propos de ces conditions. V. aussi Ch. HENNAU et J. VERHAEGEN. o.c.. 240-243 et C. HENNAU-HUBLET et J. P. PIERET o.c. RIDP, 1994, 806.

598 Cass. Belge 29 nov. 1976.Pas.1977. I. 355 : cass23 janv. 1984. Pas., 1984, I., 560 : Cass., 14 janv.1987, RDP, 1987, 375 : Cass., 15 nov. 1988, Pas., 1989.I. 276.

599 V. dans ce sens Mons, 21 mai 1985, J.T, 1985, 716 et C. HENNAU-HUBLET et J. P. PIERET o.c. RIDP, 1994, 805-806. 
En droit français, la jurisprudence est extrêmement restrictive, notamment à l'égard des professionnels. Les renseignements erronés fournis par l'administration ne sont pas toujours considérés comme une cause de justification $^{600}$.

Le principe, veut que, lorsque la loi subordonne une activité à une autorisation, et que celle-ci a été obtenue, les actes entrepris sur ce fondement ne sauraient être tenus pour pénalement répréhensibles, peu importe les vices qui entachent la permission administrative. Mais il en va autrement lorsque l'autorisation alléguée a été obtenue par fraude. Elle est alors tenue pour inexistante ${ }^{601}$.

L'exercice d'une activité conformément à une autorisation qui s'avère par la suite illicite du fait du contrôle de légalité par le juge pénal, peut également être source d'erreur invincible. Puisque cette autorisation pourrait être déclarée non obligatoire et l'émission sans autorisation mise à charge pourra être rétablie. Le même problème apparaît lorsque la validité juridique d'un acte administratif telle une autorisation, est attaquée par la voie administrative comme nous l'avions examiné dans un précédent exemple. Admettons que le Conseil d'Etat annule une telle autorisation avec effet rétroactif. Que pourraient être les conséquences d'une telle annulation à l'égard d'un détenteur de bonne foi qui a respecté l'autorisation délivrée par l'autorité et a estimé sur la base de celle -ci, qu'il agissait de manière licite, en bon père de famille. En droit pénal de l'environnement, on peut alors se demander dans quelle mesure le respect d'une autorisation illégale débouche sur une erreur de droit invincible ${ }^{602}$. Ce problème a été régulièrement discuté dans la jurisprudence belge relative aux causes

600 , Cass. France, Ch., Crim. 28 nov.1991. : Bull. crim.1991, Le Dreff $n^{\circ} 447$ en matière d'autorisation d'introduction de certaines espèces de poissons dans les eaux douces.

601 Cass. Crim. France, 4 nov.1978: Bull. crim., n²86.

602 « D'un point de vue procédural, pour apporter la preuve, le juge devra souvent d'abord évaluer la légalité de l'autorisation déposée. Si le juge estime ensuite que l'autorisation invoquée par le prévenu est illégale, l'acte sans autorisation qui est mis à sa charge pourra être déclarée établi. A titre subsidiaire, le prévenu pourra alors objecter qu'il doit encore en résulter une impunité parce qu'il a respecté les conditions d'une autorisation apparemment légale et qu'aucune culpabilité ne peut dès lors être retenue de son chef $"$. M. FAURE, Les causes exonératoires en droit pénal de l'environnement. Editions Kluwer. Aménagement- Environnement, 1995, nºspécial. p.23. 
d'urbanisme. II en est ainsi, d'un arrêt du Conseil d'Etat qui a pu juger,qu'un arrêt d'annulation du Conseil d'Etat, implique que le permis de bâtir est réputé n'avoir jamais existé et ne posséder aucune valeur juridique. Il en ressort qu'un bâtiment, érigé sur la base d'un permis annulé doit être considéré comme ayant été érigé sans permis. Face à une telle situation, le juge peut acquitter le prévenu pour cause d'erreur de droit.

En conclusion, les développements antérieurs nous montrent bien qu'il existe en droit pénal de l'environnement et précisément en droit interne béninois, une forte implication entre le droit pénal et le droit administratif. Elle a été mise en évidence par la façon dont les délits de pollution et de dégradation de l'environnement ont été formulés. Cette implication est caractérisée par une subordination de la répression pénale à l'existence de décisions préliminaires administratives. La férule du droit administratif sur le droit pénal dénature la fonction de celui-ci et est source de conséquences diverses telle le rôle fondamental des faits justificatifs diversement apprécié par les juges. La dépendance administrative du droit pénal est également source d'inconvénients et de limites. Le pollueur n'est plus un délinquant comme les autres, qu'on pourrait chercher à intimider ou a resocialiser, mais le sujet d'une espèce de droit disciplinaire très rigoureux qui prend la tournure du quasi défunt droit pénal militaire. Peut-on être coupable parce que simplement on désobéit aux ingénieurs de l'administration ? En répondant par l'affirmative, certains auteurs estiment que cette branche du droit répressif mérite tout de même d'être repensée ${ }^{603}$ pour pallier aux critiques dont il fait l'objet. D'autres, dans le souci de rendre plus effectif le droit pénal de l'environnement, vont plus loin en précisant " qu'il faut non seulement mieux adapter et proportionner les peines avec les préjudices écologiques, mais aussi instituer une répression de la pollution qui ne soit pas confondue avec la répression d'infraction sanctionnant seulement des prescriptions administratives ${ }^{604}$.

603 Robert, in, Contentieux pénal, op.cit.

604 M. PRIEUR, Droit de l'environnement, 3ème édit. Dalloz, p.859. Paris, 1996. 


\section{§ II : La pénalisation directe du droit pénal de l'environnement}

Comme nous l'avons précisé plus haut en citant le professeur A. De NAUW, la deuxième méthode d'élaboration des incriminations est le recours au droit pénal autonome. Elle a l'avantage d'appréhender directement l'infraction. En détachant les délits de la matière administrative, elle consiste à définir au regard du droit pénal, le caractère illicite d'un acte ou d'une abstention.

C'est une évidence que la loi pénale apparaît en liaison étroite avec les autres disciplines et plus particulièrement avec le droit administratif comme nous l'avons démontré plus haut. Mais en réalité, la loi pénale sanctionne en fonction du caractère d'ordre public qui s'attache à cette branche du droit, l'atteinte de base à une valeur sociale ou morale. C'est un droit «sanctionnateur ${ }^{605}$ ». L'intérêt de ce régime est de considérer le pollueur comme un délinquant au même titre que le voleur ${ }^{606}$ et de le punir conséquemment. Il existe en effet, comme le note le Professeur FAURE, des systèmes où les biens juridiques écologiques bénéficient réellement d'une protection directe du droit pénal et où la sanction ne se limite dès lors pas aux infractions à obligations de disposer d'une autorisation. Dans ce cadre, l'eau, l'air, le sol bref les ressources naturelles et environnementales sont élevées au rang de valeur juridique écologique de sorte qu'une pénalisation directe peut intervenir dès qu'il y a une émission ou une dégradation illicite. II s'agit là, comme l'explique FAURE, d'une mise " en danger concret » et non « abstrait »comme dans le cas de la dépendance administrative absolue. II se dégage donc que le délit de mise en danger concret est un délit autonome qui interviendra exclusivement en cas d'émission « illicite grave » menaçant la santé humaine et l'environnement en dépit de l'existence d'une autorisation ${ }^{607}$. C'est ce qu'a voulu signifier l'ancien ministre allemand de la justice monsieur ENGELHARD lorsqu'il écrivait que « les dispositions autonomes concernant l'environnement ne devraient donc être introduites que pour faire face à de graves atteintes à

605 F. ROGGEN, Le juge pénal et la protection de l'environnement, article, juin 1987, in, Les juges et la protection de l'environnement, $p$ : 189UAE, Bruylant, Bruxelles ; voir aussi Jules MESSINNE, Droit pénal, T 1.p :115. P.U.B

606 M. PRIEUR, Droit de l'environnement, 3ème édit. Dalloz, 1996, p. 830 Paris.

607 M. FAURE, Vers un nouveau modèle de protection de l'environnement par le droit pénal, REDE, $1 / 2005 p: 12$ 
l'environnement ayant des conséquences désastreuses pour lesquelles il n'est pas question d'appréciations divergentes entre le droit administratif et le droit pénal ${ }^{608}$ ». La conséquence qui découle d'une telle disposition est positive. Elle l'est d'autant plus qu'elle inciterait les entrepreneurs à éviter que des émissions conformes aux autorisations ne présentent un danger pour la santé. Ils seront plus prudents et agiront d'une manière diligente, en bon père de famille. Le droit béninois recèle quelques exemples de cette technique répressive d'incrimination qui ne sont pas abondant comme dans le premier modèle. Deux exemples tirés de la législation béninoise illustrent plus clairement la pénalisation directe de l'infraction et la mise en danger concrète. II s'agit du délit de pollution de l'eau d'une part et du trafic illicite des déchets toxiques d'autre part.

\section{A) Le délit de pollution de l'eau}

Dans ce premier cas, nonobstant l'article 38 du code de l'eau ${ }^{609}$ qui soumet à autorisation tout " déversement, écoulement, rejet, dépôt direct ou indirect dans une nappe souterraine ou un cours d'eau susceptible d'en modifier les caractéristiques physiques, y compris thermique et radioatomiques, chimiques, biologiques ou bactériologiques, ne peut être fait sans autorisation accordée après enquête par les ministres chargés de l'hydraulique et de l'assainissement "; les articles 51 et 52 du même code subordonnent la répression de l'infraction à un résultat dommageable, une atteinte effectivement portée au milieu aquatique sans que l'autorisation administrative puisse justifier I'infraction. Ainsi, l'article 52 punit de deux à cinq ans et/ ou d'une amende de 100.000 à 500.000F CFA « quiconque aura jeté, déversé ou laissé écouler dans les cours d'eau, lacs, étangs, directement ou indirectement des substances dont l'action ou les réactions ont détruit le poisson ou tout autre espèce animale

608 M. FAURE, op.cit.p.12.

609 Loi n87-016 du 21 septembre 1987 portant code de l'eau en République populaire du Bénin. La révision de cette loi est en cours à l'Assemblée Nationale. La nouvelle loi portant gestion de l'eau précitée réprime ( 2 mois à 12 mois de prison ou 500.000 à $2.000 .000 \mathrm{f}$ cfa d'amende) aussi directement certaines infractions "successibles d'entrainer, même provisoirement, des effets nuisibles à la santé ou des atteintes à la diversité biologique ou à l'équilibre des écosystèmes... " 
domestique ou sauvage, ou nui à leur nutrition, reproduction et compromettant la qualité des eaux ". II en est ainsi des dispositions de l'article 28 de la loicadre qui interdit " les déversements, écoulements, rejets, dépôts direct ou indirects pouvant provoquer ou accroitre la pollution des eaux ". On notera que l'infraction se réalisera soit par une action (jet, déversement) soit par une abstention consistant dans le fait de " laisser écouler » ou de rester indifférent c'est-à-dire de ne pas empêcher l'action. Un acte positif de déversement n'est donc pas la seule condition de réalisation de l'infraction. C'est ce comportement d'omission, caractérisée par l'imprudence, l'inattention, l'inobservation, la négligence, bref le défaut de précaution ou de prévoyance, mais aussi d'action matérielle qui est prévu également par la législation spécifique sur la flore ${ }^{610}$ qui caractérise le délit de pollution.

Ainsi, en visant ce comportement d'omission de l'article 52, le législateur permet une large extension du domaine d'application dudit article. Mieux, la définition du délit prévoit explicitement que les émissions tant directes qu'indirectes sont punissables. Peu importe le cheminement de la substance dès lors qu'elle atteint une eau protégée par l'article 52.

Précisons par ailleurs qu'outre l'atteinte portée à la faune aquatique, le texte incrimine aussi le fait de compromettre la qualité des eaux continentales. L'on protège ainsi tout autant le contenu que le contenant. On peut dire également qu'en réprimant le rejet " de nature à enivrer ou à détruire le poisson ", l'article 51 ne considère en revanche pour la réalisation de l'infraction que la nocivité possible des rejets constatés.

Néanmoins, les dispositions de l'article 38 du code, loin de changer la nature des infractions des articles 51 et 52 et d'affaiblir leur portée, ont plutôt instauré à notre avis un système d'incrimination hybride. D'une part I'incrimination de la non détention ou du non respect de l'autorisation administrative est une infraction à part (mise en danger abstrait) et d'autre

610 Cf. article 94 de la loi n93-009 du 2 juillet 1993 " quiconque aura par imprudence, négligence, inattention ou inobservation, causé un feu de brousse ou un incendie de plantation sera puni ... ". En ce qui concerne la faune, on note que de telles infractions sont quasiment absentes du droit béninois où toute activité est subordonnée par la détention d'un permis ou d'une autorisation. C'est le cas des art.75 à 88 de la nouvelle loi portant gestion de l'eau. 
part, l'incrimination d'une atteinte réelle portée à l'environnement en dehors de toute autorisation administrative, en est une autre (mise en danger concret). Ce système va permettre une répression nuancée, plus graduée en fonction de l'attitude du délinquant dont on pourra supposer la mauvaise foi ou l'intention coupable lorsque le déversement se fera sans autorisation administrative.

La législation belge abonde aussi dans le même sens avec notamment le cas de l'article $41 \S 1^{\text {er }}, 1^{\circ}$ de la loi du 26 mars 1971 sur la protection des eaux de surface contre la pollution qui punit notamment celui qui, en infraction de l'article 2, dépose ou fait déposer des matières solides ou liquides à un endroit où elles pouvaient être entrainées par un phénomène naturel dans les eaux visées à l'article $1^{\text {er }} .611$

Le droit pénal français est riche d'exemples, nous donne aussi un autre exemple assez intéressant parce que controversé. II s'agit de l'article 22 de la loi n92-3 du 3 janvier 1992, qui aujourd'hui avec l'entrée en vigueur du code de l'environnement, devient l'art. L 216-6. Il dispose « Le fait de jeter, déverser ou laisser s'écouler dans les eaux superficielles, souterraines ou les eaux de la mer dans la limite des eaux territoriales, directement ou indirectement, une ou des substances quelconques dont l'action ou les réactions entrainent même provisoirement, des effets nuisibles sur la santé ou des dommages à la flore et à la faune, à l'exception des dommages visés aux articles L 218-73 et L432-2, ou des modifications significatives du régime normal d'alimentation en eau ou des limitations d'usage des zones de baignades, est puni de deux ans d'emprisonnement et de 75000 euro d'amende. ". A première vue, on pourrait penser qu'il s'agit d'une disposition pénale autonome qui sanctionne directement les atteintes à l'environnement mais à voir de près, comme le précise si bien le Professeur FAURE, il n'en est pas question puisque l'article précise vers la fin que "Lorsque l'opération de rejet a été autorisée par arrêté, les dispositions de cet alinéa ne s'appliquent que si les prescriptions de cet arrêté n'ont pas été respectées (...)». Dès lors, il soutien au même titre que

611 A. De NAUW, Les métamorphoses administratives du droit pénal de l'entreprise, MYS \& Breesch, Uitgevers, .p: 84, cité par FAURE, Cour de droit pénal de l'environnement, troisième cycle de DEA, 1999. V. aussi M. FAURE, Vers un nouveau modèle de protection de l'environnement par le droit pénal, REDE, $p: 6$ 
d'autres auteurs comme D. GUIHAL que " l'autorisation administrative exonère apparemment la responsabilité pénale ${ }^{612}$, d'où la survivance, une fois de plus de la dépendance administrative. C'est dire donc que l'incrimination directe en droit pénal, porterait en elle-même, les germes de son auto destruction.

\section{B) Le trafic illicite de déchets toxiques ou dangereux}

Dans ce deuxième exemple relatif au trafic de déchets dangereux, le caractère direct de l'incrimination est mis plus en exergue par la loi suprême qu'est la Constitution et la loi-cadre sur l'environnement qui ont érigé cette infraction en crime contre la nation béninoise. En effet, " dans la tradition africaine, c'est une insulte vis-à-vis de quelqu'un que d'aller déposer des déchets dans sa cours. Cela constitue une grave insulte et peut conduire à une grave mésentente au sein de la communauté ${ }^{613}$. La réponse du Bénin à cette insulte que constitue le trafic des déchets dangereux interdit sur toute l'étendue du territoire national est à la mesure du danger que ce trafic peut faire courir non seulement à la société mais aussi à l'environnement.

Si dans les autres cas développés ci-dessus, le régime juridique est celui des autorisations assorties de conditions, ici le régime juridique est celui de I'interdiction absolue. La peine encourue est la réclusion criminelle à temps. II en est ainsi des dispositions de l'article 118 de la loi-cadre sur l'environnement, reprenant l'article 29 de la constitution qui dispose " quiconque procède ou fait procéder au transit, au stockage, à l'enfouissement, au déversement sur le territoire national de déchets toxiques ou polluants ou signe un accord pour l'autorisation de telles activités, est puni de la réclusion criminelle de cinq (5) à vingt (20) ans et d'une amende de vingt-cinq millions (25.000.000) à cinq cent millions (500.000.000) de francs CFA. " L'infraction qui, en l'espèce est une infraction formelle, couvre toutes les phases de la manipulation desdits

612 M. FAURE, Vers un nouveau modèle de protection de l'environnement par le droit pénal, REDE, 1/2005, $p: 17$

613 Message du Président en exercice de l'OUA, lu par le Ministre malien de l'environnement à la conférence de Bâle sur les déchets dangereux. Cité par M. KAMTO, op. cit. p : 36-37. V. aussi A. Gisèle SOGLO A., op cit. p : 29. 
déchets. Dès lors, l'article 118 constitue une pénalisation criminelle directe de déversement, de stockage ou d'enfouissement de déchets toxiques et peut donc être considéré comme une disposition sanctionnant la mise en danger concrète de l'environnement. Dans une certaine mesure, l'article 112 de la loi-cadre qui dispose que « quiconque contrevient à la prohibition générale contenue dans l'article $15^{614}$ est puni ... ", combiné avec l'alinéa $1^{\text {er }}$ de l'article 15 , renferme les éléments constitutifs d'un délit direct d'une émission illicite.

A ce stade de nos recherches, il est important de faire remarquer qu'en droit pénal de l'environnement, les infractions qualifiées de crimes sont, non seulement très rares, mais très difficiles à appliquer d'une manière générale. L'infraction de terrorisme écologique instituée par l'article 421-2 du NCP français, n'a jusqu'à nos jours jamais connu d'application. Il s'ensuit que la jurisprudence criminelle, est quasiment inexistante en la matière.

L’Afrique étant considérée comme le continent le plus perméable en matière de trafic de déchets dangereux où les pouvoirs publics sont moins regardants, les trafiquants européens en font leur débouché ; d'où l'émergence de crimes environnementaux.

Nous analyserons à titre illustratif l'affaire dite " des déchets toxiques d'Abidjan» qui a débouché sur des sanctions criminelles prononcées par le juge. $S^{\prime}$ il y a une affaire qui a tant défrayé la chronique en ce début du XXI ème siècle, dans le monde juridico-politique environnemental en Afrique, c'est bien cette célèbre affaire. En effet, courant 2006, ${ }^{615}$ le navire PROBO KOALA, battant pavillon panaméen, affrété par la firme néerlandaise de négoce international TRAFIGURA a déversé environ $528 \mathrm{~m}^{3}$ de produit fortement toxique dans des décharges publiques et des sites sensibles (marigots, lagunes, etc...) de la ville d'Abidjan à la faveur d'accord obtenu de diverses autorités et ce, en violation des dispositions répressives ivoiriennes ${ }^{616}$ et des conventions internationales auxquelles ce pays

614 Il dispose que « nul ne doit émettre, déposer, dégager, rejeter ou permettre l'émission, le dépôt, le dégagement, l'enfouissement ou le rejet dans l'environnement d'un contaminant au-delà de la quantité ou de la concentration prévue par les lois et règlements... »

615 Précisément le 19/8/2006

616 Notamment les articles 1,2 et 3 de la loi $n^{\circ} 88-651$ du 7 juillet 1988 portant protection de la santé publique et de l'environnement ; les articles 83, 101 et 103 de la loi-cadre $n^{\circ} 96 / 766$ du 3 octobre 1996 portant code de l'environnement 
est partie. Les conséquences d'un tel événement ont été désastreuses pour la santé humaine et pour l'environnement (atteintes majeures aux écosystèmes, en particuliers aquatiques). Selon le rapport de la commission internationale d'enquête ${ }^{617}$ et la justice ivoirienne, 17 personnes sont décédées des suites de malaises et des intoxications et 95.247 autres, ont souffert et continuent de souffrir encore des séquelles d'intoxication dues à l'exposition de ces derniers aux émanations de gaz à forte teneur en mercaptan. L'affaire, ayant connu une forte médiatisation, deux ans plus tard, la cour d'assise saisie du dossier en sa séance du 30 septembre 2008, a rendu un arrêt assez sévère et inédit en Afrique. Même si par endroit, il suscite quelque indignation au regard de circonstances atténuantes accordées à certains inculpés, à la non inculpation du capitaine et de l'affréteur du navire, deux condamnations fermes et sept (7) acquittements ont été prononcés. Le sieur Salomon UGBORUGBO, dirigeant de la Société Tommy qui s'est occupé du déversement des déchets dans la nature a échoppé $d^{\prime}$ une peine très sévère de vingt (20) ans de prison ferme et une interdiction de séjour de dix (10) ans pour emprisonnement ferme( peine maximale en droit ivoirien) et le sieur Essoin KOUAO un ivoirien, agent de la société consignataire du Probo Koala au port d'Abidjan, poursuivi dans le dossier au chef de complicité d'empoisonnement a été condamné à cinq (5) ans d'emprisonnement ferme et à dix (10)ans de privation de droits civiques. Si les principaux dirigeants de la multinationale ont échappé à une peine d'emprisonnement, la multinationale par qui le scandale est arrivé a été un peu plutôt en février 2007, à la suite d'un accord transactionnel condamné à verser à l'Etat ivoirien à titre de dommages et intérêts la somme de cent (100) milliards de francs CFA (125 millions d'euros) contre l'extinction de l'action publique à son encontre ${ }^{618}$. Notamment l'abandon des poursuites et la libération de ses dirigeants C. DAUPHIN et JP. VALENTINI respectivement Directeur de TRAFIGURA et responsable de la zone Afrique de

617 Cf. infra, §II, A) $1^{\circ}$ note 1004

618 Nos investigations ne nous ont pas encore permis d'avoir l'arrêt de la cour d'assise. Mais l'exploitation de certains documents et commentaires sur internet publiés à la suite du verdict de la cour d'assise d'Abidjan et la Déclaration du Réseau de l'Afrique Francophone des Juristes de l'Environnement (RAFJE) sur « les déchets toxiques d'Abidjan " prononcée lors de la réunion constitutive du Comité sur l'environnement de l'AHJUCAF, les 26 et 27 juin 2008 à Porto-Novo au Bénin, nous ont permis, après analyse de se faire une opinion sur l'affaire. 
l'Ouest, sous mandat de dépôt à la Maison d'Arrêt et de Correction d'Abidjan. Le montant alloué est destiné à indemniser les victimes à hauteur de $20 \%$, à financer la dépollution et la construction d'une usine de traitement des déchets ménagers.

$\mathrm{Au}$ regard de ces faits poignants et du verdict de l'arrêt de la cour, quelle signification juridique pourrait -on tirer de l'application du droit pénal de l'environnement relativement aux déchets dangereux?

En considérant les condamnations prononcées, on pourrait objecter que les peines sont empreintes de circonstances atténuantes notamment en ce qui concerne au moins cinq des sept acquittés pourtant poursuivis pour complicité d'empoisonnement contre qui, l'avocat général avait requis 20 ans de prison ferme. Ainsi, avec l'acquittement du commandant du port, de l'ancien directeur général des affaires maritimes au ministère des transports et de trois douaniers, la cour a certainement répondu à la demande des avocats de la défense qui ont martelé que leurs clients ne savaient pas ou ne pouvaient pas savoir que les déchets étaient toxiques.

En revanche, il est loisible de reconnaître que les condamnations prononcées sont certes très sévères, mais elles sont à la hauteur du crime commis conformément à la législation ivoirienne. En effet, c'est le maximum des peines prévues qui a été prononcé par les juges, voire même au-delà en ce qui concerne l’amende pénale transactionnelle ${ }^{619}$.

Mentionnons pour conclure cette partie que ces divers comportements sont punissables en eux-mêmes indépendamment du résultat ou de l'élément matériel; car le danger contenu dans ces agissements est bien intentionnel et significatif pour l'environnement, ce qui explique le caractère sévère de la peine.

A la réouverture du dossier ${ }^{620}$ par les juges d'Amsterdam, ville de l'affréteur du navire, la multinationale TRAFIGURA a été une fois de plus reconnue

619 Cf. art. 103 de la loi-cadre ivoirienne qui dispose « quiconque procède ou fait procéder à l'achat, à la vente, à l'importation, au transit, au stockage, à l'enfouissement et au déversement sur le territoire national de déchets dangereux ou signe un accord pour l'autorisation de telles activités est puni d'un emprisonnement de 10 à 20 ans et d'une amende de 500 millions à 5 milliards de francs "; voir aussi l'art. 101 de la même loi-cadre. 
coupable et condamnée au paiement d'une amende d'un million de dollar par les juges néerlandais.

L'incrimination directe des infractions, si elle a des aspects nettement positifs en ce sens que la qualification de l'infraction découle directement de l'atteinte occasionnée à l'environnement, il n'en demeure pas moins qu'elle porte en son sein des insuffisances.

\section{C) Les inconvénients de l'incrimination directe en droit pénal}

Dans son analyse de cette technique d'incrimination directe, le professeur De NAUW soulève au plan pratique, deux inconvénients majeurs.

- Il développe d'abord, que des incriminations en matière d'environnement constituent des normes floues ${ }^{621}$ qui procurent aux diverses autorités intervenant dans le système de l'administration de la justice pénale un pouvoir pratiquement sans frein. Le principe de la légalité des infractions par lequel le droit pénal classique assure la défense de l'individu dans sa confrontation au pouvoir de punir de l'Etat est difficilement conciliable avec des incriminations de type ouvert de ce genre.

- Ensuite pour lui, le détachement des délits de la matière administrative contient le risque de contradictions entre les diverses normes protectrices de l'environnement. Il est bien évident à cet égard, que l'unité et la cohérence du système juridique requiert un même jugement sur la légitimité d'un acte si bien que le comportement que l'administration autorise ne peut pas être considéré comme illicite en droit pénal. ${ }^{622}$

A l'analyse, ces inconvénients exposent d'abord le rôle essentiel que joue le principe de la légalité des délits et des peines, en terme de précision et de clarté des incriminations et des peines applicables en droit pénal et particulièrement

621 V. aussi M. FAURE, in, Un défi : les contours de plus en plus flous du droit pénal de l'environnement. Editions Kluwer. Aménagement-Environnement. 2000, nº spécial, p : 93.

622 K. TIEDEMANN, Théorie et réforme du droit pénal de l'environnement, étude de droit comparé, Rec. Sc. Crm., 1986, 263-273, spéc. pp : 264 et 265. Cité par A.DE NAUW, op. Cit. $p: 83$ 
en droit pénal de l'environnement. En effet, dans ce domaine, la définition et l'appropriation des concepts essentiellement techniques, souffrent de précision et de clarté. La qualification des infractions et la détermination des auteurs ne sont pas a priori sans équivoques. Elles sont très souvent, objet de polémiques.

Ensuiteledroitpénaldel'environnementétantundroitfondamentalement administratif, du fait du rôle prépondérant que joue les règlements établis par l'autorité administrative, il serait alors imprudent pour plus d'efficacité dans la politique répressive que le législateur conçoive une incrimination détachable de la matière comme le préconise les défenseurs de cette approche d'incrimination directe.

Enfin, avec le système d'autonomie du droit pénal, le juge pénal, malgré toute sa bonne volonté de dire le droit, peut se heurter à une question d'interprétation d'un acte administratif : c'est la question préjudicielle. La solution à une telle question comme on l'a examiné, peut amener le juge pénal vers le juge administratif. Nous y sommes dès cet instant encore de retour dans la dépendance administrative. Alors, quelle valeur d'effectivité pourraiton accorder au principe d'incrimination directe dans la mesure où le juge est amené parfois à être indulgent vis-à-vis du prévenu?

\section{SECTION II : LA TENDANCE A L'INDULGENCE EN MATIERE DE SANCTIONS PENALES ENVIRONNEMENTALES}

L'effectivité de la répression ne dépend pas seulement des difficultés de mise en mouvement de l'action publique mais aussi de la nature et du montant des peines encourues ${ }^{623}$. En droit pénal, toutes les sanctions sont susceptibles d'une mesure par le juge à l'exception de quelques unes comme la confiscation qui est par hypothèse insusceptible d'être modulée. Comme le souligne PRADEL, la mesure de la sanction est l'une des plus belles applications du principe d'individualisation puisque le juge va devoir fixer une durée ou un montant ${ }^{624}$. La loi pénale a mis à la disposition du juge, diverses techniques qui traduisent un

623 M. PRIEUR, Droit de l'environnement, 3ème édit., Dalloz, p.828.

624 J. PRADEL, Droit pénal Général, 16ème édit. CUJAS, 2006 Paris, p.611 
souci d'indulgence. Il s'agit notamment des notions de circonstances atténuantes, d'excuses atténuantes, d'excuses de minorité, de peines sursitaires, etc. Alors, au regard des préoccupations du droit pénal de l'environnement, comment le législateur et le juge arriment -ils ces techniques pénales pour garantir plus d'effectivité ? Notre étude examinera la tendance à la faiblesse des peines liées aux infractions environnementales et leur niveau d'application (§ I) par le juge avec la complicité de l'administration qui s'accommode d'une administration assez tolérante en matière se sanctions (§ II).

\section{$\S$ I : Faible application des sanctions pénales environnementales}

La faiblesse des sanctions pénales dans le domaine du droit de l'environnement apparaît comme une évidence et peut s'analyser du point de vue de leur effet dissuasif pour celles qui connaissent une exécution effective (A) et du point de vue de leur niveau d'applicabilité en général (B).

\section{A) Sanctions pénales à faible effet dissuasif}

Les atteintes à l'environnement, quelles que soit leur nature, leur origine ou le lieu où elles apparaissent, qu'elles soient délibérées ou accidentelles, elles représentent une menace qu'il conviendrait au juge pénal de sanctionner notamment lorsqu'elles sont provoquées par des comportements volontaires ou de graves négligences. Le régime des sanctions est normalement un indicateur efficace de la perception par le législateur de la valeur d'une ressource. Les peines prévues doivent atteindre le niveau de dissuasion en tenant compte du gain escompté par le contrevenant par non respect de la loi. Si la peine prévue pour l'ouverture illégale d'un commerce, par exemple, n'est pas suffisante, le propriétaire du commerce peut ne pas respecter la loi s'il en tire un bénéfice net. Mais force est de constater que les sanctions prévues sont peu dissuasives en comparaison avec le dommage écologique et à la limite " s'apparentent à 
des incitations à la fraude» ${ }^{625}$ ou à un " permis de polluer»"626 ou sont plutôt de« simples contraventions de police ou des peines légères» ${ }^{627}$.

Le droit forestier béninois regorge d'exemples où le verdict prononcé par le juge n'émeut aucunement le prévenu qui jubile à l'idée d'être aussitôt libéré ; dans la mesure où les peines prononcées sont tantôt assorties de sursis, tantôt en deçà du minimum légal ${ }^{628}$, et réprimées par les dispositions de l'article 155 de la loi relative au régime de la faune. On pourrait citer également l'infraction d'exploitation illicite d'une aire protégée dont s'est rendu coupable le prévenu qui a été condamné à 12 mois d'emprisonnement assortis de sursis et à 20.000 f CFA d'amende ${ }^{629}$. Il se développe dès lors une forte tendance à l'usage des peines sursitaires surtout à l'endroit des délinquants primaires doublées de la faiblesse des amendes. Ce faisant, le juge ne tient toujours pas compte du caractère environnemental ou du caractère rarissime de la ressource. Si les braconniers persistent dans leur activité illégale, c'est qu'ils tirent énormément profit d'une telle activité ; de sorte qu'ils sont d'accord pour assumer une légère peine aujourd'hui et gagner gros demain. Car, une amende faible se révèle non dissuasive, en particulier en ce qui concerne par exemple le braconnage d'espèces rares ou endémiques. Comme les oiseaux et les animaux protégés peuvent se vendre jusqu'à 50.000 sur le marché des collectionneurs, les réseaux de braconniers régulièrement découverts et démantelés, se recréent aussitôt ${ }^{630}$.

625 S. NGUIFO, (sous la direction de L. GRANIER), Les difficultés de l'encadrement juridique de la durabilité : le nouveau régime des forets en Afrique centrale, in, Aspects contemporains du droit de l'environnement en Afrique de l'ouest et centrale, UICN, 2008, Gland, Suisse, p.98.

626 M. PRIEUR, Droit de l'environnement, 3ème édit., Dalloz, p.828

627 M. PRIEUR, Droit de l'environnement, 3ème édit., Dalloz, p.828

628 TPI Natitingou, Jugement inédit en date du 4 mars 2008 où le sieur O. BANTIRA, a été condamné à 6 mois d'emprisonnement avec sursis et à 5.000 f CFA d'amende pour pêche illégale dans la réserve de faune de la Pendjari. . C'est le cas aussi de la décision en date de 12/2/2008 où le juge pénal a condamné les nommés S. DARI, K. NONTI, N. KOUAGOU, G. BOTIMBO, à 3 mois seulement d'emprisonnement avec sursis et $10.000 \mathrm{fcfa}$ d'amende chacun alors qu'en matière d'amende, le minimum légal est 50.000 f CFA ou 6 mois de prison ferme.

629 Jugement inédit TPI n 617/RP-8 du 23 septembre 2008.

630 M. GRANDBOIS, Le droit pénal de l'environnement : une garantie d'impunité ?, Criminologie, vol., 21, $n^{\circ} 1,1988$, p.70, érudit.org/iderudit/017258 ar. 
Le recours à l'analyse économique du droit pénal de l'environnement, illustre plus clairement l'importance de la protection de la ressource environnementale et met en relief la peine correspondante. A titre d'exemple, supposons que quelqu'un veuille importer en Belgique une tortue partiellement ou intégralement protégée de Cotonou (Bénin) et que l'intéressé ne possède pas d'autorisation de sortie de l'animal. Admettons que cette tortue a une valeur à l'achat de 1000 euros et que l'amende qui serait imposée si l'importation illégale est découverte est de 10.000 euros. En bon connaisseur de son métier, le trafiquant a la possibilité de dissimuler la tortue dans ses bagages et peut dès lors, tromper la vigilance des douaniers et réduire la probabilité de découverte à $10 \%$. En outre, s'il est découvert, notre collectionneur peut bénéficier des services d'un excellent avocat, qui peut réduire la probabilité d'être condamné à $50 \%$. Ainsi, le coût prévisionnel à charge pour le collectionneur de tortue s'élève à $10 \%$ x50\%x10.000 500 euros, alors que son avantage serait de 1.000 euros. Le criminel rationnel du modèle de Gary Becker commettra donc l'infraction, simplement parce que les avantages escomptés sont plus importants que les coûts ${ }^{631}$. II s'ensuit que le pollueur potentiel va d'abord calculer ses avantages et coûts escomptés d'une infraction et fondera ensuite sa décision de commettre ou non le délit environnemental sur le résultat d'une analyse coûts/bénéfices. Dans cet exemple, pour répondre au caractère réduit de la probabilité de découverte, l'amende devrait être au moins 20.000 euros $^{632}$ pour être optimale.

Nous obtiendrons toujours le même résultat, si nous supposons maintenant que les avantages d'un délit environnemental soient de 10.000 euros et que la sanction qui pourrait être appliquée en cas de condamnation soit de 100.000 euros. Si la probabilité de découverte est de $10 \%$ et la probabilité de condamnation de $50 \%$, les coûts escomptés pour le pollueurs potentiel sont alors de $10 \% \times 50 \% \times 100.000=5.000$ euros.

Ces exemples nous renseignent que la détermination des peines par le législateur et leur application par le juge ne se fait pas au pifomètre mais bien suivant une technique d'évaluation qui quantifie réellement le coût de la valeur

631 M. FAURE, La protection de l'environnement par le droit pénal ? Une perspective économique, op. cit., p.139. 
du bien à dégrader ou dégradé. Ainsi, si l'on veut attacher un effet à la politique criminelle en matière d'environnement, il est essentiel d'indiquer aux pollueurs potentiels, non pas seulement quelles sont les sanctions réellement imposées, mais aussi leur faire comprendre qu'il existe une probabilité relativement importante de découverte et de condamnation.

Certains textes pénaux, du fait de leur non révision ou toilettage, apparaissent en inadéquation avec les réalités socioéconomiques du pays alors $q^{\prime}{ }^{\prime} i l s$ continuent d'inspirer le juge ${ }^{633}$. Les peines ainsi prévus par ces textes, pourtant d'importance capitale car réglementant les activités quotidiennes de pollutions ou de dégradation des populations, sont très faibles et le juge est tenu de les appliquer comme telle.

Mais cette tendance à réprimer faiblement les infractions à caractère environnementales, est une tendance générale du droit de l'environnement. Ce n'est pas l'apanage du droit interne béninois ni africain. Ainsi, parlant des Etats européens, JAWORSKI déclare que " certains Etats n'ont pas du tout recourent au droit pénal mais uniquement à des sanctions administratives ou de réparation civile; d'autres ne proposent de sanctions pénales que très peu dissuasives et donc sans effet probant sur le comportement des délinquants écologiques ${ }^{634} \%$. Ces peines apparaissent effectivement peu dissuasives en comparaison avec les dommages écologiques, les gains potentiels de l'illégalité, et la faiblesse de la probabilité d'être sanctionné, l'administration comme nous l'avons vu se caractérisant, dans son ensemble par un dénouement qui rend difficile les contrôles.

En France par exemple, selon une circulaire du ministère en charge de l'environnement, il est constaté une diminution sensible des condamnations prononcées entre 1996 et 2003. Les atteintes à l'environnement ne représentent que $2 \%$ des procédures traitées par les parquets, $7 \%$ des condamnations

633 Cas des peines prévues par le code de l'hygiène et les différents textes sur les pêcheries au Bénin. C'est par exemple l'ordonnance n²0/PR/MDRC/SP du 25 août 19966 portant réglementation générale de la pêche dans les eaux continentales du Bénin, qui prévoit 2000 à 50.000 FCFA ou 1 an à 6 mois de prison en cas de pêche illégale et la possibilité d'une transaction dont un montant varie entre 2000 et 10.000 FCFA. 
prononcées pour délits et $2,53 \%$ des condamnations prononcées pour contraventions de $5^{\text {ème }}$ classe en $2003^{635}$.

On observe à travers ces jurisprudences, le faible montant des sommes allouées au titre des atteintes à l'environnement, même si ça et là, certaines juridictions se montrent de plus en plus sévères ou plus généreuses ${ }^{636}$ à l'image du tribunal correctionnel de Brest, qui dans les affaires de pollutions marines par hydrocarbures, accordent jusqu'à 100.000 euros si l'on cumul les montants revenants aux parties civiles ${ }^{637}$.

On observe aussi que le juge pénal privilégie plus l'amende comme sanction pénale au détriment de l'emprisonnement. Mais, d'une manière générale, que ça soit l'une ou l'autre de ces sanctions ou des sanctions d'inspiration administratives, la tendance est non pas à la faiblesse des sanctions prononcées par le juge mais plutôt à l'impunité des délinquants coupables d'infractions environnementales.

635 Circulaire DACG $2005-12$ 64/ du 23/5/2005, portant orientation de politique pénale en matière d'environnement.

636 V. CA. Pau, 1er mars 2007, n06/00750 ( 3000 euros de dommages intérêts alloués à une fédération de pêche pour préjudice morale et de jouissance lié à la destruction de poissons consécutive au déversement accidentel d'acide sulfurique dans un ruisseau) ; TGI Marmande, 25 janvier 2007, n05/001848 (3000 euros alloués à France nature environnement du fait de l'exploitation illégale d'une distillerie) ; TI Dax, 12 septembre 2006, Sepanso c/M. Cousseau (1500 euros pour le braconnage d'ortolans par un restaurateur de renom) ; TGI Périgueux, 4 octobre 2005, n04/02226 (3000 euros pour le déversement d'eaux usées d'une station de pompage dans un ruisseau) ; T. corr. Bordeaux, 22 septembre 2003, $n^{\circ} 1 / 66111$ (1500 euros à la suite de déversement d'eau de lavage de carottes dans un cour d'eau).

637 En cas de dégazage en mer V. notamment : T.corr. Brest, 3 janvier 2006, n05/003930 (100.000 euros) ; T. corr.Brest, 8 mars 2005, n04/008977 (20.000 euros). 


\section{B) Sanctions pénales quasi inappliquées}

L'une des caractéristiques essentielles du droit de l'environnement en Afrique et particulièrement au Bénin, est l'absence de sanction attachée en fait aux violations des règles qui le constituent.

Outre les mécanismes non juridictionnels consistant en des procédures administratives non contentieuses que peut mettre en œuvre l'administration compétente soit pour prévenir les atteintes à l'environnement soit pour sanctionner les atteintes avérées, les mécanismes juridictionnels sont des procédures contentieuses mis en œuvre par les cours et tribunaux pénaux et qui devraient aboutir à sanctionner, par une décision de justice, des atteintes ou risques d'atteintes à l'environnement prévues par les dispositions législatives et réglementaires.

Mais force est de constater le règne d'une impunité inexplicable et qui se traduit parfois par le prononcé de sanctions symboliques. En dehors du laxisme et la complaisance des autorités judiciaires à l'égard de la délinquance environnementale, qui explique cette impunité, elle s'explique aussi par la nature même de la matière environnementale.

En effet, donner un prix à la nature n'est pas chose facile. Combien pourrait- on payer pour un guib anarché ou un singe à ventre rouge, abattu par un braconnier ? Combien pourrait-on payer pour un écosystème marin altérté par une pollution aux hydrocarbures ? Les montants alloués varient d'un système juridique ou d'un juge à un autre. Ainsi, rencontre-t-on des décisions qui allouent simplement le franc symbolique pour la mort d'un rapace ${ }^{638}$ ou celle d'un loup ${ }^{639}$, quand d'autres accordent 150 euros pour la capture d'un oiseau appartenant à une espèce protégé ${ }^{640}$. S'agissant plus précisément de l'évaluation des atteintes à l'environnement à un franc symbolique, on ne peut manquer d'y voir le révélateur de la difficulté qu'éprouvent les juges du fond à chiffrer le préjudice qui n'est pas de nature pécuniaire. Dans tous les cas, prononcer des condamnations symboliques pour atteintes à l'environnement, revient à

638 CA Pau, 15 mars 2005, $n^{\circ} 00 / 400632$.

639 CA Aix-en-Provence, 21 mars 2005, n534/M/2005.

640 CA Pau, 4 décembre 2003, n03/00399 : il s'agit de la capture d'un pipit. 
refuser purement et simplement d'évaluer le préjudice. La cour de cassation ne $s^{\prime} y$ trompe pas lorsqu'elle affirme de manière constante que la « réparation n'est pas assurée par l'allocation d'un franc symbolique ${ }^{641}$ et censure les décisions qui ne respectent pas ce principe. Ainsi, la chambre criminelle de la cour de cassation, dans un arrêt du 15 janvier 1997 a-t-elle rappelé que " la réparation du préjudice subi par la victime d'une infraction doit être intégrale ${ }^{642}$. Appliqué au domaine particulier de l'environnement, il s'en infère notamment que « le préjudice né de l'édification d'une construction réalisée en violation de la loi du 3 janvier 1986 sur le littoral doit être intégralement réparé ». par conséquent, en allouant la somme symbolique de 10.000 francs destinée à compenser la perte de jouissance de la vue sur la mer (...) la cour d'appel a méconnu la règle sus visée et priver sa décision de base légale $\$ .{ }^{643}$

Au Bénin, l'absence de sanction est aussi manifeste. En effet, en termes de dégradation ou de pollution de l'environnement, l'on constate que la personne morale pollue plus que la personne physique. C'est une pollution à grande échelle comme des déversements dans les eaux de surface et sur le sol sans précaution, de déchets solides ménagers ou des déchets liquide renfermant parfois des métaux lourds. La plupart du temps, ces personnes le font impunément où lorsqu'elles sont punies tantôt c'est un avertissement verbal tantôt c'est une amende administrative dérisoire.

De plus, rarement saisis de question d'environnement, les tribunaux nationaux n'ont pas souvent l'occasion de statuer sur de telles questions pourtant répréhensibles mais qui ne font quasiment pas l'objet de poursuites pénales; ou lorsqu'elles sont portées à la connaissance du juge, ce dernier à tendance à être indulgent.

641 Récemment en ce sens : Cass. Soc., 26 avril 2007, n05/45624 (pour la cour : « le nonrespect de la procédure de licenciement entraine nécessairement un préjudice dont la réparation n'est pas assurer par l'allocation d'un euro symbolique ".

642 Cass. Crim., 15 janvier 1997, n96/82264, Bull. Crim., n¹1.

643 Idem 


\section{§ II : L’indulgence du juge pénal et tolérance administrative}

Des circonstances de nature objective, liées à l'acte infractionnel ou de nature subjective ${ }^{644}$ liées à la personne même du délinquant, peuvent amener le juge à accorder le sursis; solution à laquelle il a fréquemment recours en l'espèce. De la même manière, lorsque sa conviction, n'est pas établie, lorsqu'il subsiste un quelconque doute sérieux, il relaxe. Ce sont les circonstances atténuantes qui permettent au juge, dans l'application de la peine de descendre en dessous ou d'aller en deçà du minimum légal requis. ${ }^{645}$

\section{A) L'indulgence du juge}

Elle se manifeste aussi bien par l'octroi de sanctions sursitaires que par la relaxe pure et simple ou au bénéfice du doute.

\section{Le recours fréquent aux sanctions sursitaires}

La philosophie qui gouverne la notion de sursis remonte, au XIXème siècle avec le sénateur Béranger qui en est l'inventeur. " L'esprit de l'institution est de créer un traitement spécial pour l'homme que la justice n'a pas encore atteint et dont la moralité est restée assez intacte pour que la société n'ait rien à redouter de sa liberté ${ }^{646}$.Plus précisément par l'effet du sursis, le condamné est dispensé provisoirement d'exécuter sa peine. Il s'agit donc d'un sursis à l'exécution de la peine ou de la sanction et non pas un sursis au prononcé de la condamnation ${ }^{647}$.

644 Ce peut être " les faits les plus divers, tels que le jeune âge, la situation personnelle ou professionnelle, l'état d'ivresse ou de santé du délinquant, le repentir ou la pureté du mobile l'ayant animé, l'immoralité de la victime, voire des sévices subis leur de l'arrestation. » V. J. PRADEL, op.cit. p.615.

645 V.J. PRADEL, op.cit. p. 616.

646 Rapport du 6 mars 1890, D., 1891, Leg. 25, 2è. Colonne en haut. J. PRADEL, op.cit., p.620.

647 Idem. P.620 
Le code pénal français en compte trois sortes. II peut s'agir d'un sursis simple ${ }^{648}$, ou d'un sursis avec mise à l'épreuve ou sursis probatoire ${ }^{649}$ ou encore un sursis qui est associé à l'accomplissement d'un travail d'intérêt général ${ }^{650}$.

Le sursis simple permet de soustraire le condamné aux influences pernicieuses de la prison et réduit les risques d'une récidive en faisant planer la menace d'une révocation. II a cependant l'inconvénient de laisser le condamné livré à lui-même pendant tout le délai alors qu'il serait parfois opportun de prévoir des mesures d'assistance ou de surveillance. C'est ce qu'a compris le législateur français en prévoyant pour les mineurs, la liberté surveillée, qui peut accompagner une peine d'emprisonnement éventuellement prononcée avec sursis ${ }^{651}$. Pour tous les majeurs, le législateur a institué à partir de 1958, le sursis avec mise à l'épreuve, souvent appelée sursis probatoire, impliquant une juxtaposition à la peine de mesure d'assistance et de surveillance. Enfin, une loi du 10 juin 1983 a créé une troisième forme de sursis, celui qui est associé à l'obligation d'un travail d'intérêt général ${ }^{652}$.

D'un point de vue pratique, le sursis simple est d'application plus fréquente que les autres sursis. Quant au sursis probatoire, il est d'essence criminelle puisqu'il ne s'applique " aux condamnations à l'emprisonnement prononcées pour une durée de cinq ans, au plus en raison d'un crime ou d'un délit de droit commun ${ }^{653}$. La troisième forme de sursis, semble cadrer parfaitement avec une politique de protection de l'environnement.

Les juges béninois en matière forestière ont toujours accordé au prévenu les circonstances atténuantes de l'article $463 \mathrm{du} \mathrm{CP}^{654}$. Cette technique est souvent utilisée par le juge pénal. Ainsi, au cour de la seule année 1995, sur 30 décisions de justice relatives aux infractions forestières jugées devant le tribunal

\footnotetext{
648 Art. $132-29$ et s., C.P. et 735 et s.,CPP)

649 Instituée par une loi de 1958.v. art.132-41 CP

650 Art.747-1 et s., CPP., et 132-54 et s., CP.

651 J. PRADEL, op.cit., p.620

652 Art.747-1et s., CPP., et 132-54 et s., CP. Français. V aussi J. PRADEL, op.cit., p.620.

653 Art.132-41, al.1 CP. J. PRADEL, op.cit.

654 A cet effet, on peut rappeler le jugement du 12 février 2008 du tribunal de première instance de Natitingou (Bénin) où le juge pénal, tenant compte de la vieillesse des prévenus, n'a prononcé pour un délit de pêche illégale, qu'une condamnation de 3 mois d'emprisonnement avec sursis et 10.000 f CFA d'amende.
} 
de première instance de Lokossa (Bénin), il y a 17 condamnations avec sursis, 5 condamnations fermes, 5 décisions de relaxe et 3 décisions dans lesquelles l'action publique a été déclarée éteinte ${ }^{655}$.

Au cours de l'année 1998, sur 8 décisions rendues par le même tribunal, il y a eu 5 condamnations avec sursis, une condamnation ferme et deux décisions de relaxe. La faculté d'accorder le sursis est reconnue au juge par le code pénal. Le juge l'applique selon son intime conviction en fonction de l'espèce. Cette liberté est toutefois atténuée par l'obligation qui leur est faite de motiver leurs décisions et d'avertir ${ }^{656}$ en outre le prévenu qu'il bénéficie d'une faveur. Ce motif leitmotive est invariablement le même pour tous les délinquants : « attendu que le prévenu est un délinquant primaire n'ayant encouru aucune condamnation pour crime ou délit de droit commun ; qu'il échet de lui faire application des dispositions de l'article 585 du CPP ${ }^{657}$.

Tout récemment au cours de la saison touristique 2007-2008 dans la zone cynégétique de la Pendjari (Bénin), sur les 7 décisions rendues par le TPI de Natitingou, sur les 43 infractions constatées il y a eu 7 emprisonnements assortis de sursis ${ }^{658}$.

Il est évident que le sursis a des avantages. II permet d'abord au juge d'individualiser la peine, ensuite l'on pense que la pression psychologique de la menace d'une peine précise l'empêchera de retomber dans l'infraction. Mais si l'indulgence est souvent plus efficace sur le plan de la prévention spéciale et individuelle, elle l'est beaucoup moins sur le plan de la prévention générale car l'opinion finit par croire que le premier délit n'est pas puni ${ }^{659}$; la situation est beaucoup plus dramatique en matière de droit de l'environnement où le juge en use et en abuse.

\footnotetext{
655 G. SOGLO, mémoire, p.45.

656 Art.588 CPP béninois

657 Art. 585 CPP dispose « en cas de condamnation à l'emprisonnement ou à l'amende, si le condamné n'a pas fait l'objet de condamnation antérieure à l'emprisonnement pour crime ou délit de droit commun, les cours et tribunaux peuvent ordonner, par le même jugement et par décision motivée, qu'il sera sursis à l'exécution de la peine principale. »

658 Cf. Tableau $n^{\circ} 3$

659 J. LARGUIER, Droit pénal général et procédure pénale, Paris Dalloz 1987, p.181
} 
Il faut dire à leur décharge que le sursis ne concerne pas " les frais du procès et des dommages intérêts, ni les peines accessoires résultant de la condamnation ${ }^{160}$. Le sursis ne signifie pas que les faits ne sont pas établis; ils le sont bel et bien, or il peut arriver qu'ils ne le soient pas et qu'il subsiste dès lors le plus petit doute au niveau du juge, il relaxe « au bénéfice du doute ».

\section{Le doute comme motif de relaxe}

Lorsque les faits ne sont pas établis ou lorsque les charges contre le prévenu sont insuffisantes ou encore lorsqu'il subsiste dans l'esprit du juge le moindre doute, il doit relaxer. L'adage est ainsi connu que " le doute profite à l'accusé ". Le prévenu peut donc être relaxé au bénéfice du doute comme dans le jugement $n^{\circ} 128 / 97$ du 21 mars 1997 rendu par le tribunal de première instance de Lokossa dans l'affaire MP c/ TB. Delphin : « Attendu que le prévenu comparait devant le tribunal de céans pour avoir a Madjrè Tchékléhoué à Dogbo (Bénin), abattu 53 pieds de palmiers à huile sans autorisation administrative. Attendu qu'à la lumière des débats, il subsiste un doute sérieux sur la culpabilité du prévenu, qu'il échet de le relâcher au bénéfice du doute ${ }^{661}$.

Cette décision du juge peut en l'état faire l'objet de critique. En effet, du moment où l'inculpé a commis l'infraction sans autorisation administrative de l'autorité compétente, il est passible de sanction. Mieux l'autorisation étant un document matériel, ou elle existe ou elle n'existe pas. Le doute ne devrait plus s'installer.

Dans un second jugement $n^{\circ} 73 / 97$ en date du 21 février 1997 le même tribunal a relaxé le sieur A.P. au bénéfice du doute parce qu' " en la cause, il subsiste un doute sérieux sur sa culpabilité et qu'il est en principe cher à notre droit positif que le doute profite à l'accusé ...»

660 Art.587 CPP béninois.

661 V. aussi jugement N 430/RP09 du parquet de Natitingou du 23 juin 2009 où les prévenus poursuivis pour complicité de chasse illégale et de pêche illégale dans la zone cynégétique de la Pendjari, ont été relaxés purement et simplement au bénéfice de doute. 
A l'analyse, il se pose pourtant une question de fond, à savoir par quelle gymnastique le juge pénal arrive à prononcer la relaxe pure et simple ou la relaxe au bénéfice du doute surtout quand on sait que les procès-verbaux, établis par les agents forestiers, objet de l'assignation du prévenu font « foi jusqu'à preuve du contraire " et même " jusqu'à inscription de faux "? La doctrine a même relevé le fait que ces procès-verbaux constituent une exception du principe de l'intime conviction du juge ${ }^{662}$. N'est ce pas plutôt cette intime conviction qui l'emporte sur le procès-verbal ? II se pose ainsi, au juge pénal le problème de la validité de la preuve par procès-verbal.

Le niveau actuel de nos recherches, nous permet de faire l'analyse suivante. Si le juge arrive à relaxer, c'est parce qu'il estime que les conditions d'une inculpation ne sont pas réunies dans le procès-verbal. Dans ce cas, le juge ne lui accorde que la valeur de simples renseignements comme nous l'avons indiqué dans les précédents chapitres. En effet, dans la pratique, en droit africain forestier, l'agent forestier assermenté qui établit et signe le procès-verbal en son nom, constate rarement en personne les infractions. Elles sont plutôt constatées dans les postes forestiers par des agents non assermentés en général et en particulier par les gardes faunes, pour ce qui concerne les réserves de faunes. Se sont ces derniers qui sont chargés, par rotation de garde, de la surveillance du parc national de la Pendjari. Une fois le suspect appréhendé, ils dressent rapidement un rapport détaillé, le rapport de constat d'infraction qu'ils adressent au chef d'inspection forestière ou au chef service de la surveillance et de l'aménagement de la direction du parc, lequel, élabore le procès-verbal en s'appuyant sur la bonne foi de l'agent ou sur la confiance existant entre lui et son préposé. Cette pratique est dangereuse et la conséquence qui en découle est qu'un procèsverbal établi dans ces conditions ne puisse convaincre le juge surtout que les délinquants qu'il juge souvent sont des délinquants primaires, des nécessiteux et autres misérables animés de mobiles reposant sur la subsistance auquelle, le juge est sensible. Or, comme nous le signalons plus haut, les exploitants forestiers, les commerçants et autres industriels forestiers qui constituent les vrais " assassins de l'environnement " ne sont pas inquiétés, bénéficiant d'une immunité qui ne dit pas son nom, d'une indulgence de l'administration. 


\section{B) L'indulgence de l'administration ou tolérance administrative}

Le Bénin, dispose comme nous l'avons précisé dans le chapitre premier, d'un dispositif institutionnel adéquat de mise en œuvre de son droit de l'environnement. Toutefois, force est de constater que dans la pratique, ces mécanismes sont rarement mis en œuvre en cas d'infraction pénale. Les autorités administratives et judiciaires compétentes pour prévenir et réprimer lesdites infractions, comme le fustige le Burkinabè Vincent ZAKANE, " sanctionnent peu de telles infractions qui restent le plus souvent impunies ${ }^{663}$. Ainsi, de nombreuses activités, pourtant soumises à des autorisations ou des permis préalables, sont impunément entreprises par des citoyens et entreprises dépourvus de telles permissions. De même, des déversements anarchiques de déchets urbains et industriels sont largement pratiqués en toute impunité dans toutes les villes du pays. Certaines implantations industrielles ${ }^{664}$, par exemple, sont parfois à l'origine de graves dommages à l'environnement, comme les déversements de déchets liquides et solides dans les plans d'eau ou en plein air ou encore des pollutions de l'air et du sol, sans qu'aucune procédure judiciaire

663 L. GRANIER, (sous la direction), Problématique de l'effectivité du droit de l'environnement en Afrique : l'exemple du Burkina Faso, in, Aspects contemporains du droit de l'environnement en Afrique de l'ouest et centrale, UICN, 2008, Gland, Suisse, p.19.

664 Remarquons que les plus grosses pollutions ou dégradations de l'environnement sont l'œuvre de personnes morales dotées de la personnalité juridique comme les sociétés telles que la SONICOG. Ils ont leurs conduits de déchets liquides constitués de matières grasses, de colorants contenant un fort degré de toxicité ou de métaux lourds sont déversées journalièrement dans la mer ou dans le lac. Les sociétés cimentières $(\mathrm{SCO}$, SIM-Benin, SCB), implantés au cœur de la ville, dégagent des particules qui empêchent le voisinage de respirer de l'air pur. Et pour cause les procédures judiciaires contre ces sociétés n'ont jamais prospéré. Le droit béninois ne réprimant pas les personnes morales (cf. arrêt n²1/2000 du 27 janvier 2000 de la CA RG n.006/2000 du 27 janvier dans l'affaire société des ciments d'Onigbolo- Agent judiciaire du trésor contre Société Groupe MYC International Sarl). 
n'ait jamais été engagée contre eux. De même les coupes abusives de bois ${ }^{665}$, les feux de brousse et le braconnage qui prend de l'ampleur, dont les conséquences désastreuses sur l'écosystème national sont pourtant bien connues, sont également largement pratiqués, parfois dans l'indifférence totale des autorités administratives compétentes, chargées du contrôle ou de la surveillance et des poursuites.

On peut citer également la pollution de l'air qui sévit dans les grandes villes du Bénin et particulièrement à Cotonou. L'origine d'un tel phénomène, source de dégradation de l'environnement et de la santé humaine, est l'essence frelatée, communément appelé "Kpayo ». Bien qu'elle soit interdite de consommation et de vente par décret, elle est vendue un peu partout sur les trottoirs au vu et au su de ceux chargés de réprimer les contrevenants.

En définitive, cette première partie de nos travaux de recherche établit, dans le cadre de la préservation et de la protection de l'environnement par le droit positif béninois, un diagnostic qui révèle l'existence d'un potentiel répressif béninois. Ce potentiel pertinent, certes quelque peu virtuel, ineffectif et insuffisant, est marqué par une volonté des pouvoirs publics, de tenir compte du droit pénal de l'environnement. En effet, même s'il est vrai que seule l'application effective permet d'apprécier la valeur sociale de la règle concernée, puisque l'effectivité est essentielle à la règle de droit, une règle de droit inappliquée, n'en reste pas moins une règle de droit. Car, pour citer le Doyen Carbonnier : " à se borner à dire qu'il n'y a de règle de droit qu'effective, que la règle inappliquée est comme si elle n'existait pas, serait une attitude aussi peu scientifique que l'inverse ${ }^{666}$. Mais il est fondamental de sauvegarder l'environnement par le droit pénal. Et, dans ce cas, on ne saurait se contenter du caractère virtuel ou

665 Malgré que l'usage de la tronçonneuse soit formellement interdit et réprimé d'une peine d'amende de 50.000, à 500.000 f CFA et/ou d'un emprisonnement de 3 mois à 3 ans. Art. 99 de la loin $93-009$ du 2 janvier 1993 portant régime des forêts en République du Bénin, c'est la tronçonneuse qui est utilisée presque quotidiennement par les exploitants forestiers pour abattre les arbres et les scier et, au vu et au su des agents forestiers qui sont la plupart du temps des complices, or ce sont eux qui sont chargés de réprimer de telles agissements.

666 Cité par Aenza KONATE, dans sa communication lors de l'atelier UNITAR/AIF de formation à l'application du droit international de l'environnement pour l'Afrique de l'Ouest. La Rochelle, France, octobre 2001. 
de la faible application des textes pénaux. II conviendrait plutôt d'envisager effectivement son application à travers une politique pénale qui sort du carcan «du droit dormant » pour l'opérationnalité. Alors, quelles réponses, quels atouts et quelles perspectives pour une mise en œuvre réelle du droit pénal de l'environnement dans le domaine de la préservation de l'environnement? 


\section{DEUXIEME PARTIE}

\section{LA NECESSAIRE PROTECTION DE \\ L'ENVIRONNEMENT PAR LE DROIT PENAL \\ ET LES PERSPECTIVES}


Tout au long de la première partie de la thèse, nous nous sommes appesanti sur l'inventaire et le diagnostic du cadre institutionnel, réglementaire et législatif de mise en œuvre du droit pénal de l'environnement au Bénin. L'analyse qui en découle nous a permis de mieux apprécier les efforts accomplis dans le domaine par les pouvoirs publics béninois. Mais cette analyse nous a aussi permis d'appréhender les contraintes et les disfonctionnements tantôt liés à la complexité et à la nature même du droit pénal de l'environnement, tantôt relevant de la faiblesse du cadre normatif qui freine l'épanouissement conséquente du droit pénal de l'environnement.

La deuxième partie, s'inscrit bien dans l'objectifgénéral de la protection de l'environnement par le droit pénal et se propose pour hypothèse, nonobstant les problèmes et contraintes énumérés précédemment, de démontrer, la nécessité pour le dispositif répressif interne, de recourir au droit pénal pour sauvegarder l'environnement. Pour ce faire, notre démarche consistera d'abord à proposer des approches de solutions aussi bien théorique que pratique, en vue d'avoir un droit pénal de l'environnement exempt de disfonctionnements et tendant vers une mise en œuvre effective (Titre I). Ensuite, il serait important pour plus d'efficacité, de rendre effectif et sans équivoque la responsabilité pénale de la personne morale prévue par la loi-cadre sur l'environnement puisque les activités qui entraînent les sanctions pénales sont dues non seulement aux activités de la personne physique mais aussi et surtout aux activités de la personne morale. Enfin, il s'agira d'envisager également dans une perspective dynamique, ce que le droit pénal interne béninois peut tirer du droit pénal international (Titre II).

\section{TITRE I : VERS LA MISE EN CEUVRE EFFECTIVE DU DROIT PENAL DE L'ENVIRONNEMENT}

Pour faciliter une application effective et un suivi régulier du droit pénal de l'environnement, les pouvoirs publics, animés déjà d'une volonté politique manifeste, comme exprimée dans les chapitres précédents, doivent d'abord, dans une dynamique de refondation du droit pénal national, travailler à renforcer les moyens d'action et de mise en œuvre tant juridiques qu'organisationnelles, nécessaires à une bonne justice pénale (Chapitre V). Ensuite, ce plan éventuel de 
redressement du droit pénal interne que nous proposons, ne pourra s'inscrire que dans une démarche de clarification de concepts théoriques et d'appropriation desdits concepts par le droit interne. Enfin, il s'agira de se préoccuper du concept de qualification et de la définition des éléments constitutifs de l'infraction environnementale (Chapitre VI). C'est le point de départ de toute condamnation ou de toute politique pénale, en réponse aux difficultés liées à l'incrimination pénale. 


\section{CHAPITRE V : LE RENFORCEMENT DES MOYENS D'ACTION ET DE MISE EN CEUVRE DU DROIT PENAL DE L'ENVIRONNEMENT}

La protection effective et efficace de l'environnement par le droit pénal, nécessite l'existence de normes et de règles et standards juridiques environnementaux modernes et applicables. Dès lors, il importe d'avoir une législation environnementale suffisamment cohérente, un cadre juridique opérationnel et performant. Le cadre juridique n'est-il pas le support de toute stratégie de développement durable et la base sur laquelle repose les moyens d'action des pouvoirs publics et des institutions nationales à divers niveaux ? S'il est vrai qu'en la matière, le Bénin est compté parmi les pays africains les plus outillés en matière de textes pénaux, comme nous l'avions fait remarquer dans l'état des lieux, il n'en demeure pas moins vrai que ces textes, dans leur ensemble sont insuffisants et nécessite un toilettage, une refonte afin qu'ils s'adaptent aux exigences de la science environnementale et aux récentes innovations du droit de l'environnement en matière de protection de l'environnement. Ainsi, il nous semble important de rendre fonctionnel et pertinent le cadre juridique afin qu'il dispose de compétences nécessaires à son bon fonctionnement. Nous estimons que pour atteindre cet objectif, il faut nécessairement envisager, d'une part, la restructuration du cadre juridique interne (section I) et d'autre part, le recours à l'analyse économique comme outil de mise en œuvre du droit pénal de l'environnement (section II).

\section{SECTION I : LA RESTRUCTURATION DU CADRE JURIDIQUE}

L'analyse du cadre juridique et institutionnel présente comme nous l'avons précisé dans la première partie de nos travaux, un cadre législatif et réglementaire présentant des textes vétustes et sans cohérence avec les réalités socio- économiques. Ces textes sont dans l'ensemble inappliqués, insuffisants et obsolètes, voire en désuétude. Mieux, certains compartiments du droit de l'environnement ne sont pas réglementés. Ils sont même éparpillés et sans harmonie avec le développement du droit pénal moderne, donc peu performant. 
La réponse pénale qu'il conviendrait que les pouvoirs publics apportent pour améliorer ce tableau quelque peu sombre, c'est d'envisager l'amélioration du cadre législatif et réglementaire qui passe par l'élaboration d'une politique pénale efficace et performante. Pour réussir cette entreprise, il est nécessaire d'analyser la possibilité d'une refonte du droit pénal de l'environnement (§l) et comment tendre vers une législation pénale environnementale homogène et cohérente (§II).

\section{$\S$ I : La nécessaire refonte du droit répressif béninois}

Cette refonte doit concerner tous les compartiments de l'arsenal législatif et réglementaire mais aussi particulièrement les textes généraux comme le code pénal et le code de procédure pénale. Après ce travail de toilettage et d'élaboration de textes adéquats, interviendra l'ultime phase de codification des textes de l'environnement afin de doter le Bénin d'un outil aussi précieux que le code de l'environnement.

\section{A) La révision et l'élaboration de textes pénaux}

Les préoccupations d'ordre environnemental ont toujours été présentes dans la législation béninoise régissant l'exploitation et la mise en valeur des ressources. Des lois, même anciennes, contiennent maintes dispositions qui visent la protection du milieu naturel. Mais dans l'ensemble, ce dispositif demeure désuet et insuffisant comme sus indiqué. Pour inciter à cette réflexion, STAVROS Dimas ${ }^{667}$, déclarait à ce propos " la récente catastrophe survenue en Côte d'ivoire à la suite du transfert de déchets dangereux illustre combien les infractions commises contre l'environnement peuvent avoir des effets désastreux sur les hommes et sur l'environnement. Elle souligne une fois de plus l'urgente nécessité d'améliorer la mise en œuvre de la législation en matière d'environnement, afin d'éviter les incidents de ce type». Dès lors, les pouvoirs 
publics doivent penser une stratégie qui s'articulera d'abord autour de la révision des textes ensuite, elle définira les modalités d'élaboration de nouveaux textes.

\section{1) La révision des textes}

Pour asseoir une bonne politique pénale, il est important pour le législateur béninois de revisiter tous les textes pénaux anciens et nouveaux dans leur ensemble afin d'en " élaguer» les dispositions à caractère vétustes et sans ancrage avec la réalité pénale béninoise (amendes ou peines dérisoires et sans effet sur le délinquant). Dans la première partie du travail, nous avions énuméré largement ces incohérences contenues dans les lois telles que la loi $n^{\circ}$ 87-015 du 21 septembre 1987 portant code de l'hygiène publique en République Populaire du Bénin, la loi n 87-016 du 21 septembre 1987 portant code de l'eau en République Populaire du Bénin ${ }^{668}$; la loi sur la vaine pâture; l'ordonnance $n^{\circ} 25$ PR/MJL, du 7 août 1967 portant code de procédure pénale du Bénin; la loi sur les pêcheries au Bénin(l'ordonnance n²0/PR/MDRC/SP du 25 avril 1966 et son décret d'application qui remonte à la même date); l'ordonnance ${ }^{\circ}$ 45-1423 du 28 juin 1945 relative à l'urbanisme dans les colonies et ses décrets d'application. C'est le texte fondamental qui sert de référence ou de repère à tous les autres textes qui régissent l'aménagement et l'urbanisme au Bénin; pour ne citer que celles- là, car la liste n'est pas exhaustive.

L'obsolescence de la plupart de ces textes encore en vigueur, et datant pour beaucoup de la période coloniale avec certaines dispositions inadaptées ni au statut de pays indépendant qui caractérise le Bénin depuis 1960, ni au niveau actuel de développement économique et surtout technologique de la société béninoise. II parait donc nécessaire de procéder à la rénovation du cadre juridique. Cependant, cette révision doit se faire en tenant compte de la nécessité de combler les vides juridiques, de l'urgence à rénover les textes obsolètes et de la nécessité d'abroger certains textes confus, touffus, manquant de précision et de concision.

668 Abrogée par la Loi n 2010-44 du 24 novembre 2010 portant gestion de l'eau en République du Bénin. 
Cette révision, pour gagner en efficacité, doit, tout en s'inspirant et en intégrant le contexte international, le monde étant devenu un village planétaire, tenir compte des réalités sociologiques qui permettraient au Bénin d'imaginer des solutions administratives et pénales adaptées au contexte béninois.

Si certains textes répressifs méritent un toilettage en vue d'assurer un arrimage avec le droit pénal moderne, d'autres secteurs en matière d'environnement méritent la conception et l'élaboration de nouvelles lois qu'accompagneront de nouveaux textes d'application.

\section{2) L'élaboration de nouveaux textes.}

II sera envisagé l'élaboration de législations spécifiques suivies de textes réglementaires dans des secteurs sensibles et non encore réglementés tels que les écosystèmes marins, les inondations ou catastrophes naturels, les déchets dangereux et/ou radioactifs, la biosécurité ou les OGM, la gestion des 
risques et catastrophes naturels, la corruption ${ }^{669}$; etc. ${ }^{670}$ Le législateur devrait avoir une vision anticipatrice de l'approche pénale pour assurer une meilleure protection de la société. Par exemple, une loi sur la gestion des inondations devrait pourvoir d'abord interdire l'occupation anarchique par les populations

669 Le domaine de l'environnement est par excellence un domaine où se développe plusieurs délits de droit commun tels que la corruption, la concussion, le népotisme, le favoritisme. Ces infractions se localisent davantage au sein de l'administration judiciaire mais aussi au sein de l'administration environnementale avec la complicité des agents chargés du contrôle ou chargés de verbaliser les indélicats, comme nous l'avons précisé dans le cas de l'amende transactionnelle. Puisque «l'indépendance du pouvoir judiciaire et les procédures juridictionnelles revêtent une importance cruciale pour l'application, l'élaboration et le respect du droit de l'environnement» comme le souligne l'une des conclusions du Sommet mondial des juges, tenu à Johannesburg, en 2002 et repris dans l'allocution d'ouverture de Guy CANIVET, premier président de la cour de cassation de France, lors du colloque de l'AHJUCAF en 2008, www.courcassation.fr. La corruption étant un fait de société, donc universelle, la France lui a apporté une réponse pénale à travers une réforme du code pénal, qui aboutit au vote de la loi n91-3 du 3 janvier 1991 portant délit de favoritisme. II s'agit de l'article 432-14 du code pénal qui dispose " est puni de deux ans d'emprisonnement et de 30.000 euros d'amende le fait par une personne dépositaire de l'autorité publique ou chargé d'une mission de service public ou investie d'un mandat électif public ou exerçant les fonctions de représentant, administrateur ou agent de l'Etat, des collectivités territoriales, des établissements publics, des sociétés d'économie d'intérêt national chargées d'une mission de service public et des sociétés d'économie mixte locales ou par toute personne agissant pour le compte de l'une de celles susmentionnées de procurer ou de tenter de procurer à autrui un service injustifié par un acte contraire aux dispositions législatives ou réglementaires ayant pour objet de garantir la liberté d'accès et l'égalité des candidats dans les marchés publics et les délégations de service public.»

Le Benin, en s'inspirant d'une telle disposition peut mettre particulièrement en relief les délits forestiers et douaniers qui prennent le pas sur les autres. Afin d'asseoir une pénalisation adéquate quant à l'utilisation prudente et rationnelle des ressources naturelles. Il existe certes au Benin, la loi n 79-23 du 10 mai 1979 réprimant sur le plan pénal, les détournements, la corruption, la concussion et infractions assimilées commis par les agents permanents de l'Etat, mais elle est pratiquement tombée en désuétude et mérite une refonte. On peut tout de même affirmer maintenant qu'au bénin, des efforts sont faits par les pouvoirs publics dans le sens de doter le pays d'une loi sur la corruption véritablement en adéquation avec les réalités du droit moderne. Mais ces efforts s'avèrent insuffisants. Le gouvernement a introduit le projet de loi à l'Assemblée Nationale. Et, dès lors, cette loi était en instance au parlement béninois depuis quelques années, vient d'être votée et promulguée. C'est la loi n²011-20 du 12 octobre 2011 portant lutte contre la corruption et autres infractions connexes en République du Bénin. Cette loi, en ses art.40 à 42 , réprime sévèrement la corruption des agents publics.

670 Cf. Tableau $n^{\circ} 6$ : quelques domaines sensibles ignorés du législateur béninois, p.131. 
des bas-fonds ou des zones marécageuses ou sensibles lesquelles sont des lits naturels d'occupations des eaux ensuite définir les modalités d'intervention de l'Etat pour assainir ces sites avant de préciser les sanctions encourues en cas de non respect des prescriptions.

En ce qui concerne les déchets dangereux ou radioactifs, une loi spécifique permettrait de mieux définir les contours des infractions liées aux activités dangereuses objet de la manipulation des produits dangereux ou radioactifs. La loi-cadre se contente de réprimer les déchets dangereux ou toxiques en provenance de l'extérieur ${ }^{671}$ et renvoi à la prise d'une loi spéciale relative aux substances chimiques nocives ou dangereuses. Elle définirait par exemple :

- la liste des substances chimiques nocives ou dangereuses dont la production, l'importation, le transit et la circulation sur le territoire béninois sont interdits ou soumis à autorisation préalable du Ministre ;

- les conditions de délivrance de l'autorisation préalable nécessaire à la production, le conditionnement, l'importation, l'exportation, la mise sur le marché béninois, le stockage et le transport des matières visées cidessus ; 672

- les sanctions administratives et pénales encourues en cas d'inobservation des règlements.

Quant à la loi relative à la gestion de la biosécurité ou des $\mathrm{OGM}^{673}$, elle est importante pour réguler éventuellement les conséquences liées à l'alimentation à base d'OGM, qui, quoiqu'on dise font déjà officieusement leur entrée sur le territoire national, dans la mesure où ces produits sont manipulés dans les Etats voisins.

II ne faut surtout pas attendre que la catastrophe s'abatte sur le pays avant de rechercher comment régler les conséquences issues des suites judiciaires.

671 Art.118 loi-cadre au Bénin.

672 Art.84 de la loi-cadre au Bénin

673 A l'instar des articles L531-1 et suivants du code de l'environnement français qui réglementent la matière. 
Il est à envisager également une loi spécifique sur la responsabilité pénale des personnes morales qui définisse la politique pénale en la matière.

A la suite du pouvoir législatif, il est important que le gouvernement, après avoir joué un rôle de lobbying en amont pour que le vote des lois ait lieu, qu'il veille à la prise, dans les meilleurs délais des décrets et arrêtés d'application desdites lois qui seront ainsi votées. Après le vote et la prise des textes réglementaires, il faut pour que ces textes ne tombent en désuétude, développer une stratégie pour leur vulgarisation en vue de permettre aux citoyens de connaitre les textes et les droits dont ils sont titulaires, de les exercer pleinement pour une meilleure protection de l'environnement. La publication de la loi est un acte très important particulièrement pour l'entrée en vigueur de la loi. Cet acte est consacré par le Journal Officiel. Mais, dans les Etats africains, cette forme de publication, bien qu'elle soit prévue par les textes, n'est pas effective dans la réalité. La raison en est la parution irrégulière dudit Journal. C'est le cas du Journal Officiel de la République du Bénin. Une réflexion doit être menée à ce niveau pour lever les goulots d'étranglements qui font qu'au lieu de paraître tous les quinze jours, le JORB fait parfois plusieurs mois, voire plusieurs années sans paraître alors que des textes sont pourtant pris dans l'intervalle de temps de non parution. En revanche, il est important de faire remarquer que même si la parution était régulière, ce mode de publication ou d'information n'atteint pas le grand public qui en réalité n'a pas accès à ce journal pour diverses raisons. C'est pourquoi, pour l'information du public, il serait souhaitable, puisqu'il s'agit des textes d'environnement, qu'après la promulgation par le chef de l'Etat, de procéder à une campagne de vulgarisation desdits textes à travers le pays. Au Bénin, cette mission est dévolue au MJLDH qui doit «mettre sous forme de plaquettes toutes les lois en vue de leur vulgarisation». C'est ce qui se passe aussi dans les pays occidentaux lorsque le "Ministère de l'environnement publie toutes sortes de bulletins et de notes pour informer les industriels du contenus des nouvelles législations ${ }^{674} »$ malgré que nul n'est sensé ignoré la loi. Ceci d'autant plus que «la mise à disposition et la diffusion des textes...constituent une mission de service public au bon accomplissement de laquelle il appartient à l'Etat de veiller ${ }^{675}$ ».

674 FAURE(M), L'analyse économique du droit de l'environnement, op., cit. p.289.

675 CE. 17 décembre 1997, Ordre des Avocats à la cour de Paris, rec., p.491. 
Ces initiatives, une fois mise en œuvre, permettront, sans doute de doter le pays d'un arsenal rénové, actualisé, populaire et accessible pour le citoyen.

En tout état de cause, l'issue majeure demeure la réforme législative, qu'il s'agisse d'actualiser les dispositions anciennes, d'introduire de nouvelles règles ou de modifier par décriminalisation les régimes de sanction ${ }^{676}$. Un rapport du conseil de l'Europe synthétise parfaitement dans son introduction les perspectives gouvernant ces travaux : «on estime que si l'écart entre la loi et le public devient trop grand, les gens cesseront de respecter la loi, en partie parce qu'ils auront perdu confiance et respect envers ces «agents» et en partie parce qu'il est trop difficile de suivre des lois qu'on ne comprend ni n'approuve et qui sont en opposition avec les normes de conduite largement acceptées».

Les limites et obstacles à la mise en œuvre des législations ont souvent été présentés comme trouvant, leur source, du moins la cause de leur extension, dans l'inertie des autorités publiques chargées d'en assurer le respect. Traitant de l'inertie ou de la tolérance des pouvoirs publics, G. Ripert disait «qu'il ait des lois qui paraissent ne pas avoir été votées ${ }^{677}$ ». II situera une des grandes causes " d’insécurité juridique» dans la pratique administrative "quand l'autorité n'a pas la force ou l'habileté nécessaire pour assurer à tout instant l'exécution des lois».

Par ailleurs, la CNLC du MJLDH, organe national chargé d'élaborer des projets de lois dans tous les domaines, doit subir une réforme afin d'être plus opérationnelle. Cette commission doit connaitre un audit ou une évaluation devant aboutir à la redéfinition de sa mission, de ses attributions pour aboutir à une réorganisation structurelle avec un cahier des charges plus pertinente. Elle sera l'ossature de la réforme législative et règlementaire.

La législation environnementale interne, doit être aussi en harmonie avec les conventions internationales légalement ratifiées par le Bénin. Or, il est évident que les lois et règlements préexistants dans le pays nécessitent en plusieurs endroits, et ce, pour plusieurs raisons, des adaptations au contexte

676 LASCOUMES (P) et SEVIRIN (E), Théories et pratiques de l'effectivité du droit, Droit \& Société, $n^{\circ} 2 / 1986$, p.9 www.reds.msh-paris.fr

677 RIPERT (G), Les forces créatrices du droit, Paris, LJDG, 1955, p.372 
des nouvelles conventions ratifiées. Et, lorsque ces lois et règlements n'existent pas, ils sont à initier pour rendre compréhensible au public le sens et la portée des nouvelles conventions aux dimensions et langage plus complexes et plus universels. L'acte de ratification ou d'adhésion n'a de signification qu'à travers l'application des mesures législatives, réglementaires et administratives d'accompagnement qui sont supposées en matérialiser l'applicabilité. A cet effet, il serait judicieux de procéder à l'inventaire des traités et des accords internationaux auxquels le Bénin est partie et particulièrement ceux qui n'ont pas encore été ratifiés, et veiller à leur entrée en vigueur ou à leur réexamen.

Enfin, la réforme du code pénal ne doit pas passer inaperçu. Le code pénal actuellement en vigueur, nous l'avons signalé est désuet et anachronique. L'élaboration d'un nouveau code pénal qui s'inspirera des réalités béninoises et de l'évolution du droit de l'environnement est nécessaire pour lutter efficacement contre les dégradations de l'environnement. Mais il ne s'agira pas d'élaborer simplement un code pénal mais il faut plutôt, élaborer un code pénal qui intègre les infractions d'environnement et définit clairement les sanctions applicables. Un code pénal nécessaire pour pérenniser les délits et crimes d'environnement en créant à côté du vol ou du meurtre, des infractions d'environnement ou des incriminations de pollution, de destruction, de dégradation ou autres atteintes à la nature qui seront distinctes des infractions particulières reposant seulement sur le non respect de prescriptions légales ou réglementaires déterminées. II vaut mieux adapter et proportionner les peines aux préjudices écologiques. Il est anormal que le respect des règles administratives conduise à empêcher toute sanction pénale alors qu'il y a cependant un dommage à l'environnement ${ }^{678}$. De sorte que la tendance récente à considérer le respect d'une autorisation administrative comme un fait justificatif exonérant l'auteur d'un délit environnemental, serait très préjudiciable à la sauvegarde de l'environnement. ${ }^{679}$ Il est aussi essentiel que les peines pécuniaires soient accompagnées de mesures réparatrices telles que, remise en état des lieux, mise en place d'un dispositif dépolluant, injonction d'établir des plans de travaux de sécurité. La réforme peut aussi intégrer le recours aux astreintes pénales et aux jours -amende, l'utilisation

678 M. PRIEUR, Droit de l'environnement, op.cit., p.832

679 M. PRIEUR, Droit de l'environnement, op.cit., p.832 
des produits des amendes pénales environnementales, réellement à des fins de protection de l'environnement, l'exclusion de l'amnistie des infractions relatives à l'environnement. L'élaboration du nouveau code pénal béninois pourrait également intégrer la peine de la "remise en état des lieux» dans les peines alternatives applicables au coupable, personnes physique ou morale, afin de permettre au juge pénal d'ordonner librement cette sanction sans être limité par les prévisions restrictives des lois sectorielles concernant l'environnement ${ }^{680}$, pour remédier à cette lacune que traîne le nouveau code pénal français.

C'est à ce prix, qu'on aura un droit pénal de l'environnement autonome, dans un environnement clarifié par le code de l'environnement. Puisque la codification du droit de l'environnement devrait être l'occasion d'une refonte complète du droit pénal de l'environnement afin d'en faire disparaitre les incohérences et d'en harmoniser les dispositions.

\section{B) Le code de l'environnement, un outil nécessaire}

Les dispositions juridiques applicables se trouvent dispersées dans un grand nombre de textes juridiques dont l'économie est souvent malaisée. La réglementation se trouve contenue dans les lois mais aussi dans les décrets, dans les arrêtés ministériels ou interministériels ou même émanant des autorités locales.

Une codification du droit de l'environnement en dépit de sa jeunesse, pourrait contribuer à rendre plus aisé l'accès à cette réglementation. Vu la cadence des textes législatifs et réglementaires adoptés ou en cours d'adoption depuis $1992^{681}$, la question mérite réflexion.

Les acteurs du droit répressif (le législateur, le magistrat, l'OPJ, les inspecteurs environnementaux ou autres agents assermentés, l'autorité administrative, etc....) sont amenés à se référer à des textes pénaux divers inclus dans différents textes (code pénal, lois spécifiques ou sectorielles (eau,

680 LITTMANN (Marie-José), Code de l'environnement, droit pénal et procédure pénal : quelques réflexions, RJE, $n^{\circ}$ Spécial, p.64. 
urbanisme, agriculture, déchets, faune, flore, hygiène publique, bruit, air, etc....), qu'il convient, donc de regrouper toutes ces dispositions dans un seul code, le code de l'environnement.

Le droit de l'environnement n'existe pas comme domaine autonome de droit. Il n'est le plus souvent que la juxtaposition de règles ayant des origines diverses. Cette lacune n'est-il pas due en partie à l'absence d'une volonté d'homogénéisation des règles du domaine ou d'un code de droit de l'environnement? De toutes les façons, la période contemporaine que nous traversons est marquée par un fort mouvement de codification des règles d'environnement. Le Bénin, dès lors ne saurait rester en marge d'une telle entreprise, même si une certaine doctrine estime que la codification est «peu souhaitable parce qu'elle aurait pour effet de scléroser la règle de droit, de la rendre imperméable aux adaptations et aux mutations. En cristallisant une matière non encore mur» ${ }^{682}$. A ce reproche, il est souvent répondu que la codification n'a jamais entravé le travail jurisprudentiel et qu'une codification qui aurait ce résultat serait simplement une codification mal faite, allant trop loin dans le détail ${ }^{683}$. A l'issue de nos travaux de recherches, nous suscitons à I'intention des pouvoirs publics la discussion sur la nécessité ou non pour le Bénin d'avoir un code de l'environnement à la lumière de l'expérience française.

\section{1) La définition et les intérêts d'un code de l'environnement}

Selon le lexique des termes juridiques, «la codification est le regroupement d'un ensemble souvent complexe de dispositions législatives ou réglementaires intéressant une même matière, conservant leur portée ou leur force juridique originaire». Pour J.L. BAUDOUIN, «la codification est une technique, une méthode d'élaboration de règle de droit et de concrétisation de celui-ci dans un ensemble législatif. Le concept désigne par ailleurs des réalités

$682 \operatorname{MARTIN}($ G. J), Principes pour une codification de l'environnement, in, Quel avenir pour le droit de l'environnement ? Actes du colloque, Publication des Facultés universitaires SaintLouis, Bruxelles, 1996 sous la direction de OST (François) et GUTWIRTH (Serge). de droit, in, Unification et le droit comparé dans la théorie et la pratique, contribution à I'honneur de J.G. SAUVEPLANE, Deventer, Kluwer, 1984, p.22. 
fort différentes les unes des autres, répondant à des objectifs eux-mêmes très divers ${ }^{684}$. Mais à l'origine, l'invention du terme code est attribuée à Jeremy BENTHAM ${ }^{685}$ pour désigner le projet d'un corps complet de législation. BENTHAM utilise également le terme grec, encore plus explicite, de "pannomium» ${ }^{686}$. Pour lui, cette entreprise est par excellence un instrument de réforme utilitaire dont la fonctionnalité l'emporte sur la structure formelle. «Codifier ce n'est donc pas se borner à mettre par écrit, ou à ordonnancer le droit existant (Law as it is), c'est élaborer le droit le meilleur (Law as is ought to be).

Ainsi, l'on voit qu'il apparait de la lecture croisée de ces définitions, que la codification est d'origine lointaine. Soulignons pour plus de précision que tout ce qui précède à trait à la famille romano-germanique à laquelle appartient le droit francophone dont le droit béninois est tributaire. Ainsi, cette compilation de textes, homogène et cohérent qui organise mieux le droit de l'environnement, est digne d'intérêt particulièrement pour le droit pénal de l'environnement.

En effet, le garde des Sceaux français Jean LECANUET déclarait «je crois nécessaire pour faciliter l'action des praticiens, de faire procéder à la rédaction d'un code de l'environnement ${ }^{687}$ ». Ce code permettra d'abord de mieux connaître le droit de l'environnement puisqu'il permet de regrouper les

684 In, Réflexion sur la codification comme mode d'expression de la règle de droit, in Unification et le droit comparé dans la théorie et la pratique, contribution en honneur de J.G. Sauveplane, Devanter Kluwer, 1984, p.18, cité par LASCOUMES (P) et MARTIN J. (G) dans leur article , intitulé, Des droits épars au code de l'environnement, Droit \& Société, 30-31/1995.

685 Avant lui, reconnaissons qu'en droit romain, le code existait comme compilation de textes essentiels, on peut citer le code théodosien de 438 et le code Justinien de 534, le code du Roi HENRI III en 1603 .en 1667, le code Louis sur la procédure civile. Mais c'est au XIXème qu'il ya évolution avec le code civil de 1804 , le code de procédure civile 1807 , le code de commerce en 1807 , le code d'instruction criminel en 1808 et le code pénal en 1810 . Le XXème siècle ne viendra que confirmer ce progrès. Cité par OGOUSSAN (N), Etude de la codification de l'environnement au Bénin, de 1960 à 1990, Mémoire, maitrise en droit, UNB, 1998.

686 BENTHAM (J), Introduction to the principes of morals and legislation, 1789; J. BENTHAM, Théories des peines et des récompenses, 1811; F. OST, "codification et temporalité dans la pensée de J. BENTHAM ", in Ph. Gérard et al. Actualité de la pensée juridique de J. BENTHAM, Bruxelles, Facultés universitaires Saint Louis, 1987 ; cité par LASCOUMES (P) et MARTIN J. PRIEUR (M), Pourquoi une codification ? RJE, nºspécial 2002. 
textes jusqu'ici dispersés. Le droit de l'environnement est par son histoire et ses fondements un droit épars qui a puisé à des sources diverses et s'est édifié au coup par coup selon des aléas des enjeux sociaux. La difficulté principale réside dans l'absence de catégories homogènes pour penser les problèmes et organiser les réponses aux questions d'environnement. Tantôt, ce droit raisonne en terme d'infractions applicables aux milieux (eau, air, sol), tantôt en termes d'activités humaines nécessitant une réglementation (chasse, pêche, exploitation d'industrie, de mines, de carrières), tantôt en terme d'aménagement d'espace (littoral, montagne, réserve, parc national, site de décharge publique) tantôt enfin, en terme de protection d'espaces (faune, flore). Dans tous les cas, il s'agit d'incriminations et de sanctions hétéroclites qu'il conviendrait d'appliquer le cas échéant. C'est pourquoi, il faut harmoniser cet écheveau en posant les bases $d^{\prime}$ une codification ${ }^{688}$. Car, avec la codification on opère nécessairement une mise en ordre et des regroupements qui mettent en lumière l'importance et l'utilité du droit pénal existant. Ainsi, en concentrant un droit pénal jusqu'alors éclaté, la codification permet de consolider l'acquis environnemental, puisque l'acte de codification vaut aussi en quelque sorte confirmation du droit en vigueur. C'est à cela que pensait madame Corine LEPAGE lorsqu'elle qualifiait «le code de l'environnement d'acte de naissance du droit de l'environnement ${ }^{689}$ pour mettre l'accent sur l'importance que représente l'adoption d'un code de l'environnement.

On note également que, le code de l'environnement rend le droit de l'environnement plus accessible. Si le droit est mieux connu, on peut supposer qu'il sera plus facilement appliqué. Son regroupement le rend nécessairement plus accessible et donc plus effectif.

Le droit requiert précision et certitude, d'où la nécessité de réunir en des ensembles cohérents des règles d'origine et d'époques différentes. La codification en permettant de résoudre les contradictions, en supprimant les doubles emplois, en redressant les rédactions défectueuses et en levant les ambigüités, pouvait être l'instrument de réalisation de cet objectif. En donnant

688 LASCOUMES (P) et MARTIN J. (G) , op.cit.,p.8.

689 LEPAGE (C), Le code de l'environnement : acte de naissance officiel du droit de l'environnement ? Gaz. Pal., 6 et 7 mars 1996. 
à la matière un fil conducteur et en faisant œuvre de regroupements, le code devrait permettre, enfin de lutter contre l'éparpillement des règles et contre leur instabilité690.

Enfin, le code de l'environnement est une nécessité particulièrement impérieuse s'agissant du droit pénal et de la procédure pénale qui assure son application. En effet, le développement du droit de l'environnement a engendré celui du droit pénal de l'environnement puisque la plupart des prescriptions législatives et réglementaires, nous l'avions dit, sont assorties de sanctions pénales. Dans l'ensemble, on peut affirmer que ce recours systématique au droit répressif s'est fait dans l'improvisation, dans l'incohérence, sans souci d'harmonisation, de réflexion globale sur les objectifs de cette branche nouvelle de droit pénal spécial ${ }^{691}$. La multiplication des incriminations désordonnées, l'enchevêtrement des polices spéciales habilitées à constater les infractions limitées à certains secteurs, l'incertitude des pouvoirs qui leur étaient conférés des activités de police judiciaire, rendent particulièrement opaques et aléatoires l'application du droit pénal de l'environnement et même sa compréhension. Le remède de toutes ces incohérences était donc une codification législative afin d'harmoniser les incriminations, de rétablir une hiérarchie raisonnable des sanctions, de préciser et unifier les pouvoirs des agents habilités et rechercher lesdites infractions ${ }^{692}$.

690 LASCOUMES (P) et MARTIN J. (G), Des droits épars au code de l'environnement, Droit\&Société, 30-31/1995.p.9

691 ROBERT(J.H) \& REMOND6GROUILLOUD (M), Droit pénal de l'environnement, Masson, collection droit pénal des affaires, 1983, p.29 et s. M.J. LITTEMANN-MARTIN, Droit pénal de l'environnement, apparence redoutable et efficacité douteuse. Les juges dans le bleu. Justice, ${ }^{\circ} 122$, novembre 19898, p.15 et $s$.

692 LITTEMANN-MARTIN (M.J.), Le code de l'environnement, droit pénal et procédure pénale : quelques réflexions, RJE, n) spécial, 2002, p.55. 


\section{2) La nature et les principes de codification}

Selon la doctrine incarnée par les auteurs P. LASCOUMES, G. J. MARTIN ${ }^{693}$, deux grandes conceptions de la codification s'opposent aujourd'hui, l'une est quantitative, l'autre qualitative.

La première consiste en une simple mise sous forme écrite et exhaustive du droit dans un document unique. Dans ce cas on se contente d'opérer une compilation de solutions qui demeurent juxtaposées, de sorte que le code ne fait que refléter le processus casuistique qui a présidé à la genèse de ces solutions. Le mouvement de législation contemporain est largement de ce type, en particulier celui promu par « la Commission Supérieure de Codification en France» qui limite la rationalisation du processus au droit constant ${ }^{694}$, complété de quelques touches réformatrices sur des points présentant des caractères archaïques affirmés ou sur des contradictions fragrantes. L'histoire du code civil français de 1804 est basée en grande partie sur cette théorie. C'est l'œuvre d'un compromis entre une approche empirique dominante de la codification et une approche rationaliste modérée.

La deuxième se présente au contraire comme une systématisation poussée de la matière juridique sous forme axiologique c'est-à-dire créatrice de valeur spécifique, en terme de droit. Dans cette hypothèse s'opère une transubstantiation des règles, les solutions étant non plus juxtaposées mais hiérarchisées à partir de principes rationnels et universels et déduites les unes des autres selon des règles d'inférence logique. Dans ce cas, le code recèle ses propres règles de transformation, d'application et d'interprétation, de sorte que les imperfections législatives qui subsisteraient pourraient être surmontées à l'aide de ses dispositifs internes. La rationalité qui se dégage de cette forme de codification traduit de façon exemplaire la propriété essentielle des systèmes selon laquelle l'ensemble présente une valeur plus importante que la somme des éléments. La systématisation fait émerger des propriétés que chaque élément à

693 In Des droits épars au code de l'environnement, Droit\&Société, 30-31/1995.

694 Selon Michel PRIEUR, la notion de droit constant suppose " qu'aucune modification ne peut être apportée au fond des dispositions législatives codifiées ". C'est le cas du code de l'environnement français dont l'élaboration a été assurée par la Commission Supérieure de Codification en 2000. 
l'état isolé ne présenterait pas. Ce mode reste cependant plus théorique que réellement mis en œuvre. Dans une certaine mesure, la codification pénale, surtout celle de 1791 et de 1810, et dans une moindre mesure celle entrée en vigueur en 1994, s'inspirent en partie de ces principes.

A ces deux tendances, Bruno OPPETIT ajoute deux autres formes de codification à savoir "des codes-compilations qui ont pour seul objet de regrouper les textes sans les modifier, ni même les ordonner. Mais il conclu qu'on peut douter qu'il s'agisse de véritables codes. Ensuite, la deuxième catégorie est constituée de «codes-consolidation qui consacrent législativement des solutions jurisprudentielles, voire doctrinales, et qui réunissent et intègrent les textes existants selon un ordre logique et chronologique» ${ }^{695}$.

Comme on le constate donc, deux voies possibles s'offrent au législateur béninois en matière de codification des règles du droit de l'environnement. Quelque soit l'une ou l'autre option, on aboutit toujours au même résultat de codification, à un regroupement de tous les textes sur l'environnement pour une meilleure visibilité. En revanche, il serait plus raisonnable pour les pays africains $^{696}$ dont le droit pénal de l'environnement est encore naissant, mais avec une évolution remarquable de la politique nationale de protection des ressources de l'environnement ainsi que l'accroissement des normes et principes internationaux souscrits, d'opter pour la codification quantitative qui apparait plus simplifiée et moins complexe. Elle assure le respect de la hiérarchie des normes et la cohérence rédactionnelle des textes. Rares sont les pays africains ${ }^{697}$ qui se sont dotés d'un code de l'environnement au sens technique du terme, à ne pas confondre avec le vocable "code de l'environnement» utilisé par certaines législations africaines à l'instar du «code de l'environnement togolais ${ }^{698} »$; du

695 OPPETIT (B), L’idée de la codification, D.1996, Chron., p.33. cité par G. MARTIN, Principes pour une codification de l'environnement, op., cit., p.287.

696 Y compris mêmes certains pays européens.

697 Nous connaissons le cas du Sénégal avec la loi n²001-01 du 15 janvier 2001 portant code de l'environnement dont l'exposé des motifs spécifie clairement la partie législative et la partie réglementaire avec la lettre « $L$ » qui précède les articles législatives et la lettre « $R$ » qui précède les articles réglementaires 
"code de l'environnement burkinabè ${ }^{699}$ ", etc....Cette appellation signifie en réalité «loi» comme on pourrait parler de loi ou de «code de l'eau», de "code minier» ou encore de "code forestier». En matière de code proprement dit, tous ces "petits codes» ou lois sont mis dans un seul paquet, formant un seul texte de loi auquel s'ajoutent tous les décrets accompagnant ces textes pour ainsi former la partie réglementaire du code.

Par ailleurs, un certain nombre de principes gouvernent la rédaction du code de l'environnement. Bentham en avait précisé l'essentiel, complété depuis par quelques auteurs de référence en particulier J. VANDERLINDEN ${ }^{700}$. II s'agit de:

- La cohérence : au sens où le code réalise la concentration d'une matière jusque là éparse et fragmentaire et sa logique interne de construction doit en faciliter la consultation et la compréhension;

- L'absence de contradictions dans les solutions qu'il envisage, à cette fin le code abolit les règles antérieures;

- La complétude : un code doit ambitionner l'exhaustivité du champ qu'il couvre, sans prétendre couvrir la totalité des règles possibles; il doit surtout s'attacher à formuler des repères essentiels couvrant toutes les dimensions du secteur en cause;

- La clarté : elle est indispensable à l'accessibilité qui exige un texte écrit dans un langage précis, non ésotérique et dépourvue de terminologie anciennes;

- La maniabilité : à défaut de pouvoir toujours se réduire aux dimensions d'un bref volume, il doit contenir l'essentiel dans des formulations concises.

699 Il s'agit en réalité de la loi n ${ }^{\circ}$ 005/97/ADP portant code de l'environnement au Burkina Faso dont la structure n'a rien d'un code de l'environnement tel que décrit plus haut.

700 In, Le concept de code en Europe occidentale du XVIII au XIX ème, Essai de définition, Bruxelles, éd.de l'institut de sociologie de l'ULB, 1967 ; R. DAVID, La codification, in, le droit français, Paris, LGDG, 1960, tome I, p.12 s. cité par LASCOUMES (P) et MARTIN J. (G), Des droits épars au code de l’environnement, Droit\&Société, 30-31/1995.p.9 
- La publicité : un code doit être aisément accessible et largement diffusé, le gouvernement doit lui donner une résonnance particulière afin que «nul ne soit sensé ignoré la loi».

\section{3) Le dispositif institutionnel}

Nous allons ici nous inspirer du diapositif institutionnel français qui a aboutit à l'élaboration du code de l'environnement et analyser les modalités dans lesquelles il pourrait s'appliquer au Bénin.

En effet, en France, c'est en 1990, à la suite de l'alerte d'une partie de la doctrine, que finalement la décision fut prise de demander un rapport sur la faisabilité d'un code de l'environnement qui s'acheva dix ans après par l'ordonnance ${ }^{\circ} 2000-914$ du 18 septembre 2000 sur proposition de la Commission Supérieure de Codification. La commission d'universitaires chargée de ce travail (présidée par le doyen M. PRIEUR) présenta un rapport ${ }^{701}$ dans lequel elle concluait à la nécessité de procéder à une véritable codification du droit de l'environnement. Le gouvernement a avalisé la décision d'élaborer le code de l'environnement en mai $1992^{702}$. La commission d'Experts de 15 personnes, sous l'égide du ministère chargé de l'environnement, comprenant, juristes, universitaires, avocats, magistrats de l'ordre administratif et de l'ordre judiciaire, représentants du mouvement associatif et fonctionnaires, installée en juillet 1992 sous la présidence de G. Martin, Président du SFDE., a proposé un plan en $1993^{703}$. Le dispositif institutionnel ayant conduit à l'élaboration du code de l'environnement français se présentait suivant le schéma ci-contre :

701 PRIEUR (M) (dir.), Rapport sur la faisabilité d'un code de l'environnement, Paris, Ministère de l'environnement, 1993. V. PRIEUR (M), Pourquoi une codification ? RJE, nº Spécial 2002.

702 PRIEUR (M), Pourquoi une codification ? RJE, nº Spécial 2002.

703 LASCOUMES (P) et MARTIN op., cit.,p.11 


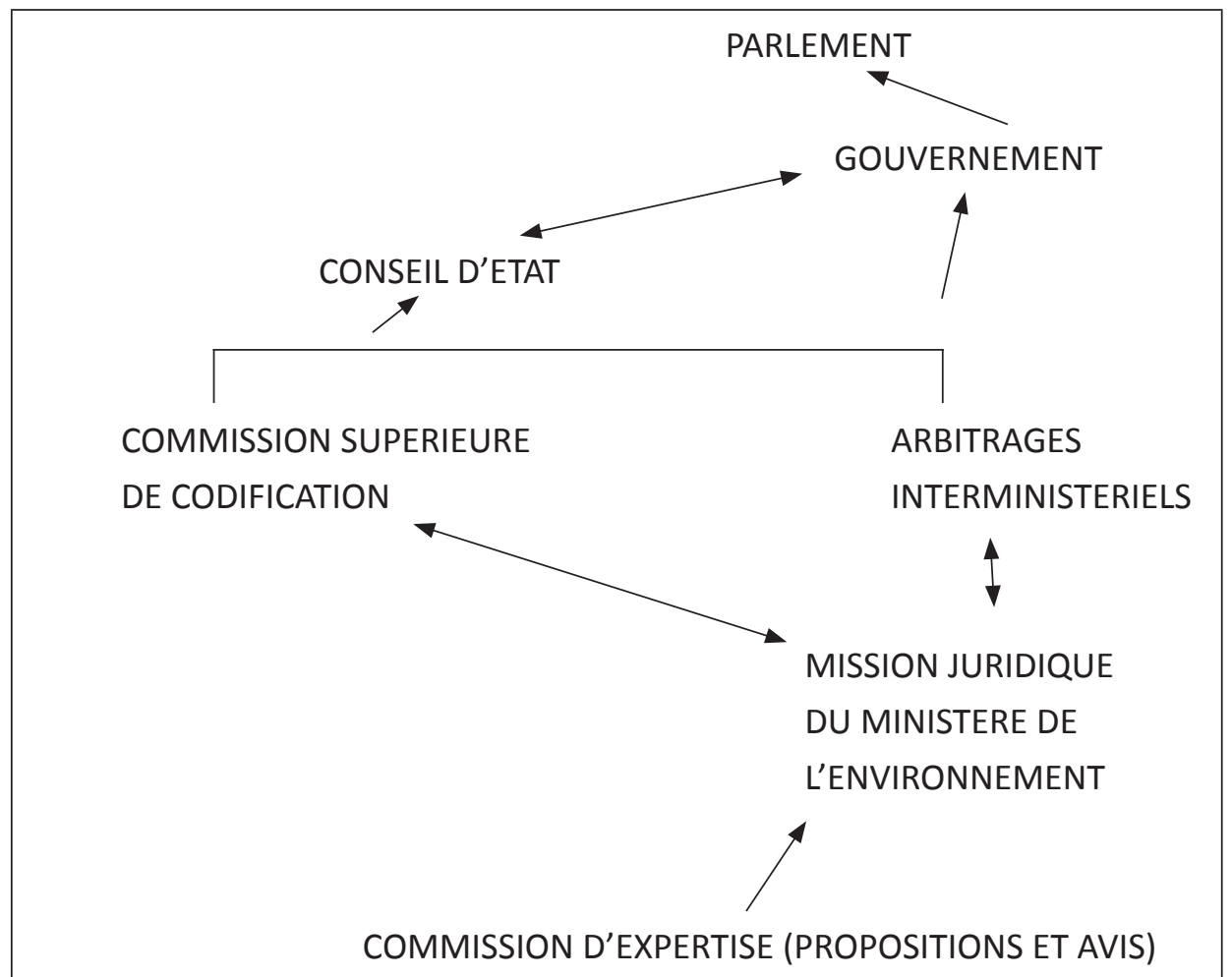

Source : LASCOUMES (P) et MARTIN J. (G),

Au Bénin, la procédure d'élaboration de la loi est presque identique à celle qui est en cours en France. Ainsi, dans le cadre de l'élaboration du code de l'environnement au Bénin, la démarche à suivre peut se présenter comme suit : 


\section{MEHU}

(CHEF DE FIL ELABORATION DES TDR)

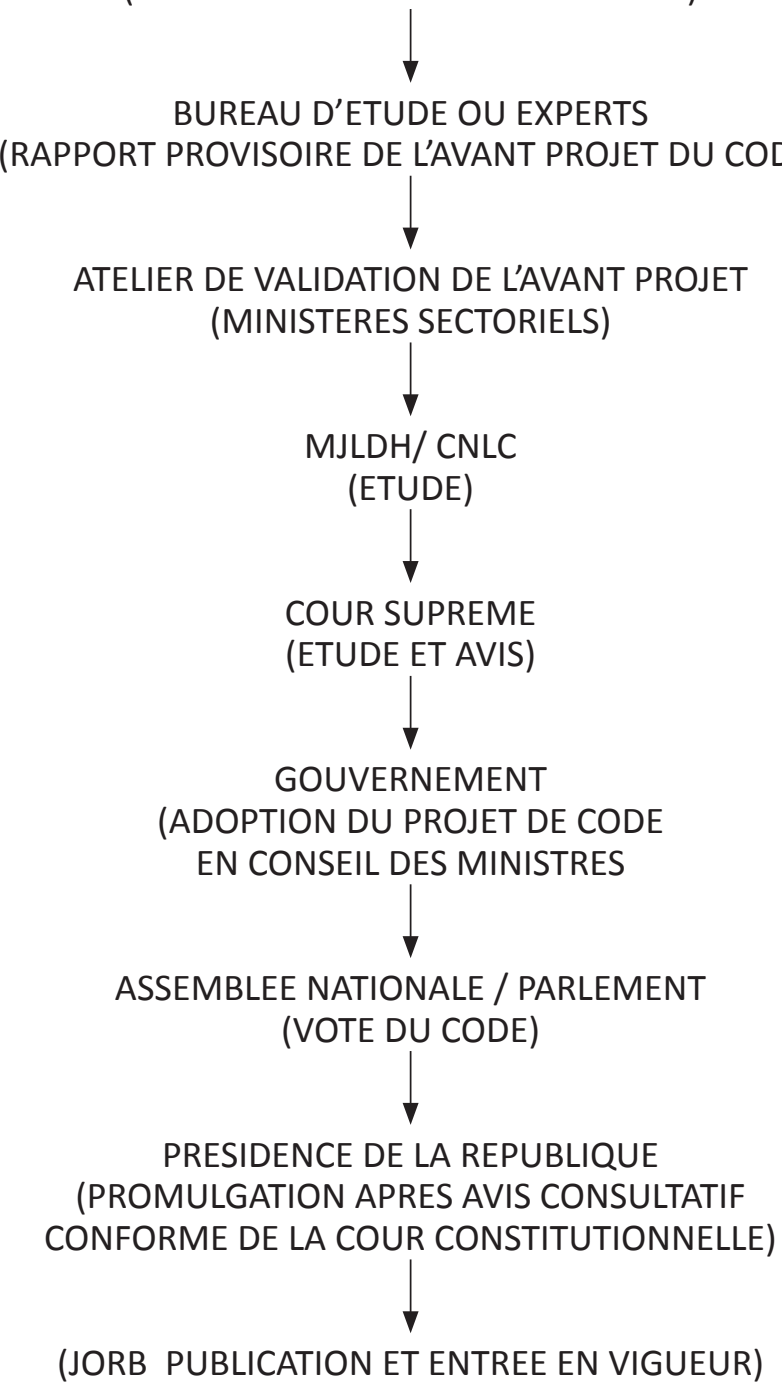

Dispositif institutionnel pour l'élaboration de la partie législative du code de l'environnement

Le Ministère chargé de l'environnement, pourrait être le chef de fil de l'élaboration du code. A ce titre, il élabore les termes de références du projet 
et lance un appel d'offre international pour la sélection d'un bureau d'étude (l'équivalent de la Commission d'expertise en France) qui aura pour mission d'élaborer l'avant-projet du code. Ensuite le ministère chargé de l'environnement organise un atelier qui réunira tous les ministères sectoriels, les universitaires, les magistrats, et autres participants jugés nécessaires pour valider l'avant projet du code. Enfin, après cette étape, le rapport définitif issu de l'atelier est transmis à la Commission Nationale de Législation et de Codification pour étude, l'équivalent en France de la Commission Supérieure de Codification. Cette dernière transmettra à son tour le document au gouvernement qui sollicitera l'avis motivé de la Cour Suprême (l'équivalent du Conseil d'Etat en France) avant de l'adopter et le transmettre au parlement pour étude et vote du projet de code (voir tableau ci-dessus). Cette procédure, qui se termine par la publication de la loi au JO, est la procédure normale en vigueur au Bénin pour le vote des projets de lois. Elle peut durer au moins cinq ans voire plus pour la codification de la partie législative du code dans la mesure où pour une simple loi, le vote peut intervenir cinq ans après.

En ce qui concerne la partie réglementaire, un comité technique d'experts nationaux suffit pour faire la compilation de tous les textes réglementaires (décrets et arrêtés) et à les ordonner dans une cohérence à la suite de la partie législative. Cette démarche nous permet d'éviter les erreurs et les incohérences de ceux qui ont précédé, notamment la France et améliorer la rédaction.

\section{4) Les limites et les écueils qui pourraient résulter de la rédaction du code}

Le code de l'environnement français, dès sa conception, présentait quelques handicaps que le législateur béninois peut éviter. Le code français est restrictif. II n'a pas pris en compte plusieurs aspects du droit de l'environnement. C'est le cas des ressources naturelles et de la diversité biologique, régies par le code forestier, de l'assainissement et de l'aménagement du territoire, régi par le 
code de l'urbanisme ${ }^{704}$. Ces codes auraient pu se fondre dans le grand ensemble que constitue le code de l'environnement. Mais, ils n'ont pas pu intégrer le " grand code » simplement parce que ces codes existaient déjà. Même le secteur du bruit n'est pas entièrement pris en compte ${ }^{705}$. De plus, le processus de son adoption a été objet à polémique. Alors que le projet de loi de ratification du code de l'environnement avait déjà été déposé à l'Assemblée Nationale en 1994 puis retiré, il fut déposé à nouveau le 27 mai 1998 et également retiré en raison de l'encombrement du Parlement. C'est alors que le gouvernement fit voter une loi d'habilitation le 16 décembre 1999 autorisant le gouvernement à adopter la partie législative de 9 codes dont celui de l'environnement, ce qui fut fait le 18 septembre 2000 par ordonnance ${ }^{706}$.

Par ailleurs, le code en termes de textes réglementaires se limite, dans la partie réglementaire, aux décrets d'application. Les arrêtés d’application y sont pas inclus alors qu'on sait que se sont ces textes d'applications, pris par les autorités compétentes que sont les ministres sectoriels concernés, qui définissent très souvent les modalités de mise en œuvre et même les incriminations. Ne pas les inclurent dans le code constitue à notre avis, une lacune, que les codes naissants peuvent corriger.

Aussi, des activités sans incidence sérieuse pour l'environnement sontelles sanctionnées des mêmes peines que celles ayant un impact gravissime : transporter le cadavre d'une buse variable ou celui d'un hérisson, se livrer au trafic international d'espèces protégées car menacées de disparition font encourir aux auteurs de ces faits six mois d'emprisonnement et 9000 euros d'amende ${ }^{707}$. Cette pénalisation, "fourre tout " n'a rien de proportionnelle à I'infraction commise. Il faut donc sérier.

704 La technique du renvoi a permis au code de l'environnement par l'article L300-1 de renvoyer au code forestier tous les aspects répressifs liés à la protection des ressources naturelles et l'article L 300-2 renvoi au code d'urbanisme.

705 PRIEUR (M), Pourquoi une codification ? RJE, n Spécial 2002, p.11.

706 Idem. p.12

707 Art. L415-3 du code de l'environnement français. V. LITTMANN (Marie-José), Code de l'environnement, droit pénal et procédure pénal : quelques réflexions, RJE, $n^{\circ}$ Spécial, p.59. 
S'inspirant toujours du code de l'environnement français, terminons cette rubrique par le manque de rigueur des rédacteurs dans l'élaboration du code, notamment des incohérences de formes et de fond.

\section{a) Eviter des incohérences de fond et de forme}

Ce défaut est justement souligné par le Professeur ROBERT. Ainsi, l'expression "dispositions pénales», la plus fréquente en cette matière, englobe les règles procédurales, les sanctions et parfois les incriminations ${ }^{708}$.

Il est parfois curieusement question de «dispositions pénales complémentaires ", intitulé qui couvre la recherche et la constatation des infractions, la transaction, les poursuites, l'action civile et les sanctions à l'occasion desquelles est développée "l'exclusion des associations agréées ». Était-il nécessaire de parler encore de dispositions pénales complémentaires ? S'interroge LITTMANN. ${ }^{709}$

Aussi, la subdivision " sanctions " couvre-t-elle parfois, les sanctions administratives et pénales, ${ }^{710}$ créant ainsi un amalgame. Mieux les dispositions pénales ne sont pas regroupées mais éparpillées dans le code rendant les recherches parfois fastidieuses. Le professeur FAURE, pour avoir contribué à la traduction anglaise de ce code, pense même qu'il est pratiquement illisible.

Au-delà de ces irrégularités de formes, subsistent des incohérences de fond.

708 V., par exemple, L V, Titre IV, chap. 1, art L541-44 et s. ; livre II, titre I, chap. 6, sect. II, mais cette section figure dans ce chapitre VI intitulé "sanctions » : art. L216-3 et s.

709 Art. L 437-1 à L437-23 du code de l'environnement français

710 Art. L 216-1 à L 216-13 du code de l'environnement français 
En effet, des critiques au sujet du code ont été formulées par la doctrine. Ainsi, le Professeur Marie-José LITTMANN-MARTIN ${ }^{711}$, citant le professeur J.H.ROBERT affirme " le recours au droit constant produit un effet de loupe qui grossit les dysharmonies du droit antérieur...Codifier à droit constant les dispositions pénales relatives à la protection de l'environnement, c'est faire en plus mal, ce que les éditeurs juridiques savaient réussir depuis longtemps en présentant le catalogue raisonné des lois qui n'avaient pas honte de leur date de naissance ". Cette conclusion du professeur ROBERT résume le bilan pessimiste de cette codification. II poursuit en précisant qu'on retrouve, dans le code de l'environnement, toutes les défectuosités qui ont été inlassablement dénoncées. Elles concernent notamment les incriminations, les sanctions et la hiérarchie déroutante de certaines qualifications et l'incertitude entourant le contenu des incriminations ${ }^{712}$. Pour illustrer ses propos, il donne quelques exemples.

- Respectant la répartition des compétences (article 34 de la constitution française), l'article111-2 du code pénal, précise : « la loi détermine les crimes et délits et fixe les peines applicables à leurs auteurs ». Les éléments constitutifs des délits devraient donc être prévus par le législateur. Or, cette situation est exceptionnelle et perdure naturellement dans le code de l'environnement. Rares sont les délits autonomes tels celui de pollution des eaux douces de surface (code rural article $L$ 232-2 devenu $L$ 432-2 du code de l'environnement) et ceux d'obstacle mis aux contrôles.

- Le déversement de substances dans une rivière ayant à la fois détruit des poissons et endommagé la flore, présente une situation concurrentielle de qualification. La question se pose de savoir quelles dispositions appliquées. Est-ce l'article L432-2 du code de l'environnement (code rural article $L$ 232-2 ancien) ou l'article $L$ 216-6 du code de l'environnement (loi-n92-3 du 3 janvier 1992, article 22) ? Puisque chacun de ces délits à son propre dispositif répressif et procédural. La même démonstration peut être faite à propos du délit prévu par l'article $L$ 216-6 du code de

711 LITTMANN (Marie-José), Code de l'environnement, droit pénal et procédure pénal : quelques réflexions, RJE, $n^{\circ}$ Spécial, p. 55 ; in, Le droit pénal dans le code de l'environnement, Dr. env. $n^{\circ} 85$ p.12 
l'environnement et de l'article L 218-73 du même code (décret-loi du 9 janvier 1852 , article $6,13^{\circ}$ ), lorsque le déversement polluant s'est produit dans des eaux salées.

- Comment défendre un code tout neuf qui prévoit trois délits réprimant la pollution des eaux alors qu'il ne prévoit aucune infraction sanctionnant la pollution de l'air ou des sols?

Cette absence totale d'harmonisation dérange le juriste orthodoxe soucieux de rationalité.

\section{b) Eviter la rédaction infidèle de certains textes}

Elles concernent notamment les oublis et les ajouts inattendus dans une codification législative à droit constant. C'est le cas par exemple de certaines incriminations, puisque se référent au code de l'environnement, on peut constater que «les interdictions énoncées à l'article L 411-1 du code de l'environnement (art. L 211-1, code rural ancien) sont incriminées par l'article L 415-3 (code rural, art. 215-3 ancien). Mais alors que le texte ancien punissait, notamment "les infractions aux dispositions de l'article L 211-1», l'article L4153 du code de l'environnement reformule les interdictions de l'article L4111 pénalement sanctionnées, mais oubli celles visant «la destruction des sites contenant des fossiles permettant d'étudier l'histoire du monde vivant ainsi que les premières activités humaines et la destruction ou l'enlèvement des fossiles présents sur ces sites» (code de l'environnement, art. L 411-1 $-4^{\circ}$ ) $\rangle^{713}$. Néanmoins, il est important de faire observer que l'abrogation, ${ }^{714} d^{\prime}$ 'une loi ou d'un règlement à l'occasion d'une codification à droit constant, ne modifie ni la teneur des dispositions transférées ni leur portée ${ }^{715}$; de sorte que «le visa des anciens numéros d'articles dans les actes de poursuites n'affecte pas la validité de ces derniers et ne fait pas obstacle à la condamnation ${ }^{716}$. Quoique la question

713 LITTMANN (Marie-José), Code de l'environnement, droit pénal et procédure pénal : quelques réflexions, RJE, $n^{\circ}$ Spécial, p.62.

714 Dans ce sens synonyme d'oubli.

715 GUIHAL (D), Droit répressif de l'environnement, op., cit., p.125.

716 GUIHAL (D), Droit répressif de l'environnement, op., cit., p.125 
soit évidente, il se trouve lors de chaque codification, des plaideurs pour poser à nouveau la question ${ }^{717}$. Par ailleurs, en matière d'oubli ou d'erreur matérielle, une nouvelle loi ou "loi de ratification» suffit pour corriger l'erreur ${ }^{718}$. C'est le cas par exemple de l'article 28-1 de la loi du 3 janvier 1992 en France sur l'eau qui prévoyait que les personnes morales pouvaient être déclarées responsables de toutes les infractions aux dispositions de cette loi, et énonçait les peines qui leur étaient applicables. L'article L 216-12 du code de l'environnement, qui a recueilli ces dispositions, renvoi à l'article L 216-5 l'énumération des infractions dont les personnes morales peuvent se rendre coupables. Or, dans le texte annexé à l'ordonnance de codification du 18 septembre 2000, l'article L 216-5 ne mentionnait pas l'article 216-6, où sont codifiées les dispositions de l'article 22 de la loi du 3 janvier 1992 réprimant certains rejets polluants ${ }^{719}$.

A partir de ces exemples, on remarquera que le code de l'environnement français, n'est pas aussi parfait qu'on puisse le croire. Son élaboration et sa mise en œuvre sont parsemées de difficultés. L'élaboration du code de l'environnement est une entreprise, reconnaissons-le difficile. A preuve, le code de l'environnement français a mis environ 10 ans avant d'être achevé. Le code allemand quant à lui, en préparation depuis 5 ans, était encore au stade du livre I en 1995.

Mais, pour avoir une bonne codification, il faut nécessairement avoir élaboré des textes cohérents et homogènes.

\section{§II : Vers une législation pénale environnementale cohérente et homogène}

L'état des lieux de l'analyse de la législation environnementale au Bénin, laisse transparaitre comme nous l'avons indiqué dans nos développements

717 Cass. Crim.31 mars 1993, Guilbert : Rev sc.crim. 93 p.792, note J H, ROBERT, à propos de la codification de la loi du 10 juillet 1976 dans le code rural. Plus précisément, le moyen a refleuri à l'occasion de la codification du droit de la consommation: cass.crim. 4mai 1995 : bull. 163.

718 GUIHAL (D), Droit répressif de l'environnement, op., cit., p.126

719 GUIHAL (D), Droit répressif de l'environnement, op., cit., p.126 
antérieurs, tantôt une pénalisation indirecte, tantôt une pénalisation directe. La question se pose de savoir quel est le modèle idéal en terme de sauvegarde de l'environnement par le droit pénal?

Nos investigations pour apporter quelque solution à cette problématique, nous ont conduites à observer qu'effectivement, le droit pénal de l'environnement, tel que pratiqué en général, offre plusieurs modèles ou théories répressives de l'environnement qui ont des buts différents. Mais, selon la doctrine allemande ${ }^{720}$, le modèle idéal consisterait à opérer une combinaison des trois modèles.

- Le premier modèle ou la théorie de la mise en "danger abstrait», consiste, nous l'avions signalé, à pénaliser le non respect d'obligations administratives ${ }^{721}$. Ce type de pénalisation était largement appliqué dans la plupart des pays. Comme le précise le professeur FAURE, «il est important de souligner qu'à l'origine, dans plusieurs pays, le droit pénal se limitait à ce stade de pénalisation ${ }^{722}$. Les limites de ce premier type de modèle ont certainement conduit à l'élaboration et à l'application du deuxième modèle.

- Le deuxième modèle est la théorie de la mise en "danger concret» ou la pénalisation directe. Elle consiste pour le législateur à réprimer essentiellement l'atteinte aux valeurs juridiques écologiques, comme des émissions illicites dégradant le sol, l'eau ou l'air ${ }^{723}$.

- Le troisième modèle, voisin du précédent, puisqu'il s'agit d'une pénalisation directe, est dénommé délit autonome. Sa particularité

720 Ce courant est particulièrement incarné par la doctrine allemande depuis les années 80 avant d'être consacré par le Conseil de l'Europe, dans la convention sur la protection de l'environnement par le droit pénal, adopté à Strasbourg le 047 novembre 1998. Pour un aperçu. V. G. Heine, "Allemagne. Crimes against the environment », Revue internationale de droit pénal, vol.65, 1994, p.731-759. Cité par le professeur FAURE, dans son article, Vers un nouveau modèle de protection de l'environnement par le droit pénal, in, Revue Européenne de droit de l'Environnement, 1/2005, p.3 à 7.

721 Cf. supra. chap.4,§1

722 Vers un nouveau modèle de protection de l'environnement par le droit pénal, op.,cit., p.13.

723 Cf. supra. chap.4, §2 
réside dans l'aggravation de la peine lorsque l'émission présente en outre un danger pour la santé humaine. Puisque les conséquences sont très graves, il va de soi que le champ d'application d'une telle disposition soit restreinte. C'est le cas d'une pollution extrêmement grave, comme le déversement des déchets toxiques ${ }^{724}$. L'article 421-2 du NCP français qui parle de terrorisme écologique, en est aussi une illustration parfaite d'infraction autonome. Le mérite de ce modèle est de «faire apparaitre le pollueur comme un délinquant au même titre que le voleur $\aleph^{725}$.

En définitive, selon cette doctrine dont nous partageons largement le contenu, c'est la combinaison de l'application de ces trois modèles qui donne le bon modèle "le modèle idéal», du droit répressif de l'environnement dont rêve le professeur FAURE. Le principe demeure toujours que se sont les autorités administratives qui sont les mieux placées pour apprécier dans quelle mesure les émissions peuvent mettre en danger l'environnement et la santé humaine. Ces décisions sont prises dans les autorisations. Le non respect de ces décisions devrait normalement conduire à des sanctions, comme c'est le cas de mise en danger abstrait de l'environnement. Mais, une bonne protection de l'environnement par le droit pénal doit aller au-delà. Les dispositions de ce premier type de modèle ont l'inconvénient d'accorder une protection uniquement à l'environnement si les dispositions administratives ont été violées. Il conviendrait d'aller au delà de la dépendance administrative, d'où la pénalisation directe ou concrète qui relativise la dépendance administrative du droit pénal de l'environnement. Enfin, pour une justice pénale dans l'équité et la transparence, il faut tenir compte de la dangerosité des infractions notamment les infractions criminelles, nuisibles à l'environnement et à la santé humaine, et observer une gradation dans les peines, la proportionnalité des peines. Ces infractions, correspondent aux délits autonomes.

Dès lors, un droit pénal idéal consisterait en une combinaison des différentes dispositions relevant des trois modèles que nous venons de décrire. Un seul pris isolement ne saurait être efficace ni cohérent. "Car il n'est pas possible de résoudre tous les problèmes d'environnement par le droit

724 Cf. supra chap.4, §2, B

725 M. PRIEUR, Droit de l'environnement, op.cit., p.830 
pénal avec un seul modèle, mais il faut différentes dispositions avec des buts différents, un lien différent avec le droit administratif et évidemment avec des peines différentes ${ }^{726}$. Ainsi, tenant compte du principe de la proportionnalité des peines, le juge pourra appliquer aisément des peines appropriées à chaque cas d'espèce.

Au Bénin ${ }^{727}$, comme nous l'avions indiqué, le droit pénal interne de l'environnement est fondamentalement basé sur le premier type de modèle mais avec une tendance à la criminalisation (le déversement des déchets toxiques, réglementé par le droit constitutionnel et par la loi-cadre). II s'ensuit que dans une reforme du droit pénal béninois ou africain de l'environnement, le législateur devra s'inspirer des différents types de modèles pour asseoir une répression en adéquation avec l'évolution du droit pénal de l'environnement tout en tenant compte des réalités du terroir. Dans tous les cas, il apparait comme une évidence qu'une formulation cohérente et homogène des incriminations dépend de la combinaison des trois modèles.

Deux instruments internationaux, sous l'égide du Conseil de l'Europe, ont consacré par la suite cette théorie qu'on pourrait appeler «théorie de la combinaison de la pénalisation indirecte et de la pénalisation directe». II s'agit de la Convention sur la protection de l'environnement par le droit pénal ${ }^{728}$ et la Décision-cadre $\mathrm{n}^{\circ} 2003 / 80 / \mathrm{JAl}$ du 27 janvier 2003 relative à la protection de l'environnement par le droit pénal ${ }^{729}$.

L'autonomie du droit pénal de l'environnement est une avancée spectaculaire dans l'amélioration du droit pénal, même si le professeur PRIEUR y voit quelques obstacles. Car, écrit-il «le droit pénal a du mal à prendre en compte

726 Vers un nouveau modèle de protection de l'environnement par le droit pénal, op.,cit., p.13

727 Comme ce fût le cas de plusieurs pays africains et européens au début du développement du droit pénal de l'environnement

728 Publié entre autres dans M. FAURE, et G. HEINE, « Environnemental Criminal Law in the european Union. Documentation of the main provisions with introduction», Freiburg im Breigau., Max Planck Institut fur Auslandisches und internationals Strafrecht, 2000, p. 407416 et aussi disponible par internet sur l'adresse hpp:/www.coe.fr/eng/legaltxt/172htm. V. sur les raisons pour cette protection de l'environnement au niveau européen $\mathrm{H}$. A. Engelhard, "Protection de l'environnement pare le droit pénal», Revue de Droit Pénal et de Criminologie, 1991, p.295-310.

729 J.O. n L29/55 du 5 février 2003. 
la globalité des problèmes d'environnement et l'interaction entre l'homme et le milieu naturel. Comme il n'est pas possible de modifier la place et le rôle des éléments qui constituent l'équilibre écologique, il faut donc modifier les règles et principes du droit pénal pour les adapter à la nouvelle demande sociale ${ }^{730}$. Cette révision des textes pénaux est indispensable pour permettre au droit pénal de jouer un rôle important dans le développement durable. Les pays particulièrement en voie de développement peuvent s'inspirer de ce modèle idéal pour créer leur " propre modèle ", de sorte que tout en emboitant le pas aux pays du nord, ils veillent à éviter les erreurs qu'ils ont connu.

Dans cette même lancée, il conviendrait pour les Etats africains, et particulièrement pour le Bénin, d'expérimenter le recours à l'analyse économique du droit de l'environnement comme outil de pénalisation des infractions d'environnement dans un cadre juridique doté de moyens d'action adéquats

\section{SECTION II : L'ANALYSE ECONOMIQUE DU DROIT PENAL DE L'ENVIRONNEMENT}

L'analyse économique du droit de l'environnement est aussi un outil à la disposition du droit pénal que les pouvoirs publics peuvent exploiter lors de l'élaboration des textes législatifs et réglementaires. Une tendance de plus en plus importante vers l'analyse couts-bénéfices en matière de politique pénale environnementale, s'observe davantage dans les pays du Nord. Plusieurs 
théories économiques ${ }^{731}$ convergent toutes vers la prise en considération de l'analyse coûts-bénéfices dans les stratégies environnementales. En Europe, nous devons nous référer aux dispositions de l'article 130R aujourd'hui articles 191 à193 du traité de Lisbonne ${ }^{732}$. Dès lors, pourquoi une intervention de l'analyse économique dans la protection de l'environnement ? Comment le droit pénal, vu sous un angle économique permet -il de lutter efficacement contre les dégradations des ressources environnementales? En partant de l'hypothèse que les pays du nord, vu leur expérience en la matière, ont apporté une réponse plus ou moins efficiente à cette problématique, la question se pose dès lors de savoir comment les pays africains et en particulier le Bénin peut s'inspirer d'une telle expérience pour avoir un droit répressif plus protecteur de l'environnement.

A la lumière de cette expérience européenne, il conviendrait d'abord d'appréhender l'intérêt de la théorie de l'analyse économique et les modalités de son application en droit pénal de l'environnement béninois. (§ I). Mais, pour réussir une telle opération, le Bénin devra améliorer son environnement humain, technique et financier, en terme de renforcement des moyens d'actions (§II).

731 Voir sur l'analyse cout-bénéfice en general: E.J MISHAN, Cost-benefit Analysis: an informal introduction, 2eme éd., Londres, Allen \&Unwin, 1974; B.A. ACKERMAN, S.ROSEACKERMAN, J. SAWYER et D. HENDERSON, The Uncertain Search for Environmental Quality, NEW Jork, Free Press, 1971 et les critiques de ce livre par W. OATES, "Book Review, The Uncertain Search for Environmental Quality ", University for Pennsylvania Law Review, vol.124, 1976, pp.864-891. Voir également P.ABELSON, Cost benefit Analysis and Environmental Problems, Farnborough, Saxon House, 1979 ; A. COCKER et C. RICHARDS, Valuing the environment, Economics Approaches to Environmental Evaluation, Londres, Bellhaven Press, 1992; B.C. FIELDS, Environmental economics: an introduction, New York, McGraw-Hil, 1994; G.S. TOLLEY, P.H.F. GRAVES et G.C. BLONQUIST, Environmental policy, Elements of Environmental Analysis, Cambridge, Ballinger Publishing Company, Vol., 1981. Cite par FAURE (Michael), in, L'analyse Economique du droit de l'Environnement, BRUYLANT, Bruxelles 2007, p.32.

732 Source internet : $\underline{w w w . u n i o n . e u r o p e ́ e n n e . O r g}$ 


\section{§I : L’intérêt de la théorie de l'analyse économique du droit de l'environnement}

L'usage des biens environnementaux soulève des problèmes d'externalité 733 qui se traduisent par l'absence d'intégration au niveau d'une relation économique, d'un coût ou d'un bénéfice propre. Par exemple, les voisins d'un propriétaire d'un domaine forestier veillant à l'entretien de ses massifs boisés bénéficient d'externalité (absence d'érosion, réduction des crues, maintient d'un débit hydrique régulier,...) sans que le propriétaire puisse pour autant leur réclamer une contrepartie d'ordre monétaire pour les avantages qu'il leur procure. On parlera dans ce cas d'externalité positive. En revanche, lorsque la production ou la consommation d'un bien ou d'un service cause des dommages à des biens environnementaux, ces activités engendrent des externalités négatives dès que leur coût n'est pas pris en compte dans le prix de revient du produit consommé ou du service rendu ${ }^{734}$. Ce raisonnement économique est sous-tendu par la possibilité d'une influence du comportement des individus par le droit pénal. Dès lors en droit pénal de l'environnement, la prise en compte de ce " coût ", en rapport au bénéfice escompté, se traduit par un choix optimal de la répression ou de la sanction à infliger en cas d'externalité négative. Pour mieux appréhender le bien fondé de ce raisonnement et apprécier son application en droit pénal, il faut comprendre d'abord les raisons qui gouvernent cette théorie.

733 Pour un essai de définition, cf. AMOUSSOUGA GERO(F), Cours d'économie de l'environnement, DEA Droit et politique de l'environnement, 2004-2005, Lomé, Togo. On qualifie d'externalité " les effets d'une action sur d'autres parties lorsqu'ils n'ont pas été pris en compte par l'auteur de l'action ». Ainsi « les externalités, celles surtout négatives, se manifestent à chaque fois qu'un individu ou une entreprise peut adopter un comportement anti-social sans subir de sanctions. Les responsables doivent, lorsque cela est possible, internaliser les externalités en faisant payer aux infracteurs le coût intégral de leur actions sur d'autres parties ».

734 De SADELEER (Nicolas), Les principes du pollueur payeur, de prévention et de précaution. Essai sur la gestion et la portée juridique de quelques principes de droit de l'environnement. Éd. Bruylant /AUF, Bruxelles, 1999, p.50. 


\section{A) Les raisons qui gouvernent la théorie économique}

La question qui se pose dans l'analyse économique du droit est de savoir pourquoi utiliser le droit pénal afin de sanctionner les délits d'environnement. Plusieurs raisons des tenants du modèle économique, concourent pour expliquer la pertinence du recours au droit pénal. Ainsi, entre autres arguments, on peut retenir: l'effet utilitaire, préventif et dissuasif du droit pénal, la faiblesse du droit civil à garantir une internalisation optimale de certaines externalités, la probabilité de découverte de l'infraction.

Le premier argument qui fonde cette théorie est basé sur le but utilitaire et préventif des règles de droit. Ainsi, si les juristes évoquent fréquemment un but moral attaché au caractère retributif de la peine, les économistes soulignent l'importance de l'effet préventif et utilitaire des règles de droit. C'est en ce sens que la peine devra être modulée en fonction du dommage social causé par le crime. II s'agit là du principe de la proportionnalité ${ }^{735}$. La ligne conductrice en droit pénal repose plutôt sur l'objectif d'éviter les infractions en adoptant des mesures correctrices pour aider le coupable à s'insérer (l'idée de resocialisation) ou l'écarter par (l'emprisonnement) en cas d'impossibilité d'amélioration ${ }^{736}$. Le criminel potentiel est en effet envisagé comme un individu raisonnable qui prend la décision de commettre ou non l'infraction sur la base d'une analyse "coûts-avantages». Il est présumé être une personne raisonnable qui désire maximiser son utilité. Voilà pourquoi, les économistes soulignent l'effet dissuasif et préventif des règles de droit. Aussi le droit pénal doit -il augmenter le "prix» de son comportement illégal par l'application de la sanction pénale.

Au delà de ce raisonnement utilitaire et préventif, le deuxième axe de réflexion des économistes se justifie par l'incapacité et l'insuffisance du droit civil à garantir et protéger les valeurs et droits fondamentaux, à garantir et réguler les intérêts socio-économiques et écologiques. Non seulement le dédommagement n'est pas optimal mais aussi la responsabilité civile est

735 Stefani(G), LeVASSEUR(G) et BOUlOC (B), Droit pénal général, 16eme éd., Paris, Dalloz, 1997, cité par FAURE(M), L'analyse économique du droit de l'environnement, op., cit. p.241.

736 LEVASSEUR(G) et BOULOC (B), Droit pénal général, 16eme éd., Paris, Dalloz, 1997, cité par FAURE(M), L'analyse économique du droit de l'environnement, op., cit. p.241. 
souvent insuffisante parce que les coûts d'une action en justice, y compris ses incertitudes et ses inconvénients, excèdent les avantages que la victime peut percevoir ${ }^{737}$. Remarquons aussi que de nombreux crimes sont commis avec une intention de nuire comme nous l'avons signalé dans le chapitre précédent. Dans de tels cas, on peut dire que «le but du droit, est plutôt de dissuader au moyen de sanctions que de compenser par le droit civil. Dans le cadre de la responsabilité civile, les individus ont en principe le droit de causer des dommages à autrui, à conditions qu'ils soient prêts à en payer le prix, c'est-à-dire à dédommager les victimes. Le droit pénal vise précisément les cas où l'on souhaite mettre un terme au comportement criminel, même si le criminel est en mesure de payer le prix. Autrement dit, le droit civil fixe les dommages en vue de la compensation, le droit pénal détermine les sanctions pour dissuader les comportements antisociaux ${ }^{738}$.Mieux, en cas de pollution, il n'y a souvent pas de victimes identifiables pouvant agir en responsabilité civile; dans d'autres cas les problèmes de causalité empêchent la victime d'utiliser la responsabilité civile. Par ailleurs il s'écoule une longue période entre le moment où le dommage environnemental se manifeste, de se fait, les problèmes de preuves et de causalité sont susceptibles de se présenter. II est aussi possible qu'entre temps, l'auteur du dommage ne soit plus identifiable. Pour toutes ces raisons, la responsabilité civile ne peut pas être appliquée ${ }^{739}$. Un autre problème étroitement lié au précédent tient dans le fait que l'application du droit privé suppose toujours que l'auteur du dommage puisse être identifié, et qu'il soit solvable et en mesure de dédommager la victime pour le dommage subi. Or, beaucoup d'entreprises ou d'individus peuvent causer un dommage écologique énorme, dont le montant est souvent plus élevé que leur patrimoine propre.

737 FAURE(M), L'analyse économique du droit de l'environnement, op., cit. p.242.

738 FAURE(M), L'analyse économique du droit de l'environnement, op., cit. p.242. Ces différences entre le droit pénal et le droit civil ont été abordées par R. COOTER, Prices and Sanctions, Columbia Law Review, Vol. 84, 1984, p.1523

739 Pour un résumé de ces difficultés, v. entre autres E.H.P. BRANS, Liability for Damage to public Natural Ressources-Standing, Damage and Damage Assessment, La Haye Kluwer Law international, 2001,pp.35-64 et M. WILDE, Civil Liability for environnemental damageA Comparative Analysis of Law and Policy and Europe and the United states, La Haye Kluwer Law international, 2002,pp.307-310 ; cité par FAURE (M), in, La protection de l'environnement par le droit pénal, ? Une perspective économique, ANTHEMIS, pp.135166. 
En ce cas, l'auteur du dommage considérera que la pollution qui est survenue cause un dommage dont l'importance n'est pas plus élevée que son patrimoine propre $^{740}$. En conséquence, lorsque le dommage potentiel est plus important que le patrimoine propre de son auteur, la responsabilité civile soufre d'un manque d'effet dissuasif ${ }^{741}$.

Le troisième axe que développent les économistes est la notion de probabilité de découverte du délinquant. Selon cette théorie, la probabilité d'identifier l'auteur d'une infraction et de le poursuivre en justice serait généralement bien inférieure à $100 \%{ }^{742}$, dans la mesure où certains facteurs peuvent intervenir entre temps et influencer ou réduire considérablement la probabilité de découverte d'un délinquant. C'est le cas par exemple d'un vol en pleine nuit, dans une rue mal éclairée, dans un quartier mal sécurisé.

A titre illustratif, supposons que monsieur $\mathrm{X}$ a l'intention de voler un livre d'une valeur de 5000 FCFA. Supposons que la probabilité que cette infraction soit découverte ne représente que 50\%, car il a l'intention de passer à l'acte lorsque la bibliothèque connaitra une animation particulière, et en l'absence du bibliothécaire. Monsieur $X$ ne sera responsable que s'il est découvert. Et s'il l'est, il risque simplement, en matière de responsabilité civile, de rembourser le livre en payant les 5000 FCFA ou de le retourner. En réduisant de moitié la probabilité de découverte, il diminue en même temps de moitié les coûts pour la commission du vol alors que le bénéfice escompté représente la valeur du livre. Ainsi, les coûts escomptés du voleur potentiel seront 0,5x5000=2500 FCFA et le bénéfice escompté s'élève à 5000 FCFA. Cela signifie que le droit civil n'a pas d'effet dissuasif efficace et, étant donné la faible probabilité de découverte, l'auteur aurait même intérêt à commettre la faute en droit civil.

Le quatrième axe de réflexion des économistes est relatif à la réduction des coûts d'erreurs. Ces coûts sont plus élevés quand les sanctions deviennent

740 Pour la simple raison qu'il ne pourra être tenu responsable de payer au-delà de son patrimoine propre.

741 SHAVELL (S), The judgement Proof Problem, International Review of law and Economics, 1986, pp.43-58

742 POSNER (R.A), Economic theory of the criminal law, Columbia Law Review, Vol.85, 1985, pp.1193-1209. Cite par FAURE(M), L'analyse économique du droit de l'environnement, op., cit. p.244 
plus graves, c'est-à-dire en cas d'application d'amendes relativement élevées ou d'une peine privative de liberté. Dans une perspective économique, la procédure relativement simple, et donc moins couteuse, du droit administratif est préférable lorsque les conséquences, (notamment l'amende), ne sont pas trop élevées et la probabilité de découverte un peu élevée. A contrario, le droit pénal doit être appliqué lorsque les sanctions deviennent plus élevées et la probabilité de découverte relativement faible, l'avantage de l'infraction aussi élevé, dès lors, les coûts d'erreurs augmentent aussi. Dans ce cas, la procédure pénale, plus couteuse se justifie, puisqu'elle offre plus de garanties de procédure et est donc de nature à réduire le risque d'erreur ${ }^{743}$.

Après avoir passé en revue les éléments essentiels qui fondent l'analyse économique, il conviendrait, d'analyser les modalités de leur application en droit pénal de l'environnement, particulièrement dans les pays en voie de développement comme le Bénin, afin qu'il s'inspire de cette expérience européenne pour améliorer son droit pénal de l'environnement.

\section{B) Les conditions de l'application et du respect de la législation pénale}

A la lumière de l'expérience européenne du modèle économique du droit pénal de l'environnement que nous venons d'analyser, le Bénin, dans sa réforme du droit de l'environnement, peut en tenir compte, en réorganisant notamment les sanctions pénales classiques : l'amende et l'emprisonnement. Au Bénin, comme un peu partout en Afrique, le droit pénal de l'environnement se cherche encore, il est en pleine construction. C'est pourquoi, il peut tirer profit des erreurs des expériences des pays occidentaux ${ }^{744}$. Les réalités béninoises ou africaines n'étant pas les mêmes avec les réalités occidentales, on peut dire, par hypothèse que l'adaptation ne peut se faire qu'en tenant compte des moyens techniques et financiers ou en tenant compte des différences structurelles et organisationnelles qui caractérisent les systèmes pénaux africains. Et, en tant

743 FAURE (M), in, La protection de l'environnement par le droit pénal?, Une perspective économique, ANTHEMIS, pp.135-166. 
que tel, toutes les expériences en la matière sont les bienvenues. Le modèle économique, en termes d'application des sanctions pécuniaires (amendes) et de peines d'emprisonnement existent dans la législation béninoise et s'appliquent plus ou moins. Mais la question se pose de savoir si la détermination des sanctions pénales tient réellement compte d'une véritable politique pénale? Comment faire pour avoir des textes clairs, précis et réellement applicables? Est-ce que la stratégie ne devrait-elle pas être de privilégier les amendes administratives ou pénales qui sont financièrement moins couteuses pour l'Etat au lieu des peines d'emprisonnement, très couteuses pour les économies africaines? Les pays africains ne se soucient presque jamais du coût qu'engendrent les procédures pénales pour leur pays. Par conséquent, ces pays ne peuvent s'offrir la possibilité d'avoir une législation très rigoureuse, voir très sévère, au risque de sacrifier les aspects de développement.

La réforme pénale peut s'orienter particulièrement vers l'application des sanctions administratives, en l'occurrence les amendes administratives pour les infractions légères et l'amende pénale et la peine de prison pour les infractions graves portant atteinte non seulement à l'environnement mais aussi à la santé humaine. Le droit pénal de l'environnement flamand et wallon nous en donne une illustration. En effet, le décret wallon du 5 juin 2008 relatif à la recherche, la constatation, la poursuite et la répression des infractions et les mesures de réparation en matière d'environnement dispose en son article D160 que "les amendes administratives peuvent être infligées pour des infractions de deuxièmes, troisième et quatrième catégorie. L'amende administrative est exclue en cas d'infraction de première catégorie» à cause certainement de sa gravité.

Nous avons beaucoup insisté sur la nécessité pour le droit pénal de l'environnement de se fonder sur une législation efficace, donc de qualité. Pour ce faire, il est primordial qu'elle soit appliquée et respectée, or ce n'est pas toujours le cas au Bénin, nous l'avons également précisé. Mais, il est aussi important de faire remarquer qu'au Bénin, cette nécessité dépend de deux conditions: l'efficacité du contrôle juridique et de la poursuite judiciaire d'une part, et la combinaison des sanctions d'autre part. 
1) L'efficacité du contrôle juridique et de la poursuite judiciaire

Nous avons dans nos développements antérieurs précisé que le véritable problème qui se pose au droit répressif béninois, est surtout la non application des textes. Il est important que les lois environnementales soient appliquées par un magistrat indépendant. En principe, la tâche du juge est de mettre en œuvre le droit de l'environnement dicté par le législateur et l'administration à travers les autorisations. Les quelques rares jugements rendus concernent le secteur des eaux, forêts et chasse. Il convient pour le juge d'aller au delà des délits forestiers et s'intéresser par exemple aux diverses pollutions environnementales. C'est vrai qu'un conflit d'intérêt peut apparaitre entre la protection de l'environnement et les intérêts économiques du pays, et, là également, nous l'avons dit, le législateur tente ou peut tenter d'établir un équilibre entre les intérêts (balance des intérêts). Car, comme le précise le professeur FAURE, «il faut éviter que cet équilibrage des intérêts soit remanié devant la cour. Le juge doit respecter la décision du législateur et de l'autorité administrative et ne prendre en charge que sa mise en œuvre ${ }^{745}$ ». Rappelons, en effet, que s'il est vrai que les contrevenants potentiels au procès environnemental ne sont pas des criminels classiques mais pour la plupart "d'honnêtes» citoyens ou des chefs d'entreprises occupant souvent des positions élevées dans la hiérarchie sociale, et contribuent au bien n'être de la communauté, il n'en demeure pas moins vrai qu'en cas d'infraction à l'environnement, par imprudence ou par intention, qu'ils ont l'obligation de répondre de leurs activités. On pourrait se demander comment cette question cruciale d'équilibrage des intérêts a été réglée dans les pays occidentaux. A ce niveau, en application de la législation environnementale européenne, au début, " les juges pénaux ont été réticents à condamner les contrevenants puisque ceux-ci n'étaient pas des marginaux de la société. L'argument en faveur de l'acquittement consistait souvent à dire que, financièrement, il était totalement impossible pour les entreprises incriminés de remplir les conditions imposées par les législations sur l'environnement. Cet argument fut mis en avant par les industriels comme base de justification ou prétexte ${ }^{746}$ ». Mais, par la suite, les juges ont compris que d'un point de vue strictement juridique, ce

745 FAURE(M), L'analyse économique du droit de l'environnement, op., cit. p.290.

746 FAURE(M), L'analyse économique du droit de l'environnement, op., cit. p.291. 
type d'acquittement est inacceptable ${ }^{747}$. Car la décision relative aux effets socioéconomiques de la législation sur l'environnement ne doit pas être prise par un seul juge mais aussi par le législateur ou l'organe administratif. Par conséquent, elle pose le problème de l'indépendance de la magistrature, du juge qui a le pouvoir de faire respecter la législation. Cette indépendance se pose avec acuité dans presque toutes les juridictions africaines.

En effet, au Bénin, les empiètements constatés à divers endroits dans le domaine classé (parcs nationaux) et dont les auteurs sont essentiellement les populations riveraines sont dus à l'état de nécessité dans lequel se trouvent ces populations. Contraintes de satisfaire des besoins sans cesse grandissants, elles n'ont d'autres ressources que d'exploiter irrationnellement les biens de la nature, le plus important étant de satisfaire coûte que coûte les besoins du moment. C'est ce qui explique aussi très souvent, la difficulté d'application des textes. Une réponse à ces préoccupations consiste à élaborer des stratégies et définir des programmes de gestion participative des forêts et réserves de faunes avec ces populations riveraines. Le Bénin depuis quelques décennies, s'est lancé sur cette voie de cogestion des forêts et des parcs nationaux de la Pendjari et de «W» avec la création des AVIGREF en partenariat avec la coopération allemande pour le parc de la Pendjari et l'UE pour le parc «W». Ces différentes actions méritent d'être encouragées et pérennisées.

\section{2) La combinaison des sanctions}

En ce qui concerne la combinaison des sanctions, reconnaissons qu'un effort est fait dans ce sens par la législation béninoise ${ }^{748}$ qui prévoit la possibilité pour le juge, d'infliger au prévenu aussi bien une amende administrative (généralement c'est l'autorité administrative compétente qui inflige l'amende administrative), une amende pénale et/ou une peine d'emprisonnement. Les sanctions infligées aux pollueurs doivent être non seulement proportionnées mais elles doivent être en adéquation avec les conventions internationales ratifiées par le Bénin. Dans l'état des lieux de la législation béninoise, on a

747 FAURE(M), L'analyse économique du droit de l'environnement, op., cit. p.291.

748 Nous l'avons indiqué dans la première partie de la thèse. 
certes, enregistré des sanctions dérisoires, mais aussi des sanctions très sévères, rigoureuses allant de 10 à 20 ans de prison et d'une amende pouvant atteindre 1 milliard CFA. ${ }^{749}$.Le juge répressif dispose outre les sanctions classiques, de l'opportunité d'appliquer des sanctions complémentaires. Pour plus d'efficacité dans la répression, ces sanctions doivent être généralisées et leur recours systématique. Ainsi, les sanctions administratives et judiciaires se cumuleront pour une protection effective de l'environnement.

En définitive, comme nous l'avions fait remarquer plus haut, en citant le professeur FAURE, un modèle idéal de droit pénal de l'environnement nécessite une combinaison des formes de sanctions pénale, administrative et même réparatrice. Un dosage savant qui tienne compte des caractéristiques spécifiques du secteur de l'environnement, du lieu et de l'époque. Nous avons déjà indiqué que les sanctions optimales dépendent de beaucoup de conditions, tels que l'avantage de l'infraction pour le contrevenant, la probabilité de découverte, les moyens financiers du contrevenant, le risque d'insolvabilité et les coûts de la sanction qui devrait être appliquée. L'irréversibilité des atteintes à l'environnement exige non seulement des mesures préventives de police qui, par des autorisations ou des interdictions, permettent d'empêcher ou de contrôler des activités susceptibles de nuire au milieu naturel et à la santé humaine, mais aussi des mesures de surveillance, de répression, de réparation et de restauration. ${ }^{750}$

En conclusion, retenons qu'il n'y a pas de réelle politique pénale en matière d'environnement si les orientations générales sont édictées en méconnaissance des réalités et contraintes sociologiques du milieu, lesquelles influencent l'application des peines. Pour être pertinente, une telle politique pénale doit bien évidemment intégrer l'état de la répression des atteintes à l'environnement (nombre de procès verbal, les types d'infractions constatées, les suites données aux plaintes et constatations, les jugements prononcées, l'état de l'exécution des peines dans les tribunaux, en un mot une statistique régulière et permanente. C'est à ces conditions que la justice pénale béninoise parviendra

749 Loi -cadres sur l'environnement du bénin

750 GBENOU $(k)$, La sanction des atteintes à l'environnement en droit togolais, Mémoire DEA Droit et politique de l'environnement, Lomé, Togo, 2004-2005, p.64 
à une protection adéquate et efficace de l'environnement par l'application effective des textes. Car, «il vaut mieux avoir de bons juges que de bonnes lois. Car les bonnes lois sont vaines si le juge est mauvais, et les plus mauvaises lois peuvent être modifiées par de bons juges ${ }^{751}$ »

Une bonne application de la loi pénale ne dépend pas seulement de l'élaboration de bons textes, elle dépend aussi du cadre de travail et des moyens disponibles pour exécuter la mission de service publique de la justice.

\section{$\S$ II : Le renforcement de capacités et de mise en œuvre efficiente du droit pénal de l'environnement}

Le droit répressif béninois de l'environnement, tel que nous l'avons présenté et analysé dans nos développements antérieurs, mérite pour être performant un renforcement de capacités et d'action en l'occurrence assurer une bonne formation aux juges en droit de l'environnement et améliorer les moyens techniques, scientifiques et financiers qui font cruellement défaut.

\section{A) Le renforcement des moyens humains}

La justice béninoise, nous l'avions fait remarquer dans la première partie de la thèse, est caractérisée par un déficit chronique de ressources humaines aussi bien au niveau du personnel des structures judiciaires, en l'occurrence les magistrats, qu'au niveau du personnel administratif chargé de la surveillance et du contrôle. Cette situation reste un défi à relever par le Bénin pour asseoir des structures répressives véritablement performantes.

751 DIDEROT (D), cité par KESSOUGBO (K), Table ronde sur l'efficacité des instruments et mécanismes de droit de l'environnement dans le contexte africain la faiblesse du dispositif juridictionnel, FDD, 2004, Lomé Togo. 


\section{1) La formation des magistrats au droit répressif de l'environnement}

Le professeur A. KISS, disait déjà «il est vrai que, trop souvent, les règlementations environnementales (principalement dans les pays en voie de développement) ne tiennent pas comptent de la capacité réelle de ceux qui devraient mettre en œuvre les obligations qu'ils créent. En effet, les pays pauvres n'ont pas toujours les moyens économiques ou scientifiques d'assurer, dans les limites de leurs juridictions, le respect, par exemple, des principes et des règles protégeant la faune et la flore sauvage ou interdisant le transport des déchets dangereux ${ }^{752}$ ». Le droit de l'environnement étant un droit relativement jeune, transversal, technique et complexe, il est important pour sa mise en œuvre par le juge, que se dernier soit doté d'un minimum d'outil pouvant lui permettre d'assumer correctement sa mission. C'est pourquoi, cette branche du droit requiert une spécialisation et nécessite une formation des magistrats, comme en témoigne C. Ghica-Lemarchand ${ }^{753}$. A notre avis, la spécialisation des magistrats apparait absolument nécessaire pour l'instauration d'une politique pénale cohérente. II s'agit, ainsi, de dispenser aux magistrats, et aux agents chargés de la constatation des infractions, une formation spécifique sur le thème de la délinquance écologique afin de les sensibiliser et de leur apporter les connaissances aux traitements des affaires environnementales ${ }^{754}$. Le fait que le Bénin abrite le siège de l'Ecole Régionale Supérieur de Magistrature(ERSUMA) est un atout pour la formation continue des magistrats. II conviendra de faire en sorte que le programme de formation intègre le droit de l'environnement et particulièrement le droit pénal. L'ERSUMA, en collaboration avec le MJLDH, le MEHU et le MESRS, avec l'appui des organismes comme le PNUE poursuivent

752 A. KISS, Introduction au droit international de l'environnement, cours 1, UNITAR, 1997, p.8.

753 In, droit pénal et la mer, Centre d'économie et de droit de la mer, UBO, 19 nov.2004, Rev. Sc. Crim, 2005 chr. P.434.

754 G. CANIVET et D. GUIHAL, dans leur article Protection de l'environnement par le droit pénal : l'exigence de formation et de spécialisation des magistrats, D. 2004, Chr., p.2728; estiment que la formation et la spécialisation des magistrats sont des conditions absolument nécessaires sinon suffisantes pour arriver ou du moins se rapprocher d'une certaine effectivité des poursuites. V. aussi Roselyne NERAC-CROISIER, Sauvegarde de l'environnement et droit pénal. op. ; cit., p.78. 
l'organisation des formations continues, des colloques ou séminaires en renforcement de capacités au profit des juges ${ }^{755}$. On peut retenir à ce propos l'exemple du colloque francophone qui a été organisé les 26 et 27 juin 2008 dans les locaux de cette école. C'est une réunion constitutive du Comité de l'environnement de I'AHJUCAF qui a rassemblée une soixantaine de participants comprenant majoritairement les magistrats, les Présidents des cours suprêmes membres de l'AHJUCAF. Entre autres points à l'ordre du jour, on peut retenir:

- la présentation des rapports nationaux sur l'état du droit de l'environnement;

- l'influence des conventions internationales sur le droit interne de l'environnement;

- la présentation de la mouture définitive du manuel judiciaire du droit de l'environnement pour les pays de droit écrit.

Au sujet de cet important ouvrage du droit de l'environnement, élaboré sous l'égide du PNUE à l'intention des juges, et qui constitue une solution dans le cadre de l'application du droit pénal, pourrait être à la base de l'enseignement puisqu'il s'agit d'un manuel de procédure. L'ouvrage poursuit deux finalités qui facilitent l'application de la loi pénale qu'il nous plaît de rappeler:

- présenter les conventions et coutumes internationales concernant l'environnement, en soulignant toutes les implications de cette source du droit non seulement en termes d'application directe des normes, mais aussi en termes d'interprétation supplétives des textes internes;

- mettre en évidence les conditions procédurales favorables à une mise en œuvre efficace du droit de l'environnement, conditions qui peuvent souvent être réalisées par des infléchissements jurisprudentielles sans requérir l'intervention du législateur.

Déjà au cours d'une réunion précédente qui a eu lieu les 3 et 4 février 2005 à Paris et qui a réunie la conférence des Présidents des cours suprêmes d'Etats francophones d'Afrique, sous le thème «la contribution du droit au développement durable», les juges de ces Etats se sont engagés à mettre 
effectivement en œuvre les instruments juridiques internationaux et nationaux de protection de l'environnement dans la perspective du développement durable. Au cours des travaux, les participants en examinant la synthèse des rapports sur l'état des capacités de traitement du droit de l'environnement dans les pays représentés ont noté une similitude de situation dans presque tout les pays, tant en ce qui concerne l'état des lieux qu'en ce qui concerne les besoins de formation. Lors des débats ouverts à propos des conditions d'organisation de la formation des magistrats en droit de l'environnement, le Président de la cour suprême du Bénin, Salifou ABOUDOU a réitéré les propositions de formation sur place dans les Etats membres des intéressés par les établissements universitaires ou professionnels appropriés, comme il l'avait suggéré dans les documents préparatoires de la conférence qu'il avait produit à la demande des organisateurs ${ }^{756}$. C'est dans ces conditions que l'ERSUMA a été retenue pour assurer la formation sur place en Afrique des juges. Cette forme pratique d'enseignement délocalisé mérite encouragement. Il est possible aussi de bénéficier d'une telle formation par cours par correspondance ${ }^{757}$.

Une enquête réalisée sous l'égide de l'AHUJCAF en direction d'une vingtaine de pays africains (les ministères chargés de la justice), montre bien la pertinence du besoin en formation des magistrats dans le domaine de la préservation de l'environnement. ${ }^{758}$ Mieux, «l'insuffisance des connaissances et les carences en matière de compétences et d'information pertinentes sont l'une des principales causes contribuant à une mise en œuvre et à un développement défectueux du droit de l'environnement ${ }^{759}$. C'est dans cette logique d'exhortation à une formation durable, que s'inscrit la conclusion de Guy CANIVET, lorsqu'il finit son allocution par les termes ci-après: «il conviendrait de sensibiliser les juges à une application plus active du droit de l'environnement, de mieux les

756 Cf. Déclaration de Paris, Colloque de l'AHJUCAF en 2005, www.courcassation.fr

757 Plusieurs programmes de formation en droit de l'environnement par correspondance existent à l'intention des fonctionnaires publics avec des conditions assez favorables (à moindre coût), on peut citer le programme de l'UNITAR à Genève.

758 Dominique GUIHAL, Synthèse des questionnaires, Colloque, AHUJCAF, Paris 2005

759759 Comme le souligne l'une des conclusions du Sommet mondial des juges, tenu à Johannesburg, en 2002 et repris dans l'allocution d'ouverture de Guy CANIVET, premier président de la cour de cassation de France, lors du colloque de l'AHJUCAF en 2005, www. courcassation.fr 
former, de mieux les spécialiser, de leur fournir des instruments indispensables, de leur faire comprendre qu'autant que la protection de la liberté, la protection du droit à un environnement sain entre dans les missions spécifiques du juge. C'est un des paris des justices du siècle qui nait. Relevons-le ${ }^{760}$.

On peut se réjouir que le Bénin ait abrité au cours de l'année 2008 à Porto-Novo, un colloque sur le droit de l'environnement qui a regroupé les magistrats venant de plusieurs pays et des juristes de l'environnement de haut niveau comme le professeur PRIEUR. Mais il reste à définir et développer des stratégies en recourant par exemple aux divers partenaires techniques financiers en partenariat avec les universités ayant une certaine expérience dans le domaine.

L'enseignement du droit de l'environnement est dispensé certes au Bénin et dans certaines universités (Maroc, Togo, Maurice, Sénégal), mais il est généralement restreint au Master et au Doctorat. II conviendrait pour le Bénin, de définir des stratégies pouvant intégrer non seulement les modules de formation de cette discipline dans le cursus de formation des magistrats à I'Ecole Nationale d'Administration cycle I et II, mais aussi dans tous les ordres d'enseignement supérieur en passant par le primaire et le secondaire. Cela contribuera énormément au changement de comportement du citoyen de «type nouveau » dont le droit pénal de l'environnement a beaucoup besoin.

Par ailleurs, la création de structures régionales africaines d'échange d'informations et d'expériences entre magistrats apparait aussi comme un atout formidable, comme un instrument privilégié d'amélioration des compétences ${ }^{761}$. II est souhaitable qu'un tel mouvement s'étende en Afrique au sud du Sahara sous le parrainage de I'UEMOA ou de la CEDEAO. Une coopération structurée entre un organisme international et les Etats d'expression francophone peut permettre de mettre en œuvre outre un plan de formation des juges mais aussi un plan de formation des formateurs afin d'avoir une expertise nationale en droit répressif. Car, dans tout système juridique, un pouvoir judiciaire indépendant,

760 Idem.

761 II faut saluer la création à cet effet,du forum des juges de l'UE pour l'environnement et de I'Union des juges arabes pour la protection de l'environnement, créés respectivement le 26 avril 2004, à Luxemburg et le 31 mai 2004, au Caire. 
des juges biens formés et disposant des instruments et moyens appropriés sont indispensables pour la mise en œuvre effective et efficace des règles de droit visant la réalisation d'un équilibre entre les considérations environnementales, sociales et de développement pour atteindre le développement durable ${ }^{762}$. On pourrait ainsi prévoir à moyen terme, un recrutement pour combler le déficit et prévoir au niveau des parquets ou des juridictions, au moins un juge spécialisé pour connaitre le contentieux d'environnement.

Le personnel non magistrat (officiers de justice, greffiers,...) est bien concerné également par le plan de formation. Ce personnel de soutien aux magistrats, est très indispensable pour le juge, de sorte que l'efficacité du magistrat dépend en grande partie de la célérité, de la perspicacité et du savoir faire du greffier dans le traitement des dossiers. C'est pourquoi, il leur faut des modules de formation, de stages et de recyclages périodiques afin qu'ils soient aussi à la pointe de la technologie en matière de gestion des affaires en droit de l'environnement. Cette formation doit être étendue au personnel chargé de la surveillance et du contrôle.

\section{2) Le personnel administratif chargé de la surveillance et du contrôle}

Le renforcement de capacité doit concerner aussi bien les structures de contrôle et de surveillance relevant du secteur public que celles relevant du secteur privé.

\section{a) Le renforcement de capacité des structures de contrôle et de surveillance publics}

Le renforcement de capacité pour la mise en œuvre des textes passe nécessairement aussi par la formation ou le recyclage des agents des diverses administrations, notamment les agents fonctionnaires chargés du contrôle et de

762 CANIVET (G), Présentations des conclusions et recommandations de la table ronde sur la réalisation par le droit des objectifs du millénaire, PNUE, 2005. www.courdecassation.fr 
la surveillance de l'environnement. Il s'agit notamment des agents assermentés ou commissionnés tels que les fonctionnaires de la gendarmerie, de la police judiciaire (OPJ), les forestiers et les agents fonctionnaires des administrations publiques. Dans leur cursus dans les Ecoles de formation des officiers ${ }^{763}$ et précisément de ceux qui ont vocation à devenir OPJ, il est important d'innover en introduisant dans leur programme de formation des modules de formation sur le droit de l'environnement, notamment sur les techniques de procédures du droit répressif de l'environnement. Aussi, au delà de l'organisation des stages de recyclage à leur intention, des séances de concertations périodiques seraient opportunes entre le parquet au niveau de chaque cour d'appel et les OPJ et autres fonctionnaires assermentés (Eaux et Forêts et Chasse et autres) territorialement compétents, pour apprécier, ensemble avec ces derniers, la procédure rédactionnelle des PV et les difficultés qui jalonnent l'exercice de l'action publique.

Ces concertations périodiques peuvent avoir pour objectifs :

- de dresser un bilan de la situation concernant les actions administratives en cours, la prévention et la répression des infractions en matière d'environnement,

- d'exposer les priorités de politique pénale définie par le parquet,

- de décider des actions à mener ; il s'agit notamment des opérations combinées entre plusieurs services et de concevoir leur mise en œuvre.

- la mise en œuvre des mesures d'accompagnement destinées à faciliter et rendre plus efficace l'application de l'arsenal législatif et réglementaire tel qu'il aura été modifié ou adapté.

Car, aussi performantes que puissent être les dispositions applicables, elles ne sont rien en dehors des agents chargés d'en assurer le respect.

Les autres agents de contrôle assermentés ou commissionnés à savoir les inspecteurs de l'environnement ou les policiers de l'environnement et leurs

763 II existe au Bénin, une Ecole de formation des officiers supérieurs de la police nationale (commissaires) basée à Cotonou et une Ecole de formation des officiers (militaires, gendarmes et forestiers) à Toffo, à environ une centaine de $\mathrm{km}$ de Cotonou. Ces écoles sont également ouvertes aux pays voisins 
homologues des administrations sectorielles doivent voir leur rôle bien défini et leur nombre s'accroitre. Les inspecteurs de l'environnement comme nous l'avions déjà dit, ont vocation à couvrir tout le territoire béninois et leur domaine de compétence couvre presque toutes les infractions en matière d'environnement. Or, ils sont seulement 24 agents. Un recrutement de nouveaux agents bien formés est donc nécessaire pour atteindre les objectifs qui leur seront assignés. Il faut réviser les textes allant dans le sens qu'ils aient des liens hiérarchiques avec le procureur de la République pour instaurer une bonne collaboration qui fait défaut actuellement entre les deux structures afin qu'il y ait une célérité dans le traitement des dossiers. Ils ont des dossiers pendant devant les tribunaux qui demeurent sans suite.

Par ailleurs, le recours à une meilleure utilisation des procédures judiciaires rapides ou règlements alternatifs, est inévitable. Ainsi, constitue une solution pénale pratique, l'extension des procédures judiciaires rapides que sont notamment l'amende forfaitaire, l'amende transactionnelle, la médiation pénale ou les classements sous condition offrant des voies nouvelles pour le traitement des infractions environnementales les moins graves. Néanmoins, il conviendrait de revoir et de mieux organiser la transaction pénale, une arme financière aux mains des structures de contrôle et de surveillance de l'environnement. Elle est une méthode certes rapide, mais elle est souvent mise en œuvre de façon opaque à l'égard des procureurs de la République. La réforme dans ce domaine devrait permettre par exemple de mieux cerner la notion de récidive qui n'apparait pas en matière transactionnelle et au regard de la poursuite devant le procureur de la République, elle peut permettre à ce dernier d'émettre son avis sur la transaction envisagée avant son opérationnalisation par l'officier assermenté. A cet effet, une statistique en la matière sera tenue afin d'apprécier l'impact de cette mesure aussi bien sur les prévenus que sur le milieu dégradé.

La présence à l'audience des représentants des administrations ou des agents ayant constaté les infractions est vivement souhaitée. Il est bénéfique pour le déroulement du procès, tant en ce qui concerne le rappel des faits et des éléments caractérisant la prévention que pour soutenir le choix de peines ou de mesures de restitution. 
b) Le renforcement de capacité des associations de défense de l'environnement

Il s'agira d'abord dans une démarche pédagogique, de clarifier dans la réforme législative avec précision les missions, les attributions et les conditions d'exercice des associations ou ONG de défense de l'environnement avant d'organiser ou de susciter à leur intention des formations de renforcement de capacité en droit de l'environnement. Puisque la loi reconnait à ces associations l'exercice de l'action publique, il faut les aider à être compétentes dans l'exercice de cette fonction pénale. II faut leur démontrer la possibilité qui leur est offerte pour ester en justice. Ces associations exercent bien souvent «un droit d'alerte» et sont fréquemment à l'origine des plaintes avec constitution de partie civile entraînant des informations judiciaires ou de citations directes devant les juridictions répressives. Les associations de défense d'environnement jouent donc un rôle très important dans le dispositif répressif. L'identification de ces associations permet au parquet et aux populations d'être en étroite collaboration avec elles. Car, la connaissance de ces associations devrait permettre d'établir un dialogue utile et d'orienter au mieux certaines plaintes. Leur liste devra aussi, suite à leur agrément par l'autorité compétente, faire l'objet de publication par les cours d'appel territorialement compétentes, dans les conditions définies par la loi. C'est une assistance juridique gratuite au profit de la protection des ressources naturelles.

En effet, en matière de contentieux de l'environnement, la tendance d'une manière générale est que les associations s'autosaisissent et s'adressent plus volontiers aux juridictions pénales et civiles qu'aux tribunaux administratifs. Pour cause, la juridiction pénale est plus spectaculaire et la juridiction administrative plus lente et pleine d'embuches ${ }^{764}$. Mais cette lenteur pourrait se dissiper en grande partie si l'administration judiciaire béninoise avait les moyens de sa politique.

764 CARLE (F), Enquête Rapport sur l'efficacité des lois d'environnement, avril 1996 TOS association pour la protection des eaux et rivières, p.56. 
B) Le renforcement des moyens techniques, scientifiques et financiers

La réforme que nous envisageons pour moderniser le droit pénal béninois de l'environnement, ne doit pas occulter la dotation des administrations environnementales et judiciaires de moyens techniques, scientifiques et financiers.

\section{1) Les moyens techniques et scientifiques}

Il est évident que les technologies utilisées dans les pays occidentaux ne sauraient être plaquées d'office dans les pays en voie de développement. Elles nécessitent une adaptation appropriée au modèle occidental ${ }^{765}$. Les normes technologiques qui seront imposées par exemple sur les eaux usées industrielles dans la ville d'Anvers en Belgique ne seront pas identiques à celles qu'ont pourraient utiliser dans les régions montagneuses de l'Atacora dans la ville de Natitingou au Bénin. Cela ne signifie pas qu'au Bénin, l'on doit continuer à utiliser des technologies obsolètes, mais qu'il faut tenir compte des réalités de chaque localité, de chaque région et de chaque pays pour que la norme soit efficace. Or, ces moyens techniques, via les connaissances des agents de contrôle et de surveillance font souvent cruellement défaut. Dès lors, il faut formés lesdits agents et les doter de connaissances techniques aux fins de contrôle de conformité à la réglementation. Pour ce faire, il faut rendre disponible les moyens techniques, technologiques et scientifiques adéquats en créant comme le recommande l'Agenda 21 national en son chapitre 29, un conservatoire béninois des technologies écologiquement rationnelles. II faut également prévoir la création d'un laboratoire de référence en matière environnementale à l'instar de celui du Maroc, le laboratoire National d'Etudes et de Surveillance de la Pollution, crée en 1994. Ce laboratoire a pour rôle de surveiller et de contrôler la qualité de l'environnement et d'identifier, hiérarchiser et de suivre les tendances 
des indicateurs de pollution ${ }^{766}$. II est nécessaire pour renforcer les capacités de l'Agence Béninoise pour l'Environnement qui est le bras technique et scientifique en matière d'environnement au Bénin, mais qui est obligé en matière d'expertise relative à la qualité de l'environnement de recourir à l'extérieur.

En effet, s'agissant des prélèvements d'échantillons, leur analyse, pour être régulière, doit être réalisée «en vertu d'une loi, par un laboratoire d'Etat ou par un laboratoire agréé par le ministre de la santé publique et ou de l'environnement ${ }^{767} »$. Or, le Bénin ne dispose pas de laboratoire spécialisé pour effectuer des analyses en matière environnementale. Les seuls laboratoires disponibles sont ceux sectoriels des hôpitaux et des instituts ou écoles de recherche des universités. Mais dans le domaine nutritionnel, nous notons l'existence d'un laboratoire créé par décret $n^{\circ} 2010-153$ du 28 avril 2010 portant création du laboratoire central de contrôle de la sécurité sanitaire des aliments, qui peine encore à être fonctionnel.

D'autre part, il faut renforcer les tribunaux en matière d'expertise de police scientifique qui fait défaut pour faciliter la tâche au juge pénal.

Enfin, toutes ces réformes nécessitent pour leur mise en œuvre non seulement une volonté politique des pouvoirs publics mais aussi et surtout assez de moyens financiers.

\section{2) Les ressources financières et les mécanismes de financements}

Au regard de l'épineux problème de financement du droit de l'environnement et en particulier du droit répressif, une politique de recherche de financement à court, moyen et long terme doit être élaboré et mis en œuvre par les pouvoirs publics. Dans la mesure où les ressources internes, très maigres des pays en voie de développement comme le Bénin, ne parviennent pas toujours

766 Etude du système d'inspection, de contrôle et de surveillance de l'environnement au Maroc. Phase1. Rapport diagnostic, provisoire. 2007 (MATEE) p.39.

767 LAMBRECHTS (C), La valeur en matière pénale, des preuves des violations de la convention Marpol 73/78, Revue de Droit Pénal, Chronique, p.735. V. aussi, La preuve en matière pénal de l'environnement, Aménagement -Environnement, 1995, p36. 
à régler les problèmes environnementaux, et ne sauraient prétendre le faire, sans concours; il faut envisager le recours au mécanisme de financement des partenaires techniques et financiers. Il en est ainsi parce que le «développement économique et social et l'élimination de la pauvreté sont les priorités premières et absolues des pays en développement ${ }^{768}$. En d'autres termes, la préoccupation de l'environnement est reléguée au second plan. C'est pourquoi, nous estimons qu'il faut d'abord que les gouvernants développent d'abord en eux une volonté politique pouvant leur permettre de comprendre que le développement et la protection de l'environnement forment un couple inséparable. Ainsi, dans le domaine législatif et réglementaire, toute réforme qui serait envisagée, devrait tenir compte en même temps du volet environnement. Or, ce n'est pas souvent le cas. Cette volonté manifeste doit s'exprimer à travers une amélioration des crédits budgétaires alloués au secteur de l'environnement. Ce qui se traduira par un relèvement des dotations des principaux ministères chargés de la réforme à savoir le ministère chargé de l'environnement et le ministère chargé de la justice, mais aussi des autres ministères sectoriels, pour engager des réformes véritablement opérationnelles touchant au cadre juridique et institutionnel.

Dans cette même logique, il serait souhaitable qu'en tant que chef de fil des consommations des crédits budgétaires relatifs à l'environnement, que lors de la préparation du budget, le ministre chargé de l'environnement soit tenu informé des crédits envisagés au titre des autres départements ministériels pour tous les aspects touchants à la protection de la nature et à l'environnement. II pourra éventuellement formuler ses observations au ministre de l'économie et des finances lors des séances d'arbitrages budgétaires. En ces mêmes matières, il est tenu informé de l'exécution du budget et reçoit communication des rapports d'inspection ou de contrôle sur l'utilisation des crédits ${ }^{769}$. Cette démarche qualitative permet au ministre chargé de l'environnement d'avoir une bonne visibilité des dépenses publiques consacrées à la protection de la nature et de l'environnement en produisant chaque année un état de l'ensemble des crédits et de réaliser des statistiques conséquemment.

768 KAMTO (M), Droit de l'environnement en Afrique, op.,cit.,p.126.

769 Cette procédure est application en France. Cf. PRIEUR (M), Droit de l'environnement, op.,cit.,p.32. Le Bénin peut bien s'en inspirer pour améliorer sa gouvernance environnementale. 
Lorsque les dossiers sont biens montés et les engagements internationaux entièrement souscrits et respectés, on peut aisément recourir aux partenaires techniques et financiers pour solliciter leur coopération. Elle est bilatérale ou multilatérale et se négocie en fonction du dynamisme de chaque Etat. La conférence de Rio avait déjà balisée le terrain en amenant les pays du nord à s'engager à porter le niveau de leur aide aux pays en développement à « $0,70 \%$ de leur produit national brut (PNB) $»^{770}$ et confirmer par « la Déclaration de Paris» sur l'aide au développement. A ce jour, cet indicateur d'objectif n'est pas atteint. La France en tant que troisième donateur mondial ${ }^{771}$ consacre un peu plus que les USA et le Japon, respectivement premier et deuxième rang mondial qui ne consacraient que $0,2 \%$ et $0,5 \%$ seulement de leur PNB à l'aide au développement ${ }^{772}$. Les partenaires techniques et financiers spécifiques au secteur de l'environnement que sont le PNUE et le PNUD et autres à savoir FAO, OMS, BM, UE, etc., offrent d'énormes opportunités de financement du droit de l'environnement, conformément à la mise en œuvre des conventions environnementales. Ces institutions apparaissent dès lors comme des mécanismes de financement à saisir par les Etats parties aux conventions.

Le Bénin a élaboré et vulgarisé son Agenda 21 national depuis janvier 1997. Ce document rédigé conformément à l'Agenda 21 international, comprend divers programmes et projets couvrant tous les compartiments de l'environnement y compris le droit de l'environnement puisqu'il recommande la refonte du cadre législatif, réglementaire et institutionnel $\left.\right|^{773}$ et propose une planification quinquennale de réalisation des programmes suivie de propositions de partenaires techniques et financiers. Mais ce document, malgré son caractère hautement stratégique, n’a jamais été mis en œuvre pris globalement, simplement par faute de financement mais surtout pas manque d'engagement politique ou de volonté politique alors qu'il était évalué à l'époque à 209.434.090.000 $\mathrm{F} \mathrm{CFA.}{ }^{.74}$.

770 KAMTO (M), Droit de l'environnement en Afrique, op.,cit.,p.128.

771 Idem, p128 mais cela date de 1996.

772 KAMTO (M), Droit de l'environnement en Afrique, op.,cit.,p.128.

773 Agenda 21 national, notamment les chapitres 33 et 34 pp.200-205.

774 Agenda 21 national, 1997, Cotonou Bénin. 
Cependant, au niveau sectoriel, indépendamment de l'Agenda, certains projets ont été réalisés. Dès lors, il ne serait pas superflu, 15 ans après, de procéder à une évaluation d'impact de l'Agenda 21 national, pour apprécier le niveau de réalisation des différents projets relatifs au droit de l'environnement et en avoir une idée chiffrée des chantiers restants à réaliser. L'évaluation peut concerner spécifiquement la mise en œuvre des objectifs du cadre législatif et réglementaire. 


\section{CHAPITRE VI : LA DEFINITION DES ELEMENTS CONSTITUTIFS DE L'INFRACTION ENVIRONNEMENTALE}

Selon les auteurs Frédéric Desportes et Francis Le Gunehec, l'infraction s'entend du comportement interdit sous la menace d'une peine telle qu'elle est définie de manière générale et impersonnelle par la loi pénale. En ce sens, l'infraction comporte deux éléments : d'une part l'incrimination c'est-à-dire la description des divers éléments constitutifs du comportement interdit, et, d'autre part la peine qui le sanctionne. II ne peut y avoir d'infraction pénale si l'un de ces deux éléments fait défaut. Un interdit ou une obligation qui n'est pas pénalement sanctionnée n'est pas une infraction. II n'est pas nécessaire qu'incrimination et sanction pénale soient formellement réunies dans un même texte. II se peut même que le texte d'incrimination et le texte de pénalité ne soient pas au même niveau dans la hiérarchie des normes. Ainsi, une obligation ou une interdiction prévue dans un texte législatif peut être sanctionnée par un texte réglementaire, et inversement. ${ }^{775}$

On en déduit que la responsabilité pénale est « l'obligation pour une personne impliquée dans une infraction d'en assumer les conséquences, c'est-àdire de subir la sanction attachée à cette infraction, cette sanction étant punitive et préventive ${ }^{776}$. Cette définition de PRADEL, appelle surtout de notre part deux observations. Il faut non seulement arriver à identifier l'agent pénal mais il faut lui faire subir les rigueurs de la loi. Cet exercice de qualification de l'infraction, qui n'est pas du tout aisé en droit de l'environnement, se fonde en droit pénal général sur la réunion des éléments constitutifs de l'infraction préalablement définie. En effet, la qualification est la définition ou l'identification du fait infractionnel par le législateur ou par le juge ${ }^{777}$. Dans ce sens, la qualification en droit pénal commun est traditionnellement orientée vers la violation des biens et des valeurs juridiques classiques comme la liberté, la propriété, l'intégrité physique. En matière environnementale, cette violation est plutôt orientée vers des valeurs juridiques écologiques.

775 (F) DESPORTES et (F) Le GUNEHEC, Droit pénal Général, 10ème édition, ECONOMICA, Paris 2003, p.10

776 PRADEL (J), Droit pénal général, 16ème édition CUJAS, Paris p.382.

777 Lexique de termes juridiques, op. cit, p.373. 
Ainsi, d'une manière générale, au regard de la doctrine ${ }^{778}$, pour qu'il y ait violation ou infraction environnementale, le juge doit d'abord prouver la réunion de trois éléments constitutifs à savoir, la violation par l'agent pénal d'une prescription légale (Section I) ensuite il faut la réalisation de l'infraction, la commission d'acte matériel proprement dit, et enfin, l'intention coupable (Section II).

\section{SECTION I : L'ELEMENT LEGAL OU L'EXIGENCE DE TEXTES CLAIRS ET PRECIS}

L'élément légal ${ }^{779}$ de l'infraction, comme le définit Dominique GUIHAL, « est le texte, ou l'ensemble de textes qui décrit le comportement prohibé, l'érige en infraction et assortit cette incrimination d'une ou de plusieurs peines ${ }^{780} \%$. Ces textes doivent émaner des autorités constitutionnellement habilitées à les éditer et préexister aux faits poursuivis ${ }^{781}$. Cela suppose que toute infraction correspond à la violation d'un texte de loi ou d'un règlement préalablement défini et pourvue d'une sanction pénale. La conséquence est qu'en absence de texte, il ne saurait avoir de sanction. Comme nous l'avions souligné dans les précédents chapitres, cet élément légal de l'infraction, principale source de droit pénal, n'est pas souvent clairement et suffisamment défini par le législateur béninois ce qui, par voie de conséquence ne facilite pas une bonne prise de décision du juge. C'est pourquoi, nous allons d'abord, au regard de la doctrine et de la jurisprudence, définir le contenu et l'évolution du principe (§l) avant d'exposer les modalités de son application (§II).

778 Cf. PRADEL(Jean), Droit pénal général, op.cit., p.276.

779 Certains auteurs parlent plutôt de "préalable légal", puisqu'il s'agit d'une prévision du fait par la loi. V. à cet effet, PRADEL(Jean), Droit pénal général, op.cit., p.279.

780 GUIHAL (D), Droit répressif de l'environnement, op. cit. p.104.

781 Idem. p.103. 


\section{§I : Le contenu et l'évolution du principe de la légalité}

On se préoccupera ici de la signification classique du principe $(A)$ et de son évolution actuelle en droit pénal de l'environnement (B).

\section{A) L'historique et la signification du principe}

Selon Roger MERLE et André VITU 782, " de toutes les règles consacrées par le droit criminel français, la plus importante est sans conteste celle de la légalité des délits et des peines, ou encore selon son expression latine, la règle " nullum crimen, nulla poena sine lege ». Ce qui signifie qu'il n'y a pas de délit ni de peine sans texte ${ }^{783}$. Autrement dit, aux termes de ce principe, la loi peut seule prévoir des incriminations et les sanctionner de peines. Les crimes et délits ne peuvent être prévus que par une loi au sens formel, c'est-à-dire un texte voté par le parlement ${ }^{784}$.Ce principe, en réalité, induit deux autres sous principes : il signifie d'abord qu'un fait ne peut déterminer l'intervention du juge répressif s'il n'a été formellement prévu par un texte : c'est le principe de la légalité des délits ensuite qu'aucune peine ne peut être infligée si elle n'est déterminée, quant à son origine, sa durée ou quantité par un texte, c'est le principe de la légalité des peines. Le prévenu devra être aussi jugé selon les formes procédurales prévues par la loi. On n'en déduit dès lors que le principe de la légalité concerne donc tout à la fois le droit pénal et la procédure pénale ${ }^{785}$ et non seulement la loi, comme on pourrait a priori le penser. Dans cette optique, il conviendrait alors de dire, avec les auteurs MERLE et VITU « nullum crimen, nulla poena, nullum juridicium sine lege $"$.

La formulation latine du principe pourrait laisser croire qu'elle remonte à l'antiquité romaine ; or il n'en est rien puisque cette formule est l'œuvre du

782 MERLE (Roger) et VITU (André), In, Traité de droit criminel, T2, Procédure pénale, Cujas, 4ème édition, Paris 1989., p.104. ; v. W.Jeandidier, J.cl. code pénal, Principes de légalité criminelle, $n^{\circ} 33$.

783 Délit est pris ici bien entendu, au sens général d'infraction.

784 GUIHAL (D), Droit répressif de l'environnement, op. cit. p.115.

785 PRADEL(Jean), Droit pénal général, op.cit., p.124. 
criminaliste allemand Feuerbach, qui, au début du XIX ${ }^{\text {ème }}$ siècle, a cru créer cette règle en réaction à l'anarchie ou à l'arbitraire ou encore à " I'Etat de police " qui régnait à cette époque. Le système pénal est ainsi fondé sur un mode d'avertissement des peines éventuellement encourues. Elle permet, en effet, d'avertir solennellement les citoyens des peines applicables. II s'agit donc de s'adresser à la raison de chacun par un effet de dissuasion et non par la terreur.

Ce principe à valeur constitutionnelle ${ }^{786}$, est présent dans presque tous les systèmes pénaux ${ }^{787}$ et il est réaffirmé par des instruments internationaux ${ }^{788}$. Cependant, au regard de la modernisation du droit pénal, le principe a connu une évolution positive favorable à l'épanouissement du droit pénal en général.

\section{B) L'évolution actuelle du principe en droit pénal de l'environnement}

Cette évolution est remarquable dès l'avènement de la vème République française en1958, dont la constitution, a opéré un partage entre la loi et le règlement ${ }^{789}$, ce que le Professeur Levasseur a appelé " une révolution en droit pénal ${ }^{790} \%$. Au Bénin, la constitution béninoise, dispose aussi que la détermination des crimes et délits sont du domaine de la loi ${ }^{791}$. Ces textes ne visant expressément que les crimes et délits, on en déduit aussi que les contraventions relevaient dorénavant du domaine réglementaire.

786 II est consacré entre autres par les constitutions des USA dès 1774; les constitutions françaises dès 1946 ; la constitution béninoise de 10 décembre 1990.

787 Notamment Art.4 C.P français dès 1810, siège du principe de la légalité, qui dispose « nul contravention, nul délit et nul crime, ne peuvent être punis de peines qui n'étaient pas prononcées par la loi avant qu'ils fussent commis »; aussi l'art.111-3 CP français, apporte des nuances en mettant l'accent sur la portée du règlement. II en est ainsi des art. 2 ou 4 des codes pénaux africains cités à la référence $n^{\circ} 56, p .28$.

788 Notamment la Déclaration des droits de l'homme et du citoyen du 27 août 1789 (art.8) ; la déclaration universelle des droits de l'homme du 10 décembre 1948, la charte africaine des droits de l'homme et des peuples.

789 Art.34 et 37, de la constitution française de 1958.

790 Une révolution en droit pénal : le nouveau régime des contraventions. ; Chronique XVIII, Recueil Dalloz, 1959, p.18

791 Art.98 de la constitution béninoise. 
La conséquence juridique qui se dégage dès lors, est que la loi, n'est plus, la seule source du droit pénal. Le législateur n'a plus seul le pouvoir de fixer les incriminations et les peines. II faut une base légale. II en est ainsi également des actes assimilés tels que les ordonnances qui relèvent du Président de la République. Le règlement (décret, arrêté) qui est l'œuvre de l'administration ou de l'exécutif, est aussi dorénavant, à l'origine de la création non seulement de normes mais aussi de peines contraventionnelles ${ }^{792}$, même s'il s'agit de peines de simples police comme des amendes, c'est énorme comme responsabilité. Cette responsabilité, eu égard au domaine abandonné au pouvoir réglementaire est bien limité. Il a été définit de façon rigoureuse par le conseil constitutionnel français qui, dans sa décision $n^{\circ} 73-80$ L du 28 novembre 1973, a indiqué que la " détermination des contraventions et des peines qui leurs sont applicables est du domaine réglementaire lorsque lesdites peines ne comportent pas de mesures privatives de liberté ${ }^{793}$ ». En conséquence de l'application de cette jurisprudence constitutionnelle, le nouveau code pénal, entré en vigueur le $1^{\text {er }}$ mars 1994, a supprimé les peines privatives de liberté en matière contraventionnelle en son article L131-13.

Le grand bénéficiaire de cette réforme pénale, est nul doute le droit de l'environnement et particulièrement le droit pénal de l'environnement. Puisque comme indiqué tout au long de la première partie, le droit pénal de l'environnement est étroitement lié au droit administratif. C'est l'administration qui la plupart du temps définit les normes et les incriminations pénales (prescriptions, interdictions, autorisations, etc....) à observer parlescitoyens. Ainsi, les lois de police spéciales ne déclarent certains comportements punissables que sous réserve de dépassement de seuils physico-chimiques ou d'inobservations de précautions énoncées par l'administration ${ }^{794}$. Se sont alors les prescriptions réglementaires qui sont sanctionnées de peines correctionnelles. II s'agit là de l'incrimination par renvoi. De la même manière, lorsque le gouvernement est

792 Art.111-3 al. 2. CP français

793 Droit pénal et droit constitutionnel, janvier 2007, France, service du conseil constitutionnel, p.3. Pour un exemple récent concernant la problématique relative à la nature de l'acte (décret en conseil d'Etat ou non) qui doit définir les contraventions, $v$. décision $n^{\circ}$ Réf $d u$ 24 mars 2005, sur des requêtes présentées par monsieur Stéphane HAUCHEMAILLE et par Monsieur Alain MEYET (Hauchemaille 17 ou hauchemaille Meyet), cons. 17. 
chargé par une loi de déterminer ses modalités d'application, il peut renvoyer lui-même, l'édiction de certaines mesures à des arrêtés ministériels, à condition d'avoir défini avec une précision suffisante les principes à mettre en œuvre. Si c'était la loi qui continuait à tout régir en cette matière, l'efficacité du droit pénal de l'environnement serait mise à rude épreuve, l'environnement étant un domaine nécessitant une réponse immédiate ou rapide en cas d'infraction.

Ainsi, dans sa mise en œuvre, le principe est mis en application non seulement par l'administration comme on le constate, mais il est surtout mis en application d'abord par le législateur et par le juge pénal.

\section{§ II : L’application du principe de la légalité en droit pénal de l'environnement}

Le principe de la légalité des délits et des peines a des implications, notamment des exigences de clarté et de précision de la norme pénale ou des incriminations aussi bien pour le législateur que pour le juge. Or, en matière environnementale, le dispositif répressif repose essentiellement sur le règlement. Ainsi, en droit répressif de l'environnement, il parait évident que " l'incrimination par renvoi ${ }^{795}$ " ou pénalité par renvoi ${ }^{796}$ est la règle et la définition d'infractions autonomes dont les éléments constitutifs sont déterminés par une seule disposition, l'exception. Dès lors, la question se pose de savoir comment arrimer les exigences de ce principe avec le droit de l'environnement afin d'éviter qu'une mauvaise définition des éléments constitutifs par le législateur, ne conduise à un défaut de base légale ou à une mauvaise décision du juge ?

\section{A) Le législateur doit légiférer avec clarté et précision}

Une application effective du principe de la légalité, induit chez le législateur une lourde responsabilité dans l'édiction des textes de loi. Au sens strict du terme, la loi est une règle écrite, générale et permanente élaborée par

795 GUIHAL (D), Droit répressif de l'environnement, op.,cit. p.104

796 PRADEL(Jean), Droit pénal général, op.cit., p.124 
le parlement ${ }^{797}$. Autrement dit, le législateur a le monopole de l'édiction des normes pénales et procédurales.

Ainsi, dans la rédaction de ces textes répressifs, créateurs d'incriminations ou porteurs de peines, des exigences particulièrement strictes s'imposent au législateur et au pouvoir réglementaire. Le législateur a l'obligation de voter des textes précis, définissant nettement les incriminations et indiquant sans erreur possible les peines applicables ${ }^{798}$. La nature et le taux des peines prévues doivent être déterminés avec précision et entrés en vigueur avant la commission des faits qui donnent lieu aux poursuites. Certains auteurs parlent même de principe de « textualité pénale ${ }^{799}$ ». Les textes flous, ou prêtant à équivoque ou encore ayant des mots ou des formulations très vagues, sont sources d'arbitraires et d'insécurité judiciaires. Les définitions d'infractions à formulation tellement vagues qu'en pratique on y peut faire entrer n'importe quel acte ${ }^{800}$, sont proscrites. Se serait le cas, si par exemple, une disposition pénale incriminait " tout acte de nature à nuire au peuple français ", comme l'avait fait en France une loi du 7 septembre 1941 instituant un tribunal d'Etat ${ }^{801}$. II conviendrait donc, pour les rédacteurs de textes d'environnement, de procéder d'abord à la clarification des concepts, à la définition des termes techniques qui pourraient soulever éventuellement des contestations, d'éviter l'emploi des mots vagues, susceptibles de plusieurs interprétations.

A cet effet, nous suggérons que la commission nationale de législation et de codification, logée au MJLDH, soit composée de membres pluridisciplinaires compétents comprenant outre des juristes de droit commun, des spécialistes de droit de l'environnement et des chercheurs de l'université en science environnementale. Ces membres, à défaut d'être membres permanents, pourront être invités à siéger lorsque l'ordre du jour de la session de la commission portera sur des préoccupations d'environnement afin de mieux apprécier l'opportunité des renvois aux textes réglementaires.

797 Cf. Lexique de termes juridiques, op. cit ; P.284 ; voir aussi PRADEL(Jean), Droit pénal général, op.cit., p.165 et Ss.

798 MERLE (Roger) et VITU (André), Traité de droit criminel, op. ;cit. note 782

799 GUIHAL (D), Droit répressif de l'environnement, op. cit., p.104

800 Idem. p.

801 Idem. 


\section{L'incrimination par renvoi, une solution}

L'incrimination par renvoi consiste à « prévoir dans une disposition finale d'une loi, la sanction d'un ensemble de dispositions techniques, en revoyant globalement pour la définition des comportements incriminés aux articles concernés de la loi ${ }^{802}$. En droit pénal de l'environnement, ce renvoi s'effectue généralement en direction d'un acte règlementaire qui définit le comportement infractionnel tout en faisant référence à la sanction prévue par le texte législatif.

Compte tenu de la complexité de la matière environnementale et de la particularité du droit pénal de l'environnement qui est intimement lié au droit administratif, les rédacteurs des textes de loi, sont pratiquement obligés de recourir à la technique de l'incrimination « par renvoi » aux textes réglementaires pour mieux expliciter des dispositions législatives. Cette technique est fréquemment utilisée en droit répressif de l'environnement. Mentionnons que le droit de l'environnement, œuvre des corps techniques de l'Etat plutôt que de juristes, contient une minorité de délits dont les éléments constitutifs tiennent tout entier dans une disposition législative se suffisant à elle-même. Ce qui fait que cette technique, toute proportion gardée, apparaît comme un outil qui contribue à régler la question d'imprécision des textes. Le législateur béninois, comme nous l'avons constaté, en fait un usage abondant mais infructueux. Puisque dans la pratique, plusieurs textes de lois demeurent encore sans décrets d'application ${ }^{803}$ et plusieurs décrets sans arrêtés d'application ${ }^{804}$. II conviendrait dès lors, pour les pouvoirs publics, de faire diligence afin que le renvoi soit effectif et viser à compléter ces différents textes de lois pour qu'ils soient plus utiles ou plus efficaces, une fois transformés en règlements ou en "lois pénales en blancs ${ }^{805}$ » comme le qualifie le professeur SILVA SANCHEZ. C'est ce que souligne Marie Josée LITTMANN-MARTIN, à propos du droit forestier en ces termes : "l'élément légal est incomplet car le législateur ne

802 (F) DESPORTES et (F) Le GUNEHEC, Droit pénal Général, op.,cit.,p.175.

803 On peut citer le décret d'application de la loi $n^{\circ} 2002-16$ du 18 octobre 2004 portant régime de la faune en République du Bénin.

804 Cf. Annexe 3 ou le Tableau $n^{\circ} 6$.

805 (Jésus-Maria) SILVA SANCHEZ, Les principes du droit pénal et de la jurisprudence constitutionnelle : le point de vue espagnol, 2000, article, p.79. (source internet) 
définit pas les espèces protégées. La détermination de ces espèces est confiée au pouvoir réglementaire ". Or, le texte réglementaire ne suit toujours pas. La formule utilisée dans ce cas par le législateur béninois est : " un décret pris en conseil des ministres, sur proposition du ministre chargé de la faune fixe, les listes des espèces intégralement protégées (catégorie $A$ ) et partiellement protégées (catégorie B) (..) $»^{806}$. A ce jour, cette liste demeure toujours inconnue, faute de décret d'application ${ }^{807}$. Conséquence, ce texte, à certains endroits ne devrait pas être opposable au tiers contrevenant puisqu'il est incomplet.

En droit espagnol par exemple, c'est le tribunal constitutionnel qui dans un arrêt a mis un terme au controverse doctrinales sur la notion de "renvoi » par une doctrine dénommée " du complément indispensable ». Selon celle-ci, les renvois normatifs, c'est-à-dire l'intégration de la loi pénale avec les normes extra pénales de complément, sont conforme à la constitution à la condition que le renvoi soit justifié pour des raisons de protection, qu'il soit proportionné et, enfin que la loi pénale contienne le noyau de ce qui est interdit, en sorte que seules les questions de détail qui constituent « le complément indispensable » seraient susceptibles de renvoi. II s'agit ici de l'adoption d'une solution de compromis entre les exigences de protection des intérêts sociaux, qui demandent une relative flexibilité des lois pénales et de la sécurité publique ${ }^{808}$. Comme on le voit, la protection de l'environnement comme valeur écologique, entre bien dans la protection des «intérêts sociaux».

Mais il conviendrait de faire remarquer aussi que l'exigence d'une technique précise pour la rédaction des textes ne saurait être évidemment poussée à l'absurde : le législateur ne peut statuer que par voie de « dispositions générales " et on ne peut lui demander, à tout instant, d'énumérer par détail toutes les hypothèses particulières que l'imagination suggère ; sa tâche deviendrait impossible. C'est pourquoi, il recourt au renvoi.

806 Art.31 de la loi n²002-16 du 18 octobre 2004 portant régime de la faune en République du Bénin.

807 Projet de texte en cours d'adoption par le gouvernement.

808 (Jésus-Maria) SILVA SANCHEZ, Les principes du droit pénal et de la jurisprudence constitutionnelle : le point de vue espagnol, article, 2000, p.79-80. 
En revanche, pour remédier aux difficultés d'exigence de clarté et de précision, le législateur béninois peut par exemple s'inspirer de certaines législations, comme la législation belge ${ }^{809}$, qui recourt à ce que l'on pourrait appeler " une disposition générale de prudence et de précaution ", dans la rédaction de certains textes; obligeant de ce fait, les potentiels pollueurs à prendre " toutes précautions nécessaires afin d'éliminer ou de limiter les nuisances environnementales au maximum ${ }^{810}$. Et ceci nonobstant le respect de toutes les conditions particulières requises dans l'autorisation d'environnement ${ }^{811}$. Ainsi, l'article 22 du décret de la Région Flamande sur l'autorisation environnementale dispose : « nonobstant l'autorisation accordée... il appartient à l'exploitant de toujours prendre toutes les mesures nécessaires afin de prévenir des dommages, des nuisances ou des accidents graves, et, en cas d'accident, de limiter autant que possible les conséquences pour l'homme et l'environnement ${ }^{812}$ ». Cependant, l'on peut se poser la question de savoir dans quelle mesure une disposition aussi générale correspond-telle au principe de la lex certa, la loi pénale établissant clairement l'obligation ou l'interdiction?

En droit belge ${ }^{813}$, les articles 12 et 14 de la constitution disposent que « nul ne peut être poursuivi que dans les cas et selon les formes que la loi a établit ». En relation avec les dispositions de l'article 22 , cela a prêté à équivoque et a suscité un contentieux ; la cour constitutionnelle belge saisie, a estimé que l'article 22 querellé n'était ni contraire aux articles 12 et 14 susmentionnés, ni à l'article 7.1 de la CEDH. Il a été jugé ainsi au motif que « la complexité de la problématique environnementale ne permet pas au législateur ou à l'administration de prévoir absolument toutes les circonstances créant un danger pouvant être circonscrit d'avance par une norme adéquate, il appartient au contraire à l'entreprise professionnelle disposant de toutes informations nécessaires, de prévoir au mieux toutes circonstances pouvant intervenir et nécessitant des mesures de précaution ; il appartient de même au juge d'apprécier in concreto, si toutes

\footnotetext{
809 Art. 2 du CP belge

810 GOETHALS (Etienne), Le droit pénal de l'environnement en Belgique, doc. Source : www. ahjucaf.org 2008.

811 Idem.

812 Idem.

813 Comme en droit béninois ou comme dans la plupart des législations.
} 
les mesures pouvant être prises par un homme raisonnable, placé dans la même situation, ont été respectées, étant entendu que cela n'implique pas que tout dommage, même celui qui ne dépasse pas le seuil du dommage normal et inhérent à une telle forme d'activité, doit être éviter sous peine de sanction pénale ${ }^{814}$.

Telle est donc la réponse que le droit pénal belge propose pour mettre un terme à la polémique doctrinale sur cette notion de " renvoi ».

D'un autre côté, et dans le même ordre d'idée, le droit pénal français quant à lui, punit d'une amende contraventionnelle de première classe, la violation des interdictions ou le manquement aux obligations édictées par les décrets et arrêtés de police ${ }^{815}$. Ce texte a parfois été considéré comme une sorte de sanction universelle applicable dans tous les cas où n'était pas prévue une répression spécifique, autonome.

Ce texte également, serait bien adapté pour la réglementation de l'environnement puisqu'il ne s'applique pas à une disposition législative ${ }^{816}$ mais aux règlements de police pris par les autorités administratives en vue de maintenir la tranquillité, la sécurité et la salubrité publique ${ }^{817}$.

L'administration béninoise environnementale peut s'inspirer de ces différents exemples pour sanctionner toutes autres formes de manquement non prévus par les décrets et arrêtés d'application et qui surviennent lors de l'exécution de l'activité pourvue d'une autorisation ou un permis régulièrement accordé $^{818}$. Un tel dispositif peut amener le promoteur à être diligent et agir en bon père de famille ${ }^{819}$.

814 GOETHALS (Etienne), le droit pénal de l'environnement belge, www.ahjucaf.org

815 En droit français, lorsqu'une peine n'est prévue par le texte objet du renvoi, l'art. R610-5 du code pénal s'applique. Voir PRADEL(Jean), Droit pénal général, op.cit., p.225 et 226

816 Cass. Crim.12 janv. 1983: Bull. crim. n¹5

817 Cass. Crim.14 mars 1989:Bull. crim. $n^{\circ} 127$

818 Un permis peut légaliser certains actes mais cela ne signifie pas qu'il accorde des droits absolus au polluant.

819 L'autorisation administrative semble-t-il ne doit pas être possible, ou si elle a été accordée, elle doit être sans importance lorsque l'utilisation de l'environnement cause la mort ou une lésion grave à une personne ou crée un risque significatif de les entrainer. 
En raison de sa commodité, la technique de l'incrimination par renvoi est fréquemment utilisée par le législateur. Elle est une approche de solution pour le droit pénal de l'environnement mais elle, soulève quelques appréhensions.

\section{Les limites de l'incrimination par renvoi}

C'est d'abord une entorse au principe de la légalité criminelle et au principe de la proportionnalitée 820 puisqu'à chaque infraction devrait correspondre une incrimination et une peine donnée, spécifique à cette infraction. C'est une pratique ou une technique législative, à l'origine des infractions obscures. ${ }^{821}$

Ainsi, l'usage des dispositions générales, dans les textes pénaux, qui ne sont pas totalement en phase avec le principe de la légalité criminelle, doit être manipulé avec prudence, pour ne pas paraître " un fourre tout ». Le texte répressif se réduit à la formule suivante : "toute infraction aux dispositions du présent code ou de la présente loi est punie de... ॥. II est dans ces conditions, très difficile de déterminer exactement quels sont les manquements pénalement sanctionnés et ceux qui ne le sont pas ${ }^{822}$. La rédaction correcte des textes réglementaires dépend de ces dispositions générales.

Il en est ainsi par exemple de l'article 87 du code minier béninois ainsi libellé : " est punit d'une amende de 1000 à 100.000 F CFA, toutes les autres infractions au présent code et aux textes pris pour son application ». De la même manière, l'article 52 de la loi du 21 septembre 1987 portant réglementation de la protection de la nature et de l'exercice de la chasse en République Populaire du Bénin, dispose comme suit : " est punit d'une amende de 2000 à 300.000 F CFA et d'un emprisonnement de 2 mois à $1 \mathrm{an}^{823}$, les infractions à la présente loi et à ses décrets d'applications ". Ces dispositions, telles que rédigées, très vagues et générales, qui renvoient à des textes d'application, ne sont pas de nature à

820 (G) STEFANI et G) LEVASSEUR, B) BOULOC, op. cit.p.21, cité par G. SOGLO, Mémoire de DEA, Lomé Togo, 1999, op. cit. p....

821 (F) DESPORTES et (F) Le GUNEHEC, Droit pénal Général, op.,cit.,p.175.

822 (F) DESPORTES et (F) Le GUNEHEC, Droit pénal Général, op.,cit.,p.175

823 Si ces lois sont aujourd'hui abrogées, la technique de rédaction ayant prévalu à la rédaction de ces textes est toujours opérationnelle. 
faciliter la rédaction desdits textes réglementaires encore moins la tâche au juge en cas de contentieux pénal. De plus, l'on court le risque d'infliger des peines souvent dérisoires qui ne correspondent pas à la réalité de chaque cas d'espèce.

Par ailleurs, la suprématie du règlement sur la loi, ne doit pas conduire les pouvoirs publics à ignorer le rôle primordial que doit jouer la loi. La ratification d'un nombre important de conventions internationales en la matière par l'Etat peut par exemple, ouvrir la voie à une production législative interne intense. Au risque de rendre cette production ineffective, il conviendrait pour le législateur de légiférer en privilégiant des incriminations directes ou autonomes et limiter au besoin, la " technique de renvoi » aux textes réglementaires afin de rester coller non seulement au principe de la légalité criminelle, mais aussi de faire ouvertement la promotion de l'application du droit pénal, en temps que discipline autonome, sans trop s'accommoder du règlement. Car, si la technique de renvoi ne peut être évitée, ne doit-on ne saurait non plus en abuser.

D’ailleurs, le législateur béninois, ${ }^{824}$ après avoir, dans le code forestier, interdit un certain nombre de comportements préjudiciables à la flore, il revient dans le chapitre 4 intitulé : " des pénalités », 825 pour préciser le comportement incriminé avant de l'assortir d'une peine. On constate d'ailleurs que ce texte ne comporte aucun renvoi.

C'est dire alors que l'entreprise n'est pas impossible et qu'il appartient au législateur d'y recourir au lieu d'abuser du « renvoi ». Car dans ce domaine plus qu'ailleurs, les frontières de la légalité doivent être tracées pour que chaque citoyen sache jusqu'où il peut aller sans s'inquiéter dans la mesure où l'acte matériel n'est pas seul requis, l'omission est également incriminée.

L'exigence d'une rédaction claire et précise des textes pénaux, outre de droit pénal de fond, concerne également la procédure pénale. Le principe de la légalité interdit au législateur et à l'administration d'incriminer les faits passés, c'est-à-dire d'ordonner la rétroactivité des lois promulguées.

824 Cf. la loi béninoise portant régime des forêts.

825 Art. 88 de la loi béninoise portant régime des forets 
De son côté, le juge est tenu de " rechercher l'exacte qualification des faits poursuivis ${ }^{826}$ " c'est à dire de rechercher dans chaque cas d'espèce, quel texte est applicable.

B) Le juge répressif doit dire le droit en fonction d'un texte

Lorsque le magistrat, est saisi d'une affaire pénale, il doit avant tout rechercher si les faits dont il est saisi comportent un préalable légal, c'est-à-dire s'ils constituent une infraction, et dans l'affirmative, laquelle. C'est l'opération dite de qualification des faits. C'est une opération intellectuelle qui permet donc d'appliquer la règle de droit au cas de l'espèce. Qualifier, " c'est dire quel délit constitue le fait incriminé et par quel texte il est prévu et puni827 ". C'est donc, essentiellement l'œuvre du juge. Dans la pratique, la formule sacramentelle est énoncée par le juge béninois, comme suit : " attendu que ces faits constituent le délit prévu et puni par les articles... de la loi $n^{\circ} . .$. ».

En effet, quant il prononce une peine, le juge doit constater dans sa décision de condamnation, l'existence des éléments constitutifs de l'infraction contenu dans l'article visé. Faute de texte, un procureur de la République devrait classer sans suite, un juge d'instruction ordonner un non lieu ou une juridiction de jugement prononcer l'acquittement ${ }^{828}$. Aux tribunaux, il est interdit d'appliquer une pénalité dans les cas non prévus par la loi. Par exemple, un texte qui prévoit des règlements d'application nécessaire à sa mise en œuvre ne peut servir de base à des poursuites tant que les règlements n'ont pas été pris. ${ }^{829}$ Une loi ne peut recevoir d'application pénale tant que les exceptions prévues par elles n'ont pas été prises par les textes réglementaires voulus. ${ }^{830}$

La chambre criminelle française, rappelle bien à cet effet, que « toute infraction doit être suffisamment définie en termes clairs et précis pour exclure

826 MERLE (Roger) et VITU (André), In, Traité de droit criminel, op.cit., p.110

827 PRADEL(Jean), Droit pénal général, op.cit., p.279.

828 MERLE (Roger) et VITU (André), In, Traité de droit criminel, op. cit., p.110

829 B (Pierre) et (PINATEL(Jean), Traité de droit pénal et de science criminelle, T I p.148. or le droit positif béninois comprend assez de textes sans textes d'application. Idem. C. Paris 15 février 1965, Gaz. Pal 1965.I.304. 
l'arbitraire et permettre au prévenu de connaître exactement la nature pénale de l'acte qu'il commet ${ }^{831}$ ». A défaut de définir clairement les termes techniques au chapitre $1^{\mathrm{er}}$, il conviendrait pour les rédacteurs, de prévoir en annexe de la loi ou du règlement, un lexique des termes techniques utilisés; ceci pourrait faciliter la tâche au juge.

Mais, face à la complexité et parfois à l'imprécision des textes juridiques environnementaux, quelle pourrait être l'attitude du juge, puisqu'il faut qu'il dise le droit ? Ce n'est qu'en ce moment qu'intervient, outre la source légale et la source réglementaire, une autre source de droit qu'est la jurisprudence.

Théoriquement, elle n'est pas une source de droit en ce qu'elle n'a pas le pouvoir de créer des infractions ni des peines, et les juges ne sont nullement liés par une décision rendue : elle n'aurait donc, légalement aucun pouvoir créateur ni aucune force obligatoire.

Cependant, l'usage démontre qu'elle pose de véritables règles de droit, soit parce que la loi est trop abstraite pour appréhender des faits concrets, soit parce qu'elle est trop générale pour pouvoir s'appliquer sans spécification préalable ; soit enfin, lorsque le juge tire de l'esprit même de la loi, le pouvoir d'étendre l'indulgence de celle-ci. Dans l'un ou l'autre des cas, le juge est tenu de dire le droit au risque de ne pas tomber dans l'infraction de déni de justice.

Cette situation d'inconsistance des textes, amène souvent le juge pénal, à procéder par interprétation judiciaire. Elle consiste pour le juge soit à solliciter l'avis de la cour suprême ou de la cour de cassation s'il ne se considère pas luimême apte à percer le sens lorsque se pose à lui une question de droit nouvelle dans ce dernier cas, il tranche lui-même la question d'interprétation ${ }^{832}$.

A défaut de jurisprudence en droit interne béninois, illustrons ces propos par une jurisprudence française au sujet de la technique de liste énumérative adoptée en droit forestier à propos de la protection des oiseaux sauvages ${ }^{833}$ et attaquée devant la CJCE. Dans l'espèce, la législation française

831 Cass. crim.20 février 2001, pourvoi $n^{\circ} 98-84.846$, décision rendue en matière de délit de presse ; voir aussi PRADEL(Jean), Droit pénal général, op.cit., p.128.

832 PRADEL(Jean), Droit pénal général, op.cit., p.172.

833 Reprise également par le droit forestier béninois 
des espèces protégées, a omis sur la liste une espèce protégée par une directive communautaire. Saisit du différend, la cour a relaxé les prévenus pour chasse d'une espèce non protégée (bruant ortolan), au motif que : « une directive n'est pas directement applicable en droit interne à défaut de législation nationale I'introduisant, que la chasse du bruant ortolan, n'est ni interdite par l'arrêté du 17 avril 1981 ni autorisée par celui du 26 juin 1987 (...) que les prévenus ne peuvent être poursuivis pour un fait qui n'est pas expressément réprimé ${ }^{834}$.

Le constat sera identique pour une espèce protégée par une convention ; telle la convention de Berne, non ratifiée par la France à la date des faits. II a été ainsi jugé qu'un loup, abattu le 17 décembre 1987 (la convention de berne a été ratifiée que le 22 août 1990) n'était pas protégé en France par un texte international ou communautaire, que ne figurant pas dans la liste des espèces protégées de l'arrêté du 17avril 1981 pris pour l'application de la loi du 10 juillet 1976, il était dépourvu de tout statut de protection spécifique en France. Le chasseur à l'origine de sa destruction échappait donc à toute responsabilité civile $^{835}$.

D'un autre côté, la loi et le règlement doivent non seulement être promulgués mais aussi publiés au JO. Le défaut de publication constitue un vice de forme. Or, ces exigences sont très rarement respectées en droit africain. La conséquence juridique de cette carence de l'administration aurait dû être I'inopposabilité de ces textes aux justiciables et l'impossibilité de les sanctionner. Mais, la chambre criminelle française, soucieuse de la protection efficace des espèces menacées, décida " que la publicité complémentaire prévue à l'aliéna 2 du décret du 25 novembre 1977, n'est requise en ce qui concerne les arrêtés

834 Pau, 17 févr.1990, Proereset Hermann, p.5

835 Trib. Inst. Nice 16 janvier 1990 : Gaz. Pal. 1990, I, 213 ; Rev. dr. Env. : suppl. annales voiries et env. 1990, n.4, p.60, note JHR; n.5, p.76, note JHR. 
interministériels, que pour ceux qui ne dictent pas les mesures applicables à l'ensemble du territoire ${ }^{836}$.

L'exigence de clarté et de précision des textes, passe aussi par non seulement la signature des conventions internationales en matière d'environnement, mais aussi et surtout leur ratification et leur déclinaison en textes d'application par le pouvoir réglementaire. En la matière, nous l'avons signalé, plusieurs conventions internationales signées par le Bénin, sont en attente d'autorisation de ratification au parlement béninois. Or la non ratification de ces conventions par le Chef de l'Etat suppose l'inexistence de ces textes internationaux en droit interne, même s'il s'avère constant qu'en droit pénal qu'il n'y a pas de responsabilité si une convention internationale non transposée en droit interne est violée. Par contre, la responsabilité civile pourrait être établie.

Par ailleurs, au regard de ce qui précède, le juge doit intervenir en tenant compte du fait qu'il n'intervient qu'après que le législateur et l'autorité administrative aient, chacun dans le domaine qui lui est attribué, formé « leur jugement » en mettant en balance les charges financières qu'entraineraient, la nécessité de protéger l'environnement, lors, par exemple, de l'attribution d'une autorisation environnementale. II n'appartient pas au juge de ce mettre à la place du législateur ni d'exercer des attributions qui relèvent de l'autorité administrative compétente. Même si l'exception d'illégalité peut être invoquée envers cette dernière, encore le juge devra-t-il être extrêmement circonspect en ne faisant entrer en ligne de compte que des circonstances qui ne pouvaient pas être prévus lors de la rédaction du texte.

836 Cass. crim.23 avril 1986 : RJE, 1986, p.276. ; Anger, 23 nov.1989 :juris Data n. 050138. A ce sujet, il a été rejeté l'exception d'illégalité des poursuites pour défaut de publicité de l'arrêté relative à la liste des espèces protégées (défaut de publication dans deux journaux régionaux ou locaux) dès lors qu'il est établi qu'il a été publié dans le recueil des actes administratifs de la préfecture du département concerné, dans le JO, et qu'il a été affiché aux portes de la mairie. ; Paris, 4 juillet 1990, Juris-data. N. 024798. Il a été jugé, a propos d'un transfert interdit de spécimens appartenant à des espèces protégées, que l'arrêté du 15 mai 1986 fixant sur tout ou partie du territoire nationale des mesures de protection des oiseaux représentés dans le département de la Guyane étant opposable au prévenu malgré l'absence de publicité ayant été assuré dans le département de la Guyane. 
Mais en droit pénal de l'environnement, pour rendre sa décision, outre l'élément légal, le juge apprécie également la pertinence d'autres éléments constitutifs de l'infraction.

\section{SECTION II : LES AUTRES ELEMENTS CONSTITUTIFS DE L'INFRACTION ENVIRONNEMENTALE}

Il s'agit ici pour le législateur ainsi que pour le juge de mettre en exergue et de définir clairement, se fondant sur le droit pénal classique, ce qu'est un comportement punissable en droit de l'environnement. En effet, les éléments constitutifs de l'infraction environnementale, dérogent, pour plus d'efficacité, aux exigences du principe de la légalité des délits et des peines. Le contenu des éléments matériels (§I) et des éléments intentionnels méritent dès lors, pour les pouvoirs publics, une réforme (§II). Ainsi, les pays africains comme le Bénin, qui entreprennent le développement de leur droit pénal de l'environnement, peuvent s'en inspirer.

\section{§I : La réforme des éléments matériels de l’infraction}

Si le droit pénal de l'environnement abandonne la rédaction de ses incriminations aux spécialistes de l'environnement, c'est qu'il est bien difficile pour le législateur (généralement ignorant en droit de l'environnement), de définir en termes clairs et précis pour éviter l'arbitraire, ce qu'est une atteinte à l'environnement. Par exemple, il serait inutile, d'écrire dans une loi « Quiconque aura réchauffé le climat sera puni de ... » ou " Quiconque aura percé la couche d'ozone sera puni de... ${ }^{837}$. On ne peut que récriminer les comportements individuels scientifiquement définis dont l'addition aboutit à ces résultats quoique chaque coupable n'y participe que pour une part infinitésimale.

Dans notre analyse sur la dépendance administrative du droit pénal de l'environnement, nous avons, en effet, précisé que les deux disciplines à savoir le droit pénal et le droit administratif, sont étroitement liées mais avec 
une suprématie du droit administratif, donc du règlement. Ce qui suppose que la définition des éléments constitutifs, notamment l'élément matériel, relève essentiellement des cadres techniques de l'administration ou de l'exécutif et non de la loi au sens originel du terme.

Ainsi, en droit de l'environnement, l'élément matériel, élément caractérisé par sa visibilité dans la commission de l'infraction, est requis. C'est l'acte prohibé ${ }^{838}$ qui suppose la manifestation de l'agent par une attitude extérieur ${ }^{839}$. Autrement dit, le simple projet délictueux ne suffit pas à caractériser I'infraction. En conséquence, ce n'est pas la manière de penser mais la manière d'agir qui est sanctionné $e^{840}$.

Cet élément matériel, que décrit généralement le règlement (ordonnance, décret, arrêté, circulaire) et accessoirement la loi, vise bien un résultat, qui place l'agent pénal dans une position de sujet actif ou passif.

\section{A) Les infractions d'action ou de commission en droit pénal de l'environnement}

Selon PRADEL, l'infraction de commission, est celle qui consiste à commettre positivement un acte prohibé par la loi ${ }^{841}$ ou par le règlement. Lorsque l'on déclare que toute infraction suppose un élément matériel, il faut entendre par là qu'il est nécessaire que l'infraction " passe de l'état de projet à celui de la réalité ${ }^{842}$ », que l'intention soit traduite par des " actes extérieures ${ }^{843}$ ». Ces actes devraient être clairement définis par le législateur. Pour le Professeur J. H. ROBERT, en affirmant que l'infraction comporte des éléments distincts les uns des autres, la doctrine invite le juge à examiner méticuleusement la situation que la partie poursuivante prétend infractionnelle.

\footnotetext{
838 GUIHAL (D), Droit répressif de l'environnement, op. cit., p.179

839 PRADEL(Jean), Droit pénal général, op.cit., p.339.

840 En latin on dira : Nemo cognitationis poenam patitur.

841 PRADEL(Jean), Droit pénal général, op.cit., p.340

842 R. VOUIN et J. LEAUTE, Droit pénal et procédure pénale, Thémis 1969, p.37 cité par G. SOGLO, mémoire de DEA, op., cit.,p.70.

843 V. MOLINIER, programme de cours de droit criminel, 1851, 2ème partie, p.87cité par J.H. Robert, L'histoire des éléments de l'infraction, Rev. Sc. Crim. Avril-juin 1977, p.273.
} 
C'est le fait de porter atteinte à l'intégrité physique de l'animal ou de l'espèce végétale protégée qui réalise le délit. Puisqu'il s'agit donc d'une infraction de résultat, le moyen utilisé pour y parvenir est sans importance. C'est pourquoi, les décisions de condamnations omettent parfois le moyen destructeur ; celui-ci n'étant pas un élément constitutif ni une circonstance aggravante de l'infraction. On notera pourtant, par exemple, que l'utilisation d'un moyen de chasse prohibé (fusil), de même que l'acte de chasse en temps et lieu prohibé (la nuit dans une réserve ou parc nationale), constituent des infractions indépendantes venant se cumuler au délit de destruction de l'animal protégé. Ce cumul réel d'infraction permet un cumul des amendes contraventionnelles et des peines correctionnelles et le prononcé de peines et mesures complémentaires prévues par le droit pénal cynégétique ${ }^{844}$.

On remarquera aussi que l'élément principal constitutif de l'infraction est « la violation d'une prescription administrative », donc d'un permis ou d'une autorisation administrative. Ce n'est donc pas, le fait de tuer l'animal protégé qu'on sanctionne, mais la non détention d'un permis. L'acte positif matériel n'est pas seul requis, l'omission doit être également incriminée.

\section{B) Les infractions de commission par omission.}

Lorsqu'un texte incrimine un fait positif générateur d'un certain résultat, il est permis de se demander si une omission volontaire et génératrice des mêmes conséquences peut être assimilée à l'action positive prévue par le texte. A priori, en se fondant sur les exigences du principe légal, qui n'admet aucune autre interprétation autre que l'interprétation stricte, on est tenté de répondre par la négative. Mais le juriste de l'environnement est tenu de répondre par l'affirmative; puisqu'en droit de l'environnement, cette forme d'infraction est légion, reconnue aussi bien par le législateur que par la doctrine et la jurisprudence.

844 LITTMANN (José Martin), La protection de la nature, Edition Technique Jurisclasseur, 1992, Fascicule 505, p.7 
L'environnement est un domaine où en majorité des infractions sont commises par " imprudence, négligence, inattention ou inobservation ${ }^{845}$ " des lois et règlements. C'est le fait de procéder à des déversements de substances toxiques ou de déchets dans les plans d'eau ou autres lieux interdits; de jeter ça et là sur le sol, des matières contaminées à proximité des habitations. Ce qui exposent les populations à des risques potentiels de maladies diverses et d'atteintes aux ressources naturelles. L'omission dans ce cas est assimilée par le législateur à l'action. Mais il peut s'agir aussi d'une pure omission.

Dans l'infraction de pure omission, on réprime la passivité, sans s'attacher au résultat qu'elle a pu engendrer ${ }^{846}$. Dans le domaine de l'environnement, on peut citer : le délit de fuite, le délit d'obstacle à agent en exercice, le délit de non assistance à personne en danger, l'omission de souscrire une déclaration, l'omission de se soumettre à une injonction de faire, etc. Il s'agit là d'infractions entre autres de pure omission qu'on rencontre fréquemment en droit pénal de l'environnement.

Si dans la plupart des cas le lien de causalité ne se pose pas ou est quasiment absent, pour ces genres d'infractions, parce que le droit pénal incrimine des comportements fautifs indépendamment de tout résultat dommageable, tel n'est pas le cas en ce qui concerne les infractions matérielles. En effet, les délits d'environnement, étant pratiquement des délits de prévention, la causalité est absente où le rapport entre le geste et le dommage éventuel est très aléatoire ${ }^{847}$.

La doctrine française est unanime pour reconnaitre la pertinence de la théorie de "l'équivalence des conditions ${ }^{848}$ »qui postule que tout facteur qui concourt à la réalisation d'un événement peut être qualifié de cause d'où la théorie de la " causalité adéquate ${ }^{849}$ ", la cause objective du résultat.

845 Cf. art.94 de la loi n93-009 du 2 juillet 1993 portant régime des forets en République du Bénin.

846 PRADEL(Jean), Droit pénal général, op.cit., p.342

847 PRADEL(Jean), Droit pénal général, op.cit., p.372 ; v. aussi (D) GUIHAL, Droit répressif de l'environnement, op. cit., p.182

848 Selon cette théorie, tous les éléments qui ont conditionné le dommage sont équivalents. Autrement dit « tout fait sans lequel le résultat ne serait pas produit est considéré comme la cause de ce résultat » PRADEL(Jean), Droit pénal général, op.cit., p.372.

849 Selon PRADEL, la cause adéquate est celle qui normalement entraine le dommage, in, Droit pénal général, op.cit., p.373. 
La jurisprudence pénale quant à elle, est pour une équivalence des " conditions tempérées par le bon sens ${ }^{850}$. Elle considère par conséquent, qu'il n'est pas nécessaire qu'existe entre la faute et le dommage « un lien de causalité directe ou immédiat ${ }^{851}$ ». C'est ainsi que dans une affaire de pollution d'eau provoquée par des effluents de purin dans le réseau communal d'eau pluviale, la responsabilité pénale du maire a été retenue au motif qu'il n'avait pas fait usage de ses pouvoirs de police pour réglementer les épandages de lisier. ${ }^{852}$

Enfin au regard du droit pénal français, les incriminations matérielles sont des infractions en voie de disparition ${ }^{853}$. Elles étaient en effet constituées en l'absence non seulement de toute faute intentionnelle, mais encore de toute faute d'imprudence ou de négligence. La commission matérielle des faits incriminés suffisait à caractériser l'infraction sans qu'il fût nécessaire de démontrer l'intention, l'imprudence ou la négligence de l'auteur. Cette situation étant la règle en matière contraventionnelle, les délits matériels étaient qualifiés de " délit contraventionnel ». il s'agit en l'occurrence des délits en matière de droit de l'environnement (chasse, eaux et forêts, urbanisme,..). Leur caractère matériel a été supprimé par l'article 339 de la loi du 16 décembre 1992 qui dispose que les délits non intentionnels prévus par d'autres textes que le code pénal ne sont constitués que s'il est rapporté la preuve d'une imprudence, d'une négligence ou a fortiori d'une mise en danger délibérée, conformément au deuxième alinéa de l'article 121-3 CP. Les seules infractions matérielles subsistant dans le droit interne français sont donc les contraventions.

L'application combinée des dispositions des articles 121-3 CP et 339 de la loi d’adaptation à donc conduit les juridictions pénales à procéder progressivement à la requalification des anciens délits matériels, tantôt en délit d'imprudence ou de négligence tantôt en délit intentionnels.

\footnotetext{
850 (D) GUIHAL, Droit répressif de l'environnement, op. cit., p.182

851 (D) GUIHAL, Droit répressif de l'environnement, op. cit., p.182 ; Cass.crim. 20 juin 1989 : Dr. Pénal 89 comment. $\mathrm{N}^{\circ} 60$, en matière d'homicide involontaire.

852 Cass. crim. 18 juill. 1995 : Dr. Pénal 95 comment. n²85, par J.H. Robert.

853 F) DESPORTES et (F) Le GUNEHEC, Droit pénal Général, op.,cit.,p.412
} 


\section{§II : La définition des éléments intentionnels de l’infraction}

G. Stefani, G. Levasseur et B. Bouloc ${ }^{854}$ estiment que pour que l'infraction existe juridiquement, il ne suffit pas qu'un acte matériel (l'élément matériel), prévu et puni par la loi pénale ait été commis ; il faut encore que cet acte matériel ait été l'œuvre de la volonté de son auteur. Ce lien entre l'acte et l'auteur, que le droit anglais appelle la mens rea (volonté criminelle) par opposition à l'actus reus (acte criminel) constitue l'élément moral. L'infraction ne peut donc se résumer à une " simple matérialité, à un simple fait ${ }^{855}$, à de simples " crispations musculaires ${ }^{856}$. En d'autres termes, " ce n'est pas l'intervention physique d'un être humain qu'il faut attacher à l'infraction mais aux caractéristiques spécifiquement humaines de son intervention ${ }^{857}$. Qu'est ce qui caractérise l'action humaine ? C'est assurément la volonté, l'intelligence. Et c'est à l'intelligence des hommes que s'adresse la règle juridique « qui n'aura d'effet que si elle est mesurée et nécessaire ${ }^{858}$. La mesure de l'infraction ici est l'élément moral. L'écarter, c'est se passer de l'homme dans la définition de l'infraction. ${ }^{859} \mathrm{Or}$ l'indifférence que le droit pénal manifeste au résultat matériel illustré par la tentative punissable ${ }^{860}$ témoigne de la valeur, de l'importance accordée à cet élément, et confirme que c'est "l'intention qui fait le crime ». ${ }^{861}$

Le législateur doit donc prévoir des incriminations pour lesquelles l'élément moral requis est suffisamment précis afin de placer magistrats et justiciables à l'abri de toute confusion.

854 Droit pénal général, précis Dalloz 1997 p.211 n²53

855 A.C Dana, Essai sur la notion d'infraction pénale, Paris LGDJ, 1982, p.28, n³2

856 E. DASKALANKIS, Réflexion sur la responsabilité pénale, PUF 1975, cité par A.C Dana,op.,cit., p. $33, n^{\circ} 31$

857 A.C Dana, cit., p. $33, n^{\circ} 27$

858 J.H. ROBERT, Infractions contre la qualité de la vie : environnement, chronique de jurisprudence, rev.sc.crim.oct-déc. 1984 p.768.

859 A.C Dana, cit., p.39, n³4

860 S. KEYMAN, Le résultat pénal, R.S.C, 1968, p.781

861 J.B. DUVERGIER, Collection complète des lois, décrets, ordonnances, règlements et avis du conseil d'Etat, T : 3, 1824 p.499 cité par J.H. ROBERT, in, L'histoire des éléments de l'infraction, op.,cit., p.271 


\section{A) La nécessité de l'élément moral}

En droit français de l'environnement, la considération de l'élément moral occupait une place minuscule. Sous l'empire du code pénal de 1810, on appliquait une théorie qui faisait une place particulière à une catégorie d'infractions, les infractions matérielles. Ces dernières regroupaient les contraventions et de nombreux délits relevant de divers domaines comme ceux de la chasse, des douanes, de l'urbanisme ou encore de l'environnement. L'élément matériel était donc, seul significatif pour le législateur. L'élément moral n'était pas expressément invoqué. II existait tout de même ! Seulement, il était absorbé par l'élément matériel. Tout ceci pour dire que, pour bien distinguer dans le crime le fait et l'intention, il faut que cette dernière soit clairement définie ${ }^{862}$. Il en est ainsi par exemple en droit béninois, de l'article 116 précité de la loi cadre sur l'environnement dont le libellé renvoi aux articles 46 à 48 en matière d'infraction relative à la pollution de l'air. Si l'on se reporte effectivement aux articles énumérés, on ne voit pas la distinction entre l'acte criminel (l'actu reus) et la volonté criminelle (mens rea). Il faut observer que cela ne se limite pas à ce seul article mais à presque tous les articles de ladite loi et des autres textes spécifiques. La lecture des articles 51 et 52 du code de l'eau soulève les mêmes inquiétudes et de telles difficultés de lecture risquent d'engendrer certains dangers tel celui qui consiste à transformer les infractions contre l'environnement en infractions purement matérielles.

Puisque le prévenu était responsable sur la base de la simple constatation matérielle des faits, c'est à dire de la constatation de l'élément matériel de l'infraction, ces infractions sont constituées indépendamment de tout élément moral, c'est-à-dire qu'à leur égard, la seule constatation matérielle des faits constitutifs de l'infraction emporte déclaration de culpabilité à moins que le prévenu n'établisse l'existence d'un cas de force majeur ${ }^{863}$. Dès lors, aucune référence à l'élément intentionnel ne figure dans les dispositions répressives. Rares sont les textes qui requièrent expressément l'élément moral.

862 Selon PRADEL, il n'existe pas de définition dans la loi, ni dans l'ancien code pénal ni dans le nouveau code. La jurisprudence non plus ne définit pas l'intention. C'est donc à la doctrine que revient le soin de définir le dol. 
En droit français, un seul texte requiert l'intention du prévenu lorsque du moins, il est dans la position d'un chef d'entreprise. ${ }^{864}$ C'est aussi le cas de la loi sur la faune béninoise, qui requiert l'intention coupable en matière de disparition frauduleux d'animaux sauvages ou de produit de chasse ou encore en matière de délit d'obstacle ${ }^{865}$.

Cette absence de dispositions générales relatives à l'élément psychologique des infractions dans l'ancien code pénal français (encore en application au Bénin) avait permis la création prétorienne de la catégorie des délits matériels punissables sans que la partie poursuivante soit tenue de faire la démonstration d'une faute. Le droit de l'environnement dans son ensemble, et le droit de pollution des eaux en particulier, étaient des domaines d'élection de cette jurisprudence, généralement critiquée par la doctrine et la jurisprudence. ${ }^{866}$

L'article 121-3 CP français, rendant cette construction caduque, a favorisé un changement qualitatif de l'élément moral. Ce changement qualitatif n'a été effectif, qu'avec la réforme du code pénal et son entrée en vigueur, le $1^{\text {er }}$ mars 1994.

Ce silence législatif fréquent dans les textes de loi ne signifie donc pas mesure dérogatoire aux principes généraux de droit. Mais, pour le législateur, la « commission d'un délit suppose inévitablement un dol général, c'est-à-dire l'exécution volontaire et consciente de l'acte matériel ou un comportement fautif ${ }^{867}$.

864 La loi du 15 juillet 1975 qui fait un sort moins favorable aux auteurs qui ont directement et matériellement réalisé l'infraction.

865 Loi n²002-16 portant régime de la faune en République du Bénin, Art.141 « quiconque détruit, endommage ou fait disparaitre intentionnellement les animaux sauvages et les produits appréhendés en situation irrégulière est passible des sanctions prévues à l'article 153... »; Art. 138, 164 « quiconque fait volontairement obstacle... »

866 Cass. Crim. 258 avril 1977, Ferrier : D. 1978 JP, p.149, note M.L. RASSAT ; JCP 1978.II.93.I, note M. Delmas-Marty ; Rev.Sc.Crim.1978,p.335, obs. VITU.

867 (W) JEANDIDIER, Droit pénal général, op. cit., p.297, n, 321 S. ; (R) MERLE et A. VITU, Droit pénal général, op., cit., p.701, n. 547 S. ; (M). PUECH, Droit pénal général, op. cit., p.185, n, $515 \mathrm{~S}$. 


\section{B) La réforme de l'élément moral pour le droit de l'environnement}

Un fait matériel incriminé par la loi pénale n'est générateur de responsabilité que s'il correspond chez son auteur, à une attitude psychologique répréhensible. Cette composante morale de l'infraction consiste soit en une hostilité à l'égard des valeurs sociales protégées par le texte de qualification, soit en une indifférence à l'égard de ces mêmes valeurs. La première dénommée intention ou dol général ${ }^{868}$, s'entend de la conscience ou de la volonté de violer la loi pénale. La seconde constitue la faute non intentionnelle d'imprudence ou de négligence ${ }^{869}$. Il conviendrait dès lors, pour les lois et règlements d'environnement de prévoir des incriminations pour lesquelles l'élément moral requis est suffisamment précis afin de placer le justiciable et le juge à l'abri de toute confusion.

\section{1) L'intérêt de l'élément moral pour le droit de l'environnement}

Dans la théorie générale du droit pénal français, l'élément moral de l'infraction a été dégagé par la doctrine et la jurisprudence dans le silence du code pénal de 1810. Le nouveau code pénal a apporté des réformes qui participent de la dynamisation et de la valorisation de l'élément moral ou psychologique au détriment de l'élément matériel en énonçant dans son article $121-3$ al. $1^{\text {er }}$ C.P qu'il « n'y a point de crime ou de délit sans intention de le commettre ». Cette disposition, dont il n'existait pas d'équivalent dans le code de 1810 consacre

868 En effet, au sujet de la notion de dol général, la doctrine classique fait preuve d'une certaine unanimité ; le dol y apparait selon E. GARCON, cité par PRADEL, dans l'ouvrage précité, ( $p .463$ ) comme « la volonté de l'agent de commettre le délit tel qu'il est définit par la loi »et « la conscience chez le coupable d'enfreindre les prohibitions légales ». Pour d'autres auteurs comme MERLE et VITU « la conscience et la volonté infractionnelle ». Enfin pour N. DENIES et N. BASECQZ, dans l'article précité, pour qu'un acte soit qualifié de comportement intentionnel, il faut, selon la définition, telle que donnée par les travaux préparatoires du code pénal belge de 1867, que l'agent ait agi « sciens et volens » avec la connaissance et la volonté de dol général ». Voyez à ce propos, Législ. Crim. (Belgique)T.III. p.558. $n^{\circ} 57$.

869 (D) GUIHAL, Droit répressif de l'environnement, op. cit., p.184. 
le principe traditionnel selon lequel une infraction suppose non seulement un comportement, que l'on qualifie d'élément matériel, mais également une " attitude intellectuelle, un état d'esprit, une psychologie particulière, que l'on appelle l'élément intellectuel de l'infraction, qualifié par la doctrine d'élément moral (peut prêter à confusion car une infraction est normalement contraire à la morale) ou d'élément psychologique (mais cette expression relève plus de la criminologie que du droit pénal car elle sous-tend une analyse comportementale du phénomène criminel), se confond avec la notion de faute pénale, que l'on peut définir comme un manquement à un devoir. Cette faute est en effet nécessaire pour déclarer pénalement responsable l'auteur d'un comportement matériel, pour établir sa culpabilité. L'étude de l'élément intellectuel de I'infraction est donc l'étude de la faute pénale. II s'agit là d'une des questions les plus importantes du droit pénal, qui a donné lieu à de complexes constructions doctrinales. L'étude de la faute pénale, dans la mesure où elle porte sur un élément immatériel, est en effet relativement délicate. Certains auteurs ont pu dire que les très nombreuses théories élaborées par la doctrine en la matière avaient surtout contribué à obscurcir la question ${ }^{870}$. Cette longue tirade sur l'élément moral de l'infraction, nous renseigne davantage sur son importance mais aussi sur la complexité de la faute pénale.

C'est pourquoi, le législateur français a souhaité, en élaborant le nouveau code pénal, clarifier la notion de faute pénale.

Cet effort de clarification n'a toujours été pas sans mal : I'article 121-3 a en effet connu trois versions successives depuis 1992. Sa rédaction initiale, qui comportait trois alinéas, fut jugé insatisfaisante par le parlement qui, à peine deux ans après l'entrée en vigueur du nouveau code pénal, l'a modifié en adoptant la loi du 13 mai 1996 relative à la responsabilité pénale pour des faits d'imprudence ou de négligence. Cette loi réécrivait particulièrement l'article 121-3, tout en le complétant d'un nouvel alinéa. On pouvait espérer la rédaction de cet article stabilisé, pourtant quatre ans plus tard, estimant que la réforme de 1996 n'avait pas produit des effets escomptés, le législateur a de nouveau modifié cet article par la loi de 10 juillet 2000 tendant à préciser la définition 
des délits non intentionnels, et cette disposition comporte désormais jusqu'a la prochaine réforme, cinq alinéas.

Il s'ensuit que toutes les infractions criminelles ou délictuelles requièrent I'intention coupable. En matière correctionnelle, l'article 121-3 du code pénal est beaucoup plus novateur ; seules les contraventions, pour la plupart, peuvent être constituées indépendamment de l'élément moral ${ }^{871}$. En droit pénal français de l'environnement, l'exemple le plus illustratif en matière d'infraction intentionnelle, est contenu dans les dispositions de l'article 421-2 du code pénal. Ainsi, est qualifié d'acte criminel tout agissement qui consiste à " introduire dans l'atmosphère, sur le sol, dans le sous sol ou dans les eaux une substance de nature à mettre en péril la santé de l'homme ou des animaux ou le milieu naturel ». Cette infraction qualifiée de " terrorisme » écologique par certains auteurs, est un acte criminel effectué sciemment dans l'intention de troubler gravement l'ordre public ${ }^{872}$. La volonté de nuire qui caractérise cette infraction, est presque identique aux infractions africaines sur les déchets dangereux.

Pour exprimer davantage cette solution, fondée sur la prééminence de l'élément moral, née avec l'entrée en vigueur du nouveau code pénal, la cour de cassation française, se sert d'une formule rituelle « la violation en connaissance de cause d'une prescription légale ou réglementaire implique de la part de son auteur l'intention coupable exigée par l'article $121-3$, al. $1^{\text {er }}$ du code pénal ${ }^{873}$ ". Cette ritournelle n'est évidemment pas invoquée pour l'imputation des crimes ou des délits traditionnellement intentionnels comme le vol, l'escroquerie, mais seulement lorsqu'il s'agit de délits relevant de matière technique, telle que l'environnement. Elle établit pourtant une sorte de présomption ${ }^{874}$, même si

871 On peut toutefois noter que, s'agissant de la contravention de tapage nocturne réprimée par l'article R.623-2 du code pénal, la jurisprudence requiert, pour qu'elle soit établie, que le prévenu ait eu conscience du trouble causé au voisinage, v. Cass. Crim. 19 novembre 1985, Bull. Crim. №361 ; v. aussi Cass. Crim. 11 janv. 2005, Bury, pourvoi nº4-83.332, condamnation du propriétaire d'un chien, informé de la gêne occasionnée par les aboiements, qui n'a pas pris des mesures nécessaires pour y mettre fin.

872 (J.)MORAND-DEVILLIER, Droit de l'environnement, édition AUPELF-UREF ESTEM, Paris 1996, p.50.

873 Cf. Cass. Crim. 2 octobre 2007, pourvoi $n^{\circ} 07-81.194$, pour un exemple d'installation classée.

874 (D) GUIHAL, Droit répressif de l'environnement, op. cit., p.187. 
elle n'est pas irréfragable. II n'est plus concevable, par exemple, de caractériser le délit de pollution des eaux par la seule constatation d'une atteinte à la vie piscicole et d'un lien de causalité avec le fonctionnement d'une installation ; des négligences, une insuffisance de précaution, l'inobservation de prescriptions administratives doivent également être mise en évidence pour emporter condamnation ${ }^{875}$. En voici quelques exemples, où la chambre criminelle française a préféré retenir la qualification intentionnelle plutôt que celle d'imprudence ${ }^{876}$ prônée par l'article 339 de la loi du 16 décembre 1992 qui veut que les délits non intentionnels déterminés dans les textes antérieurs à 1994 soient des délits d'imprudence ou de mise en danger.

Ainsi, des délits matériels sont devenus des délits intentionnels :

- Manquement aux prescriptions de la loi du 19 juillet 1976 sur les installations classées ${ }^{877}$;

- Vente sans facture par un commerçant ${ }^{878}$;

- Violation des dispositions du code de l'urbanisme sur les plans d'occupation des sols ${ }^{879}$;

- Publicité illicite en faveur du tabac 880 ;

- Construction d'un bâtiment sans permis ${ }^{881}$;

- Infractions à la législation sur la protection des espèces animales ${ }^{882}$.

Par ailleurs, dans le domaine de la protection des espèces animales, on peut aussi constater que l'activité consciente et délibérée de l'agent est parfois déduite de sa qualité de chasseur, de garde chasse, de taxidermiste qui permet

\footnotetext{
875 (D) GUIHAL, Droit répressif de l'environnement, op. cit., p.186.

876 (J) PRADEL, Droit pénal général, op.cit., p.488.

877 Crim., 25 mai 1994, BC, n²03, 1ère espèce, 1994, comm. 237, RSC., 1995.97, obs. B. Bouloc ; Cass. Crim. 11 janv.2005, SANCY, pourvoi n ${ }^{\circ} 04-82.716$.

878 Crim., 25 mai 1994, $B C, n^{\circ} 203$, 2ère espèce,

879 Crim., 12 juillet 1994, BC, n²80; JCP 1995.II.1366, note Y. REINHARD et E. JOLY SIBUET ; RDI 1995, p.622, chr.G. ROUJOU de BOUBEE ; Rev. Sc. Crim. 1995, p.97et 343, obs. B. BOULOC; Rev. Sc. Crim. 1995, p.356 obs. JH. ROBERT ; Dr.env.1994, n²7 ,p.89.

880 Crim., 30 oct. 1995, BC, $n^{\circ} 335$.

881 Crim., 10 janvier. 1996, BC, $n^{\circ} 13$.

882 Crim., 28 juin2005, BC, n¹96, RSC., 2005.839, obs. Vernelle.
} 
de présumer à la fois une connaissance de la nature et de la réglementation la concernant, quant à l'identification des espèces ${ }^{883}$.

Sont en revanche les infractions d'imprudence, les délits de pollution des eaux réprimés par l'article $6^{\circ}-13^{\circ}$ du décret-loi du 9 janv. $1852^{884}$, devenu l'article L 218-73 du code de l'environnement par l'article L 432-2 du c. env. ${ }^{885}$ ainsi que la destruction d'un spécimen appartenant à une espèce animale protégée. ${ }^{886}$ Il est remarquable que les délits intentionnels et non intentionnels puissent coexister au sein d'un même texte d'incrimination dès lors que celuici décrit plusieurs comportements prohibés. II en va ainsi de l'article L.415-3 du code de l'environnement qui réprime à la fois la destruction de spécimens d'animaux protégés : délit d'imprudence ${ }^{887}$ et l'acquisition de tels spécimens : délit intentionnel ${ }^{888}$.

En résumé, pour la doctrine ainsi que pour la jurisprudence française, l'élément moral suppose l'expression d'une volonté et d'une intelligence manifeste dans la commission de l'acte ${ }^{889}$. Ainsi, en ce qui concerne l'élément moral, les délits nécessitent soit la démonstration d'une intention soit la démonstration d'une faute, d'imprudence, de négligence ou de mise en danger.

883 (M.J.) LITTMANN-MARTIN: Rev.Jur.Env. 1984, p.132.

884 Cass.Crim. 25 oct.1995 association des marins-pêcheurs de la prud'homie de Palavas-lesFlots, Bull.crim. $\mathrm{n}^{\circ} 322$.

885 Cass.Crim. 4 déc. 2001, Guiheneuc, pourvoi, n01.80.445; Cass.Crim. 19 oct.2004, Soc. Peugeot Citroën Poissy : Bull.crim. n²47.

886 Cass.Crim. 18 sept.1997, Failler, pourvoi $n^{\circ} 96.85 .939$ : Dr.env.1998, n60, p. 13, note P. Mistretta.

887 Cass.Crim. 18 sept.1997, pourvoi n96.85.939.

888 Cass.Crim. 28 juin 2005, pourvoi n05.82.189, précité.

889 (J) PRADEL, Droit pénal général, op.cit., p.428. Selon la doctrine, il s'agit « d'une volonté libre et d'une intelligence lucide " et selon la chambre criminelle " toute infraction suppose que son auteur ait agit avec intelligence et volonté ». Le droit pénal belge s'inscrit dans la même logique puisque, à en croire (E) GOETHALS, « il ne connait pas d'infraction matérielle », in, Le droit pénal de l'environnement belge, www.ahjucaf.org 


\section{2) La faute d'imprudence et de négligence.}

D’une manière générale, le droit pénal de l'environnement fait une place importante pour des infractions non intentionnelles dans la mesure où cette catégorie d'infractions délictuelles, constitue essentiellement les infractions courantes en matière d'atteinte à l'environnement. Certains auteurs parlent même de la " disparition des délits matériels ${ }^{890}$ " ou de leur mutation en délit d'imprudence ou de négligence. II s'agira désormais pour le poursuivant de prouver l'intention, l'imprudence ou la mise en danger délibérée. Le comportement fautif, imprudent, négligeant, caractérise l'élément moral. II reviendra donc au ministère public de rechercher à qualifier cette intention particulière, pour dire, si l'intention réside dans une négligence ou dans une imprudence.

Pour illustrer la délicatesse dont le juge devra faire preuve, reportonsnous à une jurisprudence française, digne d'intérêt. En l'espèce, une entreprise charge un convoyeur de l'acheminement d'un certain nombre de déchets de son usine jusqu'au centre de destruction. Après les avoir pris en charge, le convoyeur va sous-traiter une partie du transport. Le transporteur doit conduire les marchandises jusqu'à un terrain loué par la S.N.C.F et mettre les déchets sur des wagons de la S.N.C.F. Cette dernière, prend en charge la dernière partie du transport, jusqu'à l'usine de traitement des déchets. Une partie des déchets, environ $20 \%$ arrivent à destination avec quelques jours de retard. Aussi les employés du transporteur, en l'absence de tout réceptionniste du convoyeur, décident de décharger la marchandise à terre. Alertées, les associations de défense de l'environnement portent plainte et se constituent partie civile, de sorte que les deux sociétés de transport et leurs dirigeants respectifs sont poursuivis de chef d'élimination irrégulière de déchets nuisibles : infraction prévue et réprimée par la loi ${ }^{\circ} 75-633$ du 15 juillet 1975 relative à l'élimination des déchets et à la récupération de matériaux. II leur est reproché d'avoir abandonné, déposé ou fait déposer des déchets dans des conditions contraires

890 (J) PRADEL, Droit pénal général, op.cit., p.487. Pour cet auteur, depuis la réforme du code pénal et particulièrement l'avènement de la loi du 13 mai 1996, « il n y a plus donc de délit matériel dans le code ». v. aussi (D) GUIHAL, Droit répressif de l'environnement, op. cit., p.187. 
à la loi ; fait prévu à l'article 8 de la loi et punis de deux ans d'emprisonnement et de $500.000 \mathrm{~F}$ d'amende ou l'une de ces deux peines seulement ${ }^{891}$. La société de convoyage et son dirigeant de fait, pour obtenir la relaxe, plaident la maladie de ce dernier et le respect des procédures légales d'acheminement des déchets. Pour autant, le tribunal rejette ces prétentions et condamne la société et son dirigeant pour l'essentiel à des peines d'amende (notons que l'autre société de transport et son dirigeant seront aussi condamnés), aux motifs que la société de convoyage " était responsable du transport et de l'élimination des déchets de la S.A.C. dont elle était le seul cocontractant ; qu'il est également établi que pendant plusieurs jours, les déchets pouvant créer des nuisances ont été stockés sur un site non approprié, sans mesure de sécurité ; qu'il apparait qu'en l'absence de tout représentant de la société (de convoyage) et surtout en l'absence d'organisation pour le déchargement, les chauffeurs de la société (de transport) ont déchargé et stocké directement sur le sol les produits toxiques ; " attendu que ces négligences ne sauraient être excusées par la maladie du dirigeant de fait de la société à qui il appartenait d'organiser sérieusement le réacheminement des fûts (...) ; attendu en définitive qu'en l'absence de date précise pour l'acheminement des déchets (...) sans autorisation, constituent autant d'éléments caractérisant la gravité des négligences commises par la société (...) et son dirigeant de fait ${ }^{892}$ ».

Ainsi, le tribunal, en caractérisant " la négligence " du dirigeant, confirme la mutation de l'élément moral des délits en matière d'environnement en élément de négligence ou d'imprudence. Ainsi, « la volonté du législateur d'exiger une faute intentionnelle ${ }^{893}$ » est mue en faute non intentionnelle.

Dans le même ordre d'idée, il a été condamné pour infractions aux articles 3 et 32 de la loi du 10 juillet 1976, le propriétaire d'un élevage d'animaux en liberté, qui avait détruit d'un coup de fusil une buse, venant de capturer un lapin. Le prévenu « ne saurait imputer qu'à sa seule négligence (choix de l'élevage en liberté), le comportement de l'oiseau qui a suivi son instinct et ne

891 Actuellement articles L 501-1 et suivants et L 541-46 et suivants du c. env.

892 (P) BATTISTINI, Environnement : des délits matériels aux délits de négligence, article, JAC $n^{\circ} 11$ févr.2001; tribunal correctionnel de Paris, 31ème ch. 7septembre 2000.

893 Cass. Crim. 12 janv. 1994, SRRHU, 92-86-511, Dr. pénal 1994, n¹15, obs. (J.H.) Robert. 
peut invoquer la légitime défense de l'élevage ${ }^{894} »$. Cette jurisprudence, fondée sur la théorie de négligence, n'a pas manqué pour autant de susciter des critiques, notamment en ce qui concerne le risque de transformer les crimes et délits contre l'environnement en infractions purement matérielles ${ }^{895}$.

En droit des déchets, la législation et la doctrine concordent pour définir un déchet, comme « tout bien meuble abandonné ou que son détenteur destine à l'abandon ${ }^{896}$ ").

Se référant au cas d'espèce, relatif à l'abandon des déchets (comme se fut le cas du convoyeur de déchets de la S.A.C), les auteurs DINIES et BASECQZ ${ }^{897}$, s'inspirant de la théorie de Robert LEGROS ${ }^{898}$, développent une clarification sémantique sur l'infraction relative aux déchets. Dans leur analyse, ces auteurs se préoccupent d'abord du mot " abandon " de déchet utilisé par le législateur. Doit-on y voir l'expression d'un acte volontaire de rejet ou plutôt celle d'un oubli dépourvu d'intentionnalité ? Le Conseil d'Etat belge, lorsqu'il se prononça sur le projet de décret, sembla pencher plutôt vers le sens " intentionnel » du mot. II rapprocha en effet, la notion d'abandon de déchets, de celle d'abandon en droit civil. Dans ce dernier cas, il s'agit d'un acte juridique par lequel le titulaire d'un droit réel, en particulier le propriétaire d'un bien, se débarrasse intentionnellement de ses droits sur ce bien car il a la volonté de s'en défaire. II s'en dessaisit et en délaisse intentionnellement la détention matérielle. Ensuite, ces auteurs précisent qu'il n'y a pas d'abandon dès lors que celui qui détient un objet, trouve utile de le laisser à l'endroit où il le met. L'abandon n'apparait que s'il a l'intention, se faisant de s'en débarrasser. Ces auteurs conclurent donc que

894 Paris 10 mai 1989 : Juris-Data $n^{\circ} 024854$.

895 Il est fréquent en effet, de considérer qu'en matière d'environnement que la simple violation matérielle des prescriptions légales, applicables aux cas d'espèce suffirait à qualifier l'infraction comme le dénonce C. HENNAU-HUBLET, dans son rapport au colloque préparatoire du XVème congrès international de droit pénal, « les crimes contre l'environnement ».RDCP. 1983, p.295. Voyez par exemple en matière des eaux de surface contre la pollution : B. JADOT, note sous Corr. Arlon. 2 fév.1987, Aménag. 1988/3.p.88.

896 En droit français, art. L541-1, $4^{\circ}$ C. env. ; art.47 $\$ 1$ et 2 du décret wallon du 5 juillet 1985 relatif à la gestion et à la prévention des déchets ; art.66 de la loi cadre béninoise sur l'environnement précité

897 Droit de l'environnement et droit économique et social : réflexion sur l'élément moral dans les lois et règlements particuliers, op. cit. p.474-508.

898 L'élément moral dans les infractions, Liège. Desoer, 1952. 
" le législateur a entendu réprimer l'abandon des déchets à condition toutefois qu'il s'agisse d'un abandon intentionnel ».

Au regard de cet analyse à base sémantique, on peut en déduire que dans l'infraction environnementale, même si le législateur ne l'énonce pas expressément, l'on peut entrevoir un dol général ${ }^{899}$. Il reviendra dans ce cas au juge de cerner la volonté du législateur en remontant par exemple aux travaux préparatoires mais aussi en recourant à un vocabulaire juridique approprié ainsi qu'aux principes généraux qui fondent les lois.

En définitive, à la suite d'une telle analyse de jurisprudences, l'on constate que les deux approches théoriques de solutions à savoir celle fondée sur des infractions intentionnelles et celle fondée sur les infractions d'imprudences, apparaissent concurrentielles, avec une tendance favorable aux infractions intentionnelles. Ainsi, si dans la pratique, il n'est pas toujours aisé de prouver I'intention coupable, la jurisprudence en justifie la raison d'être ; d'autant plus que la formule rituelle de la chambre criminelle française ${ }^{900}$, (violation en connaissance de cause d'une prescription légale ou réglementaire), apparait comme « le seul moyen de faire respecter les dispositions techniques, comme celles relevant du droit de l'environnement ${ }^{901}$.

Par ailleurs, retenons que les crimes sont toujours intentionnels, les délits le sont en principe saufs dispositions contraires prévoyant une faute d'imprudence ou de mise en danger et, à l'inverse, les contraventions ne supposent en principe ni intention, ni mise en danger délibéré, ni même une

899 Pour(F) DESPORTES et (F) Le GUNEHEC, Droit pénal Général, op.,cit.,p.416, C'est la volonté de commettre un acte que l'on sait interdit. C'est l'intention de violer la loi pénale. Le dol général est donc confondu à la faute pénale. Il s'oppose au dol spécial qui se préoccupe de la détermination expresse de l'élément moral constitutif spécifique à certaines infractions. Par délit non intentionnel, il faut entendre aussi que l'auteur n'a pas voulu le préjudice, mais il n'en a accepté l'éventualité en transgressant la règle de manière consciente et volontaire. (Code pénal commenté, Gabriel ROUJOU de BOUBEE, Bernard BOULOC, Jacques FRANCILLON et Yves MAYAUD, Dalloz 1996, p.26. cité par Cyril CLEMENT, Christian HUGLO, Le droit des déchets hospitaliers, ed. les études hospitalières, p.155, 1999.

900 Cf. Cass. Crim. 2 octobre 2007, pourvoi $n^{\circ} 07-81.194$, pour un exemple d'installation classée, précité, note 94, p.24. V. aussi Cass.Crim. 25 mai 1994, Dt pénal 1994, p.237, obs. Robert ; ou encore Cass.Crim., 19 dec.1994, Bull.crim. $n^{\circ} 420$.

901 (J) PRADEL, Droit pénal général, op.cit., p.489 
imprudence, sauf disposition contraire ${ }^{902}$. II s'ensuit que le législateur n'est jamais obligé de préciser la nature de l'élément intellectuel d'un crime car il s'agit toujours d'une faute intentionnelle. II n'est pas obligé de préciser celui d'un délit, qui est normalement une infraction intentionnelle, sauf lorsqu'il souhaite de façon exceptionnelle réprimer, un délit d'imprudence ou de négligence. En ce qui concerne les contraventions, le législateur doit, s'il souhaite leur conférer un caractère intentionnel ou exiger la commission d'une faute d'imprudence ou de mise en danger, l'indiquer ${ }^{903}$.

Les tribunaux devraient se poser un certain nombre de questions bien plus grandes aujourd'hui, avant de déclarer un pollueur responsable. Certains pollueurs seraient punis pour avoir sciemment violé le règlement, mais sans vouloir le résultat, d'autres moins, pour n'avoir pas pris toutes les précautions nécessaires à l'observation des règlements et avoir causé une pollution. L'on devrait par exemple pour mieux respecter le droit pénal de l'environnement tenir compte au moment d'infliger la sanction pénale, d'une gradation logique, un comportement intentionnel, s'avérant sans aucun doute plus grave qu'une simple imprudence ou une négligence.

Mais toutes ces réformes du droit pénal ne peuvent s'opérer que dans la logique de clarification de certains concepts.

\section{TITRE II : LES PERSPECTIVES POUR UN DROIT PENAL PLUS EFFICACE}

Dans les chapitres précédents, nous avions mis particulièrement l'accent, dans la recherche de solutions aux lacunes du droit pénal de l'environnement au Bénin, sur l'internalisation et le développement d'un certain nombres d'outils du droit pénal moderne de l'environnement en vue de renforcer les capacités des acteurs du secteur. Au delà de cette approche, et dans une perspective globalisante de la réponse environnementale, d'autres approches de solutions nous inspirent réflexion. II s'agira d'abord pour nous dans ce titre, d'explorer

902 (F) DESPORTES et (F) Le GUNEHEC, Droit pénal Général, op.,cit.,p.410

903 Cf. art. R605 CP français 
la possibilité pour le législateur béninois de rendre effective la responsabilité pénale de la personne morale en droit interne afin de renforcer l'arsenal répressif déjà «essoufflé» par diverses difficultés (Chapitre VII). Ensuite, le monde étant devenu un village planétaire et la responsabilité en matière d'environnement l'affaire de tous, même si elle est différenciée, il conviendrait tout en pensant locale d'agir globalement. C'est pourquoi, à notre avis, une approche répressive visant à mettre le droit pénal international au service du droit pénal interne est envisageable notamment en ce qui concerne les infractions environnementales transfrontières, lesquelles nécessitent pour leur règlement un mécanisme de procédure qui respecte les règles internationales en la matière. (Chapitre VIII). 


\section{CHAPITRE VII : L'EFFECTIVITE DE LA RESPONSABILITE PENALE DE LA PERSONNE MORALE EN DROIT INTERNE BENINOIS.}

Parmi les difficultés du droit pénal de l'environnement, le problème de l'irresponsabilité pénale de la personne morale mérite une attention toute particulière en ce sens que son application effective bousculerait le fondement même du droit pénal mais aussi probablement la croissance économique. C'est ce qui explique que pendant tout le "XIX ème siècle en France, l'idée d'une responsabilité pénale des regroupements était rejetée ${ }^{904}$ " comme le dit l'adage, "Societas delinquere non potest ». Le code pénal napoléonien était la référence, or, ce code ne l'avait pas prévu d'où cette possibilité était difficilement envisageable. De plus, les auteurs de l'époque, dans leur majorité n'étaient pas favorables à cette responsabilité. Ils estiment d'abord que la personne morale, le groupement ou l'entreprise, est une fiction car il est dénué de toute volonté personnelle, attributs des seuls individus et condition indispensable de la responsabilité pénale. Ensuite, le groupement n'accède à la vie juridique qu'en vue d'un objet social qui ne saurait évidemment être la commission d'infraction (principe de spécialité). Enfin, il existe une incompatibilité entre peine et entreprise ; l'idée de peine ne pouvant correspondre qu'à des individus ${ }^{905}$. En d'autres termes, les systèmes pénaux des pays favorables à cette responsabilité pénale, doivent déroger à certains principes cardinaux du droit pénal classique notamment : le principe de la culpabilité individuelle ou de l'imputabilité de l'acte infractionnel ; le principe d'égalité des personnes devant la loi. Une autre question préoccupante serait comment appréhender l'élément moral de l'infraction quant on sait qu'il n'est attaché qu'à l'individu. Tous ces arguments majeurs militaient en faveur de l'irresponsabilité de la personne morale tant privé que publique. En effet, selon la doctrine belge, les objections élevées contre l'introduction de

904 PRADEL(Jean), Manuel de droit pénal Général, Dalloz 16ème éd. Paris 2006, p.492.

905 PRADEL(Jean), Manuel de droit pénal Général, op.,cit.,p.492. 
cette responsabilité pénale en droit interne sont multiformes ${ }^{906}$. Mais depuis le XXème siècle, avec le développement du droit pénal des affaires, du commerce, de l'industrialisation, l'entreprise apparait comme " l'instrument " par lequel agissent certains individus. Dès lors, la réflexion sur la responsabilité pénale de la personne morale refait surface et une réplique a été apportée aux arguments défavorables précédemment évoqués ${ }^{907}$.

906 Cf. VAN REMOORTERE (Francis), La question de la responsabilité pénale des personnes morales en droit de l'environnement en Belgique, Chronique, Rev. de dr. pén. pp.6164. Cité par M. FAURE, dans son cours de droit pénal de l'environnement, DEA, Droit et politique de l'environnement, FDD, 1999, Lomé, Togo. II dénombre une quinzaine d'objections. Il s'agit de :

Les personnes morales sont des fictions, on ne peut les assimiler aux êtres humains au point de vue pénale car il y a absence de volonté criminelle propre ;

Le principe de la personnalité des personnes suppose une responsabilité pénale individuelle et fait obstacle à toute forme de responsabilité pénale du fait d'autrui ;

Les fonctions traditionnelles des peines (expiation, amendement, intimidation, réinsertion sociale), s'avèrent inopérantes à l'égard des personnes morales ;

Il y a contradiction avec le principe de la culpabilité pénale, qui exige un élément moral pour qu'il y ait infraction ;

La spécialité pour laquelle la personne morale a été créée exclut la réalisation d'infractions ; Il existe un risque d'injustice envers les bénéficiaires de fondations si les dirigeants commettent des malversations ;

Il n'y aurait risque d'injustice si on condamne la personne morales alors que celle-ci aurait exclu les personnes physiques qui ont commis l'infraction ;

Il existe un risque de sanctionner trop sévèrement les entreprises, avec les conséquences pour les classes laborieuses et les petits épargnants victimes innocentes ;

II y aurait discrimination entre personnes morales et groupements dépourvue de la personnalité juridique ;

II y a risque d'injustice lorsqu'on punit une société alors que le droit des capitaux l'y emporte sur le droit des personnes;

Le cumul ou le non cumul des peines entre personnes physique et personne morale, place devant un choix difficile ; si on poursuit cyniquement la société, on fait échapper les vrais coupables, dans l'autre hypothèse on aboutit au double emploi ;

La poursuite répressive de personnes morales suscitent des difficultés procédurales ;

Les alternatives classiques telles que le système de la responsabilité civiles des amendes sont suffisantes ;

Certaines peines étant par nature inapplicables aux personnes morale, on ne peut concevoir de leur appliquer une échelle incomplète de peines ;

L'application de la responsabilité pénale des entités de droit public est délicate, et elle paraît difficilement conciliable avec les principes de droit public. 
Aujourd'hui, en dépit de cette position plus ou moins objective de rejet de cette responsabilité pénale par certains auteurs, il y a revirement de la situation, avec l'adoption par plusieurs pays ${ }^{908}$ de la responsabilité de la personne morale et son introduction dans le droit interne. La prise de conscience des législateurs de ces pays à l'égard des problèmes environnementaux qui gagnent de l'ampleur dans le monde moderne, par l'accroissement des activités des personnes morales serait certainement à l'origine de ce revirement de position

La notion de responsabilité pénale de la personne morale, est une théorie très utilisée dans la littérature du droit de l'environnement où doctrines et jurisprudences se croisent abondamment et rivalisent d'ardeur sur la tendance favorable ou non favorable sur cette théorie. Notre objectif n'est pas d'en ajouter à la polémique ou de nous caler dans une doctrine ou dans une autre, mais plutôt d'amorcer une réflexion en procédant à une analyse de la problématique. Ainsi, on pourra d'abord, apprécier un aperçu de la portée théorique et pratique de cette responsabilité pénale des personnes morales telle que conçue et appliquée dans certains pays comme la France et la Belgique (SECTION I) et, s'inspirant surtout des expériences de ces pays, susciter quelques pistes de réflexion quant à l'effectivité du droit de la responsabilité pénale de la personne morale en droit interne au Bénin (SECTION II).

\section{SECTION I : UN BREF APERCU DE LA PORTEE DE LA RESPONSABILITE PENALE APPLICABLE A LA PERSONNE MORALE}

A la suite d'une réflexion approfondie, et vu l'ampleur de plus en plus croissante des activités des personnes morales, surtout dans le domaine environnemental, certains pays occidentaux ont perçu la nécessité d'opérer une réforme de leur droit pénal en introduisant la responsabilité pénale des personnes morales. Pour en arriver à cette conclusion, ils se sont convaincus de la non pertinence des arguments avancés par les auteurs n'épousant pas cette position et ont développé les leurs.

908 A commencer par les pays de Common Law (USA, Grande Bretagne, Canada, ...), la France, la Belgique, le Luxemburg, le Pays-Bas, l'Allemagne,... 
D'abord, au sujet du premier argument tiré de l'idée de fiction, les auteurs favorables à la prise en compte de la responsabilité de la personne morale, répondent par celui de réalité du groupement dans la mesure où dans la pratique, la délinquance des groupements est une réalité criminologique, même si en réalité toute infraction à pour origine l'acte individuel.

Ensuite, à l'argument tiré du principe de spécialité, on oppose un argument de bon sens : même si la commission d'infractions n'entre pas statutairement dans l'objet de l'entreprise, il se trouve cependant qu'en pratique, certaines entreprises ont une activité différente de celle pour laquelle ses membres l'avaient créé. Cette activité peut être à l'origine de diverses infractions. Par exemple, telle entreprise avait été créée pour fabriquer du papier, or en réalité, elle entraine en outre la pollution des cours d'eau voisins. II n'y a alors aucune raison de ne pas retenir la responsabilité de cette entreprise. ${ }^{909}$

Enfin, en ce qui concerne la notion de peine applicable à l'entreprise, cet argument présente trois aspects qu'il importe de distinguer. D'abord, pour ce qui est de la nature de la peine, il n'y a aucune difficulté, car s'il tombe sous le sens que les sanctions privatives de liberté sont inapplicables, d'autres comme l'amende, la confiscation, la fermeture d'établissement, l'interdiction d'exercer telle activité ou la dissolution (équivalent de la peine de mort) sont parfaitement applicables. On a prétendu ensuite que les buts de la peine cadrent mal avec la responsabilité des personnes morales, la fonction d'amendement, si essentielle n'ayant guère de sens ici. A cela on peut répondre que la peine a aussi une

909 Effet, en 1994, les personnes morales n'étaient responsables pénalement que dans les cas prévus par la loi ou les règlements, c'est-à-dire que dans le cas où le texte d'incrimination prévoyait expressément la responsabilité de la personne morale (principe de spécialité). Ces textes étaient très nombreux et peu cohérents. Mais avec la loi n²004-204 du 9 mars, portant adaptation de la justice aux évolutions de la criminalité dite " Perben II ", la législation française à connue une évolution qualitative, ce qui a permis l'abandon du principe de la spécialité au profit du " principe de généralité ». Ainsi, à compter du 31 décembre 2005, les personnes morales sont responsables de toutes les infractions puisque les mots " et dans les cas prévus par la loi et les règlements " sont retranchés de l'article 121-2. De sorte que les articles 124 et 125 de la loi n²009-526 du 12 mai 2009 sur la simplification et la clarification du droit et l'allègement des procédures, a pu tirer les conséquences de l'adoption du principe de généralité et supprime les normes éparses prévoyant un cas particulier de responsabilité des personnes morales. Cf. à cet effet, www. legirance.gouv.fr 
fonction d'intimidation et de prévention, parfaitement compatible avec la nature particulière de l'entreprise. On a avancé enfin que la peine, appliquée à une personne morale, atteindrait aussi bien les innocents que les coupables. C'est oublier que l'on peut imaginer des procédés pour désintéresser les membres de la société dignes de protection, tels les porteurs de bonne foi ou les salariés, tout en frappant " l'instrument » dangereux. ${ }^{910}$

En outre, il est évident que la personne morale est plus solvable que les individus. Parfois, c'est elle qui paye l'amende infligée à son personnel. Autant alors, aligner le fait sur le droit. Aussi, peut- il s'avérer délicat de poursuivre l'individu responsable notamment faute de pouvoir le déterminer avec certitude. Dès lors, vis-a-vis de l'opinion publique, un blâme de la personne morale peut être nécessaire. Il est donc raisonnable de la poursuivre puisque le principe de la responsabilité pénale des groupements est maintenant admis par presque toute la doctrine ${ }^{911}$.

Par ailleurs, l'imputabilité matérielle est la règle en droit pénal. Le fait punissable est normalement attribué ou imputé à la personne qui a matériellement commis le fait. Il en va de même pour la personne morale. Pour ce faire, les pays ayant adopté cette responsabilité ont fondé leur argument aussi sur la théorie générale d'imputabilité. Ainsi, en Angleterre, on parle de la théorie de l'identification, "idenfication theory ", en France, c'est la théorie de la " responsabilité par ricochet », aux Pays Bas, c'est la théorie de la " fonctionnalité ${ }^{912}$, la responsabilité fonctionnelle.

En France, c'est la refonte du code pénal et son entrée en vigueur en mars 1994, comme nous l'avions signifié plus haut, qui a marqué véritablement la consécration de la responsabilité pénale des personnes morales avec les dispositions des articles 121-2 et 121-3. En Belgique, c'est l'article 5 du code pénal et la loi du 4 mai 1999 qui ont institué cette responsabilité ${ }^{913}$. Comme on le constate, si l'introduction de cette responsabilité est très récente, c'est qu'elle

910 Cf. PRADEL(Jean), Manuel de droit pénal Général, op.,cit.,pp.493 et S.

911 Idem p.494

912 GEEROMS (Sofie), La responsabilité pénale de la personne morale : une étude comparative, RIDC, 3/1996, pp.540-545

913 Cf. moniteur belge du 22 juin 1999 et entré en vigueur le 2 juillet 1999. 
a été l'objet de controverses diverses. II n'a donc pas été facile d'établir cette responsabilité. C'est comme le dirait un auteur, un véritable " steeple-chase » juridique que doit se livrer celui qui veut engager une action tendant à tenir pour responsable la personne morale qui par ses activités a porté atteinte à l'environnement. Mais il n'en demeure pas moins vrai que de nos jours, établir une telle responsabilité est aussi pertinente pour la sauvegarde de l'environnement. Ainsi, pour appréhender cette responsabilité pénale environnementale, il conviendrait d'abord d'apprécier son contenu en ce qui concerne les personnes susceptibles d'être poursuivi (§l) avant d'analyser ensuite l'efficacité des peines applicables (§II). Notre analyse sera influencée surtout par les théories française et belge.

\section{§I : Le contenu de la responsabilité pénale de la personne morale}

On peut entendre par personne morale, un « groupement de personnes physiques qui dispose du point de vue juridique d'une certaine autonomie qui en fait un sujet de droit et lui permet d'être titulaire de droits subjectifs et d'obligations d'accomplir certains actes juridiques et d'agir en justice. ${ }^{914}$ ». Dans cette définition, on peut relever la prépondérance de l'idée de la personnalité juridique ${ }^{915}$ comme critère de qualification de la personne morale. Cette idée de personnalité juridique s'applique aussi bien à la personne morale de droit privé qu'à la personne morale de droit public.

914 P. DELATTE, La question de la responsabilité pénale des personnes morales en droit belge, Rev.dr. pén., 1980,163, cité par Sofie GEEROMS, La responsabilité pénale de la personne morale : une étude comparative, RIDC, 3/1996, p.555.

915 Réaffirmé par le Conseil de l’Europe «(...) les recommandations s'appliquent aux entreprises dotées de la personnalité juridique ». Mais cette position ne fait pas l'unanimité puisque certaines législations comme celles des Pays-Bas et de l'Allemagne, élargissent plutôt le champ d'application aux entreprises de faits ou dépourvues de cette personnalité. $V$. Sofie GEEROMS, La responsabilité pénale de la personne morale : une étude comparative, op.,cit., p.555 


\section{A) Les personnes morales de droit privé.}

Toutes les sociétés de droit privés sont concernées, qu'elles soient instituées par une loi ou qu'elles procèdent d'un contrat, qu'elles poursuivent ou non un but lucratif ${ }^{916}$. Mais avec cette nuance qu'il s'agit en particulier des entreprises ou sociétés privées dotées de personnalité juridique, donc capables d'ester en justice ou de répondre de ses actes devant une juridiction. Par conséquent sont exclus de ce champ d'action les sociétés de fait ${ }^{917}$ ou les entreprises qui ne sont pas régulièrement enregistrées. Ensuite, il faut que la personne morale ait agi " pour le compte » de l'entreprise. II est évident que l'être moral n'est pas engagé si le chef d'entreprise ou son représentant légal a agi dans " son seul intérêt " ou dans "l'intérêt d'un tiers » c'est-à-dire en dehors de la personne morale ou encore s'il a agi contre l'intérêt de la personne morale ${ }^{918}$.

A contrario, agir pour le compte de la personne morale, c'est agir à son profit, dans son intérêt. Il peut s'agir d'un bénéfice matériel ou moral, actuel ou éventuel, direct ou indirect. En outre c'est agir aussi simplement au nom de celle-ci, sans rechercher le moindre bénéfice, même moral ou éventuel. D’après la doctrine française, le terme profit doit être considéré dans son sens large. II comporte non seulement le profit réalisé ou recherché mais aussi le profit moral. II peut comprendre des activités ayant pour objet d'assurer l'organisation, le fonctionnement ou les objectifs de la personne morale même si elle ne tire aucun profit au sens strict. Le Conseil de l'Europe a confirmé cette position dans une recommandation en affirmant que " la personne morale ne doit pas nécessairement tirer avantage de la situation donnée. Par exemple un directeur qui néglige de s'assurer que les ouvriers portent bien un casque sur les chantiers alors même que l'entreprise en a acquis un stock suffisant. Dans

916 La personne morale comprend donc : les sociétés ou entreprises commerciales, les groupements d'intérêts économiques, les associations, les syndicats, les fondations, etc....

917 La société créée de fait " est la situation dans laquelle deux ou plusieurs personnes se sont comportées en fait comme des associés, sans avoir exprimé la volonté de former une société ", Ripert et Roblet par M. Germain, Traité de droit commercial, LGDJ.,18ème éd. 2002, 1056.

918 PRADEL(Jean), Manuel de droit pénal Général,op.,cit.,p.506. 
ce cas, la survenance d'un accident corporel peut entrainer la poursuite de la personne morale ${ }^{919}$. Une association de chasse a été concurremment avec son président, coupable d'homicide involontaire, dès lors que le tir mortel en direction de l'un des chasseurs avait été permis par l'organisation d'une battue dans des conditions non conformes aux consignes diffusées par l'office nationale de la chasse ${ }^{920}$. Il s'agit là de l'application du principe de cumul de responsabilité.

Au Bénin, se sera aussi le cas lorsque par exemple une entreprise comme la Pharmaquick (usine chimique de fabrication de médicaments, installée à Cotonou) ou comme la SONICOG (usine de fabrication de savon) à défaut d'une station d'épuration, décide de déverser des déchets liquides riches en métaux lourds (mercure, cardium, plomb) dans la lagune de Cotonou ou directement dans la mer, sa responsabilité pénale au regard de la loi-cadre sur l'environnement peut être établie. Tous ces exemples montrent bien que les infractions qui ont été commises l'ont été pour le compte des entreprises concernées. Des exemples sont légion où la responsabilité pénale de l'entreprise peut être engagée avec ou sans la responsabilité de la personne physique. II en est ainsi des personnes ayant reçu délégation de pouvoirs qu'elle soit personne morale de droit privé ou personne morale de droit public ${ }^{921}$.

\section{B) Les personnes morales de droit public}

Généralement, la responsabilité pénale des personnes morales est orientée vers les personnes morales de droit privé. Mais, vue le développement de plus en plus croissant des personnes de droit public liées au développement des activités économiques, on peut s'interroger sur l'opportunité de poursuivre aussi une personne morale de droit public ${ }^{922}$. Ainsi, dans les pays précités cette responsabilité est effective.

919 Cass.crim., 8 mars 2005, pourvoi n 04-86.208

920 Cass.crim., 8 mars 2005, pourvoi $n^{\circ}$ 04-86.208.

921 Chambre crim. française 9 nov.1999, pourvoi n D 98-81.746; chambre. crim. française, 14 déc.1999, pourvoi, $n^{\circ}$ Q 99-80.104

922 Il s'agit de l'Etat, des collectivités territoriales (Département, Région, Commune) et leurs groupements, des établissements publics, des groupements d'intérêt public, ... 
En droit français, les personnes privées comme les personnes publiques peuvent commettre des infractions, et être poursuivies pénalement devant les tribunaux. Cette responsabilité est organisée suivant les dispositions de l'article 121-2 du code pénal français dont le régime se décline en trois alinéas. D'abord l'alinéa1 ${ }^{\text {er }}$ qui forme le pilier de cet article dispose que « les personnes morales à l'exclusion de l'Etat, sont responsables pénalement ${ }^{923}$ (...), des infractions commises pour leur compte, par leurs organes ou représentants ». Ensuite le deuxième ajoute, dans cette même logique de prérogatives de puissance publique, une restriction en faveur des collectivités territoriales à savoir que « toutefois les collectivités territoriales et leurs groupements ne sont responsables pénalement que des infractions commises dans l'exercice d'activités susceptibles de faire l'objet de conventions de délégation de service public ». Enfin le troisième apporte la précision suivante que « la responsabilité pénale des personnes morales n'exclut pas celle des personnes physiques auteurs ou complices des mêmes faits, sous réserve des dispositions du quatrième alinéa de l'article 121-3 ".

De ce texte, il ressort qu'outre les personnes morales de droit privé, les personnes morales de droit public, telles les sociétés ou entreprises d'Etat (sociétés dont les capitaux relèvent majoritairement de l'Etat), à l'exception de I'Etat lui-même sont aussi pénalement responsables ${ }^{924}$. Mais aussi, en application aux collectivités locales (par exemple la Commune), cette règle connait un tempérament favorable qui fait que ces collectivités territoriales décentralisés ne peuvent être poursuivis qu'à raison d'infractions commises dans l'exercice d'activités susceptibles de faire l'objet de délégation de service public. Or la délégation, précisément la délégation de compétence, à en croire le lexique des termes juridiques, est un acte par lequel une autorité administrative décide de se dessaisir dans les limites légales d'un ou plusieurs de ses pouvoirs en faveur d'un autre agent qui les exercera à sa place. Pour GUIHAL, la délégation qui peut

923 Contrairement au droit français, en droit belge, l'exclusion des personnes morales de droit public est beaucoup plus entendue en dehors de l'Etat elle concerne les régions, les Communautés, les Provinces, l'Agglomération bruxelloise et les Communes. (Art.5. du code pénal belge). Naturellement, cette exclusion des personnes morales de droit public qui vaut immunité a été l'objet de controverses doctrinales et jurisprudentielles.

924 Crim. France, 9 nov.1999, pour une société d'économie-mixte concessionnaire de l'exploitation d'un domaine skiable; crim.18 juin 2000 pour la CNCF. 
revêtir plusieurs formes (affermage, concession, gérance...), est un contrat par lequel une personne publique confie à un tiers l'exécution même du service public, la rémunération du co-contractant étant substantiellement assurée par les résultats de l'exploitation ${ }^{925}$. En termes d'activités délégables on peut citer par exemples les transports en communs, le ramassage d'ordures ménagères, la distribution d'eau, la collecte et le traitement des eaux usées, les infrastructures portuaires ou aéroportuaires, les parcs de stationnements ${ }^{926}$. La délégation peut aussi consister à confier des pouvoirs à une autorité inférieure (Adjoint au maire ou fonctionnaire de la Mairie). C'est ainsi qu'un Adjoint au Maire titulaire d'une délégation pour les fêtes et les cérémonies, a été déclaré coupable de tapage nocturne à l'occasion de l'organisation d'une fête dont il surveillait les émissions acoustiques à l'aide d'un appareil appropriég27.

L'application effective de ce texte, appelle la réunion de deux conditions à savoir que l'infraction doit être commise par " les organes ou représentants » de la personne morale et " pour le compte » de cette dernière.

\section{1) Les organes ou représentants d'une personne morale}

Le texte de l'article 121-2 du code pénal français vise expressément et limitativement les " organes " ou " représentants», les deux termes pouvant d'ailleurs se confondre, notamment les organes de gestion sont aussi des organes de représentants. Cette terminologie marque la reconnaissance de la " théorie de la responsabilité par ricochet » ou responsabilité d'emprunt. Il s'agit bien de l'organe de gestion ou de l'organe délibératif collégial ${ }^{928}$. Elle « recouvre toutes les personnes qui, au sein de la personne morale, individuellement ou

925 GUIHAL (D), Le droit répressif de l'environnement, op.,cit.,p.212.

926 Dans un arrêt de 3 avril 2002, ch. Crim. a définit les activités délégables : " activités susceptibles de faire l'objet d'une concession de délégation de service public. Toute activité ayant pour objet la gestion d'un tel service, lorsque, au regard de la nature de celui-ci et en l'absence de dispositions légales ou réglementaires contraires, elle peut être confiée par la collectivité territoriale à un délégataire public ou privé rémunéré pour une part substantielle en fonction des résultats de l'exploitation ».

927 Cass. Crim. 4 septembre 2007, Bull. Crim. n¹93.

928 LEROY (J), Droit pénal général, LGDJ, 2003, p.288. 
collectivement, tiennent de la loi le pouvoir de gérer celle-ci et de l'engager à l'égard des tiers $1{ }^{929}$. Sont donc concernés les assemblées délibérantes que les dirigeants (dans le cas du Bénin, c'est le Maire qui engage la Commune). Ainsi, pour imputer une infraction à une personne morale, il est nécessaire que les juges établissent en quoi les organes ou représentants ont commis une faute pénale. Autrement dit, il faut caractériser la "volonté infractionnelle " ou les négligences et les manquements aux obligations de sécurité en la personne de ses organes ou représentants. Plus précisément, s'agissant des infractions intentionnelles, la personne morale étant dépourvue de conscience, il ne peut y avoir responsabilité pénale environnementale que si l'organe ou le représentant, incarné par une personne physique, a eu conscience de commettre un délit ${ }^{930}$. Ainsi, la personne morale, qui ne saurait accomplir les actes matériels qui consomment l'infraction, ni nourrir d'intention délictueuse, emprunte les éléments de sa culpabilité aux personnes physiques habilités à exprimer sa volonté. Cette position est confirmée par la chambre criminelle française, "la responsabilité d'une personne morale ne peut être engagée que par le truchement d'une personne physique à l'encontre de laquelle les éléments constitutifs de l'infraction doivent être caractérisés ${ }^{931}$. Les personnes physiques qui engagent la responsabilité de la personne morale sont donc les représentants légaux, les organes exécutifs et délibérants désignés par la loi ou les statuts ainsi que les mandataires judiciaires ${ }^{932}$ (administrateurs provisoires, administrateurs de l'entreprise en redressement judiciaire, liquidateur, gérant, PDG, directeurs généraux, etc..). En condamnant l'entreprise, la personne physique reconnue coupable peut être aussi sanctionnée, c'est le principe de cumul de responsabilité ou de sanction.

Mais, la critique au sujet de ce modèle est que la personne morale, si elle le désir, peut s'organiser structurellement pour éviter toute responsabilité. Elle

929 DESPORTES (F), La responsabilité pénale des personnes morales en droit français, CJEG 1996, p.93.

930 Crim.7 juil.1998, Bull. Crim., n²16, cite par BOULOC (B), MATSOPOULOU (H), in, Droit pénal général et procédure pénale, Sirey, 15ème ed.2004, p.127.

931 Cass. Crim.4 déc.2001, Bull. Crim., pourvoi n01-80.445, en matière de pollution de cour d'eau.

932 GEEROMS (Sofie), La responsabilité pénale de la personne morale : une étude comparative, RIDC, 3/1996, p.546. 
peut faire en sorte que la plupart des décisions soient prises par des personnes qui ne sont ni des organes ni des représentants ${ }^{933}$. C'est pourquoi, contrairement à la position française, en droit néerlandais la responsabilité pénale d'une personne morale peut être engagée par un simple employé, bien sûr, à condition que la personne morale ait un pouvoir d'autorité et d'acceptation ${ }^{934}$.

Quant aux infractions d'imprudence ou de négligence, il suffira d'établir qu'il y a eu manquement de la personne physique, organe ou représentant, au respect de telle ou telle disposition législative ou réglementaire, voire commission d'une faute simple ou d'une faute caractérisée ou délibérée $e^{935}$.

\section{2) La commission de l'infraction « pour le compte » de la personne morale.}

Comment alors comprendre l'expression " pour le compte " ? Au regard de la doctrine française, agir pour le compte de la personne morale, c'est agir à son profit, dans son intérêt. Il peut s'agir pour l'être moral, comme nous l'avions dit, d'un bénéfice matériel ou moral, actuel ou éventuel, direct ou indirect. C'est le cas du dirigeant qui déverse irrégulièrement par le biais d'un collaborateur des débris de ses activités industrielles dans le marécage voisin. La doctrine s'accorde pour considérer qu'il suffit que l'infraction ait été commise par la personne physique à l'occasion d'" activités destinées à assurer l'organisation et le fonctionnement " de la personne morale et qu'elle ne manifeste pas la poursuite de fins purement personnelles ${ }^{936}$. On parle même de responsabilité pénale « par représentation ».

A l'analyse, ce modèle français de la théorie de la responsabilité de la personne morale peut faire objet de critiques diverses. Elle est qualifiée de théorie de la responsabilité de la personne morale par ricochet ou de

933 Idem, p.546. Le droit allemand quant à lui, est plus restrictif excluant les mandataires. p.546.

934 Art.51 CP néerlandais. H.R. 1er juil.1981.NJ. 1982, 80. Cité par GEEROMS (Sofie). p.547.

935 Crim.18 janv.2000, Bull. Crim., $\mathrm{n}^{\circ} 28$

936 MARON ('A), ROBERT (J.H), Cent personnes morales pénalement condamnées : Dr.pén. 1998, chron. n²8. Cité par GUIHAL (D), in, Droit répressif de l'environnement, op.,cit.,p.214. 
responsabilité d'emprunt parce qu'elle ne se préoccupe pas directement de la personne morale elle-même comme auteur de l'acte infractionnel. En cas de commission de l'infraction, les éléments constitutifs sont à rechercher non pas à l'endroit de la personne morale mais plutôt au niveau de la personne physique, organe ou représentant. Dès lors, ce modèle empêche l'autonomie du droit pénal de la personne morale, de sorte que si on ne trouve pas l'individu responsable, et bien, il n'y aurait pas de personne morale responsable. En définitive on a tendance à croire que peut importe que la responsabilité de la personne morale soit engagée ou non. Certains auteurs parlent même d'une responsabilité d'emprunt ou d'une responsabilité par procuration ${ }^{937}$ ou encore par représentation. ${ }^{938}$ Face à cette responsabilité déléguée, le professeur FAURE, suggère aux Etats de recourir à une responsabilité plus autonome de la personne morale, à l'instar de celle qui prévaut en droit belge.

Contrairement au législateur français, le législateur belge a conçu la responsabilité pénale de la personne morale comme une réalité sociale et non comme une addition d'individus, ayant une existence propre. Elle peut commettre une faute pénale et à ce titre, doit répondre personnellement desdites infractions. En droit belge, " toute personne morale est pénalement responsable des infractions qui sont intrinsèquement liées à la réalisation de son objet, ou à la défense de ses intérêts, ou de celles dont les faits concrets démontrent qu'elles ont été commises pour son compte ${ }^{939}$

Dès lors que la responsabilité pénale de la personne morale est établie, la question se pose de savoir quelles sont la nature et les peines applicables par le juge afin d'assurer à cette forme de responsabilité pénale une meilleure efficacité.

937 GEEROMS (Sofie), op.,cit.,p.543.

938 MARON ('A), ROBERT (J.H),op.,cit.,p.543.

939 Art.5 al.1 CP belge 


\section{§II : L’efficacité des sanctions pénales applicables à la personne morale}

Une infraction est commise. Une personne morale se l'est vu imputer. II s'ensuit qu'une sanction doit être appliquée. La peine, nous le savons est nécessaire et légitime. Conformément au principe de la personnalité des peines, elle est applicable aux individus. Dès lors, il est évident que les peines applicables aux personnes physiques ne sauraient être identiques à celles applicables aux personnes morales. A l'endroit de la personne morale, c'est l'exigence des sanctions plus adaptées qui est le leitmotiv. Les sanctions applicables sont fondamentalement l'amende comme peine principale $(A)$ et une gamme de peines accessoires applicables (B).

\section{A) L'amende applicable aux personnes morales}

La peine de privation de liberté n'étant pas concevable en matière de peine applicable aux personnes morales, l'amende pénale devient la principale peine. Elle est applicable en toutes matières : criminelle, correctionnelle et contraventionnelle. Tous les systèmes répressifs prévoient un montant qui est généralement très élevé par rapport au montant prévu en ce qui concerne la personne physique. En France, le taux maximum de l'amende encourue par une personne morale est le quintuple ${ }^{940}$ du maximum du montant prévu pour I'individu commettant la même infraction. A titre illustratif, si cette situation était applicable au Bénin, on aurait par exemple, en cas d'infraction relative à l'exploitation sans autorisation d'un établissement ou d'une installation classée ou dans des conditions autres que celles prévues par l'article 76 et suivants de la loi-cadre béninois, le présumé coupable, s'il est une personne physique, il échopperait d'une amende variant entre 500.000 et 5.000.000 F CFA. Or, si c'est une personne morale, elle sera condamnée à une amende variant entre 2.500.000 et 25.000.000 FCFA pour les établissements de classe II et de 5000.000 à 25.000.000 FCFA pour la classe I ; la peine passera de 25.000 .000 à 
125.000.000 FCFA pour les personnes morales ${ }^{941}$. Le principe du quintuple reste donc appliqué aussi au Bénin sans qu'on ne l'est clairement exprimé. Ainsi, le système dépend de l'amende individuelle. L'idée de base a été de maintenir le parallélisme le plus étroit possible avec les peines qui peuvent être prononcées contre les personnes physiques pour les mêmes faits ${ }^{942}$. Il en découle qu'une personne morale poursuivie pour une infraction pour laquelle l'amende n'est pas prévue en ce qui concerne les individus ne peut être punie d'une amende. Pour remédier à cette lacune, la loi française a prévue en matière criminelle une peine d'amende unique d'un million d'euros ${ }^{943}$. Pour les délits, le problème ne se pose pas puisqu'il existe toujours une amende qui est prévue et qu'il faut multiplier par cinq. En cas de récidive, la peine maximale d'amende applicable est égale à dix fois celle qui est prévue par la loi qui réprime ce crime. La règle est donc la même que pour les personnes physiques. L'amende est multipliée par deux.

Néanmoins, il faut reconnaitre que ce système est sévère mais très dissuasif. Il a le mérite de sensibiliser les entreprises et de les inciter à mettre en œuvre les mesures efficaces de prévention. C'est pourquoi, l'on assiste de plus en plus au sein des entreprises au développement d'un système d'audit et de management environnemental (ISO 9001 et ISO 14000), pour limiter non seulement cette peine principale mais aussi les peines accessoires qui ne sont pas moins rigoureuses.

\section{B) Les peines accessoires applicables aux personnes morales}

L'article 131-38 al.2, du code pénal français, légèrement modifié par les dispositions de l'article 11 de la loi $n^{\circ} 2010-768$ du 9 juillet 2010, dresse une nomenclature impressionnante des peines spécifiques applicables aux personnes morales de droit privé ou de droit public.

941 Cf. article 120 de la loi-cadre du Bénin

942 HAMER (Ph) et ROMANIELLO (S), La responsabilité des personnes morales : principes, les sociétés bientôt punissables. Quels impacts sur la vie des entreprises ? Actes du colloque organisé le 27 mai 1999 par l'association belge des juristes d'entreprises et l'association des juristes praticiens du droit social, Bruxelles, Bruylant, 1999, p.13. 
Elles sont diverses et applicables en fonction des cas en présence. Ainsi, lorsque la loi le prévoit à l'encontre d'une personne morale, un crime ou un délit peut être sanctionné d'une ou de plusieurs des peines suivantes :

1. «La dissolution, lorsque la personne morale a été créée ou, lorsqu'il s'agit d'un crime ou d'un délit puni en ce qui concerne les personnes physiques d'une peine d'emprisonnement supérieure à cinq ans, détournée de son objet pour commettre les faits incriminés ;

2. L'interdiction à titre définitif ou pour une durée de cinq ans au plus, d'exercer directement ou indirectement une ou plusieurs activités professionnelles ou sociales ;

3. Le placement pour une durée de cinq ans au plus, sous surveillance judiciaire ;

4. La fermeture définitive ou pour une durée de cinq ans au plus des établissements ou de l'un ou de plusieurs des établissements de l'entreprise ayant servi à commettre les faits incriminés ;

5. L'exclusion des marchés publics à titre définitif ou pour une durée de cinq ans au plus ;

6. L'interdiction à titre définitif ou pour une durée de cinq ans au plus, de faire appel public à l'épargne ;

7. L'interdiction pour une durée de cinq ans au plus, d'émettre des chèques autres que ceux qui permettre le retrait des fonds par le tireur au près du tiré ou ceux qui sont certifiés ou d'utiliser des cartes de paiement ;

8. La confiscation de la chose qui a servi ou était destinée à commettre l'infraction ou de la chose qui en est le produit ;

9. L'affichage de la décision prononcée ou la diffusion de celle-ci soit par la presse écrite, soit par tout moyen de communication audiovisuelle.

Le deuxième alinéa précise que "les peines définies aux $1^{\circ}$ et $3^{\circ}$ cidessus ne sont pas applicables aux personnes morales de droit public dont la responsabilité pénale est susceptible d'être engagée. Elles ne sont pas non plus applicables aux partis ou groupements politiques ni aux syndicats professionnels. 
La peine définie au $1^{\circ}$ n'est pas applicable aux institutions représentatives du personnel. $»^{944}$

Un examen plus approfondi permet pourtant de constater que seules deux innovations réelles peuvent être notées, à savoir la dissolution (article 131$39.1^{\circ}$ ) et le placement sous surveillance (article $131-39.3^{\circ}$ ). Cette dernière est plutôt une mesure de sûreté. Bref, la seule peine nouvelle est la dissolution. Elle a un caractère grave en ce qu'elle porte atteinte à l'activité de la personne morale et à son existence. Par conséquent, l'application de cette peine, n'est prévue qu'à l'encontre de certaines personnes morales uniquement pour les infractions les plus graves. Les autres sanctions propres aux personnes morales sont souvent plus adaptées que novatrices; de sorte qu'on peut même parler de peines identiques aux personnes physiques. La plupart des peines prévues tendent à restreindre la liberté d'action de la personne morale. Elles s'en prennent à la capacité de la personne morale : parfois cette activité sera maintenue mais soumise au contrôle judiciaire, parfois cette activité sera également maintenue, mais avec des moyens réduits, parfois l'activité sera même interdite temporellement ou définitivement. Ces peines ont donc un but utilitaire : empêcher la personne morale de poursuivre ses activités délictueuses, soit en la contrôlant soit en la limitant dans sa capacité, soit en la supprimant ${ }^{945}$.

Transposées en matière environnementale, ces sanctions, éparpillées dans les lois de polices spéciales avant d'être codifiées par le code de l'environnement français sont tout à fait pertinentes et efficaces, appliquées aux personnes morales. Les peines d'amende et les peines accessoires prévues par les diverses lois spécifiques, font toutes références aux dispositions précédentes. II en est ainsi des articles $L$ 332-25-1 à $L$ 332-27 et $R$ 331-72 qui fixent les peines applicables à la personne morale en cas d'infraction en matière de gestion des parcs et réserves; les articles $L$ 428-7-1 à L428-11 fixent ces peines en matière d'infractions relatives à la protection de la faune et de la flore ; l'article L 22610 en fait autant en ce qui concerne les infractions relatives à la pollution de l'air et les articles $L 218-57$ et $L$ 216-12 pour les infractions qui relèvent de la

944 Art.131-38 et 131-39.CP français

945 VINEY (G), Conclusions, Rev.Soc.1993, 385. Cité, par GEEROMS (Sofie), La responsabilité pénale de la personne morale : une étude comparative, RIDC, 3/1996.p.571. 
pollution marine et de la pollution d'eau douce. L'une des particularités de la responsabilité de la personne pénale morale est qu'il ne fait aucune distinction entre les peines criminelles et les peines correctionnelles. La référence de la qualification est la peine encourue par la personne physique.

En droit belge, c'est la loi du 4 mai 1999, comme précisé qui institue la responsabilité pénale des personnes morales ${ }^{946}$. Au regard de cette loi et même de la loi française, en ce qui concerne la peine de "dissolution", on peut faire remarquer qu'elle est assimilable à la peine de mort, donc à la «mort» de la personne morale. Elle n'est pas couramment appliquée. Mais elle peut l'être selon le professeur MASSET, dans deux cas : « si, d'une part, il apert que la personne morale a été intentionnellement créée afin d'exercer les activités punissables pour lesquelles elle a été condamnée ou s'il s'avère, d'autre part, que son objet a été intentionnellement détourné afin d'exercer de telles activités ${ }^{947}$. Le professeur MASSET pense, et nous somme d'accord avec lui, que la dissolution ne devrait être prononcée que si le détournement de l'objet de la personne morale est répété et systématique, plutôt que résultant d'un fait isolé ou d'une série de faits. En tout état de cause, il nous semble que la peine de dissolution constitue une extrémité à laquelle il ne sera pas fréquemment recouru dans la pratique de la responsabilité pénale des personnes morales.

Dans le même ordre d'idée, l'interdiction d'exercice d'une activité relevant de l'objet social de la personne morale présente des analogies avec la peine d'emprisonnement dans la mesure où elle limite la liberté d'action de l'être collectif sanctionné de la sorte ${ }^{948}$.

Au total, l'on pourrait objecter que l'exclusion des personnes morales de droit public dont font montre les codes pénaux belge et français met à mal

946 Pour un aperçu de la jurisprudence, voir M. FAURE, in, La responsabilité pénale des personnes morales : regard sur la jurisprudence, Aménagement-Environnement, 2004, numéro spécial, pp.129-163. V. aussi www.prepa.ist.f.

$947 \operatorname{MASSET}(\mathrm{A})$, instituant la responsabilité pénale des personnes morales : une extension du filet pénal mondialisé, Journal des tribunaux, 16 oct.1999, Bruxelles. Cité par DJA (Cofi Hilaire), in, La responsabilité des personnes morales en matière d'environnement : cas du Bénin, de la Belgique et de la France, Mémoire DEA, 2004, Lomé, Togo.

948 GOLLIER (M) et LAGASSE(Fr), La responsabilité des personnes morales, le point sur la question après l'entrée en vigueur de la loi du 4 mai 1999, chron. D.S., 1999, p.523. 
le principe d'égalité devant la loi. Ce principe signifie que la loi s'applique à tous. Certes, l'Etat est en charge de l'intérêt général et par conséquent, ne peut s'auto punir, mais il est et demeure une personne morale, donc une personne juridique ayant des droits et des obligations. A ce titre, ne doit-il pas répondre des actes dommageables qu'il poserait ? On pourrait même se demander si ce traitement inégal des personnes morales de droit privé et des personnes morales de droit public ne contenait pas une forme discriminatoire, à la limite anticonstitutionnelle ? Dans tous les cas on ne saurait répondre par l'affirmative. II serait très difficile de condamner la personne morale publique, notamment l'Etat. A ce sujet, la doctrine est semble t-il unanime pour reconnaitre I'irresponsabilité de l'Etat. L'Etat détenant « le monopole de punir, ne saurait se sanctionner lui-même ${ }^{949}$, au risque de se s'aborder lui-même.

Par ailleurs, même si les expériences française et belge, de par la teneur de leurs dispositions pénales paraissent à certains égards bien décevantes, il faut reconnaitre que le droit béninois a beaucoup à tirer des mécanismes juridiques de mise en œuvre ci-dessus développés pour rendre effectif le droit de la responsabilité pénale des personnes morales dans son arsenal répressif de protection de l'environnement.

\section{SECTION II : L'EFFECTIVITE DE LA RESPONSABILITE PENALE DE LA PERSONNE MORALE AU BENIN}

En passant en revue les textes répressifs existant en matière de protection de l'environnement, tels que décrit dans la première partie de nos travaux de recherches, trois principaux textes devraient retenir notre attention quant à la prise en compte de la responsabilité pénale de la personne morale au Bénin. ॥ s'agit des textes pénaux comme le code pénal et le code de procédure pénale qui, en la matière restent muets alors que la loi-cadre sur l'environnement dans ses dispositions répressives, abordent plus ou moins clairement la question de la responsabilité pénale des personnes morales (§l). Mais l'introduction d'une telle responsabilité souffre en pratique de quelques difficultés d'application (§II). 


\section{$\S$ I : Une introduction relative de la responsabilité des personnes morales}

Il conviendrait de mettre en exergue le mutisme des textes généraux comme le code pénal et le code de procédure pénale applicables au Bénin, d'une part (A) et d'autre part, la volonté du législateur d'introduire pourtant une telle responsabilité dans la loi-cadre sur l'environnement au Bénin (B).

\section{A) Le silence des textes pénaux à caractère général}

Il est normalement du domaine du code pénal et du code de procédure pénale de réglementer la responsabilité des personnes morales. Car ce sont elles qui déterminent la politique pénale du pays en définissant d'une manière générale les incriminations, les peines et les modalités de leurs mises en œuvre. En pratique, il est évidemment inconcevable qu'un juge d'instruction convoque une personne morale dans son cabinet, sollicite qu'elle soit placée en détention provisoire...Il est donc impératif d'adapter la procédure pénale aux personnes morales. C'est pourquoi, l'article 706-41 du code de procédure pénale français dispose en ce qui le concerne que : " les dispositions du présent code sont applicables à la poursuite, à l'instruction et au jugement des infractions commises par les personnes morales, ... ». Or, au Bénin ces codes actuellement en vigueurs ainsi que les projets de codes en instance d'être votés à l'Assemblée Nationale, n'abordent pas le problème de la responsabilité des personnes morales. Comme nous l'avions dit, en France cette matière est réglementée par l'article 121-2 et 121-3 du code pénal et en Belgique, par les dispositions de l'article 5 du code pénal avant d'être mieux précisée par des lois spécifiques.

Au Bénin, la situation est inversée ; c'est plutôt la loi-n98-030 du 12 février 1999 portant loi-cadre sur l'environnement qui introduit en droit interne, la possibilité de répression aussi bien de la personne physique que de la personne morale. 


\section{B) Existence de la responsabilité de la personne morale au Bénin}

La loi-cadre sur l'environnement comme on l'a précisé dans les premiers chapitres, est le principal texte de loi qui réglemente tous les compartiments du secteur de l'environnement au Bénin. C'est la loi de référence en matière de protection de l'environnement. Comme telle, elle est la seule loi qui aborde avec plus ou moins de précision la question de la responsabilité pénale de la personne morale au même titre que la personne physique responsable.

Dans ces dispositions générales, elle plante déjà le décor en définissant clairement et sans équivoque dans l'article 2, la notion de "personne ", comme " toute personne physique ou morale, soit un individu, une société, une coopérative, une organisation, une association ou un organisme public ». Quant au pollueur, il y est définit aussi comme «toute personne physique ou morale qui, par son acte ou son activité, provoque une contamination ou une modification directe ou indirecte de l'environnement ${ }^{950}$ ».

Le lexique des termes juridiques, entend par personne morale, " tout groupement de personnes ou de biens ayant la personnalité juridique, et étant par conséquent, titulaire de droits et obligations. "Il s'ensuit que la personne morale jouit des mêmes droits et obligations que la personne physique, donc passible de sanctions pénales. Autrement dit, partout dans cette loi-cadre, il faut entendre par "personne ", personne physique ou personne morale en ce qui concerne la commission des infractions.

Ainsi, les articles 15 et 16, les articles 74 et suivants ${ }^{951}$ décrivent des incriminations concernant aussi bien les personnes physiques que les personnes morales. Les peines d'amendes prévues notamment par les dispositions des

950 Art.2 de la loi-cadre du Bénin

951 Il s'agit de loi-cadre sur l'environnement du Bénin où par exemple l'art.75 dispose : « toute personne physique ou morale, publique ou privée, propriétaire ou exploitante d'une installation doit prendre toutes mesures nécessaires pour prévenir et lutter contre la pollution de l'environnement, conformément aux dispositions de la présente loi et des textes d'application subséquents. ", l'art.76 « les installations exploitées ou détenues par toutes personne physique ou morale, publique ou privée, » 
articles 112,118 et suivants ${ }^{952}$, y afférentes devraient frapper également les deux catégories de personnes. En ce qui concerne les peines accessoires, les sanctions applicables aux personnes morales sont un peu plus claires. L'article 111 prévoit, comme peines accessoires, «le retrait ou la révocation des permis ou autorisations délivrées à l'entreprise» ainsi que "la remise en état du site dégradé ou pollué». Le juge peut prononcer «la saisie et le retrait de la circulation du produit ou de l'objet du délit»" ${ }^{953}$, «la suspension ${ }^{954}$ ou ordonner même "la fermeture de I'installation ${ }^{955}$. Mais, les dispositions de l'article 110 clarifient en ces termes : " en matière de pollution ou de rejet de contaminants dans l'atmosphère, sur le sol, dans le sol, dans le sous-sol, en mer, dans les lacs, les rivières, les lagunes et les étangs, l'action publique est engagée contre le chef d'entreprise » et non l'entreprise. L'on peut penser à juste titre que l'identification de la personne physique responsable qu'est le chef d'entreprise, est une première étape vers la sanction de l'entreprise, de la personne morale. Il en est ainsi puisqu'elle suppose toujours la recherche d'une personne physique responsable agissant pour le compte de l'entreprise.

Au total, on peut retenir, à travers ces dispositions, que l'arsenal répressif ne manque pas de possibilités, même s'il est relative, pour réprimer les gros pollueurs et entreprises indélicats que sont les industriels, les sociétés et autres entreprises non respectueuses des textes. On note ainsi, la volonté manifeste du législateur béninois de réprimer la personne morale reconnue coupable d'infraction pénale. Néanmoins, l'imprécision des polices spéciales habilités à constater des infractions limitées à certains secteurs, à certaines catégories de personnes, l'incertitude des pouvoirs qui leurs sont conférés lors de ces activités de police judiciaire, rendent particulièrement opaque et aléatoire la poursuite pénale des personnes morales en matière d'environnement.

952 Ainsi, l'art.120 dispose que " l'exploitation sans autorisation d'un établissement ou dans les conditions autres que celles prévues par les articles 76 et suivants est puni d'une amende de 500.000 à 5000.000 de francs CFA pour les établissements de classe II et de 5.000 .000 à 25.000.000 de francs CFA pour ceux de la classe I »

953 Art.116, 118 loi-cadre sur l'environnement du Bénin

954 Art.48 loi-cadre sur l'environnement du Bénin.

955 Art.76, 79 al2. loi-cadre sur l'environnement du Bénin 


\section{§II : Une possibilité de répression de la personne morale très réduite}

La possibilité de réprimer la personne morale en droit pénal, si elle existe du point de vue théorique, elle rencontre dans la pratique des difficultés. Cela s'explique par les difficultés du juge de mettre en mouvement l'action publique contre la personne morale responsable d'une infraction $(A)$ d'où la pauvreté de la jurisprudence en la matière. Elles peuvent s'expliquer aussi par l'importance accordée aux considérations économiques et politiques incarnées par ces personnes morales (B).

\section{A) Les difficultés quant à la mise en œuvre de la responsabilité de la personne morale}

Malgré les dispositions de la loi-cadre, on a tendance à penser qu'au Bénin, le principe directeur est l'inexistence de la responsabilité pénale des personnes morales puisqu'aucun article de cette loi ne dispose clairement que la personne morale peut être poursuivie et condamnée en cas d'infraction. Le législateur, devra à l'instar de la France et de la Belgique mieux organiser cette responsabilité II peut insérer des dispositions novatrices dans le projet de code pénal en instance au parlement et dans le projet de révision de la loi-cadre. Par exemple, en France, cette responsabilité pénale, adoptée par la loi du 22 juillet 1992, entrée en vigueur le $1^{\text {er }}$ mars $1994^{956}$, est organisée par les articles 121-2 à 121-7 du nouveau code pénal et réaffirmée par des lois sectorielles. Ainsi, l'article 121-2 alinéa 3 du NCP dispose : " la responsabilité pénale des personnes morales n'exclut pas celle des personnes physiques auteurs ou complices des mêmes faits, sous réserves des dispositions du quatrième alinéa de l'article 121-3 ». En Belgique, elle est organisée par l'article 5 du code pénal et par la loi du 4 mai 1999 instaurant la responsabilité pénale des personnes morales ${ }^{957}$.

956 GEEROMS(Sofie), La responsabilité pénale de la personne morale : une étude comparative, RIDC, 3/1996 p.537.

957 Ce texte est publié au Moniteur belge le 22 juin 1999 et est en vigueur depuis le 2 juillet 1999. 
Ces articles organisent comme on le constate clairement les conditions et les modalités d'incrimination de la personne morale.

Au Bénin comme un peu partout en Afrique, les pesanteurs économiques prennent le pas sur le droit de l'environnement.

\section{B) Les pesanteurs économiques freinent l'application du droit pénal des personnes morales}

En Afrique, nous l'avions déjà précisé dans nos développements antérieurs, on a tendance à penser le développement économique sans trop se soucier des aspects environnementaux. Le leitmotiv est donc, à côté du secteur public, le développement du secteur privé, source de création d'entreprises, devant conduire à l'amélioration de la croissance économique. Il s'agit de créer la richesse et l'emploi. Or, les investissements se font généralement dans les secteurs potentiellement nuisibles à l'environnement. Lorsqu'on sait que les personnes morales sont principalement les gros pollueurs de l'environnement on se demande comment appliquer une telle législation ? L'on pense à cet effet, qu'une législation trop rigide est susceptible de bloquée les investissements. Dès lors, l'application de la politique criminelle en cette matière semble être relative car elle se trouverait en concurrence avec le développement économique. La condamnation à des peines d'amende ou à des peines complémentaires de la personne morale ne risque t-il pas de "tuer " les sociétés ou les entreprises pourvoyeuses de devises et d'emplois?

Au Bénin, c'est dans ce cadre que s'inscrit les diverses pollutions occasionnées par des sociétés cimentières (SCO, CIMBENIN, SCB) ; par I'OCBN avec le transport du soufre, par des huileries et autres entreprises pollueurs à grande échelle, objet de permanents soulèvements populaires en raison des conséquences diverses de leurs activités, le juge saisit a du mal à sanctionner ${ }^{958}$. La jurisprudence béninoise a affirmé le principe de l'inexistence

958 Recours devant la Cour constitutionnelle ; Voir par exemple la note $n^{\circ} 1589 / \mathrm{CC} / \mathrm{SGA} / \mathrm{VI}$ du 4 septembre 2008 adressée au Ministre de l'Environnement et de la Protection de la Nature pour mesure d'instruction au sujet des pollutions engendrées par la SCB dans une agglomération urbaine. 
de la responsabilité pénale des personnes morales. Ainsi en a disposé l'arrêt $\mathrm{n}^{\circ}$ 21/2000 du 27 janvier 2000 de la Cour d'Appel de Cotonou, RG n 006/2000 dans l'affaire Société des ciments d'Onigbolo-Agent judiciaire du trésor contre Société Groupe MYC International Sar ${ }^{959}$. En l'espèce, la SCB, Société d'exploitation bénino-nigériane, a passé commande, courant 1997 à la société Groupe MYC international Sarl, pour des matériels et pièces de rechanges ayant fait l'objet de divers contrats.

Dans cette affaire, le juge pénal a clairement affirmé mais à tord que dans " le droit positif béninois, il n'existe pas de responsabilité pénale des personnes morales; et que les personnes morales sont des êtres juridiques fictifs dont tous les actes sont posés par des personnes physiques qui les dirigent ${ }^{960} »$. Dans le cas d'espèce, cette décision du juge est contraire à l'esprit et à la lettre des dispositions de la loi-cadre précitée. Lorsqu'il estime que seules les personnes physiques peuvent voir engager leur propre responsabilité pénale à raison des actes délictueux qu'elles commettent dans la gestion des personnes morales qu'elles servent et dirigent, il méconnait les dispositions des articles $46,47,48,116,118,121$ de la loi-cadre qui affirment le principe de la sanction de la personne morale.

Par ailleurs, ces entreprises privées sont des filiales de grands groupes étrangers multinationaux dont parfois les capitaux sont drainés vers des puissances étatiques du monde. On peut citer par exemple le groupe AREVA, une filiale française, implantée au Niger pour l'extraction minière (uranium). Cette entreprise, dans sa course effrénée à l'enrichissement, avec des dividendes certaines pour le Niger, occasionne des effets néfastes aussi bien sur l'environnement que sur l'homme d'autant plus que c'est un minerais fortement cancérigène qui y est recherché. II s'ensuit que le juge pénal influencé par le politique et les puissances d'argent, aura tendance à protéger les investisseurs au détriment de l'environnement.

Ainsi, aux pesanteurs économiques et financières s'ajoutent des considérations géostratégiques et politiques. Alors comment envisager des

959 (A.F)SAIZONOU BEDIE, Jurisprudence béninoise, recueil d'arrêt de la cour suprême et des cours d'appel de Cotonou et de Parakou, éd. N¹, 2005, p.135.

960 Idem, 
poursuites contre ces genres de sociétés à caractère stratégique et dissuasif? Quelle est réellement la portée de cette responsabilité des personnes morales? Au delà de ces questionnements il nous parait nécessaire que le législateur béninois réfléchisse sur l'opportunité de revisiter le droit des personnes morales afin de le rendre plus dynamique.

En effet, s'inspirant de certaines législations ayant adopté la responsabilité pénale des personnes morales, le Bénin peut bien refonder son système pénal en envisageant effectivement la mise en œuvre d'une telle responsabilité par l'adoption d'une nouvelle loi. Il ne s'agira pas de copier exactement les dispositions des législations européennes, car ce qui est valable en France et prospère ne l'est pas forcement au Bénin. Mais surtout d'innover en tenant compte du contexte national. Ainsi, en Afrique, il ne nous paraît pas pertinent aujourd'hui où les Etats évoluent vers un Etat plus fort et puissant, d'aller dans le sens d'une pénalisation de cette puissance publique. II faut éviter la fragilisation de la personne morale publique que constituent l'Etat et même les Communes ${ }^{961}$ qui viennent à peine de naitre au Bénin. Cette forme d'immunité pénale, dont les raisons reposent sur des considérations politiques, a pour intérêt la consolidation des acquis démocratiques et l'instauration d'un Etat de droit solide.

Cependant, en cas de délégation ou de concession d'activités, les délégataires peuvent pénalement répondre de leurs actes de gestion qui apparaissent comme détachables de la personne morale publique. II s'ensuit qu'une réforme du droit pénal dans ce sens, doit viser prioritairement la pénalisation des personnes morales de droit privé. La crainte de se voir infliger de lourdes sanctions devrait pouvoir sensibiliser ces personnes morales à agir en bon père de famille et avoir une gestion écologiquement rationnelle de leurs prestations à l'égard de l'environnement.

961 Comme au Luxemburg où, la loi du 3 mars 2010 a introduit la responsabilité pénale des personnes morales dans l'arsenal législatif. Elle est entrée en vigueur le 15 mars 2010. Cette responsabilité s'applique à toutes les personnes morales à l'exception des personnes morales publiques que sont l'Etat et des Communes. Source : internet : www.droit.belge. net. 
En conclusion, on a pu constater tout au long de ce chapitre, que I'introduction de la responsabilité pénale des personnes morales dans un système répressif n'est pas chose aisée. Si les pays comme la France, la Belgique, les PaysBas, l'Allemagne, pays à très longue tradition juridique et à forte expérience dans l'application du droit de l'environnement, après avoir été réticent pendant longtemps, ont fini par l'adopter tout récemment, c'est que, cette décision n'a pas été sans obstacles majeurs pour le législateur. C'est pourquoi, en rappelant les expériences française et belge, et en posant les principes qui sous-tendent cette responsabilité des personnes morales, particulièrement en droit de l'environnement, nous avons pour intention non pas d'apporter une solution définitive mais de susciter ou d'engager, des pistes de réflexion afin d'éveiller la conscience du législateur béninois sur l'opportunité d'expérimenter cette forme de responsabilité très efficace en matière de protection de l'environnement. Car les personnes morales, réalités économiques, deviennent de plus en plus une réalité criminologique, plus en matière environnementale que dans d'autres secteurs. Cette réflexion du législateur béninois qui doit découler de la refonte du code pénal, peut s'étendre également sur les infractions environnementales transfrontières. 


\section{CHAPITRE VIII : LA REPRESSION DE LA POLLUTION TRANSFRONTIERE}

L'humanité est confrontée depuis le développement de l'industrie à des catastrophes de tous genres, causées non pas seulement par la nature, mais aussi et surtout par la main de l'homme. Au nombre de ces catastrophes humaines, figurent les crimes environnementaux, notamment les atteintes à l'environnement qui vont au-delà des frontières d'un seul Etat, d'où la régionalisation ou l'internationalisation des crimes environnementaux. Le présent chapitre qui oriente la répression environnementale sur le terrain du droit international, n'a pas la prétention d'aborder tous les contours de la pollution transfrontière, mais se propose d'analyser les perspectives qu'offre le droit répressif en cas d'infraction relative à la pollution transfrontière des eaux (continentales et marines) et de l'air.

II importe donc de s'attacher au besoin d'universalité de la réponse pénale, afin d'atteindre les responsables au-delà de la protection des frontières, même si cette " réponse est plus timide et procède davantage de la quête que de l'acquis $»^{962}$ car, face aux crimes contre l'environnement, le droit pénal international n'a-t-il pas un gage de remède qui pourrait être aussi efficace ?

Dès lors, on pourrait affirmer que le concept de droit pénal international s'applique habituellement à deux domaines distincts du droit : les dimensions internationales du droit pénal interne, et ce qu'on pourrait appeler le droit pénal international proprement dit, c'est-à-dire le droit pénal substantiel et ses corollaires d'institutions judiciaires pénales et non juridictionnelles.

Alors que les forces policières, les procureurs et les tribunaux d'un pays ne peuvent exercer leurs fonctions qu'à l'intérieur du territoire relevant de leur compétence, la pollution transfrontière occasionne des infractions qui ne tiennent pas compte des frontières. C'est pour palier à ces conséquences néfastes sur l'environnement que les Etats ont dû concevoir des outils juridiques

962 MAYAUD (Yves), La responsabilité pénale découlant des crimes environnementaux. Communication prononcée lors de "Regional Conference on Environmental Crimes in the Arab States », Berut-Republic of Lebanon, mars 2009. 
et non juridiques susceptibles de servir dans les cas où un ou plusieurs éléments objet du délit auraient été perpétrés à l'étranger.

Comme nous le constatons, la pollution transfrontière pose beaucoup de problèmes de droit dont la résolution dépasse largement le seul cadre du droit pénal et interpelle les autres disciplines juridiques. Dès lors, le recours à ces disciplines est nécessaire pour venir à bout du contentieux de la pollution transfrontière.

Ainsi, il s'agira d'une part de mettre en relief le contentieux de la pollution transfrontière en analysant le mode de règlement juridictionnel, en mettant l'accent sur la compétence en la matière (Section I) et d'autre part, d'explorer les mécanismes et les sanctions non juridictionnelles, fondés sur la coopération interétatique (Section II).

\section{SECTION I : LA COMPETENCE EN MATIERE DE POLLUTION TRANSFRONTIERE}

Selon le professeur MOTULSKY, le contentieux consiste à « soumettre à une juridiction un litige qui met en cause une prétention tendant à la mise en œuvre d'une règle de droit ${ }^{963}$. Dans le domaine de l'environnement, on parle de contentieux civil, du contentieux pénal, du contentieux administratif et dans le domaine du droit international, on parle de contentieux international. Notre analyse $n$ 'insistera pas trop sur le contentieux civil mais se penchera davantage sur les trois derniers contentieux des pollutions transfrontières. Ce recours à I'approche international apparait à notre avis comme aussi une forme de solution aux préoccupations environnementales.

Dans les chapitres précédents, les régimes de responsabilité et de sanctions envisagées s'appliquent lorsque l'auteur de l'infraction se trouve à l'intérieur du même Etat. La question devient plus complexe lorsque l'infraction ou une partie de l'infraction prend sa source à l'extérieur de l'Etat concerné.

963 Cf. CUJAS, les cours de droit, 1973 ; cité par HUGLO (C), Contentieux : problématiques et perspectives, Fascicule 1005, Edition Techniques -Juris-Classeurs, 2, 1992. 
Ainsi, avant d'aborder le problème de la compétence des juridictions internes qui pourraient éventuellement connaitre des conflits de pollution transfrontière (§II) il conviendrait d'abord de définir et de circonscrire l'infraction environnementale transfrontière (§I).

\section{§I : La définition et les manifestations du phénomène de pollution transfrontière}

Depuis le début du XXème siècle, les problèmes relatifs aux ressources naturelles et/ou environnementales ont été résolus au niveau international. En particulier les problèmes de pollution transfrontière, ont été réglementés par des accords internationaux ${ }^{964}$, bilatéraux ou multilatéraux. C'est donc au sein de ces instruments internationaux qu'il conviendrait de rechercher les éléments de définition de la pollution transfrontière avant d'envisager ses manifestations.

\section{A) Les éléments de définition de la pollution transfrontière}

Selon les auteurs Alexandre KISS et Dina. SHELTON, qui reprennent l'article $1^{\text {er }}$ (a) de la convention de Genève sur la pollution atmosphérique transfrontière à longue distance (1979), la pollution s'entend de " l'introduction par l'homme, directement ou indirectement de substances ou d'énergie dans l'environnement qui entraînent des conséquences préjudiciables de nature à mettre en danger la santé humaine, à nuire aux ressources biologiques et aux systèmes écologiques, à porter atteintes aux agréments ou à gêner les autres utilisations légitimes de l'environnement ». Cette définition souligne le rapport étroit entre le droit de l'environnement et le comportement humain, notamment les activités anthropiques. Tous les instruments juridiques nationaux et internationaux relatifs à la pollution ont fait d'assez larges développements sur la question de sorte qu'il n'est pas trop nécessaire de s'y attarder.

Par contre, l'adjectif " transfrontière » qui s'ajoute mérite qu'on lui accorde une attention particulière. Ainsi dans le même article, en son alinéa 2 , 
la même convention, entend par pollution transfrontière, "la source physique comprise totalement ou en partie dans une zone soumise à la juridiction nationale d'un Etat et qui exerce des effets dommageables dans une zone soumise à la juridiction nationale d'un Etat et qui exerce des effets dommageables dans une zone soumise à la juridiction d'un autre Etat à une distance telle qu'il n'est pas généralement possible de distinguer les apports des sources individuelles ou groupes de sources d'émission $»^{965}$.

A partir de cette convention, plusieurs autres conventions, institutions ou organismes ont produit des définitions, lesquelles se rapprochent essentiellement de cette dernière. C'est le cas de l'Institut de Droit International qui lors de sa session du Caire sur la pollution transfrontière, a retenu la définition suivante : " toute altération physique, chimique ou biologique de la composition ou de la qualité de l'atmosphère résultant directement d'un acte ou d'une omission de l'homme et produisant des effets dommageables ou nocifs dans l'environnement d'autres Etats ou de zones situées au-delà des limites de la juridiction nationale $»^{966}$.

Quant à la pollution marine transfrontière, elle est définie comme "l'introduction directe par l'homme de substance ou d'énergie dans le milieu marin, y compris les estuaires, lorsqu'elle a ou peu avoir des effets nuisibles tels que des dommages aux ressources biologiques, à la faune et à la flore marine, des risques pour la santé humaine, des entraves aux activités maritimes, y compris la pêche et les autres utilisations légitimes de la mer, des altérations à la qualité de l'eau de mer du point de vue de son utilisation et des dégradations de valeurs d'agréments ${ }^{967}$.

Pour les organisations internationales dont l'OCDE, « il s'agit de toute pollution volontaire ou accidentelle dont l'origine physique est soumise à la juridiction nationale d'un pays et qui se situe en tout ou en partie dans la

965 KISS (A), SHELTON (D), Traité de droit européen de l'environnement, ed. frison-Roche,

966 Geraldo E. do NASCIMENTO e SILVA (Rapporteur), La pollution transfrontière de l'air, XXème Commission, Institut Droit International Session du Caire, 1987. www.idi.org/Idif/ resolutions

967 Cf. Convention de Montego Bay de 1982, art. 1er ; la Conférence de Stockholm de 1972. 
partie placée sous la juridiction nationale d'un autre pays $1 .^{968}$ Les polluants transfrontières sont des polluants les plus difficiles à endiguer. Elles ne connaissent pas les frontières tracées par le droit international. La situation peut être schématisée comme suit : un Etat A autorise des activités sur son territoire. L'exercice normal de ces activités provoque des dommages à un Etat $B$. la pollution qui s'étend au -delà des frontières de l'Etat $A$, se manifeste sur le territoire de l'Etat B et y provoque des dommages. ${ }^{969}$

Les polluants peuvent être transportés sur une distance de 1000 $\mathrm{km}$ de leur source ${ }^{970}$. La pollution de l'air ou pollution atmosphérique illustre parfaitement ce phénomène transfrontalier. En effet, c'est l'arrêt de principe rendu par la sentence arbitrale, dans l'affaire de la fonderie de Trail (1941) entre les USA et le Canada qui a été à l'origine d'une première condamnation en l'espèce. Dans cette décision, le tribunal énonça ses célèbres conclusions. ${ }^{971}$. Les conclusions de cette décision ont certainement inspiré la définition de la pollution transfrontière non seulement en matière de pollution atmosphérique mais aussi en toute autre matière environnementale comme la pollution des eaux.

\section{B) Les sources et les manifestations de la pollution transfrontière}

Au regard du droit international de l'environnement, il apparait presque évident que les premiers instruments de lutte contre les pollutions transfrontières se sont intéressés à l'air et aux eaux continentales ${ }^{972}$ mais aussi marines. En

968 V. Recommandation C (77) 28 (final), Annexe C, du 17 mai 1977, citée par A. KISS et J. P. BEURIER, Droit international de l'environnement, Paris, Pedone, 2000, p.102.

969 ASSEMBONI (Alida. N.), Le droit de l'environnement marin et côtier en Afrique Occidentale, cas de cinq pays francophones. Thèse de Doctorat, Université de limoges, Université de Lomé, 2006.

970 (L) GUNDLING, Droit international de l'environnement : atmosphère, eau douce et sol, Cour 7 UNITAR, 1999.

971 Cf. infra p.349.

972 ASSEMBONI (Alida. N.), Le droit de l'environnement marin et côtier en Afrique Occidentale, cas de cinq pays francophones. Thèse de Doctorat, Université de limoges, Université de Lomé, 2006. 
effet, la pollution transfrontalière se manifeste sous plusieurs formes. II peut s'agir de la pollution atmosphérique ou pollution de l'air, de la pollution des eaux (pollution des cours d'eau ou la pollution maritime). Une troisième forme de pollution, celle du sol est de plus en plus remarquable, même si elle n'est pas spectaculaire et plus médiatisée que la pollution marine. Pour illustrer les manifestations de la pollution transfrontière et apprécier l'ampleur de leurs effets nocifs sur l'environnement des Etats victimes, nous allons fonder notre raisonnement sur les effets et la réponse apportée à deux types d'exemples de pollution transfrontière. Le premier va concerner la pollution atmosphérique dans les pays du Nord et le second la pollution des eaux, notamment marines, dans la sous région ouest africaine.

\section{1) Les manifestations de la pollution atmosphérique transfrontières}

L'idée à l'origine part d'un principe très simple. Les Etats sont souverains sur leur territoire. Ils jouissent d'une souveraineté sur leurs ressources naturelles mais uniquement à l'intérieur de leurs frontières. Au-delà de leurs frontières nationales, ces derniers ne disposent d'aucune souveraineté sur les ressources naturelles situées dans ces zones. La décision d'un Etat de permettre ou d'autoriser l'exercice d'activités polluantes sur le territoire d'un autre Etat entraine inévitablement sa responsabilité au regard du droit international. C'est ce qui ressort de la légendaire jurisprudence de la fonderie de Trail. C'est la première affaire jugée sur le fond du droit international de l'environnement. Ainsi, cet arrêt de principe est le point de départ de la prise de conscience des Etats quant aux conséquences néfastes de la pollution de l'air occasionnée par les usines. Un rappel des faits s'impose.

L'affaire se déroule en plein XXème siècle avec le développement de l'industrie, dans une contrée dans la Colombie britannique, appelée Trail, où une compagnie canadienne exploite une des plus importantes fonderies de l'Amérique du Nord. Dans l'usine, les minerais de zincs et de plomb sont traités pour extraire leur métal. Les minerais contiennent du souffre, qui est rejeté dans l'atmosphère sous forme de dioxyde de soufre. En 1930, les émissions 
de dioxydes s'élevaient a environ 600 (à 700) tonnes par jour. Le dioxyde de carbone était transporté dans le sud, au-delà des frontières des USA et du Canada. L'ampleur des polluants disséminés dans la nature étaient énormes et des dommages considérables furent causés à l'Etat de Washington, en particulier aux cultures, aux bois, aux pâturages, au bétail et aux immeubles ${ }^{973}$. Ainsi, comme on le constate, le danger concret ou le risque potentiel de danger qui caractérise l'infraction matériel de crime contre l'environnement est, semble t-il ici apparent, puisqu'il y a là «effet dommageable » ou «altération (...) de la qualité de l'air » provenant d'un Etat sur un autre Etat voisin.

Face à ce préjudice matériel créé aux USA par l'industrie canadienne, les USA ont porté plainte contre le Canada. Par la suite, des négociations ont débuté à partir de 1927 et finalement la question a été soumise à la commission internationale établie par les deux pays qui ont accepté le principe de régler leur différend au moyen de l'arbitrage ${ }^{974}$.

En Afrique aussi des cas de pollutions de l'air transfrontière existent mais nous nous préoccuperons particulièrement de la pollution marine le long des côtes ouest africaines.

973 GUNDLING(L), Droit international de l'environnement : atmosphère, eau douce et sol, Cour 7 UNITAR, 1999 ; v. Reports of International Arbitral Awards, vol.3, pp.1903-1982.

974 Cf. infra. B.1) p.390. 


\section{2) Les manifestations de la pollution marine transfrontière}

Les pays du Sud et particulièrement les côtes africaines, sont généralement victimes non pas seulement des catastrophes naturelles ou déversements accidentels mais surtout de diverses formes de pollutions manifestement liées aux activités anthropiques, notamment minières ou industrielles.

Pour illustrer nos propos, intéressons-nous particulièrement à une usine d'extraction minière de production de phosphates togolais de Kpémè et observons sur les côtes maritimes béninoises, les manifestations et les conséquences du phénomène.

En effet, les faits remontent en 1952 à la découverte du minerai de phosphate ${ }^{975}$ dont l'extraction a débuté depuis 1954. La technique utilisée est celle de la technique de transformation du minerai brut en minerai marchand. Elle consiste, sur les côtes togolaises à l'utilisation de l'eau de mer pour laver le minerai brut et en extraire le produit fini. Le phosphate brut contenant $20 \%$ à $30 \%$ d'argile est transformé en pulpe par addition d'eau de mer dans de grands cylindres animés d'un mouvement rotatif. Une fois le produit débarrassé de sa gangue argileuse, il est ensuite admis dans les essoreuses où il est centrifugé pour l'élimination de l'eau de mer, et rincé pour l'élimination de chlore introduit lors des opérations de délitage, de lavage et de tirage. Ce mécanisme de traitement des boues de phosphates est potentiellement à l'origine d'un danger pour l'environnement marin au delà des frontières togolaises. Puisque les eaux usées issues du lavage et du rinçage du phosphate sont directement rejetées dans la mer ; de sorte que d'après les estimations faites en 1990, il a été révélé qu'avec sa capacité de production, l'usine rejetait 70.000 à $100.000 \mathrm{~m}^{2}$ d'eaux usées mélangées à 2400 tonnes d'argile et 480 tonnes de sable par jour. Par l'effet des courants marins, les mélanges de déchets rejetés par l'usine sont drainés presque dans les eaux marines béninoises ${ }^{976}$. Cette pollution est ressentie jusqu'à

975 C'est la principale source de revenu du Togo avec $40 \%$ des recettes d'exportation et $21 \%$ du PIB. Il occupe au plan mondial la 4ème place.

976 ASSEMBONI (Alida. N.), Le droit de l'environnement marin et côtier en Afrique Occidentale, cas de cinq pays francophones. Thèse de Doctorat, Université de limoges, Université de Lomé, 2006, p.185 V. aussi CHALLEMEL (Wilfried du Rosier), L'environnement industriel au Togo, PNUE, Paris 1990. 
Grand-Popo au Bénin et est visible par la coloration jaunâtre de la mer sur près de 400 à $500 \mathrm{~m}$ de la côte sur une distance d'environ 250 kilomètres. ${ }^{977}$ D'un côté comme de l'autre, les effets de cette pollution se font ressentir principalement sur les populations riveraines qui vivent essentiellement des produits de la mer.

Au Bénin, selon ASSEMBONI, la côte aurait entamée l'éloignement ou la mort de bancs de poissons d'où la baisse des activités de pêches. Certains estiment même que la concentration de phosphates dans les tissus de poissons pourrait présenter des dangers à la consommation humaine. Seulement, aucun contrôle sanitaire n'a été effectué dans cette zone concernant la toxicité des poissons consommés à Lomé et à Cotonou, de manière à lever toute équivoque sur la question ${ }^{978}$. Dans un autre document publié sur la pollution marine le long du littoral de Cotonou à Grand-Popo, il a été souligné que « la pollution des eaux marines côtières est évidente dans les régions de Grand-Popo et elle est due au rejet de l'usine de phosphates de Kpémè au Togo ${ }^{979}$. Dès lors, le Bénin n'a pas hésité a accusé le Togo de pollution marine, sans toutefois porter plainte contre l'Etat togolais ni contre l'entreprise.

Dans une dynamique coopérative de règlement de ce problème environnemental, les deux pays ont amorcé des négociations. La pollution prenant sa source au Togo et se manifestant au Bénin, a interpellé les autorités politiques des deux pays chargées des questions environnementales lesquelles ont décidé courant 2001 de la création d'un cadre de concertation au niveau régionale ${ }^{980}$. Le groupe d'experts du cadre de concertation, a réussi seulement à recenser les problèmes environnementaux communs aux deux pays à savoir : la pollution marine, l'érosion côtière, la gestion intégrée du littorale, l'aménagement du bassin du fleuve mono et gestion des aires protégées. A I'issue de ces concertations, des recommandations ont été faites notamment

977 ACOUETEY (Covi), La lutte contre les pollutions transfrontières : cas du Togo et du Bénin, Mémoire de DEA, en droit et politique de l'environnement, UL, Togo, 2000-2001, p.11.

978 ACOUETEY (Covi), op.cit.p.13.

979 « Problèmes prioritaires en rapport avec la production, l'exportation et l'utilisation de produits chimiques » sur http://ecb.jrc.it/natprof:bénin/Chapitre3.htm. Cité par A. ASSEMBONI, Thèse, op. cit. p.185

980 Ce cadre de concertation ainsi créé, a eu deux réunions. Une première a eu lieu à Lomé le 2 février 2001 et la deuxième à Cotonou en Janvier 2002. 
en ce qui concerne la gestion de ces pollutions transfrontières ${ }^{981}$. Mais, cette initiative très noble, n’a pas atteint les objectifs assignés. Ainsi, aucun résultat n'a été encore atteint.

Mais, l'on peut se réjouir tout au moins de la signature à Lomé, courant décembre 2011 par les deux délégations conduites respectivement par les deux Ministres chargés de l'environnement, de l'Accord de coopération entre les deux gouvernements dans le domaine de l'environnement et de la gestion durable des ressources naturelles ${ }^{982}$. Selon l'article 2 , “l'accord fixe les clauses sur la base desquelles les deux parties s'engagent à promouvoir et à développer, au travers d'une concertation permanente entre leurs autorités compétentes respectives, la coopération en vue de gérer durablement leurs ressources forestières respectives, de limiter les dégâts occasionnés par les inondations, de contrôler les rejets en mer des déchets de toutes sortes, de lutter contre l'érosion côtière et de mettre en œuvre les actions concertées d'identification, de résolution et d'évaluation des problèmes environnementaux d'intérêt commun ${ }^{983}$. L'article 3 quant à lui précise entre autres tâches, « l'élaboration des projets en vue de la résolution définitive du problème de pollution des eaux marines et des côtes du fait de rejet des boues de phosphates et autres ${ }^{984}$. Pour atteindre ces objectifs, l'accord prévoit la création de deux organes : un comité de pilotage ministériel présidé de façon rotative par les Ministres en charge de l'environnement des deux parties et un comité technique paritaire présidé de façon rotative par un cadre de haut rang de chaque partie.

Au regard de ce qui précède, il apparait plus ou moins clairement que le Bénin, en dépit des manifestations fragrantes de pollution marine sur ses côtes

981 "Conclusions et recommandations " de la rencontre entre les deux délégations ministérielles, Cotonou, MEHU, 2 février 2001.

982 Cf. Annexe n`IV : Accord de coopération entre le Bénin et le Togo

983 Communication en conseil des Ministres, $n^{\circ}$ 0046/MEHU/DC/CTUA/SGM/DGE/SP-C du 9 décembre 2011 portant autorisation de signature à Lomé le 15 décembre 2011, d'un accord de coopération entre la République du Bénin et la République togolaise, relatif à la gestion durable de l'environnement et des ressources naturelles et instituant un partenariat entre le Ministère de l'Environnement, de l'Habitat et de l'Urbanisme (MEHU) du Bénin et le Ministère de l'Environnement et des Ressources Forestières (MERF) du Togo. Idem. 
par le voisin togolais, a opté pour un règlement à l'amiable. Autrement dit ce règlement ne tient pas compte du droit pénal de l'environnement mais plutôt du droit administratif ou plus précisément du droit international public. II s'ensuit qu'en droit des pollutions transfrontières, le droit pénal n'intervient que très rarement. Le droit pénal d'ailleurs, n'intervient généralement que si toutes les autres voies de droit ont été épuisées.

Cependant, remarquons que le Bénin pouvait également explorer la voie judiciaire à condition que sa prétention, pour qu'elle ait un fondement juridique, et déférée devant les tribunaux, soit appuyée de documents scientifiques qui établissent la preuve de l'infraction de rejet de substances nuisibles ou dommageables à l'environnement marin au sens de pollution transfrontière. En droit de l'environnement plus qu'en droit commun, cela n'est pas facile à démontrer. Il se pose dès lors, le problème de la compétence juridictionnelle des infractions liées à cette forme de pollution.

\section{§II : La compétence des tribunaux en matière de pollution environnementale transfrontière}

Selon le professeur Yves MAYAUD, la compétence des juridictions internes dans le domaine international pénal repose sur trois critères principaux : celui de la territorialité, en application duquel sont compétentes, pour appliquer leur droit national, les juridictions du pays où l'infraction a été commise, celui de la personnalité active, qui attribue compétence aux juridictions du pays dont l'auteur de l'infraction est le ressortissant, et enfin celui de la personnalité passive, par lequel sont désignées comme pouvant appliquer leur loi nationale les pays dont les victimes sont les ressortissants. Tous ces critères conjugués débouchent naturellement sur des conflits de compétences, plusieurs juridictions de pays différents pouvant revendiquer l'application de leur droit national pour une même infraction. ${ }^{985}$ Cette situation, qui n'est déjà pas confortable en droit commun, se trouve manifestement aggravée en rapport avec les atteintes à

985 MAYAUD (Yves), Regional Conference on "environmental Crimes in the Arabs states, "Criminal responsibility arising from environmental crimes", Mars 17-18, 2009. Beirut -Republic of Lebanon. Sources: internet. www.yvesmayaud.3pdf 
l'environnement. En effet, compte tenu de la spécificité de ces atteintes qui se traduisent par des effets diffus, il en découle que les victimes peuvent être nombreuses, et avec elles les juridictions pour prétendre leur rendre justice. II n'est pas évident de régler cette concurrence, et il ne peut qu'en résulter une déperdition de réaction; la juridiction nationale qui semble finalement la mieux adaptée intègre difficilement dans sa démarche processuelle la dimension internationale des faits.

Dès lors, il conviendra de cerner le régime juridique, complexe et difficile de la pollution environnementale transfrontière. Pour ce faire, nous analyserons la réponse pénale aussi bien au niveau du droit interne à travers les tribunaux de I'Etat pollueur que de l'Etat victime (A) mais aussi au niveau du droit international à travers les tribunaux internationaux (B).

\section{A) Les tribunaux à compétence interne}

Lorsque le dommage ou le risque sérieux de dommage (concret) qui fonde une infraction particulière contre l'environnement se produit à l'extérieur de l'Etat ou l'infraction a été commise, que ce soit totalement ou en partie, il devrait être possible de poursuivre son auteur dans l'Etat où l'infraction a été commise, ou dans tel autre Etat où le dommage ou le risque sérieux de dommage, se produit à condition que les droits de la défense soient garantis et, dans le respect du droit international applicable. La solution de plus en plus acceptée est le règlement entre individus à l'intérieur des Etats en ayant recours au droit privé plutôt qu'au droit international public. Lorsqu'un habitant d'un Etat subit des préjudices dus à une pollution provenant d'un autre Etat, il peut intenter une action civile ou pénale contre le pollueur. II reviendra au tribunal d'établir le lien de causalité, d'identifier le pollueur et d'évaluer la peine encourue en fonction des textes existants.

\section{1) La compétence des tribunaux de l'Etat pollueur}

Le principe pollueur payeur, principe cardinal en droit de l'environnement exige de celui par qui le préjudice est arrivé à le réparer. C'est pourquoi, l'Etat à 
l'origine de la source de pollution serait tenu donc responsable vis-à-vis de l'Etat victime. En l'espèce, c'est le droit national de ce pays qui s'applique. A cet égard, un problème d'ordre général peut se poser. On pourrait se demander quelle serait le degré de responsabilité de l'Etat lorsque l'infraction transfrontière est occasionnée par une entreprise privée ? En effet, il est évident, que la plupart des actes de pollutions découlent des activités de personnes privées ou de personnes morales de droit privé se trouvant sous la juridiction de l'Etat ayant occasionné la source de pollution. La plupart du temps, ces activités sont des activités légales, régulièrement autorisées. La règle générale semble être que l'Etat dont le territoire sert de support aux activités causant des préjudices écologiques hors de ses frontières, ou sous le contrôle duquel a eu lieu l'acte dommageable, soit responsable pour le dommage qui en résulte. Les tribunaux de cet Etat sont donc compétents pour connaitre du contentieux pénal dès qu'une action serait engagée contre la personne physique ou l'entreprise responsable de la pollution. Puisque le droit pénal ne s'applique qu'aux individus ou aux sociétés et non aux personnes morales publiques comme l'Etat. Mais le professeur Yves MAYAUD, dans ses analyses semble n'être pas de cet avis. II reconnait certes, que "l'Etat est une entité insusceptible de sanctions pénales », mais il constate "que nombres de sanctions peuvent rester impunies tout simplement parce qu'elles trouvent leurs sources dans les initiatives des Etats eux-mêmes, ou de leur émanation. Dès lors, il estime que les Etats doivent pouvoir engager leur responsabilité lorsqu'ils interviennent, non en tant qu'autorité régalienne, mais comme un simple rouage, public ou privé, dans la chaine de production ou de distribution de biens. Il s'agit en quelque sorte de réserver la responsabilité à ce qui serait attentatoire à l'environnement indépendamment de l'exercice de prérogatives de puissance publique ${ }^{986}$. Maitre HUGLO, faisant allusion au droit civil, opte quant à lui pour une action récursoire, l'éventuelle possibilité pour l'Etat reconnu coupable de se retourner contre l'auteur matériel du dommage (l'entreprise) $)^{987}$.

986 MAYAUD (Yves), La responsabilité pénale découlant des crimes environnementaux, op.,cit. 987 Cité par CURRAT (Philippe), in, La pression de l'environnement sur le droit international, article, 2009. Source : www.philippecurrant. 
En Europe selon une certaine doctrine, qui s'oppose à la doctrine de l'ubiquité ${ }^{988}$, le droit national favori semble être la juridiction compétente du domicile du défendeur, donc de l'Etat pollueur. Car, ce dernier peut mieux se défendre devant les tribunaux locaux, d'autant plus que la preuve de la responsabilité incriminée peut être plus facilement apportée, les témoins disponibles et plus facilement convoqués et l'exécution du jugement en faveur du plaignant est assurée $e^{989}$. Mais en droit de l'environnement, les défendeurs sont généralement plus forts ou plus puissants. Dès lors, l'on peut craindre que les juges de l'Etat pollueurs aient tendance à protéger d'une manière ou d'une autre les intérêts socio-économiques du pollueur et ne pas protéger suffisamment ceux de la victime.

Dans cette logique, considérons l'hypothèse où le Bénin porte plainte contre le Togo dans l'affaire de pollution marine précédemment décrite. Dans ce cas de figure, l'affaire peut être déférée devant les tribunaux togolais par l'intermédiaire de la personne morale que représenterait le regroupement des pêcheurs riverains victimes, s'il est organisé en association des pêcheurs victimes des conséquences de l'entreprise qui exploite le phosphate togolais ${ }^{990}$ Le pollueur étant chez lui, et compte tenu de l'importance de cette entreprise pour l'économie togolaise, "la balance des intérêts " peut beaucoup jouer en faveur de la partie défenderesse.

Outre cette action directe en justice que pourrait intenter toute personne physique ou morale directement exposée aux aléas de cette pollution, l'Etat victime lui-même peut aussi exercer une action en justice contre l'Etat du pollueur dont relève l'entreprise. Mais en dépit de l'acceptation générale de cette responsabilité de l'Etat pollueur, «peut de plaintes en responsabilité international ont été déposées par des Etats $»^{991}$. Alors que la tendance générale,

988 Cf. infra p.388, A) 2. note $n^{\circ} 1004$

989 KISS (A), et SHELTON (D), Traité de droit européen de l'environnement, éd. Frison-Roche, Paris, 1995

990 Dès l'origine en 1957 c'est la Compagnie Togolaise des Mines du Bénin, en 1974 elle devient Office Togolais de phosphates, en 2002 International Fertilizer Group (IFG) Togo, et en 2007 Société Nouvelle des Phosphates du Togo (SNPT). Site officiel OTP http://www. otp.tg

991 KISS (A), et SHELTON (D), Traité de droit européen de l'environnement, éd. Frison-Roche, Paris, 1995. 
est que le droit international interdit à un Etat de faire sur son territoire des travaux qui causeraient un préjudice grave au territoire d'un autre Etat. ${ }^{992}$

D'autres auteurs font aussi remarquer que « le droit international public interdit aux Etats d'entreprendre certaines actions dans les régions frontalières » et mentionnent que la pollution des eaux internationales qui entraînent des conséquences nuisibles sur le territoire de l'Etat victime du préjudice, constitue une action interdite par le droit international. ${ }^{993}$

Par ailleurs, on peut rappeler dans une deuxième hypothèse, l'exemple, déjà cité, de la décharge des déchets toxiques aux larges des côtes de la ville d'Abidjan en Côte-D'ivoire. Outre la compétence des tribunaux ivoiriens, les autres pays impliqués d'une manière ou d'une autre dans cette affaire soit en tant qu'Etat du pavillon (Panama), soit en tant qu'Etat d'exportation ou d'embarquement des slops (Pays-Bas), soit en tant qu'Etats de transit (Nigeria et Estonie), peuvent voir aussi leurs tribunaux se déclarer compétents dans le contentieux pénal du fait de degré de leur responsabilité dans l'instance pénale. ${ }^{994}$; et ce, à condition qu'il soit établi que l'un des éléments de l'infraction ce soit déroulé. Ainsi, dans le cas d'espèce, les tribunaux des Pays-Bas et naturellement de l'Etat victime se sont déclarés compétents et ont jugé et condamné les auteurs de ces déversements de déchets dangereux ${ }^{995}$; d'où la compétence des tribunaux de l'Etat victime est établie.

\section{2) La compétence des tribunaux de l'Etat victime}

Dans de nombreux Etats du Conseil de l'Europe, la compétence conformément au principe de territorialité, se détermine en s'appuyant sur ce qu'on appelle la doctrine de l'ubiquité ou des « effets ». Celle-ci signifie qu'une

992 ANDRASSY (A), Les relations internationales de voisinage. Recueil des cours de l'Académie de la Haye, vol.79, 1951, p.95 cité par ASSEMBONI (Alida), op.cit., p.175.

993 Hans THALMANN, cité par ASSEMBONI (Alida), op.cit., p.176

994 Rapport de la commission internationale d'enquête sur les déchets toxiques déversé dans le district d'Abidjan ; par BOGUI ZIRIYO, (Président), Côte-D'ivoire, 19 février 2007, pp.5572

995 Aux Pays-Bas, le capitaine du Probo Koala a été condamné à une amende d'un million de dollar. 
infraction peut être considérée comme ayant été commise à l'endroit où une partie de celle-ci l'a été. Autrement dit, une infraction peut être considérée comme avoir été commise à l'endroit où ses conséquences et ses effets se sont manifestés ${ }^{996}$. En droit pénal de l'environnement, l'application de cette doctrine peut se confronter à des difficultés. En effet, les délits abstraits qui se caractérisent par la violation d'une obligation administrative, ne peuvent pas se manifester au-delà des frontières, n'étant pas des infractions matérielles ou autonomes. Dans ce cas, il nous semble adéquat que l'Etat du pollueur soit compétent. Si par contre, il s'agit d'un délit autonome, qui ne tienne pas compte de violation de normes administratives, le tribunal compétent serait celui de la victime.

Dès lors, on peut valablement soutenir que c'est bien les personnes privées ou morales victimes qui devraient avoir le bénéfice de leurs propres tribunaux, d'autant plus que la preuve et l'évaluation du préjudice seront plus faciles à réunir devant la juridiction de la victime. C'est, semble -t-il la voie la plus naturelle et sans doute, celle par laquelle il faut commencer, de manière à afficher à la fois la densité de l'argumentation et la fermeté des victimes d'obtenir réparation. En outre, la victime ne devrait pas avoir à supporter les frais d'un procès dans un pays étranger. Le principe de territorialité suppose que le prévenu soit jugé et condamné selon le droit de l'Etat où le délit ou le crime a été commis, indépendamment de sa nationalité ${ }^{997}$, même s'il y a la possibilité d'extrader le mise en cause. Ainsi, si nous considérons l'hypothèse relative au contentieux entre le Bénin et le Togo, en l'espèce, le tribunal béninois, est semble t-il mieux indiqué pour connaitre de ce contentieux pénal au même titre que le tribunal ivoirien dans le cas de la deuxième hypothèse ${ }^{998}$. Car la victime, étant sur place, elle pourrait mieux s'organiser pour soutenir sa requête.

Mais le risque est grand que le défendeur, qui a élu domicile dans un autre pays ne se présente pas le jour de l'audience. D'où la coopération de

996 Convention sur la protection de l'environnement par le droit pénal. Rapport explicatif. Conseil de l'Europe, Edition du Conseil de l'Europe F.G7075 Strasbourg Cedex, février 2000, pp.8-9.

997 Hans A. ENGELHARD, Protection de l'environnement par le droit pénal, Rapport, présenté devant le comité des Ministres le 5 juin 1990, pp.295-310

998 En Côte-d'Ivoire, plusieurs condamnations ont été prononcées. Cf., supra chapitre IV. 
I'Etat abritant l'entreprise pollueur, est nécessaire pour conduire à son terme la procédure pénale. C'est dans ce cadre que pourrait intervenir au besoin, la procédure d'extradition du prévenu.

Mentionnons que la responsabilité de l'Etat pollueur est ainsi engagée. Car l'Etat, a l'obligation d'imposer un régime de contrôle et de surveillance des activités menées sur son territoire et qui pourraient être préjudiciables à l'environnement dans un autre Etat. Cette obligation de prudence et de prévention, consisterait à la mise en place de régime d'autorisation imposée à des installations pouvant porter préjudice à l'environnement. Autrement dit, l'Etat se doit d'appliquer la même règle selon laquelle sa compétence territoriale s'exerce non seulement dans les limites de sa juridiction, mais aussi partout ailleurs où il doit exercer un contrôle. II en résulte enfin, l'obligation pour les Etats de ne pas causer de dommage à l'environnement dans des lieux échappant à toute compétence territoriale tels que la haute mer, son lit et l'espace aérien qui la surplombe, les grands fonds marins, l'Antarctique, ainsi que l'espace cosmique, la lune et les autres corps célestes. ${ }^{999}$

Par ailleurs, I'Institut de Droit International, s'inscrit dans cette logique lorsque dans sa résolution sur la pollution transfrontière de l'air, il précise que : « tout en reconnaissant aux Etats le droit souverain d'exploiter leurs ressources selon leur propre politique de l'environnement, souligne cependant leur devoir de prendre également toutes les mesures propres à assurer que leurs activités ou celles exercées dans les limites de leur juridiction ou sous leur contrôle ne pose pas de pollution transfrontière de l'air $»^{1000}$.

Mais parfois l'incapacité des systèmes juridiques nationaux à appliquer correctement les règles du droit international fait que les Etats recourent de plus en plus au règlement judiciaire international.

999 KISS (A) et Jean-Pierre B, cité par ASSEMBONI (Alida), op.cit., p.167

1000 Résolution de l'I'Institut de Droit international de 20 septembre 1987, Recueil francophone des textes internationaux en droit de l'environnement ; Université francophone, nouveaux supports, version CD Rom. V. aussi RJE, 1989, № spécial, p.217. 
B) Le recours au règlement judiciaire international

Le recours à une juridiction internationale est aussi une possibilité offerte aux Etats et particulièrement à l'Etat victime d'une pollution transfrontière et même aux personnes morales de droit privé. Cette forme de règlement offre deux possibilités à ceux qui ont intérêt à agir. Il peut s'agir de la voie juridictionnelle qui comprend la procédure d'arbitrage et la procédure devant la Cour International de Justice, mais aussi le recours à l'application des conventions internationales en ce qui concerne leur mise en œuvre.

\section{1) Le recours à la procédure d'arbitrage ou à la CIJ}

Dans le cadre du règlement judiciaire, les Etats ont le choix d'engager une procédure en cas de différend, devant soit une commission d'arbitrage soit devant la CIJ. L'arbitrage international selon le lexique des termes juridiques peut intervenir " lorsqu'un litige, soulevant une question de conflits de lois ou de juridictions, est porté devant un ou plusieurs arbitres, avec l'accord des parties ». En effet, l'arbitrage constitue une voie juridictionnelle de règlement des litiges, mais devant une instance qui n'est pas une juridiction nationale. Les deux parties, dans un accord formel appelé compromis d'arbitrage s'engagent à soumettre leur différend à une tierce personne et à respecter les conclusions qui en seront issues. Les parties peuvent y trouver les avantages de la souplesse et, dans certaines conditions, de la rapidité et de la discrétion.

L'un des fondements du droit international de l'environnement est, nous l'avions dit, la sentence arbitrale (1941). Dans ce cas d'espèce, le compromis d'arbitrage comprenait, trois questions posées au tribunal :

- La fonderie de Trail avait-elle causé des dommages à l'Etat de Washington depuis le $1^{\text {er }}$ janvier 1932, si oui quelle indemnité devrait être payée ?

- La fonderie de Trail devait-elle, à l'avenir, s'abstenir de causer des dommages à l'Etat de Washington et si oui, dans quelle mesure ? 
- Quelles mesures et quels régimes devraient être appliqués en vertu de la décision du tribunal ? ?001 $^{101}$

En réponse à ces questions dans l'une de ces décisions rendue le 11 mars 1941, le tribunal énonça ses célèbres conclusions si souvent citées : « tant en vertu des principes du droit international que du droit américain, aucun Etat n'a le droit d'user de son territoire ou d'en permettre l'usage de manière à ce que des fumées provoquent un préjudice sur le territoire d'un autre Etat ou aux propriétés de personnes qui s'y trouvent, s'il s'agit de conséquences sérieuses et si le préjudice est prouvé par des preuves claires et convaincantes ${ }^{1002}$ On considère que " les polluants transfrontières sont prohibés en général par le principe selon lequel aucun Etat ne peut laisser utiliser son territoire aux fins d'actes contraires aux droits des autres Etats. »"1003

Le principe a été introduit dans la déclaration de Stockholm qui l'a étendu en affirmant que les Etats ont le devoir de faire en sorte que les activités exercées dans les limites de leur juridiction ou sous leur contrôle ne causent pas de dommages à l'environnement dans d'autres Etats ou dans des régions ne relevant d'aucune juridiction nationale ${ }^{1004}$.

En ce qui concerne la Cour Internationale de Justice, c'est un organe judiciaire principal des Nations Unies, dont le statut est annexé à la Charte des Nations Unies (article 92 de la charte). Cet organe est composé de 15 juges indépendants. Sa compétence doit être explicitement acceptée par les Etats, soit par une déclaration générale relative à tous les différends entre les Etats qui ont accepté la juridiction de la cour, soit par un accord spécial pour un cas précis.

1001 Source: Repots of International Arbitral Awards, vol.3, pp.1903-1982. Cite par Lothar) GUNDLING, Droit international de l'environnement: atmosphère, eau douce et sol, Cours 7, UNITAR, Genève 1998, pp.21-23.

1002 Idem.

1003 CIJ, arrêt du 9 avril1949, affaire de Corfou (fond), Recueil, 1949, p.22, cité par A. KISS \& C. LAMBRECHTS, in, Environnement et droit de la mer : L'accord entre le Canada et les USA relatif à la qualité des eaux dans les grands lacs. V. aussi (L) GUNDLING, Droit international de l'environnement : atmosphère, eau douce et sol, Cour 7 UNITAR, 1999; et aussi. Reports of International Arbitral Awards, vol.3, pp.1903-1982 
Les décisions de la Cour sont toujours obligatoires et doivent être exécutées ${ }^{1005}$. Cette cour s'est dotée même d'une chambre spéciale pour connaitre les cas relatifs à la protection de l'environnement ${ }^{1006}$. Mais elle n'a été encore saisie d'aucun dossier.

Néanmoins, pendant la longue période qui a suivi, dans le milieu international, des cas flagrants de pollutions transfrontières n'ont jamais donné lieu à la moindre réclamation officielle de la part du gouvernement de l'Etat victime, désireux de ne pas troubler les relations avec l'état pollueur ${ }^{1007}$. Ainsi, aucune juridiction internationale et aucun tribunal arbitral n'ont traité de cas liés à l'environnement, comme ils auraient pu le faire, en dépit du fait que de nombreux traités relatifs à la protection de l'environnement déclarent que les différends résultant de l'application ou de l'interprétation de leurs clauses doivent être soumis à la $\mathrm{CIJ}$ soit à l'arbitrage. Pratiquement, tous les traités adoptés récemment dans ce domaine comprennent de telles dispositions.

Au plan planétaire, la Cour Pénale Internationale, pourrait jouer aussi un rôle pénal essentiel. Elle est à nos jours, le seul tribunal compétent pour connaitre du contentieux pénal. C'est une institution de l'ONU qui peut, contrairement à la $\mathrm{CIJ}$, exercer sa compétence uniquement à l'égard des personnes physiques ${ }^{1008}$ " pour les crimes les plus graves ayant une portée internationale (...) elle est complémentaire des juridictions pénales nationales» ${ }^{1009}$. Autrement dit, lorsqu'une juridiction d'un Etat Partie se trouve dans l'incapacité de juger les auteurs d'une infraction extraterritoriale ou internationale, il a la possibilité de saisir ce tribunal.

Mais, la CPI a des limites. Son champ d'application est limité au crime de génocide, au crime contre l'humanité et au crime de guerre. Les crimes contre

1005 KISS (A), Introduction au droit international de l'environnement. Cours 1, UNITAR, Genève 1997, p.72

1006 Idem, p.73

1007 KISS(A) \&(D) SHELTON, Traité de droit européen de l'environnement, ed. Frison-Roche, Paris, 1995.

1008 Art.25 du Statut de Rome, «la responsabilité pénale est individuelle».

1009 Art.1er du Statut de Rome de la CPI 
l'environnement n'en seraient pas encore concernés ${ }^{1010}$, du moins expressément. La question se pose de savoir si à la lecture de l'article 7(1) du Statut de Rome, il y a encore place pour une infraction environnementale. ${ }^{1011}$

Au plan régional, les institutions régionales I'UEMOA, la CEDEAO ou I'UA, pour ne citer que celles-là, n'ont pas de juridictions à compétence environnementale. Dès lors, la saisine de ces institutions en cas de crime contre l'environnement ne serait que vaine. C'est pourquoi, il urge que les Etats engagent des réflexions en vue de créer une institution ou doter l'une de celles qui existent d'une chambre ou d'une cour compétente en cette matière, pour connaitre des crimes écologiques, particulièrement graves.

C'est donc, tenant compte de ce déficit en matière de juridiction pénale, qu'il est d'ores et déjà envisagé la question de la création d'une cour internationale de l'environnement, une nouvelle juridiction spécialisée, en vue de mieux sanctionner les atteintes à l'environnement. Mais la procédure suppose, à l'instar de la création d'une Organisation Mondiale de l'Environnement (OME), l'adoption d'une convention interétatique beaucoup plus lourde. C'est pourquoi, il conviendrait déjà d'envisager d'élargir la compétence de la CPI aux crimes environnementaux les plus graves pour assurer une meilleure justice aux populations ${ }^{1012}$. Faisant observer que le Statut de la CPI vise déjà, en cas de conflit armé, un crime de guerre par attaque délibérée de l'environnement

1010 Art.7(1) du Statut de Rome 1998. V. aussi art.2 de la Convention pour la prévention et la répression du crime de génocide du 9 décembre 1948. 78 R.T.N.U. 227, conclue à New York le 9 décembre 1948, texte original. http://www.dfae.admin.ch/traties.

1011 A cette préoccupation, MANIRABONA, dans sa thèse citée plus haut, pense que l'article $7(1)$ dont le dernier point (k) met l'accent sur " autres actes inhumains de caractère analogue causant intentionnellement de graves souffrances ou des atteintes graves à l'intégrité physique ou à la santé physique ou mentale ", peut s'interpréter de manière extensive. L'auteur s'appuyant sur la jurisprudence du Tribunal Pénal International du Yougoslavie et du Tribunal Pénal International du Rouanda et également des activités polluantes des multinationales dans certains pays du Sud, notamment dans le secteur minier et des hydrocarbures avec pour conséquences des activités portant atteintes à la santé humaine et à l'environnement, conclue que les crimes contre l'environnement peuvent être éligibles comme crime de génocide ou crime contre l'humanité et que la CPI peut se déclarer compétente.

1012 C'est dans ce cadre qu'une proposition de la commission du droit international, est en cours d'examen par l'Assemblée Générale des ONU. Cf.XVème congrès international de droit pénal, ReAIDP/eRIAPL, 2006, D.01, p.123. 
nature ${ }^{1013}$, Laurent NEYRET propose soit d'étendre le paradigme du crime contre l'humanité, soit d'imaginer un nouveau paradigme, celui d' "écocide», inspiré de la déclaration de I'UNESCO sur la bioéthique, qui consacre un principe de protection de l'environnement, de la biosphère et de la biodiversité ${ }^{1014}$.

D'autres initiatives du genre sont encours. Il s'agit par exemple des réflexions des Professeurs Jean UNTERMAIER et Yves MAYAUD qui ont travaillé ces dernières années, en collaboration avec le milieu judiciaire français (Lyon), particulièrement M. le Bâtonnier Philippe GENIN. II s'agit de proposer à l'Organisation des Nations Unies, la mise en place d'une Cour pénale internationale, qui pourrait être dénommée "Arche de justice pour la terre ". Outre le symbole qu'elle représenterait à l'échelle mondiale en termes de défense de l'environnement, cette haute instance enrichirait la compétence universelle d'une dimension institutionnelle non négligeable, en ayant l'avantage de rompre avec un système de justice nationale. ${ }^{1015}$

Ainsi, en attendant la mise en place d'une juridiction pénale spécialisée en environnement, pour gérer leur litige transfrontalier, dans la pratique, les Etats préfèrent s'orienter vers la voie diplomatique pour régler leurs contentieux.

\section{2) Le recours à l'application des conventions internationales environnementales}

Le caractère transnational ou interétatique du règlement des préoccupations environnementales à amener les Etats à conclure des accords bilatéraux ou multilatéraux, parfois sous l'égide de la communauté internationale. Ces accords, règlent entre autres, la question de savoir quelle

1013 « le fait de lancer une attaque délibérée en sachant qu'elle causera incidemment des dommages aux biens de caractère civil ou des dommages étendus, durables et graves à l'environnement naturel qui serait manifestement excessifs par rapport à l'ensemble de l'avantage militaire concret et direct attendu ". Art.8 (2) iv, Statut de Rome de la CPI

1014 NEYRET (Laurent), La transformation du crime contre l'humanité, in Delmas-Marty, Fouchard, Fronza et Nyret, PUF, 2009, p.81.

1015 MAYAUD (Yves), Regional Conference on "environmental Crimes in the Arabs states, "Criminal responsibility arising from environmental crimes", Mars 17-18, 2009. Beirut -Republic of Lebanon. Sources: internet. www.yvesmayaud.3pdf 
sera la juridiction compétente ou la loi applicable. Il en est ainsi de la convention de Genève sur les polluants transfrontières à longue distance(1979), de la convention de Bâle (1989), de la convention de Bamako(1991), des conventions de la génération de Rio(1992) ${ }^{1016}$, de la convention de Montego Bay (1982), de la convention Marpol (1973/78), la convention du Conseil de l'Europe sur la protection de l'environnement par le droit pénal ; la convention d'Abidjan (1981) etc. Toutes ces conventions prévoient les mécanismes juridiques applicables en cas d'infractions ou d'atteinte à l'environnement.

Par exemple, le mécanisme juridique proposé par la convention Marpol qui, semble t-il est au centre du régime international de protection du milieu marin, renvoi l'application des sanctions pénales au droit national, des Etats parties.

En disposant d'une part, que " toute violation des dispositions de la convention est sanctionnée par la loi de l'Etat dont dépend le navire, quel que soit le lieu de l'infraction ", la Convention Marpol vise la loi et les tribunaux de l'Etat du pavillon et d'autre part, en énonçant que « toute violation des dispositions de la convention commise dans la juridiction d'un Etat contractant est sanctionnée par la législation de cet Etat ", la Convention Marpol attribue compétence aux lois et tribunaux de l'Etat " côtier » : par exemple, les lois et tribunaux français sont compétents pour juger toute infraction de rejet commise, même par un navire étranger, dans les eaux territoriales françaises et dans la zone économique française des 200 milles marins.

Au regard des mécanismes que proposent ces conventions, on peut expliquer d'une manière ou d'une autre le fait que les juridictions internationales n'aient pas été jusqu'à maintenant plus utilisées pour le règlement des différends en matière d'environnement. Une explication pourrait être que, dans de nombreux traités internationaux relatifs à l'environnement, les dispositions relatives au règlement des différends prévoient aussi le recours aux organismes créés à cet effet, tels que la Conférence des Parties ou un comité d'application,

1016 La convention des ONU sur la diversité biologique (1992), la convention cadre des ONU sur les changements climatiques (1992), la convention des ONU sur la lutte contre la sécheresse et la désertification (1994). 
pour les questions d'application et d'interprétation du traité concerné peuvent soulever, la rédaction de rapports périodiques.

Une autre explication possible serait que les Etats préfèrent manifestement donner la priorité à l'indemnisation des victimes de la pollution transfrontière ou d'autres effets dangereux pour l'environnement, plutôt que de s'engager dans des négociations internationales ou des procédures judiciaires de règlement des différends très longues et fastidieuses. La solution qui est de plus en plus acceptée est de transférer les problèmes concrets du niveau interétatique au niveau interpersonnel. Supposons qu'un élément transnational soit présent dans un cas qui pourrait créer des problèmes juridictionnels ou interétatiques; par exemple une pollution industrielle endommage une propriété privée dans un Etat voisin, on conseille au pollueur et à la victime de porter l'affaire devant les autorités internes qui sont compétentes d'après les règles du droit international privé ${ }^{1017}$.

\section{SECTION II : LA COMPETENCE NON JURIDICTIONNELLE DE REGLEMENT DE CONFLIT EN DROIT DE L'ENVIRONNEMENT}

En matière de contentieux de pollution environnementale transfrontière ou en toute autre matière de dégradation de l'environnement, le recours aux règlements non juridictionnel, semble être la voie la plus utilisée par les Etats. Plusieurs raisons dont entre autres celles liées à la coopération interétatique de bon voisinage (§I) expliquent et fondent le caractère mou des sanctions environnementales au plan international (§II).

\section{§I : La coopération interétatique de bon voisinage}

Tous les efforts d'un pays sont impuissants devant une pollution qui dépasse les limites territoriales. Aucun gouvernement ne pourra persuader les

1017 KISS (A), Introduction au droit international de l'environnement. Cours 1, UNITAR, Genève 1997, p.73 
oiseaux migrateurs de rester sur le territoire national, de renoncer au voyage qu'ils opèrent depuis des milliers de générations, pour mieux les protéger. Une protection efficace, voire durable de l'environnement ne peut être réalisée que grâce à la collaboration internationale ${ }^{1018}$.

Bien que chaque Etat souverain soit libre de conduire ses relations externes en fonction de ce qu'il considère être son intérêt, le droit international de l'environnement a développé une obligation générale de coopérer avec les autres afin de résoudre les problèmes qui concernent la communauté internationale. Le Principe 24 de la Déclaration de Stockholm est au cœur de cette coopération internationale ${ }^{1019}$. La création de nombreuses institutions internationales correspond aussi au besoin de coopération, laquelle peut se décliner d'une part en un devoir d'information et de consultation dans les relations transnationales et d'autre part en un devoir d'information et d'assistance en cas de sinistre ou de crime écologique.

\section{A) L'information et la consultation dans les relations transnationales}

En dehors des situations d'urgence ou une notification rapide et une assistance possible sont exigées, un Etat qui projette d'entreprendre ou d'autoriser des activités susceptibles d'avoir des effets mesurables sur l'environnement d'un autre Etat doit informer ce dernier et devrait lui transmettre les détails pertinents du projet, dans la mesure où la soumission des informations n'est pas interdite par la législation nationale ou par un traité international applicable. Cette position préventive est bien confortée par les Principes 21 et 22 de la Déclaration de Stockholm confirmée par les principes 19 et 27 de la Déclaration

1018 SZONYI DANDACI (Amira), La convention sur la protection de l'environnement par le droit pénal, article, RJE, 3/2003

1019 Le même principe est réaffirmé par la Charte mondiale de la nature de 1982. L'art.197 de la convention des ONU sur le droit de la mer et son art.192 qui précise que « les Etats ont l'obligation de protéger et de préserver le milieu marin » 
de Rio ${ }^{1020}$. Le principe 19 dispose par exemple que : " les Etats doivent prévenir suffisamment à l'avance les Etats susceptibles d'être affectés et leur communiquer toutes informations pertinentes sur les activités qui peuvent avoir des effets transfrontières, sérieusement nocifs sur l'environnement et mener les consultations avec ces Etats rapidement et de bonne foi $»^{1021}$. La bonne foi est une exigence générale dans les relations interétatiques et est particulièrement importante dans les effets de certaines activités. Ainsi, " les consultations et les négociations se déroulent selon le principe que chaque Etat doit de bonne foi tenir raisonnablement compte des droits et des intérêts légitimes de l'autre Etat $\aleph^{1022}$. Le même principe a été formulé dans plusieurs traités internationaux relatifs à des sujets spécifiques comme la pollution de l'air, des rivières, des lacs ou de la mer.

Dès lors, l'une des conséquences de ce principe qu'on pourrait déduire est que les Etats devront prévenir les autres Etats, même si les activités sont projetées par des acteurs non étatiques, tels que des sociétés ou entreprises de droit privé nationales ou multinationales, des individus où même des communautés locales. Cette obligation peut se comprendre dans un contexte où les activités qui sont potentiellement dangereuses pour l'environnement sont soumises à autorisation par l'Etat d'accueil de l'entreprise qui vérifie la conformité des activités avec le droit national de protection de l'environnement avant d'autoriser.

Aussi, la notification doit se faire à temps utile. C'est-à-dire que les plans du projet d'activité doivent être dans une phase initiale quand l'autre Etat se les voit notifier, pour qu'ils puissent être modifiés, afin, qu'au besoin, le site choisi puisse être déplacé ou même l'activité soit repoussée ou interdite.

1020 Action 21,. Déclaration de Rio sur l'environnement et le développement, Déclaration de principe relatif aux forêts. Principaux textes de la Conférence des ONU sur l'environnement et le développement

ONU, New York, 1993. ONU, New York, 1993. pp.3-5. La catastrophe de Tchernobyl du 26 avril 1986 a souligné l'importance d'une telle notification.

1021 Idem.

1022 Art.17(2) conventions des ONU sur les utilisations des cours d'eau internationaux à des fins autres que la navigation. 
Mais la question se pose de savoir quels détails techniques devraient être notifiés. D’après le texte rédigé par la Commission du droit international des Nations Unies chargée de la codification du droit des utilisations des cours d'eaux internationaux à des fins autres que la navigation, la notification en temps utile des mesures prévues devraient être accompagnée des données techniques et des informations disponibles afin de mettre l'Etat auquel elle est adressée à même d'évaluer les effets éventuels des mesures prévues. Le mémorandum d'accord entre les USA et le Canada concernant l'affaire de pollution de l'air transfrontière inclut, dans les informations à transmettre, les changements de politiques proposées, les réglementations ou les pratiques qui peuvent affecter d'une manière significative la pollution de l'air transfrontière à longue distance. De son côté, le critère pour déterminer l'ampleur des effets négatifs proposé par la Déclaration de Rio est l'»effet significatif», qui constitue un seuil moins précis et probablement plus bas que l'»effet nocif» ou le "dommage». Cette approche semble généralement adoptée, puisqu'aucune meilleure approche n'a été trouvée ${ }^{1023}$.

Dans la pratique, rien de tout cela ne se passe entre Etats, notamment en Afrique. Au mépris des textes internationaux, l'information et la notification ne se font presque pas. A preuve, l'entreprise togolaise de phosphates, continuent allègrement de polluer les eaux marines béninoises sans que les autorités compétentes ne comprennent et ne reçoivent aucune information ou notification en rapport auxdites activités. Or normalement, un Etat en amont d'une rivière internationale qui cause une grave pollution à cette rivière où s'il est informé qu'une importante inondation menace l'Etat en aval, il a le devoir $d^{\prime}$ informer ce dernier ${ }^{1024}$. De telles dispositions devraient être incluses dans les divers accords bilatéraux.

Un autre exemple est relatif aux déversements des déchets à Abidjan. A ce sujet, le rapport international d'enquête à clairement établi la non coopération des Etats traversés par le Probo Koala alors que ces Etats étaient bien informés

1023 KISS(A), Introduction au droit international de l'environnement, Cours 1, UNITAR, 1999, pp.98-100.

1024 Idem. p.93 
du contenu de la cargaison en partance pour l'Afrique ${ }^{1025}$. Les " autorités de ces pays avaient de bonnes raisons de croire que le port de destination où il est prévu (port d'Abidjan) de déposer les déchets ne disposent pas d'installations adéquates ou que ce port n'est pas connu et qu'il y a, par conséquent, un risque que les déchets soient déversés en mer " concluait le rapport à l'égard de ces pays. Mieux l'Etat d'exportation qu'est la Côte d'Ivoire n'avait pas donné son accord pour l'importation de ces déchets contrairement à la Convention de Bâle ou à la convention de Bamako qui en disposent ainsii ${ }^{1026}$.

Dans les relations transnationales en matière de pollution, il faut non seulement asseoir une politique préventive permettant une meilleure circulation de l'information et de consultation des Etats mais aussi assurer une assistance au voisin en cas de survenance du sinistre pour limiter et mieux contrôler les effets du préjudice.

\section{B) L'information et l'assistance en cas d'infraction transfrontière}

En matière $d^{\prime}$ infraction écologique transfrontière, la plupart des conventions internationales bi- ou multilatérales en matière d'environnement, établissent une obligation générale pour les Etats Parties de fournir entre eux toute assistance nécessaire possible et ce, conformément à leur droit national. La réaction en cas de sinistre doit être organisée afin d'assurer une action rapide et efficace, dont la notification n'est que la première étape.

En effet, d'après le Principe 18 de la Déclaration de Rio, " les Etats doivent notifier immédiatement aux autres Etats toute catastrophe naturelle ou toute autre situation d'urgence qui risque d'avoir des effets néfastes soudains

1025 Rapport de la commission d'enquête internationale, op.,cit.

1026 BOGUI(Ziriyo), (Président) Rapport de la commission internationale d'enquête sur les déchets toxiques déversés dans le district d'Abidjan, février 2007. 
sur l'environnement de ces derniers ${ }^{1027}$. Ce principe pose la question de l'aide aux Etats en cas de sinistre écologique. Aussi, dans sa déclaration de principe sur la pollution transfrontière, l'OCDE affirme que les Etats devraient s'entraider, chaque fois que cela est nécessaire, afin de minimiser et si possible, d'éliminer les effets des incidents à l'origine des catastrophes, et qu'ils devraient mettre sur pied des plans d'urgence à cet effet ${ }^{1028}$. On pourrait néanmoins, faire remarquer cependant qu'alors que le principe d'assistance, quand celui-ci est nécessaire, est généralement proclamé, l'assistance elle-même ne constitue pas une obligation générale, dans la mesure où elle ne se traduit pas par des accords spécifiques entre les Etats qui sont, ou qui pourraient être, concernés ${ }^{1029}$.

En outre, c'est l'Etat en situation critique, au sens de la convention d'Abidjan, qui fait la demande d'aide auprès des autres Etats parties à la convention lorsque visiblement ses côtes sont touchées ou sont susceptibles d'être touchées par une pollution. ${ }^{1030}$ L'assistance peut consister à fournir l'expertise ou du personnel compétent pour lutter contre la pollution, des produits et des équipements, des moyens de surveillance et de contrôle, et en assurer le renforcement, l'évacuation des substances polluantes, etc.

En ce qui concerne par exemple la pollution des côtes béninoises par les phosphates togolaises, le Bénin devrait, vu l'importance du préjudice occasionné

1027 La catastrophe de Tchernobyl du 26 avril 1986 a souligné l'importance d'une telle notification. Le fait que les autorités soviétiques n'aient pas signalé à temps aux autres Etats qu'un nuage radioactif s'approchait de leur territoire a eu pour conséquence la conclusion, par la communauté internationale, d'une convention spéciale sur la notification rapide d'un accident nucléaire ou d'une situation d'urgence radiologique, signée seulement cinq mois après l'accident, le 26 septembre 1986 et est entrée en vigueur seulement un mois plus tard.

1028 Cf. document C(74)224, 14 novembre 1974, ILM, 1975, p.234. Cité par A. KISS, Introduction au droit international de l'environnement, op.cit.p.95. V aussi l'article 199 de la convention des ONU sur le droit de la mer qui contient aussi des principes similaires, lorsqu'il dispose que : "...les Etats situés dans la zone affectée, selon leurs capacités, et les organisations internationales compétentes coopèrent, dans toute la mesure du possible, en vue d'éliminer les effets de la pollution et de la prévenir ou de réduire à un minimum les dommages. A cette fin, les Etats doivent élaborer et promouvoir conjointement des plans d'urgence pour faire fasse aux incidents entraimant la pollution du milieu marin ».

1029 A. KISS, cours 1, op.cit., p.95

1030 Cf. art.8 du Protocole relatif à la coopération en matière de lutte contre la pollution en cas de situation critique, PNUE, Nations Unies New York, 1981. 
par cette pollution, commettre une étude scientifique avec l'appui de la coopération technique compétente pour évaluer les effets et les conséquences et constituer ainsi les éléments de preuves pour une éventuelle assistance ou pour amorcer des négociations en vue d'un règlement des problèmes frontaliers liés à la pollution marine sur le fondement par exemple de la convention d'Abidjan ${ }^{1031}$.

\section{§II : Le mode de règlement pacifique des conflits en matière de pollution transfrontière}

Le besoin d'information ou de recherche d'assistance ci-dessus décrit, s'inscrit nul doute dans la recherche de solutions apaisées aux différends entre Etats au détriment du règlement juridictionnel qui, suite à son caractère contraignant fort redouté, n'apparait en pratique qu'à titre exceptionnel pour régler les conflits entre Etas dans le domaine de la pollution transfrontalière, comme nous l'avions précisé plus haut. Les Etats ont plutôt recourent au règlement non juridictionnel ou règlement diplomatique. Ce mode de règlement amiable, appelle en matière de pollution transfrontière, non pas des sanctions pénales au sens classique du terme mais des sanctions diplomatiques.

\section{A) Les mécanismes de règlement non juridictionnel}

Les modes diplomatiques ou non juridictionnels de règlement des litiges aboutissent généralement à une décision non obligatoire pour les parties, c'est à dire sans force exécutoire. Au regard du droit international et particulièrement du droit international de l'environnement, ces modes constituent en général la première phase applicable à un conflit. Le mode juridictionnel n'intervient qu'après l'échec des négociations.

1031 Convention relative à la coopération en matière en matière de protection et de mise en valeur du milieu marin et des zones côtières de la région de l'Afrique de l'Ouest et du centre. PNUE, Nations Unies New York, 1981. 
D'après l'article 33(1) de la Charte des Nations Unies : « les parties à tout différend dont la prolongation est susceptible de menacer le maintien de la paix et de la sécurité internationale doivent en rechercher la solution, avant tout, par voie de négociation, d'enquête, de médiation, de conciliation, l'arbitrage, de règlement judiciaire, de recours aux organismes et accords régionaux, ou par d'autres moyens pacifiques de leur choix ».

De toute évidence, cette disposition contenue dans presque toutes les conventions internationales, s'applique aussi aux différends en matière d'environnement. Ainsi, en matière de contentieux relativement à la pollution transfrontalière, les discussions peuvent se présenter sous diverses formes à savoir : la négociation, les bons offices, l'enquête internationale, la médiation et la conciliation. Passons en revue très rapidement ces différentes formes de règlement non juridictionnel.

\section{1) La négociation}

En cas de différend entre Etats, les usages diplomatiques exigent d'engager des discussions ou des négociations. La négociation signifie les propositions faites par l'une ou l'autre des parties à un différend et la réaction de l'autre partie, incluant les contres propositions, afin de trouver un accord. Les négociations devront être conduites de bonne foi. Les parties doivent examiner avec beaucoup d'attention les propositions de leurs partenaires et essayer de progresser vers un accord. Les actes unilatéraux qui pourraient compromettre le résultat des négociations devraient être évités. 


\section{2) Les bons offices}

Cette forme de négociation qui n'est pas citée par l'article 33(1), est d'usage dans les relations interétatiques. Les bons offices se réfèrent à I'intervention d'une tierce personne qui essaie de persuader les parties à un différend de se réunir pour trouver des moyens pacifiques de règlement du conflit.

\section{3) L'enquête internationale}

L'enquête internationale est l'établissement des faits par un organe indépendant. C'est le cas des déchets toxiques d'Abidjan. Rappelons que le Gouvernement ivoirien a créé deux commissions d'enquête ${ }^{1032}$. Une commission nationale et une commission internationale. La commission d'enquête internationale est dénommée "Commission Internationale d'Enquête sur les Déchets Toxiques dans le District d'Abidjan ". Créée par arrêté n¹68/PM/CAB du 15 septembre 2006 modifié par l'arrêté $n^{\circ} 174 / P M / C A B$ du 26 septembre 2006, elle est une commission indépendante ayant pour mission de :

- Conduire des investigations en vue de relever les violations du droit international ayant conduit au déversement de substances toxiques dans le District d'Abidjan ;

- Identifier les personnes physiques ou morales, publiques ou privées, impliquées dans ces violations et déterminer leur degré respectif de responsabilité ;

- Déterminer les modalités d'indemnisation des victimes de la part de ces responsables ${ }^{1033}$.

1032 Les Pays-Bas ont créé aussi deux commissions d'enquête.

1033 BOGUI(Ziriyo), (Président) Rapport de la commission internationale d'enquête, précité. 
Généralement à l'issue de l'enquête un rapport administratif est rédigé. II ne lie pas le juge qui ouvre de son côté une information judiciaire ${ }^{1034}$, mais il peut l'inspirer.

\section{4) La médiation et la conciliation}

Le premier consiste à rapprocher les parties à un différend et à leur soumettre des propositions concrètes pour le règlement du différend alors que le deuxième est la combinaison de l'enquête et de la médiation : une tierce personne établit d'abord les faits, puis fait des propositions pour le règlement.

\section{B) Les sanctions non juridictionnelles ou diplomatiques}

L'administration des sanctions non juridictionnelles est la conséquence nécessaire et directe $d u$ non respect des obligations imposées par les conventions. Les sanctions non juridictionnelles s'entendent de toutes sortes de mesures réprobatrices ou répressives applicables, à l'auteur d'une violation des dispositions conventionnelles ou légales, par une autorité autre qu'un organe doté de fonctions juridictionnelles ${ }^{1035}$. Le contexte non juridictionnel des sanctions est le corollaire de l'épineux et récurrent problème de la mise en œuvre des conventions. En général ces sanctions qui peuvent s'appliquer aussi bien à l'Etat en tant que sujet de droit international qu'aux personnes privées en tant que sujet de droit interne ayant intégré en son sein les obligations conventionnelles internationales, sont parfois prévues par les diverses conventions.

1034 Dans cette affaire, trois informations judiciaires ont été ouvertes : en Cote d'Ivoire, aux Pays-Bas et en Estonie.

1035 AMEGANPOE (V) et AVODE(K), (sous la direction de PAQUES(M) et FAURE(M) La force contraignante et le degré d'efficacité variable du droit international matériel et de ses principes naissants. Intensité et la règles selon les secteurs. Les sanctions non juridictionnelles. Cas de l'Afrique., op.cit., p.361. 


\section{1) Les sanctions non juridictionnelles applicables à l'Etat}

En dépit de tout, les sanctions applicables à l'Etat défaillant, le cas échéant, ne sont pas des sanctions pénales au sens classique du terme, mais plutôt un ensemble de commodités pour décourager l'Etat objet, par exemple, d'une source de pollution transfrontalière. II s'agit essentiellement de la publication de rapports sur les faits incriminant l'Etat et au pire des cas fait usage de la possibilité qui existe d'infliger à cet Etat ou aux Etats concernés, la sanction suprême qui est la suspension de cet Etat du bénéfice de la convention.

En ce qui concerne la publication de rapports, il faut préciser qu'elle intervient comme un moyen de pression politique. Pour que cette pression soit réelle et efficace, elle est exercée très souvent par des entités non étatiques. La raison, selon Karine BANNELIER-CHRISKAKIS, est que " les Etats n'aiment guère se faire de mal ${ }^{1036}$. Ce qui explique I'intervention des ONG de défense de l'environnement (Green Peace, UICN,...) plus que la Conférence des Parties, puisqu'elles détiennent une force de pression sur les Etats et sur toute la communauté internationale. On peut citer le rapport réalisé par l'association SHERPA au sujet de l'affaire des déchets toxiques d'Abidjan ${ }^{1037}$ ou Green Peace dans l'affaire du Raibow Warior ${ }^{1038}$. Elles constituent une disposition d'alerte maximale en cas de crime contre l'environnement et mettent les Etats incriminés «au banc des accusés «. Mais les rapports peuvent être élaborés et publiés aussi par une commission d'enquête internationale et indépendante. C'est le cas dans l'affaire des déchets toxiques d'Abidjan où il a été créé comme nous le disions une commission internationale d'enquête.

Autres formes de sanctions diplomatiques, sont des sanctions d'ordre économique comme l'»embargo» mais aussi les sanctions morales comme «les excuses» publiques ou formelles que pourraient présenter l'Etat victime à l'Etat

1036 IMPERIALI(Claude), in, L'effectivité du droit international de l'environnement, contrôle de la mise en œuvre des conventions internationales, Ed. Economica, 1978.p.8. Cité par AMEGANPOE (V) et AVODE(K), op.cit.p. 366.

1037 Cf. supra note $n^{\circ} 1006$

1038 Cf. supra. Affaire précédemment citée. 
ayant occasionné l'infraction. II en est ainsi, des excuses formelles présentées par la France à la Nouvelle-Zélande dans l'affaire du Rainbow Warior ${ }^{1039}$.

La sanction la plus grave et la plus importante parait être l'éventualité d'une suspension de la convention vis-à-vis de l'Etat défaillant. Elle est prévue par la convention de Vienne sur le droit des traités. Mais en matière environnementale, la suspension d'un Etat des avantages et privilèges d'un traité est-il un moyen efficace ? L'on est tenté de répondre par la négative puisque dans ce cas, l'objectif même du droit international qui est la recherche de la cohésion interétatique s'en trouverait effrité. Dès lors, la persuasion semble être l'arme diplomatique idéale efficace pouvant amener les Etats défaillants à s'associer à l'action globale de protection internationale efficace de l'environnement.

\section{2) Les sanctions non juridictionnelles applicables aux personnes privées}

Au plan du droit interne, les règles internationalement acceptées par l'Etat peuvent être sanctionnées en cas de violation par des personnes privées. Ces sanctions envisagées sont dans leur ensemble d'origine administrative. La détermination des personnes responsables et des sanctions pénales encourues est exclusivement l'œuvre des lois nationales. Les conventions se bornent en générale à fournir quelques directives mais pour l'essentiel, elles abandonnent à chaque Etat le soin d'une part, d'organiser la mise en œuvre procédurale de la répression et de déterminer d'autre part, son étendue. On sait que le régime général consiste en l'établissement et en l'application des règles permissives prohibitives, ponctuées de mesures parfois soumises à autorisation. Les sanctions applicables vont donc du refus d'autorisation, du retrait de permis, de la confiscation du matériel délictueux ou criminel, à la suspension ou à la fermeture purement et simplement de l'entreprise. En revanche, ces sanctions, quoique dissuasives, ne comblent pas toujours les attentes en raison de

1039 Nouvelle-Zélande et Greenpeace contre la France, procédure d'arbitrage (1986-1990). Cf. Décision du Secrétaire Général des Nations Unies, Perez de CUELLAR, New-York, 5 juillet 1986 ; texte dans International Legal Materials 26(1987), p.1346, incluant le rappel des faits et les discussions juridiques entre les deux parties. 
I'insuffisance ou de l'absence des moyens institutionnels, techniques, financiers et humains appropriés pour leur assurer une exécution efficace ${ }^{1040}$.

Pour finir, signalons qu'il nous a paru essentiel d'ouvrir cette perspective sur le droit international de l'environnement dans cette thèse pour éviter que notre travail ait un arrière goût d'inachevé. Nous l'avons voulu ainsi afin d'être en cohérence avec notre vision qui a consisté tout au long de ce travail à prouver l'efficacité du droit pénal interne de l'environnement. Or, une telle efficacité dépend aussi et surtout de l'internalisation par les juridictions répressives nationales des règles et principes du droit pénal international en général et en particulier du droit des pollutions transfrontalières, qui de nos jours, est en plein développement surtout avec la recrudescence des marées noires. C'est ainsi que s'est développé, depuis l'affaire de l'Amoco Cadiz, le principe de la responsabilité des maisons mères et des filiales. Dès lors, en quête de plus d'efficacité, le droit pénal béninois doit s'adapter au droit pénal international de l'environnement afin de permettre à ce dernier de jouer efficacement son rôle de complémentarité.

La responsabilité pénale des pollutions environnementales transfrontières est une responsabilité nécessairement de dimension internationale. En conséquence, faisant preuve de réalisme, on pourrait dire qu'aucune avancée sensible dans le domaine répressif ne pourrait être envisagée si la technique juridique ne se met pas au service de l'universel, donc au service du droit international et particulièrement du droit international pénal. Mais il faut reconnaitre que dans la pratique, se sont surtout les instruments du droit administratif et du droit civil qui sont le plus souvent utilisés dans la lutte contre la pollution. 


\section{CONCLUSION GENERALE}


Le droit pénal, parmi la panoplie de disciplines juridiques existant, nous parait être la discipline la plus adaptée pour résoudre les problèmes de pollutions ou de dégradation de l'environnement. II est évident que pour garantir, réguler et protéger l'équilibre précaire entre les intérêts socio-économiques et les intérêts écologiques, le droit public (entendez droit administratif et droit pénal), joue un rôle plus décisif que le droit civil alors que le droit administratif, quant à lui, demeure intimement lié au droit pénal de l'environnement. Car, le droit pénal ne protège pas l'environnement en général mais l'environnement déjà protégé par l'administration. La dépendance administrative du droit pénal de l'environnement est nécessaire pour atteindre plus d'efficacité mais elle rend difficile l'autonomie du droit pénal. Or, il est nécessaire qu'interviennent des dispositions autonomes ou criminelles pour faire face à de graves atteintes à l'environnement ayant des conséquences désastreuses aussi bien pour l'environnement que pour l'homme.

En d'autres termes, lors des diverses négociations en vue de la conception des textes répressifs de conservation de la nature, il s'avère nécessaire d'impulser une nouvelle solidarité entre le Nord, victime de son surdéveloppement et le Sud, victime de sa pauvreté ${ }^{1041}$. Plus fondamentalement, c'est la relation entre I'homme et la nature qui doit être revue. Car, « il ne doit plus s'agir aujourd'hui de protéger l'homme contre la nature mais la nature contre l'homme, contre le débordement de vitalité de puissance de l'espèce humaine afin qu'il ne vienne pas, en détruisant la nature, à se détruire lui-même $»^{1042}$.

Ainsi, à l'issue de nos travaux de recherches dont le thème porte sur « $L a$ contribution du droit pénal de l'environnement à la répression des atteintes à l'environnement au Bénin ", nous n'avons pas la prétention d'avoir cerner tous les contours de la problématique. Mais, l'objectif général qu'on s'est fixé à savoir analyser la mise en œuvre au Bénin du droit pénal de l'environnement nous a permis d'atteindre des résultats satisfaisants.

1041 SADLEER (N), La conservation de la nature au-delà des espèces et des espaces : l'émergence des concepts écologiques en droit international, P. Gérard, F. Ost et M. Van Kerchove (dir), in, Images et usages de la nature en droit, Bruxelles, Publication des facultés universitaires de Saint-Louis, 1993, p.206.

1042 Idem, p.165 
En effet, cette thèse fait l'état des lieux de l'application du droit pénal de l'environnement au Bénin, analyse ses performances, les problèmes liés à son application et propose des approches de solutions pour rendre plus effective l'exercice de ce droit au Bénin.

La première partie de la thèse consacrée au diagnostic et à l'analyse de l'existant, révèle un cadre juridique et institutionnel pas tout à fait performant certes, mais assez pertinent. Il est pertinent d'une part, du fait de l'existence d'un arsenal répressif constitué d'une part d'une constitution (la constitution du 11 décembre 1990) plus stable dont l'objectif est d'instaurer un Etat de droit mais aussi de garantir aux citoyens un environnement sain, satisfaisant et durable en mettant un accent particulier sur la répression des crimes écologiques et d'autre part, d'un ensemble de textes sectoriels législatifs et réglementaires composés des ordonnances, des lois, des décrets et de divers arrêtés. Ensuite, ces textes répressifs, qui avoisinent au total près de 600 textes de portée locale, sont complétés et renforcés par une trentaine de conventions internationales environnementales légalement ratifiées par le Bénin. L'étude dresse un répertoire assez exhaustif des textes et conventions existant en matière d'environnement. Ce répertoire constitué essentiellement des principaux textes applicables au Bénin, est déjà une avancée pour les recherches futures et pour des prises de décisions conséquentes.

A l'issue de l'analyse du système répressif béninois, on peut avouer que bien qu'étant encore embryonnaire, il est plus ou moins fonctionnel. En effet, au Bénin, l'on est passé d'une protection aux finalités essentiellement anthropocentrique, régentée par des textes coloniaux à une protection plus écocentrique, fondée sur une philosophie du développement durable avec des textes plus modernes, des textes de la génération de Rio, spécifiques à la prévention et à la répression des atteintes à l'environnement à l'instar de la loi n98-030 du 12 février 1999 portant loi-cadre sur l'environnement de la République du Bénin, laquelle a été placée au centre de nos travaux de recherches. On peut dire que des efforts ont été déployés par le Bénin en vue de maîtriser le phénomène criminel environnemental ; mais ces efforts sont cruellement insuffisants. 
En dépit de cette relative production normative dans le domaine de la protection de l'environnement, des vides juridiques persistent par endroit. II s'ensuit dès lors que le fonctionnement du système répressif reste encore limité aux infractions d'origine forestières en l'occurrence les infractions relatives aux délits de chasse, de pêche, de pâturage, bref de braconnage dans les parcs nationaux ou dans les forêts classées d'une part, les délits liés à la dégradation de la flore avec par exemple la destruction des essences forestières protégées, d'autre part. Ce qui explique que les quelques rares jurisprudences citées, relèvent du secteur de la faune et de la flore. Les infractions relatives aux diverses pollutions environnementales (eau, sol, air), ne font pas encore systématiquement objet de procédures judiciaires. II s'ensuit dès lors, des difficultés liées à l'application des textes pénaux. La thèse a répertorié ces disfonctionnements qui sont de plusieurs ordres.

L'impunité ou la non poursuite des auteurs des infractions, sous fond de complaisance, de népotisme, de favoritisme, de corruption, dans l'application des textes par le juge pénal ou par l'administration, est caractéristique de la justice répressive interne et représente le lot quotidien des problèmes auxquels est confronté la justice pénale.

Par ailleurs, l'une des causes de la défaillance du système répressif béninois s'illustre aussi par l'insuffisance des ressources humaines, la quasi absence de formation ou de renforcement de capacités des magistrats et des greffiers mais aussi surtout par l'obsolescence des moyens matériels, techniques, scientifiques et financiers, dans le domaine du droit de l'environnement. Cette situation de carence du système pénal est facilitée par une inertie de la " conscience collective commune ${ }^{1043}$ en la matière.

A ces difficultés majeures, s'ajoutent d'autres qui tiennent à la nature même du droit pénal de l'environnement, à son extrême jeunesse, à la spécificité de la délinquance écologique qui est un délit conventionnel. Aussi, les limites du droit en matière de protection de l'environnement résultent également des

1043 DURKHEIM(E), De la division de travail social, PUF. 9ème édition. 1973, cité par Delmas -Marty, La prise en compte des préoccupations d'environnement dans le domaine de I'urbanisme (Aspects de droit pénal), JCP, 1977.I. 2872. 
limites de la connaissance scientifique des problèmes écologiques, donc de l'état de développement du droit pénal général.

Pourtant, au regard de ces problèmes majeurs que rencontre le droit pénal de l'environnement, on ne saurait conclure, à l'inutilité du droit pénal dans la préservation de l'environnement en général et en particulier au Bénin. N'est -ce pas que mieux valent ces normes inappliquées qu'un univers a-juridique? L'expérience du processus démocratique sur le continent africain, a montré et montre encore davantage dans certains pays comment un droit dormant finit par se réveiller lorsque la nécessité d'une régulation normée des rapports sociaux vient à se saisir de la conscience d'une communauté ${ }^{1044}$.

En fait, cette thèse, en répondant par l'affirmative à l'utilité du droit pénal dans la protection de l'environnement, plaide pour une véritable «révolution judiciaire», pour la justice béninoise. Mais cette révolution ne saurait être brusque. Elle doit se faire à un rythme raisonnable. L'enjeu, nous l'avons stigmatisé dans la seconde partie de nos travaux, est bien évidemment d'assainir le système juridique et judiciaire, d'accroitre et de renforcer les capacités de l'administration judiciaire pour permettre à la justice de remplir convenablement sa mission. Une justice protectrice du droit du citoyen aussi bien que du droit de l'environnement. Ce n'est qu'ainsi que le droit, celui surtout de l'environnement, au lieu d'être célébré sera vécu. Car, il vaut mieux avoir de bons juges que de bonnes lois. Car, les bonnes lois sont vaines si le juge est mauvais et les plus mauvaises lois peuvent être modifiées par de bons juges ${ }^{1045}$. Cette réforme du droit pénal de l'environnement doit concerner l'ensemble du droit positif béninois. Se faisant, elle doit, pour plus d'efficacité et d'effectivité dans son application, s'inspirer et intégrer le contexte international.

On ne saurait conclure ces travaux de recherches sans relever l'un des résultats auxquels on est parvenu à savoir que le droit pénal de l'environnement est certes utile et applicable, mais il apparait comme une constance qui intervient

1044 KAMTO (M), Droit de l'environnement en Afrique, op., cit.,p.18.

1045 DIDEROT (D), cité par KESSOUGBO (K), Table ronde sur l'efficacité des instruments et mécanismes du droit de l'environnement dans le contexte africain : la faiblesse du dispositif juridictionnel, DEA, FDD, UL, décembre 2004. 
comme un « ultimum remedium », c'est-à-dire qu'il intervient généralement en dernier ressort, après notamment le droit administratif et le droit civil.

\section{TABLE DES TABLEAUX}

Tableau $\mathbf{N}^{\circledR} \mathbf{1}$ : $\quad$ Récapitulatif de quelques sanctions pénales applicables par le juge béninois

Tableau $\mathrm{N}^{\circ} 2$ : $\quad$ Récapitulatif du nombre de décisions de justice rendues en matière environnementale au cours des cinq dernières années par le TPI de Natitingou

Tableau $\mathbf{N}^{{ }^{\circ} \mathbf{3}}$ : $\quad$ Point des infractions et condamnations liées aux délits constatés dans la réserve de la biosphère de la Pendjari saisons touristiques de 2006 à 2009

Tableau $\mathbf{N}^{\circ} \mathbf{4}$ : $\quad$ Récapitulatif des décisions rendues par rapport aux infractions constatées au cours des saisons touristiques et cynégétiques de 2006 à 2009

Tableau $\mathbf{N}^{\circ} \mathbf{5}^{2}$ : $\quad$ Récapitulatif des recettes issues des transactions au cours des saisons touristiques et cynégétiques de 2006 à 2009

Tableau $N^{\circ} 6$ : $\quad$ Quelques domaines sensibles ignorés du législateur ou de l'exécutif

Tableau $\mathbf{N}^{\circ}$ 7: $\quad$ Taux de dossiers sortis par les TPI de 2005 à 2008

Tableau $\mathbf{N}^{\circ} \mathbf{8}$ : $\quad$ Point statistique des magistrats béninois et leur masse de travail dans les tribunaux (Année de référence 1995

Tableau $\mathbf{N}^{\circ} \mathbf{9}$ : $\quad$ Effectif des personnels greffiers en exercice dans les TPI et CA de 2005 à 2008

Tableau N¹0: $\quad$ Effectif des magistrats en exercice dans les TPI et CA de 2002 à 2008

Tableau $\mathbf{N}^{\circ} 11$ : $\quad$ Nombre de magistrats actuellement en fonction dans les cours et tribunaux du Bénin

\section{SIGLES, ABREVIATIONS ET ACRONYMES}

- $\quad$ ABE : Agence Béninoise pour l'Environnement

- $\quad$ AHJUCAF : Association des Hautes Juridictions d'Expression Française

- al : alinéa

- AN : Assemblée Nationale

- ANR : Assemblée Nationale Révolutionnaire

- $\quad$ APJ : Agent de Police Judicaire :

- $\quad$ Art : Article 
- Ass. plén. : Assemblée plénière

- AUF : Agence Universitaire de la Francophonie

- AUPELF : Association des Universités des Pays ayant en partage la Langue française

- $\quad$ BM : Banque Mondiale

- Bull. civ. Bulletin des arrêts de la cour de cassation (chambre civile)

- Bull. crim. : Bulletin des arrêts de la cour de cassation (chambre criminelle)

- C. pr.pén. : Code de procédure pénale

- C.civ. : Code civile

- C.env. : Code de l'environnement

- C.pén. : Code pénal

- C.urb. : Code de l'urbanisme

- c/. : contre

- Cah. env. : Cahier de l'environnement

- Cass. : cassation

- CBD : Convention sur la Diversité Biologique

- CCD : Convention sur la Lutte contre la Désertification.

- CCI. : Chambre de commerce Internationale

- CCNUCC : Convention Cadre des Nations Unies sur les Changements Climatiques

- CE : Conseil d'Etat

- CEDEAO : Communauté des Etats de l'Afrique de l'Ouest

- CEDE : Cour Européenne des Droits de l'Homme

- CENAGREF : Centre National Gestion des Ressources Forestières

- CES : Conseil Economique et Social 
- Cf. : Confer

- Ch. acc. : chambre d'accusation

- Ch. arb. : chambre arbitrale

- Ch. : chambre

- Ch.corr. : chambre correctionnelle

- Chap. : chapitre

- CIJ : Cour Internationale de Justice

- CIMBENIN : Ciment Bénin

- Cir. Interm. : circulaire interministérielle

- Circ. : circulaire

- CITES: Convention on International Trade in Endangered Species of wild Fauna and Flora.

- CJCE : Cour de Justice de la Communauté Européenne

- CNDD : Commission Nationale pour le Développement Durable

- CNLC : Commission Nationale de Législation et de Codification

- Coll. : collection

- Cons. const. : conseil constitutionnel

- Const. : Constitution

- Conv. : convention

- Conv.inter. : convention internationale

- CPIR : Cour Pénale Internationale pour le Rwanda

- D : Dalloz

- DC : Directeur de Cabinet

- DCC : Décision de la Cour Constitutionnelle

- DDEHU : Direction Départementale de l'Environnement, de l'habitat et de l'urbanisme 
- DDEPN Direction Départementale de l'Environnement et de la Protection de la Nature

- DEA : Diplôme d'Etude Approfondie

- DFPRN : Direction des Forets et de la protection des Ressources Naturelles

- DFRN : Direction des Forets et des Ressources Naturelles

- DGE : Direction Générale de l'Environnement

- DGFRN : Direction Générale des Forets et des Ressources Naturelles

- Dr.pén. : droit pénal ;

- DST : Direction des Services Techniques

- DUA : Direction de l'Urbanisme et de l'Assainissement

- EIE : Etude d'Impact Environnemental ;

- ERSUMA : Ecole Régionale Supérieur de Magistrature

- FADESP : Faculté de Droit et de Sciences Politiques

- FAO : Food and Agricultural Organization

- FEM : Fonds pour l'Environnement Mondial

- FNE : Fonds national pour l'Environnement au Bénin

- Gaz.pal. : Gazette du palais

- $\quad$ hts : Habitants

- Id. : idem

- In. : extrait de

- JCP : Juris-classeur périodique

- JORB ou JO: Journal officiel de la République du Bénin

- JORF : Journal Officiel de la République Française

- MEHU : Ministère de l'Environnement, de l'Habitat et de l'Urbanisme 
- MEPN (ex-MEHU) : Ministère de l'Environnement et de la Protection de la Nature

- MERF : Ministère de l'Environnement et de la Recherche Forestière

- MESRS : Ministère de l'Enseignement Supérieur et de la Recherche Scientifique

- MJL: Ministère de Justice de la Législation

- MJLDH : Ministère de Justice de la Législation et des Droits de l'Homme

- OCBN : Organisation Commune Bénin- Niger de Chemin de fer

- OCDE: Organisation pour le Commerce et le Développement Economique

- OGM : Organisme Génétiquement Modifié

- OME : Organisation Mondiale de l'Environnement

- OMS : Organisation Mondiale de la Santé

- ONG : Organisation Non Gouvernementale

- ONU : Organisation des Nations Unions

- Op.cit. : opera citao

- OPJ : Officier de Police Judiciaire

- Ord. : Ordonnance

- p. : page

- PNUD : Programme des Nations Unies pour le Développement

- PV : Procès-verbal

- REDE : Revue Européen de Droit de l'Environnement

- Rev.jur.env. : Revue juridique de l'environnement

- RGPH3 : $3^{\text {ème }}$ Recensement Général de la Population et de l'Habitat

- RIDC : Revue Internationale de Droit Comparé

- $\quad$ S. : Sirey

- SCB : Société des Ciments du Bénin 
- SCO : Société des Ciments d'Onigbolo

- SFDI : Société Française de Développement International

- SGM : Secrétaire Général du Ministère

- SONAPRA : Société Nationale des Produits Agricoles

- SONICOG : Société National des Industries des Corps Gras

- $\quad \mathbf{T}$ : Tome

- T. corr. : Tribunal correctionnel

- TGI. : tribunal de grande instance

- TPI : Tribunal de Première Instance

- TPIY : Tour Pénale Internationale pour la Yougoslavie

- Tri.inst. : Tribunal d'instance

- Trib. : Tribunal

- UA : Union Africaine

- UAC : Université d'Abomey-Calavi

- $\quad$ UB /UL : Université de Bénin, actuellement Université de Lomé

- UE : Union Européenne

- UEMOA : Union Economique Monétaire Ouest Africaine

- $\quad$ UICN : Union Internationale de Conservation de la Nature

- UNESCO : Organisation des Nations Unies pour la Science et la Culture

- UNITAR : Organisation des Nations Unies pour la Recherche

- UREF : Union des Réseaux Francophones

- V. : voir

- Vol. : volume 


\section{BIBLIOGRAPHIE}

\section{OUVRAGES GENERAUX DE DROIT ET DE DROIT PENAL}

- BeLET (J.M.) et COLARD (D), Les droits de l'homme, Tome I, Economica, Paris 1982.

- BOULOC (Bernard), Pénologie, exécution des sanctions adultes et mineures, $2^{\mathrm{ème}}$ éd. Précis Dalloz, Paris, 1998.

- DESPORTES (Frédéric) et LE GUNEHEC (Francis), Droit pénal général, 10ème édition. 2003, Paris édition. Economica, 975p.

- GIROUX (M) et OSSULLIVAN(E), Droit pénal Général, Volume 7, édition Yvon Blais Inc, Québec, 1997.

- GIROUX (Michel) \& O'SULLIVAN (Eugène), Droit pénal général, vol 7. Edition Yvon Blais Inc, 1997 Canada, 107p.

- KELLENS (Georges), Précis de pénologie et de droit des sanctions pénales, édition Collection Scientifique de la Faculté de Droit de Liège 1991, 311p.

- LAGUIER (Jean), et CONTE Philippe, Procédure pénale, Mémentos $21^{\text {ème }}$ édition, Dalloz, Paris 2006,328p.

- LAGUIER (Jean), Procédure pénale, 12 $2^{\mathrm{ème}}$ édition, Mémentos Dalloz, Paris 1989,131p.

- PRADEL(Jean), Manuel de Droit pénal Général, $16^{\text {ème }}$ édition CUJAS, Paris 2006, $803 \mathrm{p}$.

- SOYER(Jean-Claude), Manuel de droit pénal et procédure pénale, édition LGDJ 17ème édition, Paris, 2003, 443p.

- STEFANI (G) et LEVASSEUR (G), Droit pénal général et procédure pénale. T1, $5^{\text {ème }}$ édition, Dalloz, 1971, 524p.

- VINCENT (Jean), GUINCHARD (Serge), VARINARD (André), La justice et

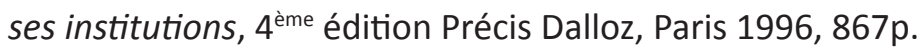




\section{MANUELS OU OUVRAGES SPECIALISES EN DROIT DE L'ENVIRONNEMENT}

- CHEROT(Jean-Yves), SERIAUX (Alain), FLORY(Maurice), BRAMOULLE(Gérard), LE ROY(Etienne), FALQUE(Max), HAROUEL(JeanLouis), MARTIN (Gilles-J), Droit et environnement : propos pluridisciplinaires sur un droit en construction ; édition Presse Universitaires d'Aix-Marseille, 1995 ;

- CLEMENT(Cyril) \& HUGLO(Christian), Le droit des déchets hospitaliers, édit. Les études hospitalières, Paris, 1999.

- Cour de Cassation, conférence des Présidents des cours suprêmes des Etats francophones d'Afrique sur la contribution du droit au développement durable. Actes de la conférence, de février, Paris 2005.

- DE NAUW (Alain), Les métamorphoses administratives du droit pénal de l'entreprise, Mys\& Brusch, Utigeves, 1994.

- De SADELEER (Nicolas), Les principes de pollueur payeur, de prévention et de précaution. Essai sur la gestion et la portée juridique de quelques principes de droit de l'environnement. Edition Bruylant, Bruxelles, 1999.

- DEJEANT-PONS(Maguelonne) \& PALLEMAERTS (marc), Droit de l'homme et environnement, édit. Du Conseil de l'Europe, Strasbourg, 2002.

- DIJON(Xavier), Méthodologie juridique : I'application de la norme, KLUWER Editions Juridiques Belgique et E. Story Scientia, Collection à la rencontre du droit, Bruxelles 1996, $169 \mathrm{p}$.

- DREYFUS (Simone) \& NICOLAS-VULLIERME(Laurence), la thèse de doctorat et de mémoire, étude méthodologique, science juridique et politique, $3^{\text {ème }}$ édit., Cujas, Paris 2000, 486p.

- ENGelHARD Hans A. (Protection de l'environnement par le droit pénal, Rapport présenté devant le comité des ministres, 1990.

- FAURE (Michael), L'analyse économique du droit de l'environnement, Bruylant/Bruxelles 2007, 362p. 
- GRANIER (Laurent), Aspects contemporains du droit de l'environnement en Afrique de I'Ouest et centrale, UICN, Droit et politique de l'environnement, $n^{\circ} 69$, Gland Suisse 2008, 223p.

- GUiHAl (Dominique), Droit répressif de l'environnement, $3^{\text {ème }}$ édit., économica, Paris 2008, 851p.

- GUNDLING (L), Droit international de l'environnement : atmosphère, eau douce et sol, cour 7, UNITAR, 1999.

- IMPERIALI(Claude), l'effectivité du droitinternational de l'environnement, contrôle de la mise en œuvre des conventions internationales. Edition Economica, 1998, Paris 291p.

- KAMTO (Maurice), Droit de l'environnement en Afrique, Paris EDICEF/ AUPELF, 1996, 415p.

- KISS (A) \& SHELTON (D), Traité de droit européen de l'environnement. Édition Trison-Roche, Paris 1995, 554p.

- KISS (A) et SHELTON (D), Traité de droit européen de l'environnement, édition. Frison-Roche, paris 1995.

- NERAC-CROISIER (Roselyne) (sous la dir), Sauvegarde de l'environnement et droit pénal, Collection Sciences criminelles, l'Harmattan, 2005, Paris, $373 p$.

- $\quad \operatorname{NeURAY}$ (J.F), Principes de droit de l'environnement. KLUWER Editions Juridiques Belgique et E. Story Scientia, Collection à la rencontre du droit, Bruxelles 1995, $271 \mathrm{p}$.

- OST(François) \& GUTWIRTH (Serge), Quel avenir pour le droit de l'environnement ? Publications des Facultés Universitaires Saint-Louis, Bruxelles 1996, 487p.

- PAQUES(Michel) et FAURE (Michael), La protection de l'environnement au cœur du système juridique international et du droit interne. Acteurs, valeurs et efficacité. Metro ; Faculté de droit de l'université de Liège, Octobre 2001. 
- PRIEUR (Michel) \& DOUMBE-BILLE (Stéphane), (sous la direction) Recueil francophone des textes internationaux en droit de l'environnement, édit. AUPELF-UREF, Bruylant/Bruxelles, 1998, 719p.

- PRIEUR (Michel), Vers un nouveau droit de l'environnement ? Réunion mondiale des juristes et associations de l'environnement. centre internationale de droit comparé (CIDE), Limoges, 2003.

- PRIEUR (Michel), Droit de l'environnement, Précis Dalloz, $3^{\text {ème }}$ édition, Paris 1996, 916p.

- SAUSSAY (Christian du), La législation sur la faune et les aires protégées en Afrique. Etudes législatives, n²5, FAO, Rome 1981.

- SPD\&IDPD (Société Française pour le Développement et Institut du Droit de la Paix et du Développement), Le dommage écologique, en droit interne communautaire et comparé. (Actes du Colloque organisé les 21 et 22 mars 1991 à la faculté de droit, d'économie et de gestion de Nice Sophia-Antipolis). Collection Droit et économie de l'environnement, Economica, Paris 1992, 254p.

\section{THESES ET MEMOIRES}

- ACOUETEY(Covi), La lutte contre les pollutions transfrontières : cas du Togo et du Bénin, mémoire de DEA, droit de l'environnement, UL Togo, 2000-2001.

- ADELOUI (Arsène-Joël), Transition démocratiques et coopération au développement : approche comparative du bénin, Mali, Niger et Togo., Thèse, UAC, FADESP, Chaire UNESCO, droit de la personne et de la démocratie, 2006, 589p.

- ASSEMBONI (Alida Nabobué) Epse OGUNJIMI (sous la direction de Michel PRIEUR), Le droit de l'environnement marin et côtier en Afrique Occidental, cas de cinq pays francophones. Thèse de doctorat d'Etat, CRIDEAU-CNRS-INRA. Université de Limoges, Faculté de droit et de 
Sciences économiques. Ecole doctorale des sciences de l'homme, et de la société ; UL, FDD, 2006.

- DJA (Hilaire Coffi), La responsabilité pénale des personnes morales en matière d'environnement : cas du Bénin, de la Belgique et de la France. Mémoire de DEA, UL, FDD, 2004-2005. Lomé Togo.

- DJOGBENOU (Joseph), Les privations de liberté individuelles de mouvement non consécutives à une décision pénale de condamnation, Thèse de Doctorat unique en droit, option droit privé, UAC, 2007.

- GBENOU (KOkouvi), La sanction des atteintes à l'environnement en droit togolais. Mémoire de DEA, UL, FDD, 2003-2004. Lomé Togo.

- GOUgBedII (Cyrille), La protection de l'environnement dans les pays de l'Afrique de l'ouest : aspects juridiques et politiques. (Bénin, Burkina Faso, Niger, Sénégal et Togo). Thèse de doctorat unique, Chaire UNESCO, UAC FADESP, 2011.

- HUGUES (Patricia) et MOSSMAN (Jane Mary), Repenser l'accès à la justice pénale au Canada : un examen critique des besoins, des réponses et des initiatives de justice réparatrice. Thèse Canada, 2001

- MANIRABONA (Amissi Melchiade), la responsabilité pénale des sociétés canadiennes pour les crimes contre l'environnement survenu à l'étranger. Thèse Université de Montréal ; 2009 Canada, 412p.

- SOglo AGUede(Gisèle), Le droit pénal de l'environnement en droit positif béninois : possibilité et limites de la répression. Mémoire de DEA, UB, FDD, 1997-1998. Lomé Togo.

- TCHOCA F. (François), Analyse critique du cadre institutionnel des politiques environnementales en Afrique : le cas du Bénin. Mémoire de DEA, UB, FDD, 1997-1998. Lomé Togo. 


\section{ARTICLES \& RAPPORTS}

1. Articles

- ANGELI (Guillaume), L'action devant le juge pénal des associations de protection de l'environnement, RJE, nºspécial 2002.

- BAYLE (M), La responsabilité pénale des dirigeants des sociétés en droit français de l'environnement, Revue de droit commercial Belge, 1992.

- BILLET (Philippe) Le juge administratif et les techniques processuelles au service de l'environnement, Colloque international sur le droit de l'environnement, Paris 2005, www.courdecassation.fr.

- BOSLY (D. Henri), La preuve en droit pénal de l'environnement, Aménagement-Environnement, 1995.

- BOSLY (D. Henri), Mise en œuvre des poursuites et pouvoirs d'investigation dans l'entreprise, Aménagement-Environnement, Université de Liège, 1991.

- BOTHE(Michael), Le droit à l'environnement dans la constitution allemande, RJE, nº spécial 2005.

- DE LOS RIOS (Isabel), Le projet de code organique du Venezuela, RJE, nspécial 2002.

- DELNOY(Michel), Faut-il codifier les règles relatives aux enquêtes publiques en matière d'urbanisme et d'environnement ? Editions Kluwer, Aménagement-Environnement, 2005, nº spécial.

- Dispositions constitutionnelles dans certains pays africains, RJE, $n^{\circ}$ spécial 2005.

- DOUMBE-BILLE (Stéphane), évolution des institutions et des moyens de mise en œuvre du droit de l'environnement et du développement, RJE, n¹/ 1993.

- ENGelhard(H.A), Protection de l'environnement par le droit pénal, Revue de droit pénal. 
- FAURE(Michael), La protection de l'environnement par le droit pénal ? Une perspective économique. Acteurs et outils du droit de I'environnement. Rotterdam Institute of Law \& Economics . ANTHEMIS, 2010, pp.135-166

- FAURE(Michael), Les causes exonératoires en droit pénal de l'environnement, Aménagement-Environnement, nº spécial 1995.

- FAURE(Michael), Un défi : les contours de plus en plus flou du droit pénal de l'environnement. Edition Kluwer. Aménagement-Environnement. 2000, nspécial.

- FAURE(Michael), Vers un nouveau modèle de protection de l'environnement par le droit pénal. REDE, 1/2005.

- GEEROMS(Sofie), La responsabilité pénale de la personne morale : une étude comparative, RIDC, 1996.

- GONTHIER (D), L'action du juge en matière d'environnement : quelques réflexions sur les principes et leur mise en œuvre (colloque international, sur le droit de l'environnement, Paris 2006 www.courdecassation.fr.

- GUIHAL(D) \& THIEFFRY(P.), L'incrimination pénale, instrument ultime de mise en œuvre du droit européen de l'environnement. Gazette du Palais, France, janvier 2009.

- GUIHAL(Dominique), La charte de l'environnement et le juge judiciaire, RJE, nºspécial 2005.

- HUGLO (Christian) Contentieux : problématique et perspectives, Fascicule 1005, Edition Techniques Juris-Classeurs, 2,1992.

- HUGLO (Christian), Le régime juridique de la remise en état dans le domaine des mines : des progrès sont-ils possibles ? in, Annales des mines, Paris 1998.

- JADOT(B), L'intérêt à agir en justice pour assurer la protection de l'environnement, in, Les juges et la protection de l'environnement, Bruylant/Bruxelles, 1997. 
- JAWORSKI (Véronique), L'union européenne et la protection pénale de l'environnement, www.cdpt.u-strasbg.fr.

- JAWORSKI (Véronique), La charte constitutionnelle de l'environnement face au droit pénal, RJE, nºspécial 2005.

- KIFER (F.), Questions à propos du délit d'obstacle à la surveillance en droit belge, RTDH, Liège, $n^{\circ} 56 / 2003$.

- La constitution et l'environnement : vers un droit de l'environnement renouvelé. Cahiers du Conseil constitutionnel n¹5, juillet 2003.

- LAScoumes (P) et MARTIN J. (G), Des droits épars au code de l'environnement, Droit \& société, 30-31/1995.

- LASCOUMES (Pierre), La nature comme intérêt protégé par le droit pénal : les trois étapes d'un parcours incertain ; Faculté universitaire Saint-Louis, Bruxelles, 1993.

- LASCOUMES(P) \& SEVERIN (E), Théories et pratiques de l'effectivité du droit, Droit \& Société $n^{\circ} 2 / 1986$. www.reds.msh-paris.fr.

- Le Journal 29 de I'UNIGE, Débat sur l'application du droit pénal international, www.unige.ch/lejournal.

- $\quad$ LITTMANN-MARTIN (Marie-José), Code de l'environnement, droit pénal et procédure pénale : quelques réflexions, RJE, nºspécial 2002.

- LITTMANN-MARTIN (Marie-José), La protection de la nature, édition Technique Juris-classeur, 1992, Fascicule 505.

- MAYAU (Yves), La responsabilité pénale découlant des crimes environnementaux. Communication-prononcée lors de " régional Conférence on Environmental Crimes in the Arab States ", BerutRepublic of Lebanon, mars 2009.

- MeKOUAR (M. Ali), Le droit de l'environnement dans la charte africaine des droits de l'homme et des peuples,

- NEYRET (Laurent), La réparation des atteintes à l'environnement par le juge judiciaire. Colloque international Paris 2006 www.courdecassation. fr. 
- OUEDRAOGO (Clarisse), Les sanctions alternatives et complémentaires aux peines classiques en droit de l'environnement : étude comparative (France et Burkina Faso). RJE, n4/ 2000.

- PRIEUR(Michel), Pourquoi une codification ?, RJE, nspécial 2002.

- ROBERT (Christian-Nils), Limites du droit pénal : quelques interrogations. Travaux CETEL, 1989.

- ROBERT (J.H), Le contentieux pénal, Paris 2006 www.courdecassation.fr.

- ROBERT (J.H), Le problème de la responsabilité pénale et des sanctions pénales en matière d'environnement, RIDP, 1994.

- ROGGEN(F), La répression des infractions contre l'environnement, in, L'actualité du droit de l'environnement, Bruxelles, Bruylant 1995.

- ROGGEN(F), Le juge pénal et la protection de l'environnement, in, Les juges et la protection de l'environnement, Bruylant/Bruxelles, 1997.

- SEUVIC (Jean-François), Force ou faiblesse de la constitutionnalisation du droit pénal, www.legifrance.gouv.fr.

- SZONYI DANDACHI(Amira), La convention sur la protection de l'environnement par le droit pénal, RJE, nºctobre 2003.

\section{Rapports et documents divers}

- Action 21, Déclaration de Rio sur l'environnement et le développement, Déclaration de principes relatifs aux forêts. Principaux textes de la CNUED,

- BOGUI (Ziriyo) (Président), Rapport de la commission internationale d'enquête sur les déchets toxiques déversés dans le District d'Abidjan, 19 février 2007.

- do NASCIMENTO Geraldo E. SILVA (Rapporteur), La pollution transfrontière de l'air, XXème commission, Institut droit international Session du Caire, 1987 www.idi.org 
- Enquête-Rapport sur l'efficacité des lois de l'environnement, (par l'association nationale pour la protection des eaux et rivières). France, 1996.

- $\quad$ FAURE(Michael), Sanctions pénales, Rapport, vol.I, Liv. III, Titre. III, 1989 Belgique.

- HUGUES (Patricia) et MOSSMAN (Mary Jane), Repenser l'accès à la justice pénale au Canada : un examen critique des besoins, des réponses et des initiatives de justice réparatrice. Division de la recherche et de la statistique, Ministère de la Justice, Canada, mars 2001.

- Le renforcement et structuration des polices de l'environnement en France, (Rapport commission interministérielle, 2005).

- MATEE/GTZ, Etude sur le système d'inspection, de contrôle et de surveillance de l'environnement au Maroc. (Rapport 2007).

- MEHU, Agenda 21 National du Bénin, 1997.

- MEHU, Plan d'Action Environnementale du Bénin, 1993 (révision 2001).

- MEHU/ABE, Rapport intégré sur l'état de l'environnement au Bénin, 2002.

Nations Unies, New York, 1993.

- Pallaruelo(Guy), Mieux maitriser le risque pénal en matière d'environnement (commission juridique de la commission du commerce intérieur et de la commission de l'aménagement régional, de l'environnement, du tourisme et des transports) adopté par l'assemblée générale du 7 mars 2002. Chambre de Commerce et d'Industrie de Paris.

- PRABHU (M), Rapport général du congrès international sur les crimes contre l'environnement, AIDP, Ottawa, 1994.

- Rapport sur l'étude de prospective à long terme Bénin 2025, 2000.

- Rapport, MJL, Etude de pré-diagnostic, Etat des lieux et diagnostic d'ensemble, Réhabilitation du système judiciaire au Bénin, Ass.SCHENE. avril 1996. 
- Résolution sur le XVème Congrès international de droit pénal, Rio RDP 1994.

- UNITAR, Environnement et justice : responsabilité civile et pénale en matière d'environnement, Rome 2005, www.unitar.org.

\section{CODES ET TEXTES LEGISLATIFS ET REGLEMENTAIRES}

1. Au niveau national

- Loi n90-32 du 11 décembre 1990 portant Constitution de la République du Bénin.

- Loi n98-030 du 12 février 1999 portant loi-cadre sur l'environnement en République du Bénin.

- Loi n93-09 du 02 juillet 1993 portant régime des forêts en République du Bénin.

- Loi n97-029 du 15 janvier 1997 portant organisation des Communes en République du Bénin.

- Loi n²002-16 du 18 octobre 2004 portant régime de la faune en République du Bénin.

- Loi n87-015 du 21 septembre 1987 portant code de l'hygiène publique en République populaire du Bénin.

- Loi n²007-03 du 16 octobre 2007 portant régime foncier en République du Bénin.

- Loi n²008-07 du 28 février 2011 portant code de procédure civile, commerciale, administrative, sociale et des comptes.

- Loi n²006-18 portant code pétrolier en R.B.

- Loi n²001-37 du 27 aout 2002 portant organisation judiciaire en République du Bénin. 
- Loi n 87-016 du 21 septembre 1987portant code de l'eau en République Populaire du Bénin.

- Loi n²004-07 du 23 octobre 2007 portant composition, organisation, fonctionnement et attributions de la cour suprême au Bénin.

- Loi n²004-20 du 17 août 2007 portant règles de procédures applicables devant les formations juridictionnelles de la cour suprême au Bénin.

- Loi- n²010-44 du 24 novembre 2010 portant gestion de l'eau en République du Bénin.

- Loi- n²011-20 du 12 octobre 2011 portant lutte contre la corruption et autres infractions connexes en République du Bénin

- Ordonnance n²5 P.R. /MJL, du 07 aout 1967 portant code de procédure pénale au Bénin.

- KILANYOSSI (M.V. Mardochée), Droit pénal spécial. Législation pénale du Bénin : recueil des lois et règlements de droit pénal applicable au Bénin en dehors du code pénal (1960-2006), Cotonou, 2007692 p.

- Décret n²001-235 du 12 juillet 2001 portant organisation de la procédure d'étude d'impact sur l'environnement au Bénin.

- Décret n²001-190 du 19 juin 2001 portant organisation de la procédure d'audience publique en République du Bénin.

- Décret n²001-093 du 20 février 2001 fixant les conditions d'élaboration de l'audit environnemental en République du Bénin.

- Décret n²001-095 du 20 février 2001 fixant portant création et fonctionnement des cellules environnementales en République du Bénin.

- Décret n²001-109 du 04 avril 2001 fixant les normes de qualité des eaux résiduaires en République du Bénin.

- Décret n²001-110 du 04 avril 2001 fixant les normes de qualité de l'air en République du Bénin. 
- Décret n²001-109 du 04 avril 2001 fixant les normes de qualité de l'eau potable en République du Bénin.

- Décret n²001-096 de février 2001 portant création, attributions et fonctionnement de la police environnementale au Bénin.

- Décret $n^{\circ}$ 2005-437 du 22 juillet 2005 portant organisation de la procédure d'inspection environnementale en République du Bénin.

- Décret n97-616 du 18 décembre 1997 du 19 juin 2001 portant application de la loi n87-015 du 21 septembre 1987 portant code de I’hygiène publique en République du Bénin.

- Décret n97-624 du 31 décembre 1997 portant structure, composition et fonctionnement de la police sanitaire.

- Décret n96-271 du 2 juillet 1996 portant modalité d’application de la loi n 93-009 du 02 juillet 1993 portant régime des forêts en République du Bénin.

- Décret $n^{\circ}$ 2002-484 du novembre 2002 portant gestion rationnelle des déchets biomédicaux en République du Bénin

- Arrêté interministériel $\mathrm{n}^{\circ}$ 136/MISAT/MEHU/MS/DC/DATC/DE/DHAB du 26 juillet 1995, portant réglementation des activités de collecte, d'évacuation, de traitement et d'élimination des déchets solides en République du Bénin.

- SERHAU-SEM (Société d'Etudes Régionales d'Habitat et d'Aménagement Urbain), Recueil des textes principaux en matière de droit domanial, de droit de l'Urbanisme et de droit foncier, MEHU Cotonou, 1999.

2. Au niveau régional et international

- Loi $n^{\circ} L / 99 / 013$ AN portant code foncier et domanial guinéen, www. droit.afrique.com.

- Loi n 98-164 du 20 février 1998 portant code forestier du Sénégal, www. jurisafrica.com. 
- Loi $n^{\circ}$ 14/PR/98 définissant les principes généraux de la protection de l'environnement au Tchad, www.droit.afrique.com.

- Loi n98-005 du 14 avril 1998 portant régime de l'eau en République du Cameroun, www.droit.afrique.com.

- Loi n0016101 du 31 décembre 2001 portant code forestier en République gabonaise www.droit.afrique.com.

- Loi n88-651 du 7 juillet 1988 portant protection de la santé publique et de l'environnement en Côte-d'Ivoire.

- Loi-cadre n96/766 du 3 octobre 1996 portant code de l'environnement en Côte-d'Ivoire.

- Loi n² 2001-01 du 15 janvier 2001 portant code de l'environnement sénégalais.

- Loi n 2001-01 du 12 avril 2001 portant application du code de l'environnement du Sénégal, www.droit.afrique.com.

- Décret $n^{\circ}$ 2001-282 du 12 avril 2001 portant application du code de l'environnement du Sénégal, www.droit.afrique.com.

- Code de l'environnement français, édition 2010 version internet : $\underline{w w}$. legifrance.gouv.fr.

- Loi n 005/97/ADP du 30 janvier 1997portant code de l'environnement du Burkina Faso

- La charte de l'environnement en France, 28 février 2005. www.legifrance. gouv.fr.

- Code pénal Dalloz, 1991-1992.

- Code pénal annoté, Recueil Sirey, paris 1952 (Emile GARCON).

- Recueil annoté des textes de droit pénal applicables en AOF (BOUVENET (Gaston-Jean) et HUTIN(Paul).

- Circulaire nº DCG2005-12G4/23-5-2005 portant orientation de politique pénale en matière d'environnement. $\underline{w w w . e n v i r o n n e m e n t . a d e r . g o u v . f r}$. 


\section{TABLE DES MATIERES}

REMERCIEMENTS 9

SOMMAIRE

INTRODUCTION GENERALE

PREMIERE PARTIE: UN CADRE JURIDIQUE ET INSTITUTIONNEL PERTINENT MAIS INEFFECTIF $\begin{array}{ll}\text { ET INSUFFISANT } & 21\end{array}$

TITRE PREMIER : UN CADRE JURIDIQUE ET INSTITUTIONNEL PERTINENT 23

CHAPITRE Ier : LES ELEMENTS D'UNE POLITIQUE CRIMINELLE ENVIRONNEMENTALE 23

SECTION I ère : UNE LEGISLATION ENVIRONNEMENTALE PERTINENTE

§। : L'apport du droit constitutionnel béninois $\quad 25$

A) La consécration constitutionnelle du droit à l'environnement 25

1. Le droit à un environnement sain $\quad 27$

2. L'environnement, objet d'un droit de l'homme 33

B) La criminalisation constitutionnelle des infractions environnementales $\quad 35$

§II : L'existence de dispositions législatives et réglementaires répressives. 37

A) Les textes de portée générale 38

1. Les anciens textes répressifs 38

a) Le Code de Procédure Pénale 38

b) Le recueil de Code pénal «BOUVENET » 39

2. Les possibilités offertes par la loi-cadre sur l'environnement au Bénin 41

a) L'énoncée des principes généraux de l'environnement 42

b) Les incriminations ou infractions prévues par la loi-cadre 44

B) Une législation sectorielle en évolution 49

1. Dans le domaine de la flore, de la faune et de la chasse 50

2. Dans le domaine de l'eau et des pollutions et nuisances. 53

3. Dans le domaine foncier 54

4. Dans le domaine de la gouvernance locale $\quad 54$

§III : L’apport des conventions internationales dans le développement du droit pénal interne de l'environnement 56

SECTION II : LES ASPECTS INSTITUTIONNELS DE LA POLITIQUE CRIMINELLE 60

§।: La contribution des institutions nationales.

A) L'influence des institutions constitutionnelles dans la répression des atteintes à l'environnement

1. Le Président de la République 61

2. L'Assemblée Nationale 63

3. La Cour Constitutionnelle 63

4. La Cour Suprême 65

5. La Haute Cour de Justice 65 
$\begin{array}{ll}\text { B) Les institutions gouvernementales } & 67\end{array}$

$\begin{array}{ll}\text { 1. Le Ministère chargé de l'Environnement } & 67\end{array}$

2. Le Ministère chargé de la justice et de la législation 69

3. Le Ministère chargé de l'agriculture, de la pêche et de l'élevage 69

§II : L'expérience béninoise de la Police Environnementale 70

A) Les moyens d'action $\quad 71$

B) Les activités répressives $\quad 72$

§ III : La contribution des associations de défense de l'environnement 73

A) Les conditions d'accès des associations à la justice 75

B) Les modalités de leur action au pénale 76

chapitre II : l'existence d'un systeme repressif ENVIRONNEMENTAL EN DEVELOPPEMENT 78

Section I : LA mise en mouvement de l'action publique $\quad 78$

§। : La constatation des infractions : l'exercice de l'action publique 79

A) L'enquête préliminaire par les OPJ $\quad 79$

1) La constatation des infractions $\quad 80$

a) Les acteurs classiques de constatation des infractions : les OPJ $\quad 80$

b) Les nouveaux acteurs de constatation des infractions 83

2) La force probante du procès-verbal de constatation 89

a) Les conditions de validité des procès-verbaux 89

b) Les pouvoirs d'investigation $\quad 95$

B) Le ministère public au centre de l'exercice de l'action publique 97

§II : Le régime juridique de la surveillance et du contrôle 100

A) Le caractère hybride de la surveillance ou du contrôle 100

B) Le caractère particulier et nécessaire du contrôle et de la surveillance. 104

SECTION II : LE REGIME REPRESSIF TEL QUE PREVU PAR LES TEXTES 107

§I : Le régime juridique des peines 107

A) Les sanctions pénales 108

1. Les peines principales : l'amende et l'emprisonnement 109

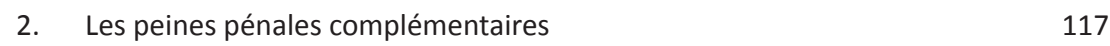

B) Les sanctions administratives $\quad 122$

1. Les sanctions administratives relevant du juge administratif 122

2. Les sanctions complémentaires relevant des autorités administratives 124

§II : Les sanctions alternatives $\quad 128$

A) Le recours de plus en plus fréquent à la transaction 129

B) Les autres mesures alternatives aux sanctions classiques 139

1) Le classement sous condition $\quad 139$

2) L'ajournement de la peine, $\quad 140$

3) La médiation pénale et la composition pénale $\quad 140$ 
TITRE II : UN DISPOSITIF ENVIRONNEMENTAL REPRESSIF INEFFECTIF, INSUFFISANT ET PEU PERFORMANT

CHAPITRE III : UN ARSENAL REPRESSIF PEU PERFORMANT

SECTION I : LE CADRE NORMATIF PENAL

§। : Le caractère insuffisant et vétuste des textes pénaux

A) Le caractère insuffisant ou incomplet des textes répressifs

B) Le caractère vétuste et caduc des textes pénaux existants

§II : L'éparpillement des textes répressifs

SECTION II : L'ACCES A LA JUSTICE PENALE

$\S$ । : Les obstacles liés au mode de fonctionnement de la justice

A) Quant aux constatations des infractions et à leurs poursuites

B) Quant au mode d'organisation de la justice pénale

1. La dépénalisation des infractions

2. Les carences organisationnelles et la complexité de la procédure pénale

3. Le caractère spécifique de l'infraction pénale environnementale

§ll : Les obstacles socio-économiques et politiques à l'accès à la justice

A) Un contexte sociologique africain peu favorable

1. L'analphabétisme et l'ignorance

2. Une crainte excessive mais justifiée à l'égard de la justice

B) La carence des moyens matériels, financiers et humains

1. Le coût élevé de la justice pour les justiciables

2. Un déficit chronique de magistrats spécialisés.

$\S$ I: La pénalisation indirecte ou dépendance administrative du droit pénal de l'environnement

A) Au niveau des violations de normes administratives 194

B) Au niveau du contrôle de légalité 200

C) Au niveau des faits justificatifs 202

1) L'état de nécessité 202

2) L'erreur de droit ou erreur invincible 207

§II : La pénalisation directe du droit pénal de l'environnement 210
A) Le délit de pollution de l'eau
B) Le trafic illicite de déchets toxiques ou dangereux
C) Les inconvénients de l'incrimination directe en droit pénal

SECTION II : LA TENDANCE A L'INDULGENCE EN MATIERE DE SANCTIONS PENALES ENVIRONNEMENTALES

§।: Faible application des sanctions pénales environnementales

A) Sanctions pénales à faible effet dissuasif 
B) Sanctions pénales quasi inappliquées 225

§ II: L'indulgence du juge pénal et tolérance administrative 227

A) L'indulgence du juge $\quad 227$

1. Le recours fréquent aux sanctions sursitaires 227

2. Le doute comme motif de relaxe 230

B) L'indulgence de l'administration ou tolérance administrative 232

DEUXIEME PARTIE : LA NECESSAIRE PROTECTION DE L'ENVIRONNEMENT PAR LE DROIT PENAL ET LES PERSPECTIVES

TITRE I : VERS LA MISE EN CEUVRE EFFECTIVE DU DROIT PENAL DE L'ENVIRONNEMENT 236

CHAPITRE $V$ : LE RENFORCEMENT DES MOYENS D'ACTION ET DE MISE EN đEUVRE DU DROIT PENAL DE L'ENVIRONNEMENT 238

SECTION I : LA RESTRUCTURATION DU CADRE JURIDIQUE 238

§।: La nécessaire refonte du droit répressif béninois 239

A) La révision et l'élaboration de textes pénaux 239

1) La révision des textes 240

2) L'élaboration de nouveaux textes. 241

B) Le code de l'environnement, un outil nécessaire 247

1) La définition et les intérêts d'un code de l'environnement 248

2) La nature et les principes de codification 252

3) Le dispositif institutionnel 255

4) Les limites et les écueils qui pourraient résulter de la rédaction du code 258

a) Eviter des incohérences de fond et de forme 260

b) Eviter la rédaction infidèle de certains textes 262

§II : Vers une législation pénale environnementale cohérente et homogène 263

SECTION II : L'ANALYSE ECONOMIQUE DU DROIT PENAL DE L'ENVIRONNEMENT 267

§I : L'intérêt de la théorie de l'analyse économique du droit de l'environnement 269

A) Les raisons qui gouvernent la théorie économique 270

B) Les conditions de l'application et du respect de la législation pénale 273

1) L'efficacité du contrôle juridique et de la poursuite judiciaire 275

2) La combinaison des sanctions 276

$\S$ II : Le renforcement de capacités et de mise en œuvre efficiente du droit pénal de l'environnement

A) Le renforcement des moyens humains $\quad 278$

1) La formation des magistrats au droit répressif de l'environnement 279

2) Le personnel administratif chargé de la surveillance et du contrôle 283

a) Le renforcement de capacité des structures de contrôle et de surveillance publics 283

b) Le renforcement de capacité des associations de défense de l'environnement

B) Le renforcement des moyens techniques, scientifiques et financiers 287 
1) Les moyens techniques et scientifiques

2) Les ressources financières et les mécanismes de financements

CHAPITRE VI : LA DEFINITION DES ELEMENTS CONSTITUTIFS DE L'INFRACTION ENVIRONNEMENTALE

SECTION I : L'ELEMENT LEGAL OU L'EXIGENCE DE TEXTES CLAIRS ET PRECIS

$\S$ I : Le contenu et l'évolution du principe de la légalité

A) L'historique et la signification du principe 294

B) L'évolution actuelle du principe en droit pénal de l'environnement 295

§ II : L’application du principe de la légalité en droit pénal de l'environnement 297

A) Le législateur doit légiférer avec clarté et précision 297

1. L'incrimination par renvoi, une solution 299

2. Les limites de l'incrimination par renvoi 303

B) Le juge répressif doit dire le droit en fonction d'un texte 305

SECTION II : LES AUTRES ELEMENTS CONSTITUTIFS DE L'INFRACTION ENVIRONNEMENTALE 309

§। : La réforme des éléments matériels de l'infraction 309

A) Les infractions d'action ou de commission en droit pénal de l'environnement 310

B) Les infractions de commission par omission. 311

§II : La définition des éléments intentionnels de l'infraction 314

A) La nécessité de l'élément moral 315

B) La réforme de l'élément moral pour le droit de l'environnement 317

1) L'intérêt de l'élément moral pour le droit de l'environnement 317

2) La faute d'imprudence et de négligence. 322

TITRE II : LES PERSPECTIVES POUR UN DROIT PENAL PLUS EFFICACE 326

CHAPITRE VII : L'EFFECTIVITE DE LA RESPONSABILITE PENALE DE LA PERSONNE MORALE EN DROIT INTERNE BENINOIS. 328

SECTION I : UN BREF APERCU DE LA PORTEE DE LA RESPONSABILITE PENALE APPLICABLE A LA PERSONNE MORALE $\quad 330$

§l: Le contenu de la responsabilité pénale de la personne morale 333

A) Les personnes morales de droit privé. 334

B) Les personnes morales de droit public 335

1) Les organes ou représentants d'une personne morale 337

2) La commission de l'infraction « pour le compte » de la personne morale. $\quad 339$

§II : L’efficacité des sanctions pénales applicables à la personne morale 341

A) L'amende applicable aux personnes morales 341

B) Les peines accessoires applicables aux personnes morales 342

SECTION II : L'EFFECTIVITE DE LA RESPONSABILITE PENALE DE LA PERSONNE MORALE AU BENIN $\quad 346$

§l: Une introduction relative de la responsabilité des personnes morales $\quad 347$

A) Le silence des textes pénaux à caractère général 347 
B) Existence de la responsabilité de la personne morale au Bénin 348

§ll : Une possibilité de répression de la personne morale très réduite 350

A) Les difficultés quant à la mise en œuvre de la responsabilité de la personne morale

B) Les pesanteurs économiques freinent l'application du droit pénal des personnes morales

CHAPITRE VIII : LA REPRESSION DE LA POLLUTION TRANSFRONTIERE 355

SECTION I : LA COMPETENCE EN MATIERE DE POLLUTION TRANSFRONTIERE 356

§। : La définition et les manifestations du phénomène de pollution transfrontière $\quad 357$

A) Les éléments de définition de la pollution transfrontière 357

B) Les sources et les manifestations de la pollution transfrontière 359

1) Les manifestations de la pollution atmosphérique transfrontières 360

2) Les manifestations de la pollution marine transfrontière 362

§II : La compétence des tribunaux en matière de pollution environnementale transfrontière 365

A) Les tribunaux à compétence interne 366

1) La compétence des tribunaux de l'Etat pollueur 366

2) La compétence des tribunaux de l'Etat victime 369

B) Le recours au règlement judiciaire international 372

1) Le recours à la procédure d'arbitrage ou à la $\mathrm{CIJ} 372$

2) Le recours à l'application des conventions internationales environnementales 376

SECTION II : LA COMPETENCE NON JURIDICTIONNELLE DE REGLEMENT DE CONFLIT EN $\begin{array}{ll}\text { DROIT DE L'ENVIRONNEMENT } & 378\end{array}$

§। : La coopération interétatique de bon voisinage 378

A) L'information et la consultation dans les relations transnationales $\quad 379$

B) L'information et l'assistance en cas d'infraction transfrontière 382

§II : Le mode de règlement pacifique des conflits en matière de pollution transfrontière $\quad 384$

A) Les mécanismes de règlement non juridictionnel 384

1) La négociation 385

2) Les bons offices $\quad 386$

3) L'enquête internationale 386

4) La médiation et la conciliation $\quad 387$

B) Les sanctions non juridictionnelles ou diplomatiques 387

1) Les sanctions non juridictionnelles applicables à l'Etat 388

2) Les sanctions non juridictionnelles applicables aux personnes privées $\quad 389$

CONCLUSION GENERALE $\quad 391$

TABLE DES TABLEAUX 396

SIGLES, ABREVIATIONS ET ACRONYMES

$\begin{array}{ll}\text { BIBLIOGRAPHIE } & 402\end{array}$

I. OUVRAGES GENERAUX DE DROIT ET DE DROIT PENAL 402 
II. MANUELS OU OUVRAGES SPECIALISES EN DROIT DE L'ENVIRONNEMENT 403

III. THESES ET MEMOIRES 405

IV. ARTICLES \& RAPPORTS

$\begin{array}{lll}\text { 1. } & \text { Articles } & 407\end{array}$

2. Rapports et documents divers 410

V. CODES ET TEXTES LEGISLATIFS ET REGLEMENTAIRES 412

1. Au niveau national 412

2. Au niveau régional et international 414

table des matieres $\quad 416$

ANNEXES 423

ANNEXE I : Principaux Accords bilatéraux et multilatéraux signés ou ratifiés par le Bénin en matière d'environnement. 424

ANNEXE II: Liste des agents outre que les OPJ, habilités à constater (contrôle et de la surveillance) les infractions au droit de l'environnement dans le dispositif pénal béninois

430

ANNEXE IV : $\quad 436$

ACCORD DE COOPERATION

$\begin{array}{ll}\text { ENTRE } & 437\end{array}$

LE GOUVERNEMENT DE LA REPUBLIQUE DU BENIN

ET $\quad 437$

LE GOUVERNEMENT DE LA REPUBLIQUE TOGOLAISE

DANS LES DOMAINES DE L'ENVIRONNEMENT ET DE LA GESTION DURABLE DES RESSOURCES NATURELLES 
ANNEXES 


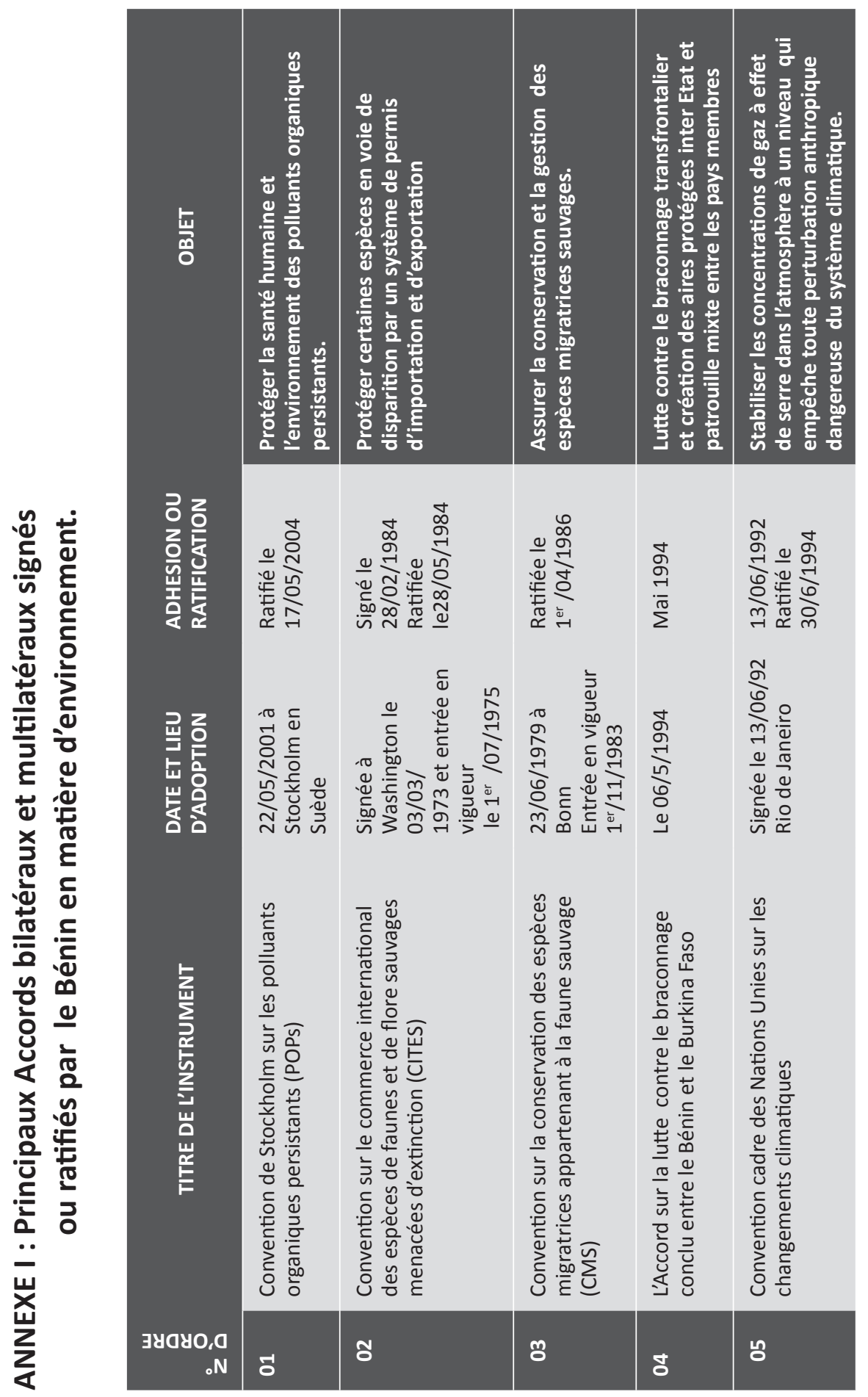




\begin{tabular}{|c|c|c|c|c|c|}
\hline $\begin{array}{l}\text { 点 } \\
\text { 。̊ }\end{array}$ & 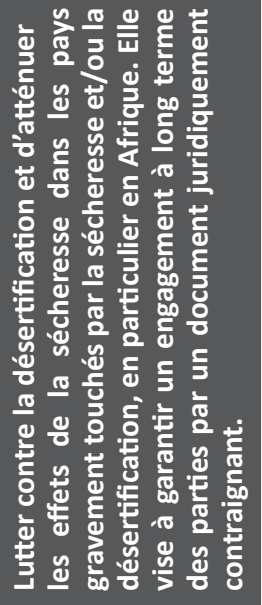 & 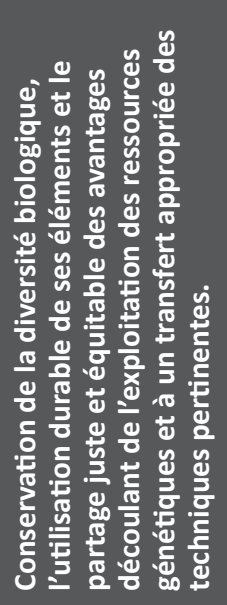 & 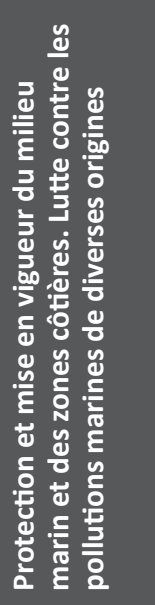 & 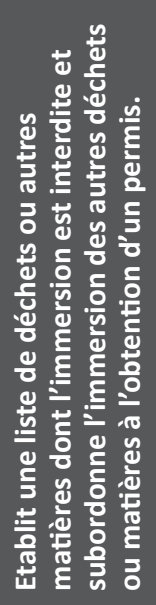 & 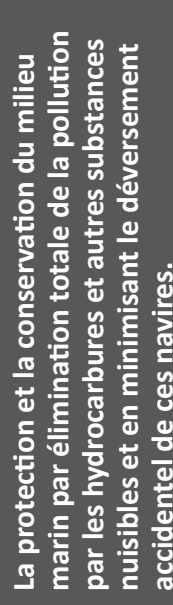 \\
\hline 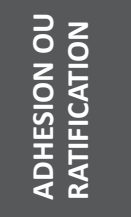 & 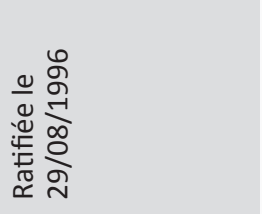 & 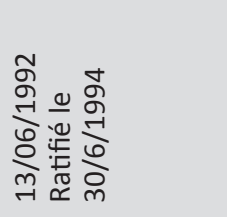 & 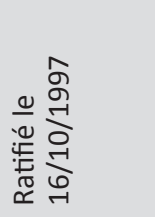 & 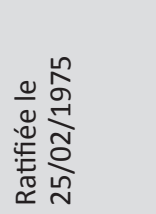 & 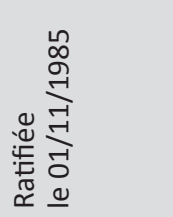 \\
\hline 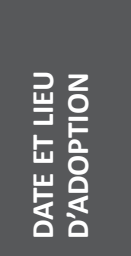 & 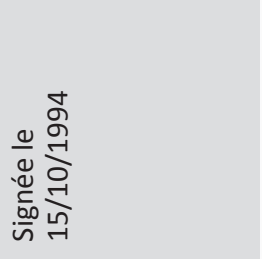 & 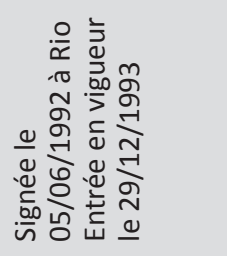 & 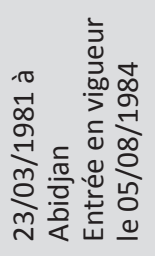 & 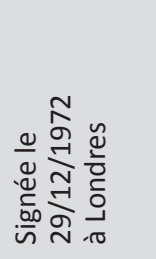 & 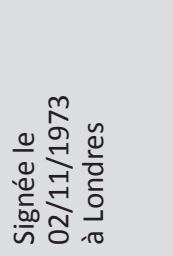 \\
\hline 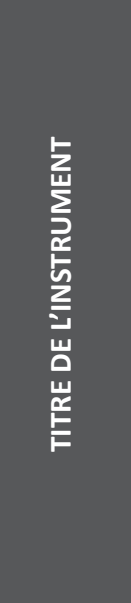 & 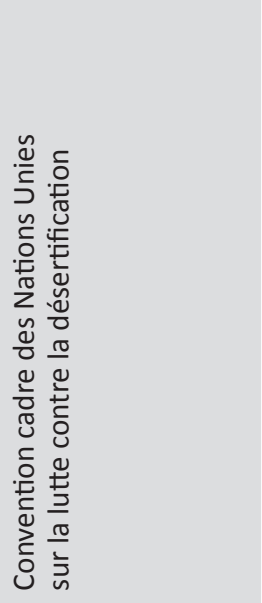 & 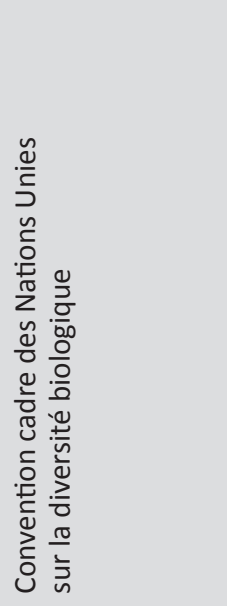 & 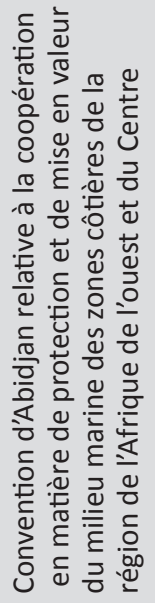 & 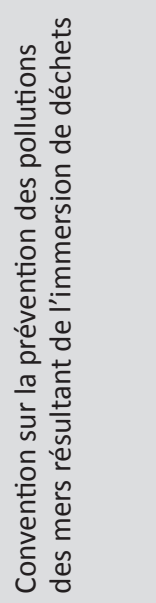 & 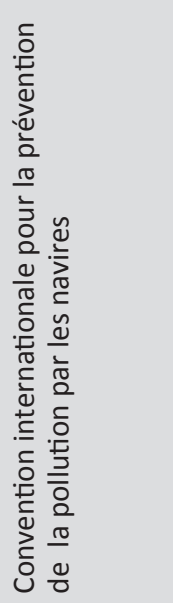 \\
\hline $\begin{array}{r}940,0 \\
\text { oN }\end{array}$ & 8 & s & ஜ & 8 & 음 \\
\hline
\end{tabular}




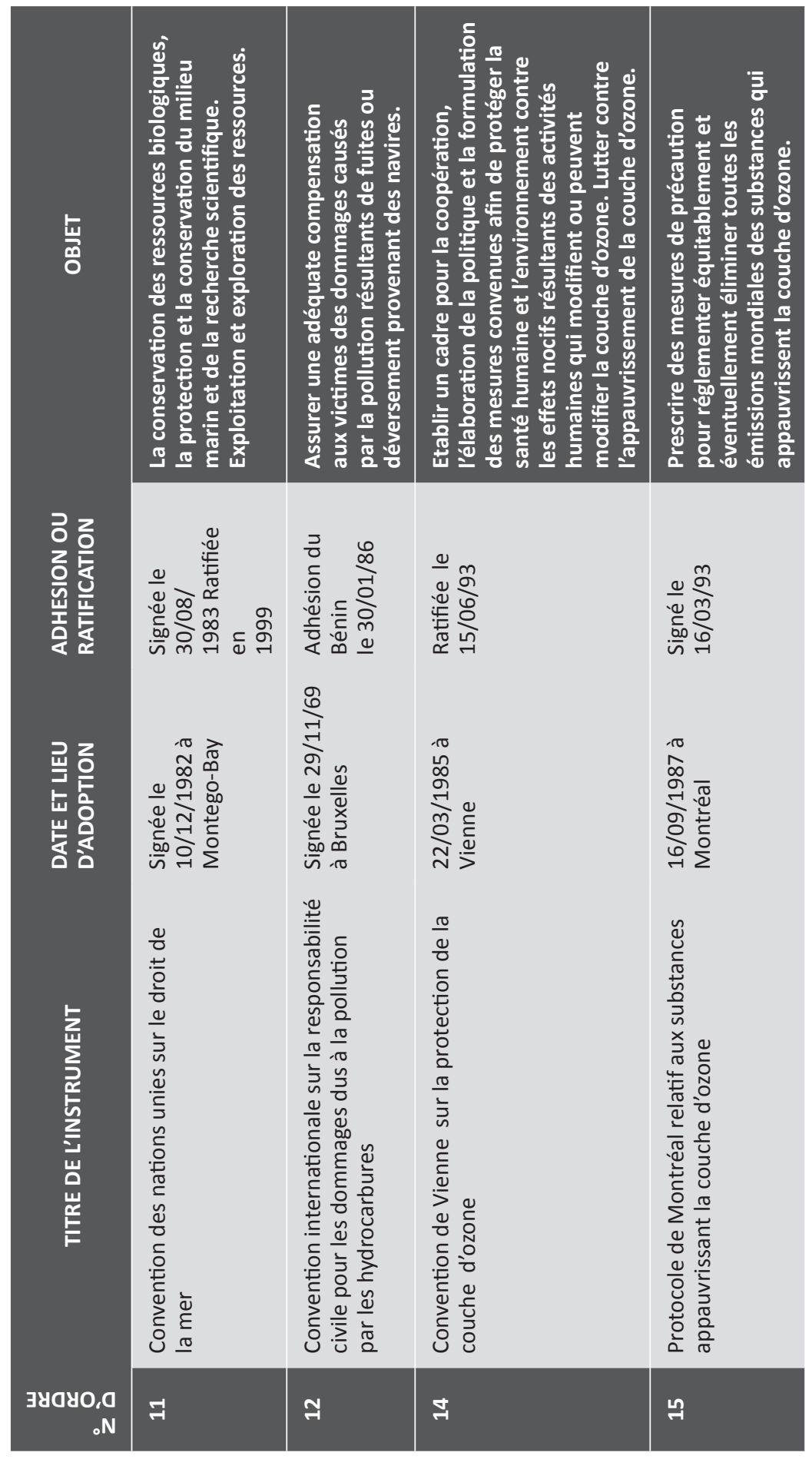




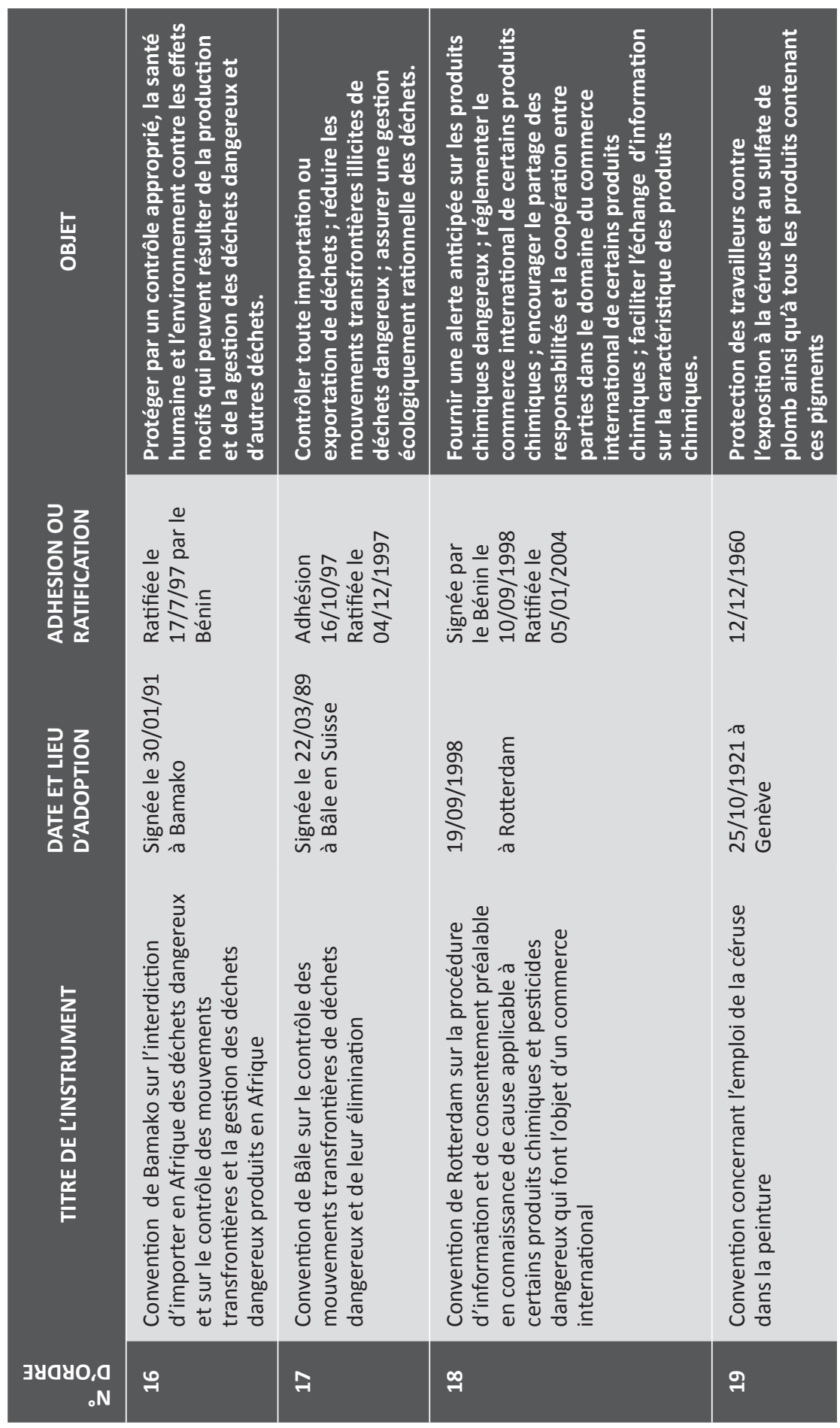




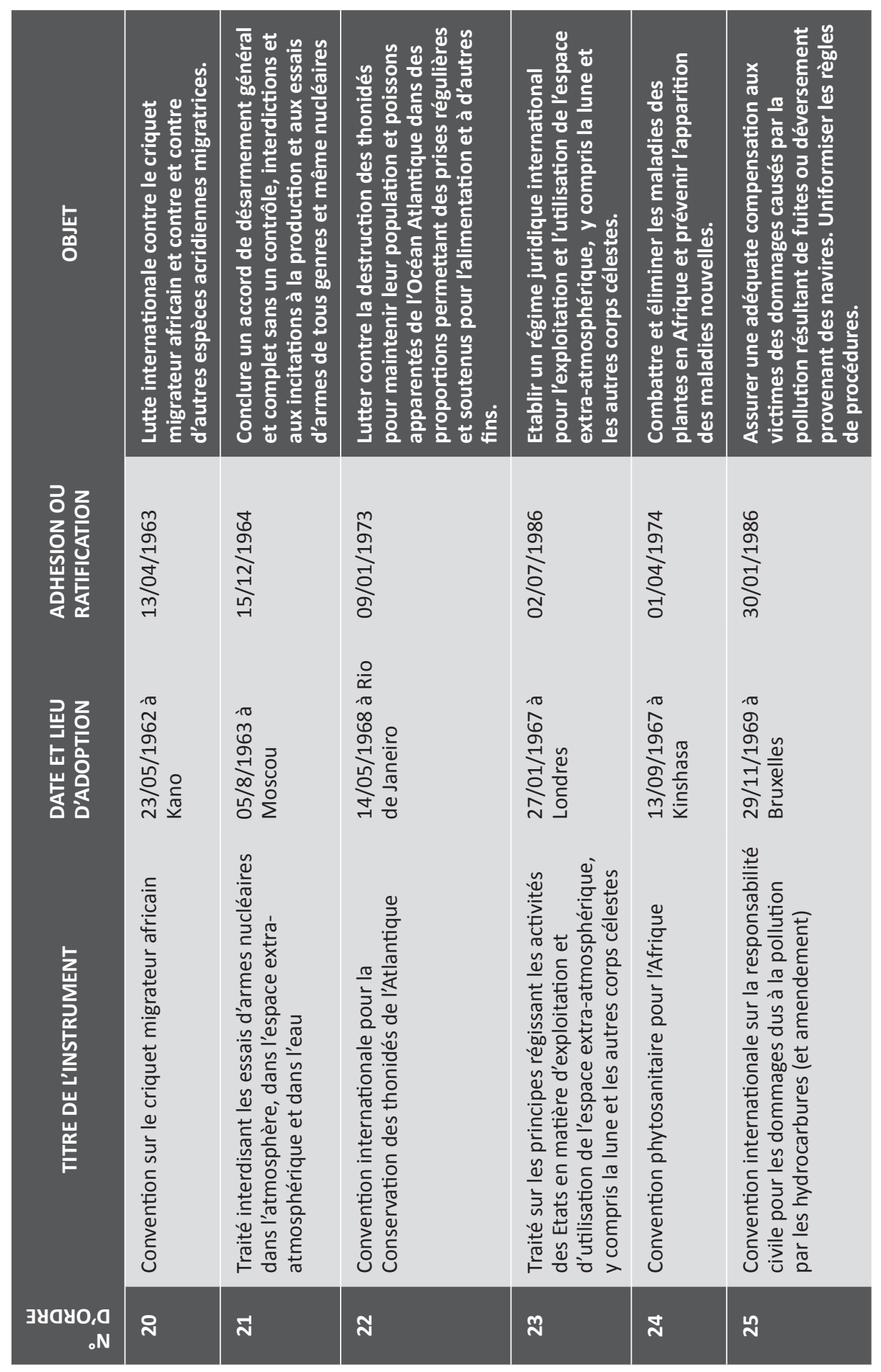




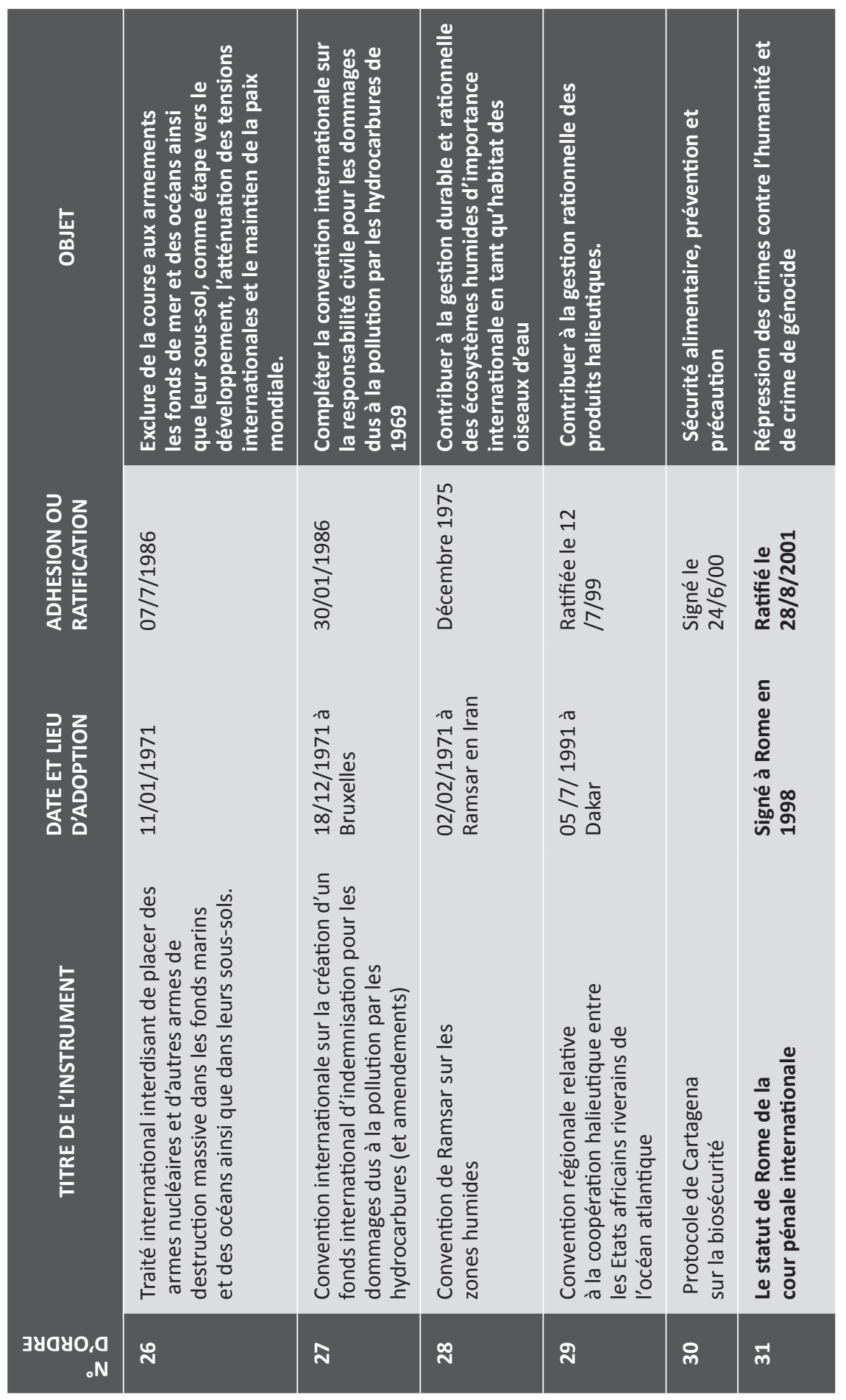




\section{ANNEXE II: Liste des agents outre que les OPJ, habilités à constater (contrôle et de la surveillance) les infractions au droit de l'environnement dans le dispositif pénal béninois}

\begin{tabular}{|l} 
N $\mathbf{N}^{\circ}$ Agents assermentés ou commissionnés \\
$01 \quad \begin{array}{l}\text { Le capitaine ou le responsable de tout } \\
\text { navire et le représentant qualifié de } \\
\text { l'autorité maritime }\end{array}$ \\
\hline 02 Le Ministre chargé de l'environnement
\end{tabular}

03 Les agents fonctionnaires du Ministère chargé du commerce en matière de répression de fraudes douanières

\section{Textes d'habilitation}

Ordonnance $n^{\circ} 38 /$ PR/MTPTPT du 18/6/68 portant code de la marine marchande de la RB (art.274 et 289)

Loi ${ }^{\circ} 98-30$ de la 12/02/99 portant loi cadre sur l'environnement en république du Bénin (art.106)

Loi ${ }^{\circ} 98-30$ de la 12/02/99 portant loi cadre sur l'environnement en république du Bénin (art.85) et la loi-n90-005 du 15 mai 1990 fixant les conditions d'exercice des activités de commerce en RB (art.46)

\section{Les agents assermentés de l'Agence Béninoise pour l'Environnement}

Loi $n^{\circ} 98-30$ de la 12/02/99 portant loi cadre sur l'environnement en république du Bénin (art.85)
05 Les agents assermentés ou commissionnés des Eaux, Forêts et Chasse

Loi ${ }^{\circ} 93-009$ du 2/7/93 portant régime des forêts en RB (art. 64, 68, 70) et la Loi $n^{\circ} 2002-016$ du 18 octobre 2004 portant régime de la faune en $\mathrm{RB}$ (art 126 et suivants).

06 Les agents assermentés des services Ordonnance $n^{\circ}$ 20/PR/MDRC du 25 avril de pêche et du ministère chargé du 1966 portant réglementation de l'exercice développement rural de la pêche dans les eaux continentales du Bénin (art.15) et ses textes d'application.
07 Les agents fonctionnaires assermentés de la direction chargée des mines

Loi $n^{\circ} 2006-17$ du 17/10/06 portant code minier et fiscalités minières en R.B. (art.138)
08 Les agents fonctionnaires assermentés de la direction chargée des hydrocarbures

09 Les Inspecteurs de la police environnementale

Loi $n^{\circ} 2006-18$ du 17/10/06 portant code pétrolier en R.B. (art.87)

Loi $n^{\circ} 98-30$ de la 12/02/99 portant loi cadre sur l'environnement en république du Bénin 


\section{$\mathbf{N}^{\circ} \quad$ Agents assermentés ou commissionnés \\ 10 Les agents d'hygiène et agents de santé publique assermentés}

\section{Textes d'habilitation}

Loi n87-015 du $21 / 9 / 87$ portant code de l'hygiène publique (art.15, 16, 102et 143 et suivants) et la Loi n ${ }^{\circ} 84-009$ du 15 mars 1984 sur le contrôle des denrées alimentaires

Décret n`97-624 du 31 /12/97 portant structure, composition et fonctionnement de la police sanitaire et la Loi $n^{\circ} 87-015$ du $21 / 9 / 87$ portant code de l'hygiène publique (art.143 et suivants))

12 Le Directeur Général de la Foret et des Ressources Naturelle

Loi $n^{\circ} 93-009$ du 2/7/93 portant régime des forêts en RB (art. 64, 68, 70) et la Loi $n^{\circ} 2002-016$ du 18 octobre 2004 portant régime de la faune en RB (art 126 et suivants).

\begin{tabular}{|c|c|c|}
\hline 13 & Les agents des douanes & $\begin{array}{l}\text { Ordonnance } n^{\circ} 54 / P R / M F A E / D D ~ d u \\
1^{\text {r }} / 01 / 67 \text { portant code des douanes (art. } \\
250 \text { et suivants) }\end{array}$ \\
\hline 14 & $\begin{array}{l}\text { Les Directeurs Départementaux de } \\
\text { l'Environnement et de la Protection de } \\
\text { la Nature }\end{array}$ & $\begin{array}{l}\text { Loi } n^{\circ} 98-30 \text { de la 12/02/99 portant loi } \\
\text { cadre sur l'environnement en république } \\
\text { du Bénin (art106) et décret } n^{\circ} 2007- \\
493 \text { du } 02 / 11 / 07 \text { portant attributions, } \\
\text { organisation et fonctionnement du MEPN } \\
\text { (art.36). }\end{array}$ \\
\hline 15 & Le Maire & $\begin{array}{l}\text { Loi- } n^{\circ} 97 \text { - du } 15 / 01 / 97 \text { portant régime des } \\
\text { communes en RB }\end{array}$ \\
\hline 16 & $\begin{array}{l}\text { Les agents assermentés ou } \\
\text { commissionnés du CENAGREF }\end{array}$ & $\begin{array}{l}\text { Loi- }{ }^{\circ} 87-014 \text { du } 21 / 9 / 87 \text { portant } \\
\text { réglementation de la nature et de } \\
\text { l'exercice de la chasse en RPB (art. } 44 ; 47 \text { ). }\end{array}$ \\
\hline 17 & $\begin{array}{l}\text { Les agents fonctionnaires } \\
\text { commissionnés du MEPN }\end{array}$ & $\begin{array}{l}\text { Loi } n^{\circ} 98-30 \text { de la 12/02/99 portant loi } \\
\text { cadre sur l'environnement en république } \\
\text { du Bénin }\end{array}$ \\
\hline 18 & $\begin{array}{l}\text { Les Inspecteurs vétérinaires } \\
\text { assermentés }\end{array}$ & $\begin{array}{l}\text { Ordonnance } \mathrm{n}^{\circ} 72-31 \text { du } 27 \text { septembre } \\
1972 \text { portant réglementation de la police } \\
\text { sanitaire des animaux et de l'inspection } \\
\text { des denrées alimentaire d'origine animale } \\
\text { (art. } 1^{\text {er }} \text { ). }\end{array}$ \\
\hline 19 & Le préfet & $\begin{array}{l}\text { Loi-n }{ }^{\circ} 97-\text { du } 15 / 01 / 97 \text { portant régime des } \\
\text { communes en RB }\end{array}$ \\
\hline
\end{tabular}




\section{$\mathbf{N}^{\circ} \quad$ Agents assermentés ou commissionnés Textes d'habilitation \\ 20 Les agents de contrôle de conditionnement \\ Loi-n ${ }^{\circ} 87-008$ du 21 septembre 1987 portant régime des taxes du contrôle du conditionnement et de normalisation de produits agricoles}

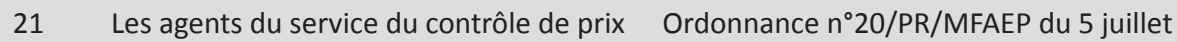 1967 portant réglementation des prix et stocks (art.40) \\ 22 Les agents de la direction des impôts Ordonnance $n^{\circ} 20 /$ PR/MFAEP du 5 juillet 1967 portant réglementation des prix et stocks (art.40) et le Code des impôts (art.250 et suivants)}

\section{Les agents du service de la répression des fraudes et du conditionnement \\ $24 \quad$ Les agents de la direction de l'hydraulique ou de la direction du génie sanitaire et de l'assainissement}

Ordonnance $n^{\circ} 20 / P R / M F A E P$ du 5 juillet 1967 portant réglementation des prix et stocks (art.40) Loi-n $87-016$ du 21 septembre 1987 portant ode de l'eau en RB (art.16).

25 Les agents chargés de la protection des végétaux assermentés

26 Les agents assermentés des administrations chargées de la protection de l'environnement
Loi $n^{\circ}$ 91-004 du 11 février 1991 portant réglementation phytosanitaire en $\mathrm{RB}$ (art.9)

Loi $n^{\circ} 98-30$ de la 12/02/99 portant loi cadre sur l'environnement en république du Bénin (art.106) 


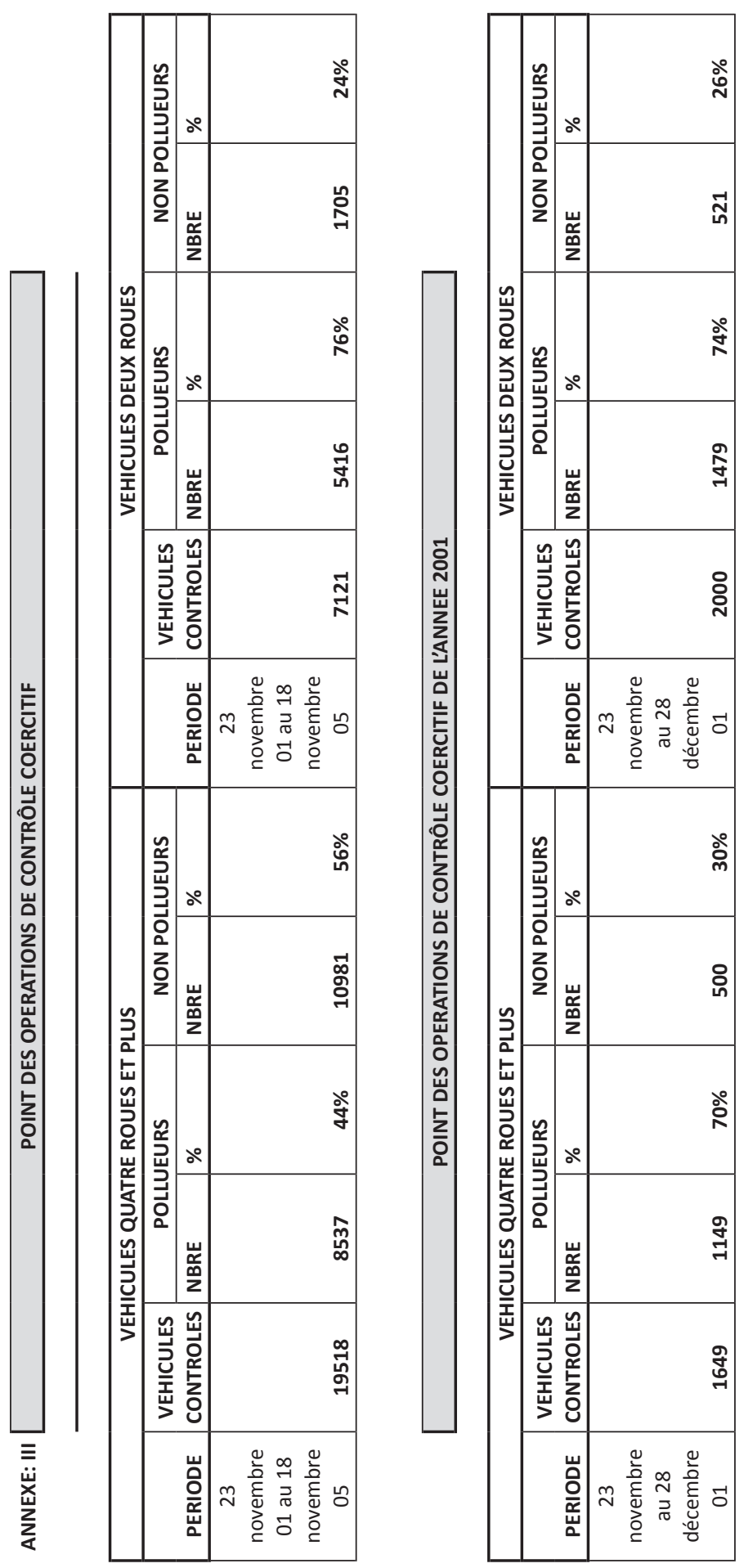




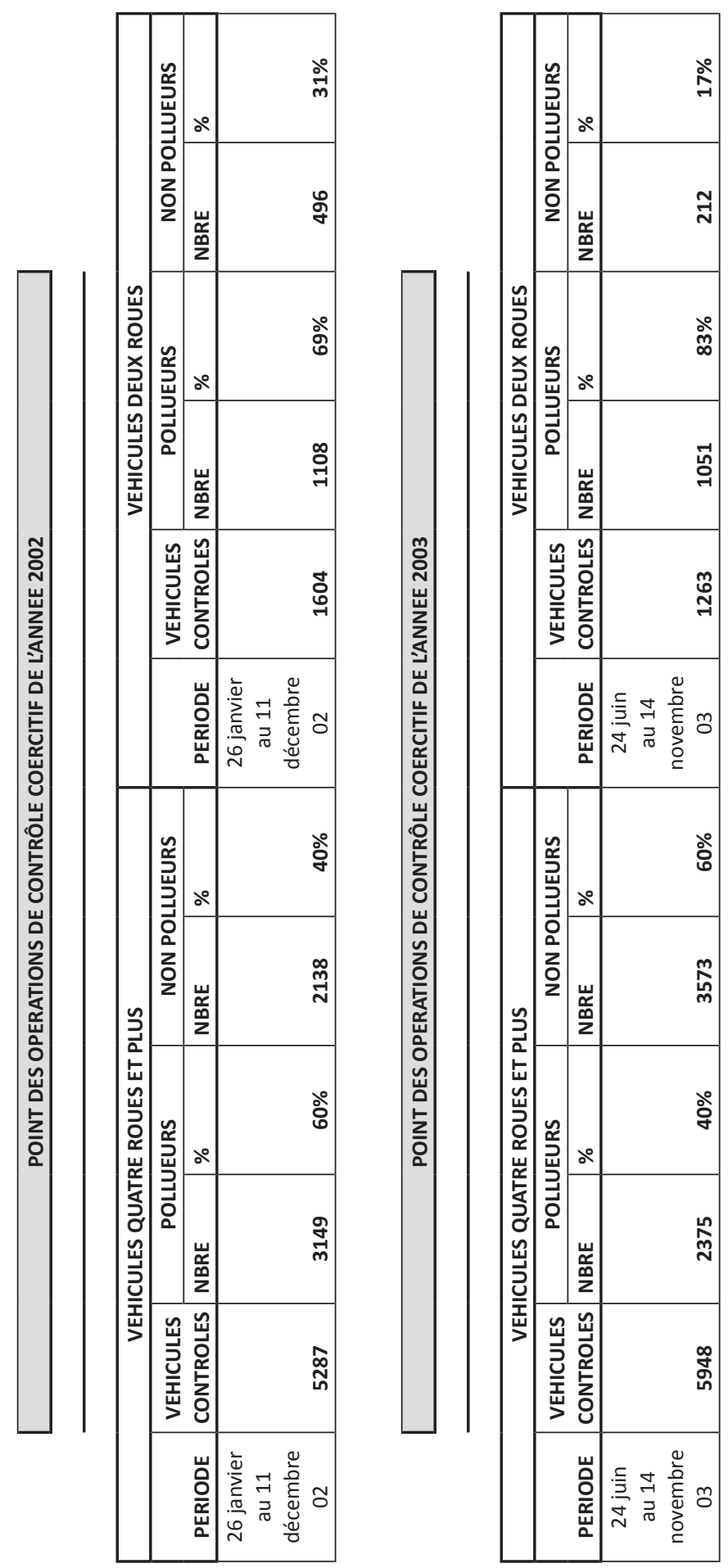




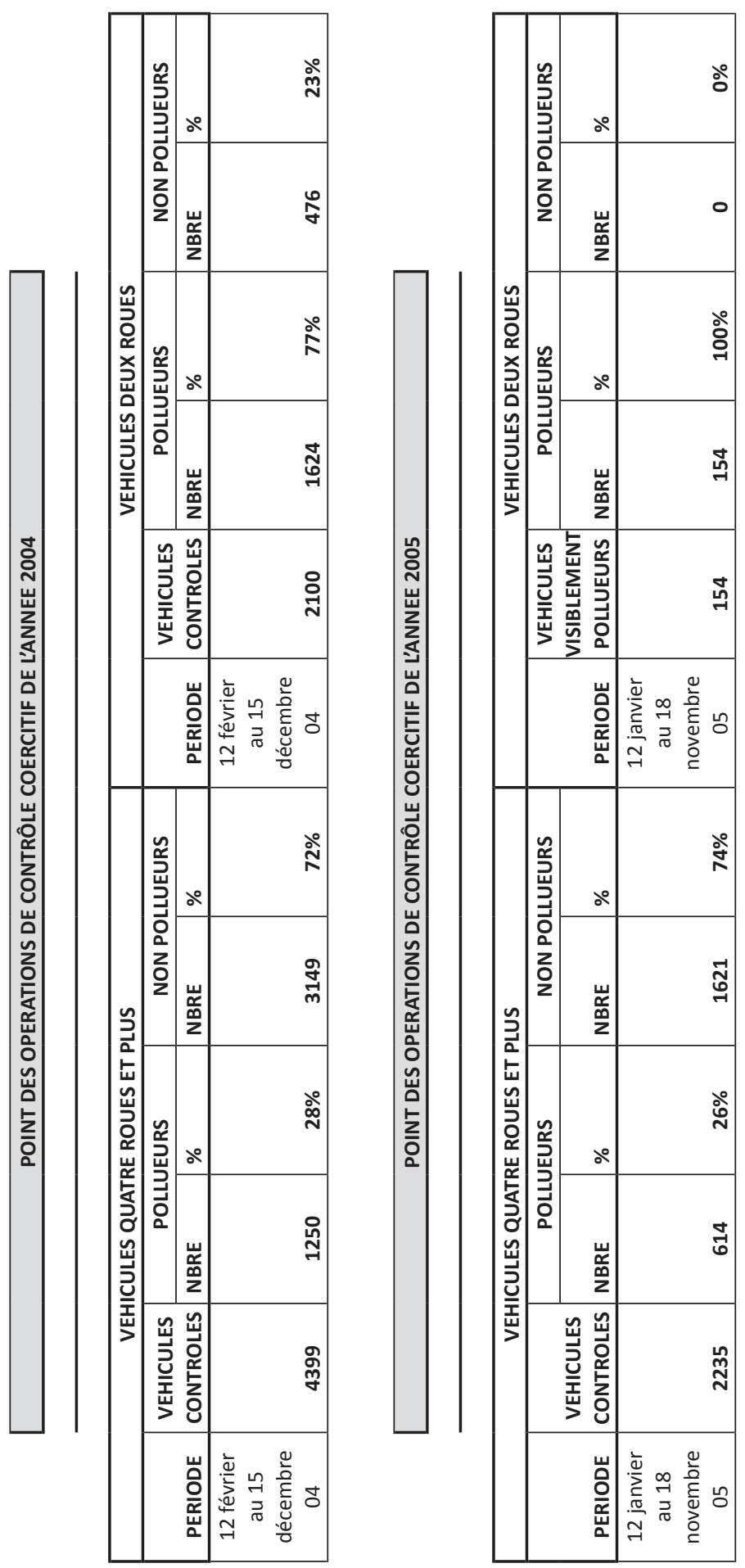




\section{ANNEXE IV :}

L'accord de coopération entre le gouvernement de la République du Bénin et le gouvernement de la République togolaise dans les domaines de l'environnement et de la gestion durable des ressources naturelles 


\title{
ACCORD DE COOPERATION
}

ENTRE

LE GOUVERNEMENT DE LA REPUBLIQUE DU BENIN

ET

LE GOUVERNEMENT DE LA REPUBLIQUE TOGOLAISE

\author{
DANS LES DOMAINES DE \\ L'ENVIRONNEMENT ET DE LA GESTION \\ DURABLE DES RESSOURCES NATURELLES
}


Le Gouvernement de la République du Bénin, d’une part,

Et

Le Gouvernement de la République Togolaise, d’autre part,

Ci-après dénommés « les Parties »

Considérant les relations traditionnelles de fraternité, d'amitié et de coopération existant entre les deux pays et les deux peuples ;

Conscient de la nécessité pour le plus grand profit de leurs populations respectives, d'une coopération étroite entre leurs deux pays en vue d'une gestion durable de l'environnement et des ressources naturelles ;

Désireux de créer un cadre spécifique de concertation entre les responsables de leurs départements ministériels respectifs en vue de résoudre les problèmes communs dans les domaines de l'environnement et de la gestion durable des ressources naturelles;

Se rappelant les différentes rencontres et consultations de haut niveau ;

Vu le procès verbal des séances de travail des délégations du Ministère de l'Environnement de l'Habitat et de l'Urbanisme (MEHU) et du Ministère de I'Environnement et des Ressources Forestières (MERF) du Togo, tenues à Lomé les 19 et 20 octobre 2011 ;

Sont convenu de ce qui suit :

\section{Article premier : Définitions}

Aux fins du présent accord, les termes et expressions suivants s'entendent, sauf indications contraires dans le contexte comme ci-après : 
«Autorités compétentes » : Autorités compétentes chargées de la mise en œuvre du présent accord :

a. en ce qui concerne la République du Bénin, le Ministère de l'environnement de l'Habitat et de l'Urbanisme (MEHU) ;

b. en ce qui concerne la République togolaise, le Ministère de I'Environnement et des ressources Forestière (MERF) ;

«CEB » : Communauté Electrique du Bénin ;

« OIBT » : Organisation Internationale des Bois Tropicaux ;

« $O A B$ » : Organisation Africaine de Bois ;

« CPM » : Comité de Pilotage Ministériel ;

« CTP » : Comité Technique Paritaire

\section{Article 2: Objet}

Le présent accord fixe les clauses sur la base desquelles les deux parties s'engagent à promouvoir et à développer, au travers d'une concertation permanente entre leurs autorités compétentes respectives, la coopération en vue de gérer durablement leurs ressources forestières respectives, de limiter les dégâts occasionnés par les inondations, de contrôler les rejets en mer des déchets de toutes sortes, de luter contre l'érosion côtière et de mettre en œuvre des actions concertées d'identification, de résolution et d'évaluation des problèmes environnementaux d'intérêt commun.

\section{Article 3 : Domaines de coopération}

La coopération visée à l'article 2 ci-dessus couvre les domaines définis ci-après :

\section{- Domaine de l'environnement}

- Identification des problèmes environnementaux et les mauvaises pratiques en matière d'environnement ; 
- Elaboration des projets en vue de la résolution définitive du problème de pollution des eaux marines et des côtes du fait du rejet des bouts de phosphate et autres ;

- Elaboration des projets communs visant la fixation des berges des cours d'eaux transfrontaliers (Mono, Couffo et Oti-Pendjari), en vue d'atténuer les effets des inondations récurrentes dont sont victimes les populations riveraines;

\section{- Domaine forestier}

- Identification des problèmes de gestion des ressources naturelles et les mauvaises pratiques en la matière ;

- Adoption et mise en œuvre des stratégies visant à éliminer le sciage à la tronçonneuse par la promotion de technologie plus appropriées (scies mobiles et autres) ;

- Mise en place d'un dispositif pour enrayer le trafic illicite de bois par l'organisation de séances de concertation entre les administrations des deux pays en charge des forêts ;

- Elaboration des programmes de gestion concertée et participative des ressources naturelles à l'instar de la « muraille verte »;

- Mise en place d'un mécanisme concerté de gestion des aires protégés, des forêts et des espèces protégés (lutte contre le braconnage, protection des hippopotames, surveillance des espèces migratrices protégées) ;

- Renforcement du statut de la bande de terre séparant les deux complexes du parc national de la Pendjari (côté béninois) et de celui de Oti-Kéran Mandouri (côté togolais) pour en faire une réserve de faune ;

- Evaluation des services environnementaux des éco systèmes des deux pays ;

- Valorisation de toutes les composantes des forêts (surtout les produits forestiers non ligneux) ; 


\section{- Domaine des échanges d'expériences}

- Evaluation de' »la contribution des ressources forestières au produit Intérieur Brut (PIB);

- Mise en place des marchés ruraux de bois énergie ;

- Suivi de l'évolution du couvert forestier à travers des inventaires forestiers nationaux concertés ou conjoints ;

- Promotion de la recherche et de l'échange de données et d'informations en matière de foresterie, de traitement des eaux marines et de lutte contre l'érosion côtière ;

- Promotion du commerce de sciage de bois de teck ;

- Suivi et promotion des plantations privées ;

- Promotion du partenariat secteur public/secteur privé, en matière de développement de la foresterie privée ;

- Promotion de l'échange d'expériences et des pratiques dans le cadre du renforcement des capacités des acteurs en matière d'environnement et des ressources naturelles.

\section{Article 4 : Consultations bilatérales dans les organisations} internationales compétentes dans les domaines de l'environnement et de la gestion durable des ressources naturelles

Les Parties se consulteront, par l'intermédiaire de leurs Missions Permanente auprès d'Organisations Internationales compétentes dans les domaines de l'environnement et de la gestion durables des ressources naturelles, telles I'Organisation Internationales des Bois Tropicaux (OIBT) et l'Organisation Africaine des Bois $(O A B)$, pour harmonier leurs points de vue et leurs positions sur les sujets d'intérêt communs. 


\section{Article 5: Création, mission et attribution du CPM et CTP}

1. Les Parties créent un Comité de Pilotage Ministériel (CPM) présidé de façon rotative par les ministres en charge de l'environnement des deux Parties.

Le CPM est appuyé par un Comité technique paritaire (CTP) composé des structures compétentes en matière de l'environnement, des forêts, de la lutte contre la pollution marine et l'érosion côtière des deux Parties et présidé de façon rotative par un cadre de haut rang respectivement par l'autorité compétente de chaque Partie.

2. Sous la supervision du CPM, le CTP a pour mission d'examiner toutes les questions liées à la mise en œuvre du présent accord.

A ce titre, elle est chargée de :

a. Définir des programmes spécifiques et des projets de coopération ;

b. Mettre en œuvre les accords spécifiques conformément aux clauses du présent accord ;

c. Examiner et promouvoir l'exécution des programmes, projets et accords de coopération ;

d. Analyser et évaluer leur état d'exécution ;

e. Identifier de nouveaux domaines en vue du développement d'une coopération multisectorielle entre les deux (02) pays ;

f. Echanger des informations d'intérêts mutuels dans les domaines de l'environnement et de gestion durable des ressources naturelles ;

g. Adopter des mesures et recommandations relatives au développement de la coopération dans les domaines sus énumérés.

3. Le CPM soumet à l'examen de la commission mixte coopération béninotogolaise coprésidée par les ministres des affaires étrangères des deux (02) pays ou toute autre personne désignée à cet effet, les questions politiques liées à l'environnement et la gestion durable des ressources naturelles et des propositions visant à améliorer et à renforcer la coopération dans ces domaines entre les deux (02) Parties. 


\section{Article 6 : Mode de fonctionnement}

1. Le comité de pilotage ministériel se réuni une fois par semestre et de façon rotative entre les deux pays. La première réunion du comité de pilotage se tient au Bénin.

2. Le Comité Technique Paritaire se réuni en session ordinaire une fois par trimestre. La deuxième et la quatrième réunion du Comité Technique Paritaire coïncide avec les sessions ministérielles. La première session ordinaire du CTP se tient au Togo.

3. En cas de besoin, le CPM et le CTP peuvent se réunir en session extraordinaire, à la demande de l'un des Présidents de chaque organe.

\section{Article 7 : Conditions de financement}

Les frais liés à l'organisation des sessions sont à la charge de la Partie hôte ; les frais de missions (déplacement, perdîmes et hébergements) des membres du CPM et du CTP sont à la charge de chacune des deux Parties.

Chaque Partie peut solliciter de l'assistance auprès des partenaires techniques et financiers de son pays dans le cadre de l'organisation des sessions.

\section{Article 8 : Communications officielles}

1. Les autorités compétentes échangeront par voies diplomatiques toutes les informations sur les activités relatives à la mise en œuvre du présent accord ;

2. Les Parties s'engagent à :

a. Travailler en étroite collaboration avec le ministre en charge des affaires étrangères de leurs pays respectifs ;

b. Partager tous les documents techniques relatifs aux domaines de coopération entre les deux Parties. 


\section{Article 9 : Conditions et modalités d'application}

Les conditions et modalités d'application du présent accord seront dé «terminées le cas échéant, par des Protocoles additionnels et des échanges de lettres.

\section{Article 10 : Règlement des différends}

Tous différents découlant de l'interprétation et/ou de l'application du présent accord sera réglé à l'amiable par voie diplomatique.

\section{Article 11 : Durée, entrée en vigueur, amendement et dénonciation}

1. Le présent accord entre en vigueur dès sa signature par les deux Parties.

2. Il est conclu pour une durée de dix ans renouvelable par tacite reconduction, à moins que l'une des Parties notifie à l'autre, par voie diplomatique, son intention de le dénoncer. La dénonciation prend effet douze (12) mois après sa notification.

3. Il peut être amendé d'un commun accord par les Parties. Les amendements entreront en vigueurs conformément aux dispositions du paragraphe 1 du présent article.

En deux exemplaires originaux en langue française

Fait à Lomé, le vendredi 16 mars 2012 
Pour le Gouvernement de la République du Bénin, Le Ministre de l'Environnement, de l'Habitat et de l'Urbanisme

Blaise Onésiphore

AHANHANZO-GLELE
Pour le Gouvernement de la République Togolaise, Le Ministre de l'Environnement et des Ressources Forestières

Kossivi AYIKOE 